NUREG/CR-1757

\title{
Technology, Safety and Costs of Decommissioning a Reference Uranium Hexafluoride Conversion Plant
}

Prepared by H. K. Elder

Pacific Northwest Laboratory Operated by Battelle Memorial Institute

Prepared for U.S. Nuclear Regulatory Commission 


\section{NOTICE}

This report was prepared as an account of work sponsored by an agency of the United States Government. Neither the United States Government nor any agency thereof, or any of their employees, makes any warranty, expressed or implied, or assumes any legal liability or responsibility for any third party's use, or the results of such use, of any information, apparatus product or process disclosed in this report, or represents that its use by such third party would not infringe privately owned rights.

\section{Available from}

GPO Sales Program

Division of Technical Information and Document Control

U. S. Nuclear Regulatory Commission

Washington, D. C. 20555

Printed copy price: $\$ 9.50$

and 


\section{Technology, Safety and Costs of Decommissioning a Reference Uranium Hexafluoride Conversion Plant}

Manuscript Completed: June 1981

Date Published: October 1981

Prepared by

H. K. Elder

Pacific Northwest Laboratory

Richland, WA 99352

\section{Prepared for}

Division of Engineering Technology

Office of Nuclear Regulatory Research

U.S. Nuclear Regulatory Commission

Washington, D.C. 20555

NRC FIN B2036 


\section{Availability of Reference Materials Cited in NRC Publications}

Most documents cited in NRC publications will be available from one of the following sources:

1. The NRC Public Document Room, 1717 H Street., N.W. Washington, DC 20555

2. The NRC/GPO Sales Program, U.S. Nuclear Regulatory Commission, Washington, DC 20555

3. The National Technical Information Service, Springfield, VA 22161

Although the listing that follows represents the majority of documents cited in NRC publications, it is not intended to be exhaustive.

Referenced documents available for inspection and copying for a fee from the NRC Public Document Room include NRC correspondence and internal NRC memoranda; NRC Office of Inspection and Enforcement bulletins, circulars, information notices, inspection and investigation notices; Licensee Event Reports; vendor reports and correspondence; Commission papers; and applicant and ficensee documents and correspondence.

The following documents in the NUREG series are available for purchase from the NRC/GPO Sales Program: formal NRC staft and contractor reports, NRC-sponsored conference proceedings, and NRC booklets and brochures. Also available are Regulatory Guides. NRC regulations in the Code of Federal Regulations, and Nuclear Regulatory Commission issuances.

Documents avaitable from the National Technical Information Service inciude NUREG series reports and technical reports prepared by other federal agencies and reports prepared by the Atomic Energy Commission, forerunner agency to the Nuclear Regulatory Commission.

Documents available from public and special technical libraries include all open literature items, such as books, journal and periodical articles, transactions, and codes and standards. Federal Register notices, federal and state legislation, and congressional reports can usually be obtained from these libraries.

Documents such as theses, dissertations, foreign reports and translations, and non-NRC conference proceedings are available for purchase from the organization sponsoring the publication cited.

Single copies of NRC draft reports are available free upon written request to the Division of Technical Information and Document Control, U.S. Nuclear Regulatory Commission, Washington, DC 20555. 


\section{STUDY LEADER}

H. K. Elder

CONTRIBUTORS

M. H. Chopper

P. L. Hendrickson

W. E. Kennedy, Jr.

J. L. Pindak

R. I. Smith

Editor

D. R. Payson 

FOREWORD

BY

NUCLEAR REGULATORY COMMISSION STAFF

The NRC staff is reappraising its regulatory position relative to the decomissioning of nuclear facilities. (1) As a part of this activity, the NRC has initiated two series of studies through technical assistance contracts. These contracts are being undertaken to develop information to support the preparation of new standards covering decomissioning.

The basic series of studies covers the technology, safety, and costs of decommissioning reference nuclear facilities. Light water reactors and fuelcycle and non-fuel-cycle facilities are included. Facilities of current design on typical sites are selected for the studies. Separate reports will be prepared as the studies of the various facilities are completed.

The first report in this series, published in FY 1977, covers a fuel reprocessing plant; ${ }^{(2)}$ the second, published in FY 1978, covers a pressurized water reactor; (3) and the third, published in FY 1979, deals with a small mixed oxide fuel fabrication piant. (4) An addendum to the pressurized water reactor report, ${ }^{(5)}$ issued in FY 1979, examines the relationship between reactor size and decommissioning cost, the cost of entombment, and the sensitivity of cost to radiation levels, contactual arrangements, and disposal site charges. The fifth report in this series, published in FY 1980, deals.with a low-level waste burial ground; ${ }^{(6)}$ the sixth, published in FY 1980 , covers a large boiling water reactor power station; (7) and the seventh, published in FY 1981 , examines a uranium fuel fabrication plant. (8) The eighth report, published in FY 1981 , covers the decommissioning of non-fuel-cycle nuclear facilities. (9) This report, ninth in the series, deals with the decommissioning of a reference uranium hexafluoride conversion plant.

Additional topics will be reported on the tentative schedule as follows:

FY 1982 - Multiple Reactor Facilities

FY 1982 - Research/Test Reactors

FY 1982 - LWR Post-Accident

FY 1982 - Independent Spent Fuel Storage Installations 
The second series of studies covers supporting information on the decommissioning of nuclear facilities. Three reports have been issued in the second series. The first, published in FY 1979, consists of an annotated bibliography on the decommissioning of nuclear facilities. (10) The second, published in FY 1979, is a review and analys is of current decommissioning regulations. (11) The third, published in FY 1980 , covers the facilitation of the decommissioning of light water reactors, (12) identifying modifications or design changes to facilities, equipment, and procedures that will improve safety and/or reduce costs.

The information provided in this report on uranium hexafluoride conversion facilities, including any comments, will be included in the record for consideration by the Commission in establishing criteria and new standards for decommissioning. Comments on this report should be mailed to:

Chief

Fuel Process Systems Standards Branch

Division of Engineering Standards

Office of Standards Development

U.S. Nuclear Regulatory Commission

Washington, DC 20555

\section{REFERENCES}

1. Plan for Reevaluation of NRC Policy on Decommissioning of Nuclear Facilities. NUREG-0436, Rev. 1, Office of Standards Development, U.S. NucTear Regulatory Commission, December 1978.

2. Technology, Safety and Costs of Decommissioning a Reference Nuclear Fuel Reprocessing Plant. NUREG-0278, Pacific Northwest Laboratory for U.S. Nuclear Regulatory Commission, October 1977.

3. Technology, Safety and Costs of Decommissioning a Reference Pressurized Water Reactor Power Station. NUREG/CR-D130, Pacific Northwest Laboratory for U.S. Nuclear Regulatory Commission, June 1978.

4. Technology, Safety and Costs of Decommissioning a Reference Small Mixed 0xide Fuel Fabrication Plant. NUREG/CR-0129, Pacific Northwest Laboratory for U.S. Nuclear Regulatory Commission, February 1979.

5. Technology, Safety and Costs of Decommissioning a Reference Pressurized Water Reactor Power Station. NUREG/CR-D130 Addendum, Pacific Northwest Laboratory for U.S. Nuclear Regulatory Commission, August 1979. 
6. Technology, Safety and Costs of Decommissioning a Reference Low-Level Waste Burial Ground. NUREG/CR-0570, Pacific Northwest Laboratory for U.S. Nuclear Regulatory Commission, June 1980.

7. Technology, Safety and Costs of Decommissioning a Reference Boiling Water Reactor Power Station. NUREG/CR-0672, Pacific Northwest Laboratory for U.S. Nuclear Regulatory Commission, June 1980.

8. Technology, Safety and Costs of Decommissioning a Reference Uranium Fuel Fabrication Plant. NUREG/CR-1266, Pacific Northwest Laboratory for U.S. Nuclear Regulatory Commission, October 1980.

9. Technology, Safety and Costs of Decommissioning Reference Non-Fuel-Cycle Nuclear Facilities. NUREG/CR-1754, Pacific Northwest Laboratory for U.S. Nuclear Regulatory Commission, February 1981.

10. Decomissioning of Nuclear Facilities - An Annotated Bibliography. NUREG/CR-0131, Pacific Northwest Laboratory for U.S. Nuclear Regulatory Comnission, August 1979.

11. Decommissioning of Nuclear Facilities - A Review and Analys is of Current Regulations. NUREG/CR-0671, Pacific Northwest Laboratory and Batte?le Human Äffairs Research Centers for U.S. Nuclear Regulatory Commission, August 1979.

12. Facilitation of Decommissioning of Light Water Reactors. NUREG/CR-0569, Pacific Northwest Laboratory for U.S. Nuclear Regulatory Comission, December 1979. 


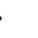




\section{ABSTRACT}

Safety and cost information is developed for the conceptual decommissioning of a commercial uranium hexafluoride conversion (UF ${ }_{6}$ ) plant. Two basic decomissioning alternatives are studied to obtain comparisons between cost and safety impacts: DECON, and passive SAFSTOR. A third alternative, DECON of the plant and equipment with stabilization and long-term care of lagoon wastes, is also examined.

DECON includes the immediate removal (following plant shutdown) of all radioactivity in excess of unrestricted release levels, with subsequent release of the site for public use. Passive SAFSTDR requires decontamination, preparation, maintenance, and surveillance for a period of time after shutdown, followed by deferred decontamination and unrestricted release. DECON with stabilization and long-term care of lagoon wastes (process wastes generated at the reference plant and stored onsite during plant operation) is also considered as a decommissioning method, al though its acceptability has not yet been determined by the NRC.

The decommissioning methods assumed for use in each decommissioning alternative are based on state-of-the-art technology. The elapsed time following plant shutdown required to perform the decommissioning work in each alternative is estimated to be: for DECON, 8 months; for passive SAFSTOR, 3 months to prepare the plant for safe storage and 8 months to accomplish deferred decontamination. Planning and preparation for decommissioning prior to plant shutdown is estimated to require about 6 months for either DECON or passive SAFSTOR. Planning and preparation prior to starting deferred decontamination is estimated to require an additional 6 months. DECON with lagoon waste stabilization is estimated to take 6 months for planning and about 8 months to perform the decompissioning work.

Decomissioning cost, in 1981 dollars, is estimated to be $\$ 5.91$ million for DECON. For passive SAFSTOR, preparing the facility for safe storage is estimated to cost $\$ 0.88$ million, the annual maintenance and surveillance cost is estimated to be about $\$ 0.095$ million, and deferred decontamination is estimated to cost about $\$ 6.50$ million. Therefore, passive SAFSTOR for 10 years is estimated to cost $\$ 8.33$ mijlion in nondiscounted 1981 dollars. DECON with lagoon waste 
stabilization is estimated to cost about $\$ 4.59 \mathrm{million}$, with an annual cost of $\$ 0.011$ million for long-term care. All of these estimates include a $25 \%$ contingency. Waste management costs for DECON, including the net cost of disposal of the solvent extraction lagoon wastes by shipping those wastes to a uranium mill for recovery of residual uranium, comprise about $38 \%$ of the total decommissioning cost. Disposal of lagoon waste at a comercial low-level waste burial ground is estimated to add $\$ 10.01$ million to decommissioning costs.

Safety analyses indicate that radiological and nonradiological safety impacts from decommissioning activities should be small. The 50-year committed dose equivalent to members of the public from airborne releases during normal decommissioning activities is estimated to be about 4.0 man-rem.

Radiation doses to the public from accidents are found to be very low for a) phases of decomissioning. Occupational radiation doses from normal decommissioning operations (excluding transport operations) are estimated to be about 79 man-rem for DECON and about 80 man-rem for passive SAFSTOR with 10 years of safe storage. Doses from DECON with Tagoon waste stabilization are about the same as for DECON except there is less dose resulting from transportation of radioactive waste. The number of fatalities and serious lost-time injuries not related to radiation is found to be very small for all decommissioning al ternatives.

Comparison of the cost estimates shows that DECON with lagoon waste stabilization is the least expensive method. However, this alternative does not allow unrestricted release of the site. The cumulative cost of maintenance and surveillance and the higher cost of deferred decontamination makes passive SAFSTOR more expensive than DECON.

Several methods to assure that the licensee has adequate funds for decommissioning are considered. The methods investigated (all based on expected decominissioning costs) range from a single payment when plant operations begin, to payments into a sinking fund during the nomal plant operating period, to a single payment when nomal plant operations cease and decormissioning begins. 


\section{REPORT CONTENTS OUTLINE}

SECTIONS

SECTION 1 - INTRODUCTION

SECTION 2 - SUMMARY

SECTION 3 - REVIEW OF DECOMMISSIONING EXPERIENCE

SECTION 4 - DECOMMISSIONING ALTERNATIVES AND STUDY APPROACH

SECTION 5 - REGULATORY CONSIDERATIONS

SECTION 6 - ALTERNATIVE APPROACHES TO FINANCING DECOMMISSIONING

SECTION 7 - CHARACTERISTICS OF THE REFERENCE URANIUM HEXAFLUORIDE CONVERSION PLANT

SECTION 8 - SUGGESTED METHODOLOGIES FOR DETERMINING ACCEPTABLE RESIDUAL RADIOLDGICAL AND CHEMICAL CONTAMINATION LEVELS FOR THE DECOMMISSIONED REFERENCE UF 6 CONVERSION PLANT

SECTION 9 - DECOMMISSIONING ACTIVITIES

SECTION 10 - DECOMMISSIONING COSTS

SECTION 11 - PUBLIC AND OCCUPATIONAL SAFETY DURING DECOMMISSIONING OF THE REFERENCE UF 6 CONYERSION PLANT

SECTION 12 - DISCUSSION OF STUDY RESULTS

SECTION 13 - CONSIDERATIONS FOR THE FACILITATION OF DECOMMISSIONING

SECTION 14 - äLOSSARY

APPENDICES

APPENDIX A - REFERENCE URANIUM HEXAFLUORIDE CONVERSION FACILITY DESCRIPTION

APPENDIX B - REFERENCE SITE DESCRIPTION

APPENDIX C - RESIDUAL RADIONUCLIDE INVENTORY ESTIMATES

APPENDIX D - PAYMENTS NEEDED TO FINANCE DECOMMISSIONING

APPENDIX E - RADIATION DOSE MODELS AND CALCULATED MAXIMUM ANNUAL DOSES

APPENDIX $F$ - GENERAL DECOMMISSIONING CONSIDERATIONS

APPENDIX G - DECOMMISSIONING ACTIVITY DETAILS

APPENDIX H - COST ASSESSMENT DETAILS

APPENDIX I - SAFETY ASSESSMENT DETAILS 



\section{CONTENTS}

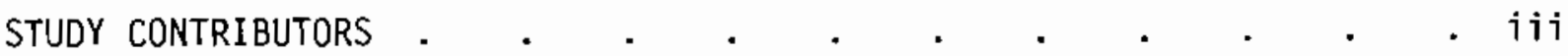

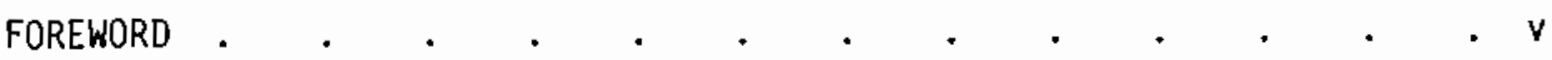

ABSTRACT • . . . . . . . . . . . . . . ix

REPORT CONTENTS OUTLINE . . . . . . . . . . . . . . . . . . xi

1.0 INTRODUCTION

2.0 SUMMARY . . . . . . . . . . . . . . . . . . . . . . . .

2.1 REVIEW OF DECOMMISSIONING EXPERIENCE . . . . . . . 2-2

2.2 FEDERAL REGULATIONS AND GUIDELINES . . . . . . . 2-3

2.3 APPROACHES TO FINANCING DECOMMISSIONING . . . . . . 2-4

2.4 SUGGESTED METHODOLOGY FOR DETERMINING ACCEPTABLE RESIDUAL

RADIOACTIVE AND CHEMICAL CONTAMINATION LEVELS FOR A UF 6 PLANT 2-4

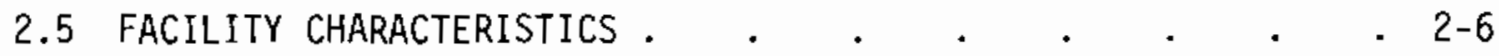

2.6 ESTIMATED RADIDNUCLIDE INVENTORIES . . . . . . . 2-6

2.7 DECOMMISSIONING METHODS • . . . . . . . . . . 2-6

2.7.1 DECON Procedures . . . . . . . . . 2-7

2.7.2 Passive SAFSTOR Procedures . . . . . . 2-8

2.7.3 Site Stabilization Procedures . . . . . 2-8

$2.8 \operatorname{cosTS} \quad . \quad . \quad . \quad . \quad . \quad . \quad . \quad . \quad . \quad 2-9$

2.9 SAFETY . . . . . . . . . . . $2-11$

2.10 WASTE MANAGEMENT . . . . . . . . . 2-13

2.11 STUDY CONCLUSIONS . . . . . . . . . . . 2-14

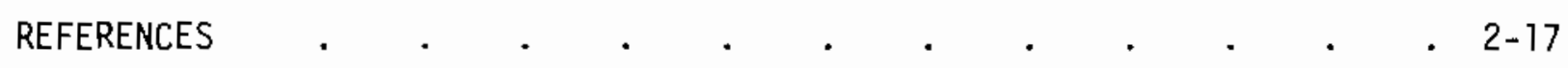

3.0 REVIEW OF DECOMMISSIONING EXPERIENCE . . . . . . . . . 3-1 
3.1 STATUS OF UF 6 PLANTS IN THE UNITED STATES $+\cdots$

3.2 DECOMMISSIONING PLAN FOR WELDON SPRING CHEMICAL PLANT . . . . . . . . . . . . . $3-2$

3.3 DECOMMISSIONING EXPERIENCE AT OTHER URANIUM PROCESSING FACILITIES $\quad . \quad . \quad . \quad . \quad . \quad . \quad . \quad . \quad 3-3$

3.4 LESSONS LEARNED FROM EXISTING DECOMMISSIONING EXPERIENCE 3-4 4.0 DECOMMISSIONING ALTERNATIVES AND STUDY APPROACH . . . . . 4-1

4.1 DECOMMISSIONING ALTERNATIVES . . . . . . . . . $4-1$

4.1.1 Definition of and Rationale for DECON . . . . 4-1

4.1.2 Definition of and Rationale for SAFSTOR . . . 4-2

4.1.3 Definition of and Rationale for ENTOMB . . . 4-6

4.1.4 Decommissioning Methods for Lagoon Waste . . . 4-7

4.1.5 Alternatives Selected for Study . . . . . 4-8

4.2 TECHNICAL APPROACH . . . . . . . . . . . . $4-9$

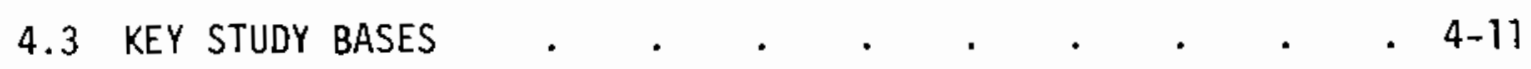
REFERENCES . . . . . . . . . . . . . . . . . . . . 4-15

5.0 REGULATORY CONSIDERATIONS $\quad . \quad$. $\quad . \quad$. . . . . . . . $\quad$. $5-1$

5.1 EXISTING REGULATIONS, STANDARDS, AND GUIDES . . . . 5-1

5.1 .1 Federal Jurisdiction . . . . . . . . . $\quad$. $5-1$

5.1.1.1 NRC Regulations. . . . . . . . 5-4

5.1.1.2 License Termination . . . . . 5-6

5.1.2 State and Local Jurisdiction . . . . . 5-7

5.1.3 Regulation of Effluents . . . . . . . . 5-9

5.1.4 Licensing Changes and Decommissioning Plan . . . 5-10

5.2 SAFEGUARDS CONSIDERATIONS $\quad . \quad$. $\quad . \quad$. $\quad . \quad$. $\quad$ 5-12

5.3 LICENSE TERMINATION AND FACILITY RELEASE + . • . • . 5-15

5.3.T License Temination by Stabilization . . . . 5-15 
5.3.2 License Termination by Removal . . . . . 5-17

5.4 CONCLUSIONS . $. \quad . \quad . \quad . \quad . \quad . \quad . \quad . \quad 5-18$

REFERENCES . . . . . . . . . . . . . . . 5-19

6.0 ALTERNATIVE APPROACHES TO FINANCING DECOMMISSIONING . . . 6-

6.1 NEED FOR ASSURANCE OF DECOMMISSIONING FUNDS . . . . .

6.2 APPROACHES TO PROVIDING FUNDS FOR DECOMMISSIONING AND LONG-.
TERM CARE ...
.

6.2 .1 Sinking Fund. . . . . . . . . . 6-3

6.2.2 Prepayment of Anticipated Costs . . . . . 6-5

6.2.3 Surety Bond . . . . . . . . . 6-6

6.3 DECOMMISSIONING FUNDING IN THE EVENT OF PREMATURE CLOSURE . 6-8

6.3.1 Initial Cash Payment . . . . . . . . 6-8

6.3.2 Higher Initial Sinking Fund Payments . . . . 6-9

6.3 .3 Surety Bonds . . . . . . . . . . . 6-9

6.3.4 Premature Shutdown Insurance . . . . . 6-10

6.4 RECENT REgULATORY DEVELOPMENTS . . . . . . . 6-10

6.4.1 Uranium Mi11 Sites . . . . . . . 6-10

6.4.2 Non-Nuclear Hazardous Waste Facilities . . . 6-12

6.5 FEDERAL INCOME TAX CONSIDERATIONS . . . . . . . 6-12

REFERENCES . . . . . . . . . . . . . . . . 6-15

7.D CHARACTERISTICS OF THE REFERENCE URANIUM HEXAFLUORIDE CDNVERSION

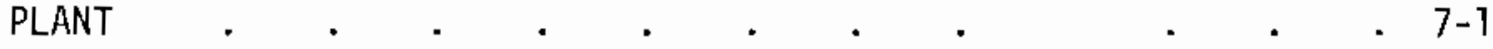

7.1 SITE DESCRIPTION . . . . . . . . . . . . . $7-7$

7.2 PROCESS DESCRIPTION . . . . . . . . . . . . 7-4

7.2.1 Wet Solvent Extraction Fluorination Process. . . 7-4

7.2.2 Effluents and Wastes. . . . . . 7-7 
7.2.2.1 Gaseous and Airborne Particulate Waste . . 7-8

7.2.2.2 Liquid Waste . . . . . . . 7-10

7.2.2.3 Solid Waste . . . . . . 7-10

7.3 PLANT DESCRIPTION . . . . . . . . . . . 7-12

7.3.1 Process Building Description . . . . 7-12

7.3.2 Ventilation System Description . . . . . 7-14

7.4 RESIDUAL RADIOACTIVITY ESTIMATES . . . • . . 7-15

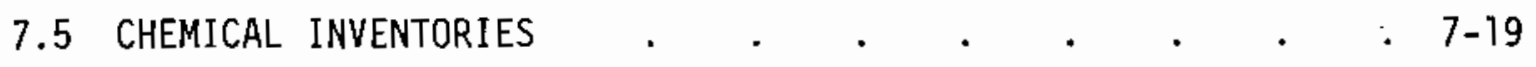

REFERENCES . . . . . . . . . . . . . . 7-20

8.0 SUGGESTED METHODOLOGIES FOR DETERMINING ACCEPTABLE RESIDUAL RADIO-

ACTIVE AND CHEMICAL DECONTAMINATION LEVELS FOR THE DECOMMISSIONED

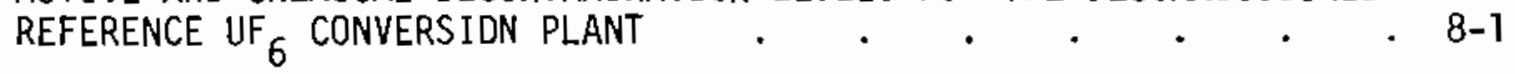

8.1 TECHNICAL APPROACH . . . . . . . . . . . 8-1

8.1.1 Terminology and Definitions . . . . . . 8-3

8.1.2 Definition of Use Categories . . . . . 8-4

8.1.3 Acceptable Residual Radioactive Contamination Levels . 8-5

8.1.4 Acceptable Residual Chemical Contamination Leve1s . 8-8

8.2 CALCULATION OF EXAMPLE ACCEPTABLE RESIDUAL RADIOACTIVE CON-

TAMINATION LEVELS FOR THE REFERENCE UF 6 CONVERSION PLANT • 8-10

8.2.1 Example Acceptable Residual Radioactive Contamination Levels in the Reference $\mathrm{UF}_{6}$ Conversion Plant . . 8-10

8.2.2 Example Acceptable Residual Radioactive Contamination Levels on the Reference $U_{6}$ Conversion Plant Site . 8-11

8.2.3 Summary of Example Acceptable Residual Radioactive Contamination Levels . . . . . . 8- .

8.2.4 Acceptable Contamination Levels on $\mathrm{UF}_{6}$ Conversion
Plant Equipment . . . . . ${ }^{\circ}$. $8-15$

8.3 CALCULATION OF EXAMPLE ACCEPTABLE RESIDUAL CHEMICAL CONTAMI-

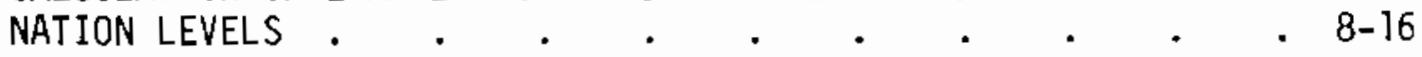


8.4 EXISTING GUIDANCE ON ACCEPTABLE RESIDUAL RADIOACTIVE CON-

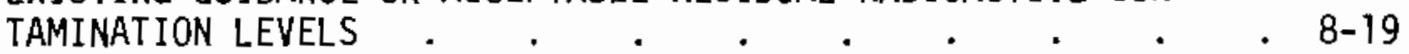

8.5 RESIDUAL CONTAMINATION LEVEL MEASUREMENTS . . . . . 8-20

8.5.1 Radioactivity Measurements . . . . . . 8-21

8.5.2 Chemical Contamination Measurements . . . . 8-24

REFERENCES . . . . . . . . . . . . . . . 8-25

9.0 DECOMMISSIONING ACTIVITIES $\quad . \quad$. . . . . . . . . . . .

9.1 DECOMMISSIONING BY DECON . . . . . . . . . . . . . 9-1

9.1.1 Program Plan. . . . . . . . . 9-1

9.1.1.1 Planning and Preparation . . . . . 9-2

9.1.1.2 Dismantlement and Decontamination . . . 9-5

9.1 .1 .3 Transportation . . . . . . . . . 9-5

9.1.1.4 Waste Management . . . . . . 9-6

9.1.1.5 Lagoon Waste Management . . . . . . 9-7

9.1.1.6 Finar Release Survey. . . . . . . 9-9

9.1.2 Essential Systems and Services . . . . . 9-9

9.1 .3 Security . . . . . . . . . 9-11

9.2 DECOMMISSIONING 8Y PASSIVE SAFSTOR . . . . . . . 9-11

9.2.1 Program Plan. . . . . . . . . 9-12

9.2.1.1 Planning and Preparation . . . . . 9-14

9.2.1.2 Waste Treatment Facilities Stabilization . . 9-16

9.2.1.3 Equipment Deactivation . . . . . 9-17

9.2.1.4 Isolation of Contaminated Areas . . . 9-78

9.2.1.5 Final Preparations for the Safe Storage Period
of Passive SAFSTOR . . . . 9-18

9.2.1.6 Safe Storage Period of Passive SAFSTOR . . 9-18

9.2.1.7 Deferred Decontamination . . . . . 9-21 
9.3 DECOMMISSIONING BY DECON OF THE PLANT AND EQUIPMENT WITH ONSITE DISPOSAL OF LAGOON WASTES . . . . . . 9 . $9-22$

REFERENCES . . . . . . . . . . . . . . . 9-24

T0.0 DECOMMISSIONING COSTS . . . . . . . . . . . . . . .

10.1 COST ESTIMATES FOR DECON $. \quad . \quad . \quad . \quad . \quad . \quad . \quad$. $10-1$

10.1.1 Manpower Requirements and Costs for OECON. . 10-2

10.1.1.1 Manpower Requirements . . . . . 10-3

10.1.1.2 Manpower Costs . . . . . . . 10-6

10.1.2 Material and Equipment Requirements and Costs for DECON. . . . . . . . 10-8

10.1.3 Waste Management Requirements and Costs for DECON - 10-9

10.1.3.1 Waste Management Requirements . . . . 10-9

10.1.3.2 Waste Management Costs . . . . . 10-11

10.1.3.3 Lagoon Waste Management Costs . . . . 10-12

10.1.4 Misce1laneous Owner Expenses for DECON . . . 10-13

10.2 ESTIMATEO COSTS OF THE PREPARATIONS FOR SAFE STORAGE PERIOD

OF PASSIVE SAFSTOR . . . . . . . . . . . 10-14

10.2.1 Manpower Requirements and Costs of Preparations for
Safe Storage. 10-15

10.2.1.1 Manpower Requirements . . . . . 10-15

10.2.1.2 Manpower Costs. . . . . . 10-15

10.2.2 Estimated Material and Equipment Requirements and
Costs of Preparations for Safe Storage . 10-18

10.2.3 Miscellaneous Owner Expenses for Preparations for Safe Storage . . . . . . . . 10-18

10.3 COST ESTIMATES FOR THE SAFE STORAGE PERIOD OF PASSIVE SAFSTOR 10-19

10.3.1 Manpower Requirements and Costs for Safe Storage . 10-20

10.3.2 Security and Surveillance Costs for Safe Storage . 10-21 
10.3.3 Material and Equipment Requirements and Costs for Safe Storage . . . . . . . . 10-22

10.3.4 Miscellaneous Owner Expenses During Safe Storage - 10-22

10.3.5 Maintenance Contractor . . . . . . . 10-22

10.4 COST ESTIMATES FOR THE DEFERRED DECONTAMINATION PERIOD OF

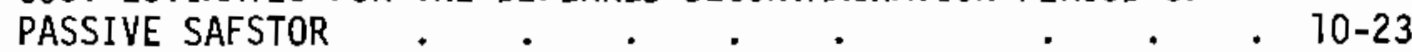

10.4.1 Manpower Requirements and Costs for Deferred Decontamination. . . . . . . . 10-24

10.4.2 Material and Equipment Requirements and Costs for Deferred Decontamination . . . . . . 10-27

10.4.3 Waste Management Requirements and Costs for Deferred Decontamination . . . . . . . 10-28

10.5 COST ESTIMATES FOR DECON OF PLANT AND EQUIPMENT WITH ONSITE DISPOSAL OF LAGOON WASTES $. \quad . \quad . \quad . \quad . \quad . \quad .10-28$ REFERENCES

11.0 PUBLIC AND OCCUPATIONAL SAFETY OURING DECOMMISSIONING OF THE REFERENCE UF ${ }_{6}$ CONVERSION PLANT $\cdot$.

11.1 TECHNICAL APPROACHES . . . . . . . . . . . 11-2

11.2 PUBLIC SAFETY ASPECTS OF DECOMMISSIONING THE REFERENCE UF 6 CDNVERSION PLANT

11.2.1 Public Radiation Doses from Routine Decommissioning Tasks . . . . . . . . . . 11-4

11.2.2 Public Radiation Doses from Postulated Accidents During Decommissioning . . . . . . 11-6

11.2.3 Nonradiological Public Safety Evaluation . . . 11-7

11.3 OCCUPATIONAL SAFETY EVALUATION OF DECOMMISSIONING THE REFERENCE $U_{6}$ CONYERSION PLANT $\cdot$.

11.3.1 Radiological Safety Evaluation of Routine Decommissioning Tasks . . . . . . . . .

11.3.2 Evaluation of Industrial Accidents . . . . 11-13 11.4 TRANSPORTATION SAFETY $. \quad . \quad . \quad . \quad . \quad . \quad . \quad$. $11-15$ 
11.4.1 Radiation Doses from Routine Decormissioning Transportation Tasks . . . . . . . . 11-15

11.4.2 Radiation Doses from Postulated Transportation Accidents . . . . . . 11-17

11.4.3 Casualties from Traffic Accidents . . . . 11-18 REFERENCES

12.0 DISCUSSION OF STUDY RESULTS . . . . . . . . . . 12-1

12.1 DECOMMISSIONING TECHNOLOGY . . . . . . . . . . 12-1

12.2 DECOMMISSIONING COSTS . . . . . . . . . . . 12-2

12.3 PUBLIC AND OCCUPATIONAL SAFETY . . . . . . . 12-3 REFERENCES . . . . . . . . . . . . 12-4

13.0 CONSIDERATIONS FOR THE FACILITATION OF DECOMMISSIONING . . 13-1

13.1 DESIGN AND CONSTRUCTION . . . . . . . . . . . . $13-2$

13.1.1 Design . . . . . . . . . . . . 13-2

13.1 .2 Construction . . . . . . . . . 13-3

13.2 OPERATION . . . . . . . . . . . . . . $13-4$

13.3 DECOMMISSIONING . . . . . . . . . . . . . $13-5$

14.0 GLOSSARY . . . . . . . . . . . . . . . . . . . . . .

14.1 ABBREVIATIONS, ACRONYMS, SYMBOLS, AND SI UNITS • . . $14-1$

14.2 GLOSSARY DEFINITIONS . . . . . . . . . . . 14-3

REFERENCES . $. \quad . \quad . \quad . \quad . \quad . \quad . \quad . \quad . \quad . \quad \cdot 14-19$

$\begin{aligned} & \text { APPENDIX A - REFERENCE URANIUM HEXAFLUORIDE CONVERSION FACILITY } \\ & \text { DESCRIPTION . } . . \cdot .\end{aligned}$

A.1 PROCESS DESCRIPTION . . . . . . . . . . . . . A-1

A.1.1 Production Systems Descriptions . . . . . A-4

A.1.1.1 Sampling the Dry Ore Concentrate . . . A-4 
A.1.1.2 Ore Concentrate to Purified $\mathrm{UO}_{2}\left(\mathrm{NO}_{3}\right)_{2}$. . A-5

A.1.1.3 Digestion of Dry Yellowcake . . . . A-5

A.1.1.4 Unloading, Sampling, and Digestion of Wet
Yellowcake. . A-5

A.1.1.5 Unloading, Sampling, and Digestion of Wet $\mathrm{UF}_{4} \cdot{ }^{4} \cdot \mathrm{A}-7$

A.1.1.6 Purification . . . . . . . A-8

A.1.1.7 Preparation of Uranium Trioxide . . . A-8

A.1.1.8 Evaporation and Denitration . . . . A-10

A.7.1.9 $\begin{aligned} & \text { Reduction of Uranium Trioxide to Uranium } \\ & \text { Dioxide }\end{aligned}$
A-10

A.1.1.10 Hydrofluorination of Uranium Dioxide to
Uranium Tetrafluoride . . A-11

A.1.1.11 Fluorination and Condensation . . . . A-11

A.1.1.12 Fluorination of Uranium Tetrafiuoride to Uranium
Hexafluoride

A.1.1.13 UF 6 Condensation . . . . . . A-13

A.1.1.14 Fluorine Production. . . . . . A-13

A.1.2 Effluent and Waste Disposal . . . . . . A-14

A.1.2.1 Liquid Waste Treatment and Disposal Systems . A-14

A.1.2.2 Solid Waste Treatment and Disposal . . . A-16

A.1.2.3 Gaseous and Particulate Control . . . A-18

A.1.3 Ventilation Systems . . . . . . . A-21

A.1.3.1 Main Plant Dust Collection System . . . A-21

A.1.3.2 $\mathrm{F}_{2}$ Cell Maintenance Area Fume Exhaust . . A-23

A.2 PLANT OESCRIPTION . . . . . . . . . . . . . A-24

A.2.1 Buildings . . . . . . . . . A-24

A.2.1.1 Main Building . . . . . . . A-27 
A.2.1.2 Solvent Extraction Building . . . . A-27

A.2.2 Detailed Plant Descriptions . . . . . . A-27

A.2.2.1 Sampling Station . . . . . . A-27

A.2.2.2 ADU Slurry Receiving and Storage . . . A-28

A.2.2.3 UF $\mathrm{UF}_{4}$ STurry Processing . . . . . A-29

A.2.2.4 Dissolution of Ore Concentrate . . . . A-29

A.2.2.5 Solvent Extraction . . . . . . A-30

A.2.2.6 Concentration of Uranyl Nitrate . . . A-30

A.2.2.7 Denitration Area . . . . . . A-31

A.2.2.8 Reduction Area . . . . . . . A-31

A.2.2.9 Hydrofluorination Area . . . . . A-32

A.2.2.10 Fluorination Area . . . . . . A-32

A.2.2.11 Fluorine Generation Area . . . . . A-32

A. 2.2.12 Nitric Acid Recovery Area . . . . . A-34

A.2.2.13 Instrument Repair Shop . . . . . A-34

A.2.2.14 Temporary Radwaste Facility . . . . A-34

A.2.2.15 Decontamination Facility . . . . . A-35

A.2.2.16 Laundry Facility . . . . . . A-35

A.2.2.17 Change Rooms . . . . . . . . A-36

A.2.2.18 Incinerator Facility . . . . . . A-36

A.2.2.19 Piping, Ductwork, Trays, and Light Fixtures . A-36

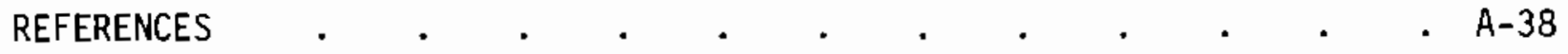

APPENDIX B - REFERENCE SITE DESCRIPTION . . . . . . . . . B-

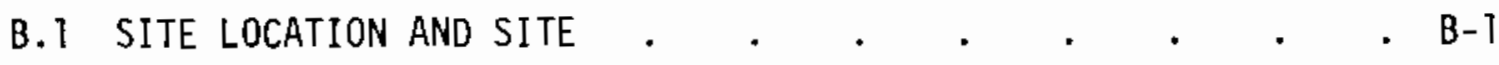

B.2 DEMOGRAPHY . . . . . . . . . . . . B-2 
B.3 LAND USE . . . . . . . . . . . . . . B-2

B.4 METEOROLOGY . . . . . . . . . . . . B-3

B.5 ESTIMATES OF RESIDUAL RADIOACTIVITY. . . . . . . B-7

B.6 ESTIMATES OF RESIDUAL CHEMICALS . . . . . . . . B-10

B.6.1 Gaseous Chemical Releases . . . . . . B-7l

B.6.2 Liquid Chemical Réleases . . . . . . B-11

REFERENCES . . . . . . . . . . . . . . . . B-13

APPENDIX C - RESIDUAL RADIONUCLIDE INVENTORY ESTIMATES . . . . . C-1

C.. KEY ASSUMPTIONS . . . . . . . . . . . . C-1

C.2 REFERENCE RADIONUCLIDE MIXTURE FOR THE UF ${ }_{6}$ CONVERSION PLANT . C-2

C. 3 ESTIMATES OF RESIDUAL RADIOACTIVITY LEVELS IN THE UF 6 PLANT • C-3

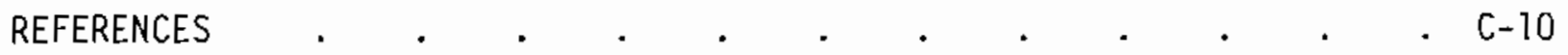

APPENDIX D - PAYMENTS NEEDED TO FINANCE DECOMMISSIONING — . . . D-1

D. 1 FORMULAS FOR COMPUTATION OF PAYMENTS . . . . . D-

D.2 COMPUTATION OF PAYMENTS . . . . . . . . . . D-2

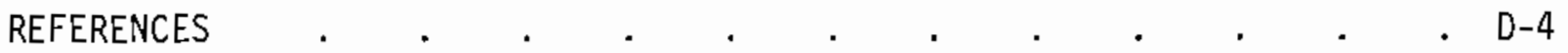

APPENDIX E - RADIATION DOSE MODELS AND CALCULATED MAXIMUM ANNUAL DOSES E-1

E.1 RADIATION DOSE TERMINOLOGY AND DEFINITIONS . . . . . E-1

E.2 GENERAL MODELS FOR ESTIMATING RADIATION DOSE . . . . . E-3

E.2.1 External Exposure . . . . . . . . . E-6

E.2.2 Ingestion . . . . . . . . . . . E-6

E.2.2.1 Deposition on Food Products or Ground Surfaces. E-7

E.2.2.2 Concentration in Vegetation . . . . . E-8

E.2.2.3 Concentration in Animal Products . . . E-9

E.2.3 Inhalation . . . . . . . . . E-10

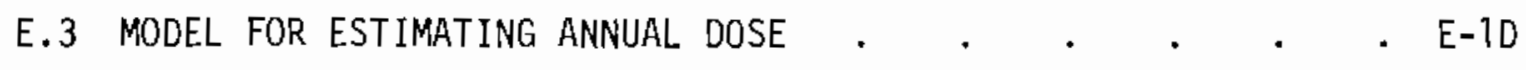


E.4 CALCULATED MAXIMUM ANNUAL DOSES AT THE DECOMMISSIONED REFERENCE

$\mathrm{UF}_{6}$ CONVERSION PLANT $\cdot \quad \cdot \quad \cdot \quad \cdot \quad \cdot \quad \cdot \quad \cdot \quad \cdot$ E-16

E.4.l Assumptions for Calculating Maximum Annual Dose . . E-16

E.4.2 Radionuclide Inventories for Calculating Maximum

Annual Doses. . . . . . . . E-17

E.4.3 Maximum Annua] Dose Listingș . . . . . E-17

REFERENCES . . . . . . . . . . . . . . . E-22

APPENDIX F - GENERAL DECOMMISSIONING CONSIDERATIONS . . . . . $\quad \mathrm{F}-1$

F. 1 GENERAL DECONTAMINATION METHODS . . . . . . . F-1

F.1.1 Surface Cleaning Procedures . . . . . . . F-2

F.1.2 Chemical Decontamination . . . . . . . F-2

F.1.3 Concrete Removal Techniques . . . . . . . F-3

F.2 SPECIAL EQUIPMENT REQUIREMENTS . . . . . . . . . . F-5

F.2.1 High-Speed Cutting Devices . . . . . . . F-6

F.2.2 Mechanical Cutting Devices . . . . . . F-6

F.2.3 Tools for Concrete Surface Removal . . . . . F-8

F.2.4 Portable Equipment . . . . . . . F-10

F.3 PACKAGING AND SHIPPING OF RADIOACTIVE MATERIALS • • • • F-10

F.3.1 Packaging of Radioactive Materials . . . . . . F-11

F.3.2 Shipping of Radioactive Materials . . . . . F-11

F.4 QUALITY ASSURANCE . . . . . . . . . . . . F-13

F.4.1 Methods Review . . . . . . . . F-15

F.4.2 Procurement Document Control . . . . . F-15

F.4.3 Work Instructions, Procedures, and Drawings . . F-16

F.4.4 Document Control . . . . . . . . F-16

F.4.5 Identification and Control of Procured Items . . F-16 
F.4.6 Special Processes . . . . . . . . . F-17

F.4.7 Inspection and Test . . . . . . . F-17

F.4.8 Calibration. . . . . . . . . . F-17

F.4.9 Shipping and Receiving. . . . . . . F-17

F.4.10 Operating Status . . . . . . . . F-18

F.4.11 Nonconformance and Corrective Action . . . . F-18

F.4.12 Special Quality Records . . . . . . F-18

F.4.13 Quality Auditing . . . . . . . . F-18

F.5 ENVIRONMENTAL SURVEILlanCE PROgRAM . . . . . . . F-18

F.5.1 Environmental Surveillance Program During DECON . - F-18

F.5.2 Environmental Surveillance Program for the Safe Storage
Period of Passive SAFSTOR . . . . F-21

REFERENCES . . . . . . . . . . . . . . . . F-23

APPENDIX G - DECOMMISSIONING ACTIVITY DETAILS . . . . . . G-1

G.1 FINAL PROCESSING INVENTORY CLEANOUT . . . . . . G-1

G.2 DECON ACTIVItIES

G.2.1 DECON Details

G.2.2 DECON Operations .

G.2.2.1 Drum Receiving - Area 1 . . . . . . G-7

G.2.2.2 ADU Slurry Receiving and Storage Area - Area 2. G-7

G.2.2.3 Sampling Station - Area 3 . . . . . G-7

G.2.2.4 Laboratory - Area 4 . . . . . . G-9

G.2.2.5 UF 4 Slurry Processing - Area 5 . • • . G-9

G.2.2.6 Ore Concentrate Dissolution - Area 6 • . G-9

G.2.2.7 Solvent Extraction Building - Area 7 • . G-9

G.2.2.8 Uranyl Nitrate Concentration - Area 8 . . G-11 
G.2.2.9 Denitration Area - Area 9 . . . . . G-11

G.2.2.10 Nitric Acid Recovery - Area 10. . . . G-11

G.2.2.11 Reduction Systems - Area 11 . . . . G-11

G.2.2.12 Hydrofluorination - Area 12 . . . . G-13

G.2.2.13 Fluorination - Area 13 . . . . . G-14

G.2.2.14 CyTinder Loading - Area 14 . . . . G-14

G.2.2.15 Fluorine Generation - Area 15 . . . . G-15

G.2.2.16 $\mathrm{F}_{2}$ Cel1 Rework - Area 16 . . . . . G-15

G.2.2.17 Instrument Repair Shop - Area 17 . . : G-16

G.2.2.18 Ammonia Cracking - Area 18 . . . . G-16

G.2.2.19 Waste Gas Disposal - Area 19 . . . . G-16

G.2.2.20 Hydrogen Fiuoride Condensing - Area 20 . . G-16

G.2.2.21 Temporary Radwaste Facility - Area 21 . . G-16

G.2.2.22 Temporary Decontamination Facility - Area 22 . G-17

G.2.2.23 Incinerator Facility - Area 23 . . . . G-17

G.2.2.24 Laundry and Change Rooms - Area 24 . . . G-17

G.2.2.25 Final Cleaning of the Entire Facility . . G-18

G.2.3 Site Decontamination Operations . . . . . G-18

G.2.3.] Extraction Waste Treatment System . . . G-18

G.2.3.2 Fluoride Waste Effluent Treatment System . . G-21

G.2.3.3 Miscellaneous Buried Waste . . . . G-22

G.2.3.4 Drum Storage Area . . . . . . . G-23

G.2.3.5 Cylinder Storage and Washing Area . . . G-23

G.2.3.6 Plant Stack . . . . . . . . G-23

G.2.3.7 Overall Final Site Survey and Cleanup . . G-23 
G.3 PASSIVE SAFSTOR ACTIVITIES . . . . . . . G-23

G.3.l Stabilization of Waste Treatment Facilities . . G-24

G.3.2 Deactivation of Unneeded Equipment . . . . G-24

G.3.3 Isolation of Contaminated Areas . . . . . G-25

G.3.4 Final Preparations for Safe Storage . . . . G-25

G.4 DECOMMISSIONING ACTIVITIES FOR DNSITE DISPOSAL OF LAGOON

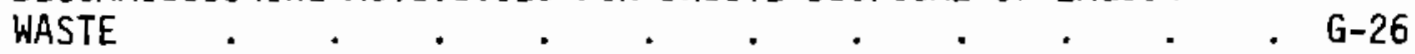

G.5 LAGOON WASTE STABilizATION DETAILS . . . . . . . G-27

G.5.1 Soil Cover . . . . . . . . . . G-27

G.5.2 Site Topography Adjustment . . . . . . G-28

G.5.3 Revegetation. . . . . . . . . G-28

G.5.4 Leachability Reduction. . . . . . . G-29

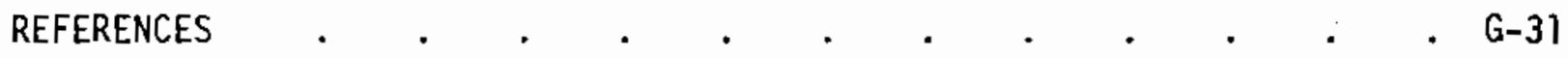

APPENDIX H - COST ASSESSMENT DETAILS . . . . . . . . $\mathrm{H}-\mathrm{l}$

H. 1 COMPILATION OF UNIT COST FACTORS . . . . . . . $\mathrm{H}-\mathrm{T}$

H.1.1 Unit Manpower Costs . . . . . . . H-1

H.1.2 Unit Waste Management Costs . . . . . . $\mathrm{H}-1$

H.1.2.1 Unit Shipping Container Costs . . . . $\mathrm{H}-1$

H.1.2.2 Unit Transportation Costs . . . . . H-I

H.1.2.3 Unit Waste Disposal Costs. . . . . H-5

H.1.3 Unit Costs of Special Equipment and Supplies . . H-5

H.2 COST ASSESSMENT DETAILS FOR DECON . . . . . . . H-8

H.2.1 Decommissioning Manpower Details for DECON . . . H-8

H.2.1.1 Staff Labor Job Descriptions . . . . $\mathrm{H}-\mathbf{9}$

H.2.1.2 Decommissioning Worker Manpower Requirements . H-10

H.2.2 Waste Management Details for DECON . . . . $\mathrm{H}-10$ 
H.2.2.1 Waste Management Requirements . . . . $\mathrm{H}-12$

H.2.2.2 Waste Management Costs . . . . . $\mathrm{H}-14$

H.2.2.3 Lagoon Waste Management Costs . . . . H-16

H. 3 COST ASSESSMENT DETAILS FOR PREPARATIONS FOR THE SAFE STORAGE

PERIOD OF PASSIVE SAFSTOR . . . . . . . . . . H-18

H.3.1 Decommissioning Worker Manpower Requirements for

Preparations for Safe Storage . . . . . H-18

H.4 LAGOON WASTE ONSITE BURIAL . . . . . . . . . . H-21

\section{REFERENCES}

APPENDIX I - SAFETY ASSESSMENT DETAILS . . . . . . . . . I I 1

I. 1 TECHNICAL APPROACH . . . . . . . . . . . I-

I.2 DECON PUBLIC SAFETY ASSESSMENT . . . . . . . . I-4

I.2.1 Routine DECON Tasks . . . . . . . . I -4

1.2.1.1 Methods for Calculating Atmospheric Releases of Radioactivity . . . . . . . I-5

1.2.1.2 Atmospheric Releases from DECON Tasks . . I-16

1.2.1.3 Public Radiation Doses from DECON Tasks . . I-16

1.2.2 Postulated Accidents During DECON • • . . I-25

I.2.2.1 Postulated Operational Accidents . . . I-25

I.2.2.2 Natural Phenomena . . . . . . I-4]

I.2.2.3 Aircraft Crashes . . . . . . I-42

I.2.2.4 Man-Caused Events . . . . . . I-42

I.2.2.5 Radiation Doses from Postulated DECON Accidents I-43

I.3 PASSIVE SAFSTOR PUBLIC SAFETY ASSESSMENT . . . . . I-43

I.3.1 Routine Tasks During Preparations for Safe Storage . I-43

I.3.2 Postulated Accidents During Preparations for Safe Storage. . . . . . . . . . I-45 
I.4 OCCUPATIONAL DOSE ESTIMATES FOR DECON AND SAFSTOR OF THE REFERENCE UF ${ }_{6}$ CONVERSION PLANT

I.5 RADIATION DOSES FROM WASTE TRANSPORT FOR DECOMMISSIONING THE REFERENCE UF 6 CONVERSION PLANT . . . . . . I-46 I.5.1 Technical Approach . . . . . . . I I-46 I.5.2 Doses from Routine Offsite Transport of Wastes. . I-5I 1.5.3 Transportation Accidents . . . . . . I-5I I.6 HAZARDOUS CHEMICAL RELEASES DURING DECOMMISSIONING OPERATIONS I-55 I.6.1 Chemical Residuals from Plant 0perations . . . 1-55 I.6.2 Chemical Residuals from Decontamination Agents . . I-57

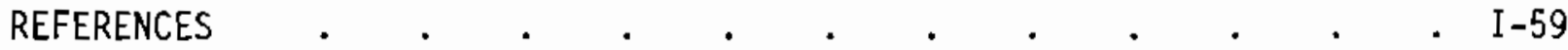


$-$ 


\section{FIGURES}

3.2-1 Time Phased Program by Task . . . . . . . . 3-2

4.2-1 Approach for Decommissioning Study . . . . . . . . 4-9

7.2-1 UF Production - Wet Solvent Extraction Fluorination Process

Simplified Block Flow Diagram. . . . . . . . 7-5

7.2-2 UF $\quad$ Production - Dry Hydrofluorination Process Simplified

Block Flow Diagram . . . . . . . . . . . 7-6

7.3-1 Isometric Drawing of the Reference $\mathrm{UF}_{6}$ Conversion Plant . 7-13

8.1-1 Relationship of Acceptable Contamination Level Analys is

Between Generic and Site-Specific Studies . . . . 8-2

8.1-2 Suggested Methodology for Determining Acceptable Residual

Radioactive Contamination Levels . . . . . . 8-7

9.1-1 Sequence and Schedule of Major Activities for Decommissioning

by $\mathrm{DECON}$. $\quad . \quad$. $\quad . \quad$. $\quad . \quad$. . . $9-2$

9.1-2 Sequence and Schedule of the Planning and Preparation Phase of DECON . . . . . . . . . . . . . 9-3

9.2-1 Sequence and Schedule for Major Activities for Passive SAFSTOR . . . . . . . . . . . 9-12

9.2-2 Sequence and Schedule of the Planning and Preparation Phase
of Passive SAFSTOR. . . . . . . . . . 9-14

10.1-1 Postulated Organization Chart for DECON . . . . . 10-3

10.2-1 Postulated Organization Chart for Preparations for Safe
Storage . . . . . . . . . . . . . . . .

10.3-1 Postulated Organization Chart for the Safe Storage Period . 10-21

A.1-1 UF Production - Wet SX - Fluorination Simplified Block Flow
Diagram . . . . . . . . . A-2

A.1-2 Schematic Flow Sheet of the Reference Plant . . . . A-3

A.1-3 ADU Slurry Receiving and Storage Flow Sheet . . . . A-6

A.1-4 UF 4 Slurry Processing . . . . . . . . . . A-9

A.1-5 Solvent Extraction waste Treatment System Flow Sheet . . A-15

A. -6 Fluoride Waste Treatment Flow Sheet . . . . . A-17 
A. 2-1 Site Layout of the Reference Plant . . . . . A-25

A.2-2 Main Building Layout of Reference Plant . . . . . A-26

B.4-1 Average $\left(\bar{\chi} / Q^{-}\right)$Values Versus Distance in a Sector from the Reference Site . . . . . . . . . . B-6

E.3-1 Time-Dependent Surface Resuspension Factor for the Site. E-15

F.2-1 Schematic of Concrete Spaller. . . . . . . F-9

F.3-1 Radiation Dose Limits for Exclusive-Use Vehicles . . . F-13

G.2-I Schedule and Sequence for DECON Activities of the Reference

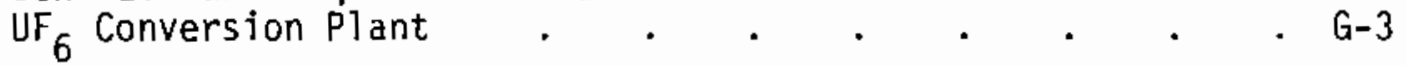

G.2-2 Schematic of the Extraction Waste Treatment System . . G-19

G.2-3 Schematic of the Fluoride Waste Treatment System . . . G-21 


\section{$\underline{\text { TABLES }}$}

2.4-1 Sumnary of Example Acceptable Residual Radioactive.Contamination Levels for Unrestricted Release of the Reference $\mathrm{UF}_{6}$ Conversion Plant and Site . . . . • • . 2-5

2.8-1 Summary of Estimated Costs for Decommissioning the Refer-

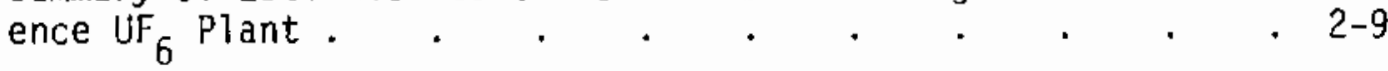

2.8-2 Decomissioning Cost Distribution of the Reference UF Plant

2.9-1 Summary of Safety Analysis - Decommissioning of Reference $\mathrm{UF}_{6}$ Plant . $\quad . \quad \cdot \quad \cdot \quad \cdot \quad \cdot \quad \cdot \quad \cdot \quad \cdot \quad \cdot 2-12$

2.11-1 Comparison of Decommissioning Alternatives for the Reference UF $_{6}$ Plant.

3.1-1 Information on $\mathrm{UF}_{6}$ Conversion Plants in the U.S. . . . 3-1

4.1-1 Characteristics of the Various Decomissioning Alternatives . 4-2

5.1-1 Principal Federal Agencies and Statutory Authority that May Affect Decommissioning . . . . . . . . 5-2

5.1.2 Checklist of Principal Federal Regulatory Requirements that Apply to Decommissioning a $\mathrm{UF}_{6}$ Conversion Facility . . 5-11

5.2-1 Estimated Uranium Inventory in Major Pieces of Equipment in the Reference Plant After Final Inventory Cleanout . . 5-14

7.1-1 Estimated Quantities of Radioactive Material Deposited on the Reference Site After a 4D-Year Operating Lifetime . . . 7-3

7.2-1 Estimated Annual Atmospheric Release of Radionuclides from the Reference $U_{6}$ Conversion Plant . . . . . . 7-8

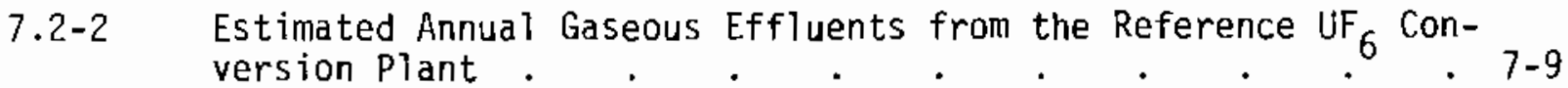

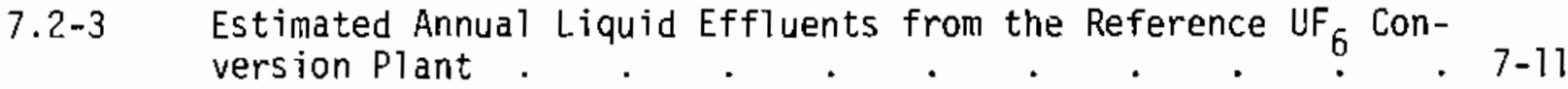

7.4-1 Specific Radioactivity of Residual Uranium in the Reference UF Plant at the Time of Plant Shutdown and at Various Times Afler Shutdown.

7.4-2 Estimated Uranium Inventory in Major Pieces of Equipment in the Reference $U_{6}$ Plant After Final Inventory Cleanout . . 7-17 
8.2-1 Example Acceptable Contamination Level Within the Reference

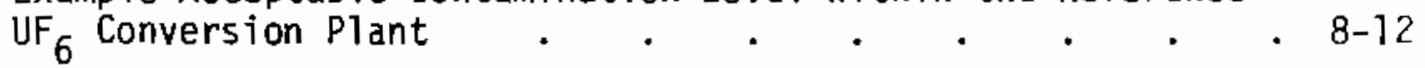

8.2-2 Example Acceptable Residual Contamination Levels on the Reference $U_{6}{ }_{6}$ Conversion Plant Site at Plant Shutdown . . . 8-13

8.2-3 Summary of Example Acceptable Residual Radioactive Contamination Leveis for the Reference $\mathrm{UF}_{6}$ Conversion Plant and its Sites

8.3-1 Example Acceptable Chemical Contamination Levels in the Reference $U_{6}$ Conversion Plant--Inhalation, Airborne Pathway

8.3-2 Example Acceptable Chemical Contamination Levels Within the Reference Facility--Ingestion Pathway . . . . . 8-18

8.4-] Regulatory Guide 1.86 Acceptable Surface Contamination Levels 8-19

8.4-2 ANSI N13.12 Surface Contamination Limits . . . . 8-20

8.5-1 Detection Capabilities for Environmental Sample Analysis . 8-22

8.5-2 Comparison of Measurement Methods for Radiation Surveys to Permit Unrestricted Use . . . . . . . . 8-23

9.1-1 Systems and Services Required During DECON . . . . 9-1D

9.2-1 Systems and Services Required During the Safe Storage Period of Passive SAFSTOR . . . . . . . . . 9-21

10.1-1 Summary of Estimated DECON Costs . . . . . . 10-2

10.1-2 Surmary of Manpower Utilization and Staff Costs for Planning and Preparation Phase of DECON . . . . . . 10-7

10.1-3 Surmary of Manpower Utilization and Staff Costs for the Dismantlement and Decontamination Phase of DECON . . . 10-7

10.1-4 Estimated Material and Equipment Requirements and Costs for DECON

10.1-5 Waste Disposal Packaging and Shipping Data for DECON . . 1D-10

10.1-6 Estimated Waste Management Costs for DECON . . . . 10-11

10.1-7 Cost of Lagoon Waste Management Options for DECON . . . 10-12

10.1-8 Estimated Miscellaneous Owner Expenses for DECON . . . 10-13 
10.2-1 Summary of Estimated Costs of Preparations for Safe Storage . 10-14

10.2-2 Summary of Manpower Utilization and Staff Costs for Planning and Preparation Phase of SAFSTOR . . . . . 10-17

10.2-3 Summary of Manpower Utilization and Staff Costs for Decomissioning Phase of SAFSTOR . . . . . . . . 10-17

10.2-4 Estimated Costs of Equipment and Supplies for Preparations for

Safe Storage . . . . . . . . . 10-18

10.2-5 Estimated Miscellaneous Owner Expenses During Preparations

for Safe Storage . . . . . . . . . 10-19

10.3-1 Estimated Annual Costs of the Safe Storage Period . . . 1D-20

10.3-2 Estimated Annual Staff Requirements for Safe Storage . . 10-22

1D.4-1 Summary of Estimated Deferred Decontamination Costs . . 10-23

1D.4-2 Summary of Manpower Utilization and Staff Costs for Planning and Preparations Phase of Deferred Decontamination . . 10-25

10.4-3 Summary of Manpower Utilization and Staff Costs for Decommissioning Phase of Deferred Decontamination . . . 10-26

10.4-4 Estimated Material and Equipment Requirements and Costs for Deferred Decontamination. . . . . . . 10-27

10.5-1 Summary of Estimated Cost for DECON of Plant with Onsite Burial of Lagoon Waste . . . . . . . 10-29

10.5-2 Cost of Onsite Burial of Lagoon Waste . . . . . 10-29

11.2-1 Summary of Ca1culated Radiation Doses to the Maximum-Exposed Individual from Atmospheric Releases During Routine Decommissioning Tasks . . . . . . . . . . 11-5

11.2-2 Summary of Calculated Radiation Doses to the Population from Atmospheric Releases During Routine Decommissioning Tasks . 11-5

11.2-3 Summary of Radiation Doses to the Maximum-Exposed Individual from Postulated $\mathrm{UF}_{6}$ Conversion Plant Decommissioning Accidents

11.3-1 Estimated Occupational Radiation Dose for DECDN . . . 11-10

11.3-2 Estimated Occupational Radiation Dose for SAFSTOR . . . 11-12 
11.3-3 Summary of Estimated Collective Occupational Radiation Doses at the Reference $\mathrm{UF}_{6}$ Conversion Plant . . . . . 11-13

11.3-4 Estimated 0ccupational Lost-Time Injuries and Fatalities During DECON and Preparations for Safe Storage . . . 11-14

11.3-5 Estimated Occupational Lost-Time Injuries and Fatalities During Safe Storage . . . . . . . . . 11-14

11.4-1 Calculated Radiation Doses from Routine Radioactive Waste Transportation. . . . . . . . . . 11-16

11.4-2 Estimated Casuatties from DECON Transportation Accidents . 11-18

A.2-1 Sampling Station Equipment and Laboratory . . . . A-28

A.2-2 Wet Yellowcake System Equipment . : . . . . A-28

A. 2-3 Uf 4 Slurry Equipment . . . . . . . . A-29

A.2-4 Ore Concentrate Dissolution Equipment . . . . . A-29

A.2-5 Solvent Extraction Equipment . . . . . . . A-30

A.2-6 Uranyl Nitrate Concentration Equipment . . . . . A-30

A.2-7 Denitration Equipment . . . . . . . . A-31

A.2-8 Uranium Trioxide to Uranium Dioxide Reduction Equipment - A-31

A.2-9 Hydrofluorination Equipment . . . . . . . A-32

A.2-10 Fluorination Equipment . . . . . . . . A-33

A.2-11 Fluorine Generation Equipment . . . . . . . A-33

A.2-12 Nitric Acid Recovery Equipment . . . . . . A-34

A.2-13 Equipment in the Instrument Repair Shop . . . . . A-34

A.2-14 Equipment in the Radwaste Room . . . . . . A-35

A.2-15 Equipment in the Decontamination Facitity . . . . A-35

A.2-16 Equipment in the Laundry. . . . . . . . A-36

A.2-17 Equipment in the Change Rooms . . . . . . . A-36

A.2-18 Equipment in the Incinerator facility . . . . . A-37 
A.2-19 Volumes and Weights of Piping, Ductwork, Trays and Light Fixtures . . . . . . . . . A-37

8.2-1 Population Distribution Around the Reference Site for the

B.4-1 Monthly Meteorological Statistics at the Reference Site . B-3

B.5-1 Estimated Annual Atmospheric Release of Radionuclide from the

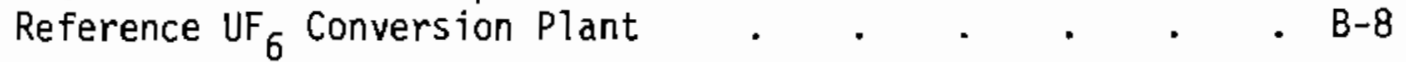

B.5-2 Estimated Quantities of Radioactive Materials Deposited on the Reference Plant Site After a 40-Year Operating Lifetime . B-10

B.6-1 Estimated Annual Gaseous Effluents from the Reference UF 6

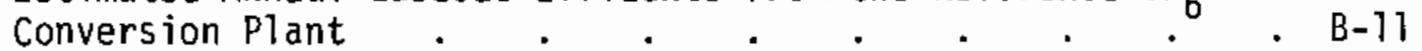

B.6-2 Estimated Annual Liquid Effluents from the Reference UF 6 Conversion Plant . . . . . . . . B-12

C.2-1 Specific Radioactivity of Residual Uranium in the UF 6 Plant at the Time of Plant Shutdown and at Various Times After Shutdown. . . . . . . . $\mathrm{C}-3$

C.3-1 Estimated Inventory of Uranium in Process Areas of the Reference $U_{6}$ Plant . . . . . . . . . C $\mathrm{C}-5$

E.2-1 Parameters Used for Calculation of Radiation Doses from Consumption of Foods . . . . . . . . E-5

E.4-1 Calculated Maximum Annual Radiation Doses to the MaximumExposed Individual Working in the Released Decommissioned $\mathrm{UF}_{6}$ Conversion Plant - Class W Material . . . . . E-78

E.4-2 Calculated Maximum Annual Radiation Doses to the MaximumExposed Individual Working in the Released Decommissioned $\mathrm{UF}_{6}$ Conversion Plant - Class Y Material . . . . . E-19

E.4-3 Calculated Maximum Annual Radiation Doses to the MaximumExposed Individual Residing on the Released Decommissioned $\mathrm{UF}_{6}$ Conversion Plant Site - Class W Material . . . . E-20

E.4-4 Calculated Maximum Annual Radiation Doses to the MaximumExposed Individual Residing on the ReTeased Decommissioned $\mathrm{UF}_{6}$ Conversion Plant Site - Class Y Material . . . . E-21

F.1-1 Concrete and Reinforcing Steel Removal Methods . . . F-4

F.2-1 Special Tools and Equipment for Dismantlement . . . F-7 
F.5-1 Recommended Basic Environmental Monitoring Program for the Period of Active Deconmissioning Operations . . . . F-20

G.2-1 General Sequence of Equipment Removal from the ADU Slurry Receiving and Storage Area . . . . . . . G-8

G.2-2 General Sequence of Equipment Removal from the Samping Station . . . . . . . . . . G-8

G.2-3 General Sequence of Equipment Removal from the Laboratory . G-9

G.2-4 General Sequence of Equipment Removal from the UF 4 Slurry Processing Area

G.2-5 General Sequence of Equipment Remova] from the Ore Concentrate Dissolution Area . . . . . . . . G-10

G.2-6 General Sequence of Equipment Removal from the Solvent Extraction Building .

G.2-7 General Sequence of Equipment Removal from the Uranyl Nitrate Concentration Area . . . . . . . G-ll

G.2-8 General Sequence of Equipment Removal from the Denitration Area . . . . . . . . . . G-12

G.2-9 General Sequence of Equipment Removal from the Nitric Acid Recovery Area . . . . . . . . . . G-12

G.2-10 General Sequence of Equipment Rerroval from the Reduction System Area . . . . . . . . . . . . G-13

G.2-11 General Sequence of Equipment Removal from the Hydrofiuorination Area

G.2-12 General Sequence of Equipment Removal from the Fluorination Area. . . . . . . . . . . . G-14

G.2-13 General Sequence of Equipment Removal from the Fluorine Generation Area . . . . . . . . . . G-15

G.2-14 General Sequence of Dismantling the Extraction Waste Effluent Treatment System . . . . . . . . . G-20

G.2-15 General Sequence of Dismantling the Fluoride Waste Effluent Treatment System $. \quad . \quad . \quad . \quad . \quad . \quad$. G-22

H.1-1 Decommissioning Labor Cost Data . . . . . . . . H-2

H.1-2 Unit Costs of Shipping Containers . . . . . . $\mathrm{H}-3$ 
H. 1-3 Transportation Rates for Legal-Sized and -Weight Shipments . H-4

H. 1-4 Additional Charges when Gross Vehicle Weight Exceeds

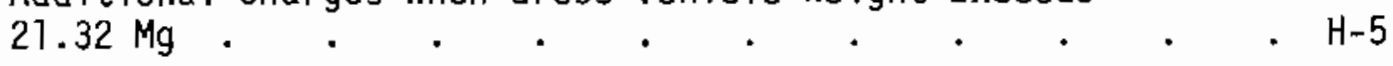

H.1-5 Commercial Shallow-Land Burial Charges . . . . . H-6

H.1-6 Unit Costs for Special Tools and Equipment . . . . H-7

H.2-1 Estimated Decommissioning Worker Manpower Requirements for DECON of the Reference Plant. . . . . . . H-ll

H.2-2 Shipping VoTumes of Equipment, Pipes, Ducts, and Other Materials. . . . . . . . . . $\mathrm{H}-13$

H.2-3 Postulated Sources of Concrete Rubble Generated During DECON H-14

H.2-4 Details of Estimated Costs for Radioactive Waste Management

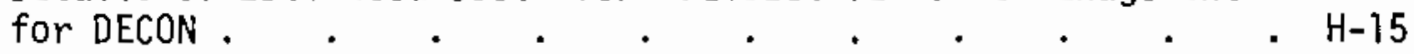

H.2-5 Detaijs of Costs for the Onsite Burial Option . . . H-16

H.2-6 Detaiis of Lagoon Waste Management Costs for Shipment to Uranium Mil1. . . . . . . . . H-17

H.2-7 Details of Lagoon Waste Management Costs for Shipment to LLW Burial . . . . . . . . . . H-19

H.2-8 Details of Estimated Costs for Shipment of Lagoon Wastes to a Commercial Waste Dump . . . . . . . . . $\mathrm{H}-20$

H.3-1 Estimated Decommissioning Worker Manpower Requirements While Preparing the Reference Plant for Safe Storage . . H-20

H.4-1 Details of Costs for Lagoon Waste Onsite Burial . . . H-2l

I.2-1 DECON Safety Analysis Summary . . . . . . . . I-6

I.2-2 Cutting Parameters for Piping and Equipment Removal . . I-13

I.2-3 Public Safety Analysis Data Sumary for DECON and Preparations for Safe Storage of the $\mathrm{UF}_{6}$ Conversion Plant . . I-17

1.2-4 Calculated Atmospheric Releases for DECON at the Reference $\mathrm{UF}_{6}$ Conversion Plant $. \quad . \quad . \quad . \quad$. . . . I-22

I.2-5 Radiation Doses to the Maximum-Exposed Individual from Atmospheric Releases During Routine DECON and Preparations for Safe Storage Tasks at the Reference $\mathrm{UF}_{6}$ Conversion Plant 
1.2-6 Radiation Doses to the Population from Atmospheric Releases During Routine DECON Tasks in the Reference $\mathrm{UF}_{6}$ Conversion Plant

I.2-7 Postulated Accidentai Atmospheric Reieases During DECON and Preparations for Safe Storage at the Reference $U_{6}{ }_{6}$ Conversion Plant

I.2-8 Example Explosive Data for Acetylene/Air Mixtures. . . I-35

I.2-9 LPG Explosion Information . . . . . . . I-39

R.2-10 Radiation Doses to the Maximum-Exposed Individual from
Atmopsheric Releases During DECON . . . . . I-44

1.4-1 Estimated Occupational Radiation Doses for DECON . . . I-47

I.4-2 Estimated Occupational Doses for Preparations for Safe Storage I-49

1.4-3 Estimated 0ccupational Radiation Doses During Safe Storage . I-50

I.5-1 Calculated Radiation Doses from Routine Radioactive Waste Transportation. . . . . . . . . . I-52

1.5-2 Transportation Accident Severity Categories . . . . I-53

I.5-3 Minor Accidents for Type A Packages During Truck Transportation . . . . . . . . . . I-54

I.5-4 Severe Accidents for Type A Packages During Truck Transportation.

I.5-5 Radiation Doses to the Maximum-Exposed Individual for Releases from Selected Transportation Accidents . . . I-55

I.6-1 Potential Chemical Residuals from Plant Operations . . I-56 


\section{D INTRODUCTION}

The purpose of this study is to provide information on the technology, safety, and costs of decommissioning uranium hexafluoride conversion ( $\mathrm{UF}_{6}$ ) piants. This information is intended for use as background data for the development of regulations and regulatory guides pertaining to decomissioning of $\mathrm{UF}_{6}$ plants and for use by plant licensees in planning for decommissioning of their facilities. Decommissioning techniques are reviewed and conceptually applied to a reference facility.

Decommissioning of a nuclear facility can be defined as the measures taken at the end of the facility's operating lifetime to ensure the continued protection of the public from any residual radioactivity and other potential safety concerns associated with the retired facility. A spectrum of decommissioning alternatives, all resulting in unrestricted release, are possible for such a facility. For this study, two specific alternatives are examined: DECON and passive SAFSTOR.

As used in this study, these decormissioning alternatives are defined as follows:

- DECON - Radioactive materials are removed and the facility is decontaminated and disassembled immediately following final shutdown. Upon completion, the property is released for unrestricted use.

- Passive SAFSTOR - Radioactive materials and contaminated areas are secured, and the structures and support systems are deactivated for a period of time ending in deferred decontamination. Until deferred decontamination is finished, the facility remains under a modified nuclear 7 icense. Decontamination is deferred for reasons specified by the facility owner, with NRC approva 1. Upon completion of decontamination, the property is released for unrestricted use.

The reference plant selected for this conceptual analysis is defined using a combination of existing facilities and no attempt is made to use a single plant as a model for all the design features. 
For each of the decommissioning alternatives studied, a work plan is developed for the conceptual decommissioning of the reference $U_{6}$ plant. These plans describe decommissioning methods, technology, and scheduling, from the planning phase through disposal of material and completion of decommissioning. From these plans, estimates are developed of manpower, major equipment and material needs, material disposal requirements, and the resultant costs. The primary guidelines for the development of these plans are:

- to ensure adequate public and occupational safety while utilizing costeffective decommissioning practices

- to use only current, proven decommissioning techniques.

To accomplish the decommissioning options, a number of variations in the work plans and techniques described in this study is possible. However, the methods postulated in this study appear to be representative of activities expected to be used for decommissioning a $U F_{6}$ plant, and are believed to reflect an appropriate balance of safety and cost.

The safety aspects of perfoming the decommissioning activities are assessed, as they affect both the general public and the decommissioning workers. Safety and cost issues are evaluated for the safe storage period of passive SAFSTOR, wherein periodic surveillance and maintenance at the site will be required to assure the continued protection of the public from the radioactive materials remaining in the facility.

Safeguards and accountability for handing fissile materials, quality assurance needs, and methods for assuring decommissioning finances are examined. Relative environmental and societal advantages and disadvantages are compared, where possible, for the decommissioning alternatives studied. Suggested criteria are developed for permissible contamination levels for unrestricted facility and site reuse, based on the potential for radiation exposure to the public.

Many aspects of decommissioning (e.g., plans, methods, safety, and costs) may be sensitive to variations in facility location, specific facility shutdown conditions, and residual contamination levels in the plant. The bases 
and assumptions used in this study must be carefully examined before the results can be applied to a different facility and site.

The results of this study are presented in sections and appendices. The sections summarize the key information developed and contain a summary as well as general background information (i.e., past experience in decommissioning selected types of facilities, decomissioning alternative definitions, study approach, applicable regulations and safeguards considerations, plant and site descriptions, and an overview of the suggested methodology used to develop acceptable residual contamination leveis). Decomissioning techniques are described, and cost and safety analyses for each of the decomissioning alternatives are presented. Also included is a discussion of basic methods for assuring financial capability for decomissioning, and a glossary of terms used in the report. The appendices contain the supporting data, methodology, and analyses that support the results and are organized corresponding to the report sections. References are presented at the end of each major section and appendix. 



\subsection{SUMMARY}

The results of this study to conceptually decommission a reference uranium hexafluoride conversion $\left(\mathrm{UF}_{6}\right)$ plant are summarized in this section. The purpose of the study is to identify the technology available and to evaluate the safety and costs related to decommissioning such a facility. The study is intended to provide background information for the development of regulations and regulatory guides pertaining to decomnissioning of $\mathrm{UF}_{6}$ plants and for use by plant licensees in planning for decommissioning of their facilities.

The reference plant used as the basis for this study is assumed to have processed 10,000 metric tons per year of natural uranium. The basis for the reference plant comes from a combination of existing and retired facilities and no attempt is made to use a single existing plant for the reference design. For this study, the facility is assumed to be located on a reference site having characteristics typical of midwestern or southeastern areas. 0ecommissioning plans, procedures, and schedules are developed for all plant areas that contain radioactive materials and for the inseparable adjacent areas that contain no radioactivity.

Two basic decommissioning alternatives (a) are considered in detail for the $U_{6}$ plant and site: OECON, and passive SAFSTOR. Waste generated by the reference plant is stored onsite in waste lagoons during plant operation. Potential decomuissioning methods for these waste lagoons are: 1) onsite burial including site stabilization followed by long-term care, and 2) removal of the waste to an authorized disposal site. Since onsite burial of the waste lagoons does not result in unrestricted release of the site (as required by OECON and SAFSTOR), another decommissioning method is also presented, DECON of the plant with stabilization followed by iong-term care for the waste lagoons. Costs and safety impacts are estimated for these alternatives, and comparisons of overall costs and potential risks are made. Methodology developed for previous decomissioning studies is modified and applied to determine example acceptable contamination levels for the reference facility and site.

(a) See Section 4 for descriptions of these alternatives. 
Some of the key bases for the study are:

- Decommissioning plans are selected on the basis of providing good public and occupational safety in a cost-effective manner.

- Decommissioning operations are evaluated assuming efficient performance of the work.

- current decommissioning technology and techniques are used.

- Expected contamination levels within the facility/site at the time of plant shutdown are based on known typical housekeeping practices during plant operation. The residual radioactive material is assumed to have accumulated at the rate of 1/40 per year for the assumed 40-year plant life.

- A radiation dose of $50 \mathrm{mrem} /$ year to the maximum-exposed individual is used as the basis for the determination of suggested levels of radioactivity that can remain on the site and the facility when the property is released for unrestricted use.

The results obtained in this study are specific to the above key bases and to the other bases and assumptions used in this study. Use of other conditions, bases, and assumptions (e.g., contamination levels) may change the results significantly.

\subsection{REVIEW OF DECOMMISSIONING EXPERIENCE}

A review of information on $U_{6}$ facilities in the United States shows that a) though several UF 6 plants have been shut down, none have been completely decommissioned. A proposed plan for decommissioning a U.S. Department of Energy $U F_{6}$ plant is used as an example of potential decomissioning experience. Two low-enriched uranium fuel fabrication facilities have been decomissioned, which provides some related experience. The review shows that: 1) experience exists in government and private organizations regarding methods and equipment for performing decomnissioning operations of nuclear fuel cycle facilities, and 2) technology exists to successfully decommission UF 6 plants. 


\subsection{FEDERAL REGULATIONS AND GUIDELINES}

Regulatory and federal guidelines are reviewed relative to their general application to decomissioning of $U_{6}$ plants. The review shows that in many cases the regulations do not speak specifically to decommissioning but can be interpreted as being applicable.

Areas where our review of current regulations indicate that more specific guidance could be helpful are:

- Financial qualifications and responsibilities for decommissioning need to be clarified to better define the commitments of the facility owner for achieving the final decomissioned status of the property. Specific definitions need to be established as to what are accaptable methods for assuring the availability of funds at the time of decomissioning.

- Some centralization, or a central indexing, of regulations pertaining to decomissioning in the Code of Federal Regulations would be very helpful.

- Existing guidance on what levels of residual radioactivity are acceptable on materials, structures, and sites for unrestricted use is somewhat fragmentary and does not have a common identifiable basis. The suggested methodology demonstrated in this study could form that basis, predicated on a decision by regulatory agencies as to what constitutes an acceptable annual radiation dose to the maximum-exposed individual from unrestricted use of decommissioned property.

Both site stabilization and the removal of the contaminated material are considered in this study as alternatives for the decommissioning of the waste lagoons. The NRC has not yet determined whether site stabilization would be acceptable; its acceptability would have to be considered on a case-by-case basis. Legislation and information pertaining to uranium mill tailings piles contained in the Uranium Mi11 Tailings Control Act of 1978, (1) in the Generic Environmental Impact Statement on Uranium Milling, (2) and in new regulations on uranium mill tailings licensing ${ }^{(3)}$ can be used for guidance. However, there are differences between uranium mill tailings and the reference plant wastes and other considerations will be involved. 


\subsection{APPROACHES TO FINANCING DECOMMISSIONING}

Three general approaches to financing future decormissioning costs are identified: 1) creation of a sinking fund by annual payments during the operating lifetime of the facility, 2) an initial payment into a trust fund at the time of facility startup, and 3) purchase of a surety bond or an equivalent method of guaranteeing funds for decommissioning. A set of five criteria is identified that may be helpful in evaluating the desirability of each of these financing approaches. These criteria are: 1) the extent to which decomissioning is financially assured, 2) the present value cost of each approach, 3) the extent to which the beneficiaries of the operation of the facility pay for its decomissioning, 4) the extent to which the approach facilitates the consideration of decomissioning costs when making selections between alternative power generation systems, and 5) the ease with which the approach can be administered.

\subsection{SUGGESTED METHODOLOGY FOR DETERMINING ACCEPTABLE RESIDUAL RADIOACTIVE AND CHEMICAL CONTAMINATION LEVELS FOR A UF 6 PLANT}

Methodology presented in this report is used to develop numerical values for acceptable residual radioactive and chemical contamination levels for decommissioned $U F_{6}$ facilities and sites. The suggested methodology for radioactive levels is based on maximum annual doses to any member of the public from all probable radiation exposure pathways resulting from unrestricted use of the reference facility or site.

Numerical dose 1 imits for unrestricted use of decommissioned facilities and sites by members of the public are currently being investigated by the Nuclear Reguiatory Commission and the Environmenta] Protection Agency. For this study, it is assumed that the i imit that will apply is an annual dose of 10 mrem. The use of 10 mrem in this study is consistent with the current NRC recommendations for an annual dose range to be used as guidance in decommissioned nuclear facilities. Example calculations for a maximum annual dose of 10 mrem are summarized in Table 2.4-1. These numbers are based on a specific radionuclide mixture expected to be present in the reference $U_{6}$ facility and in the site soil, resulting from normal production operations and associated 
IABLE 2.4-1. Sumary of Example Acceptable Residual Radioactive Contamination Levels for Unrestricted Release of the Reference UF ${ }_{6}$ Conversion Plant and Site

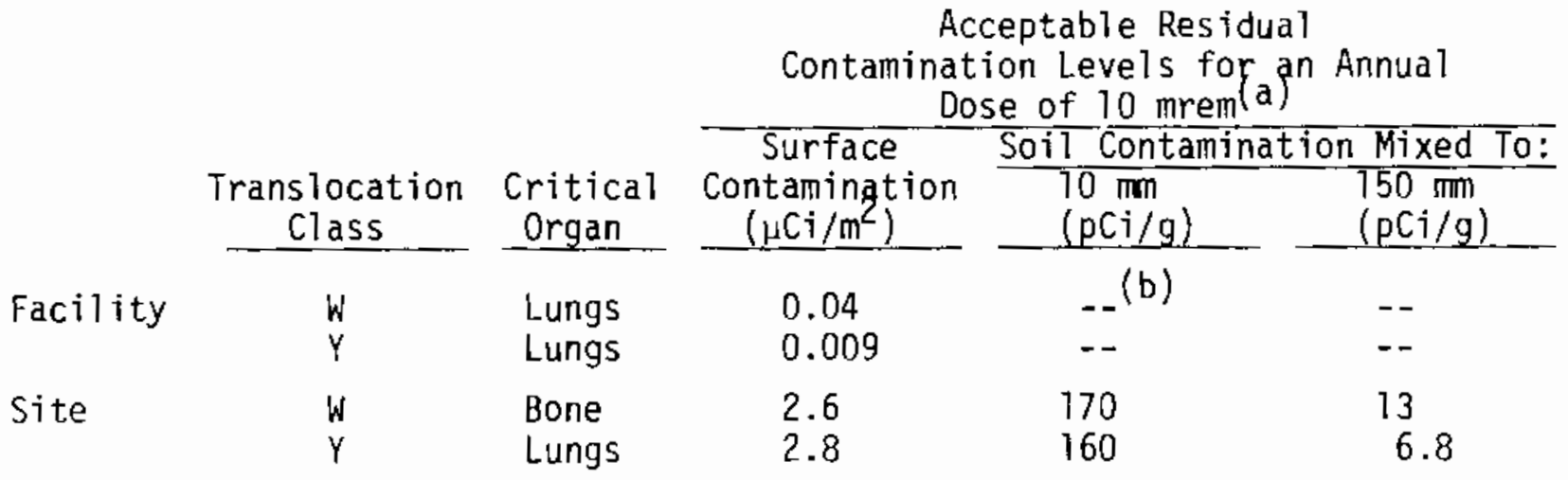

(a) Based on the natural uranium mixtures shown in Table 7.4-1 for the facility and Table 7.1-l for the site.

(b) A dash indicates that soil contamination levels are not calculated for surface contamination inside the facility.

atmospheric releases. For the site, acceptable residual contamination levels are determined for various times between plant shutdown and final decommissioning. The principal contributors to the calculated annual dose are found to be $234 \mathrm{U}, 235 \mathrm{U}$, and $238 \mathrm{U}$.

The methodology developed to determine chemical contamination levels is based on the radiological methodology. Acceptable residual chemical contamination levels are determined for inhalation and ingestion pathways. Inhalation exposure level limits are based on 0.01 of the threshold limit value, and ingestion Timits are based on exposure not exceeding EPA drinking water standards. These leveis provide a safety factor that accounts for exposure to the most susceptible individuals.

Since dose limits for decommissioned facilities and sites are promulgated by federal agencies, corresponding acceptable residual contamination levels can be derived using the suggested methodology developed in this study for conditions specific to a particular facility. The examples of acceptable contamination levels derived in this study are specific to the facility and site conditions assumed to exist at the reference $U_{6}$ plant. 


\subsection{FACILITY CHARACTERISTICS}

The plant is assumed to be operated for 40 years at a production rate of 10,000 metric tons of natural uranium per year. The feed to the plant is natural uranium $\mathrm{U}_{3} \mathrm{O}_{8}$ (yellowcake). Yellowcake concentrate extracted from uranium ore is converted to the volatile compound uranium hexafluoride (UF 6 ) for enrichment by the gaseous diffusion process. Two processes are in commercial use at this time which differ primarily in the method of purification of the product. The purification step is added either at the beginning using a solvent extraction process or at the end by a fractional distillation of the $U_{6}$. The reference plant employs the wet chemical solvent extraction step at the head end of the process to prepare a high-purity uranium feed to the reduction, hydrofluorination, and fluorination steps. The effluents consist of impurities contained as dissolved solids in the solvent extraction waste stream. The second waste stream, fluoride waste, is generated primarity by the hydrofluorination system. Solvent extraction and fluoride wastes are entrapped in waste lagoons onsite.

\subsection{ESTIMATED RADIONUCLIDE INVENTORIES}

Estimates are made of the amount of residual radioactivity within the plant (after final operational flushing and chemical decontamination) and on the plant site from 40 years of normal operation. Numerous activities could occur during the operational phase of the facility that could significantly affect radionuclide inventories. The inventories used in this study are presented in Table 7.4-2 of Section 7 and are based on engineering judgment that considers the characteristics of the reference facility. After operational inventory cleanout, the total uranium inventory in the main plant building is estimated to be about $12,400 \mathrm{~kg}$. Chemical decontamination activities during decommissioning reduce this inventory to about $5,700 \mathrm{~kg}$ of uranium.

\subsection{DECOMMISSIONING METHODS}

A plan and a set of procedures are developed for each of the two basic alternatives studied for decommissioning the reference $U_{6}$ plant. Decommissioning is 
assumed to start after termination of production operations. Termination includes a process inventory cleanout and audit similar to that done periodically between operating campaigns for material segregation and accountability.

The first decommissioning phase for each alternative is termed "planning and preparation." This phase takes place during the last year of normal plant operation. During this phase, the decomissioning staff is assembled; a decommissioning plan and procedures are prepared; safety analysis reports and an environmental impact evaluation are prepared; an application for an amended license is prepared; a quality assurance program is established; health and safety requirements are developed; and bulk quantities of unneeded process chemicals, radioactive materials, and nonessential uncontaminated equipment are removed.

In general, decommissioning work is assumed to be done on the basis of 5 days per week with one shift of workers. Certain operations (such as extraction waste processing and plant security) are carried out on a 3-shift-day, 7-day-week basis.

\subsubsection{DECON Procedures}

After about 6 months of planning and preparation, DECON activities are initiated. These activities are generally divided into four phases:

- physical and chemical decontamination of equipment and facilities

- removal of equipment and facilities

- radioactive materials handling, packaging, and shipping

- final cleaning and survey.

These phases can proceed simultaneously in different parts of the facility. Approximately 8 months are needed to complete all phases and release the site for unrestricted use.

Chemical decontamination involves flushing of internal surfaces of process piping and equipment. Physical decontamination involves disassembly of equipment and enclosures and removal of the contaminated materials. Physical decontamination also involves removal of contaminated portions of structural and site materials. These contaminated materials are packaged and transported offsite 
as waste, or they are processed through the plant radwaste and incinerator facilities for recovery. Upon completion of dismantlement, decontamination, shipping, and final cleaning and survey, the facility can be released for unrestricted use.

\subsubsection{Passive SAFSTOR Procedures}

After about 6 months of planning and preparation, active decommissioning efforts (preparations for safe storage) are divided into four phases:

- waste treatment facilities stabilization

- equipment deactivation

- isolation of contaminated areas

- final preparations for safe storage.

Many of the decomissioning activities associated with preparations for safe storage can proceed simultaneously. It is estimated that approximately 3 months are required to place the plant and site in safe storage.

Decontamination efforts for passive SAFSTOR are similar to those performed for DECON, but are performed to a lesser extent. Also involved are deactivation and isolation of contaminated areas, sealing of contamination by adding durable seals or covering with paint, and installation of improved alarm and protection systems for fire, intrusion, or malfunctioning equipment.

Activities during the safe storage period include routine inspection, corrective and preventive maintenance on safety systems, environmenta] survei1lance, and prevention of unauthorized intrusion by man.

Safe storage must be terminated eventually by deferred decontamination. Activities are generally similar to those for DECON, with allowances for the prior decontamination efforts and for retraining of new decommissioning staff. An estimated 14 months are needed to decontaminate the facility at the conclusion of the period of safe storage, including 6 months for planning and preparation and 8 months for active decommissioning.

\subsubsection{Site Stabilization Procedures}

Site stabilization is assumed to include the following procedures. The lagoon waste is covered with a $50-\mathrm{mm}$-thick layer of asphalt. This asphalt 
layer is then covered with $1 \mathrm{~m}$ of soil. The soil is mounded slightly at the center to allow water to drain from the soil cover and to prevent the accumulation of runoff from rainfall or snow melt. After compaction and contouring of the soil cover, the area is seeded with grass.

\subsection{COSTS}

The estimated costs in 1981 dollars for the decommissioning alternatives in this study are summarized in Table 2.8-1. These cost estimates include a $25 \%$ contingency. For $D E C O N$, the cost is estimated to be $\$ 5.91$ million. For passive SAFSTOR, placing the plant in safe storage is estimated to cost $\$ 0.88$ million; the annual cost of maintaining the plant in passive safe storage is estimated to be about $\$ 0.095 \mathrm{million}$; and deferred decontamination of the plant is estimated to cost $\$ 6.50$ million. Therefore, passive SAFSTOR with final decontamination after 10 years is estimated to cost about $\$ 8.33$ million. The cost of DECON with stabilization of the lagoon wastes is estimated to be $\$ 4.59$ million, with an annual cost of $\$ 11,000$ for long-term care. All costs are in non-discounted 1981 dollars. DECON with stabilization of the lagoon wastes is

IABLE 2.8-1. Summary of Estimated Costs for Decommissioning the Reference $\mathrm{UF}_{6}$
PTant (Millions of 1981 Dollars)

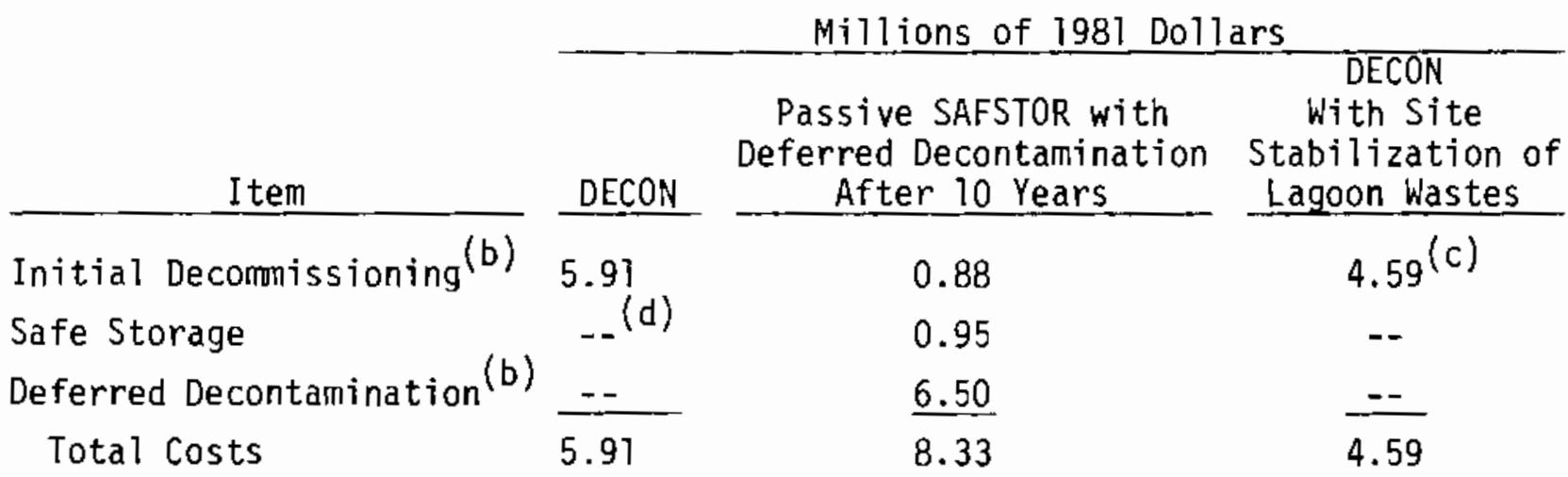

(a) Cost estimates include $25 \%$ contingencies.

(b) Costs are based on five shifts/week (single shift) for most of the decommissioning. Decommissioning on a two-shift/day basis would reduce time requirements but costs would be about the same.

(c) Plus $\$ 11,000$ per year for long-term care. Amended 7 icense must be retained.

(d) Dash indicates cost item not applicable to that decommissioning alternative. 
the least expensive option. However, the NRC has not yet determined the acceptability of this alternative. This analysis of decomissioning costs indicates an economic disincentive to defer decontamination, primarily because of the cost of safe storage. Deferred decontamination costs more than DECON because of increased labor costs for the following items: 1) removal of seals and barricades erected for safe storage, 2) replacement and testing of ventilation filters, and 3) training of the decommissioning staff.

The breakdown of costs by major cost element for DECON and SAFSTOR is given in Table 2.8-2. Labor costs are about $40 \%$ of total cost. Thus, there is considerable incentive to develop plans or techniques that could reduce labor costs. The deferral of decontamination requires additional costs to modify facilities, to reinstitute a trained decomissioning organization, and to provide an anaiysis of the planned final decontamination to obtain the dismantlement order. Also, passive SAFSTOR costs increase with longer storage time. Other costs of deferred decontamination are about the same as for DECON.

Cost of management of the wastes from DECON amounts to about $38 \%$ of the total cost. Of the waste management cost, transfortation accounts for about $20 \%$ and disposal accounts for about $50 \%$.

TABLE 2.8-2. Decommissioning Cost Distribution of the Reference $U_{6}$ Plant
(militions of 1981 dollars)

\begin{tabular}{|c|c|c|}
\hline I tern & DECON & $\begin{array}{l}\text { Tjons of } 1981 \text { Dollars } \\
\text { Passive SAFSTOR with } \\
\text { Deferred Decontamination } \\
\text { After } 10 \text { Years }\end{array}$ \\
\hline Labor & 2.56 & 3.86 \\
\hline Materials & 0.19 & 0.45 \\
\hline Waste Management & 2.23 & 2.37 \\
\hline Subcontracts & -- & 0.27 \\
\hline Utilities, Taxes & $\underline{0.93}$ & 1.38 \\
\hline Tota?s & 5.91 & 8.33 \\
\hline $\begin{array}{l}\text { (a) Includes } 25 \% \\
\text { (b) Includes the } \\
\text { years before }\end{array}$ & $\begin{array}{l}\text { contin } \\
\text { costs } \\
\text { decont }\end{array}$ & $\begin{array}{l}\text { ncy. } \\
\text { safe storage for the } \\
\text { ination. }\end{array}$ \\
\hline
\end{tabular}




\subsection{SAFETY}

Generally conservative estimates are made of the potential safety impacts on the public and on the workers from decommissioning the reference UF 6 plant. Events are analyzed relative to potential consequences and approximate frequency of occurrence. Radiation exposures from normal operations and potential accidents are investigated for immediate and deferred decomissioning activities, storage of partly decomissioned facilities, and transportation of radioactive materials. The results are summarized in Table 2.9-1.

The 50-year committed dose equivalent to the populace located within $80 \mathrm{~km}$ of the facility from airborne releases resulting from DECON activities is conservatively estimated to be about 4 man-rem to the lungs. This radiation dose is a very small fraction of the dose received by the affected population from naturally occurring radiation. Radiation doses to members of the pubiic during the period of passive safe storage are essentially negligible. Doses from DECON with stabilization of lagoon wastes are the same as for the DECON alternative. All of the postulated radiation doses are low, primarily because of greatly reduced radionuclide inventories during most of the decommissioning operations and the utilization of efficient process and ventifation filtration systems.

The estimated occupational radiation dose for DECON is 79 man-rem. The doses for passive SAFSTOR are 0.18 man-rem for preparations for safe storage, 0.087 man-rem for each year of safe storage, 62 man-rem for deferred decontamination, and 17 man-rem for transportation, for a total of 80 man-rem. Because of the long-lived radionuclides, deferral of decontamination does not reduce the occupational dose. The occupational dose for DECON with stabilization of lagoon wastes is 66 man-rem.

Potential radiation doses to members of the public from accidents are generally found to be quite low. The major accident postulated to result in the largest atmospheric release of radioactivity is an oxyacetylene explosion during the removal of piping and equipment in the ADU slurry receiving and storage area of the plant. This accident is estimated to release $1.8 \times 10^{-3} \mathrm{Ci}$ of uranium. 

TABLE 2.9-1. Summary of Safety Analys is - Decommissioning of Reference $\mathrm{UF}_{6}$
Plant

\begin{tabular}{|c|c|c|c|c|c|}
\hline $\begin{array}{c}\text { Type of } \\
\text { Safety Concern }\end{array}$ & $\begin{array}{l}\text { Source of } \\
\text { Safety Concern }\end{array}$ & Units & DECON & $\begin{array}{l}\text { Passive SAFSTOR with } \\
\text { Deferred Decontamjination } \\
\text { After } 10 \text { Years (a) }\end{array}$ & $\begin{array}{c}\text { DECON } \\
\text { with Site } \\
\text { Stabilization }\end{array}$ \\
\hline \multicolumn{6}{|c|}{ Public Safety (b) } \\
\hline \multirow{4}{*}{$\begin{array}{l}\text { Population Dose } \\
\text { Radiation } \\
\text { Dose }\end{array}$} & $\begin{array}{l}\text { Decommissioning } \\
\text { Operations }\end{array}$ & man-rem $(c)$ & 4.0 & 4.0 & 4.0 \\
\hline & Transportation & man-rem & 1.7 & 1.7 & 0.35 \\
\hline & Safe Storage & $\operatorname{man}-\operatorname{rem}(\mathrm{c})$ & $N / A^{(d)}$ & 0.0003 & $N / A$ \\
\hline & & Totals & 5.7 & 5.7 & 4.35 \\
\hline \multicolumn{6}{|c|}{ Occupational Safety } \\
\hline \multirow[t]{4}{*}{$\begin{array}{l}\text { Serious Lost- } \\
\text { Time Injuries }\end{array}$} & $\begin{array}{l}\text { Decommissioning } \\
\text { Operations }\end{array}$ & Injuries & 0.25 & 0.27 & 0.25 \\
\hline & Transportation & Injuries & 1.5 & 1.5 & 1.5 \\
\hline & Safe Storage & Injuries & $N / A$ & 0.077 & $N / A$ \\
\hline & & Totals & 1.8 & 1.8 & 1.8 \\
\hline \multirow[t]{4}{*}{ Fatalities } & $\begin{array}{l}\text { Decommissioning } \\
\text { Operations }\end{array}$ & Fatalities & 0.0016 & 0.0017 & 0.0016 \\
\hline & Transportation & Fatalities & 0.09 & 0.09 & 0.09 \\
\hline & Safe Storage & Fatalities & $N / A$ & 0.0006 & $y / A$ \\
\hline & & Totals & 0.092 & 0.092 & 0.092 \\
\hline \multirow[t]{4}{*}{ Radiation } & $\begin{array}{l}\text { Decommissioning } \\
\text { Operations }\end{array}$ & man-rem & 62 & 62 & 62 \\
\hline & Transportation & man-rem & 17 & 17 & 3.6 \\
\hline & Safe Storage & man-rem & $N / A$ & 0.87 & $N / A$ \\
\hline & & Totals & 79 & 80 & 66 \\
\hline
\end{tabular}

(a) Time after reference facility final shutdown; includes 1 year of preparations for safe storage.

(b) Radiation doses from postulated accidents are not included. They are given in Section 1]. Both public and occupational doses include the waste exhumation, packaging, and offsite disposal option for the extraction pond, fluoride lagoons, and other onsite wastes.

(c) 50-year comitted dose equivalent to the lung.

(d) Not applicable.

Chemical poliutants that could be released during decommissioning activities are found to come from residuals from plant operations and from decontamination chemicals. Chemical releases during decommissioning are examined and the quantities released are found to have no significant effect on the public. occupational exposure to toxic chemicals is assumed to be limited by conventional industrial contamination control techniques. 


\subsection{WASTE MANAGEMENT}

Radioactive wastes generated during the decommissioning of a $\mathrm{UF}_{6}$ plant are packaged and shipped to a licensed low-level waste burial ground. There are no high-level or TRU wastes present in the reference plant. The radioactive wastes generated include: process and facility equipment and components, pipe, concrete rubble, filters, trash, decontamination liquids, miscellaneous waste buried onsite, fluorination tower ash and sludge and material from the waste lagoons.

About $1260 \mathrm{~m}^{3}$ of the radioactive waste from the main process building and the solvent extraction building is assumed to be packaged and shipped to lowlevel waste burial. About $1870 \mathrm{~m}^{3}$ of materials and equipment from the buildings and site are decontaminated and excessed or sent to commercial waste burial.

Sludges from the solvent extraction and fluoride lagoons must be disposed of for $U F_{6}$ plant decommissioning. Several alternative methods of disposal for the lagoon wastes are available. These are: onsite burial including site stabilization followed by long-term care (similar to SAFSTOR), 2) removal of waste to a uranium mill for recovery of residual uranium, 3) removal of waste to an LLW burial ground, and 4) removal of waste to a chemical or commercial waste dump.

The solvent extraction waste $\left(21,600 \mathrm{~m}^{3}\right)$ sludge has a uranium concentration of about $0.28 \mathrm{wt} \%$ uranium, which puts it at levels slightly higher than the levels in uranium mill tailings. For the DECON alternative, the extraction wastes must be removed from the site to allow unrestricted release.

The NRC has not yet determined whether stabilization of the lagoon wastes would be acceptable; its acceptability would have to be considered on a caseby-case basis. Information about the technology and costs of stabilizing uranium mill tailings and burial grounds that is contained in the uranium mil7 ing EIS ${ }^{(2)}$ and the burial ground decommissioning study ${ }^{(4)}$ can be used as guides in developing decommissioning requirements for waste stored onsite during operation.

For the reference plant, the extraction waste can be processed by a milling contractor to recover the residual uranium. The uranium concentration 
in the extraction waste for the reference plant is about the level of uranium concentrates in ore being currently mined.

The decision to recover the uranium would be based on an economic study to determine whether the cost of shipping and recovery less the value of the recovered uranium would be less than the cost of burial. Based on current prices for uranium and the inflationary trends in yellowcake cost, it is expected that the economic value of the recovered uranium would make it cost effective to process the extraction waste.

The fluoride waste does not contain sufficient uranium to warrant recovery and that option is not included in this analysis.

If the extraction waste is not processed to remove the residual uranium, it would be disposed of at a low-level waste burial ground at the time of decommissioning. If fluoride waste cannot be stored onsite it would be shipped to LLW burial.

An alternative to low-level waste disposal of the extraction waste would be a reduction of the residual radioactivity levels by incorporation of nonradioactive fill material and storage onsite or shipment to a chemical or commercial waste dump. The concentration of uranium in the resultant waste would need to be less than a value defined by federal regulations as acceptable for unrestricted release. There is presently no clear definition of what constitutes acceptable levels of uranium in bulk waste.

\subsection{STUDY CONCLUSIONS}

Decommissioning of a $\mathrm{UF}_{6}$ plant is technically feasible with current technology. Decommissioning can be done with virtualiy no impact on the safety of the general public. Further development of some techniques (such as decontamination and waste volume reduction) could lead to reductions in costs.

A comparison of the decommissioning alternatives for the various parameters used in this study is given in Table 2.11-1. The main parameters considered are the costs, the potential radiation doses, and the impacts of the DECON and passive SAFSTOR alternatives on staffing requirements and on space requirements at waste disposal facilities. 
TABLE 2.11-1. Comparison of Decommissioning Aiternatives for the Reference $\mathrm{UF}_{6}$ Plant

\begin{tabular}{|c|c|c|c|}
\hline Parameter & DECON & $\begin{array}{l}\text { Passive SAFSTOR with } \\
\text { Deferred 0econtamination } \\
\text { After } 10 \text { Years }\end{array}$ & $\begin{array}{r}\text { DECON with } \\
\text { St.abilization } \\
\text { of Lagoon Wastes } \\
\end{array}$ \\
\hline $\begin{array}{l}\text { Decommissioning Cost (a) } \\
\text { (millions of } 1981 \text { dollars) }\end{array}$ & 5.91 & 8.33 & 4.59 \\
\hline $\begin{array}{l}\text { Occupational Radiation Dose } \\
\text { (man-rem) }\end{array}$ & 79 & 80 & 66 \\
\hline Staff Required (man-years) & 60 & $72^{(b)}$ & 48 \\
\hline $\begin{array}{l}\text { Waste Volume }\left(\mathrm{m}^{3}\right) \text { (to LLW } \\
\text { disposal site) }\end{array}$ & 1280 & 1280 & 1280 \\
\hline Final Site Status & Unrestricted & Unrestricted & $\begin{array}{l}\text { Restricted } \\
\text { with Long- } \\
\text { Term Care }\end{array}$ \\
\hline
\end{tabular}

(a) Estimates include a $25 \%$ contingency.

(b) Includes 17.4 man-years for preparations for safe storage and 9.1 man-years for safe storage.

DECON with stabilization of the lagoon wastes is the least expensive option. However, the NRC has not yet approved this disposal method. It does not allow unrestricted release of the site, and decommissioning methods that convert contaminated sites into waste repositories are not compatible with current national policy and regulatory guidelines for radioactive waste disposal.

Removal of the waste for disposal is more costiy than stabilization. However, if the waste is left at the site, the radioactivity would remain for hundreds of thousands of years. Long-term care following stabilization would provide a period for assessing the effectiveness of stabilization procedures.

DECON costs are considerably lower than the cost of passive SAFSTOR, mainly because of the cost of safe storage. Radiation doses to workers are slightly higher for the passive SAFSTOR alternative because of the doses received during safe storage. The total radiation doses (received mostly by the decommissioning workers) do not decrease with time for deferral of decontamination. The waste volume is essentially the same for all decomissioning alternatives. 
The decontamination of $\mathrm{UF}_{6}$ facilities is highly labor intensive. Thus, labor is a major component of the total decommissioning cost. Facility and equipment designs and decontamination systems and techniques that minimize labor could help reduce overall decomissioning costs.

The conditions in effect at a specific facility at the time it is decommissioned, including sociological aspects, may dictate the choice of the decommissioning alternative to be used. Therefore, the results and conclusions in this report should be used oniy in the context of the reference site and facility studied and the key bases and assumptions used. 


\section{REFERENCES}

1. U.S. Congress, 95th Congress, Public Law 95-604, "The Uranium Mill Tailings Radiation Control Act of 1978."

2. Generic Environmental Impact Statement on Uranium Mi1ling, NUREG-0511, Draft, U.S. Nuclear Regulatory Commission, Office of Nuclear Material Safety and Standards, Washington, DC, April 1979.

3. Federal Register, Vo1. 45, p. 65521, October 3, 1980.

4. E. S. Murphy and G. M. Holter, Technology, Safety and Costs of Decommissioning a Reference Low-Level waste Burial Ground, NUREG-CR/0570, U.S. Nuclear Regulatory Commission Report by Pacific Northwest Laboratory, June 1980 . 



\subsection{REVIEW OF DECOMMISSIONING EXPERIENCE}

Information specific to the decommissioning of uranium hexafluoride $\left(\mathrm{UF}_{6}\right)$ conversion plants is not available in the open literature since no plants have been decommissioned to date. Information regarding decontamination experience at $\mathrm{UF}_{6}$ facilities that have been shut down is also very limited. A proposed plan for the decommissioning of the U.S. Department of Energy (DOE) Weidon Spring Chemical Plant that has been closed for some time is included in this section as an example of potential decommissioning activities. Information on the decommissioning of other types of uranium processing facilities is also included since some of the decommissioning problems encountered may be similar to those anticipated for decommissioning of conmercial UF 6 plants.

\subsection{STATUS OF UF 6 PLANTS IN THE UNITED STATES}

Table 3.1-l gives information on the location and operating status of $\mathrm{UF}_{6}$ facilities in the U.S. Although several $\mathrm{UF}_{6}$ plants have ceased operations, none have been decommissioned. The DOE has terminated $U_{6}$ conversion at all of its plants 1 isted in Table 3.1-1 except for a small hexafluoride plant for converting returned and reclaimed uranium compounds to feed material for the Cascade Enrichment Plant.

TABLE 3.7-1. Information on $\mathrm{UF}_{6}$ Conversion Plants in the U.S.

\begin{tabular}{|c|c|c|}
\hline Plant Operator & Plant Location & Present Status \\
\hline Allied Chemical & Metropolis, IL & Operating \\
\hline Babcock and Wilcox $(a)$ & Apoilo, PA & Shut Down \\
\hline Kerr-HcGee & Sequoyah County, OK & Operating \\
\hline Mallinckrodt Chemical - DOE & Weldon Spring, MI & Shut Down \\
\hline National Lead of Ohio - DOE & Cincinnati, $\mathrm{OH}$ & Shut Down \\
\hline Portsmouth $=D O E^{(b)}$ & Portsmouth, $\mathrm{OH}$ & Shut Down \\
\hline Union Carbide - DOE & Oak Ridge, TN & Shut Down \\
\hline Union Carbide - DOE & Peducah, KY & Shut Down \\
\hline
\end{tabular}

(a) Formerly Nuclear Materiais and Equipment Corp. (NUMEC.)

(b) The large hexafluoride conversion plant was put into safe storage. in the 1961-62 period. It has since been converted to another use. There is currently a smali hexafluoride plant for converting returned and reclaimed uranium compounds to feed for the Cascade Enrichment Plant. 


\subsection{DECOMMISSIONING PLAN FOR WELDON SPRING CHEMICAL PLANT}

The Weldon Spring Chemical Plant was operated from 1957 to 1966 by the Mallinckrodt Chemical Works, and in 1966 it was shut down. During operation, the buildings, equipment, and immediate terrain became contaminated with uranium, thorium, and their decay products. In 1967 the Army began a major effort to decontaminate and dispose of three process buildings for other use. The cleanup was not successful and the project was carcelled in 1969. The site entered care and custody status at that time.

A program plan for decontamination of the Weldon Spring Chemical Plant was prepared in 1979. The technical approach was to remove all equipment and buildings from the site and then decontaminate all land so that the approximately 80 hectare $(200$-acre) site could be released for unrestricted use. Figure 3.2-] shows the Weldon Spring Program Plan for decontamination and disposition. As shown in the figure, the plan consists of five major tasks performed in sequence by similarity of skills required and by degree of contamination involved.

This approach allows the operation to proceed in stages, staffing as necessary to accommodate funding or resolution of problems such as the potential for recontamination.

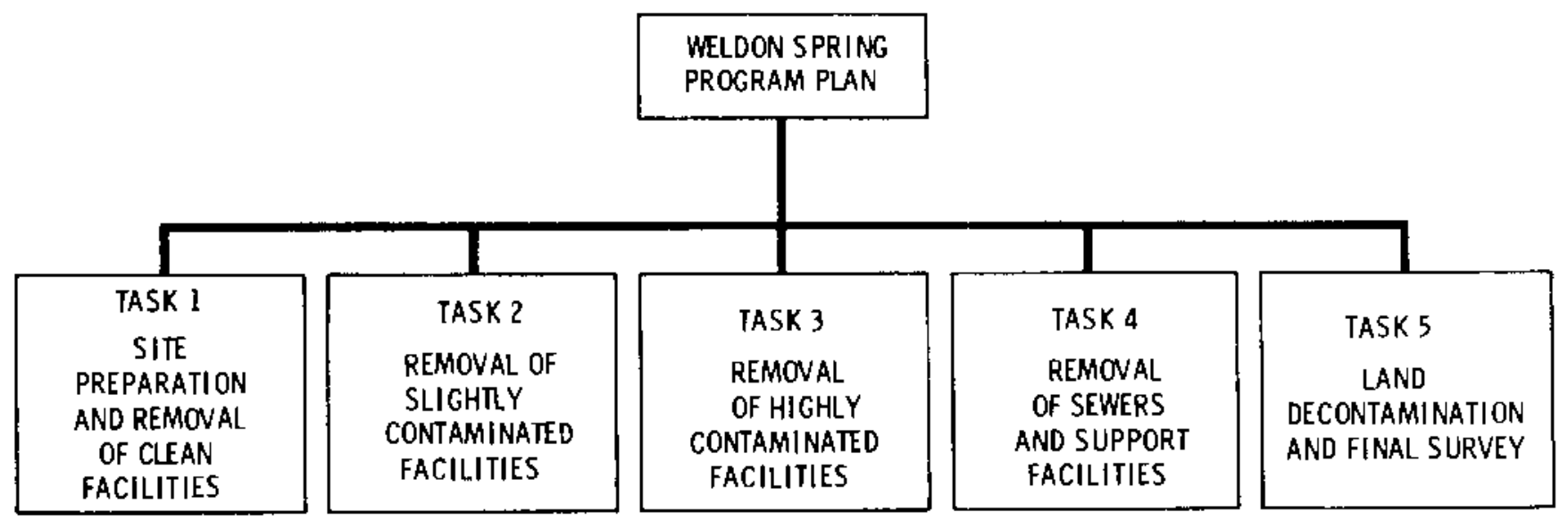

FIGURE 3.2-1. Time-Phased Program by Task 
The first task involves site preparation for performance of the program and removal of clean facilities. In the second task, all slightly contaminated facilities are removed. In the third task, all highly contaminated (aboveground) facilities are decontaminated and removed. Once this is done, all below-ground and support facilities are removed. In the final task, contaminated soil is removed and a final site survey is performed, and site restoration compatible with adjacent properties is accomplished.

\subsection{DECOMMISSIONING EXPERIENCE AT OTHER URANIUM PROCESSING FACILITIES}

Other uranium processing facilities, such as low-enriched uranium fuel fabrication (U-Fab) plants, have been decommissioned that might offer experiences valuable to $U_{6}$ plant decomissioning.

Among the low-level enriched U-Fab plants, two facilities that have been shut down are exampies of decommissioning experience. A Kerr-McGee plant at Crescent, 0klahoma, has been partly decomissioned. The plant is still intact, and the waste ponds have been cleaned up. Contaminated waste from the plant was loaded into drums and shipped to a low-level waste burial ground.

The most complete experience with decomissioning a low-enriched U-Fab plant has been the General Electric U-Fab plant in San Jose, California. At shutdown, the area was cleaned to administrative control levels not exceeding $1000 \mathrm{dpm} / 100 \mathrm{~cm}^{2}$ for alpha radiation. Deconmissioning was accomplished by dismantling and removing all of the equipment and ventilation system and cleaning the building. Pipes and lighting fixtures were vacuumed or hosed down with water; fluorescent tubes were replaced; ceilings, walls, pipes, and lighting fixtures were damp-wiped; baseboard moldings and tile floors were removed; and concrete floors were vacuumed and mopped. Pump basins that had been formed by constructing concrete berms were cleaned up by removing the berms and wetgrinding any hot spots. The decommissioning effort was more extensive than would have normally been necessary because of an operating accident that had released a relatively large amount of $U_{6}$ inside the plant. This accident contaminated not only all of the building and fixture surfaces in the production areas but also some otherwise clean areas. 


\subsection{LESSONS LEARNED FROM EXISTING DECOMMISSIONING EXPERIENCE}

Technology for decontamination and decommissioning exists and has been applied to a variety of nuclear installations. Because of the uniqueness of each facility, no two have had identical decommissioning problems or conditions. However, the basic approach to any mode of decommissioning remains virtually unchanged (i.e., the gathering of staff manpower and a period of planning and preparation, followed by chemical decontamination and mechanical removal operations). The decommissioning plan and execution varies primarily with plant design and with the inherent refinements potentially available or needed for a given facility. Areas that could use improvements in technology are remotehandling equipment, disassembly techniques, decontamination techniques, and waste volume reduction.

From the standpoint of decontamination, all walls should be seamless and have a smooth durable surface to aid in flushing and cleaning. Separation of process areas into compartments allows for more effective control of radioactive migration. Sealed-off access areas behind processing pipes and highly contaminated equipment provide an effective means of controlling radioactive contamination, while also providing a suitable work area for personnel. Building and hood fluid services, located either beneath the floor level or in some area away from work areas, tend to minimize the hazardous effects of pipe leaks. Location of building service systems (such as vacuum systems, corrosive vapor removal systems, and exhaust systems) in isolated areas allows maintenance work to be performed with little interruption of ongoing processing operations. These are some of the most obvious improvements in design that could enhance decommissioning. A more comprehensive listing of design considerations favorable to decommissioning of the reference facility is given in Section 13. New techniques, as well as improvernents in current decommissioning techniques, can be expected to occur. These improvements, in turn, will directly impact future decommissioning considerations. 


\subsection{DECOMMISSIONING ALTERNATIVES AND STUDY APPROACH}

Dnce a uranium hexafluoride conversion $\left(U_{6}\right)$ plant reaches the end of its useful operating life, it must be decontaminated or placed in a condition such that future risk to public safety from the facility and its site is within regulatory limits. Several decommissioning alternatives are possible to satisfy these general requirements. These alternatives range from minimal initial cleanup requiring continued surveillance and physical security followed by later more complete cleanup, to inmediate complete cleanup and removal of contaminated materials resulting in unrestricted public use of and access to the facility and site. For all of the alternatives categorized, the ultimate goal is unrestricted access to the facility.

In this section, decommissioning alternatives are evaluated for a reference $\mathrm{UF}_{6}$ conversion plant and the reasons for selecting certain alternatives are discussed. The approach of this decommissioning study is also discussed. Certain assumptions must be made in the absence of specific data, to permit general application of the results. The important overall assumptions for the study and the rationale for their selection are identified.

\subsection{DECOMMISSIONING ALTERNATIVES}

The general characteristics of the basic decommissioning alternatives are summarized in Table 4.1-1. Each of the alternatives as applied to the reference $U F_{6}$ conversion plant is defined and discussed in the following subsections.

\subsubsection{Definition of and Rationale for DECON}

DECON (immediate decontamination to unrestricted release) provides a way to meet the requirements for termination of a nuclear license in the near term, thus eliminating long-term security, maintenance, and surveillance needs and making the site available for unrestricted use within about 1 year following facility shutdown. To accomplish DECON requires that all potentially contaminated systems be disassembled and removed from the facility and transported to a reguiated disposal site. 


\section{TABLE 4.1-1. Characteristics of the Various Decommissioning Alternatives}

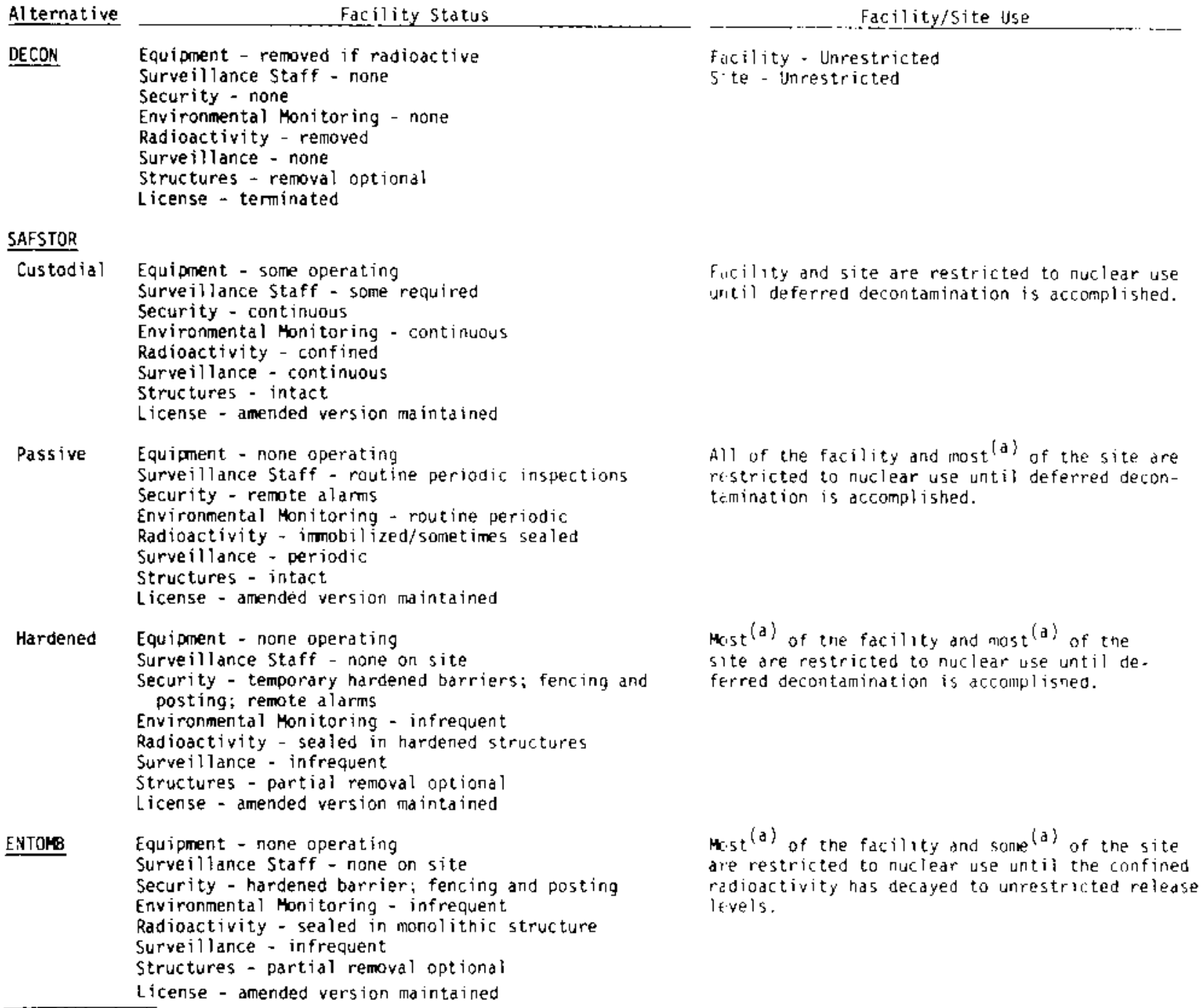

Fucility and site are restricted to nuclear use uritil deferred decontamination is accomplished.

All of the facility and most ${ }^{(a)}$ of the site are restricted to nuclear use until deferred decontimination is accomplished.

Mast (a) of the facility and mast(a) of the site are restricted to nuclear use until de. ferred decontamination is accomplisned.

Mast ${ }^{(a)}$ of the facility and some ${ }^{(a)}$ of the site are restricted to nuclear use until the confined radioactivity has decayed to unrestricted release levels.

(a) Implies a release of part of the site or the facility for unrestricted use, while malrtainirid control of the licensed portion that contains radioactive materials above releasable levels.

In the DECON alternative, larger initial commitments of money are made in exchange for prompt availability of the plant site for other purposes, reuse of plant components, and elimination of continuing costs for security, maintenance, and surveillance.

\subsubsection{Definition of and Rationale for SAFSTOR}

SAFSTOR includes all operations needed to prepare for safe storage, surveillance and maintenance during safe storage, and complete decontamination to 
unrestricted release following safe storage. The facility is placed in such a condition that risk to the public can be kept within acceptable bounds while the facility is maintained in storage, and the facility can be subsequently decontamination to unrestricted release at the end of the safe storage period.

Several subcategories of safe storage for the SAFSTOR alternative are possible. These are:

- Hardened SAFSTOR [temporary entombment ${ }^{(a, b)}$ ] - A comprehensive cleanup effort is coupled with the construction of barriers around areas containing sufficient quantities of radioactivity. These barriers are of sufficient strength to make accidental intrusion impossible and deliberate intrusion extremely difficult. Surveillance requirements during safe storage are limited to detection of intrusion through the barriers and maintenance of the integrity of the structures. The primary restriction to facility and site use is that of prohibiting activities such as excavating, drilling, or any other means of breaking the barriers that confine the radioactivity, until deferred decontamination is accomplished.

- Passive SAFSTOR [mothba11, (a) protective storage $\left.{ }^{(b)}\right]$ - A significant cleanup effort is performed initially, sufficient to permit deactivation of the active protective (ventilation and utility) systems during the period of safe storage. The structures are strongly secured and electronic surveillance is provided to detect accidental or deliverate intrusion. During the safe storage period, maintenance of the integrity of the structures is required. Plant use is limited to nuclear only while site use may be non-nuclear, with certain restrictions, until deferred decontamination is accomplished.

- Custodial SAFSTOR [layaway ${ }^{(b)}$ ] - A minimum cleanup effort is made initially, followed by a period of safe storage with the active protection systems (principally the ventilation, utility, and fire protection systems) kept

(a) This nomenclature is used in Regulatory Gujde 1.86 (
(b) This nomenclature is used in NUREG-0278. 
in service throughout the storage period. Onsite personnel will be required for surveillance and maintenance of the operating systems. An electronic urveillance system is required to detect accidental or deliberate intrusion into the facility and the subsequent exposure to radiation or dispersal of radioactivity byond the confines of the facility. Use of the facility and site is generally limited to nuclear activities until deferred decontamination is accomplished.

A11 categories of safe storage are open-ended and some positive action is required at the conclusion of the period of safe storage to release the property for unrestricted use and terminate the license for radioactive materials. Depending on the nature of the nuclear facility and its operating history, the necessary action can range from a radiation survey that shows the property to be releasable, to dismantlement and removal of residual radioactive materials. These latter actions, whatever their scale, are generically identified as deferred decontamination.

SAFSTOR is used as a means to satisfy the requirements for protection of the public while minimizing the initial commitments of time, money, occupational radiation exposure, and waste repository space. Modifications to the facility during the preparation stage are limited to those that assure the security of the buildings against intruders and to those required to assure containment of radioactive or toxic material. It is generally not intended that the facility would ever be reactivated, although reactivation is a possible option. For a $\mathrm{UF}_{6}$ plant, there is no significant decay of residual radioactivity and personnel exposure to radiation is not reduced during reasonable periods of safe storage (a few tens of years). Thus, placing an inactive UF 6 facility in safe storage for a reasonable period of time produces no benefit in terms of reducing radiation exposure to decommissioning personnel.

The reduced initial effort (and cost) of the SAFSTOR alternative is tempered somewhat by the need for continuing surveillance and physical security to assure the protection of the public. For all SAFSTOR aiternatives, electronic surveillance devices are in service full-time, with off-shift readouts monitored 
in a local law enforcenent office or a private security agency. These devices, which monitor for intruders, radiation-level increases, and fire detection, require periodic checks and maintenance. For custodial SAFSTOR, a small operating and security staff is required at the retired facility to provide for equipment operation, general maintenance, and plant security.

Maintenance of the facility's outer-confinement barriers and surfaces and an on-going program of environmental surveillance are also necessary for all SAFSTOR alternatives.

The duration of the period of safe storage before final decomissioning may vary, depending on the needs of the plant owner, based primarily on economic and safety trade-offs. For example, if the value of the site property for unrestricted use is large and the cost of storage is also large, there would be incentive to complete decontamination reasonably soon. On the other hand, a potential alternative use of the facility may suggest maintaining the facility in safe storage for an extended time period. Regulatory requirements and public concerns may also influence the duration of the safe storage period.

At the end of the safe storage period, several things remain to be done before the facility can be made available for unrestricted use and before the amended nuclear license can be terminated. The remaining quantities of long1 ived radioactivity that exceed unrestricted release 1 imits must be removed and contaminated equipment must be packaged and removed to a regulated disposal site. Once the remaining levels of radioactivity are less than the unrestricted release limits, the facility nuclear license can be terminated.

For a $\mathrm{UF}_{6}$ plant there is not much difference in the amount of cleanup required for either the passive or custodial SAFSTOR alternatives. Passive SAFSTOR involves shutdown of the ventilation and utility systems, and less surveillance is required during the safe storage period than for the custodial alternative. Thus, the passive SAFSTOR alternative appears to be most applicable to short-term inactivation (e.g., 5 to 10 years) of a UF ${ }_{6}$ plant; to a multifacility site where surveillance, security, maintenance and operating capabilities exist; or to the situation where the likelihood exists for later use of the retired facility. 
Deferred decontamination, as would occur at the end of an extended period of safe storage, perhaps a few tens of years, continues decommissioning actjvities beyond those done during the preparations for safe storage. Decontamination activities will still be controlled by residual long-lived radioactivity in the plant. The benefits to be gained by deferred decontamination of a UF 6 plant (i.e., the possibility of re-use of the facility and the deferral of decontamination costs) will depend on the characteristics of each facility at the time of final production shutdown. These benefits must be weighed against disadvantages of deferring decontamination (i.e., costs of safe storage), value of and need for the reclaimed site, and the need to familiarize the new decommissioning staff with the facility.

\subsubsection{Definition of and Rationale for ENTOMB}

ENTOMB for a nuclear reactor facility requires the encasement of the radioactive materials in concrete or other structural materials sufficiently strong and structurally long-lived to assure retention of the radioactivity until it has decayed to levels that permit unrestricted use of the site. The amount and half-life of the residual radioactivity in the facility to be entombed determines the time period that the integrity of the structure must be assured and whether or not re-entry for additional decommissioning is required. ENTOMB refers to the entire process of first entombing and then continuing some surveillance to assure the integrity of the structure until the entire site is confirmed to have decayed enough to allow unrestricted release.

The Environmental Protection Agency (EPA) is developing generally applicable environmental protection criteria for management of all radioactive wastes that will impact NRC decommissioning standards and guidelines. In a background report entitled Considerations of Environmental Protection Criteria for Radioactive Waste, $(3)$ the EPA proposes a criterion 1 imiting reliance on institutional controls to a finite period of time. The EPA suggests that the use of institutional control to protect the public from hazards in retired nuclear facilities should be limited to a period of 100 years at most and preferably to less than 50 years. After the allowable institutional care period is over, the site would have to meet radioactive protection levels established for release for unrestricted use. 
Based on the definition of ENTOMB and the EPA-proposed criteria, (3) it is concluded that any "permanently" entombed structure must be designed to outlast any contained radiological or chemical hazard to man, or to be designed perhaps to dilute these hazards to innocuous leveis as the structure disintegrates. Unless the structure is to be re-entered later and decommissioned further, these potential chemical and radiological hazards should vanish in no more than about 100 years, in order to fulfill the bases for ENTOMB. Taking no credit for the dilution effects of entombment, these criteria and guidance virtually prohibit entombing any nuclear facility containing long-lived radionuclides or toxic chemical elements.

In addition, while it is reasonable to assume that man can design and construct high-integrity, long-lived surface structures, it is also reasonable to assume that any long-term human controls on or responsibility for that facility will ultimately disappear and that the long-lived radionuclides, chemicals or toxic elements contained therein will ultimately be dispersed into the environment. The ENTOMB alternative also results in the proliferation of decomissioned plant sites containing residual radioactivity. Therefore, ENTOMB is considered not viable for a $U F_{6}$ conversion plant.

\subsubsection{Decommissioning Methods for Lagoon Waste}

Decomissioning methods for Iagoon waste are assumed to be the same as those for uranium mill tailings or low-level waste burial grounds, namely, stabilization of the waste lagoon plus long-term care (similar to SAFSTOR), and removal of the waste to an authorized disposal site (OECON). The NRC has not yet determined whether stabilization would be acceptable; its acceptability would have to be determined on a case-by-case basis.

Use of a site as a temporary waste repository might also be necessary because of a shortage of disposal space at authorized waste burial sites. However, decommissioning aiternatives that convert contaminated sites into waste repositories are not compatible with current national policy and regulatory guidelines for radioactive waste disposal. The government is presently engaged in a program (the Formerly Utilized Sites Remedial Action Program ${ }^{(5)}$ ) to survey sites with suspected radioactive contamination and to take appropriate action to prepare these sites for unrestricted pubtic use. 
Information about the technology and costs of uranium mill tailings and burial ground decommissioning that is contained in the uranium milling EIS ${ }^{(6)}$ and the burial ground decommissioning study ${ }^{(7)}$ can be used as guides in developing decommissioning requirements for the reference plant lagoon waste. Removal of the waste to an authorized disposal site is more costly than stabilization. However, if the waste is left at the site, the radioactivity would remain for hundreds of thousands of years. Therefore, the purpose of long-term care following stabilization is to provide a period for assessing the effectiveness of stabilization procedures.

To arrive at a decision about which decommissioning alternative to use for lagoon waste management, the following factors need to be considered:

- levels of radioactivity remaining in the waste

- the physical and chemical forms of the material

- the chemical toxicity of the material

- hydrologic and geologic properties of the site

- potentiar uses of the site

- political and social concerns about site proliferation

- a balance between costs and safety.

\subsubsection{Alternatives Selected for Study}

The principal alternative selected for study is DECON (immediate decontamination), since the half-lives of the uranium isotopes are so long $\left({ }^{235} \mathrm{U:} 7 \times 10^{8}\right.$ years; ${ }^{238} \mathrm{U:} 4.5 \times 10^{9}$ years) deferring decontamination for any reasonable time period ( $<100$ years) would have no effect on the levels of contamination or the radiation dose rates.

The only likely reason to select a safe storage alternative would be if the owner wished to retain the capability to restart the plant sometime in the near future (probably within 5 years). Since passive SAFSTOR would permit restart of the facility, this alternative is also examined.

Hardened SAFSTOR or ENTOMB are not viable alternatives for decommissioning a $U_{6}$ plant because the plant is relatively easy to decontaminate and decay of the uranium isotopes over any reasonable storage period would be negligible. 
Since the initial cost of either hardened SAFSTOR or ENTOMB would be greater than that of passive SAFSTOR, and the total cost of these alternatives would exceed that of DECON, there are no incentives to use these alternatives; thus, they are not considered further.

Since stabilization of the lagoon waste on the $\mathrm{UF}_{6}$ plant site does not result in unrestricted release of the site as do the other decommissioning methods, another method is presented, DECON of the plant with stabilization followed by long-term care for the waste lagoons.

\subsection{TECHNICAL APPROACH}

The initial effort in this study is to develop a plan to accomplish the study objectives. The plan is developed by a team of key personnel with expertise in the primary areas of interest. The areas of expertise include fuel fabrication plants and their operation, decommissioning techniques, chemica 1 decontamination, chemical and radiological toxicant regulations, safety analyses (including pathways of toxic materials in the environment), operational health physics, and cost and benefit estimating and analyses. The resultant approach is shown in simplified form in Figure 4.2-1. The study is then carried out by the same staff or by staff with similar backgrounds.

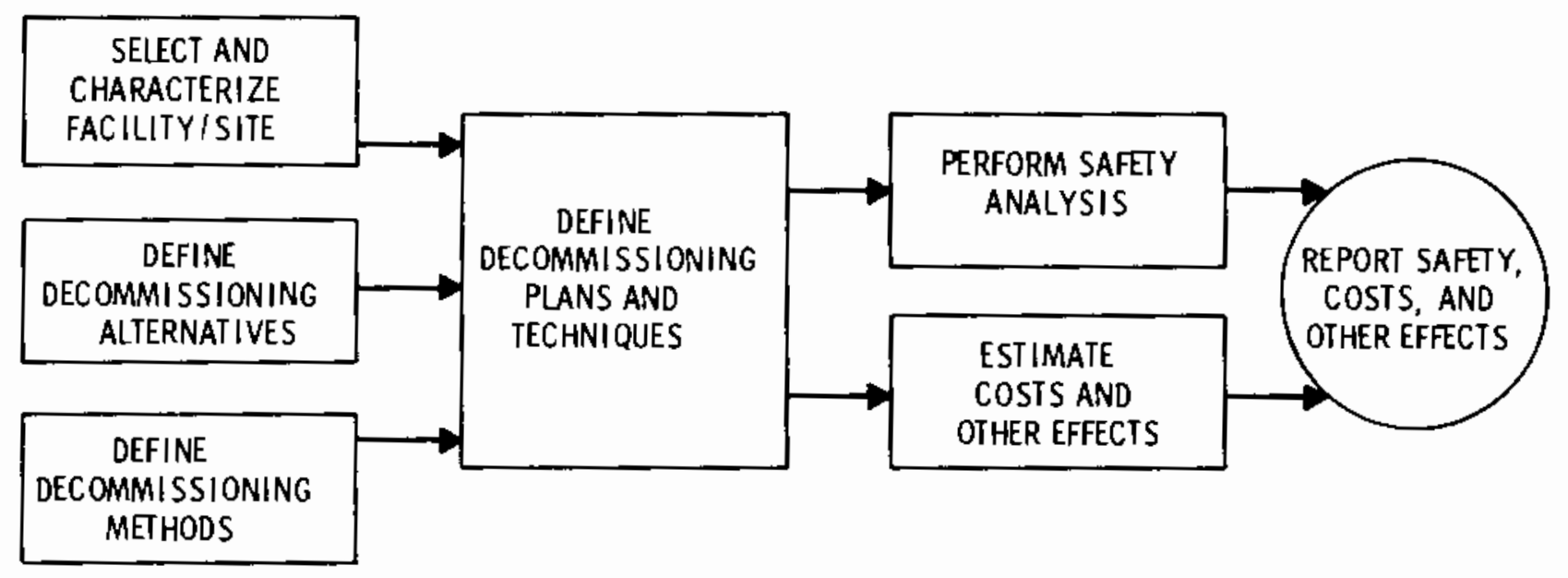

FIGURE 4.2-1. Approach for Decommissioning Study 
The first step in conducting the analysis is to select and characterize the reference facility in sufficient depth to perform an engineering and safety analysis of decomissioning the facility. An existing plant is selected on the basis of having characteristics typical of JF $_{6}$ plants that will be subjected to decommissioning in the foreseeable future.

The total facility is assumed to be on a conceptual generic site that is also being used in similar and related studies of other fuel cycle facilities. A detailed description of the facility is compiled that includes information such as plant equipment and material sizes, volumes, surface areas, and weights. Pre-decomissioning conditions for the plant and site are defined, including residual radioactivity levels.

Viable decomissioning alternatives (i.e., DECON and passive SAFSTOR) and site use limitations for facilities being decommissioned (i.e., restricted to nuclear use only, and unrestricted use) are selected. Related regulatory guidance is reviewed, summarized, and used as an aid and basis in the study.

Methodology is developed for defining suggested residual radioactivity levels in facilities and sites that would permit unrestricted use of decommissioned facilities, in terms of allowable radiation dose to the maximum-exposed member of the public. The variety of potential pathways through which radionuclides could reach man are considered in determining these acceptable levels. This methodology is applied to develop example acceptable levels of residual radionuclides, based on the assumed radionuclide mixtures at the plant/site.

Past decomissioning experience of facilities with characteristics related to the reference facility is reviewed. From this review, a summary of insights from these decomissioning experiences is derived and applied where applicable to this study.

Techniques for decontamination of facilities are reviewed. For both decommissioning alternatives, a work schedule and a time schedule are developed to conceptually decommission the reference facility. The techniques used are selected on the basis of engineering judgment, while maintaining a balance of safety and cost. 
Safety analyses are performed for the decommissioning alternatives studied. These analyses include radiological and chemical exposures to the public and workers from normal decommissioning operations and from potential accidents. Nonradiological industrial accidents to workers are also estimated. The safety analyses utilize established data and methodology to estimate the various factors required, such as release mechanisms, dispersion pathways, and exposure modes for the released materials.

Direct costs of decommissioning are estimated, including labor, materials, equipment, packaging, transportation, waste disposal, and surveillance costs where applicable. Alternatives for financing decommissioning are examined. For both decomissioning alternatives, all of these factors are combined into an overall comparison of their safety-costs-benefits and advantages and disadvantages.

The study is summarized in this report, documenting the main study information and appendices containing supporting details.

\subsection{KEY STUDY BASES}

From the outset, a number of important ground rules are established to guide the emphasis of the study. These bases are derived from the primary objective of the study, which is to provide an analysis of safety, costs, and other factors involved in decommissioning a $\mathrm{UF}_{6}$ conversion plant. The study is intended to provide background information useful to regulators, plant designers, and operators of such facilities. From these objectives, the key bases are established for all aspects of the study to assure that the overall study objectives (see Section 1) are achieved. These key bases can have major impact on the issues of safety, cost, and time for decommissioning. Many aspects of decommissioning will change with facility location, specific facility shutdown conditions, and residual contamination levels in the plant. The bases and assumptions used in this study must, therefore, be carefully examined before the results can be applied to a different facility and site.

The key study bases are:

1. The study is to yield realistic results based on 1981 cost data. This primary basis is a requisite to meeting the objectives of the study, and provides the foundation for most of the other study bases. 
2. The objective of decommissioning is to assure the continued protection of public from the residual radioactivity and any other potential safety hazards in the retired facility.

3. The study is to evaluate a contemporary facility. This basis is an obvious necessity to meet the study objectives and the primary basis above. The reference facility for the study is based on current technology.

4. The study is to include an analysis of the viable decommissioning alternatives: DECON and passive SAFSTOR.

5. Only facilities expected to contain radioactive material and contiguous areas are included in this study. Decommissioning of separate nonradioactive subfacilities is to be accomplished by conventional demolition/ salvage techniques and is outside the scope of this study.

6. The UF 6 facility is assumed to have operated for 40 years prior to plant shutdown and the onset of decommissioning operations. During the operation, the plant is assumed to have had a processing capacity of 10,000 metric tons per year of natural uranium.

7. Current and proven decommissioning technology and techniques are used in the study. Where developmental techniques are conceptualized, they are in an advanced state of development and believed to be ready for application in this study.

8. A single decommissioning plan is evaluated for each of the two decommissioning alternatives analyzed. Where different techniques or assumptions have significant impact on the study results, the effects of alternatives are discussed at least qualitatively.

9. Decommissioning techniques conform to the principle of keeping occupational radiation doses As Low As is Reasonably Achievable (ALARA).

10. Decomissioning plans are selected to provide public/occupational safety in a cost-effective manner.

11. A11 personnel assigned to decommissioning operations are assumed to be experienced radiation workers with previous experience in the operation of a $U_{6}$ plant or other similar nuclear facilities. 
12. The performance of decomissioning is assumed to be relatively troublefree; that is, no scheduling or cost allowances are made for unforeseen events that might impede the conduct of the work. This assumption may lead to somewhat optimistic results, but is believed to be achievable with good planning and preparations.

13. It is assumed that plant process areas have been kept relatively clean during the operating period to allow for easier operational maintenance. As a result, expected contamination levels are generally modest and should be reasonably consistent with the quality of operation expected in modern commercial facilities. Any major contamination episodes are assumed to have been reasonably well cleaned up immediately following the event.

14. A final operational cleanup of the more important inventories of radionuclides is done as part of normal operations, and is not charged to decommissioning. This cleanup is assumed to be routine and similar to those done periodically between normal processing campaigns to improve equipment performance, segregate materials, and to recover materials unaccounted for. Subsequent decontamination efforts are charged to decommissioning.

15. The quantity and mixture of radioactive contamination present at plant shutdown is assumed to represent an accumulation of contamination that is fairly difficult to clean during operations. Specifically, contamination inventories are assumed to accumulate at the rate of 1/40th per year of the total accumulation, for the assumed 40 years of plant operation.

16. The isotopic inventory of input to the plant is typical of that used in the manufacture of uranium hexafluoride.

17. A1l materials shipped to the plant and waste shipments from the plant are assumed to be transported by truck.

18. Estimates of external radiation exposure to the public and to decommissioning workers from normal decommissioning activities are based on assumptions 
believed to be realistic. Estimates of internal radiation exposure (i.e., those from internally deposited radioactive material) from nomal decommissioning activities and from potential accidents are based on assumptions beljeved to be conservative. 


\section{REFERENCES}

1. Termination of Operating Licenses for Nuclear Reactors, U.S. Atomic Energy Commission ReguTatory Guide 1.86 , June 1974.

2. K. J. Schneider and C. E. Jenkins, Technology, Safety and Costs of Decommissioning a Reference Nuclear Fuel Reprocessing Plant, NUREG-0278, U.S. Nuclear Regulatory Commission report by Pacific Northwest Laboratory, October 1977.

3. Considerations of Environmental Protection Criteria for Radioactive Waste, EPA Docket No. PR-30, 40, 50, 70 (43 FR 10370), August 1978.

4. Guidelines for Decontamination of Facilities and Equipment Prior to ReTease for Unrestricted Use or Termination of Licenses for By-Product, Source, or Special Nuclear Material, U.S. Nuclear Regulatory Commission Draft Guide, November 1976.

5. D. G. Jacobs and H. W. Dickson, A Description of Radiological Problems at Inactive Uranium Mill Sites and Formerly Utilized MED/AEC Sites, ORNL/OEPA-6, Oak Ridge National Laboratory, Oak Ridge, Tennessee, February 1979.

6. Generic Environmental Impact Statement on Uranium Mil]ing, NUREG-0511, Draft, U.S. Nuclear Regulatory Commission, Office of Nuclear Material Safety and Safeguards, Washington, DC, October 1980.

7. E. S. Murphy and G. M. Holter, Technology, Safety and Costs of Decommissioning a Reference Low-Level Waste Burial Ground, NUREG/CR-0570, Pacific Northwest Laboratory for U.S. Nuclear Regulatory Commission, June 1980. 


\subsection{REGULATORY CONSIDERATIONS}

A viable plan for decommissioning a uranium hexafluoride conversion (UF ${ }_{6}$ ) plant must include consideration of applicable regulations that exist to ensure public and occupational safety. The following sections discuss these issues in general and as they apply to the reference $U F_{6}$ conversion plant. Also, areas are identified where guidance is incomplete or where application of existing guidance to decommissioning is ambiguous.

\subsection{EXISTING REGULATIONS, STANDARDS, AND GUIDES}

A general discussion of the background of present regulatory responsibility and the division of the responsibility among the regulatory agencies is provided in this section. A]though an extensive framework of government requirements apply to decomissioning of nuclear facilities, many of the requirements that affect decommissioning do so only indirectly. Examples of requirements that apply to decommissioning but were originally directed towards other primary purposes include extensive government requirements regarding nuclear facility construction and operation, the possession of nuclear materials, and limitations of occupational radiation dose.

Regulations and guidelines in this area are dynamic and new regulations are forthcoming. The U.S. Nuclear Regulatory Commission (NRC) is considering the development of a more explicit overall plan with regard to decommissioning. (1) With increasing public and regulatory attention being paid to decomissioning issues, requirements can be expected that will have the purpose of establishment of rules for governing the decomissioning of nuclear facilities.

\subsubsection{Federal Jurisdiction}

Several federal agencies have jurisdictions that can affect the decommissioning of nuclear facilities. The principal agencies with jurisdiction are the NRC, the Environmental Protection Agency (EPA), the Department of Transportation (DOT), and the Department of Energy (DOE). This subsection briefly identifies these agencies and summarizes their regulatory jurisdiction, as identified in Table 5.1-1. 


\section{TABLE 5.1-1. Principal Federal Agencies and Statutory}

Authority that May Affect Decommissioning

Agency
Nuclear Regulatory Commission
Environmental Protection Agency
Department of Transportation
Department of Energy

Pursuant to the Energy Reorganization Act of 1974, the AEC was abolished.
Statutory Authority

- Atomic Energy Act of 1954

- Energy Reorganization Act of 1974

- Reorganization Plan No. 3 of 1970

- Clean Air Act Amendments of 1977

- Safe Drinking Water Act

- Hazardous Materials Transportation Act

- Energy Reorganization Act of 1974

- Department of Energy Organization Act

The DOE assumed the disbanded AEC's research and development functions and its promotion of new technology activities and the NRC inherited its regulatory authority under the Atomic Energy Act of 1954. (3) Among other things, the NRC is responsibie for assurance of safety to life and property from the civilian use of nuclear material. NRC authority extends to all persons who possess, use, or transfer byproduct, source, or special nuclear materials.

The EPA is the federal government's chief environmental regulator. The EPA assumed the duties of the Federal Radiation Council under the President's Reorganization PIan No. 3 of $1970{ }^{(4)}$ The EPA has authority to regulate radioactive emissions into the air under the Clean Air Act Amendments of 1977. (5) The EPA also has authority to regulate doses from radioactive discharges under the Safe Drinking Water Act. ${ }^{(6)}$ Under these authorities, the EPA has established maximum contaminant levels in public drinking water systems. Regulations by the EPA that establish standards for radioactive contaminant levels in drinking water are contained in 40 CFR 141.

The principal federal agencies concerned with the transportation of radioactive materials are the DOT under the Hazardous Materials Transportation Act of $1974,{ }^{(7)}$ and the NRC under the Atomic Energy Act of 1954 . Federal safety regulations concerning nuclear materials transportation are outlined in Reference 8 . 
The following federal regulations are applicable to the transport of the radioactive materials associated with a UF 6 conversion plant that processes only natural uranium:

- Title 49 Code of Federal Regulations Parts 170-199 (49 CFR 170-199) - DOT regulations governing the transport of hazardous materials.

- 10 CFR 71 - NRC regulations governing the packaging and shipment of radioactive materials.

- 14 CFR 103 - FAA regulations for shipment of radioactive materials by air.

- 47 CFR 146 and 149 - U.S. Coast Guard regulations governing the shipment of radioactive materials by water.

The OOT and the NRC regulations are the most important for shipments made during the decommissioning of nuclear facilities.

Occupational safety is also of major importance during decommissioning. Radiation protection to workers is regulated by 10 CFR Part 20. Sections 20.101 through 20.105 define the external exposure limits. The operating philosophy of ALARA (As Low As is Reasonably Achievable) applies to these exposure limits. The NRC describes this operating philosophy in Regulatory Guide 8.8, "Information Relevant to Maintaining Occupational Radiation Exposure as Low as Practicable (Nuclear Reactors)," and Regulatory Guide 8.10, "Operating Philosophy for Maintaining 0ccupational Radiation Exposure as Low as Reasonably Achievable." Although not specifically cited for application to decommissioning activities, the guides are intended to apply. Additional information can be found on how to comply with the ALARA concept in the NRC Standard Review Plan for the Review of Safety Analys is Reports for Nuclear Power Plants, Section 12.1, "Assuring that Occupational Radiation Exposures are As Low As is Reasonably Achievable."

One of the goals of decommissioning a nuclear facility is to make the land available for other uses if desired. To release the facility and/or site for unrestricted use, the residual radioactive contamination must be at a level sufficiently low to assure public protection. Several attempts have been made to define the permissible levels of residual radioactivity. Guidance is found 
in Regulatory Guide $1.86^{(9)}$ and $40 \mathrm{CFR} 190^{(10)}$ and the proposed ANSI Standard N328, Control of Radioactive Surface Contamination on Materials, Equipment and Facilities to be Released for Uncontrolled Use. Other guidance ${ }^{(11)}$ from the NRC for terminations of byproduct, source, and SNM licenses (similar to Regulatory Guide 1.86) contains a table of "Acceptable Surface Contamination Levels" identical to that in Regulatory Guide 1.86. Thus, the NRC, the EPA, the DOT, and the DOE are the federal agencies with the principal responsibilities affecting decommissioning. To the extent that regulations of more than one agency apply, a nuclear facility operator needs to comply with all such regulations.

\subsubsection{NRC Regulations}

Throughout the decommissioning process there is potential for various levels of radiation to be present. For this reason, there are no changes in regulatory procedures relating to occupational exposure, or lowering of existing safety precautions for decommissioning. 10 CFR 20, "Standards for Protection Against Radiation," specifies standards for allowable radiation doses to workers (10 CFR 20.101 - 20.105), diagnostic requirements (10 CFR 2.107 - 20.108), precautionary procedures (10 CFR 20.201 - 20.207), radiation exposure in waste disposal (10 CFR 20.301 - 20.305), and requirements for records, reports, and notification (10 CFR $20.401-20.409$ ).

Section 40 CFR 190.10(a) provides standards for allowed radiological dose to any member of the public outside the plant, and Section 190.10(b) provides standards for the total quantity of radioactive materials allowed to enter the general environment from the entire uranium fuel cycle. As used in 40 CFR 190, the uranium fuel cycle includes chemical conversion of uranium, milling of uranium ore, isotopic enrichment of uranium, uranium fuel fabrication, reprocessing of spent uranium fuel, and generation of electricity by a light water cooled nuclear power plant using uranium fuel.

$\mathrm{UF}_{6}$ conversion plants are currently 7 icensed under 10 CFR 40 . The only reference made to modification and termination of licenses under Part 40 jurisdiction is included in 10 CFR 40.71 (d), and states:

"The Commission may terminate a specific license upon request submitted by the licensee to the Commission in writing." 
10 CFR Part 40 does not stipulate the specific decommissioning actions that must be taken prior to termination of a facility jicense. When a licensee decides to permanently discontinue all activities involving iicensed material, Section 40.41 ( $f$ ) of the Code of Federal Regulations requires written notification of such action to the NRC. (12)

Sections 10 CFR 70, "Domestic Licensing of Special Nuclear Material," and 10 CFR 73, "Physical Protection of Plants and Materials, "do not apply to UF 6 conversion plants. Section 10 CFR 75, "Safeguards on Nuciear Material - Implementation of the US-IAEA Agreement," applies to $\mathrm{UF}_{6}$ conversion plants, and deals with establishment of a material control and accounting system for the application of safeguards. Again, decommissioning is not specifically addressed.

There is little in existing regulations that elaborates on the subject of decommissioning financing; some financial information requirements for operating and shutdown reactors are given in 10 CFR 50.33(f). The NRC is considering the need for additional assurance that adequate funds will be available for decommissioning when required. $(13,14)$

The goals in the area of financing the decomissioning of nuclear facilities should be to provide reasonable assurance that the 7 icensee will pay the costs and to allow a broad range of approaches to implement that assurance. (15)

Another subject that must be considered when dealing with decomissioning activities is effluent monitoring reporting, which is covered in 10 CFR 40.65. However, in 10 CFR 40.65 and the rest of the regulations mentioned, the requirements and criteria for decommissioning are covered in only a very limited fastion.

Radioactive waste will be accumulated, treated, packaged, stored, and transported to a disposal site in accordance with existing regulations. These regulations include:

- 10 CFR 20 Standards for Protection Against Radiation

- 10 CFR 71 Packaging of Radioactive Materials for Transport.

Means for complying with these regulations must be defined in the license amendment request. 
Further regulations and guidelines relevant to the shallow-land burial of waste may be forthcoming based on the technology now being developed to characterize the performance of low-level waste burial sites.

Because of the low hazards associated with uranium contamination of components and systems of the front end of the fuel cycle, the standard procedure for decommissioning is decontamination of the facility and disposal of equipment. This is done in accordance with the NRC's guidelines for release of the facility for unrestricted use. (11)

With the increased attention now being given to decommissioning, more specific guidance is needed to identify public environjental radiation standards that apply explicitly to the decommissioning process, as opposed to facility operation.

Thus, while the NRC is responsible for assuring the public health and safety of all licensed facilities, NRC oversight of decomissioning is not explicitly required by statute and is currently limited to a case-by-case review. In addition, NRC's exercise of decommissioning procedures seems to address only those operational steps involved in the physical process of decontamination and dismantling. Other aspects of decommissioning such as advance planning and financing are not yet formally addressed.

\subsubsection{License Termination}

Under 10 CFR $40.41(f)$ the licensee must notify the NRC when the decision is made to permanently shut down the facility. Because of the nature of some of the decomissioning activities anticipated at the site, the NRC may elect to issue an amended 1 icense with administrative controls and facility requirements appropriate for the decommissioning option selected. The rationale behind this logic is that, although the plant operating functions have changed significantly during decommissioning, many unit operations may be similar (i.e., chemical decontamination and waste treatment). There will be active operations conducted in the plant involving radioactive materials and utilizing existing systems and components that can result in release of effluents to the environment.

The NRC requirements for terminating a license for nuclear reactors and fuel reprocessing plants are contained in 10 CFR 50.82. They require an application that specifies certain information on planned decommissioning procedures. The 
regulation authorizes temination procedures, specifies additional conditions, provides for notice to interested persons, and states that if such procedures and conditions are followed, then a termination of license will be granted. In lieu of formal regulatory guidance in 10 CFR 40, the NRC has currently adopted the decommissioning guidelines provided in Reference 11 . The clear implication of the 10 CFR 50.82 regulation is that dismantling and disposal are the exclusive objectives of the decomissioning process. However, regulatory guides discussed above also provide for other decomissioning al ternatives that may not return a site to unrestricted use.

For facilities utilizing source or by-product materials, 10 CFR 40.71 , "Modification, Revocation, and Termination of Licenses" and Section 40.41, "Terms and Conditions of Licenses," provide very general guidance by which a licensee may amend his license. It is likely that rules will be developed in 10 CFR 40 similar to 10 CFR 50.59 and Section 50.90 for reactors, which provide specific regulations and guidance for amending licenses. This amended state for facility licenses results from NRC approval to change requirements in the technical specifications that are applicable to normal facility operations. It seems that such approval can be extended to include the necessary requirements to ensure public safety during decommissioning.

Another potential question arises from the fact that the long-term care outlined in the Regulatory Guides could extend for a period that considerably exceeds the normal licensing period for nuclear facilities (typicaliy 1 to 5 years between licensing renewals for 10 CFR 70 facilities). There is no indication in the regulations what the term of an amended license might be. This raises questions as to whether renewal of an amended license would be permitted and what the standards for such renewal would be.

\section{1 .2 State and Local Jurisdiction}

A nuclear facility operator is also subject to state statutes, regulations, orders, and court decisions. Where conflicts exist between state and local requirements, state requirements generally prevail. Similarly, where there is a conflict between a federal requirement and a state requirement, the federal requirement controls, with some exceptions, as noted in the Clean Air 
Act. (5) Where no conflict exists, or where Congress has elected not to fully occupy a given legislative area, an operator must generally comply with all applicable federal, state, and local requirements in the conduct of his affairs.

Under the terms of 10 CFR 150, "Exemptions and Continued Regulatory Authority in Agreement States Under Section 274," agreement states of the NRC are authorized to issue byproduct, source material, and SNM 1icenses (1imited quantities of SNM) to NRC 1icensees. Since Section 274(b) of the Atomic Energy Act of 1954 requires agreement state programs to be compatible with NRC regulations, the NRC will require that agreement state programs reflect the NRC's lead in the area of decommissioning.

Section 274k of the Atomic Energy Act of 1954 provides that "nothing in this section shall be construed to affect the authority of any state or local agency to regulate activities for purposes other than frotection against radiation hazards." (16) Thus, state requirements relating to such matters as land use, zoning, building construction standards, drainage regulations, and similar requirements are generally not preempted under the Atomic Energy Act, even though they can have an important impact upon the location, construction, and operation of licensed nuclear facilities.

State governments also exercise some control over shipments of radioactive materials. State highway departments regulate gross vehicle weights, vehicular dimensions and other parameters for radioactive shipments just as they do for other kinds of shipments. Currentiy, about haif of the states have adopted the DOT Hazardous Materials Regulations to cover intrastate shipments. (17) Several states have adopted or proposed additional regulations concerning radioactive materials. $(18,19)$ The variation of regulations between adjacent states can often require special considerations for interstate shipments.

There is potential conflict between some of the proposed state laws and the provisions of the Hazardous Materials Transportation Act of 1974 (Public Law 93-633 signed in 1975). (7) This 1 aw prohibits the states from adopting laws or regulations more stringent than federal regulations unless the state regulations improve transportation safety. Even in this case, such rules can be adopted only if they do not unreasonably burden commerce. 
The 1977 Clean Air Act Amendments clarify that states are no longer precluded from establishing and enforcing standards regulating radioactive emissions into the air. Thus, any state or locality may potentially establish standards more stringent than federal standards, or where a federal standard has not been established, may establish any standards it deems appropriate. ${ }^{(5)}$

\subsubsection{Regulation of Effluents}

During decommissioning operations, it will be necessary for radioactive air and water emissions to be kept as low as reasonably achievable. Specific regulations pertaining to radioactive emissions during decormissioning have not been issued. In the license termination application, however, an operator must ensure that decommissioning will not be inimical to public health and safety (see 10 CFR 50.82 as an example).

The radioactive effluents from waste processing operations or other activities during decommissioning must comply with EPA regulations as well as with 10 CFR Part 20. Currently, no specific EPA regulations exist for decommissioning. The EPA's $25 \mathrm{mrem} / \mathrm{yr}$ limit of exposure to the whole-body for any member of the general public from operating facilities of the nuclear fuel cycle, defined in 40 CFR Part 19D, Environmental Radiation Protection Standards for Nuclear Power Operations, excludes waste management activities, but such limits are now being developed. It is anticipated that a radiation dose 1 imit from waste management operations similar to the $25 \mathrm{mrem} / \mathrm{yr}$ fuel cycle limit will be developed by the EPA. This new limit may well include the impact of decommissioning.

The Clean Air Amendments of $1977^{(5)}$ include radioactive emissions within the regulatory framework of the Clean Air Act. Section 122 of the Clean Air Act Amendments of 1977 creates an important statutory exception to the NRC's primary jurisdiction over radioactive emissions from 1 icensed nuclear facilities. The 1977 Amendments make it clear that radioactive emissions into the air (which is presumed to be applicable to effluents from decommissioning) are subject to the regulatory framework of the Clean Air Act, in addition to determining whether emissions of radioactive pollutants will endanger public health.

EPA also has authority to regulate radioactive effluent and waste discharge through the Safe Drinking water $\mathrm{Act}^{(19)}$ that establishes maximum contaminant 
Tevels in public drinking water systems. Since contaminant is defined to include "any...radiological substance or matter in water," ${ }^{(20)}$ any activity relating to a nuclear facility that could potentially contaminate public water systems is subject to EPA jurisdiction.

Additional public and environmental radiation standards are found in 10 CFR 40.65 (effluent monitoring reporting requirements) and 10 CFR 20, Appendix $B$ (concentrations in air and water above natural background). Other sources include proposed or existing EPA limits on radioactivity levels in water, ${ }^{(6)}$ soil, and effluents, and all EPA drinking water standards (40 CFR 141).

\subsubsection{Licensing Changes and Decommissioning Plan}

The principal regulatory issues during decommissioning of a $\mathrm{UF}_{6}$ conversion plant will be public and occupational safety, environmental protection, and nuclear material safeguards. The regulatory jurisdictions, cognizant agencies, codes and guides for each of these have been reviewed above. A summary of the regulatory guidance provided in the Code of Federal Regulations is given in Table 5.1-2. When the decommissioning plan is prepared and the license amendment application is made for decommissioning, those regulatory issues will need to be addressed.

Since the major requirement of the planning phase is to provide the NRC with the necessary documentation for amending the facility operating license or negotiating a "decommissioning license," the licensee must provide:

- a description of the current facility status

- an inventory of the onsite radioactive materials

- a description of the proposed decommissioning activities

- a description of the proposed measures to minimize radioactive releases

- safety analyses of the proposed activities.

In addition, the 1 icensee must submit a radioactive waste handling plan, a quality assurance plan, an environmental report, and a safeguards plan.

This information is then incorporated into the detailed work plans and procedures which contain all the information required to actually carry out the 
TABLE 5.1-2. Checklist of Principal Federal Regulatory Requirements that Apply to Decommissioning a $\mathrm{UF}_{6}$ Conversion Facility

Regulatory Documents

Material License Requirements

10 CFR 40

Environmental Protection

10 CFR 51

10 CFR 20, Appendix 8

10 CFR 20.300

40 CFR 190.10

40 CFR 1500

NRC Staff Report (no number given)

Employee Protection

10 CFR 20

Transportation

10 CFR 71

49 CFR $170-199$
Functions Regulated

Materials licenses relating to source material

Licensing and regulatory policy and procedures for environmental protection

offsite releases

Waste disposal

Environmental radiation protection requirements for normal operations in the uranium fuel cycie (EPA)

CEQ guidelines for preparation of environmental impact s tatements

Guidelines for decontamination of facilities and equipment to release unrestricted use or termination of licenses for byproduct, source or special nuclear material (NRC, Nov. 1976)

Standards for protection against radiation

Packaging of radioactive material for transport and transportation of radioactive material under certain conditions

Department of Transportation hazardous material regulations

decominissioning tasks. The plans and procedures should cover all aspects of the decommissioning project, including:

- decommissioning methods

- radioactive waste management

- radiological and industrial safety

- equipment requirements

- environmental impact 
- security and safeguards measures

- quality assurance.

\subsection{SAFEGUARDS CONSIDERATIONS}

Prior to initiating decommissioning of a $\mathrm{UF}_{6}$ conversion plant, consideration must be given by the 1 icensee to the necessity of safeguarding the quantities of residual uranium that can be expected to be found in the facility during the dismantlement and decontamination of the equipment, buildings, and site. The regulations for operating facilities licensed to possess and use source material require special accounting and reporting measures, as specified in 10 CFR 40, for all source material receipts, inventories, transfers, and discards. (a) Similar procedures will probably be required by the NRC during decommissioning for application whenever the licensee possesses, transfers, or disposes of source material found in the facility, or in the wastes generated. (21) The actual requirements will be specified in the license agreement and may differ from facility to facility because no specific regulations for safeguards during decommissioning are presently in force.

The requirements stemming from the implementation of the US/IAEA agreement on July 31,1980 (described in 10 CFR 40.31, 10 CFR 70.21, and 10 CFR 75) will probably not be applied to $\mathrm{UF}_{6}$ conversion plant decommissioning. However, if the licensee expects to possess more than 10,000 kilograms of uranium (one effective kilogram) at any time during decommissioning, the possibility of application of the procedures required by 10 CFR 75 must be considered in the licensing negotiations. It seems unlikely that this will be necessary.

Considerations relating to safeguarding source materials, as well as those pertaining to protection of the environment and the general health and safety, were discussed in the preceding sections. The regulations and guidelines specifically applicable to safeguarding natural uranium in a licensed conversion plant are summarized as follows:

(a) Source material is defined as uranium or thorium or any combination of them, but not including enriched uranium. 
The 1 icensee who possesses and uses source material is required to:

- transfer the material only to authorized persons or institutions as defined in 10 CFR 40 , Section 40.51

- verify before the transfer that the intended recipient is authorized to possess such material

- keep records showing the receipt, transfer, and disposal of source material

- retain all source material records for the minimum time periods specified in 10 CFR 40 , Section 40.61

- afford to the NRC opportunities at reasonable times to inspect the materiar, premises, facilities and material accounting records, and to perform such tests as the NRC considers appropriate or necessary

- complete and distribute the Nuclear Material Transaction Report, Form NRC-741, whenever a transfer or a receipt of $1000 \mathrm{~kg}$ or more of source material is made

- if licensed to possess $1000 \mathrm{~kg}$ or more of source material, submit a statement of this inventory once a year

- to report promptly to the NRC any known attempt to commit a theft or unlawful diversion of more than 15 pounds of source material

- if licensed to produce uranium hexafluoride, report every 6 months the quantity and principal radionuclides released to unrestricted areas in liquid or gaseous effluents.

There are no physical protection requirements for a source material licensee except as deemed necessary for the health and safety of the public.

At the end of normal operations, the types of nuclear material remaining in the $U F_{6}$ conversion plant will be similar to the types of nuclear materials stored and processed in the plant prior to shutdown. After decommissioning cleanout of the plant and the process equipment, the physical form and concentration of the material may be different from its original form due to the methods used to remove 
the material from the areas in which they have been entrapped during normal operation. An estimate of the quantities and locations of uranium in the facility when decomissioning begins is given in Section 7, Table 7.4-2. A summary of those data is given in Table 5.2-1.

TABLE 5.2-]. Estimated Uranium Inventory in Major Pieces of Equipment in the Reference Plant After Final Inventory Cleanout

\begin{tabular}{lr}
\multicolumn{1}{c}{ Equipment } & $\begin{array}{c}\mathrm{kg} \text { of } \\
\text { Uranium }\end{array}$ \\
\cline { 1 - 2 } Sampling Station Equipment & 200 \\
Solvent Extraction & 1100 \\
Concentrator Units & 2000 \\
Denitration & 800 \\
Reduction & 400 \\
Hydrofluorination & 2100 \\
Fiuorination & $\underline{2600}$ \\
$\quad$ Total & 9200
\end{tabular}

The problem of safeguarding uranium in a facility during decommissioning is unlike that in an operating facility. During decommissioning, the uranium will be on the surfaces of process enclosures and equipment, entrapped within equipment, in sumps, and distributed in waste and rubble. In genera1, it will be in inaccessible places. The easily removed SNM would be recovered during the final operational cleanup and any chemical decontamination activity during the initial phases of decommissioning. Measurable quantities of uranium will be obtained in cleanup and decontamination solutions and sludges. In addition, kilogram amounts of uranium compounds may be obtained in some cases during dismantling of certain processing equipment. The decommissioning plan will need to describe the intended procedures for measurement and accounting, record keeping, and reporting of those quantities of uranium. It is likely that NRC will require measurement, accounting, record keeping and reporting of transfers and disposals of uranium in a manner similar to that specified in 10 CFR 40 for operators. These were summarized above. 
Most of the uranium will probably be in disposable decommissioning waste. Regulations do not provide restrictions on the quantity or concentration of uranium in disposable waste, but only provide rules for packaging and shipping and the manner of disposal (see 10 CFR 40, 10 CFR 20, 10 CFR 71, 40 CFR 190, and 49 CFR 199). The licensee's safeguards responsibilities are simply to measure and record the quantities of uranium present in an annual inventory accounting, and report all transfers and disposals of uranium-bearing material.

\subsection{LICENSE TERMINATION AND FACILITY RELEASE}

A primary goal of decommissioning is to terminate the nuclear license and release the facility for unrestricted use. To do this, the residual radioactive contamination must be at acceptable levels for public protection. There are no federal regulations that stipulate the actions to be taken to terminate a license for the facilities of this study. However, regulations, guidelines, and standards do exist that provide guidance on acceptable residual contamination levels for conditional or unrestricted release of uranium mill tailings piles. This guidance is reviewed in this section.

\subsubsection{License Termination by Stabjlization}

Stabilization may be a method of decommissioning considered for the lagoon waste at the reference $U_{6}$ plant. At this time, the NRC has not determined whether this will be acceptable; its acceptability would have to be considered on a case-by-case basis.

In decommissioning a $\mathrm{UF}_{6}$ waste lagoon by stabilization, attention must be given to two items: first, stabilizing the lagoon to minimize radionuclide release, and second, monitoring the site to detect any such release or human intrusion. Experience in dealing with uranium mill tailings may be relevant to this study.

Legislation and information pertaining to post-operational activities at uranium mill tailings piles are contained in the Uranium Mill Tailings Control Act of $1978^{(22)}$ and the Generic Environmental Impact Statement (GEIS) on Uranium Milling, (23) respectively. These documents may also be considered for guidance in establishing regulations for the decomissioning and long-term care of the reference plant lagoon wastes. 
Four major provisions of the Uranium Mill Tailings Control Act are: 1) government ownership of tailings and tailings disposal sites, 2) financial surety that the mill operator is responsible for the costs of site decommissioning and long-term care, 3) elimination to the extent practicable of long-term maintenance, and 4) reclamation and management of tailings to national standards both before and after termination of a license. The Uranium Mill Tailings Control Act amends the Atomic Energy Act as follows:

- Section 83, covering ownership and custody of tailings and tailings disposal areas, is added. Before either a new license or a license renewal issued after October 1981 can be terminated, the licensee must clean up the site and transfer ownership of the tailings to the federal government or the government of the state in which they are located. In addition, for new licenses three land ownership options are stipulated: 1) ownership by the United States, 2) ownership by the state at the state's option, or 3) private ownership if the NRC determines that government ownership is not necessary.

- Section 161x, covering financial arrangements for decommissioning and longterm care, is added. The new section provides authority to require financial surety arrangements by licensees to permit completion of site cleanup and reclamation prior to termination of the 1icense. If long-term care is required, financial arrangements must also be made; however, the need for long-term care should be minimized to the extent possible.

- Section 274 is expanded to require state standards that are equivalent to, or more stringent than, NRC standards for tailings disposal sites. The amended section describes procedures for state rulemaking paralleling basic federal procedures, and mandates the preparation of a written environmental analysis for each license.

- Section 275 is added, granting authority to the EPA to promulgate general standards for protection of the environment from both radiological and nonradiological releases from mill tailings. The NRC is responsible for enforcement of the EPA-promulgated standards. 
The GEIS on uranium milling provides an informational and decisional base for the preparation of regulations covering decommissioning, decontamination, site reclamation, transfer of title on termination of operations, future site use, and long-term care of uranium mill tailings piles. Major institutional questions addressed in the document include:

- the need for land use controls and site monitoring

- the methods of providing financial surety that decommissioning is accomplished by the mill operator

- the need for and funding of long-term care that may be necessary.

The recommendations contained in the uranium milling GEIS are based on government ownership and surveillance of mill tailings. It recommends that decommissioning of other portions of a mill site provide for unrestricted use, but that the mill tailings pile be treated as a low-level waste burial site containing very long-iived radionuclides and requiring continued control to ensure that tailings are not disturbed by either human activities or natural weathering processes. In addition, it recommends that the continued control should be provided through government ownership and custody after the licensee has satisfied decommissioning requirements and the license is terminated, but no transfer of ownership is contemplated for $\mathrm{UF}_{6}$ plants.

The NRC recently issued a Branch Position stipulating interim performance objectives for low-level waste burial site closure and stabilization. (24) These performance objectives could also provide guidance for a rare-metals refinery operator in developing tailings pile closure and stabilization plans in anticipation of transferring the pile to a custodial government agency. Major provisions of this Branch Position deal with: 1) measures to stabilize the site in a condition that requires only passive surveillance and monitoring during the long-term care period that follows license termination, and 2) funding assurance to permit site closure and stabilization.

\subsubsection{License Termination by Removal}

Removal of $\mathrm{UF}_{6}$ plant lagoon waste involves the removal, packaging, and offsite shipment of the waste to a disposal facility. Presumably, after 
removing the tailings and demonstrating that the contamination in the surrounding soil does not exceed a level to be prescribed by federal regulations, the operating license can be terminated and the site can be released for unrestricted use.

The EPA has issued interim standards for cleanup of open lands and buildings contaminated with residua] radioactive materials (mainly tailings) from inactive uranium processing sites. (25) The standards apply to open lands and buildings that are part of any processing site designated by the Secretary of Energy under Public Law 95-604, Section 102. (22) The EPA standards might be considered for guidance on a case-by-case basis in defining standards for the cleanup of the reference plant.

The interim EPA standards limit radon decay product concentrations in contaminated buildings to 0.015 Working Level (WL). (a) Gama radiation is limited to $0.02 \mathrm{mR} / \mathrm{hr}$ above normal background levels. The standards impose a limit of $5 \mathrm{pCi}$ of ${ }^{226} \mathrm{Ra}$ per gram of soil for tailings on open land. The maximum radon emissions and gamma radiation that will result under the standards are within the variations that would normally occur from undisturbed land areas.

\subsection{CONCLUSIONS}

Although there are numerous regulations that can be applied to deconmissioning by implication and analogy, specific and comprehensive regulatory requirements for decommissioning nuclear plants are presently lacking. For decomissioning a $U_{6}$ conversion plant, a plan should be prepared that includes health, safety, environmental, and safeguards considerations. With regard to safeguards, the plan must cover the accounting procedures for quantities of uranium present and identifiable in the plant, and any measurable quantities recovered or identified in accountable and measurable forms during dismantlement and decontamination of the equipment, facjlity, and site. These quantities of uranium must be measured, accounted for, and disposed of in a manner acceptable to the NRC.

(a) A Working Level is defined as any combination of short-lived radon decay products in 1 liter of air that will result in the ultimate emission of alpha particles with a total energy of 130 billion electron volts. Studies of indoor background radioactivity at Grand Junction (Colorado), New York, and New Jersey showed that at least $10 \%$ of the houses with basements exceed the interim standard's remedial action level of $0.015 \mathrm{WL}$. (25) 


\section{REFERENCES}

1. U.S. Nuclear Regulatory Commission, Plan for Reevaluation of NRC Policy on Decomissioning of Nuclear Facilities, Office of Standards Development, NUREG-0436, Rev. 1, December 1978; Supplement 1, August 1980; Supplement 2, March 1981.

2. 42 USC 5801 et seg., Energy Reorganization Act of 1954 .

3. 42 USC 2011 et seq., Atomic Energy Act of 1954.

4. 35 Federal Register 15623 (July 9, 1970; effective December 2, 1979); 23 USC 4321, 1973.

5. 42 USC 7401 et seq., Clean Air Act Amendments of 1977.

6. 42 USC Amendments, $300 \mathrm{f}-\mathrm{j}-9$, Safe Drinking Water Act of 1977.

7. 49 USC 1801 et seq. Hazardous Material Transportation Act of 1974.

8. U.S. Department of Transportation, A Review of OOT Regulations for Transportation of Radioactive Materials, August 1976.

9. U.S. Atomic Energy Commission Regulatory Guide 1.86, Termination of Operating Licenses for Nuclear Reactors, June 1974.

10. U.S. Code of Federal Regulations, Title 40, Part 190, "Environmental Radiation Protection Standards for Nuclear Power Operations," Superintendent of Documents, GPO, Washington, DC 20555, January 1980.

11. U.S. Nuclear Regulatory Commission, Guidelines for Decontamination of Facilities and Equipment Prior to Release of Unrestricted Use or Termination of [icenses for By-Product, Source, or Special Nuclear Material, November 1976 .

12. "Timely Notification of Discontinued Licensed Activities," Federal Register, vol. 44, p. 19479, March 22, 1979.

13. G. D. Calkins, Thoughts on Regulation Changes for Decommissioning, Office of Standards Development, U.S. Nuclear Regulatory Commission, NUREG-0590, Rev. 2, August 1980.

14. "Decommissioning of Nuclear Facilities," Federal Register, Vol. 44, No. 230, pp. 68307-68308, November 28, 1979.

15. R. S. Wood, Draft Assuring the Availability of Funds for Decommissioning Nuclear Facilities, NUREG-0584, Rev. 1, November 1979; Rev. 2, October 1980.

16. 42 USC $2021(k)$, Atomic Energy Act of 1954. 
17. A. H. Shilling, et al., Decomissioning Commercial Nuclear Facilities: A Review and Analysis of Current Regulations, NUREG/CR-0671, August 1979.

18. W. A. Brobst, "The State of State Regulations," in Proceedings of the 4 th International Symposium on Packaging and Transportation of Radioactive Material, CONF-740901, Miami Beach, Florida, September 1974.

19. 42 USCA $300 \mathrm{f}-j-9$. Safe Drinking Water Act Amendments of 1977 (1977 Supplement).

20. 42 USCA $300 F(6)$. Safe Drinking Water Act Amendments of 1977 (1977 Supplement).

21. U.S. Nuclear Regulatory Commission, Guide for the Preparation of Applications for Licensees to Possess Source Material, Regulatory Guide 10.4, Rev. 1, March 1977.

22. U.S. Congress, 95th Congress Public Law 95-604, "The Uranium Mill Tailings Radiation Control Act of 1978."

23. Generic Environmental Impact Statement on Uranium Milling, NUREG-0511, Draft, U.S. Nuclear Regulatory Commission, Office of Nuclear Material Safety and Safeguards, Washington, DC, October 1980.

24. "Branch Position - Low-Level Waste Burial Ground Site Closure and Stabilization," Low-Leve] Waste Branch, U.S. Nuclear Regulatory Commission, Washington, DC, Revision 1, May 17, 1979.

25. "Interim Cleanup Standards for Inactive Uranium Processing Sites," Federal Register, Vol. 45, No. 79, pp. 27366-27368, April 22, 1980. 


\subsection{ALTERNATIVE APPROACHES TO FINANCING OECOMMISSIONING}

The Nuclear Regulatory Commission (NRC) has for several years been considering possible regulatory changes for the decomissioning of fuel cycle facilities. (1) Possible regulatory changes relating to financial assurance is one of the areas under active consideration. Most financial assurance attention has been directed to power reactors; ${ }^{(2)}$ however, other fuel cycles have also received attention. A1l of the decommissioning study reports prepared by Pacific Northwest Laboratory for the NRC have contained a chapter on assurance of funds for decommissioning. The NRC has issued a staff report on financial assurance of decommissioning funds that contains separate chapters applicable to reactors and other nuclear facilities. (3) Regulations have also been issued by the NRC to assure funds for uranium mill decommissioning. ${ }^{(4)}$

This section identifies the alternatives for assuring the availability of decormissioning funds and discusses the relative merits of these alternatives. In addition, current regulatory developments in the area of decormissioning financing are discussed.

\subsection{NEED FOR ASSURANCE OF DECOMMISSIONING FUNDS}

The state in which a $\mathrm{UF}_{6}$ conversion plant is located and the NRC have two principal financial concerns. First, they are concerned that when the facility ceases operation there will be sufficient funds available to perform a thorough decommissioning, and that sufficient funds will be available for care of the property before and after decommissioning until the site is released for unrestricted use. This concern exists for plants that operate throughout their anticipated life as well as for plants that are shut down prematurely. Second, they are concerned that funds will be available to provide for unexpected accidents and contingencies, both during the operating life of the facility and before decomissioning is completed. The principal focus of this section is on the first concern.

The basis of the state concern for availability of decommissioning funds is its inherent obligation to protect the health and safety of its citizens. 
The basis of NRC concern is its obligation under the Atomic Energy Act of 1954 to regulate atomic energy and nuclear facilities so as to protect the health and safety of the public. If the $U_{6}$ conversion plant operator defaults on his decommissioning responsibility, conducts decommissioning in a deficient manner, or unreasonably delays the decommissioning process, public health is potentially jeopardized.

\subsection{APPROACHES TO PROVIDING FUNDS FOR DECOMMISSIONING AND LONG-TERM CARE}

There are three principal alternatives to assure the availability of decommissioning funds for nuclear facilities other than power reactors: ${ }^{(5)}$

1. Creation of a sinking fund to accumulate sufficient decomissioning funds in a trust account during the facility's operating life,

2. Prepayment of the present value of future decommissioning funds into a trust account fund prior to facility start-up,

3. Purchase of a surety bond or an equivalent guaranteeing funds for decommissioning.

Each alternative is discussed in this section. It is also possible that these options can be combined in an acceptable manner. For example, alternative 1 might be supplemented by a bond guaranteeing the availability of funds in the event of premature facility closure. Internal decommissioning funding (where funds for decommissioning are set aside by the operator or where decommissioning costs are simply paid out of cash flow as costs are incurred) is not considered here because it has a relatively low assurance of providing funds unless it is supplemented by some other method.

The NRC staff has developed five criteria to evaluate the relative effectiveness of the financial assurance alternatives: 1) the degree of assurance provided by the alternative, 2) the cost of providing the assurance, 3) the equity of the alternative, 4) the ability of the alternative to respond to changing financial parameters, and 5) the ability of the alternative to 
effectively meet different ownership and jurisdictional arrangements. 3 , p.6\} These criteria are used as guidance in the discussion that follows.

\section{2 .1 Sinking Fund}

This alternative contemplates the formation of a sinking fund tied to $\mathrm{UF}_{6}$ production to generate enough funds during the operating life of the facility to pay anticipated decommissioning costs. Payments would be made into a trust account permanently outside the control of the facility operator and his creditors. This approach is currently used by the three states (Nevada, South Carolina, and Washington) that license and regulate low-level radioactive waste burial grounds.

Payments to the sinking fund would be based on UF 6 production. The charge per unit of product would be determined by estimating total decommissioning and associated administrative costs and total anticipated production over the facility's operating life. An amount would be paid into the fund per unit of product so that the payments, plus compound interest earned by investing the fund during and after the plant operating life, would be sufficient to pay all anticipated costs and provide a reasonable contingency of perhaps 10 to $15 \%$ of estimated costs.

The payment per unit of product into the sinking fund could be adjusted regularly to account for changing financial parameters. For example, the rate of return achieved by the fund stewards (i.e., trustee) in relation to decommissioning cost escalation will likely change. The production rate for the facility will not be completely constant over time. The real (i.e., nonescalated) decomissioning cost can also be expected to change with time because of technological innovations, added facilities, and new regulatory requirements. It is also likely that the expected life of a plant will change. All of these changes can be periodically accounted for by adjustments to the sinking fund payment. If such changes are not severe and are regularly reflected in the payments, the value of the sinking fund should be close to the needed funds when the facility is retired.

A variety of entities could be designated to provide stewardship for the sinking fund. Possibilities include state government, the federal government, 
or a private financial institution. An independent "Decomissioning Assurance Agency" could be chartered by each state to retain and invest sinking fund payments from various nuclear facilities and perhaps oversee decomissioning activities and disburse funds to those conducting the activities. The pooling of decommissioning funds into such a centralized agency could help to ensure decomissioning performance even if a particular facility operator defaults in some manner. There could also be certain federal income tax advantages if the Agency is a subdivision of state government (see Section 6.5).

An advantage of the annual payment sinking fund approach is that it should generally assure that decommissioning activities actually occur. With funds set aside to cover the costs, the question of who should pay them is alleviated and arguments about responsibility are less likely to occur.

A second advantage of the sinking fund option is that it should improve decision-making when power-generating options are being considered. Currentiy, future decommissioning costs of nuclear facilities may not be reflected in the electricity prices paid by consumers. If all such facilities were required to have sinking funds to provide for future deconmissioning and waste management expenses, these anticipated costs would be evaluated and equitably reflected in the cost of fuel and in power-generation costs and consumers' power bills.

Another advantage of the sinking fund approach is that it is reasonably equitable to consumers. As long as increases in estimated decommissioning costs are reflected in adjusted payment schedules, all consumers should pay their approximately proportional share of costs in dollars of approximately equivalent buying power.

Several potential problems and concerns with the sinking fund option should be recognized. The principal difficulty is the possible shortage of decommissioning funds in the event of premature facility closure. This potential problem is discussed in Section 6.3. Another concern relates to the care and investment of the fund. Professional management of the fund would be desirable. The trustee will be faced with the same problem other conservative investors are; i.e., how can assets be invested with minimal risk to earn a return that 
at least matches the rate of cost escalation due to inflation? If the trustee is not able to match the rate of cost escalation, the payments to the fund (in year of start-up dollars) will have to be increased over time at a rate that exceeds the rate of escalation. A third concern is that decommissioning costs must be estimable with reasonable accuracy to provide a basis to calculate an appropriate sinking fund payment. Although revised estimates can be made and reflected in the sinking fund payments later in the facility lifetime, the initial estimate is especially important if the expected operating life is relatively short.

It must also be recognized that establishment and control of a decomissioning trust fund would, by its nature, create some administrative complexities. In addition to the problems of fund management and control, an additional government or quasi-government agency might be required to oversee the operation of one or more funds.

\subsubsection{Prepayment of Anticipated Costs}

The general framework of the prepayment alternative is similar to the sinking fund option. A trust fund would be established. The trustee would invest the monies until they are required for decommissioning. The difference is that the present value of anticipated decommissioning and administrative costs would be paid into the fund before facility start-up. Adjustments to the fund may be required to account for changes in such factors as the trust fund earnings rate relative to the decomissioning cost escalation rate; facility life; added production capacity; and changing technology, safety, and regulatory requirements.

The principal advantage of the prepayment approach is that it provides the highest degree of assurance that decommissioning funds will actually be available when needed. This is because sufficient money should be available for decommissioning operations even if the facility owner ceases operation prematurely.

One disadvantage of the prepayment option is that it may be the most expensive of the three financial assurance alternatives. The money deposited in the trust fund is likely to earn less than if it were being directly 
utilized by the facility owner. This is because the discount rate utilized by a $U_{6}$ conversion facility operator will likely exceed the interest rate obtainable by the trustee. The discount rate favored by the operator will approximate his minimum rate of return on alternative investments. By requiring the operator to prepay the expected decommissioning cost, society loses the productive value represented by the incremental return the operator could realize on the funds over what the trustee could realize.

To the extent debt funds are used to prepay the present value of decommissioning costs, the borrowing capacity of the operator is reduced and consequently his avajlable supply of funds for capital investment is reduced. However, the prepayment approach would increase the amount of funds available for purchase of the conservative government and private security issues that a trustee would be likely to purchase.

One can argue that the prepayment approach unfairly raises the cost of nuclear power. Prepayment of decommissioning costs represents an extraordinary expense not incurred to the same degree in the fuel cycle cost of other powergenerating technologies. The prepayment option may also penalize current consumers because future power consumers may not pay their full share of the decommissioning costs. Finally, it can be argued that the prepayment option unfairly discriminates against smaller businesses without the access to capital funds that a larger business would have.

\subsubsection{Surety Bond}

Under this alternative, the UF $_{6}$ conversion facility operator would be required to purchase a surety bond prior to start-up which would guarantee a specific amount of funds for decommissioning performance. A functional equivalent to a surety bond such as certain bank letters of credit are possible substitutes to the bond. It must be determined in advance whether the surety is equally responsible for decommissioning performance with the principal obligor, the UF 6 conversion plant owner, or whether the surety's liability arises only when all attempts to make the principal obligor perform have faited. 
The surety bond approach does have precedent. A performance surety bond that guarantees reclamation of lands that are surface-mined for coal is required under the Surface Mining Control and Reclamation Act. Applicable regulations are in 30 CFR 800 . Wyoming requires a bond to assure reclamation of any surfacemined lands. ${ }^{(6)}$ The amount of the bond is adjusted annually to reflect new land reclamation cost estimates. The surety bond alternative was also selected by the NRC as the principal financial assurance mechanism to assure decommissioning of uranium mill sites and the reclamation of any associated tailings or waste disposal areas (see Section 6.4).

A major advantage of the surety alternative is that administration expense is low. The bonds are not inexpensive, however. Depending on the credit rating of the operator and the degree of risk in the decommissioning operation, the cost of a bond, if it can be obtained, will likely be on the order of 1 to $2 \%$ per year of the guaranteed amount. $(7)$

There are several problems with obtaining a surety bond. The principal difficulty is that surety companies may not be interested in selling a longterm bond because of the many uncertainties affecting their obligation. If the bond is renewable at given intervals, the surety may very well decline renewal if the operating company becomes financially weak. Also, the guaranteed amount of the bond will have to be readjusted periodically to reflect revised decommissioning estimates. If the surety does not agree ahead of time to automatic escalation of the guarantee, the usefulness of the bond is again substantially reduced. Designation of appropriate criteria for determining when the facility owner has not performed decommissioning satisfactorily and, correspondingly, when the surety becomes liable may be difficult. An additional problem is that even if a bond can be obtained, financial assurance depends on the soivency of the surety. Finally, collecting on a surety bond could be more difficult (possibly requiring litigation) than utilizing funds previously paid into a trust fund.

It may be possible for a well-financed company to obtain a bond to assure the decommissioning of a $U_{6}$ conversion facility under the DECON decomnissioning 
alternative. For a weakly financed company, or under the SAFSTOR deconmissioning alternative, a bond may be very difficult to obtain and require significant collateral if it is obtainable.

\subsection{DECOMMISSIONING FUNDING IN THE EVENT OF PREMATURE CLOSURE}

With the sinking fund financial assurance option, the state runs the risk that sufficient funds will not have been collected to cover decommissioning costs if the facility closes prematurely. If the facility operator can and will pay the difference between the fund balance and the needed decommissioning funds, no problem arises. If he is financially unable to do so, the state or possibly the federal government could be forced to provide the needed funds. No special problem exists with the prepayment option because funds should be available whenever closure occurs. This is the principal advantage of the prepayment approach.

If the sinking fund financial assurance alternative is chosen, several options are available to assure the availability of funds in the event of premature closure. The options include one or more of the following:

- an initial extra cash payment to the sinking fund prior to production

- higher per unit sinking fund payments (in real, i.e., constant dollars) during the initial years of operation

- a bond posted by the facility operator

- premature shutdown insurance.

The first two options can be considered variations of the sinking fund and prepayment atternatives.

\subsubsection{Initial Cash Payment}

This option contemplates that an initial significant cash payment would be made to the trust fund prior to start-up. This money would become part of the trust fund and would thus presumably be outside the reach of the facility owner and his creditors. The size of the payment could be flexible and might 
depend on the financial resources of the operator, the probability of premature closure, the extent of anticipated decommissioning problems, the anticipated operating life of the facility, and other factors. In general, however, it seems that an initial payment on the order of at least $10 \%$ of total estimated decommissioning costs (in year of start-up dollars) would be appropriate.

The principal advantage of this option is the added assurance it provides that the initial funds, plus sinking fund payments, will be sufficient to cover decomissioning costs. If the prepayment portion is a relativeiy small portion of total decomnissioning cost, there is no significant disadvantage to this option. If it is a significant portion, the difficulties associated with the prepayment option discussed in Section 6.2 .2 are relevant.

\subsubsection{Higher Initial Sinking Fund Payments}

This option contemplates that payments to the sinking fund in constant dollars would be initially higher than average and then would decline with time. The precise sliding scale can be determined by the licensing agency. One variation of this option would be to attempt to have constant payments in nominal dollars over the lifetime of the facility. (Nominal dollars are dollars of the year in which payments are made.) This option also could be utilized in conjunction with an initial cash payment.

The advantages and disadvantages of this option are comparable to those for the initial payment option. The main advantage is the added assurance that sufficient decomissioning funds will be available when needed. It is also reasonably equitable to the operator and his customers because both required sinking fund payments per unit of production and actual decommissioning costs per unit of production (assuming premature facility closure) will decline as the total quantity of $\mathrm{UF}_{6}$ produced increases.

\section{3 .3 Surety Bonds}

Surety bonds are another alternative for providing funds in the event of premature facility closure. The chief difficulty is the problem of obtaining a long-term commitment from a surety company, as discussed in Section 6.2.3. 
If a suitable bond can be obtained, there are two potential advantages. First, it may be a more equitable alternative for the smaller company that is unable to make a significant initial cash payment. Second, it reduces the distortion effect on nuclear power-generation costs of a high initial cash payment.

\subsubsection{Premature Shutdown Insurance}

Insurance is an additional approach to decomissioning assurance. The policy would provide for payment of the additional funds needed for decommissioning in the event of premature facility closure. An insurance pool with many nuclear facilities participating may be the preferred way to implement this alternative. Participating facilities could be determined by type of facility, by geographic area, or by a combination thereof. Setting appropriate insurance premiums could be difficult, and the insurance pool concept may require federal participation for implementation. Insurance can also be used to provide liability and property damage coverage in case of an accident at the facility. The NRC has retained a contractor to investigate the feasibility of insurance to provide financial assurance for decommissioning a power reactor and funds to rebuild in case of an accident. (8)

\subsection{RECENT REGULATORY DEVELOPMENTS}

New regulations relating to financial criteria for decommissioning uranium mill sites and non-nuclear hazardous waste disposal sites have recentiy been issued. Both sets of regulations may be used as guidance for providing financial assurance for decomissioning a $U_{6}$ conversion facility.

\subsubsection{Uranium Mill Sites}

New licensing requirements that include financial criteria for uranium and thorium milling activities, including tailings and wastes generated from these activities, were issued by the NRC in October 1980 and are found in Appendix A to 10 CFR 40. ${ }^{(4)}$ The requirements apply to all new or renewa license applications as of November 1980, and are effective for existing licensees in August 1981. Criterion 9 requires mill operators to obtain 
financial surety arrangements acceptable to the NRC that will assure decommissioning performance. Arrangements generally acceptable to the Comission are: surety bonds, cash deposits, certificates of deposit, deposit of government securities, irrevocable letters or lines of credit, and various combinations of these. The surety bond seems likely to be the favored approach. The NRC or the cognizant state regulatory agency must be named the beneficiary of the financial assurance mechanism. The surety mechanism must be reviewed annually and the amount of the bond or guarantee must be increased if necessary to assure the availability of adequate funds. The surety agreement should idealiy extend throughout the operating life of the facility. If it is for a fixed term that is less than the operating life, and the surety declines to renew, the regulations provide that the bond will be forfeited unless the licensee can locate a replacement surety. The licensee is also required to make a sufficiently large cash deposit with the appropriate regulatory agency such that interest from the deposit will enable long-term site surveillance.

In addition to the requirements for uranium mill licensees, the NRC is also preparing proposed regulations related to low-level waste burial grounds that will include a decommissioning financial assurance element. The proposed regulations are scheduled to be issued during the summer of 1981 . Final regulations are scheduled to be issued in 1982 and will appear in 10 CFR 61.

Although the financial assurance requirements for uranium mill licensees emphasize the surety mechanism rather that a sinking fund or prepayment, it is not clear whether this will provide a precedent for other nuclear facilities. The decommissioning regulations applicable to uranium mills and low-level waste burial grounds are being prepared separately from NUREG-0436, the plan for reevaluation of NRC policy on decommissioning of nuclear facilities. ( $8, p .3)$ The surety bond approach to decomnissioning financial assurance is likely to be most suitable when expected decommissioning costs are relatively low. An NRC survey of surety companies found none willing to provide the required surety for power reactors, $(3, P .45)$ which have high decommissioning costs compared to $\mathrm{UF}_{6}$ plants. Total estimated decomissioning costs at the model uranium mill 
utilized in the Final Generic Environmental Impact Statement on Uranium Mil1ing are approximately equal to or exceed the expected costs of deconmissioning the reference $U_{6}$ conversion facility described in this document. If mill operators are successful in obtaining decomissioning performance bonds, this approach may also be acceptable for $U_{6}$ conversion plants if the difficulties discussed in Section 6.2.3 can be resolved.

\subsubsection{Non-Nuclear Hazardous Waste Facilities}

The Enviromental Protection Agency (EPA) has recently issued revised proposed regulations designed to provide financial assurance for closure and postclosure care for non-nuclear hazardous waste disposal facilities. (10) The regulations were issued under the authority of the Resource Conservation and Recovery Act. The facility owner can select from several acceptable financial assurance mechanisms including a trust fund, a surety bond, a letter of credit, or an acceptable combination of these.

The principal distinction of the EPA regulations in relation to the NRC uranium mill regulations is the availability of the trust fund built up with periodic payments over the operating life of the facility as an acceptable financial assurance mechanism. The regulations call for a bank or other financial institution to act as trustee for the fund. A required form of the trust agreement is provided in the regulations. The EPA acknowledges that the trust fund may not provide adequate protection in the event of premature facility closure and indicates that this problem is under further study.

\subsection{FEDERAL INCOME TAX CONSIDERATIONS}

The treatment of the various financial assurance alternatives under the Internal Reverlue Code (the "Code") is an important element for both the NRC and a facility operator to consider in selecting an appropriate approach. The potential application of the Code to the three principal financing alternatives is discussed in this section.

The surety bond financial assurance mechanism appears to have the most straightforward tax treatment. Premiuns for the surety bond should be an allowable deduction for the operator in computing taxable income as an ordinary 
and necessary business expense under Section 162 of the Code. Actual decommissioning costs should also be deductible under Section 162 as they are incurred.

The important federal tax issues for the trust fund and prepayment financial assurance options are similar. First, are the periodic trust fund payments deductible from gross income by the facility owner/operator in the tax year they are made to the trustee? Second, is the income earned by the trust fund subject to federal tax, and, if so, who should pay the tax?

In general, it appears that periodic payments to a trust fund would be deductible by the facility operator. As long as the payments are required by a regulatory agency, they should qualify as an ordinary and necessary expense. If the trust funds are subsequently parceled back to the operator by the trustee, as the EPA hazardous waste regulations provide, they would be income to the operator as received. This income, however, would be offset by allowable expenses for actual decommissioning expenses. With the prepayment financing alternative, the tax treatment may be different. There is a reasonable possiblity in this case that the Internal Revenue Service would not allow deduction of the full prepayment in the year paid, but rather would require amortization over the expected operating life of the facility. This interpretation would be costiy to the operator because the time value of the tax savings realized by taking the deduction for the prepayment in the year paid would be lost.

It is also at least possible that the Internal Revenue Service would not allow current deductions for any payments made to a trust fund. This position would presumably be based on the claim that the monies paid to the trustee are not really an ordinary and necessary expense, but simply a temporary transfer of funds to a custodial trustee. This position would be quite undesirable for the facility owner and also seems inequitable. Several steps can potentially be taken to minimize the likelihood of this claim. $(3, p .20)$ The most effective step would be discretion on the part of the trustee or regulatory agency to retain someone other than the facility operator to conduct decommissioning operations. In this case the trust fund payments would not be merely a temporary transfer of funds because there is a possibility that the 
operator would never see them again. A second step would be to preclude the trustee from investing in the stock or debt issues of the facility owner. A third step would be to assure that the trustee is truly independent of the facility operator. A fourth provision would be to require that any excess trust funds remaining after decomissioning and long-term care would revert to the state.

The interest earned by the trust fund can be exempt from federal taxes if the administering trustee is an agency of state government, (12) or if the trustee invests in debt obligations issued by state governments or any political subdivision thereof, the District of Columbia, or any U.S. possession. (13) If these conditions do not apply, there will be federal tax liability. The trust will be a separate tax paying entity and will be taxed in the same manner as an individual. (14) The facility owner/operator is the logical entity to pay the federal taxes as well as any other taxes assessed against the trust account. The potential tax liability must be estimated in advance so that sufficient funds are collected from the operator to make the required tax payments. 


\section{REFERENCES}

1. Plan for Reevaluation of NRC Policy on Decomissioning of Nuclear Facilities, NUREG-0436, U.S. Nuclear Regulatory Commission, March 1978; Revision 1, December 1978; Supplement 1, August 1980; Supplement 2, March 1981.

2. Financing Strategies for Nuclear Power Plant Decommissioning, NUREG/CR1481, Temple, Barker and SToane, Inc., July 1980.

3. R. S. Wood, Assuring the Availability of Funds for Decommissioning Nuclear Facilities, NUREG-0584, Rev. 2, U.S. Nuclear Regulatory Commission, October 1980.

4. 45 Federal Register, 65535, October 3, 1980.

5. Draft Generic Environmental Impact Statement on Decommissioning of Nuclear Facilities, NUREG-0586, U.S. Nuclear Regulatory Commission, p. 0-41, January 1981. 46 Federal Register, 11667, February 10, 1981.

6. Wyoming Statutes, Section 35-502.

7. Financing Alternatives for Stabilization, Reclamation, and Long-Term Monitoring and Maintenance of Uranium Mill Tailing Piles, Science Applications, Inc., Los Angeles, California, Prepared for Argonne Nationa 1 Laboratory, p. 18, October 1977.

8. G. D. Calkins, Plan for Reevaluation of NRC Policy on Decommissioning of Nuclear Facilities, NUREG-0436, Rev. 1 Suppi. 2, U.S. Nuclear Regulatory Commission, p. 7, March 1981.

9. Final Generic Environmental Impact Statement on Uranium Milling, NUREG-D706, U.S. Nuclear Regulatory Comission, September 1980.

10. 40 CFR 264, Subpart H, 46 Federal Register 2851, January 12, 1981.

11. 46 Federal Register 2824, January 12, 1981.

12. Internal Revenue Code, Section 115.

13. Internal Revenue Code, Section $103(a)$.

14. Internal Revenue Code, Section 641 . 



\subsection{CHARACTERISTICS OF THE REFERENCE URANIUM HEXAFLUORIDE CONVERSION PLANT}

The reference uranium hexafluoride $\left(U_{6} F_{6}\right)$ conversion plant, the reference site on which it is assumed to be located, and the physiochemical processes used in the plant are described in this section. Estimates are presented of residual radioactivity levels and residual chemical levels on the site and in the plant when conversion operations are terminated.

$\mathrm{U}_{3} \mathrm{O}_{8}$ concentrate extracted from uranium ore must be converted to the volatile compound uranium hexafluoride $\left(U_{6}\right)$ for enrichment by the gaseous diffusion process. Two processes are in use for UF 6 production. One process employs a wet chemical solvent extraction step at the head end of the process to prepare a high-purity uranium feed prior to the reduction, hydrofluorination, and fluorination steps. The second process, dry hydrofluorination, consists of continuous successive reduction, hydrofluorination, and fluorination of the ore concentrates, followed by fractional distillation of the crude uranium hexafluoride to obtain a pure product.

The nature of the effluents from the two processes differs. In the wet process, the bulk of the yellowcake impurities is contained as dissolved solids in a solvent extraction waste stream. In the dry process, the bulk of the impurities entering with the crude uranium feed is rejected from the hydrofluor process as solids.

The reference plant used as the basis for this study is based on the wet solvent extraction process. The plant is assumed to have processed 10,000 metric tons (MT) per year of natural uranium and to have been in operation for about 20 years. The reference plant is defined using current information from a combination of existing facilities, and no attempt is made to use all design features from a single plant.

Details of the plant and the plant process descriptions are presented in Appendix A; site description details are given in Appendix B; and the bases for residual radioactivity estimates are presented in Appendix $C$.

\subsection{SITE DESCRIPTION}

A reference site is developed to aid in assessing the public safety of conceptually decommissioning the reference plant. The meteorological parameters 
and population distributions used for this reference site are taken from the ALAP Study (1) for the river site in the year 2000. The ecological data are taken from environmental information provided for an operating nuclear reactor. The remainder of the information is obtained from a variety of sources, and is thought to be representative of potential sites for nuclear fuel cycle facilities in the midwestern or southeastern United States. This reference site description is developed for use in a series of studies examining deconmissioning of nuclear fuel cycle facilities. The detailed supporting information relating to this abbreviated description is found in Appendix $B$.

Individual features for specific sites will likely vary from those of the reference site described in this study. It is believed, however, that use of a reference site rather than a specific site will result in a more meaningful overall analysis of the potential safety impacts associated with the decommissioning of nuclear fuel cycle facilities. Site-specific environmental information will be required for the detailed safety analysis and the environmental report submitted with the request for license modification prior to decomissioning a particular facility.

The reference site occupies $4.7 \mathrm{~km}^{2}$ in a rectangular shape of $2 \mathrm{~km}$ by $2.35 \mathrm{~km}$. A river of moderate size runs through one corner of the site.

The site is located in a rural area that has a relatively low population density. Higher population densities are located at distances 16 to $64 \mathrm{~km}$ away, and gradually reducing population densities are encountered out to $177 \mathrm{~km}$. The closest moderately large city, population 40,000 , is about $32 \mathrm{~km}$ distant. The closest large city, population $1,800,000$, is about $48 \mathrm{~km}$ away. The total population in a radius of $80 \mathrm{~km}$ is about $3.52 \mathrm{million}$.

The plant facilities are located within a fenced portion of the site. The minimum distance from the point of plant atmospheric releases to the outer boundary of the reference site is about $1 \mathrm{~km}$. About $80 \%$ of the 1 and surrounding the reference site is used for farming.

Atmospheric dispersion factors used in this study are derived as an average from the meteorological data of 16 nuclear sites. The resulting annual average atmospheric dispersion factor at the closest point on the site boundary (i.e., $1 \mathrm{~km}$ ) is about $5 \times 10^{-8} \mathrm{sec} / \mathrm{m}^{3}$ (2) 
The reference site is slightiy contaminated with radioactive material as a result of deposition from the release of normal operating effluents over the assumed 40-year plant operating $1 \mathrm{ife}$. It is assumed that accidental releases of radioactive material are cleaned up immediately following the event. Estimates of the maximum site contamination levels at the time of plant shutdown and selected times after shutdown are shown in Table 7.1-1 for natural uranium. The site contamination estimates are based on the deposition of predicted normal operating atmospheric releases of particulates. (3) The assumptions and calculational methods for relating the normal plant effluents to site surface contamination are found in Appendix $B$.

TABLE 7.1-1. Estimated Quantities of Radioactive Material Deposifed on the Reference Site After a 40-Year Operating Lifetime(a)

\begin{tabular}{|c|c|c|c|c|c|}
\hline \multirow[b]{2}{*}{ Radionuclide } & \multirow{2}{*}{$\begin{array}{l}\text { at Plant } \\
\text { Shutdown }\end{array}$} & \multicolumn{4}{|c|}{ Oeposited Radioactivity $\left(\mu \mathrm{C} i / \mathrm{m}^{2}\right)$} \\
\hline & & 5 Years & 10 Years & 30 Years & 100 Years \\
\hline${ }^{230} \mathrm{Th}$ & $8.8 \times 10^{-4}$ & $1.1 \times 10^{-3}$ & $1.3 \times 10^{-3}$ & $2.1 \times 10^{-3}$ & $5.0 \times 10^{-3}$ \\
\hline${ }^{231} \mathrm{Th}$ & $6.8 \times 10^{-3}$ & $6.8 \times 10^{-3}$ & $6.8 \times 10^{-3}$ & $6.8 \times 10^{-3}$ & $6.8 \times 10^{-3}$ \\
\hline${ }^{234} \mathrm{Th}$ & $7.5 \times 10^{-2}$ & $7.5 \times 10^{-2}$ & $7.5 \times 10^{-2}$ & $7.5 \times 10^{-2}$ & $7.5 \times 10^{-2}$ \\
\hline${ }^{231} \mathrm{~Pa}$ & $9.0 \times 10^{-6}$ & $1.1 \times 10^{-5}$ & $1.3 \times 10^{-3}$ & $2.2 \times 10^{-5}$ & $5.3 \times 10^{-5}$ \\
\hline${ }^{234 m} \mathrm{~Pa}$ & $1.0 \times 10^{-1}$ & $1.0 \times 10^{-1}$ & $1.0 \times 10^{-1}$ & $1.0 \times 10^{-1}$ & $1.0 \times 10^{-1}$ \\
\hline${ }^{234} \mathrm{~Pa}$ & $1.0 \times 10^{-4}$ & $1.0 \times 10^{-4}$ & $1.0 \times 10^{-4}$ & $1.0 \times 10^{-4}$ & $1.0 \times 10^{-4}$ \\
\hline${ }^{226} \mathrm{Ra}$ & $5.2 \times 10^{-5}$ & $5.2 \times 10^{-5}$ & $5.2 \times 10^{-5}$ & $5.2 \times 10^{-5}$ & $5.2 \times 10^{-5}$ \\
\hline${ }^{234} U$ & $1.0 \times 10^{-1}$ & $1.0 \times 10^{-1}$ & $1.0 \times 10^{-1}$ & $1.0 \times 10^{-1}$ & $1.0 \times 10^{-1}$ \\
\hline${ }^{235} \mathrm{U}$ & $4.5 \times 10^{-3}$ & $4.5 \times 10^{-3}$ & $4.5 \times 10^{-3}$ & $4.5 \times 10^{-3}$ & $4.5 \times 10^{-3}$ \\
\hline $238 U$ & $1.0 \times 10^{-1}$ & $1.0 \times 10^{-1}$ & $1.0 \times 10^{-1}$ & $1.0 \times 10^{-1}$ & $1.0 \times 10^{-1}$ \\
\hline Totals & $3.9 \times 10^{-1}$ & $3.9 \times 10^{-1}$ & $3.9 \times 10^{-1}$ & $3.9 \times 10^{-1}$ & $3.9 \times 10^{-1}$ \\
\hline
\end{tabular}

(a) Based on the ratio of radionuclides in uranium and the isotopic ratios given in Reference 3. 


\subsection{PROCESS DESCRIPTION}

The reference $U_{6}$ conversion plant is designed to receive yellowcake $\left(\mathrm{U}_{3} \mathrm{O}_{8}\right)$ in $0.21-\mathrm{m}^{3}$ drums from various uranium mills located in the western United States and to convert the feed stock to uranium hexafluoride $\left(\mathrm{UF}_{6}\right)$. The two processes for $U_{6}{ }_{6}$ conversion in use today differ only in the method of purification. The major steps in either process are:

1. pre-process handling, weighing, sampling, and storage

2. conversion of the yellowcake $\left(\mathrm{U}_{3} \mathrm{O}_{8}\right)$ to uranium trioxide $\left(\mathrm{UO}_{3}\right)$ by roasting

3. reduction of the $\mathrm{UO}_{3}$ to $\mathrm{UO}_{2}$ with hydrogen

4. hydrofluorination of the $\mathrm{UO}_{2}$ to $\mathrm{UF}_{4}$ with hydrogen fluoride

5. fluorination of the $U F_{4}$ to $U F_{6}$ with elemental fluorine

6. storage of the purified $U_{6}$ in shipping cylinders.

The purification step is added either at the beginning using a solvent extraction process or at the end by fractional distillation of the UF ${ }_{6}$. The solvent extraction purification step (the wet process) results in the radioactive uranium daughters $\left({ }^{230} \mathrm{Th}\right.$ and $\left.{ }^{226} \mathrm{Ra}\right)$ and impurities being left in the solvent extraction waste stream. This waste may be buried onsite, solidified and disposed of in a shallow-land burial ground, or returned to the mill for disposal with the tailings (see Figure 7.2-1). (4) The dry process, however, removes the impurities from the $U_{6}$ product stream by fractional distillation and incorporates them with other waste products for disposal as solid waste in a shallow-land burial ground (see Figure 7.2-2).

\subsubsection{Wet Solvent Extraction Fluorination Process}

The reference plant is designed to produce 10,000 MT per year of uranium as $\mathrm{UF}_{6}$ from concentrates (yellowcake) supplied by various uranium mills. Yellowcake, received in $0.21-\mathrm{m}^{3}$ drums, is transferred into a sampling system designed to remove $0.1 \%$ of the feed as a representative sample of the material for accounting purposes. (4) The main yellowcake stream is conveyed either to a redrumming station or to storage hoppers in the digestion area. The yellowcake is dissolved batchwise in hot $40 \%$ nitric acid and the resulting 


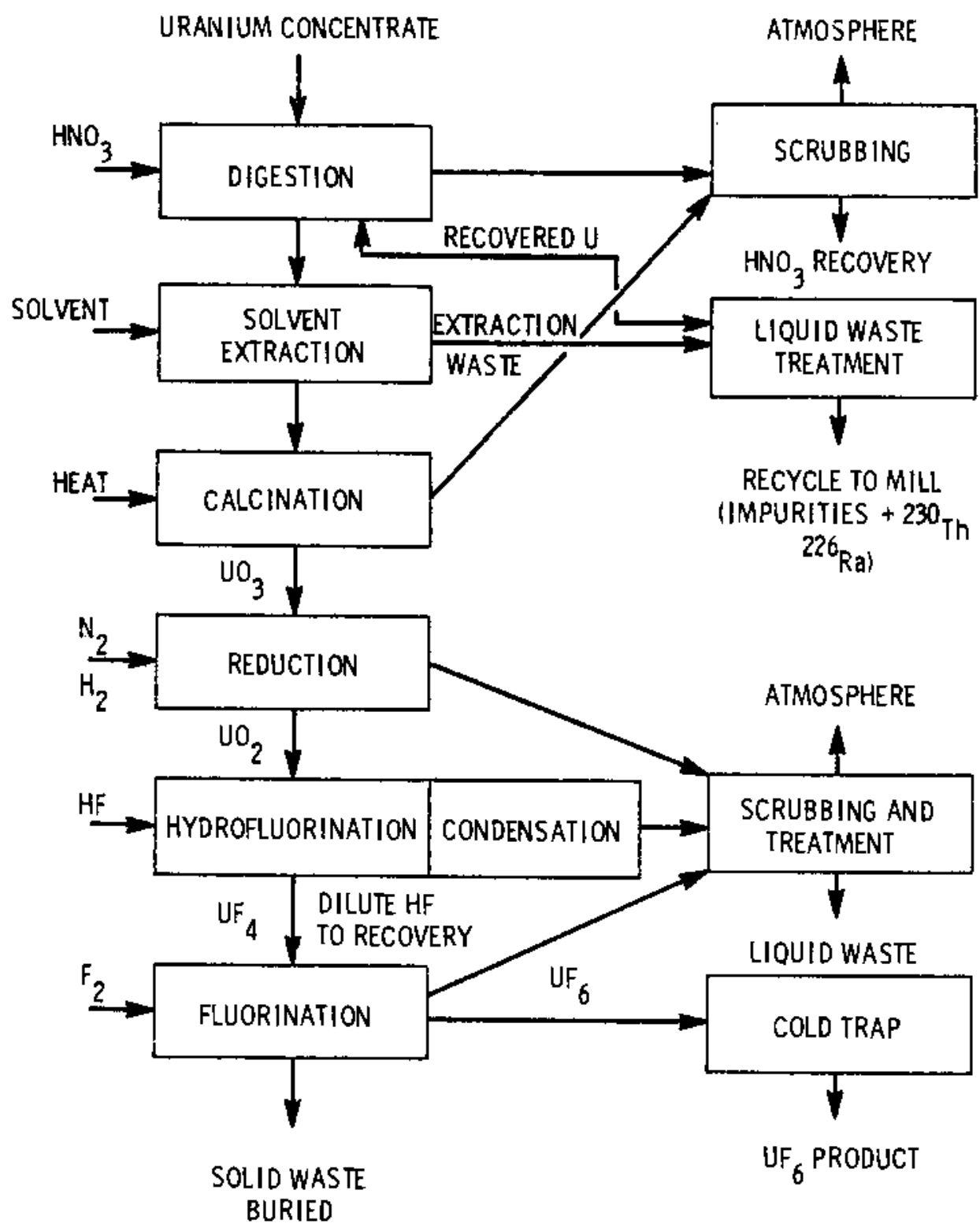

FIGURE 7.2-1. UF6 Production - Wet Solvent Extraction Fluorination Process Simplified Block Flow Diagram

impure uranyl nitrate solution is processed by counter-current extraction in pumper-decanters using tributylphosphate-hexane solvent. After passing through a two-stage scrub section, the loaded solvent is stripped in a pulse column to recover the uranium values as a pure aqueous solution of uranyl nitrate. (4) 


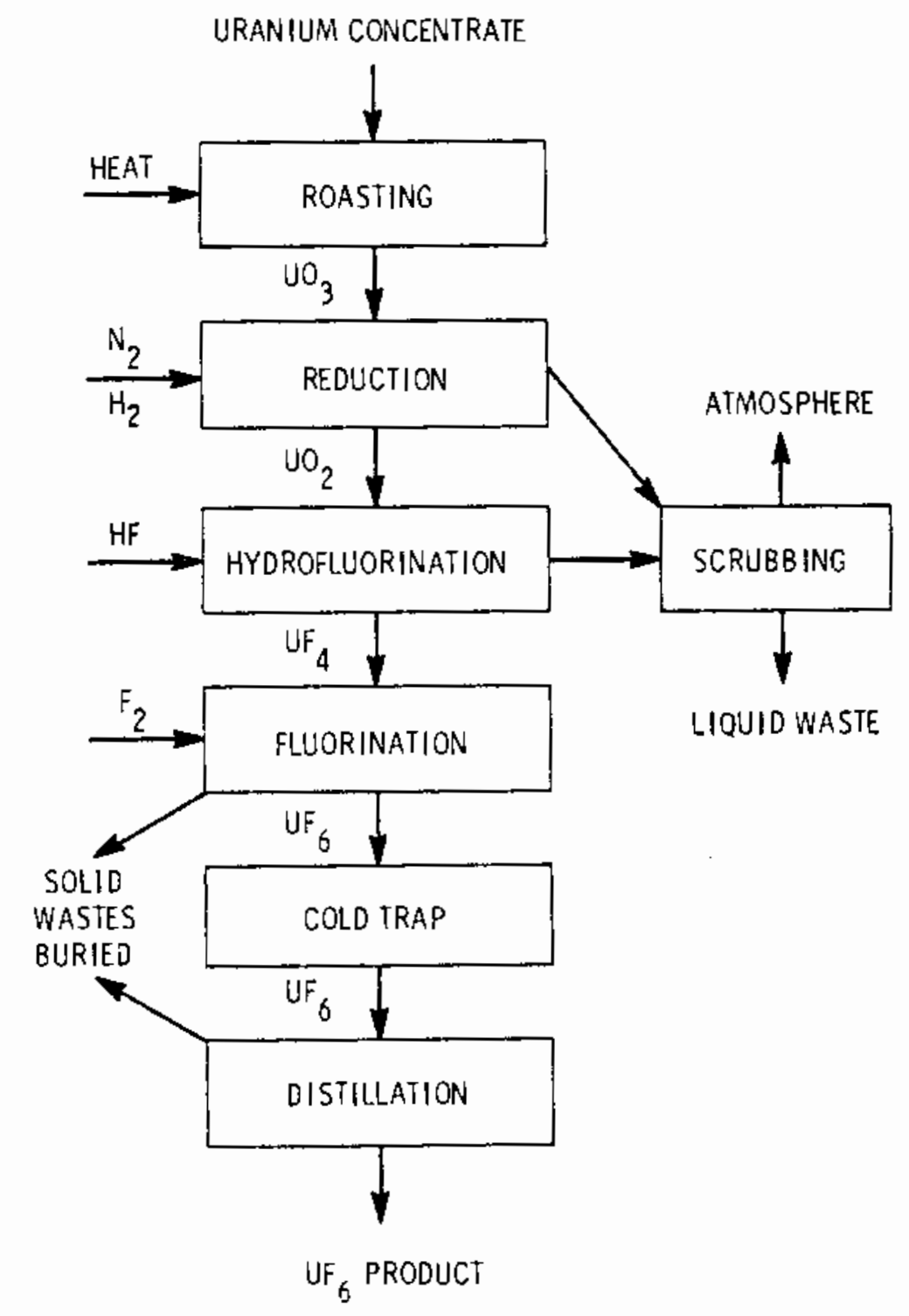

FIGURE 7.2-2. UF 6 Production - Dry Hydrofluorination Process Simplified Block Flow Diagram

This solution is concentrated by a two-step process, first in a singleeffect evaporator (after scrubbing with hexane to remove any residual organic), and then in a boildown tank to which sulfuric acid is added to improve product reactivity in subsequent steps. The concentrated solution, containing about $1200 \mathrm{~kg}$ of uranium per $\mathrm{m}^{3}$, is then decomposed in a trough-type denitrator to uranium trioxide, oxides of nitrogen, and nitric acid vapor. These 
volatile nitrogen compounds, along with those generated in the yellowcake digestion step, are recovered as nitric acid for reuse in the process.

The purified uranium trioxide is contacted with cracked ammonia in fluid bed reactors to produce uranium dioxide which in turn is reacted with anhydrous $\mathrm{HF}$ in a two-stage fluid bed hydrofluorinator to produce uranium tetrafluoride. The $\mathrm{UF}_{4}$ is then conveyed to a series of fluorination towers where it is reacted with elemental fluorine to produce high-purity gaseous uranium hexafluoride. The $\mathrm{UF}_{6}$ gas is cooled and condensed in cold traps as a solid that is periodically melted by heating with steam and drained into approved 9.1-Mg cylinders for shipment to gaseous diffusion enrichment plants.

Off-gas from the reduction fluid beds is passed through sintered metal filters to remove particulates and is then burned before being discharged to the atmosphere. ${ }^{(4)}$ The resulting gas is released through the main plant stack as a mixture of nitrogen, oxygen, and water vapor containing a small amount of sulfur dioxide. The hydrofluorinator off-gas is also filtered to remove particulates and is then condensed with the aqueous hydrofluoric acid collected and returned to the anhydrous HF supplier. The non-condensible off-gases are scrubbed with water before being vented to the atmosphere through the plant stack and the resulting dilute $\mathrm{HF}$ is neutralized with slaked lime.

Process fluorine is produced as needed by the electrolysis of hydrogen fluoride dissolved in a fused salt bath of potassium bifluoride, using mediumtemperature water-cooled cells. Both product strearns, fluorine as well as hydrogen, are passed through filters to remove any entrained electrolyte, then compressed and cooled to recover the hydrogen fluoride contained in the process gas. The fluorine is fed to the process and the hydrogen is piped to a waste gas burner along with air and any non-condensibles passing through the UF $F_{6}$ product cold-trap system. The burner off-gas, now containing water vapor and some hydrogen fluoride, is fed into the scrubber used for treatment of the hydrofluorinator off-gases and then to the plant stack.

\subsubsection{Effluents and Wastes}

Normal operation of the facility produces a variety of solid, liquid, and gaseous wastes that are treated to meet federal and state pollution control 
standards before being released to the environment. Liquid wastes containing significant quantities of radioactive materials are impounded in settling lagoons and stored. Other liquid wastes containing traces of radioactivity are diluted and released. All airborne effluents are treated to remove uranium contamination and gases produced in the manufacturing process.

\subsubsection{Gaseous and Airborne Particulate Waste}

Operating areas having the potential for producing dusts, mists, or fumes containing radioactive or other toxic materials are provided with state-of-theart pollution abatement or ventilation equipment designed to reduce occupational and offsite exposures to levels as low as reasonably achievable.

Trace quantities of gaseous $U_{6}$ pass through the product cold-trap system with the non-condensible gases. This uranium is discharged to the atmosphere as particles of uranyl fluoride after hydrolysis with the water vapor in the plant stack off-gas. Additional natural uranium compounds $\left(\mathrm{UO}_{3}, \mathrm{UO}_{2}\right.$, and $\left.\mathrm{UF}_{4}\right)$ are released occasionally as a result of entrainment in ambient air streams from leaking packing glands or spillage during handling and from small amounts of leakage through particulate filters used in solids transfer and vacuum cleaning systems. The total release of uranium-containing particulates from groundlevel sources as well as from the 46-m main plant stack during operation of the plant is shown in Table 7.2-1.(3)

TABLE 7.2-1. Estimated Annual Atmospheric Release of Radionuclides from the Reference $U_{6}$ Conversion Plant $(a)$

\begin{tabular}{|c|c|c|}
\hline Radionuclide & $\begin{array}{c}\text { Half }- \text { Life } \\
\text { (days) } \\
\end{array}$ & $\begin{array}{l}\text { Release } \\
(\mathrm{C} i / \mathrm{yr})\end{array}$ \\
\hline${ }^{230} \mathrm{Th}(\mathrm{b})$ & $2.8 \times 10^{7}$ & $1.4 \times 10^{-3}$ \\
\hline${ }^{234} T h^{(b)}$ & $2.4 \times 10^{1}$ & $1.2 \times 10^{-1}$ \\
\hline $225_{R a}(b)$ & $5.8 \times 10^{5}$ & $8.3 \times 10^{-5}$ \\
\hline $234_{U}(c)$ & $8.9 \times 10^{7}$ & $1.6 \times 10^{-1}$ \\
\hline $235_{U}(c)$ & $2.6 \times 10^{11}$ & $7.4 \times 10^{-3}$ \\
\hline $238_{u}(c)$ & $1.5 \times 10^{12}$ & $3.6 \times 10^{-1}$ \\
\hline & & $4.5 \times 10^{-1}$ \\
\hline
\end{tabular}

(a) Based on information from Reference 3.

(b) Based on isotopic ratios in yellowcake.

(c) Based on the ratio of radionuclides in natural uranium. 
In addition to the airborne particulate uranium, the plant produces several off-gases. These off-gases are also treated to minimize their environmental impact. 0xides of nitrogen are generated at three points in the process as well as in the combustion of natural gas for steam production. The process sources are: 1) the primary digesters where the concentrate feed is dissolved, 2) the miscellaneous digester used for dissolution of tower ash and other recycled solids, and 3) the denitrators where uranium trioxide is produced from uranyl nitrate hexahydrate. The digesters are operated at subatmospheric pressure to prevent leakage to the atmosphere. The off-gases from these operations are processed to recover nitric acid, which is returned for reuse in the process. The loss of $\mathrm{NO}_{2}$ from the nitric acid absorber amounts to about $6.3 \mathrm{~kg}$ per hour, while an additional estimated $8.2 \mathrm{~kg}$ per hour is produced from natural gas combustion. Both streams are discharged from the top of the main plant stack and, as shown in Table 7.2-2, result in a relatively insignificant increase in the ambient air concentration of this material.

\section{TABLE 7.2-2. Estimated Annual Gaseous Effluents from the} Reference $U_{6}$ Conversion Plant

\begin{tabular}{|c|c|c|}
\hline Effluent & $\mathrm{kg} / \mathrm{day}$ & $\mathrm{kg} /$ year \\
\hline $\mathrm{HF}$ & $1.5 \times 10^{1}$ & $5.4 \times 10^{3}$ \\
\hline $\mathrm{SO}_{2}$ & $5.6 \times 10^{2}$ & $2.0 \times 10^{5}$ \\
\hline $\mathrm{NH}_{3}$ & $2.4 \times 10^{1}$ & $8.7 \times 10^{3}$ \\
\hline $\mathrm{H}_{2} \mathrm{~S}$ & $8.6 \times 10^{-3}$ & $6.0 \times 10^{0}$ \\
\hline Hexane & $4.4 \times 10^{2}$ & $1.6 \times 10^{5}$ \\
\hline $\mathrm{NO}_{2}$ & $2.6 \times 10^{2}$ & $9.5 \times 10^{4}$ \\
\hline
\end{tabular}

Other gaseous effluents are also treated to remove undesirable materials before being released to the environment. Unreacted hydrogen and hydrogen sulfide from the reduction towers are burned in air to water vapor and sulfur dioxide before being discharged to the plant stack. Total sulfur dioxide leaving the plant process is estimated to be about $2.3 \mathrm{~kg}$ per hour. In addjtion, waste hydrogen from the fluorine plant is combined with the trace quantities of fluorine and $U_{6}$ from the product cold trap system and fed with combustion 
air to a waste gas burner. (4) The burner product along with the aqueous HF condenser off-gases are scrubbed with water before being vented through the main stack. Fluoride sources other than the HF scrubber include material discharged from the fluorine cell rework area as well as discharges from the fluorine emergency vent. The total combined fluorine and fluoride emission from ground-level sources as well as from the $46-\mathrm{m}$ plant stack is estimated to be about $4.5 \mathrm{~kg}$ per day.

\subsubsection{Liquid Waste}

The plant process generates two major liquid waste streams. The first 1 iquid waste stream, the solvent extraction stream leaving the solvent extraction circuit, is primarily a solution of ammonium nitrate, nitric acid, heavy metal salts, and small quantities of uranium and the radioactive daughters of normal uranium decay. This liquid is combined with spent sodium hydroxide from the solvent treatment and the miscellaneous digester scrubber systems along with recovered weak acids. The liquid is neutralized with ammonia and impounded in four solvent extraction waste storage lagoons.

The second liquid waste stream is generated primarily by the hydrofluorination system off-gas scrubber. This fluoride stream is combined with various other plant waste liquids and treated with slaked lime to neutralize the contained acid and precipitate the fluoride as calcium fluoride. The resulting sludge is allowed to settle in a retention pond, and the overflow is treated with sulfuric acid to adjust the $\mathrm{pH}$ and precipitate excess calcium as calcium sulfate. The clarified treated waste liquid overflows and is combined with clean intake water, sanitary wastes, and sewage lagoon overflow in a concrete stilling basin before being discharged through a metering weir to the river. The estimated annual liquid effluent from the reference plant is shown in Table 7.2-3.

\subsubsection{Solid Waste}

Various solids containing recoverable uranium values are generated at several points in the process. These include dusts collected on the exit filters from the tower reactors as well as "ash" that escaped conversion to UF 6 in the 
TABLE 7.2-3. Estimated Annual Liquid Eff]uents from the Reference $U_{6}$ Conversion Plant

\begin{tabular}{|c|c|c|}
\hline Effluent & $\mathrm{kg} /$ day & $\mathrm{kg} /$ year \\
\hline & $7.8 \times 10^{0}$ & $2.8 \times 10^{3}$ \\
\hline $\mathrm{F}^{-3}$ & $1.8 \times 10^{0}$ & $6.6 \times 10^{2}$ \\
\hline & $2.9 \times 10^{2}$ & $1.1 \times 10^{5}$ \\
\hline & $4.5 \times 10^{-1}$ & $1.6 \times 10^{2}$ \\
\hline $\mathrm{Ca}^{7+}$ & $1.9 \times 10^{0}$ & $6.9 \times 10^{2}$ \\
\hline $\mathrm{Na}^{+}$ & $1.0 \times 10^{3}$ & $3.6 \times 10^{5}$ \\
\hline $\mathrm{K}^{+}$ & $1.3 \times 10^{2}$ & $4.8 \times 10^{4}$ \\
\hline $\mathrm{HCO}_{3}^{-}$ & $2.6 \times 10^{3}$ & $9.5 \times 10^{5}$ \\
\hline $\mathrm{Cl}^{-}$ & $7.8 \times 10^{0}$ & $2.8 \times 10^{3}$ \\
\hline $\mathrm{Fe}$ & $1.6 \times 10^{0}$ & $5.6 \times 10^{2}$ \\
\hline
\end{tabular}

fluorination step. These materials are recycled to a miscellaneous digester where they are dissolved in an ammonium nitrate solution and fed back through the solvent extraction system. The fluorination-tower ash that is left at the end of plant life is processed through the solvent extraction system as part of the final inventory cleanout.

Radioactive waste materials such as scrapped equipment, gloves, respirators, and other contaminated solids are buried onsite or, in the case of drums, are accumulated for disposal through a licensed steel scrap dealer. These are the miscellaneous wastes buried onsite.

Additional solid wastes generated include the contaminated calcium fluoridecalcium hydroxide-calcium sulfate sludge produced by lime neutralization of the $\mathrm{HF}$ scrubber products and $\mathrm{pH}$ adjustment with sulfuric acid. This material is disposed of by onsite burial in the fluoride waste lagoons.

Another source of radioactive solid wastes is the sludge produced by neutralizing the solvent extraction waste stream with ammonia to precipitate most of the uranium, thorium, and other heavy metals. This sludge settles to the bottom of the solvent extraction waste storage lagoons. Additional treatment of the supernatant liquid with barium chloride precipitates a mixture of barium and radium sulfates that is also allowed to settle, thereby removing most of the residual radioactivity from the liquid. 


\subsection{PLANT DESCRIPTION}

The reference conversion plant, shown in an isometric drawing in Figure 7.3-1, plant is assumed to occupy about 30.4 hectares within the site described in Section 7.1. The plant consists of three buildings containing approximately $11,150 \mathrm{~m}^{2}$ of floor area. The buildings are of normal industrial construction, with heavy concrete floors to support equipment. The principal structures are the main building, the solvent extraction facility, a warehouse, a cooling tower, retention lagoons, and other storage areas. The main building, which occupies about $7,400 \mathrm{~m}^{2}$, contains the major processing and fluorine generating facilities, the utility and maintenance areas, administrative offices, the laboratory, and the ore concentrate sampling plant. The $46-m$ plant stack is located near the northwest corner of the main building. ${ }^{(4)}$

For the wet process, the solvent extraction facility is located in a separate $370-m^{2}$ building west of the main structure.

A single story warehouse is located north of the main building. A cooling tower is located north of the solvent extraction building, and retention ponds for sanitary sewage, fluoride treatment, clarification, and raffinate storage are located west of the plant buildings.

Additional plant facilities include a large electrical substation, a UF 6 cylinder storage area, a chemical tank farm north of the main building, and a drum storage area at the southwest corner of the building.

\subsubsection{Process Building Description}

The main process building is a 55-m by 10D-n structure. The height of the building is $20 \mathrm{~m}$ over the sampling plant area, and most of the roof above the manufacturing area is about $12.5 \mathrm{~m}$ above ground. The building is fabricated of 40-m insulated metal siding attached to a steel framework. The interior walls are constructed of concrete block and sheetrock. The roof consists of a $40-\mathrm{mm}$ insulated corrugated metal deck that is capped with asphalt and gravel.

In the main process building, the plant operations are divided into the following operations:

- sampling facilities

- digestion

- conversion 


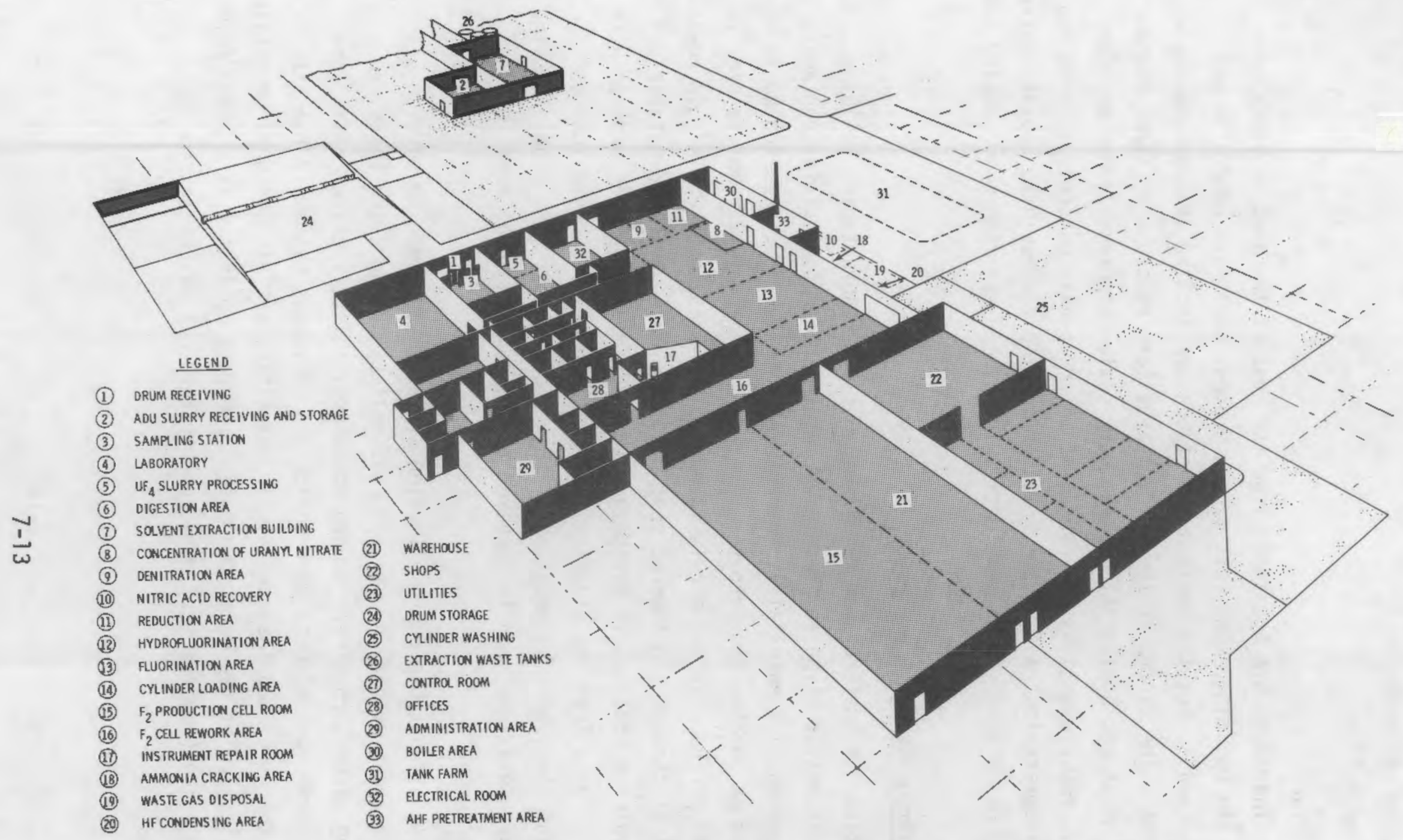

FIGURE 7.3-1. Isometric Drawing of the Reference $\mathrm{UF}_{6}$ Conversion Plant 
- denitration reduction

- hydrofluorination

- fluorination.

The sampling facilities are separated from the rest of the area by partition walls within the building. The rest of the process areas are generally not partitioned by walls, but the various operations are located in separate areas of the building. The floors in the process areas are concrete or steel plate. The chemical areas and contaminated areas have sealed concrete floors or steel plate floors. Non-production, non-contaminated areas have concrete floors, and offices and laboratories have either tiled or painted floors. The solvent extraction building has a steel frame with metal siding, and the floors are sealed concrete.

\subsubsection{Ventilation System Description}

Ventilation systems are provided throughout the manufacturing building, with special attention given to those areas having the potential for contamination with radioactive materials. Process areas in the manufacturing building are ventilated by forcing air into the building at a rate sufficient to provide 10 air changes per hour as the air is exhausted through eleven $8.5-\mathrm{m}^{3} / \mathrm{min}$ powered vents as well as through non-powered roof hatches. Both vents and hatches are sampled to evaluate radioactive discharges to the atmosphere in accordance with 10 CFR 40.65. Fumes from the fluorine cell maintenance area are discharged directly to the atmosphere by means of a $450-\mathrm{m}^{3} / \mathrm{min}$ exhaust fan. The exhaust from each laboratory fume hood is conveyed to the sampling area roof through separate sampled ducts.

A central, all-purpose dust collection system is provided to service all dry-processing areas within the plant. Dust collection hoods are installed around packing glands, routinely opened equipment, solids transfer areas, and the discharge from special-duty dust collectors or vacuum systems. The size and shape of the hoods and the exhaust air velocities are all designed to obtain efficient collection of the generated dust. The dust collector is a $785-\mathrm{m}^{3} / \mathrm{min}$ 5-zone plenum pulse (reverse jet), bag-type filter that discharges to the 
atmosphere through a monitored stack. Collected solids are drummed and recycled to process. The stack sampler operates continuously with a 24-hour sample collected and analyzed daily.

Four additional vacuum cleaning and dust collection systems providing separate vacuum sources, cyclone separators, and bag filters are used in specialized plant areas. The sampling plant has separate vacuum cleaner and dust collection systems for recovery and direct recycle of spilled yellowcake, with the filtered air from the vacuum cleaner discharged to the sample plant dust collector. Filtered air from this system in turn discharges to the main plant dust collector, thus providing three stages of filtration. Two additional vacuum recovery systems, each consisting of a cyclone separator, bag filter, and vacuum pump in series, are provided, with both bag filters discharging to the main plant dust collector for backup filtration. One system, called the main plant vacuum system, services all areas after yellowcake sampling through the reduction area and discharges collected solids to the miscellaneous digester. The second unit, the $\mathrm{UF}_{4}$ ash vacuum system, services the hydrofluorination and fluorination areas, with collected solids drummed for transfer to the ash-grinding system. Both systems are used for general plant clean-up in their respective service areas and for removal of uranium materials from equipment components prior to maintenance operations.

The entire ash-grinding system provided for all-purpose crushing, pulverizing, and screening of fluorination tower ash or other materials capable of direct recycle is housed in an enclosure that is vented to the main plant dust collection system.

\subsection{RESIDUAL RADIOACTIVITY ESTIMATES}

The radionuclide mixtures found in the reference UF $_{6}$ conversion plant at the time of plant shutdown and 5, 10, 30, and 100 years after plant shutdown are shown in Table 7.4-1. Using this mixture of radionuclides, Table 7.4-2 summarizes estimated residual radionuclide inventories of natural uranium in major pieces of equipment of the reference plant after final inventory cleanout. Key assumptions and rationale on which the inventory estimates are based 
TABLE 7.4-1. Specific Radioactivity of Residual Uranium in the Reference $\mathrm{UF}_{6}$ Plant at the Time of Plant Shutdown and at Various Times Afler Shutdown

\begin{tabular}{|c|c|c|c|c|c|}
\hline \multirow[b]{2}{*}{ Radionuclide } & \multicolumn{5}{|c|}{ Specific Activity ( $\mu \mathrm{C} i / g$ of mixture) ${ }^{(a)}$} \\
\hline & Shutdown & 5 Years & 10 Years & 30 Years & 100 Years \\
\hline${ }^{230} \mathrm{Th}$ & $2.9 \times 10^{-3}$ & $3.7 \times 10^{-3}$ & $4.4 \times 10^{-3}$ & $7.2 \times 10^{-3}$ & $1.7 \times 10^{-2}$ \\
\hline${ }^{231} \mathrm{Th}$ & $2.2 \times 10^{-2}$ & $2.2 \times 10^{-2}$ & $2.2 \times 10^{-2}$ & $2.2 \times 10^{-2}$ & $2.2 \times 10^{-2}$ \\
\hline${ }^{234} \mathrm{Th}$ & $2.5 \times 10^{-1}$ & $2.5 \times 10^{-1}$ & $2.5 \times 10^{-1}$ & $2.5 \times 10^{-1}$ & $2.5 \times 10^{-1}$ \\
\hline & $3.0 \times 10^{-5}$ & $3.7 \times 10^{-5}$ & $4.4 \times 10^{-3}$ & $7.4 \times 10^{-3}$ & $1.8 \times 10^{-2}$ \\
\hline $234 \mathrm{~m} \mathrm{~Pa}$ & $3.3 \times 10^{-1}$ & $3.3 \times 10^{-1}$ & $3.3 \times 10^{-1}$ & $3.3 \times 10^{-1}$ & $3.3 \times 10^{-1}$ \\
\hline${ }^{234} \mathrm{~Pa}$ & $3.3 \times 10^{-4}$ & $3.3 \times 10^{-4}$ & $3.3 \times 10^{-4}$ & $3.3 \times 10^{-4}$ & $3.3 \times 10^{-4}$ \\
\hline${ }^{226} \mathrm{Ra}$ & $3.0 \times 10^{-4}$ & $3.0 \times 10^{-4}$ & $3.0 \times 10^{-4}$ & $3.0 \times 10^{-4}$ & $3.0 \times 10^{-4}$ \\
\hline $234 U$ & $3.3 \times 10^{-1}$ & $3.3 \times 10^{-1}$ & $3.3 \times 10^{-1}$ & $3.3 \times 10^{-1}$ & $3.3 \times 10^{-1}$ \\
\hline${ }^{235} U$ & $1.5 \times 10^{-2}$ & $1.5 \times 10^{-2}$ & $1.5 \times 10^{-2}$ & $1.5 \times 10^{-2}$ & $1.5 \times 10^{-2}$ \\
\hline $238 \mathrm{U}$ & $3.3 \times 10^{-1}$ & $3.3 \times 10^{-1}$ & $3.3 \times 10^{-1}$ & $3.3 \times 10^{-1}$ & $3.3 \times 10^{-1}$ \\
\hline Totals & 1.3 & 1.3 & 1.3 & 1.3 & 1.3 \\
\hline
\end{tabular}

(a) Based on the ratio of radionuclides in uranium and the isotopic ratios given in Reference 3.

and detailed inventories for each system are presented in Appendix C. Final inventory cleanout operations and decomissioning decontamination operations are described in Appendices $F$ and $G$.

At shutdown and before final inventory cleariout, the uranium inventory in the reference plant is estimated to be about $105,000 \mathrm{~kg}$, while after final inventory cleanout it is estimated to be approximately $46,800 \mathrm{~kg}$. This inventory consists of $8,600 \mathrm{~kg}$ in each of the solvent extraction lagoons or about 34,400 $\mathrm{kg}$ total, 2,500 in the fluoride lagoons, $9,200 \mathrm{~kg}$ in the equipment, and $3,200 \mathrm{~kg}$ in the buildings and ventilation system. Final cleanout, done periodically during plant operations between processing campaigns, removes process materials, chemicals, trash, visible quantities of contamination, scrap, scrap solutions, and contaminated solutions from the facility. Empty product, scrap, and waste handling tanks are also rinsed to flush out remaining process solutions. These operational inventory cleanout operations are charged to plant operations and not to decommissioning. 
TABLE 7.4-2. Estimated Uranium Inventory in Major Pieces of Equipment in the Reference $\mathrm{UF}_{6}$ Plant After Final Inventory Cleanout

$\mathrm{kg}$ of

Equipment

Uranium

Sampling Station

Drum Elevator

Yellowcake Receiving Bin 50

Primary Sampler I 10

Primary Sampler II 10

Secondary Sampler 10

Yellowcake Transfer Screw 40

Bucket Elevator 25

Digest Feed Bin 50

Subtotal 200

Solvent Extraction

Digesters 700

Adjustment Tanks 200

Pumper Decanters 50

Scrub Decanter 60

Re-extraction Pulse Column 90 Subtotal 1,100

Concentration

Evaporator 1000

Boildown Tanks 500

UNH Filter 100

Denitrator

Subtota 1 300 2,000

Denitration

Oenitrator Scrubber Cooler 600

Cooling Screw 20

$\mathrm{UO}_{3}$ Vertical Elevator 30

Pulverizer and Surge Bin

Subtota] 150 800 
TABLE 7.4-2. (Contd)

Equipment

$\mathrm{kg}$ of

Uranium

Reduction

$\mathrm{UO}_{3}$ Storage Bin

Reduction Fluid-bed

350

Subtotal

400

Hydrofluorination

$\mathrm{UO}_{2}$ Filter Bin

100

1st Stage Hydrofluorination

800

2nd Stage Hydrofluorination Fluid-bed

600

$\mathrm{UF}_{4}$ Seal Hopper

$\mathrm{UF}_{4}-\mathrm{UO}_{2}$ Intermediate Seal Hopper

$\mathrm{UF}_{4}$ Purge Conveyor

Redler Conveyor 509

$\mathrm{UF}_{4}$ Storage Hopper

400

Redler Conveyor 510

Subtotal

2,100

Fluorination

Primary Fluorination Tower $\quad 800$

Redler Conveyor $511 \quad 20$

Primary Filter 60

Primary cold Trap $\quad 110$

Product Cylinder $\quad 70$

Back-up Filter 80

Clean-up Reactor Feed Hopper $\quad 100$

Clean-up Reactor $\quad 600$

Redler Conveyor 512

Back-up Filter $\quad 500$

Secondary Cold Trap

Subtotal 2,600

Total 9,200 
Decommissioning decontamination operations start with thorough flushing and chemical decontamination of all process equipment and piping. Decontamination procedures include spray cleaning, hot corrosive acid flushing, dry cleaning, and handwiping of dry processing equipment. These procedures are estimated to reduce the inventory of uranium in the buildings and equipment to approximately $1,200 \mathrm{~kg}$ of natural uranium.

\subsection{CHEMICAL INVENTORIES}

Several potentially toxic chemical compounds are used in processing and scrap recovery operations in the reference plant. These compounds include anhydrous ammonia, lime, nitric acid, sodium hydroxide, sulphuric acid, hydrofluoric acid, potassium fluoride, and tributylphosphate-hexane solvent. Most process chemicals not planned to be used for decommissioning are assumed to be renoved from the plant as part of final inventory cleanout operations. Inventories of these chemicals will therefore be 1 imited to residuals in process equipment and piping at the start of decomissioning. Except for nitric acid, fluoride salts, and degassing agents used in chemical decontamination operations, no significant inventories of toxic chemicals are anticipated in the plant when decomnissioning begins. 


\section{REFERENCES}

1. U.S. AEC, Final Environmental Statement Concerning Proposed Rule-Making Action: Numerical Guides for Design Objectives and Limiting Conditioning for Operation to Meet the Criteria "As Low as Practicable" for Radioactive Material in Light Water-Cooled Nuclear Power Reactor Effluents, WASH-T258, Directorate of Regulatory Standards, Volume I of 3 , Figure $6 \bar{B}-1$, p. $6 \mathrm{~B}-43$, and Figure $6 \mathrm{C}-8$, p. $6 \mathrm{C}-12$, July 1973 .

2. U.S. AEC, Final Environmental Statement Related to Operation of Monticello Nuclear Generating Plant, Docket No. 50-263, pp. II-15 through II-26, November 1972.

3. U.S. NRC, Environmental Impact Appraisal of the ATlied Chemical Corporation Nuclear Service Division Uranium Hexafluoride Conversion Facil ity, Metropolis, IlTinois, Docket no. 40-3392, pp. 4-1 through 4-16, August 1974.

4. U.S. NRC, Materials License Application Sub. 1010 - Kerr McGee Corporation, Docket No. 040-08027, July 1, 1975, Rev. August 18, 1977. 


\subsection{SUGGESTED METHODOLOGIES FOR DETERMINING ACCEPTABLE RESIDUAL RADIOACTIVE AND CHEMICAL CONTAMINATION LEVELS FOR THE DECOMMISSIONED REFERENCE UF 6 CONVERSION PLANT}

This section contains a discussion of suggested methodologies for determining acceptable levels of residual radioactive and chemical contamination at decormissioned nuclear facilities. Demonstrations of the suggested methodologies are also presented using the reference inventories of radionuclides and chemicals, and the reference site description developed for this study.

Detailed information about the mixture of radionuclides and chemicals found in the reference $U F_{6}$ conversion plant and on its site is contained in Appendices $B$ and $C$. Descriptions of the reference facility and site are presented in Appendices $A$ and $B$, respectivety. Discussions of the radiation dose models and parameters used to determine the acceptable radioactive contamination levels are presented in Appendix E.

\subsection{TECHNICAL APPROACH}

The ultimate disposition of a decommissioned nuclear facility and its surrounding site depends on the degree and type of radioactive and chemical contamination remaining. This section describes and demonstrates suggested methods for determining acceptable radioactive and chemical contamination levels for unrestricted use of the decomissioned reference plant and its site. The basic premise for these suggested methods is that no member of the public will receive an annual radiation dose or chemical exposure in excess of a specific limit (which is yet to be established by U.S. federal agencies).

Examination of existing guidelines and regulations shows that there is a need for these general methods. $(1,2)$ Currently, some guidance exists defining the levels of radioactive surface contamination that are acceptable to the NRC for the termination of operating licenses. $(3,4)$ Other guidance addresses specific types of nuclear facilities, or accident situations involving radioactivity. $(5-10)$ There are currently no regulations or specific guidance on acceptable chemical exposures to the public from a decommissioned nuclear facility. Current 
guidance on chemical exposures that could be useful for decommissioning is specifically written for working environments or drinking water, $(11,12)$

None of these guidelines is sufficiently flexible to accommodate the various radionuclide mixtures, chemical forms, or site-specific features found at each unique nuclear facility. This suggests that the methods used to calculate the acceptable levels of residual radioactive or chemical contamination should be based on general concepts that can accommodate either generic or site-specific features. The relationship between these calculated acceptable levels and generic or site-specific studies is shown in Figure 8.1-1.

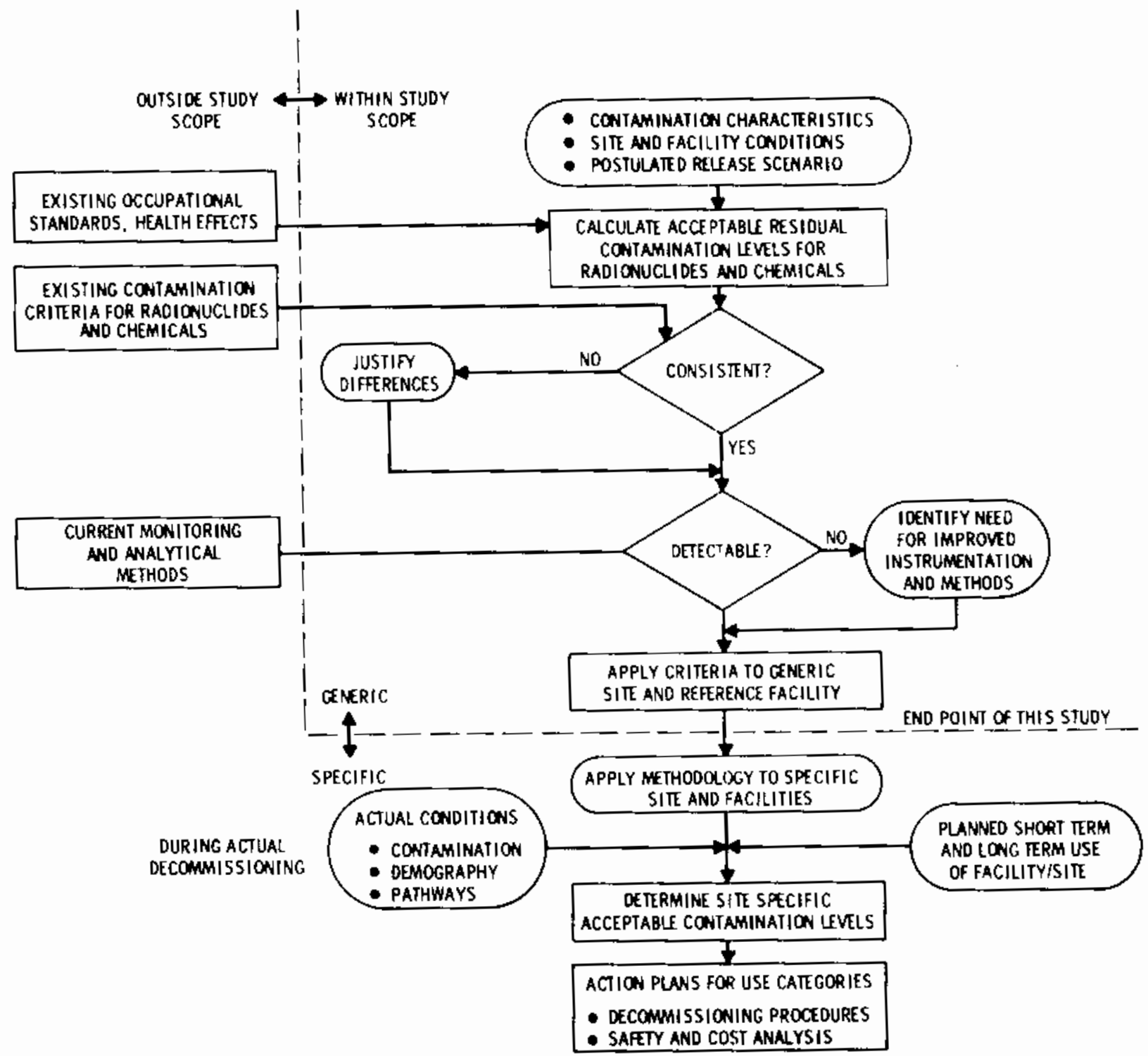

FIGURE 8.1-1. Relationship of Acceptable Contamination Level Analysis Between Generic and Site-Specific Studies 
For residual mixtures of radionuclides, the methodology suggested in this study is to compare an established annual dose limit with calculated annual doses to members of the public to determine acceptable radioactive contamination levels. The contamination levels derived from a maximum annual dose concept take into account the exposure of individuals to contamination remaining at a decomnissioned facility or on its site following unrestricted release. The NRC has endorsed using an annual dose limit for determining unrestricted release of decommissioned property. $(13,14)$ In a Federal Register notice, they stated that because of the variety of facilities and radioactive materials, a single dose limit is difficult to establish. (13) Thus, the basis of their recommendations is that the doses from residual radioactive materials are to be maintained as low as reasonably achievable (ALARA) within a maximum annual whole-body dose equivalent range of less than $10 \mathrm{mrem}$ per year. The NRC stresses that a range of dose values less than 10 mrem per year gives the needed flexibility for an adequate cost and benefit effectiveness analysis. For special situations, a case-by-case analysis, using a radiation dose pathway model, wi1l determine the exact acceptable dose limit.

For residual chemicals, the methodology suggested in this study is to limit chemical exposures, so that no member of the public is exposed to more than $1 \%$ of the most restrictive occupational chemical exposure standard. This procedure results in a safety factor of 300 , and should account for the most sensitive individuals in a large population. It should also account for unpreficted long-term or environmental behavior that could increase the toxicity of a chemical.

\subsubsection{Terminology and Definitions}

The following terminology and definitions are used to develop methods for determing acceptable residual radioactive and chemical contamination levels:

Exposure Pathways. The potential routes by which people may be exposed to the effects of residual radioactive or chemical contamination. Exposure pathways in the environment that are considered in this study include: external or direct contact exposure, ingestion of residual contamination, and inhalation of airborne contamination. Exposure pathways inside the $\mathrm{UF}_{6}$ conversion plant 
are: external or direct contact exposure and inhalation of airborne contamination. Air submersion as a radiation exposure pathway is not considered since previous studies have shown it to be insignificant compared to the others. $(1,15,16)$

Organs of Reference. These are the organs of the human body for which radiation doses are calculated. For this study, the organs of reference are the total body, lungs, bone, and lower large intestine (LLI) of the GI-tract. The total body is the head and trunk of the human body and includes active blood-forming organs, eye lenses, and gonads.

Maximum-Exposed Individual. This is the individual who receives the maximum radiation dose to an organ of reference. The maximum-exposed individual is assumed to reside at the location of the highest airborne radionuclide concentration. Maximized exposure pathway parameters are used.

Annual Dose. This is the radiation dose equivalent calculated during any year following the start of continuous exposure. It is the sum of the dose received by an organ of reference during the year of interest from all exposure pathways and the dose received during that year from radionuclides deposited in the organ of reference during the previous year.

Maximum Annual Dose. This is the largest of the annual doses calculated to occur during the 50 years following the start of continuous exposure.

Threshold Limit Values (TLV). TLVs refer to the time-weighted air concentrations of chemical substances under which it is believed nearly all workers may be repeatedly exposed to day after day without adverse effect. TLVs should be used as guides for the control of hazardous substances, and not as "fine lines" between safe and dangerous air concentrations. (11)

\subsubsection{Definition of Use Categories}

During the planning stages of decomissioning, a variety of future uses may be considered for the $U_{6}$ conversion plant and its site. Two general use categories after decomissioning are considered in this study:

- Restricted Use - permits activities at the decommissioned UF 6 conversion plant within a nuclear-license restriction. Since this category requires 
a continuation of a nuclear license, the residual radioactive and chemical contamination levels may be similar to those found at other licensed operating nuclear facilities. Therefore, public and occupational exposure are controlled by the restrictions imposed by the nuclear license.

- Unrestricted Use - permits, without 1 icense restrictions, public use of the released portions of the decommissioned $\mathrm{UF}_{6}$ conversion plant. In this category, the potential exposure to members of the public from residual radioactive or chemical contamination levels attributable to the decomissioned facility/site will not exceed either an assumed annual radiation dose limit of 50 mrem to the maximum-exposed individual, or $1 \%$ of the most restrictive occupational standard on chemicals. Decomissioning a site will, in general, result in the unrestricted public use of land areas which had been restricted during the operational life of the $\mathrm{UF}_{6}$ conversion plant.

No attempt is made to define all of the possible specific uses that may fall into these two general categories. The ability to enforce the license restrictions required for the first category for long periods of time requires continuous surveillance. Since license restrictions can only be enforced by a government agency, and since it is not reasonable to assume that this government agency will exist for all time, no calculations are attempted for the restricted use category. Example calculations of the acceptable residual radioactive and chemical contamination levels are performed for the unrestricted use category only.

\subsubsection{Acceptable Residual Radioactive Contamination Levels}

Determination of acceptable radioactive contamination levels for the reference plant is necessarily linked with other decomissioning considerations. Acceptable radioactive contamination levels are calculated using previously develaped methods. $(1,15)$ The method for determining acceptable radioactive contamination levels is based on the assumption that an annual radiation dose limit is established for decomissioned nuclear facilities.

Currently, there are no unique regulations or specific guidance on acceptable annual dose to individuals living on or near a decommissioned site. Guidance that could be interpreted as recommending annual radiation dose limits for decomissioned facilities or sites includes: 
- Federal Register, Vol. 46, No. 27, 1981. "Nuclear Regulatory Comnission, 10 CFR Parts 30, 40, 50,70, and 72, Decommissioning Criteria for Nuciear Facilities: Notice of Availability of Draft Environmental Impact Statement" (NRC). (13)

- Recommendations of the International Commission on Radiological Protection (ICRP), Publication 9. (17)

- Surgeon General's Guidelines (DHEW). (18)

- Appendix I of 10 CFR 50, Guides for Design Objectives for Light-WaterCooled Nuclear Power Reactors (NRC).

- Proposed Federal Guidance for the Environmental Limits of Transuranium Elements (EPA). (20)

- 40 CFR 190, Environmental Radiation Protection Standards for Normal Operations of Activities in the Uranium Fuel Cycle (EPA).

Most of this guidance provides limits for operating nuclear facilities. Only the NRC Federal Register notice is specifically written to provide an annual dose limit that defines unrestricted release conditions for decommissioned property. However, the annual dose range of less than 10 mrem per year given by the NRC is a recommendation only, and it has not been formally written into the U.S. Code of Federal Regulations.

It is beyond the scope of this study to recomend annual radiation dose limits for public exposure to radioactive materials. Instead, example acceptable residual radioactive contamination levels are calculated for a single assumed annual radiation dose limit of $10 \mathrm{mrem} / \mathrm{yr}$. The selection of this assumed limit is intended to be consistent with current NRC recommendations. Corresponding levels for any other radiation dose 1 imit can be found through direct ratio. The actual levels achieved at nuclear facilities will be determined based on a cost-benefit study for each facility and site. It is also assumed that any annual dose 1 imit established for decommissioning applies to the maximum annual dose to any organ of reference, thus ensuring that applicable regulatory limits on annual radiation dose will not be exceeded. 
The method for determining radioactive contamination levels, based on annual radiation dose, is illustrated in Figure 8.1-2 and is briefly discussed below:

- Calculation of the Maximum Annual Radiation Dose for the Use Category Selected. For this study, the maximum annual radiation dose during 50 years of continuous exposure after decommissioning is calculated using the dose models discussed in Appendix $E$. Characteristic radionuclide inventories at the reference $\mathrm{LF}_{6}$ conversion plant, used in the calculations, are presented in Appendices B and C. Site-specific exposure pathway parameters, defined for the reference site in Appendix B, are used in these dose calculations. After decommissioning, unrestricted use of the $U_{6}{ }_{6}$ conversion plant and its site is assumed.

- Comparison of the Maximum Annual Dose to the Annual Dose Limit. For this study, since assumed or calculated levels of contamination are used, no direct comparison is made. Rather, the quantities of the radionuclide inventories corresponding to a dose of $10 \mathrm{mrem} / \mathrm{yr}$ are calculated to demonstrate the suggested methodology both for the facility and for the site.

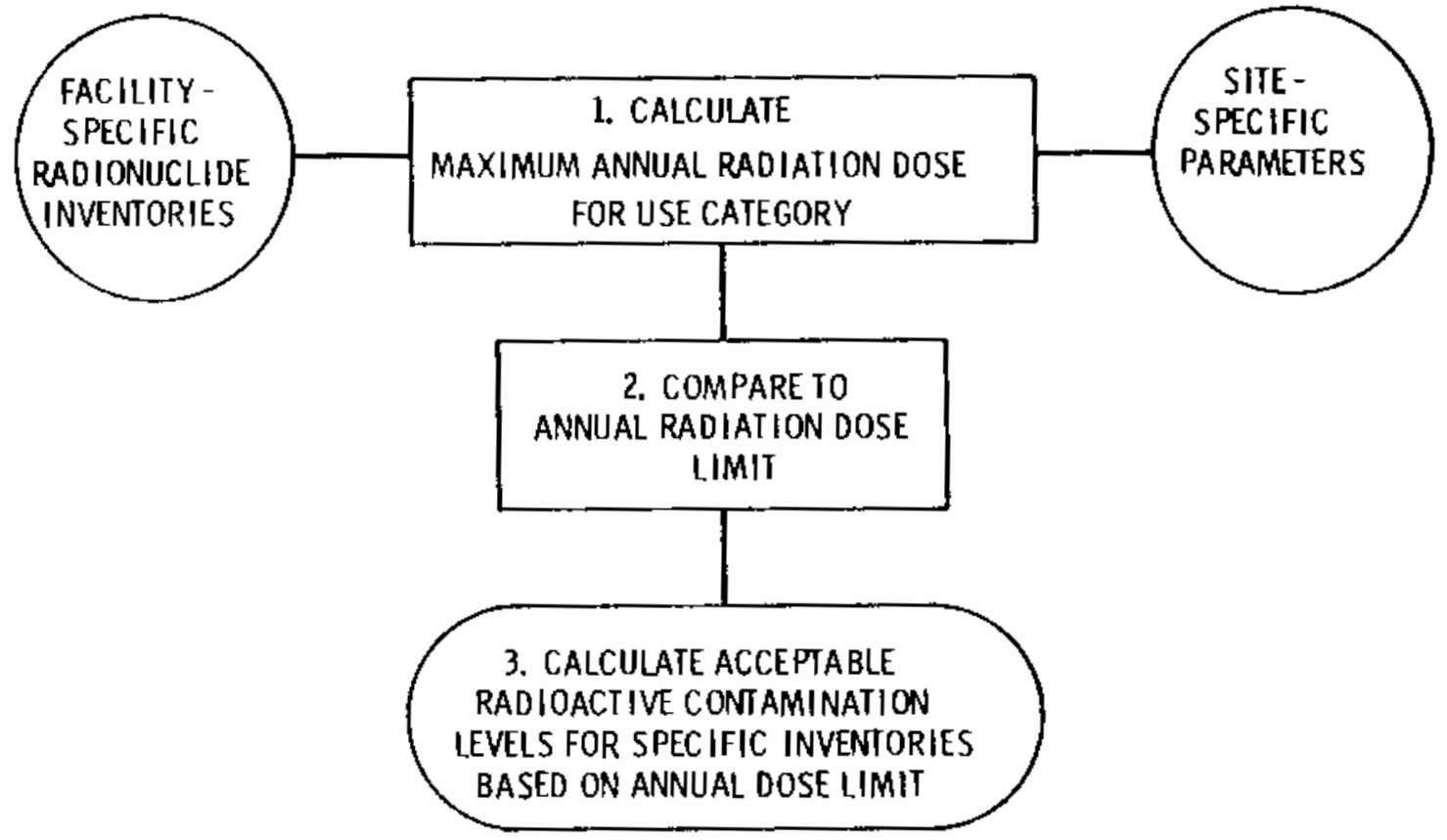

FIGURE 8.1-2. Suggested Methodology for Determining Acceptable Residual Radioactive Contamination Levels 
In site-specific studies that use measured radioactivity levels, this step can be used as a decision point to determine the need for further decontamination efforts.

- Calculation of Acceptable Levels Based on the Assumed Dose Limit. The acceptable radioactive contamination levels in the decommissioned reference $\mathrm{UF}_{6}$ conversion $\mathrm{plant}$ and on its site are calculated and presented in Sections 8.2.1 and 8.2.2. These reported levels are determined by selecting the largest calculated organ dose derived from all exposure pathways. Acceptable contamination levels are reported in units of $\mu \mathrm{Ci} / \mathrm{m}^{2}$ for surface area and $\mathrm{pCi} / \mathrm{g}$ for soil.

\subsubsection{Acceptable Residual Chemical Contamination Levels}

Analysis and determination of acceptable chemical contamination levels for a $U_{6}{ }_{6}$ conversion plant have not previously been conducted. However, the method used in this study is consistent with the relationship developed in Figure 8.1-7, and with the model developed for decommissioning a reference $U$-Fab plant.

There are currentiy no regulations or specific guidance on acceptable chemical exposures to individuals from a decommissioned nuclear facility. Guidance that could be used includes:

- Threshoid Limit Values for chemical substances and physical agents in the workroom environment. (11)

- EPA interim primary and proposed secondary drinking water standards.

- National Institute of Occupational Safety and Health Bulletins, Recommended Standard for Occupational Exposure to Various Chemicals.

- EPA and state environmental standards.

None of these guides provides specific information on public exposures to residual chemicals remaining in decommissioned facilities. This lack of definitive guidance makes it difficult to determine acceptable residual chemical levels. The following factors further complicate the selection process: 
- Unlike radioactive contaminants, for which the combined dose to an individual or population serves as a measure of the effect, chemical contaminants must presently be considered individually, with no accepted cormmon index of accumulated dose.

- Once released to the environment, many chemicals undergo reactions which alter their characteristics and effects.

- Some chemical pollutants can cause a number of different effects, depending on factors such as concentration and duration of exposure.

- Additive and synergistic effects of chemical combinations are poorly understood and difficult or impossible to predict.

It is not within the scope of this study to recommend annual chemical exposure limits for the public. The following limits have been assumed for the purpose of determining acceptable residual chemical contamination levels:

- Inhalation--exposures should not exceed $0.01 \mathrm{TLV}$. The factor 0.01 is a safety factor which accounts for nonoccupational exposures to most susceptible individuals.

- Ingestion--exposures should not exceed the equivalent of the EPA interim primary and secondary drinking water standards.

- Direct Contact--exposures should not cause any dermatitis or burns upon contact with open wounds or skin.

Based on the above criteria, residual contamination limits are determined as follows:

- Establish Chemical Contamination Characteristics. The chemical contamination characteristics of the plant and site are established by appropriate sampling or record review.

- Compute the Maximum Acceptable Residual Chemical Contamination Levels. The maximum acceptable residual chemical levels are estabiished so the exposure to any individual by the most limiting pathway will not exceed the criteria for that pathway. 


\subsection{CALCULATION OF EXAMPLE ACCEPTABLE RESIDUAL RADIOACTIVE CONTAMINATION}

LEVELS FOR. THE REFERENCE UF 6 CONVERSION PLANT

The methodology for determining acceptable radioactive contamination levels is best demonstrated by calculating example levels for the reference UF ${ }_{6}$ conversion plant and site based on the methods described in Section 8.1.3.

\subsubsection{Example Acceptable Residual Radioactive Contamination Levels in the Reference $\mathrm{UF}_{6}$ Conversion Plant}

Example contamination levels in the decommissioned reference plant are calculated using the maximum annual dose methodology presented in Appendix $E$. The surface contamination inventory of radionuclides in the reference plant is presented in Section 7 and Appendix C. Contamination is assumed to accurnulate on exposed surfaces over the entire 40-year operating life of the plant. Surface contamination estimates for the reference $\mathrm{UF}_{6}$ conversion plant in this study are based on a variety of assumptions. In actuality, contamination levels are specific to the facility design and its operating history. Thus, the levels are best determined by measurements on a case-by-case basis for each facility. It is reasonable, however, to predict the isotopic composition of this contamination. Therefore, surface contamination levels for the facility in this study are normalized to $1 \mathrm{pCi} / \mathrm{m}^{2}$ for the dose analysis contained in Appendix E. The actual radioactivity levels and isotopic composition encountered in the facility at shutdown are important in determining the degree of decontamination required; however, only the isotopic composition is necessary in determining acceptable levels.

The residual radioactive contamination levels present during decommissioning operations are assumed to be appropriately monitored and recorded. The decommissioning operations discussed in Section $g$ and Appendices $F$ and $G$ are designed to remove surface radioactive contamination until the radiation levels are acceptable for unrestricted use of the facility. These levels for the facility are derived in this section based on radioactive surface contamination, with the assumption that all volumetric wastes generated during decommissioning are disposed of as radioactive wastes. 
For the maximum annual dose calculations, airborne radionuclide concentrations in the reference $\mathrm{UF}_{6}$ conversion plant are calculated using a constant resuspension factor of $5 \times 10^{-6} \mathrm{~m}^{-1}$, as discussed in Section E.3 of Appendix E. Results of actual measurements of airborne radionuclide concentrations in decommissioned facilities could alter the acceptable contamination levels calculated here.

The maximum annual radiation doses to people working in the released decomissioned facility are calculated using a 40-hr week and are listed in Tables E.4-1 and E.4-2 of Appendix E for translocation Class $W$ and $Y$ material, respectively. These tables contain doses calculated for selected organs of reference from the inhalation and direct exposure pathways, and for all radionuclides that contribute more than $1 \%$ to the total dose. The doses in Tables E.4-1 through E.4-4 apply for specific times after operation shutdown, out to 100 years. The total residual contamination level does not change significantiy from radioactive decay and daughter buildup during the first 100 years. Only two radionuclides, ${ }^{237} \mathrm{~Pa}$ and ${ }^{230} \mathrm{Th}$, actually increase with time, but they do not contribute significantly to the total dose. The corresponding contamination levels are next calculated for an annual dose of 10 mrem. These calculated residual contamination levels, expressed in units of microcuries per $m^{2}$ of surface contamination $\left(\mu \mathrm{Ci} / \mathrm{m}^{2}\right)$, for translocation $\mathrm{Class} W$ and $Y$ material are shown in Table 8.2-1. For the total body and other organs of reference, the dominant radionuclide contributors to the dose are ${ }^{234} \mathrm{U},{ }^{235} \mathrm{U}$, and ${ }^{238} \mathrm{U}$.

\subsubsection{Example Acceptable Residual Radioactive Contamination Levels on the Reference $\mathrm{UF}_{6}$ Conversion Plant Site}

Information about the levels and nature of the radionuclide contamination present on the reference site is derived in Appendix B. Acceptable levels are calculated based on the estimated 40-year accumulated depositions on the site from routine annual releases during production operation. Airborne concentrations of radionuclides in the plant environs are calculated using the timedependent resuspension factor discussed in Section E.3 of Appendix E. The radionuclide inventories, showing the 40-year accumulated ground depositions and the values at each selected decay period, are listed in Table 7.7-1 of 
TABLE 8.2-1. Example Acceptable Contamination Level Within the Reference $\mathrm{UF}_{6}$ Conversion Plant (unrestricted use)

\begin{tabular}{|c|c|c|c|}
\hline $\begin{array}{l}\text { Organ of } \\
\text { Reference }\end{array}$ & $\begin{array}{l}\text { Maximum } \\
\text { Year(a) }\end{array}$ & $\begin{array}{c}\text { Translo- } \\
\text { cation } \\
\text { Class } \\
\end{array}$ & $\begin{array}{c}\text { Surface } \\
\text { Contamina } \\
\left.\text { tion ( } \mathrm{Cl} / \mathrm{m}^{2}\right) \\
\text { Corresponding } \\
\text { to a Maximum } \\
\text { Annual Dose } \\
\text { of } 10 \text { mrem }\end{array}$ \\
\hline Total Body & $\begin{array}{l}2 \\
2\end{array}$ & $\begin{array}{l}W \\
y\end{array}$ & $\begin{array}{l}2.4 \\
4.6\end{array}$ \\
\hline Bone & $\begin{array}{l}2 \\
4\end{array}$ & $\begin{array}{l}W \\
Y\end{array}$ & $\begin{array}{l}0.28 \\
1.1\end{array}$ \\
\hline Lungs & $\begin{array}{l}1 \\
2\end{array}$ & $\begin{array}{l}W \\
Y\end{array}$ & $\begin{array}{l}0.040 \\
0.0092\end{array}$ \\
\hline LLI & $\begin{array}{l}1 \\
1\end{array}$ & $\begin{array}{l}W \\
Y\end{array}$ & $\begin{array}{l}4.6 \\
4.6\end{array}$ \\
\hline
\end{tabular}

(a) The year in which the maximum annual dose occurs following the start of continuous exposure.

(b) Ingestion pathways from contamination in the released decommissioned facility are nonexistent.

Section 7. A more complete discussion of the calculational methods and assumptions used to relate normal plant effluents to deposited surface contamination on the site are found in Section B.5 of Appendix B.

At plant shutdown, these radionuclides are assumed to be mixed to a depth of $10 \mathrm{~mm}$ in the soil with no mechanical mixing or weathering effects. If the site contamination levels are measured to be below acceptable levels at the time of decommissioning, plowing is not required as a decommissioning activity. A dry soil "surface density" factor of $224 \mathrm{~kg}$ per square meter mixed to a depth of $150 \mathrm{~mm}$ (or soil density of $1.49 \mathrm{~g} / \mathrm{cm}^{3}$ ) is used to determine soil radioactivity concentrations. Example acceptable soil contamination levels are calculated for surface contamination and for soil contamination uniformly mixed to depths of $10 \mathrm{~mm}$ and $150 \mathrm{~mm}$. 
It should be noted that the contamination levels assumed for the site are probably higher than might actualiy be encountered at a UF 6 conversion plant. This is primarily because no credit is taken in the calculations for weathering effects on the radioactive contamination either during the 40-year $\mathrm{UF}_{6}$ conversion plant operating iife or during the subsequent decay times. For specific sites, comprehensive measurements will be necessary at the time of production shutdown to characterize the quantity and mixture of the deposited radioactive contamination.

Maximum annual doses calculated using the reference site radionuclide inventory at plant shutdown are 1 isted in Tables E.4-3 and E.4-4, Appendix E. Again, these tables contain the calculated doses for the environmental exposure pathways considered, the organs of reference, and the radionuclides that contribute $1 \%$ or more to the total dose. The corresponding residual contamination levels are calculated for an annual dose of 10 mrem and are listed in Table 8.2-2 for Class $W$ and $Y$ material. The dominant radionuclide contributors to the organ doses are ${ }^{234} \mathrm{U},{ }^{235} \mathrm{U}$, and ${ }^{238} \mathrm{U}$.

TABLE 8.2-2. Example Acceptable Residual Contamination Levels op the Reference UF $_{6}$ Conversion Plant Site at Plant Shutdown (a)

\begin{tabular}{|c|c|c|c|c|c|c|c|c|}
\hline \multirow[b]{3}{*}{ Reference } & \multirow[b]{3}{*}{ Year $(H / Y)^{(b)}$} & \multirow{3}{*}{$\begin{array}{c}\text { Dominant } \\
\text { Radionucl ide } \\
\text { Contributors } \\
\text { To Dose } \\
\end{array}$} & \multirow{2}{*}{\multicolumn{2}{|c|}{$\begin{array}{l}\text { Acceptable Residual } \\
\text { Radioactive Surface } \\
\text { Contamination tevels } \\
\left(\mu \mathrm{Ci} / \mathrm{m}^{2}\right)(\mathrm{c})\end{array}$}} & \multicolumn{4}{|c|}{$\begin{array}{c}\text { Acceptable Soil } \\
\text { Contamination Levels }\end{array}$} \\
\hline & & & & & Mixed & to $10 \mathrm{~mm}$ & Mixed $t$ & $00.15 \mathrm{~m}$ \\
\hline & & & $\frac{(\mu \mathrm{L} T / \pi}{\mathrm{Class} W}$ & Class $Y$ & $(\mathrm{pCi} / \mathrm{g})$ & (pCi/g) & $(p C i / g)$ & $(p C i / g)$ \\
\hline tal Body & $3 / 50$ & ${ }^{238} U+D$ & 30 & 30 & $2.0 \times 10^{3}$ & $2.0 \times 10^{3}$ & $1.3 \times 10^{2}$ & $1.3 \times 10^{2}$ \\
\hline ione & $50 / 50$ & $234 \mathrm{v}$ & 2.6 & 2.8 & $1.7 \times 10^{2}$ & $1.9 \times 10^{2}$ & $8.8 \times 10^{0}$ & $1.3 \times 10^{1}$ \\
\hline & $1 / 1$ & $238^{I J+D}$ & 11 & 2.4 & $7.6 \times 10^{2}$ & $1.6 \times 10^{2}$ & $5.0 \times 10^{1}$ & $6.8 \times 10^{0}$ \\
\hline & $1 / 1$ & ${ }^{238} 8_{U+D}$ & 16 & 16 & $1.0 \times 10^{3}$ & $1.0 \times 10^{3}$ & $7.0 \times 10^{1}$ & $7.0 \times 10^{7}$ \\
\hline
\end{tabular}

(a) Corresponding to an annual dose rate of 10 mrem/yr to specific organs of reference.

(b) The year in wich the maximum annual dose occurs following the start of continuous exposure for Class $W$ material and Class $Y$ material $(W / Y)$.

(c) These values can be compared to the acceptable contamination levels listed in NUREG/CR-1266 for a uranium fuel fabrication plant by dividing the values mixed to $0.15 \mathrm{~m}$ (in $\mathrm{pC} / \mathrm{g}$ ) shown in this table by 15 , (2)

(d) The to notation indicates that after deposition in the organ of reference, the decay energy of the daughter is included with the parent. 


\subsubsection{Summary of Example Acceptable Residual Radioactive Contamination Leve1s}

The example acceptable residual contamination levels calculated in this study are sumnarized in Table 8.2-3. For the facility, the inhalation pathway dominates and the lungs are the critical organ receiving the most dose and

TABLE 8.2-3. Summary of Example Acceptable Residual Radioactive Contamination Levels for the Reference $U_{6}$ Conversion Plant and its Sites

Acceptable Residual

Contamination Levels for an Annual

Dose of $10 \mathrm{mrem}$ (a)

\begin{tabular}{|c|c|c|c|c|c|}
\hline & $\begin{array}{c}\text { Translocation } \\
\text { Class } \\
\end{array}$ & $\begin{array}{c}\text { Critical } \\
\text { Organ } \\
\end{array}$ & $\begin{array}{c}\text { Surface } \\
\text { Contamination } \\
\left(\mu \mathrm{Ci} / \mathrm{m}^{2}\right) \\
\end{array}$ & $\begin{array}{l}\text { Soi] Contam } \\
10 \mathrm{mim} \\
(\mathrm{pCi} / \mathrm{g})\end{array}$ & $\begin{array}{c}\text { ination Mixed To: } \\
150 \mathrm{~mm} \\
(\mathrm{pCi} / \mathrm{g})\end{array}$ \\
\hline Facility & $\begin{array}{l}W \\
Y\end{array}$ & $\begin{array}{l}\text { Lungs } \\
\text { Lungs }\end{array}$ & $\begin{array}{l}0.040 \\
0.0092\end{array}$ & $\ldots^{(b)}$ & $\begin{array}{l}-- \\
-\end{array}$ \\
\hline te & $\begin{array}{l}W \\
Y\end{array}$ & $\begin{array}{l}\text { Bone } \\
\text { Lungs }\end{array}$ & $\begin{array}{l}2.6 \\
2.8\end{array}$ & $\begin{array}{l}170 \\
160\end{array}$ & $\begin{array}{l}13 \\
6.8\end{array}$ \\
\hline
\end{tabular}

(a) Based on the natural uranium mixtures shown in Table 7.4-1 for the facility and Table 7.1-1 for the site.

(b) A dash indicates that soil contamination levels are not calculated for surface contamination inside the facility.

yielding the most restrictive acceptable contamination levels. For the site, the dominant exposure pathways are ingestion of farm products for Class $W$ material and inhalation of resuspended radioactivity for $\mathrm{Class} Y$ material. The critical organs are bone and lungs for Class $W$ and Class $Y$ material, respectively. It should be noted that, because of the time dependent resuspension factor in the Anspaugh ${ }^{(22)}$ model (see Appendix E), the dominant exposure pathway for $\mathrm{Class} Y$ material changes from inhalation to ingestion, the critical organ changes from lungs to bone, and the acceptable contamination levels approach those calculated for $C l$ ass $W$ material. These changes occur because the resuspension factor in the Anspaugh model decreases with time. 


\subsubsection{Acceptable Contamination Levels on $\mathrm{UF}_{6}$ Conversion Plant Equipment}

The problems associated with releasing equipment used in the nuclear industry for unrestricted public use have been addressed in two recent studies. $(23,24)$ The first of these studies describes aneric methodology for estimating potential radiation doses to man from recycling radioactively contaminated metals reclaimed during decommissioning a nuclear power plant. ${ }^{(23)}$ The methodology is demonstrated for 27 radionuclides from six recycle pathways with a contamination level of $10 \mathrm{pCi} / \mathrm{g}$. The resuits in Reference 23 are for a generic case and several key assumptions are made to obtain radiation dose estimates to exposed population groups. However, the methodology presented in Reference 23 should be useful in determining acceptable radioactive contamination levels for the release of contaminated equipment.

The second study is a draft environmental impact statement concerning a possible exemption from licensing of smelted alloys containing residual ${ }^{99}$ Tc and low-enriched uranium. (24) Exposure pathways are considered for the recycle of scrap copper, nickel, and iron resulting from improvement of the Department of Energy's gaseous diffusion plants. The primary environmental impacts considered are the doses to foundry and metal fabrication workers, and the doses to members of the public who use items made from the recycled metal. The results obtained in Reference 24 are for six exposure scenarios and indicate that less than one health effect could be expected for recycle of the materials selected.

Release of much of the equipment recovered from the $\mathrm{UF}_{6}$ conversion plant after decontamination could be covered by standards developed by the ANSI Committee $\mathrm{N} 13.12$; $^{(10)}$ however, the NRC has not yet endorsed this standard. The complexities of decontaminating equipment for public release are great and are briefly discussed in Appendix $\mathrm{H}$. Because decomissioning an actual $\mathrm{UF}_{6}$ conversion plant requires special procedures to release equipment on a piece-bypiece basis, no further effort is made in this report to analyze equipmentrelease conditions. 


\subsection{CALCULATION OF EXAMPLE ACCEPTABLE RESIDUAL CHEMICAL CONTAMINATION LEVELS}

The methodology for developing chemical contamination levels is based on human health impact potential and compliance with environmental standards. Example acceptable chemical contamination levels for the decommissioned reference plant are calculated using methodology discussed in Section 8.1.4. Contamination is assumed to accumulate both in the facility and on the site over the entire 40-yr operating plant lifetime. The residual contamination levels present during decommissioning are assumed to be known from sensitive analytical techniques similar to those used for occupational exposures to dusts, vapors, and gases. It should be noted that although specifically directed towards removal of radionuclides, the decommissioning tasks discussed in Section 9 and Appendices $F$ and $G$ will also remove or reduce chemical contamination levels.

Because of complex chemical-surface interactions, it is difficult to estimate the concentration of residual chemicals in the air above contaminated surfaces. Thus, no attempt is made in this study to consider diffusion or evaporation as driving forces in the concentration calculations. Instead, a simple resuspension analysis, similar to the analysis done for radionuclides in a facility, is used to calculate example chemical concentrations in air. However, it should be remembered that for some chemicals a diffusion analys is may be more adequate when determining acceptable surface contamination levels in a decommissioned facility. Results of actual measurements in a decommissioned facility could also significantly alter the example chemical contamination levels calculated in this study.

Table 8.3-1 shows the example acceptable surface contamination levels calculated to be in the reference $\mathrm{UF}_{6}$ conversion plant, based on a resuspension factor of $5 \times 10^{-6} \mathrm{~m}^{-1}$. The data in this table indicate relatively large allowable levels of surface contamination resulting in air concentrations that are a factor of 0.01 below the ILV. The chemicals that are considered in Table 8.3-1 are shown in Tables 7.2-2 and 7.2-3, and are discussed in Appendix B.

An appropriate ingestion exposure pathway must be defined before acceptable chemical surface contamination levels can be developed based on direct ingestion. 
TABLE 8.3-1. Example Acceptable Chemical Contamination Levels in the Reference $U_{6}$ Conversion Plant (unrestricted use)--Inhalation, Airborne Pathway

\begin{tabular}{|c|c|c|}
\hline Chemica] & $\underline{T L V}\left(\mathrm{mg} / \mathrm{m}^{3}\right)$ & $\begin{array}{c}\text { Allowable } \\
\text { Maximum Surface } \\
\text { Contamina } \\
\text { tion }\left(\mathrm{g} / \mathrm{m}^{2}\right) \\
\end{array}$ \\
\hline$F^{(b)}$ & 2.5 & 5.0 \\
\hline HF & 2.0 & 4.0 \\
\hline $\mathrm{SO}_{2}$ & 13 & 26 \\
\hline $\mathrm{NH}_{3}$ & 18 & 36 \\
\hline $\mathrm{H}_{2} \mathrm{~S}$ & 15 & 30 \\
\hline Hexane & 360 & 720 \\
\hline $\mathrm{NO}_{2}$ & 9 & 18 \\
\hline Uranium (insoluble) & 0.2 & 0.4 \\
\hline Uraniulii (soluble) & 0.2 & 0.4 \\
\hline $\mathrm{H}_{2} \mathrm{SO}_{4}$ & 1.0 & $2.0^{(\mathrm{c})}$ \\
\hline $\mathrm{HNO}_{3}^{2}$ & 30 & $6.0^{(c)}$ \\
\hline Nitrate & High & $>50$ \\
\hline Sulfate & High & $>50$ \\
\hline
\end{tabular}
(a) Corresponding to $1 \%$ of the TLV as a product of the resuspension factor of $5 \times 10^{-6} \mathrm{~m}^{-1}$.
(b) Fluoride limit is for inorganic fluoride; no specific limit for $\mathrm{CaF}_{2}$ is given.
(c) Not expected to be present as a surface con- taminant over any appreciable surface area.

The EPA drinking water standards provide a basis for fluoride, nitrate, and sulfate limits. Acceptable daily ingestion of these three chemicals is assumed to be the amount consumed by an individual drinking $1.2 \mathrm{l} /$ day of water containing the EPA maximum level. Acceptable daily ingestion rates for other chemicals, for which no drinking water limit is published, are found based on an analysis using TLVs. For this analysis, it is assumed that an individual will ingest surface contamination from $8 \times 10^{-4} \mathrm{~m}^{2}$ of surface during an 8-hour day. (25) This amount of ingestion agrees with the assumptions made by Healy in References 25 for the ingestion of removable radioactive surface contamination. It 
is further assumed that this amount of ingestion equals the amount the individual would inhale during a 24-hour day (at the rate of $1 \mathrm{~m}^{3} / \mathrm{hr}$ ) at an air concentration of $1 \%$ of the TLV. The acceptable surface contamination levels calculated for ingestion are intended to be "example" levels showing how to apply the calculational methods, and are not intended to reflect the specific conditions found at an existing facility. The example acceptable chemical surface contamination levels calculated for ingestion are shown in Table 8.3-2.

TABLE 8.3-2. Example Acceptable Chemical Contamination Levels within the Reference Facility (unrestricted use)--Ingestion Pathway

\begin{tabular}{|c|c|c|}
\hline Chemical & $\begin{array}{c}\text { Maximum } \\
\text { Acceptable } \\
\text { Oaily } \\
\text { Ingestion } \\
\text { (mg/day) }\end{array}$ & $\begin{array}{c}\text { Estimated } \\
\text { Acceptable } \\
\text { Surface } \\
\text { Contamjnatjon } \\
\left(\mathrm{g} / \mathrm{m}^{2}\right)(\mathrm{a}) \\
\end{array}$ \\
\hline$F^{(b)}$ & $2.9^{(c)}$ & 3.6 \\
\hline HF & $0.48^{(d)}$ & 0.60 \\
\hline $\mathrm{SO}_{2}$ & $3.1^{(d)}$ & 3.9 \\
\hline $\mathrm{NH}_{3}$ & $4.3^{(d)}$ & 5.4 \\
\hline $\mathrm{H}_{2} \mathrm{~S}$ & $3.6^{(d)}$ & 4.5 \\
\hline Hexane & $86^{(d)}$ & 110 \\
\hline $\mathrm{NO}_{2}$ & $2.2^{(d)}$ & 2.7 \\
\hline Uranium (insoluble) & $0.05^{(d)}$ & 0.06 \\
\hline Uranium (soluble) & $0.05^{(d)}$ & 0.06 \\
\hline $\mathrm{H}_{2} \mathrm{SO}_{4}$ & $0.24^{(\mathrm{e})}$ & 0.30 \\
\hline $\mathrm{HNO}_{3}$ & $7,2^{(\mathrm{e})}$ & 9.0 \\
\hline Nitrate & $12^{(\mathrm{c})}$ & 15 \\
\hline Sulfate & $300^{(c)}$ & 380 \\
\hline
\end{tabular}

(a) Assumes a person ingests the contamination from $8 \times 10^{-4} \mathrm{~m}^{2}$ of surface per day.

(b) Fluoride limit is for inorganic fluoride; no specific limit for $\mathrm{CaF}_{2}$ is given.

(c) Based on EPA interim primary and proposed primary drinking water standards and a daily water consumption of $1.2 \ell$.

(d) Based on the amount inhaled by a person breathing $1 \mathrm{~m}^{3} / \mathrm{hr}$ at $1 \%$ of TLV for $8-\mathrm{hr} /$ day.

(e) Not expected to be present as a surface contaminant over any appreciable surface area. 
Using this method, the acceptable concentrations of chemical contaminants appear to be limited by the ingestion pathway calculations. It should be emphasized that the levels calculated here could change significantly if a different resuspension factor, a diffusion calculation for air concentrations, or different assumptions for ingestion are used. Thus, site-specific information will help determine the magnitude of the chemical contamination problem and will also influence the calculated acceptable contamination levels.

\subsection{EXISTING GUIDANCE ON ACCEPTABLE RESIDUAL RADIOACTIVE CONTAMINATION LEVELS}

Existing guidance on acceptable radioactive contamination levels for the unrestricted release of decommissioned nuclear reactors is found in Regulatory Guide $1.86,(26)$ in the draft ANSI Standard N13.12, (10) and in a Federal Register notice by the NRC. (13) The levels reflected in References 26 and 10 are 1 isted in Tables 8.4- 1 and 8.4-2. Since the radiation dose basis of $10 \mathrm{mrem} / \mathrm{yr}$ and calculations presented in this study are different from the instrumentation capability basis used in Reference 26 and 10 , the resulting contamination level

TABLE 8.4-1. Regulatory Guide 1.86 Acceptable Surface Contamination Levels

$\frac{\text { Radionuclide }(a)}{U-n a t, 235_{U}, 238 \mathrm{U} \text { and associated }}$ decay products

Transuranics, ${ }^{226} \mathrm{Ra},{ }^{228} \mathrm{Ra},{ }^{230} \mathrm{Th}$

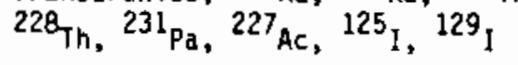

Th-nat, ${ }^{232} \mathrm{Th},{ }^{90} \mathrm{Sr},{ }^{223} \mathrm{Ra},{ }^{224} \mathrm{Ra}$,

$232_{1}, 126_{1}, 131_{I}, 133_{1}$

Beta-ganma enitters (nuclides with decay modes other than alpha emission or spontaneous fission) except

90 sr and others noted above

$\begin{array}{lll}\text { Average }(b, c) & \text { Maximum }(b, d) & \text { Removable }(b, e) \\ 5000 \mathrm{dpm} a / 100 \mathrm{~cm}^{2} & 15000 \mathrm{dpm} a / 100 \mathrm{~cm}^{2} & 1000 \mathrm{dpm} \alpha / 100 \mathrm{~cm} \\ 100 \mathrm{dpm} / 100 \mathrm{~cm}^{2} & 300 \mathrm{dpm} / 100 \mathrm{~cm}^{2} & 20 \mathrm{dpm} / 100 \mathrm{~cm}^{2} \\ 1000 \mathrm{dpm} / 100 \mathrm{~cm}^{2} & 3000 \mathrm{dpm} / 100 \mathrm{~cm}^{2} & 200 \mathrm{dpm} / 100 \mathrm{~cm}^{2}\end{array}$

$5000 \mathrm{dpm} B Y / 100 \mathrm{~cm}^{2} 15000 \mathrm{dpm} B Y / T 00 \mathrm{~cm}^{2} 1000 \mathrm{dpm} B Y / 100 \mathrm{~cm}^{2}$

(a) Where surface contamination by both alpha- and beta-gamma-emitting nuclides exists, the limits established for alpha- and beta-gama-emitting nuclides apply independently.

(b) Used in this table, dpm (disintegrations per minute) means the rate of emission by radioactive material as determined by correcting the counts per minute observed by an appropriate detector for background, efficiency, and geometric factors associated with the instrumentation.

(c) Measurements of average contaminant should not be averaged over more than $1 \mathrm{~m}^{2}$. For objects of less surface area, the average should be derived for each object.

(d) The maximum contamination level applies to an area of not more than $100 \mathrm{~cm}^{2}$.

(e) The amount of removable radioactive material per $100 \mathrm{~cm}^{2}$ of surface area should be determined by wiping that area with dry filter or soft absorbent paper, applying moderate pressure, and assessing the amount of radioactive material on the wipe with an appropriate instrument of known efficiency. When removable contamination on objects of less surface area is determined, the pertinent levels should be reduced proportionally and the entire surface wiped. 


\section{TABLE 8.4-2. ANSI N13.12 Surface Contamination Limits}

Radionucl ide ${ }^{\text {(a) }}$

\section{Group 1:}

Nuclides for which the nonoccupational $\mathrm{MPC}_{\mathrm{a}}{ }^{(b)}$ is $2 \times 10^{-13} \mathrm{Ci} / \mathrm{m}^{3}$ or less $\mathrm{gr}$ for which the nonoccupational $\mathrm{MPC}_{\mathrm{H}}(\mathrm{C})$ is $2 \times 10^{-7} \mathrm{Ci} / \mathrm{m}^{3}$ or less; includes $\mathrm{AC}-227$;

Am-241, $-242 m,-243 ;$ Cf-249, -250, -251, -252; Cm-243, $-244,-245,-246,-247,-248 ;$ I-125, I-129; Np-237;

$\mathrm{Pa}-231$; Pb-210; Pu-238, -239, -240, -242, -244; Ra-226, -228 ; Th-228, -230 .

Group. 2:

Those nuclides not in Group 1 for which the nonoccupationa) $\mathrm{MPC}_{\mathrm{a}}$ is $1 \times 10^{-12} \mathrm{Ci} / \mathrm{m}^{3}$ or for which the nonoccupational $\mathrm{MPC}_{\mathrm{w}}$ is $1 \times 10^{-6} \mathrm{Ci} / \mathrm{m}^{3}$ or less; includes Es-254; Fm-256; I-126, -131, -133; Po-210; Ra-223; Sr-90; Th-232; $\mathrm{U}-232$.

Group 3:

Those nuclides not in Group 1 or Group 2.

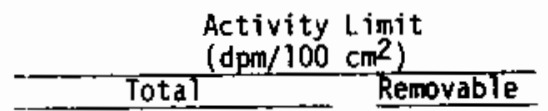

Nondetectable ${ }^{(d)}$

20

Nondetectable $\left.e^{(\beta, \gamma)}\right)^{(e)}$ 200 $2000(\alpha)$

(a) Values presented here are obtained from 10 CFR Part 20 . The most limiting of all given MPC values (e.g., soluble vs. insoluble) are to be used. In the event of the occurrence of mixtures of radionuclides, the fraction contributed by each constituent of its own limit shall be determined and the sum of the fractions must be less than 1 .

(b) MPCa: maximum permissible concentration in air applicable to continuous exposure of members of the public as published by or derived from an authoritative source such as NCRP, ICRP or NRC (10 CFR Part 20 Appendix B Table 2, Column 1).

(c) MPG : maximum permissible concentration in water applicable to members of the public.

(d) The instrument utilized for this measurement shall be caiculated to measure at least $100 \mathrm{pC} i$ of any Group-l contaminants uniformly spread over $100 \mathrm{~cm}^{2}$.

(e) The instrument utilized for this measurement shall be calibrated to measure at least $1 \mathrm{nCi}$ of any Group-2 beta or gamma contaminants uniformly spread over an area equivalent to the sensitive area of the detector. MOTE: Direct survey for unconditional release should be performed in areas where the background is $\leq 100 \mathrm{c} / \mathrm{m}$. When the survey must be performed in a background exceeding $100 \mathrm{c} / \mathrm{m}$, it may be necessary to use the indirect survey method to provide the additional sensitivity required.

criteria do not directly compare and require analysis. Using the maximum annual dose as the general basis for determining acceptable radioactive contamination levels permits the necessary flexibility for considering the various radionuclide mixtures expected at decommissioned nuclear facilities.

\subsection{RES IDUAL CONTAMINATION LEVEL MEASUREMENTS}

After final inventory cleanout is completed, residual contamination levels in the reference plant must be measured to determine the amount of effort required to decommission the facility and site. Methods of measurement are discussed in this section. 


\subsubsection{Radioactivity Measurements}

The capability of measuring the maximum acceptable residual contamination levels in Table 8.2-3 is dependent on the sensitivity of the instrumentation utilized and the time available for surveying. The latest scintillation alpha survey meters have the capability to detect as $10 \mathrm{w}$ as $50 \mathrm{~d} / \mathrm{m}$ per probe area. This detection level corresponds to a contamination level of $0.004 \mu \mathrm{Ci} / \mathrm{m}^{2}$. The most restrictive acceptable levels for the reference facility shown in Table $8.2-3$ is $0.046 \mu \mathrm{Ci} / \mathrm{m}^{2}$, or about $1,000 \mathrm{~d} / \mathrm{m}$ per $100 \mathrm{~cm}^{2}$. Thus, measurement of activity levels for the reference facility corresponding to an annual dose of 50 mrem is possible using survey instrumentation available commercially.

Inside generally contaminated spaces, in the presence of large contaminated equipment items, or over large generally contaminated surfaces, it may be necessary to use indirect survey methods to measure radiation levels. On hard nonporous surfaces, smears or scrapings may be taken and removed for analysis to a lower-background location or a low-level laboratory counting instrument.

The acceptable surface contamination levels shown in Table 8.2-3 imply that the history of the material or the mixture of radionuclides being measured is known. Sampling for laboratory identification measurements and specific radionuclide contamination levels are desirable even when the characteristics of the contamination are known. Sampling is absolutely essential when such preliminary information is lacking.

Sampling techniques for bulk materials such as soils have many variations. Practicality limits the fraction of any large area that can be sampled and analyzed. A fixed scheme is needed for selecting sampling stations and the number, size, and spacing of sample aliquots at each location. A fixed sampling scheme is desirable not only for appropriate statistical inferences but also for reproducibility and comparability. For soil, variability of overlying vegetation and inclusion of rock and gravel is a problem. Regulatory Guide $4.5^{(27)}$ provides one commonly used scheme that is generally applicable for soil sampling. Adequate sampling of bulk materials requires sampling to depths of 0.3 to $1 \mathrm{~m}^{\prime}$ in soil, depending on climate and history. 
There is no commonly accepted procedure for translation of surface concentration limits to mass contamination limits or vice versa. However, with reasonable assumptions as to soil bulk density and the volume of soil seen by a portable alpha probe, the value of $12 \mu \mathrm{Ci} / \mathrm{m}^{2}$, shown in Table 8.2-3, translates to approximately $34,000 \mathrm{pCi} / \mathrm{kg}$, or $\sim 10^{3}$ times the lower limit of detection (LLD) for laboratory analysis given in Table $8.5-1 .(28,29)$ For all radionuclides in environmental media, sample radioanalysis can provide the sensitivity required by any of the proposed limits in Section 8.4 or the example radioactive surface contamination levels in Table 8.2-3. The cost will depend on whether chemical separation is required and on the length of counting time needed to measure a particular radionuclide at a given level above instrumental and sample background.

TABLE 8.5-1. Detection Capabilities for Environmental Sample Analysis (a)

\begin{tabular}{|c|c|c|c|c|}
\hline \multirow[b]{2}{*}{ Analysis } & \multicolumn{4}{|c|}{ Lower Limit of Detection (LLO) ${ }^{(b)}$} \\
\hline & $\begin{array}{l}\text { Water } \\
(\mathrm{p}(i / \ell)\end{array}$ & $\begin{array}{l}\text { Vegetation } \\
\text { (pCi } \mathrm{i} / \mathrm{kg}, \text { wet })\end{array}$ & $\begin{array}{c}\text { Soil } \\
\text { (pCi/kg, dry) }\end{array}$ & Air $\left(p c i / \mathrm{m}^{3}\right)^{(c)}$ \\
\hline $235_{U}(d)$ & 2 & 50 & 30 & $6 \times 10^{-5} \mu \mathrm{g} / \mathrm{m}^{3}$ \\
\hline $238_{U}(d)$ & 2 & 50 & 30 & $6 \times 10^{-5} \mathrm{Hg} / \mathrm{m}^{3}$ \\
\hline
\end{tabular}

(a) This table is intended to be comparable to a similar table in Regulatory Guide 4.8 reflecting current experience at a conmercial radioanalytical laboratory. (28)

(b) The normal lower limit of detection is defined in HASL 300 , Appendix D, Rev. $8 / 74$, at the $95 \%$ confidence level.(29) The LLD for radionuclides analyzed by ganma spectrometry will vary according to the number of radionuclides encountered in environmental samples.

(c) LLD based on $300 \mathrm{~m}^{3}$ sample volume and alpha proportional counter.

(d) Fluorometric analysis.

Scintillation alpha survey meters are capable of measuring the radioactive contamination levels presented in Table 8.2-3. Sampling of soil, vegetation and ground water would be required to assure compliance with acceptable levels. These samples would be collected based on a statïstical design to assure that acceptable levels are met. ${ }^{(30)}$ Analytical procedures involve chemical 
concentration and separation of the nuclide of interest. Detecting the activity of the concentrated samples is done with gas flow proportional counters or other systems with similar or superior detection capabilities.

Table 8.5-2 sumbrizes relative advantages and disadvantages for comon methods of determining radioactive contamination levels. Further discussion of instrument capabilities may be found in LBL-1. (3T) Further discussion of

TABLE 8.5-2. Comparison of Measurement Methods for Radiation Surveys to Permit Unrestricted Use

\begin{tabular}{|c|c|c|}
\hline Measurement Method & Advantages. & Disadvantages \\
\hline \multicolumn{3}{|l|}{ Direct } \\
\hline Portable Instruments $(a)$ & $\begin{array}{l}\text { Relatively fast; } \\
\text { Relatively inexpensive; } \\
\text { Readily available; } \\
\text { Able to delineate not } \\
\text { spots. }\end{array}$ & $\begin{array}{l}\text { Limited sensitivity; usually not } \\
\text { nuclide-specific; } \\
\text { Subject to interferences from } \\
\text { high background and surface } \\
\text { conditions; } \\
\text { For alpha and beta emitters, } \\
\text { useful for exposed surfaces only. }\end{array}$ \\
\hline Aerial Survey & Extremely fast. & $\begin{array}{l}\text { Useful in general for ganma emit- } \\
\text { ters only; } \\
\text { Insensitive to sma } 11 \text { areas. }\end{array}$ \\
\hline \multicolumn{3}{|l|}{ Indirect } \\
\hline Smears, Scrapings & $\begin{array}{l}\text { Avoidence of high back- } \\
\text { ground interference. }\end{array}$ & $\begin{array}{l}\text { Not indicative of total activity } \\
\text { present, highly variable results; } \\
\text { Incomplete coverage of large } \\
\text { surfaces; } \\
\text { Not applicable to loose or con- } \\
\text { fined materials. }\end{array}$ \\
\hline $\begin{array}{l}\text { - with direct field } \\
\text { count. }\end{array}$ & $\begin{array}{l}\text { Relatively fast; } \\
\text { Relatively inexpensive. }\end{array}$ & Not nuclide-specific. \\
\hline $\begin{array}{l}\text { - with laboratory } \\
\text { counting }\end{array}$ & $\begin{array}{l}\text { Nuclide identification } \\
\text { possibie (but more } \\
\text { expensive); } \\
\text { Greater sensitivity than } \\
\text { direct field count. }\end{array}$ & Relatively slow and expensive. \\
\hline \multicolumn{3}{|l|}{ Sampiing and Laboratory } \\
\hline Analysis & $\begin{array}{l}\text { Nuclide-specific; } \\
\text { Highly sensitive. }\end{array}$ & $\begin{array}{l}\text { Relatively slow; } \\
\text { Relatively expensive; } \\
\text { Applicable only when sample of } \\
\text { material can be taken to } \\
\text { laboratory; } \\
\text { Provides data for only small part } \\
\text { of total surface. }\end{array}$ \\
\hline
\end{tabular}


environmental survey techniques may be found in ERDA-77-24 ${ }^{(32)}$ and NCRP Report No. $50,(33)$ as well as in the health physics literature.

\subsubsection{Chemical Contamination Measurements}

Virtually all of the chemical contaminants would require laboratory analysis to provide detection capability of all the chemical contaminants at or below the unrestricted release criterion. Such methods are currently available and should be considered as part of the routine monitoring done prior to release of the decomrissioned $\mathrm{UF}_{6}$ conversion plant. 


\section{REFERENCES}

1. K. J. Schneider and C. E. Jenkins, Technology, Safety and Costs of Decommissioning a Reference Nuclear Fuel Reprocessing Plant, NUREG-0278, Section 6, Prepared by Pacific Northwest Laboratory for the U.S. Nuclear Regulatory Commission, October 1977.

2. H. K. Elder, and D. E. Blahnik, Technology, Safety and Costs of Decommissioning a Reference Uranium Fuel Fabrication Plant, NUREG/CR-1266, Section 8, Prepared by Pacific Northwest Laboratory for the U.S. Nuclear Regulatory Commission, October 1980.

3. U.S. NRC, Plan for Reevaluation of NRC Policy on Decomissioning of Nuclear Facilities, NUREG-0436, Rev. 1, December 1978.

4. U.S. NRC, Guidelines for Decontamination of Facilities and Equipment Prior to Release for Unrestricted Use or Termination of Licenses for By-Product, Source or Special Nuclear Material, November 1976.

5. U.S. Code of Federal Regulations, Title 49, Part 173, "Shippers--Genera1 Requirements for Shipments and Packaging," Superintendent of Documents, GPO, Washington, DC 20555, 1976.

6. U.S. ERDA, "Prevention Control and Abatement of Air and Water Pollution," U.S. ERDA Manua]. Chapter 0510, ApriT 2, 1975.

7. J. W. Healy, A Proposed Interim Standard for Plutonium In Soi1s, LA-5483-MS, Los Alamos Scientific Laboratory, Los ATamos, New Mexico, January 1974.

8. C. E. Guthrie and J. P. Nichols, Theoretical Possibilities and Consequences of Major Accidents in 233 $\mathrm{U}$ and $239 \mathrm{Pu}$ Fuel Fabrication and Radioisotope Processing Plants, ORNL-344], Oak Ridge National Laboratory, Oak Ridge, Tennessee, April 1964.

9. A. J. Hazle and B. L. Crist, Colorado's Plutonjum In-Soil Standard, Colorado Department of Health, Occupational and Radiological Health Division, Denver, Colorado, 1975.

10. ANSI Standard N13.12, Control of Radioactive Surface Contamination On Materials, Equipment and Facilities to be Released for Uncontrolled Use, in publication for ANSI National Trial and Use.

11. American Conference of Governmental Industrial Hygenists, TLV's--Threshold Limit Values for Chemical Substance and Physical Agents in the Workroom Environment with Intended Changes for 1977, ACGIH, Cincinnati, Ohio. 
12. U.S. Environmental Protection Agency, Interim Primary and Proposed Secondary Drinking Water Standards, Federal Register, Vol. 43, No. 243, December 18 , 1978.

13. U.S. NRC, Federal Register, "Nuclear Regulatory Commission, 10 CFR Parts 30, 50, 70, and 72, Decomissioning Criteria for Nuclear Facilities; Notice of Availability of Draft Environmental Impact Statement," Vol. 46, №. 27, Washington, DC, 1981.

14. G. D. Calkins, Plan for Reevaluation of NRC Policy on Decommissioning of Nuclear Facilities, NUREG-0436 (Rev. 1) (Supp. 2), U.S. Nuclear Regulatory Commission, Washington, DC, 1981.

15. R. I. Smith, G. J. Konzek and W. E. Kennedy, Jr., Technology, Safety and Costs of Decommissioning a Reference Pressurized water Reactor Power Station, NUREG/CR-0130, Section 8, Prepared by Pacific Northwest Laboratory for the U.S. Nuclear Regulatory Comission, June 1978.

16. C. E. Jenkins, E. S. Murphy and K. J. Schneider, Technology, Safety and Costs of Decomissioning a Reference Small Mixed Oxide Fuel Fabrication Plant, NUREG/CR-0129, Section 8, Prepared by Pacific Northwest Laboratory for the U.S. Nuclear Regulatory Commission, February 1979.

17. "Recommendations of the International Commission on Radiological Protection," ICRP Publication 9, Pergamion Press, London, 1966.

18. Surgeon Genera], U.S. Public Health Service, Surgeon General's Guidelines, "Use of Uranium Mill Tailings for Constructive Purposes," Hearings Before the Subcommittee on Raw Materials of the Joint Committee on Atomic Energy, October 28 and 29, 1971, pp. 52-54, 1971 .

19. Code of Federat Regulations, Title 10, Part 50, Appendix I, "Licensing of Production and Utilization Facilities," Superintendent of Documents, GP0, Washington, DC, 20555, 1976.

20. U.S. Environmenta1 Protection Agency, Proposed Guidance on Dose Limits for Persons Exposed to Transuranium Elements in the General Environment, EPA 520/4-77-016, September 1977.

21. U.S. Code of Federal Regulations, Title 40, Part 190, "Environmental Radiation Protection Standards for Nuclear Power Operations," Superintendent of Documents, GP0, Washington, DC, 20555, January 1977.

22. L. R. Anspaugh, J. H. Shinn and P. L. Phelps, Resuspension and Redistribution of Plutonium in Soi1s, UCRL-76419, pp. $\overline{14-18}$, January 1975.

23. F. R. O'Donnel, et a1., Potential Radiation Dose to Man From Recycle of Metals Reclaimed from a Decommissioned Nuclear Power Plant, NUREG/CR-0T34, U.S. Nuclear ReguTatory Commission Report prepared by Oak Ridge Nationa] Laboratory, Oak Ridge, Tennessee, December 1978. 
24. U.S. NRC, Draft Environmental Statement Concerning Proposed Rulemaking Exemption from Licensing Requirements for Smelting Alloys Containing Residual Technetium-99 and Low-Enriched Uranium, NUREG-0518, Office of Standards Development, U.S. Nuclear Regulatory Commission, October 1980.

25. J. W. Healy, Surface Contamination: Decision Levels, LA-4558-MS, Los Alamos Scientific Laboratory, Los Alamos, New Mexico, 1971.

26. U.S. NRC, Termination of Operating Licenses for Nuclear Reactors, Regulatory Guide T.86, June 1974.

27. Directorate of Regulatory Standards, Measurements of Radionuclides in the Environment--Sampling and Analys is of Plutonium in Soil, Regulatory Guide 4.5, U.S. Nuclear Regulatory Commission, Washington, DC, May 1974.

28. Directorate of Regulatory Standards, Environmental Technical Specifications for Nuclear Power Plants, Regulatory Guide 4.8, U.S. Nuclear ReguTatory Conmission, Washington, DC, December 1975.

29. J. H. Harley, ed., HASL Procedures Manual, HASL-300, Supplement 2, Health and Safety Laboratory, HASL 300 REV, pp. D-09-01, 02, 03, New York, New York, August 1974.

30. R. D. Gilbert, et al., Statistical Analys is of ${ }^{239-240} \mathrm{Pu}_{\mathrm{u}}$ and ${ }^{241}$ Am Contamination of Soil Vegetation on NAEG Study Sites, The Radioecology of Plutonium and Other Transuranics in Desert Environments, NV0-153, June 1975.

31. Environmental Instrumentation Group, Instrumentation for Environmental Monitoring, LBL-1, Vol. 3--Radiation, University of California, Lawrence BerkeTey Laboratory, Berkeley, Cal ifornia, 1972.

32. J. P. Corley, et al., A Guide for Environmental Radiological Surveillance at ERDA Installations, ERDA-77-24, U.S. Energy Research and Development Administration, Washington, DC, March 1977.

33. National Council on Radiation Protection and Measurements, Environmental Radiation Measurements, NCRP Report No. 50, NCRP, Washington, DC 1976. 


\subsection{DECOMMISSIONING ACTIVITIES}

As discussed in Section 4, two alternatives for decommissioning the reference uranium hexafluoride conversion $\left(U_{6}\right)$ plant are selected for evaluation in this study: 1) DECON, and 2) passive SAFSTOR. An outline of the major components of a Master Decommissioning Plan (MDP) for both of these alternatives is presented in this section, together with discussions of the major work items in each plan. In addition, decommissioning activities for onsite disposal of the UF ${ }_{6}$ plant lagoon waste is summarized in this section.

\subsection{DECOMMISSIONING BY DECON}

In choosing to decommission a $\mathrm{UF}_{6}$ conversion plant by the DECON alternative, the owner trades potential further use of the plant for near-term release of the site for unrestricted use. The program plan and the postulated work schedules and sequences for decontamination, together with a brief discussion of essential systems and services and security, are presented in the following subsections. Details specific to the DECON decommissioning alternative are found in Section G.2 of Appendix G.

\subsubsection{Program Plan}

Decommissioning of the reference $\mathrm{UF}_{6}$ conversion plant by the DECON alternative involves four phases: planning and preparation, dismantlement and decontamination, transportation, and the final release survey. Some of these activities will proceed simultaneously in different sections of the facility. To minimize scheduling conflicts and accidents, a well-defined sequence and schedule for dismantlement and decontamination of the various portions of the plant must be created and followed carefully. The major activities considered and scheduled for decontaminating the facility are illustrated in Figure 9.1-1.

The 6 months prior to final plant shutdown are used for planning and preparation. It is estimated that approximately 8 months are required to dismantle and decontaminate the facility and site. Uranium and contaminated materials are removed and transported in parallel. The time and work estimates 
ACTIVITIES

\section{PLANNING AND PREPARATION \\ DISMANTLEMENT AND DECONTAMINATION \\ MAIN PROCESS BUILDING AREAS \\ SOLVENT EXTRACTION BUILDING \\ LABORATORIES, SHOPS AND SUPPORTING FACILITIES \\ EXTRACTION WASTE TREATMENT SYSTEMS \\ FLUORIDE AND MISCELLANEOUS WASTE}

TRANSPORTATION OF URANIUM AND CONTAMINATED OFFSITE FOR DISPOSITION

FINAL CLEANUP, SURVEY AND RELEASE OF SITE

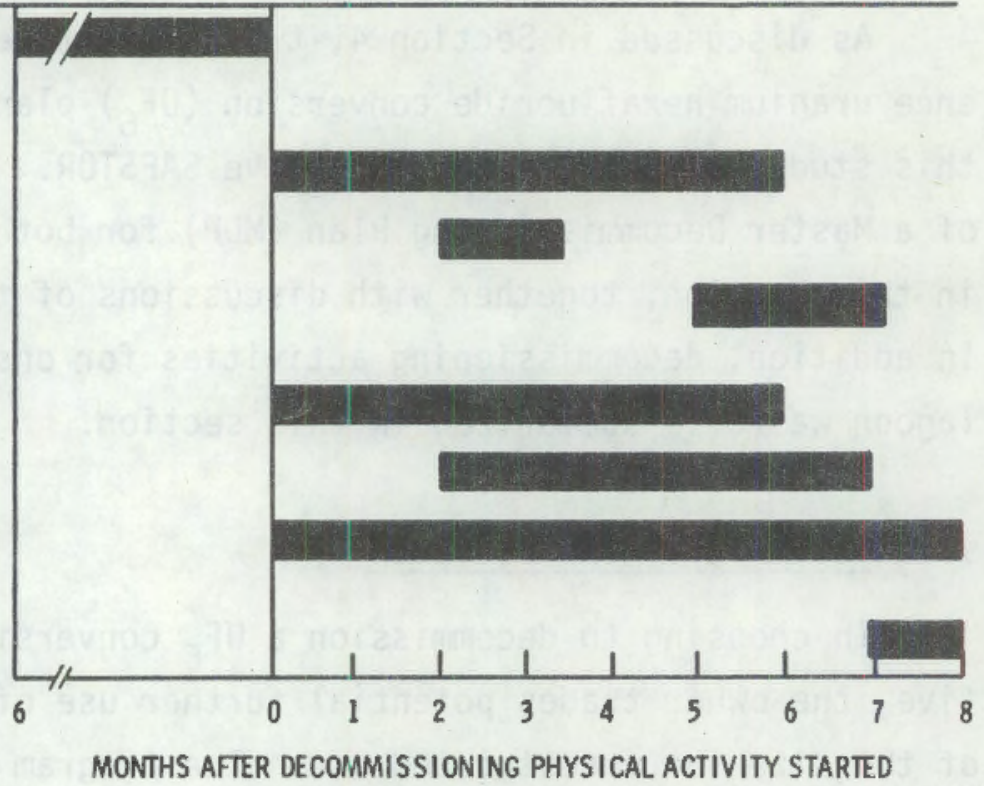

FIGURE 9.1-1. Sequence and Schedule of Major Activities for Decommissioning by DECON

assume reasonable success, with a minimum of delays and/or major unanticipated problems. A detailed schedule for the DECON phase is shown in Figure G.2-1 of Appendix G.

An extensive quality assurance (QA) program is carried on throughout the decommissioning effort to assure that: 1) all applicable regulations are met, 2) the work is performed according to plan, and 3) the associated radiation releases do not endanger public and decommissioning worker safety. A more detailed review of the anticipated elements of an appropriate QA program for the decontamination effort is given in Section F.4 of Appendix F.

\subsubsection{Planning and Preparation}

Essential to the results of this study is the assumption that the facility owner/operator becomes the prime contractor of the DECON work; otherwise, a more extensive training program would be necessary to acquaint workers with details of the facility. Approximately 6 months prior to final plant shutdown 
work begins in the engineering and operations departments of the parent organization to perform the planning needed to amend the license to permit DECON. The proposed sequence and timing schedule for the planning and preparation phase of decommissioning the facility and site is illustrated in Figure 9.1-2.

An important part of the planning involves a review of all regulations and guides, which may provide guidance to the decommissioning planning. A review of these regulations is presented in Section 5.

Important $i$ tems to consider in planning are: preparation and submittal of a decommissioning plan for NRC review and approval, preparation of detailed plans and procedures for dismantlement and decontamination of intact systems, detailed sequences for equipment and systems removal, and sectioning and disposal of contaminated equipment. In addition, design, procurement, and testing of

\section{ACTIVITIES}

PREPARE DATA FOR ENVIRONMENTAL IMPACT ASSESSMENT

PREPARE TECHNICAL SPECIFICATION REVISIONS

PREPARE DECOMMISSIONING PLAN FOR NRC

NRC REVIEW, DECOMMISSIONING LICENSE ISSUED

PREPARE DETAILED WORK PLANS AND PROCEDURES

DESIGN, PROCURE AND TEST SPECIAL EQUIPMENT

SELECT AND TRA IN STAFF

SELECT SPEC IALTY CONTRACTORS

FINAL INVENTORY CLEANOUT

(NOT CHARGED TO DECOMMISSIONING)

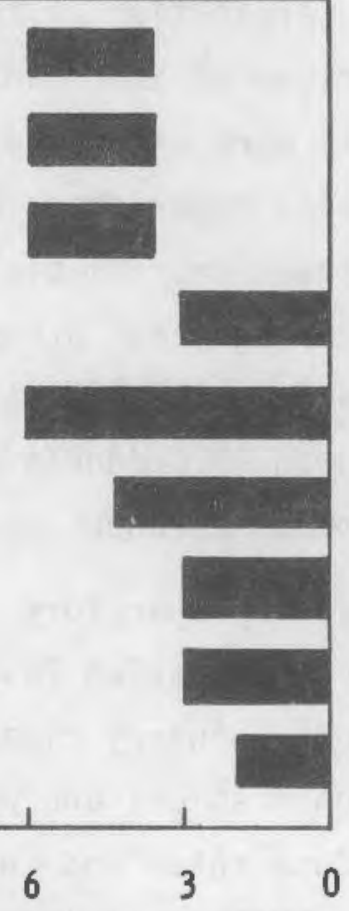

MONTHS BEFORE DECOMMISSIONING PHYSICAL ACTIVITY BEGINS

FIGURE 9.1-2. Sequence and Schedule of the Planning and Preparation Phase of DECON 
special devices and equipment must be initiated during the 6-month period before final plant shutdown to ensure that work can proceed without undue delay after shutdown.

Creation of a decommissioning organization within the present organization is initiated about 6 months prior to final plant shutdown, with the structure and staffing requirements identified, and comitments obtained from engineering and operating personnel to fill key positions. Orientation and training of personnel identified as members of the decommissioning organization is carried on during the last few months of plant operation. A suggested organizational structure and staffing requirements are given in Section 10 .

Selection of the various specialty contractors required for the DECON effort is accomplished during the final few months of plant operation. The types of specialty contractors anticipated to be required are 1 isted in Section 10.1.5.

After termination of routine plant production operations, an extensive inventory cleanout and uranium audit is conducted. These cleanout operations are slightly more extensive than those conducted periodically to audit uranium. Based on plant experience, cleanout operations are estimated to remove one-half of the residual uranium plant inventory. Because these cleanouts are done typically during plant production, they are also considered a part of normal plant operations in this study and are not charged to decommissioning. All recovered uranium products are shipped to offsite locations. Details of the final inventory cleanout and uranium audit are found in Section G. 1 of Appendix G.

The final preparatory step is a comprehensive survey of radiation dose rates and contamination levels within the facility. Taken after final plant shutdown and inventory cleanout, this survey provides the baseline data for decisions on chemical and physical decontamination, as well as initial data on radiation dose rates and contamination levels likely to be encountered during the various DECON activities. Physical decommissioning is assumed to start upon completion of the survey and receipt of NRC approval for the decomissioning. 


\subsubsection{Dismantlement and Decontamination}

The dismantlement and decontamination phase of the DECON program was summarized previously in Figure 9.1-1. The detailed schedule is provided in Figure G.2-1 of Appendix G. Detailed descriptions of the activities are also contained in Appendix $G$.

The general approach is to clean up the areas that contain the largest amount of uranium contamination first. The $U_{F}$ conversion, solvent extraction, and waste treatment areas are cleaned up in parallel. Within the UF ${ }_{6}$ conversion area, work progresses from sampling and preparation of yellowcake through the conversion process to fluorination of the uranium into the UF ${ }_{6}$ product.

Laboratories, the fluoride separation facilities, and other auxiliary facilities are cleaned up near the end of the campaign because their contamination levels are very low.

Dismantlement of the uranium recovery areas (incinerator, temporary radwaste facility, etc.) is saved until the bulk of the site decontamination effort is completed. Also, the other service facilities, such as the temporary decontamination room, are dismantled near the end of the program.

The temporary radwaste treatment facility is the last system to be dismantled, so it can be utilized throughout the program.

The final areas to be dismantled and decontaminated are the laundry and the change rooms.

\subsubsection{Transportation}

The transportation phase of the DECON alternative is initiated during the inventory cleanout stage and is continued throughout all the physical activities. All uranium and radioactively contaminated materials or equipment (most equipment is decontaminated onsite) are transported offsite for disposition at licensed low-level waste burial sites.

Packaging of contaminated materials for disposal is accomplished in accordance with DOT regulations published in 49 CFR, Parts 173 through 178, NRC regulations published in $10 \mathrm{CFR}$, Part 71, and Regulatory Guide 7.1. Shipping of packaged contaminated materials from the facility to a low-level waste 
disposal site is accomplished using trucking companies that are licensed to transport special materials. The volume of these materials to be transported and the number of shipments required are estimated in Appendix $\mathrm{H}$, and costs are summarized in Table H.2-5.

\subsubsection{Waste Management}

Radioactive wastes generated during DECON must be packaged and shipped to a low-level waste burial ground. The radioactive wastes generated include: process and facility equipment and components, pipe, concrete rubble, filters, trash, decontamination liquids, miscellaneous waste buried onsite, and sludge and material from the waste lagoons.

About $1260 \mathrm{~m}^{3}$ of the radioactive waste from the main process building and the solvent extraction building is assumed to be packaged and shipped to low-level waste burial. About $1870 \mathrm{~m}^{3}$ of equipment from the buildings and site are decontaminated and excessed or sent to commercial waste burial.

The solvent extraction lagoon waste $\left(21,600 \mathrm{~m}^{3}\right)$ is removed for offsite disposal and the fluoride lagoon waste $\left(5700 \mathrm{~m}^{3}\right)$ is either buried onsite or removed for disposal offsite. Handling of the lagoon wastes is discussed in Section 9.1.1.5.

Process and Facility Equipment and Piping. Equipment and piping from the process system and the facility is decontaminated and disassembled for shipment. The equipment is packaged in plywood boxes for disposal.

Concrete Rubble. Concrete rubble from decontamination of floors and walls in the main and solvent extraction buildings is packaged in plywood boxes for shipment to an LLW burial ground.

Filters. Roughing filters and HEPA filters from building air ventilation systems and temporary decommissioning tents are packaged for disposal in steel boxes.

Solidified Decontamination Liquids. Decontamination liquids are assumed to be processed by evaporation, in the temporary radwaste system, with the residues solidified with cement. Solidified decontamination liquids are packaged for disposal in $0.21-\mathrm{m}^{3}$ steel drums. 
Trash. Trash is essentially all other kinds of radioactive waste that is generated. It consists of contaminated equipment, tools, rags; wipes, etc. All trash is packaged for disposal in $0.21-\mathrm{m}^{3}$ steel drums.

\subsubsection{Lagoon Waste Management}

Sludges from the solvent waste extraction and fluoride lagoons must be disposed of for $\mathrm{UF}_{6}$ plant decommissioning. Several alternative methods of disposal for the lagoon wastes are available. These are: 1) onsite burial, 2) removal of waste to a uranium mill for recovery of residual uranium, 3) removal of waste to an LLW burial ground, and 4) removal of waste to a chemical or commercial waste dump.

Onsite Burial. The solvent extraction waste sludge has a uranium concentration of about $0.28 \mathrm{wt} \%$ uranium, which puts it at levels slightly higher than the levels in uranium mill tailings. For the DECON alternative, the extraction wastes must be removed from the site to allow unrestricted release.

The reference plant generates fluoride waste that is nearly insoluble and so low in radioactive material that it is barely distinguishable from ordinary waste containing naturally occurring radioactive materials. These wastes are assumed to be buried onsite for the DECON alternative.

Removal of Waste to a Uranium Mill. For the reference plant, the extraction waste $\left(21,600 \mathrm{~m}^{3}\right)$ is assumed to be processed by a milling contractor to recover the residual uranium. The uranium concentration in the extraction waste for the reference plant is about $0.28 \%$, which is about the level of uranium concentrates in ore being currently mined.

The decision to recover the uranium would be based on an economic study to determine whether the cost of shipping and recovery less the value of the recovered uranium would be less than the cost of burial. Based on current prices for uranium and the inflationary trends in yellowcake cost, it is expected that the economic value of the recovered uranium would make it cost effective to process the extraction waste.

The fluoride waste does not contain sufficient uranium to warrant recovery and that option is not included in this analysis. 
Removal of Waste to an LLW Burial Ground. If the extraction waste is not processed to remove the residual uranium, it would have to be disposed of at a low-level waste burial ground at the time of decommissioning. The waste material would be loaded into plywood boxes and shipped to the nearest LLW disposal site.

If fluoride waste cannot be stored onsite it would be shipped to LLW burial. The waste would be shipped in plastic-lined, $10-\mathrm{m}^{3}$ dump trucks to the nearest LLW burial ground.

Removal of Waste to a Commercial Waste Dump. A potential alternative to low-level waste disposal of the extraction waste would be reduction of the residual activity levels by dilution and storage onsite or shipment to a chemical or commercial waste dump. There is presently no clear definition of what constitutes acceptable levels of uranium in bulk waste.

Several proposals and requests for acceptable values for contamination in bulk materials $\left(\mathrm{CaF}_{2}, \mathrm{NO}_{3}\right.$ waste) have been made to the NRC, but no specific regulation has yet been developed. Permission has been given in specific cases to discharge to the environment 1 iquid from $\mathrm{CaF}_{2}$ and $\mathrm{NO}_{3}$ wastes containing low levels (2 to $5 \mathrm{ppm})$ of uranium. $(\mathrm{a}, \mathrm{b}, \mathrm{c})$ However, no general limit exists as, for example, in transportation regulations (.49 CFR 173.389), where radioactive material is defined as "material in which the estimated specific activity is greater than or equal to 0.002 microcuries per gram." (d)

Lacking a definitive regulatory lower limit value for uranium in solid waste, for this report, estimates of residual levels of uranium in the extraction waste that would permit disposal as nonradioactive waste are based on

(a) NRC License \#SNM 1097, Section 1.6.4 of Appendix A. (Genera7 Electric Co., Wilmington, NC, plant).

(b) Westinghouse Licensing Correspondence, DOCKET \#70-1151, August 10, 1979, letter to NRC.

(c) Kerr McGee Licensing Correspondence, Docket \#40-8027, March 3, 1978, 1etter to NRC.

(d) Westinghouse SNM License \#1107, Condition \#13 specifically prohibits use of the 49 CFR 173.389 cutoff level $(0.002 \mu \mathrm{Ci} / \mathrm{g})$ if the activity is a result of contamination with SNM. 
guidance developed in the National Environmental Studies Project report AIF/ NESP-016 "de minimis Concentrations of Radionuclides in Solid Wastes." (1) Based on a maximum total body dose of $1 \mathrm{mrem} / \mathrm{yr}$, the acceptable level of activity for natural uranium was found to be about 100 picocuries per gram of waste material. At $0.28 \%$ uranium content, the activity level of the extraction waste and uranium mixture would be about $920 \mathrm{pCi} / \mathrm{g}$ of waste material. Thus, a dilution factor of about 9 parts soil to 1 part extraction waste would be required to satisfy the limit based on Reference 1 . The residual uranium concentration in the waste that corresponds to this lower 1 imit would be about $310 \mathrm{ppm}$, compared to $2800 \mathrm{ppm}$ for the waste stored at the reference $\mathrm{UF}_{6}$ conversion plant.

Since the uranium concentration is low, burial of fluoride waste in a commercial waste dump would be governed by regulations of the state in which the $\mathrm{UF}_{6}$ plant is located. The question of chemical or cormercial waste burial of extraction and fluoride wastes would also be determined by the regulations of the state where the $U_{6}$ conversion plant is located.

\subsubsection{Final Release Survey}

The final task is to perform a radiation and chemical survey of the $\mathrm{UF}_{6}$ plant, the auxiliary facilities, and the entire site. Any remaining spots of radioactivity and chemical contamination higher than the amount allowable for unrestricted use are removed and the contaminated materials are disposed of at a licensed low-level waste burial site.

This concludes the DECON responsibilities of the site owner. The NRC then audits the project and sponsors an overcheck survey. In the event of a discrepancy, the owner provides the necessary corrective action.

The NRC then terminates the nuclear license, releases the site for unrestricted use, and discontinues their surveillance and responsibilities at the site. The owner is then free to use the site for unrestricted applications.

\subsubsection{Essential Systems and Services}

Some of the facility systems and services must remain in place until all radioactive and/or contaminated materials are removed from the site to 
ensure that no significant amounts of radioactive or hazardous materials are released to the environs. In addition, some of the systems are needed to facilitate the cleanup and disassembly efforts. As areas within the facility are readied for unrestricted use, the extensions of services into those areas are deactivated and removed, while maintaining continuity of the services to the remaining work areas. The required support systems, together with the justification for retaining each system, are listed in Table 9.1-1.

\section{TABLE 9.1-1. Systems and Services Required During DECON}

Systems or Components

Electrical power, including emergency diesel backup system

HVAC Systems

Environmental Surveillance and Safeguards Program

Water Supply (service and domestic systems)

Fire Protection System (direction and suppression)

Compressed Air Systems (control and suppression)

In-Plant Communications Systems (telephones and intercoms)

Radiation Monitoring Systems

Solid and Liquid Contaminated Waste Systems

Clean Scrap and Dirty Scrap Recovery Systems

Sewage Treatment Plant (septic tanks and sewage lagoon)

\section{Justification}

Required for HVAC, lighting and radiation monitoring

Required for ventilation and contamination confinement

Required to identify and quantify any releases of radioactivity to the environs from dismantlement activities and to identify and safeguard any significant quantities of uranium discovered during dismantlement

Required for decontamination, clean up, fire protection, and general potable water usage

Required for health and safety

Required for operation of pneumatic controls, for operation of pneumatically operated tools

Required to facilitate and coordinate activities

Required for protection of personnel

Required for treatment and disposal of potentially contaminated liquids and solids

Required for recovery of uranium from liquid, solid non-combustible, and incincerated wastes

Required for sewage treatment

Essentially the same environmental monitoring program carried on during plant operation is continued during the DECON period. This program is to identify and quantify any releases of radioactivity to the surrounding areas resulting from DECON activities. The proposed program, detailed in Section F.5 of Appendix F, is sufficient to permit evaluation of any significant releases. Additional short-term surveillance efforts may be added for emergency situations involving radionuclide releases from events such as fires or malicious acts that may necessitate prompt energency action. 


\section{1 .3 Security}

Protection of the public (often against the consequences of their own actions) is an important dimension of the security program throughout the decommissioning effort. Security during decommissioning is assumed in this study to be similar to, but less stringent than, that needed during plant production operations.

\subsection{DECOMMISSIONING BY PASSIVE SAFSTOR}

The goal of the passive SAFSTOR alternative is to achieve a condition that ensures that residual radioactivity is kept confined to the $\mathrm{UF}_{6}$ conversion plant site. Modifications to the facility are limited to those that ensure the security of the buildings and to those required to ensure containment of radioactive material. The passive SAFSTOR alternative allows deferral of the decision regarding final disposition until no further use is found for the plant. To achieve this goa1, the facility is left structurally sound. All loose contamination in readily accessible locations is removed. Hoods and equipment are vacuumed and handwiped. Access into contaminated areas is 1 imited. All systems and equipment not required to be in operation during the safe storage period of passive SAFSTOR are deactivated. The preparations for safe storage and the period of safe storage that follows should be recognized as only temporary stages in the total decommissioning process. Current NRC philosophy encourages a decommissioning approach that ends in the termination of the plant's nuclear license and the release of the property for unrestricted use within a finite period of time. Thus, decontamination to unrestricted levels is required eventually.

The major benefits gained from decommissioning the facility by the passive SAFSTOR alternative are: 1) postponement of final decommissioning activities, 2) possible reuse of the facility by the owner, if so desired, and 3) low initial outlay of funds.

The passive SAFSTOR period may vary from a few years to a few tens of years, depending on the needs and desires of the facility owner and the public safety risks. 
General work sequences and procedures for passive SAFSTOR are presented in this section. These sequences and procedures are developed under the assumption that the physical activities commence immediately following plant shutdown and final operational inventory cleanout operations. The program plan is discussed below.

\subsubsection{Program Plan}

The passive SAFSTOR alternative is divided into seven major phases:

- planning and preparation

- waste treatment facilities stabilization

- equipment deactivation

- isolation of contaminated areas

- final preparations for safe storage

- safe storage (security, surveillance, and maintenance)

- deferred decontamination or restartup of production.

The approximate schedule for these work phases is given in Figure 9.2-1. It is estimated that the planning and preparation will take about 6 months. About 3 months are required for physical decommissioning activities before the facility and site enters the period of safe storage. Safe storage consists primarily of security, surveillance, and maintenance. At the conclusion of safe storage the site undergoes deferred decontamination to prepare it for

ACTIVITIES

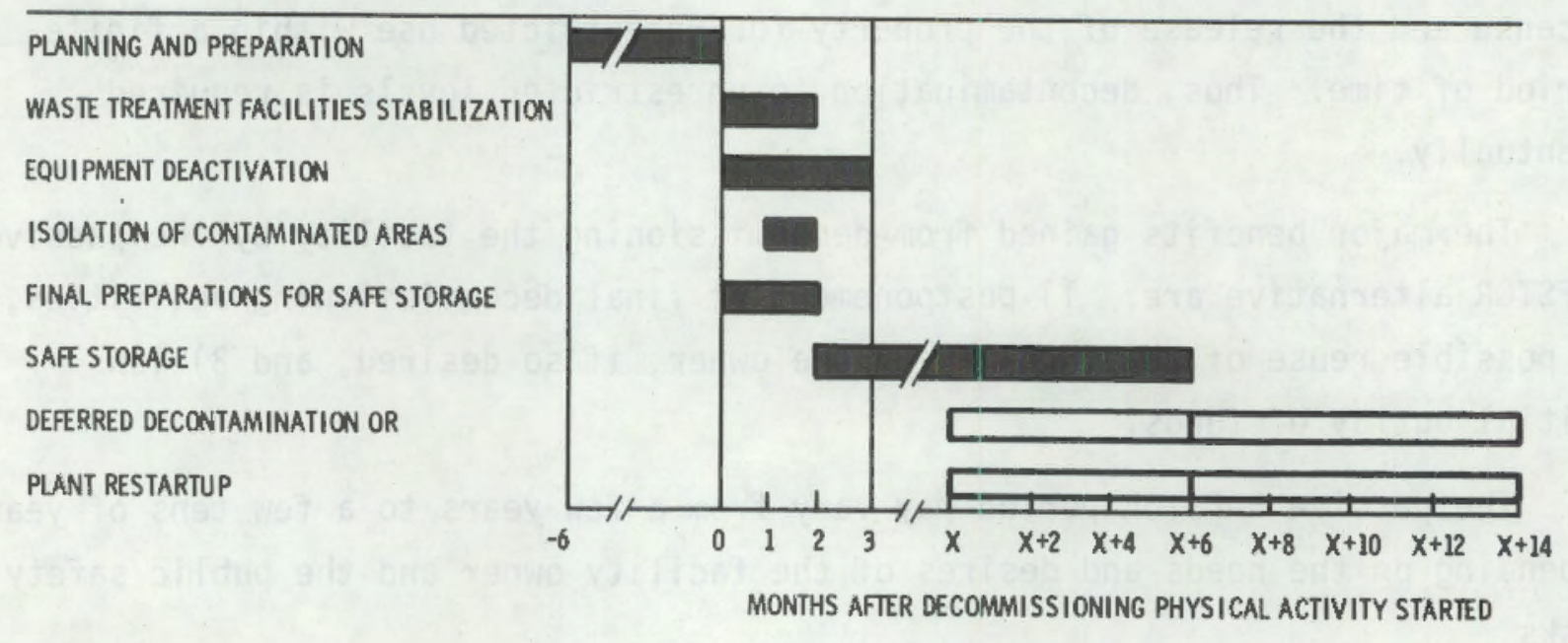

FIGURE 9.2-1. Sequence and Schedule for Major Activities for Passive SAFSTOR 
unrestricted use. An estimated 14 months are required to plan and prepare for and to perform deferred decontamination. An unlikely alternative is to restartup the plant for uranium fuel production. The time and work estimates assume reasonable success with a minimum of delays and/or major unanticipated problems.

Most of the time in this decomaissioning alternative is spent in safe storage. During that state, the plant condition is one where most of the transportable radioactivity is either removed or confined. The small amount of radioactivity remaining is spread thinly throughout the facility.

The areas listed in the passive SAFSTOR decommissioning plan are kept in the restricted-use category, as defined in Section 8 . The areas are in a condition amenable to security, surveillance, and maintenance, but generally unavailable for any other use. Access is 1 imited in accordance with the requirements of 10 CFR 20.103 and the provisions detailed in Section 9.2.1.6.

The onsite restricted areas assumed in this study include:

- the contaminated portions of the main building and the solvent extraction building

- the extraction waste and fluoride waste treatment facilities

- excess equipment storage yard

- uranium storage areas and cylinder storage areas.

Activities at the site during the safe storage period are limited primarily to: 1) operation of the building utility systems and fire prevention systems, 2) system maintenance, 3) building maintenance and radiation monitoring, 4) environmental radiation surveillance, and 5) security. The facility is patrolled by a security contractor on a periodic basis during the safe storage period. Periodic surveillance and maintenance of the facility structures and of passive safety and security-related systems are also required. The outerperimeter site fence is maintained and no unauthorized entry is permitted. Detailed accounts of the decomissioning operations are stored at the facility and made a part of the public record. These accounts are required for use when final decontamination of the facility is performed. 
Discussions of the seven major work phases of passive SAFSTOR are given in the following subsections.

\subsubsection{Planning and Preparation}

The planning and preparation activities for passive SAFSTOR are carried out concurrently within the final 6 months of facility operation. Figure 9.2-2 shows the time sequence for the planning and preparation phase of decommissioning for passive SAFSTOR. Work begins in the engineering and operations departments of the company organization to prepare the analyses and documentation needed to amend the operating license following final plant shutdown.

ACTIVITIES

PREPARE DATA FOR ENVIRONMENTAL IMPACT STATEMENT

PREPARE DECOMMISSIONING PLAN FOR NRC

NRC REVIEW, DECOMMISSIONING LICENSE ISSUED

PREPARE DETAILED WORK PLANS AND PROCEDURES

DESIGN, PROCURE AND TEST SPECIAL EQUIPMENT

SELECT AND TRA IN STAFF

SELECT SPECIALTY CONTRACTORS

FINAL INVENTORY CLEANOUT

(NOT CHARGED TO DECOMMISSIONING)

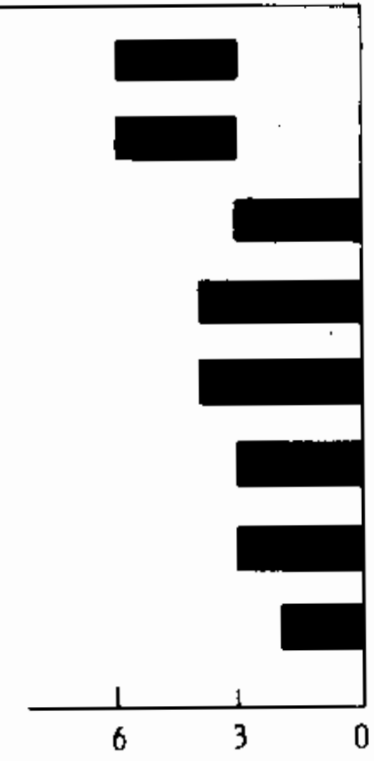

MONTHS BEFORE DECOMMISSIONING

PHYSICAL ACTIVITY BEGINS

FIGURE 9.2-2. Sequence and Schedule of the Planning and Preparation Phase of Passive SAFSTOR

The initial steps include gathering data for the environmental impact assessment and the technical specification revisions. The data are used in the submittal of a decomissioning plan for NRC review and approval. 
The decommissioning plan submitted to the NRC includes the following types of information:

- facility current status description

- general description of the overall plan

- description of measures taken to contain radioactivity

- proposed changes to the technical specifications

- necessary disassembly/retirement activities to be performed

- safety analysis of activities

- inventory of radioactive materials and their location in the facility

- security plan for total decommissioning program.

As stated earlier, a review of regulations and guides applicable to decommissioning is given in Section 5 .

Detailed work plans and procedures are prepared to accomplish the physical activities in the most efficient and safe manner. Work is divided into easily manageable tasks. Available decommissioning techniques are reviewed and decisions are made on the general techniques to be used to accomplish each task. Detailed procedures are developed, including those for the inventory cleanup of the facility. Equipment and material requirements, manpower estimates, cost estimates, and work schedules are prepared. The plan is documented in detail, safety analysis reports are prepared, and all necessary documents are submitted for approval of plant management and appropriate regulating agencies.

Design, procurement, and testing of any special devices and equipment needed for decommissioning is also accomplished. This will assure that work can proceed without undue delay after plant shutdown.

A decommissioning organization within the company is initiated, with the structure and staffing requirements identified, and commitments are obtained from key engineering and operating personnel to fill strategic positions. Orientation and training of personnel identified as members of the decommissioning staff are carried on during the final 2 months of plant operation. The decommissioning staff draws on their own experience, as well as on the experience of the operations staff to assist in the planning activities. 
It is assumed that most of the planning and the actual decommissioning activities are performed by plant operating and maintenance personnel. The various specialty contractors required for the decomissioning effort are selected during the final 2 months of plant operation.

Upon termination of routine plant production operations, an extensive final inventory cleanout and uranium audit are conducted. These cleanout/audit operations are similar, but slightly more extensive, than those conducted periodically to audit uranium content. Based on plant experience, clean-out operations are estimated to remove one-half of the residual uranium plant inventory. Because these cleanouts are done typically during plant production, they are also considered a part of normal plant operations in this study and are not charged to decommissioning. Details of the final inventory cleanout and uranium audit are found in Section G.I of Appendix G.

A variety of other activities are carried out as part of plant shutdown and inventory cleanout operations. These activities include: 1) reduction of inventories of process chemicals and nonessential materials and equipment, and 2) an engineering review of effluent control and safety systems necessary for deconmissioning.

Final preparatory steps to decomissioning are confirmation of radioactive materials inventories and a comprehensive survey of radiation dose rates at contaminated areas within the facility. These steps are taken immediately after uranium inventory cleanout and plant shutdown. In addition, a comprehensive radiation survey of the site is performed.

\subsubsection{Waste Treatment Facilities Stabilization}

The waste treatment lagoons for extraction waste and fluoride all require stabilization. These effluents contain uranium, which settles out in the lagoons. The extraction waste and fluoride lagoons are also drained and plastic covers with weights are placed over the remaining solids.

The remainder of the waste treatment systems is made up of pipes, pumps, valves, tanks, etc., that provide a closed system that contains any of the residual radioactivity left after being flush-rinsed several times. 


\subsubsection{Equipment Deactivation}

Essential safety systems (such as lighting, utilities, radiation detection alarms, security monitors, and fire detection and portable fire fighting equipment) remain in operation during the safe storage period. All other equipment and systems are placed in a condition that provides maximum safety with minimum maintenance. When possible, equipment is left in a condition that permits startup or salvage at a later date.

The first step in equipment deactivation is a safety audit of al1 pumps and pipes used for radioactive materials or chemicals to ensure that hazardous or corrosive materials are removed. Electrical service is disconnected from all pumps not required to be in operation during the safe storage period.

Deactivation and isolation techniques include closing and securing installed valves; sealing hoods; capping ventilation exhaust stacks; installing blank flanges; and disconnecting electrical power, compressed air, and other utilities. A safety audit of all systems is performed to ensure that all flammable and other potentially hazardous materials are removed. All deactivated equipment and systems are tagged for identification and status.

In general, all systems not necessary to prevent the spread of contamination are deactivated. (See Section 9.2.1.6 for systems retained.) All equipment, valves, circuit breakers, etc., are tagged when deactivated. These tags identify the piece of equipment, the system it is in, and its condition.

Systems inside the building are deactivated by a variety of methods. Many piping systems are isolated using the installed valves, with handles or valve operators removed. Pipes that lead from uncontaminated to contaminated zones are blanked where flanges are readily accessible. Some uncontaminated systems are drained and left open to the atmosphere. All cranes are disabled by removal of their circuit breakers to prevent their unauthorized use during the safe storage period. Other electrical equipment that should not be operated during the safe storage period is disabled in a similar manner. Electrical service is disconnected from instrumentation not required to be in operation during the safe storage period. 


\subsubsection{Isolation of Contaminated Areas}

Portions of the $\mathrm{UF}_{6}$ conversion plant containing uranium contamination are isolated by the installation of high-security locks on entryways. Indirect access routes, however unlikely, are investigated from as-built drawings and secured. Such routes may include (but are not 1 imited to) access through ventilation ductwork, roof plugs, or pipe trenches. Temporary barriers are constructed to block potential pathways for unauthorized entry. Warning signs are posted. The same steps are taken for the incinerator and waste treatment facilities. Fences around the waste treatment lagoons and storage areas are also secured, and posted with warning signs.

\subsubsection{Final Preparations for the Safe Storage Period of Passive SAFSTOR}

Final preparations for safe storage are:

- installing and/or upgrading monitoring systems and radiation alarms

- installing or relocating intrusion alarms

- performing a comprehensive radiation survey of both the restricted and unrestricted areas at the site; spots of excessive contamination in the unrestricted areas are decontaminated

- shipping all recovered uranium materials offsite for disposition

- training of personnel and contractors employed during the storage period

- conducting final survey.

\subsubsection{Safe Storage Period of Passive SAFSTOR}

Activities at the site during the safe storage period are limited primarily to services operations, security, building and equipment maintenance, radiation monitoring, and environmental radiation surveillance. The facility is not manned on a continuous basis after being placed in safe storage. Periodic surveillance and maintenance of the facility structures and of active and passive safety and security-related systems are required. The outer perimeter site fence is maintained and no unauthorized entry is permitted. Detailed accounts of the decommissioning operations are stored at the facility and made a part of the public record. These accounts are required for use when final decontamination of the facility is performed. 
Surveillance and Maintenance Activities. The surveillance and maintenance programs are structured so that personnel inspect various portions of the facility on a routine basis. Radiation monitoring is done at each preestablished surveillance point at least monthly. These checks are staggered so that the monitoring takes place on different days of each month. Preventive maintenance activities and routine equipment inspections are also distributed throughout the safe storage period. Warning signs and physical barriers are inspected routinely and repaired as necessary. Electrical distribution systems, fire alarms, and radiation and intrusion alarms are operated and monitored continuously by an offsite contractor. Routine inspections of these systems, which were performed by outside experts during plant operation, continue on a reduced frequency during safe storage.

Environmental Surveillance Activities. A somewhat abbreviated version of the environmental monitoring program conducted during plant operation is carried out during the safe storage period; this is to identify and quantify any releases of radioactivity to the environment. This surveillance program is adequate for evaluating most potential nonroutine or accidental releases. For situations involving releases from events such as fire or malicious acts that may require prompt emergency actions to minimize public risk, special surveillance requirements are added. This program is discussed in more detail in Section F.5 of Appendix F.

Security Activities. The protection of the public, principally against the consequences of their own actions, is an important dimension of the security program used for the safe storage period. Conventional security detection and notification systems normally used to protect the plant owner against loss or damage are augmented by audible alarms. These alarms, strategically located outside secured radiation zones, loudly warn an intruder of his potential danger. Silent sensors simultaneously alert offsite security personnel.

Routine patrol checks are carried out by offsite guards. A reputable private security agency is contracted to ensure adequate surveillance and prompt response to alarms. Liaison with local law enforcement agencies is maintained and their assistance is called for when necessary. 
Security is provided during the safe storage period by two basic methods: offsite guards and security systems. Locks on the fence around the decomissioned facility provide the first line of security. The fence is maintained in good condition throughout the surveillance and maintenance period. Facility security is maintained at all times by intrusion alarms and high-security locks on exterior doors. Intrusion, fire, and radiation alarms are monitored continuously by an offsite security firm. Depending on the situation indicated by the alarms, offsite security agency personnel are available to respond immediately.

Physical security to prevent inadvertent radiation exposure of surveillance and maintenance personnel is provided by locked barriers, which make it extremely difficult for unauthorized access to areas where radiation or contamination is present.

The facility manager is responsible for controlling authorized access into and movement within the facility. The facility manager is further charged with the responsibilities of appropriate actions and notifications regarding breaches of security, upkeep of plant surveillance, and maintenance programs. He is also charged with administrative reporting of these events, as required by state and federal regulations. He is responsible for health physics work, uranium accountability, and record keeping.

Essential Systems and Services. The support systems requiring surveillance and maintenance during the safe storage period are 1 isted in Table 9.2-1. These systems remain in operation throughout the safe storage period. These systems, in combination with inherent facility structural integrity, provide the primary means for minimizing the release of hazardous material to the environment. The equipment in these systems is inspected and renovated to ensure adequate equipment reliability before the surveillance and maintenance period begins. In addition, the intrusion alarm system within the facility and on the perimeter fence are both modified to provide offshift surveillance capability by a commercial security agency. 
TABLE 9.2-1. Systems and Services Required During the Safe Storage Period of Passive SAFSTOR

Systems or Components

Electric power

Fire Protection System

(detection and suppression)

In-Plant Commication Systems

Radiation Monitoring Systems

Security Systems
Justification

Normal and emergency power are maintained for: radiation monitoring systems and alarms, lighting circuits, fire protection systems and alarms, and surveillance monitoring systems and alarms. Switchboards are aligned so that no electrical power is fed to deactivated systems.

Portable fire extinguishers remain at selected locations and fire detection systems remain in operation as required for safety.

Required for normal communication.

Radiation monitors and alarms remain in operation at strategic locations throughout the facility sections. The locations of some devices may be installed to ensure that important areas are adequately covered. Selected monitoring programs are also continued.

Security devices and alarms (provided with both normal and backup emergency power) are maintained by a security agency subcontractor. In addition to intrusion system monitoring and maintenance, it is postulated that the security agency responds appropriately to intrusions.

\subsubsection{Deferred Decontamination}

The deferred decontamination phase is essentially the same as the DECON decomissioning case discussed in Section 9.7 .

As defined in Section 4, deferred decontamination is the final stage of decomissioning when passive SAFSTOR is utilized. The facility and site must be shown to have residual radioactivity levels sufficiently low to permit unrestricted use when decontamination is complete.

The same basic operations are performed during deferred decontamination as were performed during DECON. The primary decontamination done for the safe 
storage period does not need repeating. A small amount of additional manual decontamination and cleanup effort is performed to collect loose smearable contamination that may have moved during the safe storage period. Some sealed areas need to be unsealed. The same disassembly techniques and contamination control methods employed during DECON are required.

It is anticipated that a new staff is needed for deferred decontamination. The hiring could be done by the facility operator or the decommissioning contractor. Extensive training and familiarization of this staff with the facility is necessary, because of dispersal of personnel from the operations staff during the extended period of safe storage. Additional effort is required to restore some services needed for decontamination and to remove the various enclosures, doors, locks, and temporary barricades used to secure the facility from unauthorized entry during safe storage.

In view of these considerations, it is reasonable to assume that a work force of about the same size as was used for DECDN is required for deferred decontamination and over approximately the same period. Essentially, the same volumes of contaminated and uncontaminated materials must be removed and transported to an authorized burial site, except for those materials removed during decontamination for safe storage. The items that increase the costs of deferred decontamination with respect to DECON are the labor costs associated with training a decommissioning staff, removing covers from the lagoons, and restoring services needed for decontamination.

The program plan outlined for DECON in Section 9.1 is assumed to be valid for deferred decontamination, except in the planning and preparation phase. Portions of the environmental impact assessment and technical specifications have to be revised. The final inventory cleanout need not be repeated. Other elements in the planning and preparation phase (Figure 9.1-2) are likely to take slightly more manpower and time due to lack of experienced personnel.

\subsection{DECOMMISSIONING BY DECON OF THE PLANT AND EQUIPMENT WITH ONSITE DISPOSAL OF LAGOON WASTES}

DECON of the plant and equipment is covered in Section 9.1. Decommissioning activities for onsite disposal of the lagoon wastes is sunmarized in this section. Details of onsite disposal are contained in Section G.4 of Appendix G. 
Decommissioning of the lagoon wastes begins with planning and preparation activities that include a radiological survey to determine the radiological condition of the waste lagoons. The site survey includes measurements of ganma radiation levels, measurements of the rate of radon emanation from the pile, and the analysis of soil samples.

For stabilization of the lagoon wastes, the following procedures are assumed. The lagoon is covered with a 50-nm-thick layer of asphalt. This asphalt layer is then covered with $1 \mathrm{~m}$ of soil. The soil is mounded slightly at the center of the lagoon to allow water to drain from the soil cover and to prevent the accumulation of runoff from rainfall or snow melt. After compaction and contouring of the soil cover, the area is seeded with grass. 


\section{REFERENCES}

1. W. A. Rodger, et al., "de minimus" Concentrations of Radionuclides in Solid Wastes, National Environmenta1 Studies Project, AIF/NESP-016, Atomic Industrial Forum, Washington, DC, April 1978. 


\subsection{DECOMMISSIONING COSTS}

This section presents estimates of the costs for decommissioning the reference uranium hexafluoride conversion $\left(U_{6} F_{6}\right.$ plant. Cost estimates are made for DECON, for passive SAFSTOR including preparations for safe storage, safe storage, and deferred decontamination and for DECON of the plant buildings with onsite burial of the lagoon wastes. The costs are based on decommissioning procedures developed in detail in Appendix $G$ and summarized in Section 9. Costs are included for direct support and decommissioning worker labor, equipment and materials, contaminated waste packaging, transportation and disposal, utilities and other miscellaneous owner expenses, and specialty contractors. All costs are in 1981 dollars.

The basic cost estimates presented in this section assume relatively efficient performance of the decormissioning activities. A $25 \%$ contingency is added to the cost estimate totals as an allowance for unforeseen problems or scheduling delays that may arise during the decommissioning. The total costs presented are believed to be representative of actual expenses that would be incurred to decommission the reference facility using the methods described in this report.

\subsection{COST ESTIMATES FOR DECON}

The estimated costs for DECON of the reference plant are summarized in Table 10.1-1. DECON is estimated to require about 8 months (plus 6 months for planning and preparation) at a cost of approximately $\$ 5.91$ million. If disposal of lagoon waste at a commercial low-level waste (LLW) burial ground is necessary, the cost is estimated to be about $\$ 21$ million.

Manpower costs include both support staff and decommissioning workers and represent about $57 \%$ of the total cost of DECON. In Table 10.1-1, manpower costs are shown separately for the planning and preparation and the decommissioning phases of DECON. These costs include onsite labor for packaging radioactive waste materials for shipment. Labor costs related to radioactive waste transportation are included in waste management costs. 
TABLE 10.1-1. Summary of Estimated DECON Costs

Cost Category. Cost in Millions of 1981 Dollars $(a)$

$\begin{array}{ll}\text { Manpower } & \\ \text { Planning and Preparation } & 0.304 \\ \text { Oecommissioning } & 1.749 \\ \text { Equipment and Supplies } & 0.149 \\ \text { Oisposal of Radioactive Material } & 0.509 \\ \text { Miscellaneous Owner Expense } & \underline{0.740} \\ \text { Subtotal } & 3.451\end{array}$

\begin{tabular}{|c|c|c|c|}
\hline Lagoon Waste Management Options & $\begin{array}{l}\text { Ship to } \\
\text { Mi] } 1\end{array}$ & $\begin{array}{c}\text { Ship to } \\
\text { LLW } \\
\text { Burial Ground }\end{array}$ & $\begin{array}{c}\text { Ship to } \\
\text { Commercial Dump } \\
\end{array}$ \\
\hline Extraction Waste & 1.219 & 10.011 & $1.219^{(b)}$ \\
\hline Fluoride Waste & $0.055^{(c)}$ & 3.301 & 1.071 \\
\hline Subtotal (includes lagoon waste) & 4.725 & 16.763 & 5.681 \\
\hline $25 \%$ Contingency & 1.181 & 4.191 & 1.420 \\
\hline Total Costs & 5.906 & 20.954 & 7.101 \\
\hline
\end{tabular}

(a) Number of figures shown is for computational accuracy and does not imply precision to the nearest thousand dollars.

(b) Not feasible to ship extraction waste to commercial dump. Cost is for extraction waste shipped to mill.

(c) Not feasible to ship fluoride waste to mill. Cost is for fluoride waste buried onsite.

Waste management accounts for about $38 \%$ of the $\$ 5.91 \mathrm{million}$ cost of DECON. Waste management costs include shipping container costs, transportation charges, and fees for waste disposal at a commercial LLW burial ground.

\subsubsection{Manpower Requirements and Costs for OECON}

Estimates are made for the work force required to plan and execute the decommissioning activities for DECON described in Section 9.1. These work force estimates are used, together with the unit manpower costs given in Section H.l of Appendix $H$, to estimate DECON manpower costs. The bases for these manpower estimates and the results in terms of decommissioning manpower costs are described in this section. 


\subsubsection{Manpower Requirements}

The decominissioning work force organizational chart for DECON is shown in Figure 10.1-1. The work force is described in two parts: 1) the decommissioning support staff that $\mathrm{plans,}$, supervises and provides support for the

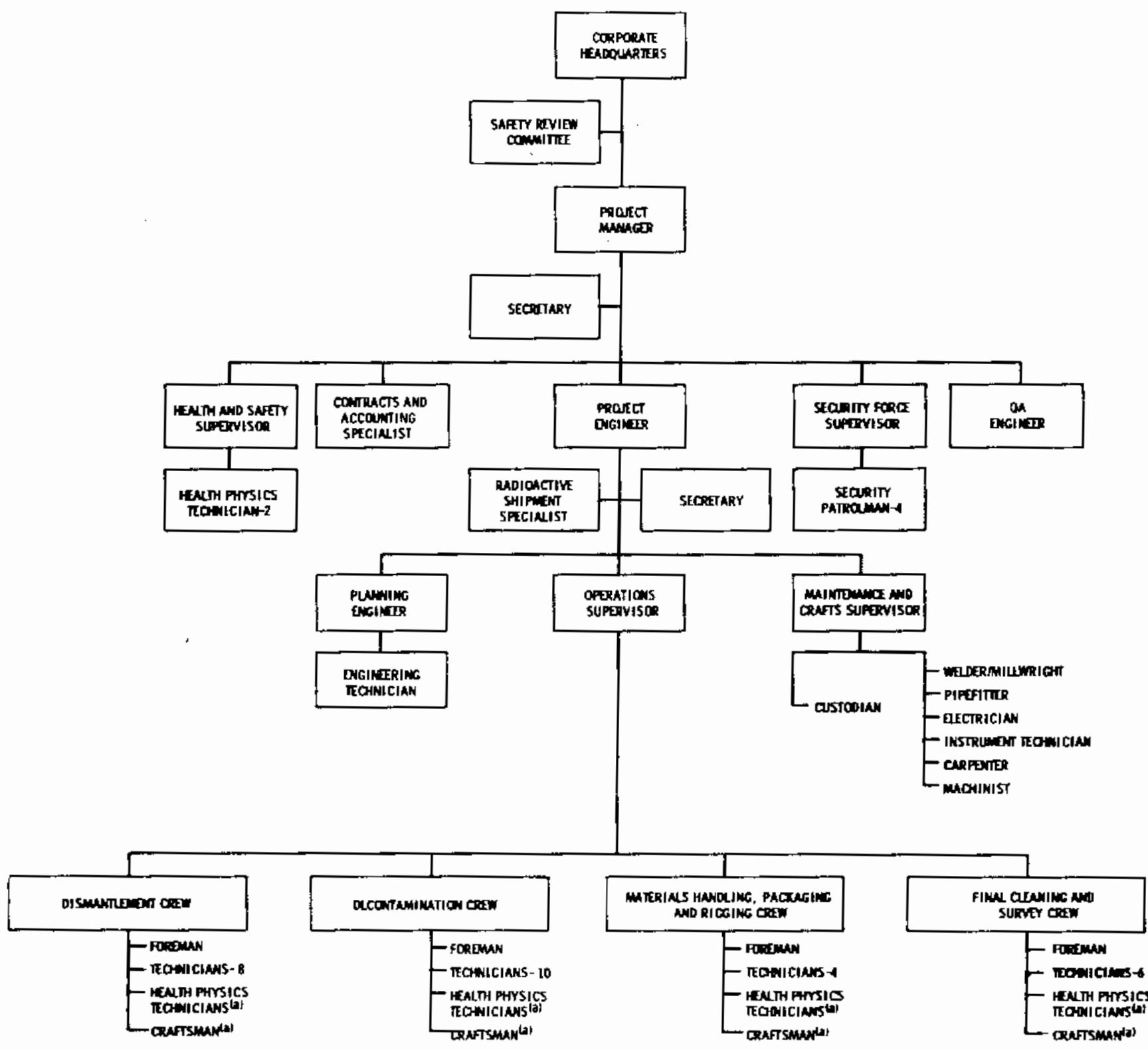

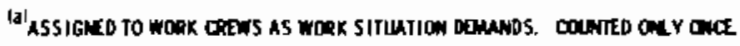

FIGURE 10.1-1. Postulated Organization Chart for DECON 
decomissioning activities, and 2) the decomissioning workers who perform the actual decomissioning activities. The seven general types of functions performed during decommissioning are described briefly below:

- Project Management - prepare and implement the decommissioning plan in a safe and cost-effective manner.

- Quality Assurance (QA) - develop the QA plan and monitor the safety and performance of the decommissioning activities.

- Decommissioning Operations - develop the decommissioning plan and carry out the actual decommissioning activities.

- Plant Operations and Maintenance - operate and maintain plant equipment that must be operated during the decommissioning.

- Safety Protection - develop methods to assure the safety of the public and decormissioning workers.

- Security - provide protection for the site and facility against unauthorized entry.

- Support Services - providing accounting, procurement and stores, secretarial and clerical services in support of the decormissioning activities.

Decommissioning operations are carried out by crews that consist of a foreman, four to twelve decomissioning technicians, and health physics technicians and craftsmen who are added to the crews as the work situation demands.

A key assumption in estimating the manpower and time for the basic events is that the decommissioning work force is composed primarily of former plant operating and maintenance personnel. The decommissioning workers are, therefore, familiar with plant facilities and equipment and experienced with radiation work procedures. The duties and experience of the members of the basic decommissioning crew are outlined below.

Foreman. This person supervises the performance of all decommissioning activities. He coordinates with the engineering staff through the operations supervisor to plan and execute each day's activities. He assembles the crew 
and equipment required to perform these activities and instructs the crew on procedures and safety precautions to be followed. The foreman is assumed to perform some of the actual decommissioning activities as well as supervise other members of his crew. It is anticipated that the foreman would have been employed in a position comparable to a process shift supervisor or maintenance supervisor during plant operations, so that he has detailed knowledge of plant systems and equipment.

Decommissioning Technicians. These people perform the bulk of the actual decommissioning operations. They are assumed to possess a variety of skills either through past experience in the plant or through specialized training prior to or during the decommissioning. The technicians are assumed to be employed in positions comparable to process operators, maintenance technicians or mechanical technicians during plant operations. It is anticipated that they would be qualified in several craft disciplines, including operation of much of the plant equipment.

Health Physics Technician. This person is assigned to the work crews as the work situation demands to provide instruction in radiation and industrial safety precautions to be followed for each task and to monitor compliance with written radiation work procedures for the task. He performs on-the-job radiation measurements and has the authority to stop work on the job if any potentially unsafe situation arises.

Craftsmen. These are people who are added to the basic crew to carry out particular tasks that require assistance of a/an:

- welder

- pipefitter

- carpenter

- electrician

- instrument technician

- miliwright

- machinist. 
The decommissioning staff is assembled during the planning and preparation phase. Initial management staff consists of the project manager, project engineer, quality assurance supervisor, and operations supervisor. Other staff personnel are added as their services are required during the planning and preparation phase. Planning and preparation activities take place during the final 6 months of plant operation. Therefore, support activities such as plant maintenance and plant security are available as part of plant operations and are not charged to decommissioning during the planning and preparation phase.

The decommissioning staff is generally sized and structured on a 1-shift, 5-day week. Certain operations such as security are carried out on a 4-shift, 7-day week. Decommissioning activities require that workers wear protective clothing, and in some cases, respiratory protection. Because of the inconveniences of the physical environment in which decommissioning tasks are carried out, manpower requirements are developed on the basis of an assumed worker time efficiency of $75 \%$. Ouring the approximately 8 -month period of dismantlement and decontamination, the staff size is estimated to remain approximately constant.

\subsubsection{Manpower Costs}

Table 10.1-2 shows manpower and associated cost estimates for the planning and preparation phase of DECON and Table 10.1-3 shows manpower requirements and costs for the dismantlement and decontamination phase of OECON. A total of about 6 man-years is estimated to be required for planning and preparations, at a labor cost of about $\$ 304,000$. A total of about 43 man-years is estimated to be required to decontaminate and remove contaminated materials from the facility, at a labor cost of about $\$ 1.75$ million. The total labor cost for DECON is estimated to be about \$2.1 miltion without contingencies. Manpower costs shown in Table 10.1-3 include labor costs for packaging radioactive waste materials for shipment. These costs do not include specialty labor costs discussed in Section 10.1.3 for transportation and in Section 10.1.5 for other specialty contractors.

It is recognized that completion of decommissioning activities may take longer than the estimated times, resulting in higher labor costs. These cost 
TABLE 10.1-2. Summary of Manpower Utilization and Staff Costs for Planning and Preparation Phase of DECON

Title or Function

Man-Years $\begin{gathered}\text { Cost } \\ \text { (\$.thousands) }\end{gathered}$

Project Manager
Project Engineer
Health and Safety Supervisor
Contracts and Accounting Specialist
Radioactive Shipment Specialist

$0.65 \quad 58$

$0.50 \quad 38$

$0.20 \quad 12$

$0.50 \quad 24$

$0.20 \quad 8$

Q.A. Engineer

$0.50 \quad 24$

Planning Engineer

$0.50 \quad 26$

Engineering Technician $\quad 0.50 \quad 20$

Operations Supervisor $\quad 0.50 \quad 26$

Foreman $\quad 0.85 \quad 38$

Secretary $\underline{1.25} \quad \underline{30}$

$\begin{array}{ll}\text { Total Man-Years } & 6.15 \\ \text { Total Cost } & \end{array}$

(a) Number of figures shown is for computational accuracy and does not imply precision to the nearest thousand dollars.

(b) Contingency of $25 \%$ is not included.

TABLE 10.1-3. Sumary of Manpower Utilization and Staff costs for the Dismantlement and Decontamination Phase of DECON

Title or Function

Project Manager

Project Engineer

Heal th and Safety Supervisor

Health Physics Technician

Security Force Supervisor

Security Patrolman

Contracts and Accounting Specialist

Radioactive Shipment Specialist.

Q.A. Engineer

Planning Engineer

Engineering Technician

Maintenance and Crafts Supervisor

Custodian

Craftsman

Operations Supervisor

Foreman

Technician

Secretary

Total Man-Years

Total Cost
Man-Years (\$thousands) $(a, b)$

0.75

67

0.75

57

0.75

1. 25

45

0.75

38

42

$3.0 \quad 76$

$0.75 \quad 35$

$0.75 \quad 30$

$0.75 \quad 35$

$0.75 \quad 39$

$0.75 \quad 29$

$1.50 \quad 70$

$0.75 \quad 23$

$3.41 \quad 109$

$0.75 \quad 39$

$3.29 \quad 147$

$21.17 \quad 832$

$1.50 \quad 36$

43.37

1749

(a) Number of figures shown is for computational accuracy and does not imply precision to the nearest thousand dollars.

(b) Contingency of $25 \%$ is not included. 
increases may be offset by reducing the labor force after the most Tabor-intensive tasks are completed. Final deactivation and cleanup activities, for example, may be accomplished by a relatively small work force.

\subsubsection{Material and Equipment Requirements and Costs for DECON}

Estimates of material and equipment requirements and costs for DECON are shown in Table 10.1-4. Equipment requirements are based on decommissioning

TABLE 10.1-4. Estimated Material and Equipment Requirements and Costs for DECON

\begin{tabular}{|c|c|c|c|}
\hline Description & Quantity & $\begin{array}{c}\text { Estimated } \\
\text { Unit Cost } \\
(\$ \text { thousands) } \\
\end{array}$ & $\begin{array}{l}\text { Estimated } \\
\text { Total Cost } \\
(\$ \text { thousands) } \\
\end{array}$ \\
\hline Oxyacetylene Torch & 4 ea. & 1.0 & 4.0 \\
\hline Guillotine Pipe Saw & $2 \mathrm{ea}$. & 4.0 & 8.0 \\
\hline Tube Cutter & 2 ea. & 0.41 & 0.82 \\
\hline Ratcheting Pipe Cutter & 6 ea. & 0.07 & 0.42 \\
\hline Reciprocating Saw & 4 ea. & 0.80 & 3.2 \\
\hline Nibbler & 2 ea. & 1.0 & 2.0 \\
\hline High-Velocity Liquid Jet & l ea. & 6.9 & 6.9 \\
\hline Low-Yelocity Liquid Jet & 2 ed. & 2.8 & 5.6 \\
\hline Hydraulic Concrete Surface Spalling Device & 1 ea. & 5.0 & 5.0 \\
\hline Concrete Drill & 3 ea. & 0.28 & 0.84 \\
\hline Electric Pneumatic Hammer & 2 ea. & 0.70 & 1.4 \\
\hline Portable A-Frames & 2 ea. & 4.1 & 8.2 \\
\hline Portable Wash Sinks & 2 ea. & 2.8 & 5.6 \\
\hline Portable Spray Clean Booth & 1 ea. & 5.5 & 5.5 \\
\hline Portable Greenhouse Erection Kit & 1 ea. & 2.8 & 2.8 \\
\hline Portable Powered Brushes & 20 ea. & 0.21 & 4.2 \\
\hline HEPA Filter & 5 ea. & 0.20 & 1.0 \\
\hline Roughing Filter & $20 \mathrm{ea}$. & 0.10 & 2.0 \\
\hline Decontamínation Chemicals & & & 11.0 \\
\hline cleaning Supplies & & & 22.1 \\
\hline Expendable Tools & & & 11.0 \\
\hline Protective Clothing (including laundry) & & & 19.9 \\
\hline Office Supplies: Planning and Preparation & & 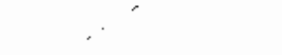 & 11.0 \\
\hline Decomissioning & & & 6.6 \\
\hline Total ${ }^{(b)}$ & & & 149.1 \\
\hline
\end{tabular}

(a) Number of figures shown is for computational accuracy and does not imply precision to the nearest thousand dollars.

(b) Total is shown as direct addition of prior numbers to retain calculational information. Precision is less than shown. Contingency of $25 \%$ is not included. 
procedures described in detail in Appendices $F$ and $G$ and summarized in Section 9.1. Costs of decontamination chemicals are calculated on the basis of quantities required for decontamination and unit costs given in Section H. 1 of Appendix $\mathrm{H}$. Cleaning supplies represent a major cost item and include assorted cleaning agents, rags, mops, brushes, plastic bags, plastic sheeting, etc. The cost of protective clothing includes the cost of laundering the clothing onsite and is estimated to be about $\$ 620$ per week. The total cost of material and equipment for DECON of the reference plant is estimated at about $\$ 149,000$ without contingency.

\subsubsection{Was te Management Requirements and Costs for OECON}

Waste management requirements and costs for DECON are described in this section. Estimates are made of quantities of radioactive wastes generated during OECON of the reference plant and of packaging, transportation and disposal requirements and costs for managing these wastes. These estimates are based on decontamination procedures described in Section 9.1 , and on unit waste management costs given in Appendix H.T.

\subsubsection{Waste Management Requirements}

Radioactive wastes generated during OECON must be properly packaged and shipped to an LLW burial site. Radioactive wastes generated during DECON include:

- contaminated process equipment, tanks, and piping;

- concrete rubble from the mechanical decontamination of contaminated floors and walls;

- HEPA and roughing filters;

- sections of ventilation ductwork;

- combustible and noncombustible trash (protective clothing, contaminated tools, rags, paper, plastic, metal scrap, etc.);

- sludge, liners, and soil from the waste lagoons.

All of the material that must be packaged for disposal will be contaminated with uranium. The equipment and material wastes are assumed to be disposed of 
at licensed LLW burial sites. Assumed waste shipping volumes for contaminated process equipment, tanks, piping, ducts, etc., postulated to require disposal at an LLW burial site are given in Table H.2-2 of Appendix H.

A11 shipments of decommissioning wastes are assumed to be made in compliance with federal, state and local regulations, as described in Section F.3.2 of Appendix F.

Table 10.1-5 gives estimated weights and volumes of decommissioning wastes from OECON of the reference plant, together with the type of packaging and the number of shipments required for these wastes. Detailed information about waste quantities is given in Section H.2 of Appendix $H$.

TABLE 10.1-5. Waste Disposal Packaging and Shipping Data for DECON

\begin{tabular}{|c|c|c|c|c|}
\hline Waste Category & $\begin{array}{c}\text { Shipping } \\
\text { Weight } \\
(\mathrm{kg})(\mathrm{d})\end{array}$ & $\begin{array}{l}\text { Shipping } \\
\text { Volume } \\
\left(\mathrm{m}^{3}\right) \text { (a) }\end{array}$ & Type of Container & $\begin{array}{r}\text { Numbe } \\
\text { of } \\
\text { Shipme }\end{array}$ \\
\hline Equipment and Components & 380000 & 855 & Plywood Boxes & \\
\hline $\begin{array}{l}\text { Pipe, Conduit, Duct, Trays, } \\
\text { Fixtures, etc. }\end{array}$ & 219200 & 195 & Plywood Boxes & \\
\hline Concrete Rubble & 64000 & 99 & Stee] Drums & \\
\hline $\begin{array}{l}\text { Disposal of Solid Waste } \\
\text { Buried Onsite }\end{array}$ & 48000 & 80 & Steel Drums & \\
\hline Miscellaneous & 17500 & 12 & Steel Drums & \\
\hline Micellaneous & 12000 & 18 & Plywood Boxes & \\
\hline Total LLW & 740700 & 1259 & & \\
\hline \multicolumn{5}{|l|}{ agoon Wastes } \\
\hline Extraction Waste & 37260000 & 22270 & $--(b)$ & 1840 \\
\hline Fluoride Waste & $18 \quad 200 \quad 000$ & 5700 & - (b) $^{\prime}$ & 552 \\
\hline Total Lagoon Waste & 55460000 & 27970 & & 239 \\
\hline
\end{tabular}

(a) Number of significant figures shown is for computational accuracy and does not imply precision to three or more significant figures.

(b) Lagoon waste packaging is covered in Section 10.1.3.3. 


\subsubsection{Waste Management Costs}

The estimated costs for containers, transportation, and disposal of the radioactive wastes from buildings and for miscellaneous waste buried onsite during operations for OECON of the reference plant are summarized in Table 10.1-6.

TABLE 10.1-6. Estimated Waste Management Costs for DECON

Waste Category

$\frac{\text { Costs in } 1981 \text { Dollars (a) }}{\text { Container }}$ Transportation Burial Total (b)

To Low-Level Waste Burial:

Equipment and Components

Pipe, Conduit, Duct, Trays,

23500

31560

262660

317700

Fixtures, etc.

5400

15780

59900

81100

Concrete Rubble

Disposal of Soljd, Waste

Buried Onsite (c)

14160

1) 430

Miscellaneous

Miscell aneous

Totais
1170

500

56700
8510

6580

1320

2430

66180
30410

24580

53100

42590

$3690 \quad 6700$

$5.530 \quad 8500$

$386770 \quad 509700$

(a) Number of figures is for computational accuracy and does not imply precison to three or more significant figures.

(b) Contingency of $25 \%$ is not included.

(c) This waste is exhumed onsite and shipped to LLW buriat.

Cost estimates are based on projected packaging and shipping data summarized in Table 10.1-5 and on waste management cost data in Section H.2 of Appendix H. Waste management cost details are also given in Section H.2. The waste management cost exclusive of lagoon wastes for OECON is estimated to be about $\$ 510,000$ without contingency. The cost of management for the lagoon wastes is covered in the following section on lagoon waste management costs.

About $1260 \mathrm{~m}^{3}$ of the total waste volume of $31,100 \mathrm{~m}^{3}$ is assumed to be shipped to LLW burial. The remainder is assumed to be decontaminated and sent to commercial waste disposal, buried onsite, or processed to recover residual uranium. 


\subsubsection{Lagoon Waste Management Costs}

The sludges from the solvent extraction waste lagoon and the fluoride lagoons must be disposed of as part of decommissioning. The alternatives are discussed in Section 9. Cost estimates for the alternatives are provided in this section in Table 10.1-7.

TABLE 10.7-7. Cost of Lagoon Waste Management Options for OECON

\begin{tabular}{|c|c|c|c|}
\hline \multirow[b]{2}{*}{ Method of Waste 0isposal } & \multicolumn{2}{|c|}{$\frac{\text { Cost in } 1981 \text { 0011ars }}{\text { Type of Waste }}$} & \multirow[b]{2}{*}{$\begin{array}{l}\text { Total } \\
\text { Cost }\end{array}$} \\
\hline & $\begin{array}{l}\text { Extraction } \\
\text { Waste }\end{array}$ & $\begin{array}{l}\text { Fluoride } \\
\text { Waste }\end{array}$ & \\
\hline $\begin{array}{l}\text { Ship to Uranium Mill for } \\
\text { Processing }\end{array}$ & $1218720^{(a)}$ & $54900^{(b)}$ & 1397700 \\
\hline Ship to LLW Burial Ground & 10011100 & 3301020 & 13312000 \\
\hline Ship to Commercial Waste Oump & $1218720^{(c)}$ & 1011340 & 2343540 \\
\hline
\end{tabular}

(a) Includes $\$ 270,600$ for contaminated soil and liner shipped to LLW burial ground.

(b) Not feasible to ship fluoride waste to mill; cost is for onsite burial.

(c) Not feasible to ship extraction waste to commerical dump; cost is for shipment to mill.

Solvent Extraction Waste Disposal Cost. Shipment of extraction waste to a uranium mi11 costs about $\$ 1,218,700$, including $\$ 270,600$ for shipment of liner and contaminated soil material to an LLW burial ground. It also includes a credit of $\$ 2,156,900$ for the value of the residual uranium, which is assumed to be $95 \%$ reclaimed at a value of $\$ 66$ per kilogram of uranium.

Shipment of extraction waste to an LLW burial ground is estimated to cost $\$ 10,011,100$. Shipment to a commercial waste dump would require that the extraction waste be mixed with soil at a ratio of 9 parts soil to 1 part waste. This results in a very large cost and is not considered to be viable.

Fluoride Waste Disposal cost. Fluoride waste disposed of by onsite burial is estimated to cost $\$ 65,500$. It is not feasible to ship the fluoride waste to 
a mill for reprocessing since the uranium content is very small. The cost of shipment of fluoride waste to an LLW burial ground is estimated to cost about $\$ 3,301,000$ and shipment to a commercial waste dump is estimated at $\$ 1,011,300$.

The waste disposal costs summarized in this section are specific to the reference plant and should not necessarily be considered representative of other UF 6 plants. Waste volumes generated at other UF 6 facilities may be different and waste disposal costs could be significantly different from those discussed in this section.

\subsubsection{Miscellaneous Owner Expenses for OECON}

Estimated miscellaneous owner expenses for OECON are given in Table 10.1-8.

TABLE 10.1-8. Estimated Miscellaneous Owner Expenses for DECON

\begin{tabular}{|c|c|}
\hline Cost Category & $\begin{array}{c}\text { Cost in Thousands } \\
\text { of }(a, b) \\
1981 \text { Dollars }\end{array}$ \\
\hline Utilities & 340 \\
\hline Taxes & 180 \\
\hline $\begin{array}{l}\text { Inspections and } \\
\text { License Amendments }\end{array}$ & 70 \\
\hline Insurance & 150 \\
\hline Total & 740 \\
\hline
\end{tabular}

(a) Number of figures shown is for computational accuracy and does not imply precision to the nearest thousand dollars.

(b) Contingency of $25 \%$ is not included.

The annual inspection fees for safety inspections at the operating $\mathrm{UF}_{6}$ plant is estimated to be $\$ 20,000$. (1) In addition, fees for license amendments for decommissioning could total $\$ 50,000$ or more. Thus, the license-related costs during the first year following shutdown of operations are estimated to be about $\$ 70,000$. 
The cost of nuclear liability insurance for a facility being decommissioned has also not been determined. An allowance of $\$ 150,000$ is included for the annual insurance premium for nuclear liabitity and conventional insurance.

\subsection{ESTIMATEO COSTS OF THE PREPARATIONS FOR SAFE STORAGE PERIOD OF PASSIVE SAFSTOR}

The estimated costs of preparing the reference plant for the safe storage period are summarized in Table 10.2-1. These decomnissioning activities are estimated to require about 6 months at a cost of approximately $\$ 881,000$.

TABLE 10.2-1. Summary of Estimated Costs of Preparations for Safe Storage

\begin{tabular}{|c|c|c|}
\hline Cost Category & $\begin{array}{l}\text { Cost in Thousand } \\
\text { of }(a, b) \\
1981 \text { Dollars }\end{array}$ & $\begin{array}{l}\text { Percent } \\
\text { of } \\
\text { Total } \\
\end{array}$ \\
\hline \multicolumn{3}{|l|}{ Manpower } \\
\hline Planning and Preparation & 169 & 24.0 \\
\hline Decommissioning & 205 & 29.1 \\
\hline Equipment and Supplies & 125 & 17.7 \\
\hline Disposal of Radioactive Material & 5 & 0.7 \\
\hline Misceilaneous Owner Expense & $\underline{201}$ & 28.5 \\
\hline Subtotal & 705 & 100.0 \\
\hline $25 \%$ Contingency & $\underline{176}$ & \\
\hline $\begin{array}{l}\text { Total Costs of Preparations for } \\
\text { Safe Storage }\end{array}$ & 881 & \\
\hline
\end{tabular}

(a) Number of figures shown is for computational accuracy and does not imply precision to the nearest thousand dollars.

Manpower represents about $53 \%$ of the total cost of preparations for safe storage. Manpower costs include both support staff and decommissioning worker labor. Breakdown of manpower costs are shown separately for planning and preparation activities and for decomrnissioning activities described Tater in the text. The annual costs of safe storage are described in Section 10.3. 


\subsubsection{Manpower Requirements and Costs of Preparations for Safe Storage}

Estimates are made of the work force required to plan and execute the preparations for safe storage described in Section 9.2. These work force estimates are used, together with the unit manpower costs given in Section H. 1 of Appendix $\mathrm{H}$, to estimate manpower costs. The bases for these manpower estimates and the results in terms of decommissioning manpower costs are described in this section.

\subsubsection{Manpower Requirements}

The organizational chart of the decommissioning work force for preparations for safe storage is shown in Figure 10.2-1. This work force includes the support staff that plans, supervises and provides support for decommissioning activities and the workers who perform the actual decommissioning activities. Job description details for key individuals in the decommissioning work force are given in Section H.2 of Appendix H.

The decommissioning staff is assembled during the planning and preparation phase that takes place during the final 6 months of plant operation. Initial management staff consists of the project manager, project engineer, quality assurance engineer and operations supervisor. Other staff personne 1 are added as their services are required during the planning and preparation phase.

Actual decomissioning activities require approximately 2 months following plant shutdown.

\subsubsection{Manpower Costs}

Table 10.2-2 shows manpower and associated cost estimates for the planning and preparation phase, and Table 10.2-3 shows support staff and worker manpower requirements and costs for the active decommissioning phase of preparations for safe storage. About 3 man-years are estimated to be required for planning and preparations, at a labor cost of about $\$ 169,000$. About 5 man-years are estimated to be required to deactivate the facility, at a labor cost about $\$ 205,000$. The total labor cost for placing the facility in safe storage is estimated to be about $\$ 374,000$ without contingencies. 


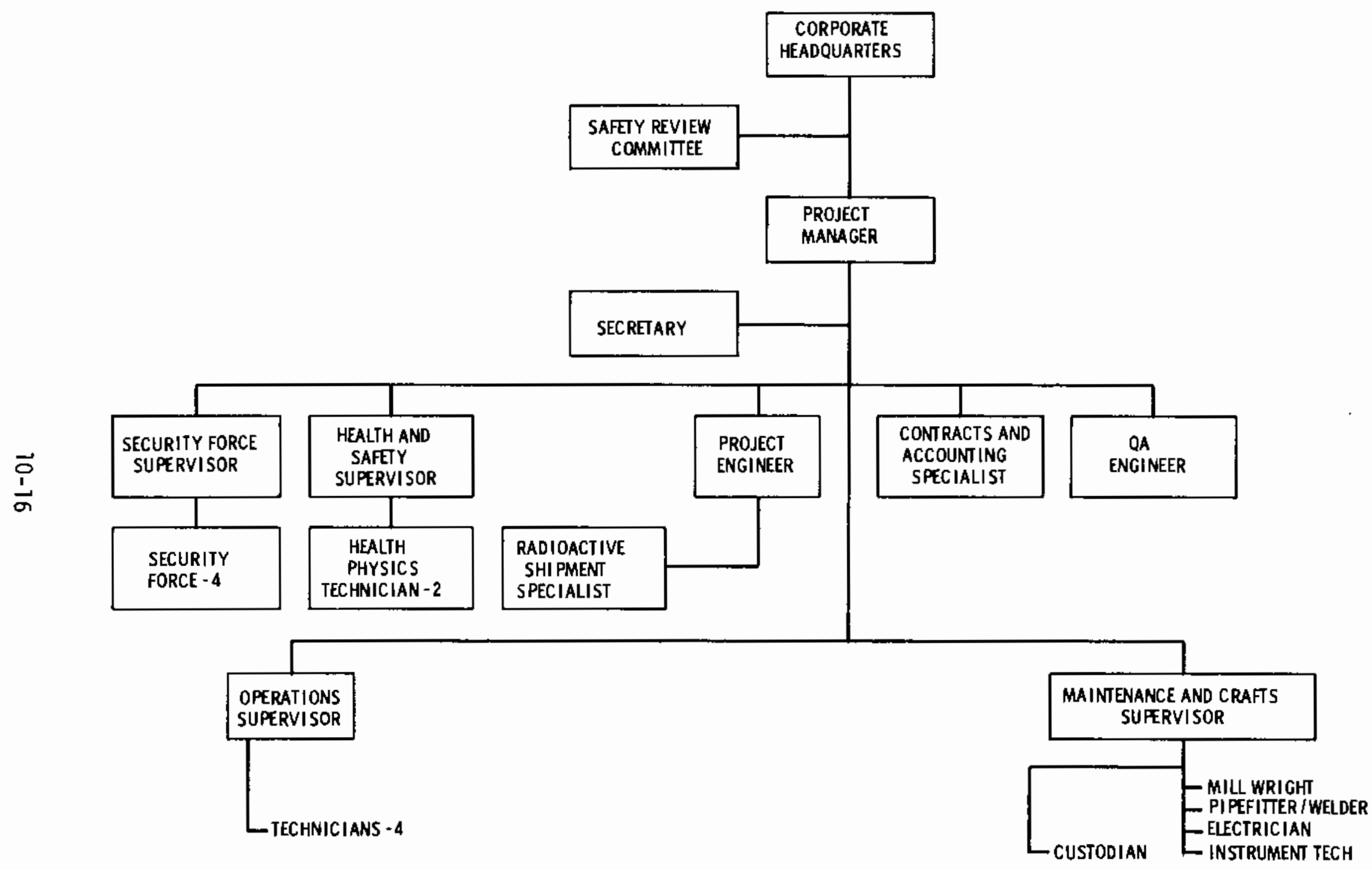

FIGURE 10.2-1. Postulated Organization Chart for Preparations for Safe Storage 
TABLE 10.2-2. Summary of Manpower Utilization and Staff Costs for Planning and Preparation Phase of SAFSTOR

\begin{tabular}{|c|c|c|}
\hline Title or Function & Man-Years & $\begin{array}{c}\cos t \\
\text { (s thousands) }\end{array}$ \\
\hline Project Manager & 0.50 & 45 \\
\hline Project Engineer & 0.50 & 38 \\
\hline Health and Safety Supervisor & 0.25 & 15 \\
\hline Contracts and Accounting Specialist & 0.25 & 12 \\
\hline Q.A. Engineer & 0.25 & 12 \\
\hline Radioactive Shipment Specialist & 0.25 & 10 \\
\hline Operations Supervisor & 0.25 & 13 \\
\hline Maintenance and Crafts Supervisor & 0.25 & 12 \\
\hline Secretary & $\underline{0.50}$ & 12 \\
\hline Total Man-Years & 3.00 & \\
\hline Total Cost & & 169 \\
\hline
\end{tabular}

(a) Number of figures shown is for computational accuracy and does not imply precision to the nearest thousand dollars.

(b) Contingency of $25 \%$ is not included.

\section{TABLE 10.2-3. Summary of Manpower Utilization and Staff Costs for Decommissioning Phase of SAFSTOR}

Title or Function

Project Manager
Project Engineer
Health and Safety Supervisor
Health Physics Technician
Security Force Supervisor
Security Patroiman
Contracts and Accounting Specialist
Q.A. Engineer
Radioactive Shipment Specialist
Maintenance and Crafts Supervisor
Custodian
Craftsman
Operations Supervisor
Technician
Secretary
Total Man-Years
Total Cost

Man-Years $\left(\begin{array}{c}\text { Cost } \\ \text { thousands })^{(a, b)}\end{array}\right.$

$0.25 \quad 22$

$0.25 \quad 19$

$0.25 \quad 15$

$0.35 \quad 11$

$0.25 \quad 14$

$0.07 \quad 2$

$0.25 \quad 12$

$0.35 \quad 16$

$0.17 \quad 7$

$0.25 \quad 12$

$0.17 \quad 5$

$0.67 \quad 22$

$0.25 \quad 13$

$0.75 \quad 29$

$\underline{0.25}$

4. 50

(a) Number of figures shown is for computational accuracy and does not Imply precision to the mearest thousand dollars.

(b) Contingency of $25 \%$ is not included. 
10.2.2 Estimated Material and Equipment Requirements and Costs of Preparations for Safe Storage

Estimates of material and equipment requirements and costs of preparing the reference plant for safe storage are shown in Table 10.2-4. Equipment requirements are based on decommissioning procedures described in detail in Appendices $F$ and $G$ and summarized in Section 9.2. The total cost of material and equipment for placing the reference plant in safe storage is estimated at about $\$ 125,000$ wi thout contingency.

\section{TABLE 10.2-4. Estimated Costs of Equipment and Supplies for Preparations for Safe Storage}

\begin{tabular}{|c|c|}
\hline Description & $\begin{array}{c}\text { Estimated } \\
\text { Total Cost } \\
(\mathrm{a}, \mathrm{b}) \\
\end{array}$ \\
\hline Decontamination Chemicals & 2.0 \\
\hline Cleaning Supplies & 2.5 \\
\hline Expendable Tools & 2.0 \\
\hline $\begin{array}{l}\text { Protective Clothing } \\
\text { (including laundry) }\end{array}$ & 4.0 \\
\hline Intrusion Alarm System & 100.0 \\
\hline Misceltaneous & 7.0 \\
\hline \multicolumn{2}{|l|}{ Office Supplies } \\
\hline Planning and Preparation & 5.0 \\
\hline Decommissioning & -3.0 \\
\hline Total & 125 \\
\hline
\end{tabular}

\subsubsection{Miscellaneous Owner Expenses for Preparations for Safe Storage}

Estimated miscellaneous owner expenses for preparing the reference plant for safe storage are shown in Table 10.2-5. These expenses are calculated on the same bases as were simitar expenses for DECON (see Section 10.1.4), except that the time period is only 2 months. 
TABLE 10.2-5. Estimated Miscellaneous Owner Expenses

During Preparations for Safe Storage

$\begin{array}{lc}\text { Utilities } & \begin{array}{c}\text { Cost in Thousands } \\ \text { of }\end{array} \text { (a,b) } \\ \text { Taxes } & 68 \\ \text { Regulatory Fees } & 30 \\ \text { Insurance } & 70 \\ \text { Total } & \frac{33}{201} \\ \text { (a) Number of figures is for computa- } \\ \text { tional accuracy and does not imply } \\ \text { precision to the nearest thousand } \\ \text { dollars. } \\ \text { (b) Contingency of } 25 \% \text { is not included. }\end{array}$

In estimating the applicable safety and safeguards inspection fees during preparations for safe storage, it is assumed that the full operating fees are paid, pius the fees for 1 icense amendments. These fees are assumed to be the same as for DECDN $(\$ 7 D, 000)$ during the first year. The annual insurance premium for nuclear liability and conventional insurance is assumed to be at the same rate as for DECON.

\subsection{COST ESTIMATES FOR THE SAFE STORAGE PERIOD OF PASSIVE SAFSTOR}

This section presents estimates of the annual manpower and material requirements and costs for the safe storage period of passive SAFSTOR.

Activities carried out at the plant to assure the continued protection of the public safety during this phase include:

- monitoring of alarm systems

- perindic radiation surveys of the facility

- periodic environmental surveys

- maintenance of alarm systems and protective barriers

- inspection of facility structures, protective barriers and alarm systems

- site and facility security

- fulfillment of regulatory requirements. 
The annual costs of safe storage are summarized in Table 10.3-1. Safe storage is estimated to cost about $\$ 95,000$ annually in 1981 dollars. Staff labor costs represent about $40 \%$ of this total.

TABLE 10.3-1. Estimated Annua] Costs of the Safe Storage Period

\begin{tabular}{|c|c|c|}
\hline Cost Category & $\begin{array}{l}\text { Annual Cost in } \\
\text { Thousands of } \\
1981 \text { Dollars } a, b)\end{array}$ & $\begin{array}{c}\text { Percent } \\
\text { of } \\
\text { Total } \\
\end{array}$ \\
\hline Staff Labor (b) & 30 & 39.5 \\
\hline Supplies and Equipment & 4 & 5.3 \\
\hline Security Contractor & 12 & 15.8 \\
\hline Maintenance Contractor & 10 & 13.2 \\
\hline Annual ATlowance for Repairs & 4 & 5.3 \\
\hline Utilities & 7 & 9.2 \\
\hline Taxes & 3 & 3.9 \\
\hline Insurance & 5 & 6.5 \\
\hline Regulatory Fees & 1 & 1.3 \\
\hline Subtotal & 76 & 100.0 \\
\hline $25 \%$ Contingency & 19 & \\
\hline Total Annual Cost & 95 & \\
\hline
\end{tabular}

(a) Number of figures shown is for computational accuracy and does not imply precision to the nearest thousand dollars.

(b) See Table 10.3-2 for cost details.

\subsubsection{Manpower Requirements and Costs for Safe Storage}

Annual manpower requirements and costs for safe storage are described in this section. The work force required to perform safe storage activities at the decommissioned UF 6 conversion plant is shown in Figure 10.3-1.

Surveiliance and maintenance activities are supervised by a facility manager who reports directly to corporate headquarters. This person directs routine and corrective maintenance and radiation and environmental surveys; 


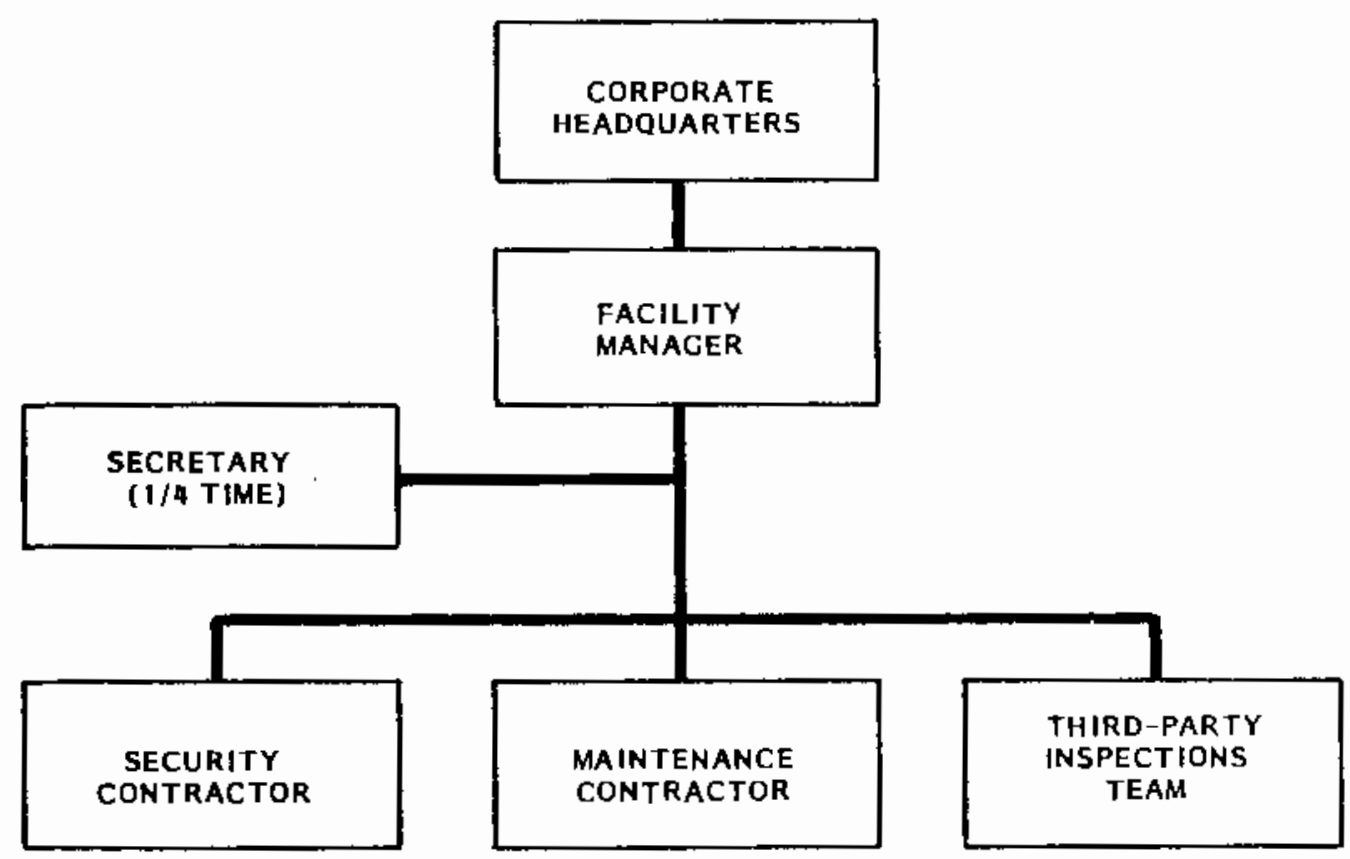

FIGURE 10.3-1. Postulated Organization Chart for the Safe Storage Period

performs routine physical inspections of the facility; arranges for third-party inspections of facility structures and equipment; assures that all regulatory requirements are fulfilled; and makes routine reports to corporate headquarters and regulatory agencies.

Third-party inspections are assumed to be carried out by a two-man team on a semi-annual basis.

Table 10.3-2 shows annual manpower requirements and costs for safe storage. Manpower requirements are based on the safe storage staff organization chart shown in Figure 10.3-1. Costs are based on unit cost data in Section H. 1 of Appendix $H$. Third-party inspection costs are based on an assumed cost of $\$ 600$ per man-day.

\subsubsection{Security and Surveillance Costs for Safe Storage}

The cost for the security and surveillance contractor is estimated to be about $\$ 11,600$ per year based on information from Reference 2 with a cost escalation factor added. 
TABLE 10.3-2. Estimated Annual Staff Requirements for Safe Storage

\begin{tabular}{lcc} 
Title or Function & $\begin{array}{c}\text { Man-Years/ } \\
\text { Year }\end{array}$ & $\begin{array}{c}\text { Annual Cost } \\
\text { 1981 Dollars (a,b) }\end{array}$ \\
\cline { 1 - 1 } Facility Manager & 0.25 & 19000 \\
Secretary & 0.25 & 6000 \\
Third-Party Inspection Team (c) & $\underline{0.03}$ & $\underline{4700}$ \\
$\quad$ TotaT Man-Years & 1.03 & \\
Total Costs/Year & & 29700
\end{tabular}

(a) The number of figures carried is for computational accuracy and does not imply precision to the nearest dollar.

(b) Contingency of $25 \%$ is not included.

(c) Third-party inspection costs are based on an assumed $\$ 600$ per man-day.

\subsubsection{Material and Equipment Requirements and Costs for Safe Storage}

An annual allowance of $\$ 4,000$ for equipment and supplies is included in the material and equipment cost estimate. This allowance includes funds for monitoring supplies, secretarial supplies, etc.

Repairs to monitoring instruments, security alarm systems, etc., are assumed to be made by outside contractors. An annual allowance of $\$ 4000$ for facility repairs is included in the cost estimate.

\subsubsection{Miscellaneous Owner Expenses During Safe Storage}

Miscellaneous owner expenses during the safe storage period include the costs of taxes, regulatory fees and insurance. Except for the regulatory fees, annual costs for these items are assumed to be about $2 \%$ of the annual costs during DECON because it is an inactive facility. Cost of utilities was estimated at $\$ 7,000$, based on an estimate from Reference 2 , since only the alarm systems are operating.

\subsubsection{Maintenance Contractor}

The annual cost of a maintenance contractor is estimated to be about $\$ 10,000$, including $\$ 2,000$ for supplies. The maintenance contractor performs 
routine maintenance and minor repairs to the safety and security systems. The cost is based on an estimate of 0.25 man-years required for maintenance on the plant during safe storage.

10.4 COST ESTIMATES FOR THE DEFERRED DECONTAMINATION PERIOD OF PASSIVE SAFSTOR

The estimated costs of deferred decontamination following safe storage of the reference plant are summarized in Table 10.4-1.

TABLE 10.4-1. Summary of Estimated Deferred Decontamination Costs Cost Category Cost in Millions of 1981 Dollars (a)

Manpower

Planning and Preparation

0.589

Decommissioning

1.826

Equipment and Supplies

0.151

Disposal of Radioactive Material

0.509

Miscellaneous Owner Expense

$\underline{0.740}$

Subtotai

3.815

\begin{tabular}{|c|c|c|c|}
\hline Lagoon Waste Management Options & $\begin{array}{c}\text { Ship to } \\
\text { Mil? }\end{array}$ & $\begin{array}{c}\text { Ship to } \\
\text { LLW } \\
\text { Burial Ground } \\
\end{array}$ & $\begin{array}{c}\text { Ship to } \\
\text { Commercial Dump }\end{array}$ \\
\hline Extraction Waste & 7.332 & 10.011 & $1.332^{(b)}$ \\
\hline Fluoride Waste & $0.055^{(c)}$ & 3.301 & 1.011 \\
\hline Subtotal (includes lagoon waste) & 5.202 & 17.127 & 6.158 \\
\hline $25 \%$ Contingency & 1.301 & 4.282 & 1.540 \\
\hline Total Costs & 6.503 & 21.409 & 7.698 \\
\hline
\end{tabular}

(a) Number of figures shown is for computational accuracy and does not imply precision to the nearest thousand dollars.

(b) Not feasible to ship extraction waste to commercial dump. Cost is for extraction waste shipped to mill.

(c) Not feasible to ship fluoride waste to mill. Cost is for fluoride waste buried onsite. 
Deferred decontamination is estimated to require about 8 months (plus 6 months for planning and preparation), at a cost of approximately $\$ 6.5$ million.

Manpower costs represent about 55\% of the total cost of deferred decontamination. Manpower costs include both support staff and decomissioning worker labor costs. In Table 10.4-1, manpower costs are shown separately for the planning and preparation and the decomissioning phases of deferred decontamination. Details of manpower requirements and costs for deferred decontamination are given in Section 10.4.1.

Material and equipment costs represent about $3.5 \%$ of the total cost of deferred decontamination. Details of material and equipment requirements and costs are given in Section 10.4.2.

Waste management costs represent about $36 \%$ of the total cost of deferred decontamination. Details of waste management requirements and costs are given in Section 10.4.3.

Miscellaneous owner expenses are assumed to be the same for deferred decontamination as for DECON, measured in 1981 dollars.

\subsection{Manpower Requirements and Costs for Deferred Decontamination}

Estimates are made of the work force required to plan and execute the decommissioning activities for deferred decontamination. These work force estimates are used, together with unit manpower costs given in Section $H .1$ of Appendix $H$, to estimate deferred decontamination manpower costs. It is assumed that the work force organizational chart for deferred decontamination is similar to that for DECON, as shown in Figure 10.1-1. The same basic operations are performed during deferred decontamination as are performed during DECON, with the following exceptions :

- Lagoon covers will have to be removed, but not having to drain the lagoons will compensate.

- Additional time and manpower (about 14 man-weeks) will be required to remove seals and barricades erected during preparations for safe storage, to restore services, and to perform a small amount of manual decontamination and cleanup. 
- Because deferred decontamination occurs 10 to 30 years after plant shutdown, training of the decommissioning staff will be necessary during the planning and preparation phase.

Table 10.4-2 shows manpower requirements and costs for planning and preparation, and Table 10.4-3 shows manpower requirements and costs for the decommissioning phase of deferred decontamination. A total of about 12 man-years is estimated to be required for planning and preparation, at a labor cost of about $\$ 589,000$. The decommissioning staff is generally sized and structured on a 1-shift, 5-day week.

IABLE 10.4-2. Summary of Manpower Utilization and Staff Costs for Planning and Preparations Phase of Oeferred Decontamination

Titie or Function

Project Manager

Project Engineer

Heal th and Safety Supervisor

Contracts and Accounting Specialist

Radioactive Shipment Specialist

Q.A. Engineer

Planning Engineer

Engineering Technician

Maintenance and Crafts Supervisor

Operations Supervisor

Foreman

Technician (training)

Craftsman (training)

Secretary

Total Man-Years

Total Cost
Man-Years $(\begin{array}{c}\text { Cost } \\ \text { thousands) }\end{array} \underbrace{(a, b)}$

$1.00 \quad 89$

$0.75 \quad 57$

$0.67 \quad 40$

$0.67 \quad 32$

$0.38 \quad 15$

$0.67 \quad 3]$

$0.67 \quad 35$

$0.67 \quad 26$

$0.67 \quad 31$

$0.67 \quad 35$

$1.50 \quad 67$

$2.00 \quad 79$

$0.50 \quad 16$

$1.50 \quad 36$

12.20

589

(a) Number of figures shown is for computational accuracy and does not imply precision to the nearest thousand dollars.

(b) Contingency of $25 \%$ is not included. 
IABLE 10.4-3. Surmary of Manpower Utilization and Staff costs for Decommissioning Phase of Deferred Decontamination

Title or Function

Cost

\begin{tabular}{|c|c|c|}
\hline Title or Function & Man-Years & $(\$ \text { thousands })^{(a, b)}$ \\
\hline Project Manager & 0.75 & 67 \\
\hline Project Engineer & 0.75 & 57 \\
\hline Health and Safety Supervisor & 0.75 & 45 \\
\hline Health Physics Technician & 1.50 & 45 \\
\hline Security Force Supervisor & 0.75 & 42 \\
\hline Security Patrolman & 3.00 & 76 \\
\hline Contracts and Accounting Specialist & 0.75 & 35 \\
\hline Radioactive Shipment Specialist & 0.75 & 29 \\
\hline Q.A. Engineer & 0.75 & 35 \\
\hline Planning Engineer & 0.75 & 39 \\
\hline Engineering Technician & 0.75 & 29 \\
\hline Maintenance and Crafts Supervisor & 0.75 & 35 \\
\hline Custodian & 0.75 & 23 \\
\hline Craftsman & 3.00 & 96 \\
\hline Operations Supervisor & 0.75 & 39 \\
\hline Foreman & 3.50 & 155 \\
\hline Technician & 24.0 & 943 \\
\hline Secretary & 1.50 & $\underline{36}$ \\
\hline Total Man-Years & 45.5 & \\
\hline Total Cost & & 1826 \\
\hline
\end{tabular}

(a) Number of figures shown is for computational accuracy and does not imply precision to the nearest thousand dollars.

(b) Contingency of $25 \%$ is not included.

A total of about 45 man-years is estimated to be required for decontamination activities, at a labor cost of about $\$ 1.8$ million. The total labor cost for deferred decontamination is estimated to be about $\$ 2.4$ million without contingencies. 


\subsubsection{Material and Equipment Requirements and Costs for Deferred Decontamination}

Estimates of material and equipment requirements and costs for deferred decontamination are shown in Table 10.4-4. Material and equipment costs are expected to be about the same for deferred decontamination as they are for DECON. A small additional cost is required for training supplies. The total material and equipment costs are estimated at about $\$ 151,000$.

TABLE 10.4-4. Estimated Material and Equipment Requirements and Costs for Deferred Decontamination

\begin{tabular}{|c|c|c|c|}
\hline Description & Quality & $\begin{array}{c}\text { Estimated } \\
\text { Unit Cost } \\
\text { (\$ thousands) }\end{array}$ & $\begin{array}{l}\text { Estimated } \\
\text { Total Cost } \\
\text { (\$ thousands) }\end{array}$ \\
\hline Oxyacetylene Torch & 4 ea. & 1.0 & 4.0 \\
\hline Guillotine Pipe Saw & 2 ea. & 4.0 & 8.0 \\
\hline Tube Cutter & 2 ea. & 0.4 & 0.8 \\
\hline Ratcheting Pipe Cutter & 6 ea. & 0.07 & 0.4 \\
\hline Reciprocating Saw & $4 \mathrm{ea}$. & 0.8 & 3.2 \\
\hline Nibbler & 2 ea. & 1.0 & 2.0 \\
\hline High-Velocity Liquid Jet & 1 ea. & 6.9 & 6.9 \\
\hline Low-Velocity Liquid Jet & 2 ea. & 2.8 & 5.6 \\
\hline Hydraulic Concrete Surface Spalling Device & i ea. & 5.0 & 5.0 \\
\hline Concrete Drill & 3 ea. & 0.3 & 0.9 \\
\hline Electric/Pneumatic Hanmer & 2 ea. & 0.7 & 1.4 \\
\hline Portable A-Frames & 2 ea. & 4.1 & 8.2 \\
\hline Portable Wash Tanks & 2 ea. & 2.8 & 5.6 \\
\hline Portable Spray Clean Booth & l ea. & 5.5 & 5.5 \\
\hline Portable Greenhouse Erection Kit & 1 ea. & $2 . B$ & 2.8 \\
\hline Hand Powered Brushes & 20 ea. & 0.2 & 4.0 \\
\hline HEPA Filter & 5 ed. & 0.2 & 1.0 \\
\hline Roughing Filter & $20 \mathrm{ed}$. & 0.1 & 2.0 \\
\hline Decontamination Chemicals & & & 11.0 \\
\hline Cleaning Supplies & & & 22.1 \\
\hline Expendable Tools & & & 11.0 \\
\hline Protective Clothing (inciuding laundry) & & & 19.9 \\
\hline Office Supplies: Planning and Preparation & & & 13.2 \\
\hline $\begin{array}{l}\text { Decommissioning } \\
\text { Total }\end{array}$ & & & $\frac{6.6}{151.0}(a, b)$ \\
\hline
\end{tabular}

(a) Total is shown as direct addition of prior numbers to retain calculational information. Precision is less than shown.

(b) Contingency of $25 \%$ is not included. 


\subsubsection{Waste Management Requirements and Costs for Oeferred Decontamination}

The estimated weights, volumes, and number of shipments of decomissioning wastes from deferred decontamination are the same as from DECON of the plant, as given in Table 10.1-5. The estimated costs of containers, transportation and disposal of the radioactive wastes from buildings and of the miscellaneous waste buried onsite during operation for deferred decontamination are the same as from DECON, which are summarized in Table 10.1-6. Cost estimates are based on projected packaging and shipping requirements in Table 10.1-5 and on waste management cost data in Section H. 2 of Appendix H. The total waste management cost for deferred decontamination of the buildings is estimated to be $\$ 509,000$ without contingencies. Lagoon waste management costs for deferred decontamination are the same as for OECON and are summarized in Table 10.1-7.

\subsection{COST ESTIMATES FOR OECON OF PLANT AND EQUIPMENT WITH ONSITE OISPOSAL OF LAGOON WASTES}

The estimated cost for OECON of the reference plant and equipment with onsite burial of the lagoon waste is summarized in Table 10.5-1. The total decommissioning cost is estimated to be $\$ 4.6 \mathrm{million}$, with an annual cost for long-term care estimated to be $\$ 11,000$.

The cost of onsite burial of the lagoon waste is summarized in Table 10.5-2. If the solvent extraction waste is buried onsite with site stabilization provided, the cost is estimated to be $\$ 210,200$ including contingency, with an annual cost for long-term care of $\$ 8,000$. The cost of onsite burial of the fluoride waste is $\$ 68,600$ including contingency, with an annual cost of long-term care of $\$ 3,000$.

The total cost of onsite burial of the lagoon waste is $\$ 278,800$ including contingency, with an annual cost for long-term care of $\$ 11,000$. 
IABLE 10.5-1. Summary of Estimated Cost for DECON of Plant with Onsite Burial of Lagoon Waste

\begin{tabular}{|c|c|}
\hline $\begin{array}{c}\cdot \\
\text { Cost Category }\end{array}$ & $\begin{array}{l}\text { Cost in Millions } \\
\text { of } \\
1981 \text { Dollars (a) }\end{array}$ \\
\hline \multicolumn{2}{|l|}{ Manpower } \\
\hline Planning and Preparation & 0.304 \\
\hline Decommissioning & 1.749 \\
\hline Equipment and Supplies & 0.149 \\
\hline Disposal of Radioactive Material & 0.509 \\
\hline Miscellaneous Owner Expense & 0.740 \\
\hline Subtotal & 3.451 \\
\hline Lagoon Waste Management Options & Onsite Burial \\
\hline Extraction Waste ${ }^{(b)}$ & 0.168 \\
\hline Fluorid Waste ${ }^{(c)}$ & $\underline{0.055}$ \\
\hline Subtotal (includes lagoon waste) & 3.674 \\
\hline $25 \%$ Contingency & 0.919 \\
\hline Total Costs & 4.593 \\
\hline
\end{tabular}

(a) Number of figures shown is for computational accuracy and does not imply precision to the nearest thousand dollars.

(b) Not feasible to ship extraction waste to commercial dump. Cost is for extraction waste shipped to mill.

(c) Not feasible to ship fluoride waste to mill. cost is for fluoride waste buried onsite.

TABLE 10.5-2. Cost of Onsite Burial of Lagoon Waste ${ }^{(a)}$

\begin{tabular}{|c|c|c|}
\hline Type of Waste & $\begin{array}{c}\text { Cost in } 1981 \\
\text { Onsite Burial } \\
\text { with } \\
\text { Stabilization }\end{array}$ & $\begin{array}{l}\text { Dltars } \\
\text { Annual } \\
\text { Care } \\
\end{array}$ \\
\hline Solvent Extraction & 210200 & 8 D00 \\
\hline Fluoride & 68600 & 3000 \\
\hline Total Costs & 278800 & 11000 \\
\hline
\end{tabular}

(a) Includes $25 \%$ contingency. 


\section{REFERENCES}

1. Title 10, Code of Federal Regulations, Parts 140.31 and 170.32, September 1978.

2. R. I. Smith, G. J. Konzek and W. E. Kennedy, Jr., Technology, Safety and Costs of Decommissioning a Reference Pressurized Water Reactor Power Station, NUREG/CR-0130, U.S. Nuclear Regulatory Commission Report by Pacific Northwest Laboratory, June 1978. 
11.0 PUBLIC AND OCCUPATIONAL SAFETY DURING DECOMMISSIONING OF THE REFERENCE $\mathrm{UF}_{6}$ CONVERSION PLANT

Public and occupational safety impacts from decommissioning activities at the reference $\mathrm{UF}_{6}$ conversion plant are surmarized in this section. The safety evaluation includes a consideration of the impacts of public radiation exposure, occupational radiation exposure, industrial accidents, and chemical pollutants. This evaluation utilizes current data and state-of-the-art methods to estimate the information required. A conservative approach, using parameters that tend to maximize the consequences, is used to evaluate the safety impacts of each decommissioning task. Safety assessment details are provided in Appendix I.

The safety evaluation is divided into three major parts: public safety, occupationa1 safety, and transportation safety. Within each of these major parts are discussions of the radiological and nonradiological impacts of both routine and accident situations. Public radiological considerations are determined by using the atmospheric release scenarios in Appendix $I$ and the radiation dose evaluation methods presented in Appendix E. Occupational radiation doses are estimated using information about expected dose rates and man-hour job requirements discussed in Section 10 and Appendices $C, G$ and $H$.

The decommissioning alternatives selected for analysis are OECON and passive SAFSTOR, as discussed in Sections 4 and 9 . The radiological safety evaluation is accomplished by calculating radiation doses to the public from airborne radionuclide releases and to the decommissioning and transportation workers from direct external exposure.

The fifty-year committed dose equivalent to the public from routine airborne releases during DECON (transportation not included) is calculated to be about 4.D man-rem to the lungs, and the 50-year committed dose equivalent to the maximum-exposed individual from the worst postulated accident is calculated to be about 0.13 rem to the lungs. Radiation doses to the public resulting from preparations for safe storage are significantly less than those calculated for DECON since no major decontamination or demolition tasks are required. 
The estimated occupational radiation doses are calculated to be about 62 man-rem for OECON, about 0.12 man-rem for preparations for safe storage, about 0.087 man-rem for each year of safe storage, and about 62 man-rem for deferred decontamination (the same as for DECON).

Radioactive waste material transportation activities associated with decommissioning are estimated to give a radiation dose to the total population along the transport route of about 1.7 man-rem for DECON or deferred decontamination. occupational doses from the transportation of radioactive wastes are estimated to be about 1.7 man-rem from DECON or deferred decontamination shipments. These doses include the impacts of 1877 shipments of wastes recovered from the extraction waste pond and the fluoride lagoons.

\subsection{TECHNICAL APPROACHES}

The safety evaluation is divided into two areas of interest: radiological safety and nonradiological safety. Radiological safety is evaluated using a three-part technical approach. First, a description of the reference facility is developed (see Section 7). Second, the radionuclide inventories and external dose rates within the facility are characterized and quantified (see Appendix C). Finally, reference decommissioning tasks are defined for each alternative to permit calculation of radiation exposures (discussed in Appendix I.) The nonradiological safety evaluation is based on industrial and transportation accidents that result in injuries or fatalities. The technical approach is divided into two parts. First, the total labor requirements for each decommissioning alternative are analyzed and divided into categories of effort (discussed in Appendices $G$ and $I$ ); second, injuries and fatalities are calculated based on statistical information from the literature on accident frequencies for the different categories of effort.

Key assumptions are made during the safety evaluation to coordinate the parts of each of the technical approaches. Some of the major assumptions are:

1. The maximum potential radiological consequences of a given decommissioning task are associated with performing that task in the area of the UF 6 conversion plant with the highest radionuclide inventory. 
2. The plant equipment areas are kept relatively free of radioactive contamination during the operating lifetime to permit operational maintenance. As a result, expected radioactive contamination levels are generally modest and are reasonably consistent with the quality of operation expected in modern $U F_{6}$ conversion plants.

3. The maximum release from a specific decommissioning task applies to that task whenever it is used in the facility. In performing the dose calculations for releases of radionuclides from routine tasks, the estimated total releases for the entire decommissioning period are released at a uniform rate during a l-year period. This process results in a conservatively large estimate of releases and doses, but this conservatism is used to compensate for uncertainties in the analysis.

4. Radiation protection techniques applied conform to the principle of keeping occupational radiation dose as low as reasonably achievable (ALARA).

5. All radioactive wastes are shipped $800 \mathrm{~km}$ by truck to a commercial shallowland burial ground.

6. For natural uranium, inhalation of airborne radionuclides is the dominant radiation exposure pathway to members of the public during decommissioning.

7. The dominant radiation exposure pathway to the decommissioning worker is the external radiation received during normal decommissioning operations. Workers are assumed to wear adequate respiratory protection gear to prevent significant internal deposition of radionuclides.

8. For onsite waste management from the extraction pond and fluoride lagoons, the only option considered for public and occupational dose calculations is the exhumation, packaging, and offsite disposal option. Methods similar to those defined in Reference 1 are used to estimate atmospheric releases and occupational doses from waste exhumation and packaging tasks.

Other specific assumptions for calculating public and occupational safety impacts for DECON or SAFSTOR tasks are discussed in Appendix I. 


\subsection{PUBLIC SAFETY ASPECTS OF DECOMMISS IONING THE REFERENCE UF 6 CONVERSION PLANT}

The consequences of atmospheric releases of radioactivity during routine decommissioning tasks are determined by calculating radiation doses to the maximum-exposed individual and to the population residing within $80 \mathrm{~km}$ of the site. Radiation exposure pathways considered for routine atmospheric releases are direct external exposure, inhalation, and ingestion of food products. The consequences of postulated accidents are determined by calculating inhalation radiation doses to the maximum-exposed individual. The radiation dose calculations for both the routine and accidental releases use the environmental information discussed in Appendix $B$ and the radiation dose models and parameters discussed in Appendix E. These calculations use current data and methodology to quantify the atmospheric releases and obtain results that are useful in comparing the decommissioning alternatives discussed in this study. The following sections contain summaries of the calculated radiation doses to the public during DECON and passive SAFSTOR.

\subsubsection{Public Radiation Doses from Routine Decommissioning Tasks}

Loss of confinement of radioactive materials resulting in public radiation exposure is a primary safety concern during decommissioning. The primary sources of radioactive effluents from routine decommissioning operations are the release of contaminated vaporized metal during cutting and equipment removal, the release of contaminated concrete dust during decontamination or removal of concrete structures, and the release of contaminated aerosols during chemical decontamination. Equipment and concrete removal operations are minimal during preparations for safe storage.

A complete discussion of the methods used to calculate atmospheric releases during decommissioning is found in Appendix I. The calculated atmospheric releases for DECON and preparations for safe storage are shown in Table I.2-4. Complete listings of the calculated radiation does to the maximum-exposed individual and to the public residing within $80 \mathrm{~km}$ of the site are given in Tables I.2-5 and 1.2-6. These doses are 1isted for each area and general method considered. Summaries of these doses are shown in Tables 11.2-1 and 11.2-2 for the maximum-exposed individual and the population, respectively. The doses 
TABLE 11.2-1. Summary of Calculated Radiation Doses to the Maximum-Exposed Individual from Atmospheric Releases During Routine Decommissioning Tasks (a)

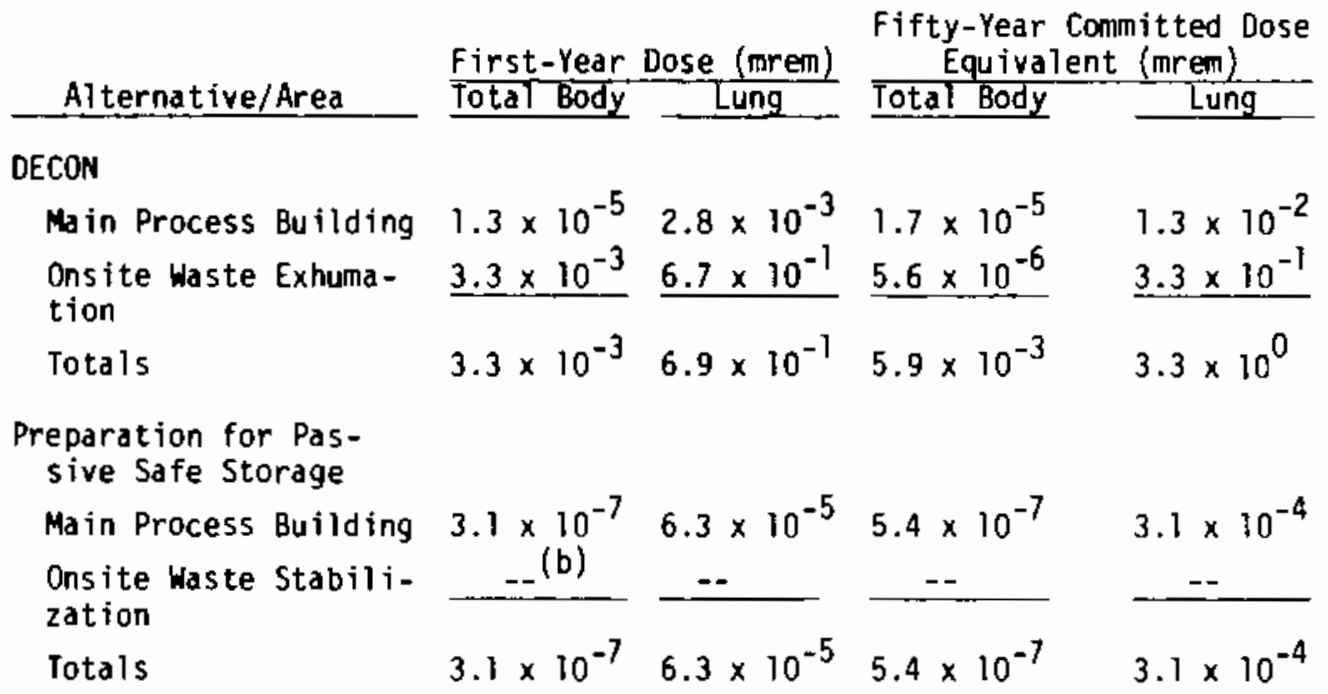

(a) More detailed information for each area and general decommissioning method is shown in Table I.2-5.

(b) Dashes indicate no doses resulted for this area and al ternative.

TABLE 11.2-2. Summary of Calculated Radiation Doses to the Population from Atmospheric Releases During Routine Decormissioning Tasks $(a)$

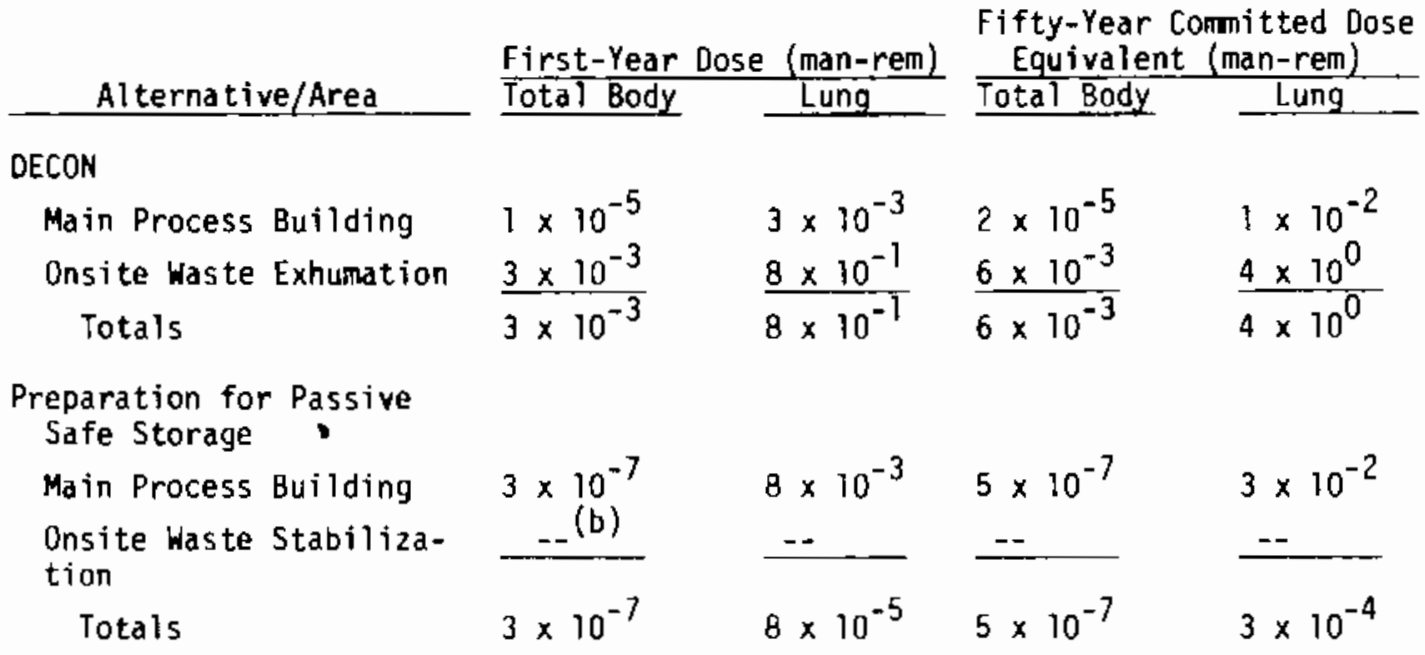

(a) More detailed information for each area and decommissioning method is shown in Table 1.2-6. All calculated population doses are rounded to one significant figure, and are for the population of $3.5 \mathrm{million}$ people residing within an $80-\mathrm{km}$ radius of the site.

(b) Oashes indicate no doses were calculated. 
shown in these tables are for total body and lung, for both the first-year dose and the fifty-year committed dose equivalent. The calculated doses for DECON are about a factor of $10^{4}$ larger than the doses for preparations for safe storage. The radiation doses shown in Tables 11.2-1 and 11.2-2 are extremely small by comparison to the range of annual radiation dose to an individual from natural background in the United States (from 80 to 170 mrem per year). (2)

The release of uranium during safe storage is expected to be negligible compared to the releases during either DECON or preparations for safe storage. This is because of the steps taken during preparations for safe storage to isolate the uranium within the plant, and steps taken during safe storage to limit human activities within the plant. Thus, no public doses are calculated for safe storage. Since the radionuclides in the uranium mixture are generally long-lived, for this study the doses from deferred decontamination are assumed to be equal to those calculated for DECON.

\subsubsection{Public Radiation Doses from Postulated Accidents During Decommissioning}

The consequences of postulated decommissioning accidents that result in atmospheric releases of radioactivity are determined by calculating the inhalation dose to the maximum-exposed individual. For OECON tasks, postulated accidents are discussed and analyzed in Section I.2.2 of Appendix I. Using engineering judgment, a general estimate of the frequency of occurrence of the level of atmospheric release is made for each accident. The frequency of occurrence is judged to be "high" if the occurrence of a release of similar magnitude per year is greater than $10^{-2}$, "medium" if between $10^{-2}$ and $10^{-5}$, and "low" if less than $10^{-5}$. While it is beyond the scope of this study to evaluate every potential accident for each decommissioning alternative, an attempt is made to identify the most significant potential accidents associated with DECON tasks. Accidents during preparations for safe storage are determined by direct comparison with DECON, with no attempt at further analysis. Thus, several of the accidents postulated for DECON do not apply to preparations for safe storage, since the latter does not involve the removal of activated concrete or components. 
A summary of the postulated accidents considered in this study is given in Table 11.2-3. These accidents are listed in order of decreasing magnitude of atmospheric release. First-year radiation doses and fifty-year conmitted radiation dose equivalents are listed for the total body and lung of the maximumexposed individual. The accident that is postulated to result in the largest atmospheric release of radioactivity is the oxyacetylene explosion during the removal of piping and equipment in Area 2, the ADU slurry receiving and storage area. This explosion is assumed to occur in the contamination control envelope, releasing the uranium collected in the control envelope HEPA filters. It is calculated that $1.8 \times 10^{-3} \mathrm{Ci}$ of uranium could be released. The frequency of occurrence of this accident is estimated to be "medium." Transportation accidents are included in Table 11.2-3 for comparison purposes. These accidents are discussed in Section 11.4 .

\subsubsection{Nonradiological Public Safety Evaluation}

Chemical pollutants that could be released during decommissioning activities are examined and the quantities released are found to have an insignificant safety impact on the public. Potentially hazardous chemicals are found to come from two sources: 1) residuals from $\mathrm{UF}_{6}$ conversion plant production operations, and 2) chemicals employed to chemically and physically decontaminate the plant. From the relatively small quantities of hazardous chemicals used, the low likelihood of their dispersal into the environs, and the dilution factors involved in the dispersal of hazardous material from the plant to the environs, it can be concluded that chemical pollutants from decommissioning operations do not pose a significant public hazard. A more detailed discussion of the potential chemicals and their impacts is given in Section I.6 of Appendix I. 


\section{TABLE 11.2-3. Sumary of Radiation Doses to the Maximum-Exposed Individual from Postulated UF
Conversion Plant Decommissioning Accidents}

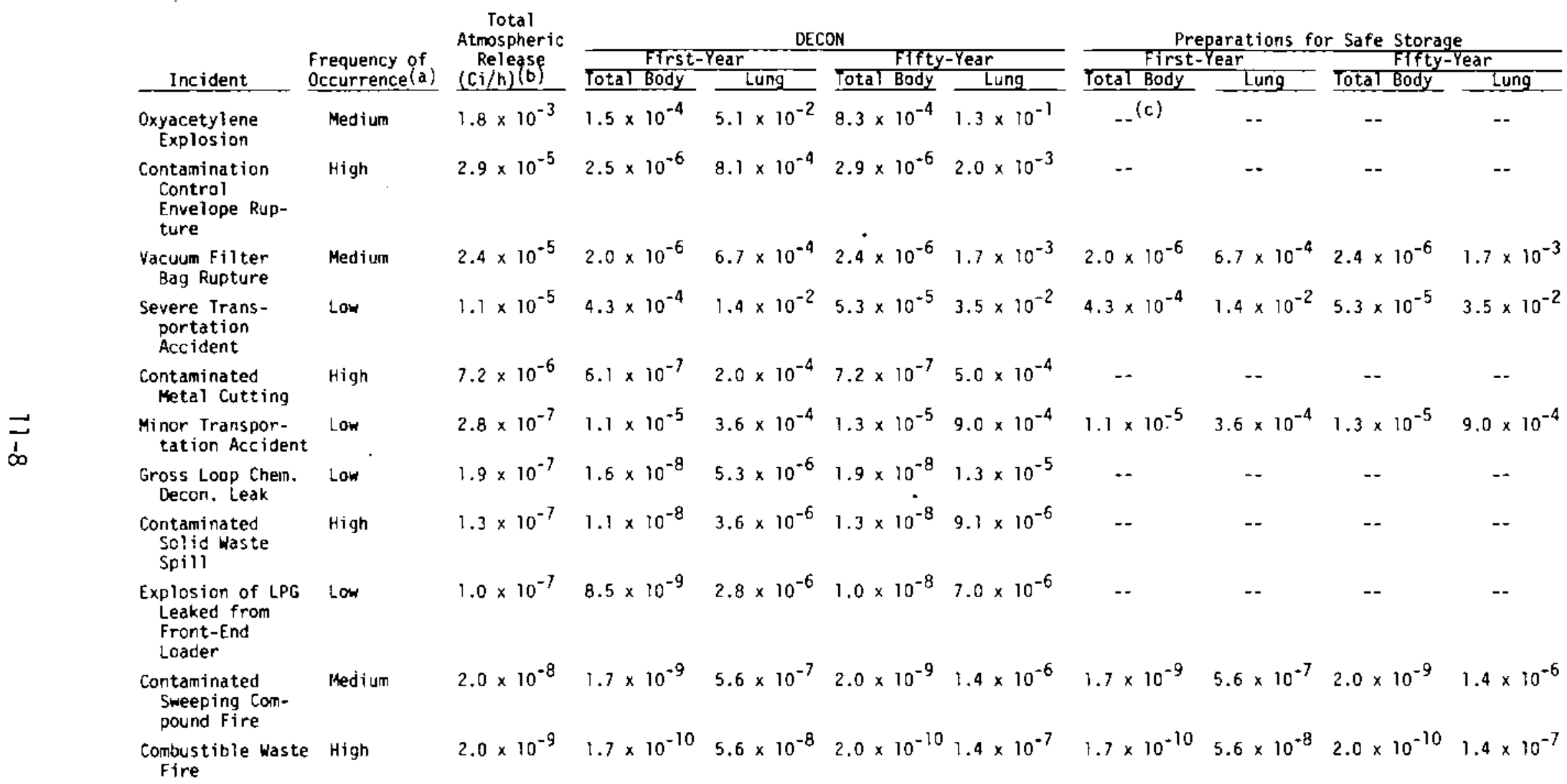

(a) The frequency of occurrence considers not oniy the probability of the accident, but also the probability of an atmospheric release of similar magnitude. The frequency of occurrence is listed as "high" if the occurrence of a release is >10-2 per year. "medium" if between $10^{-2}$ and $10^{-5}$, and "low" if $<10^{-5}$.

(b) All releases are assumed to occur in a 1-hour period for comparison purposes.

(c) Dashes indicate that the accident shown does not apply for the alternative shown. 


\subsection{OCCUPATIONAL SAFETY EVALUATION OF DECOMMISSIONING THE REFERENCE UF 6 CONVERSION PLANT}

Occupational safety impacts for DECON and SAFSTOR are evaluated for both radiological and nonradiological events. The analysis considers routine radiological events and postulated nonradiological accidents.

Radiation doses to workers are calculated based on estimated radiation dose rates for various areas of the reference $\mathrm{UF}_{6}$ conversion plant and on the estimated labor requirements to perform the decommissioning work. Summaries of the appropriate detailed information in Appendices $C$ and I are given in this section. An estimate of worker injuries and fatalities resulting from decommissioning tasks is also presented, based on nuclear industry experience.

\subsubsection{Radiological Safety Evaluation of Routine Decommissioning Tasks}

Summaries of the estimated worker hours and occupational radiation exposures for DECON and SAFSTOR are given respectively in Tables 11.3-1 and 11.3-2. These tables summarize tasks in each area of the reference UF ${ }_{6}$ conversion plant, manhour estimates for each area, and man-rem estimates of the accumulated external radiation dose to all workers in each area. Detailed estimates of occupational radiation doses, showing worker categories and average dose rates, are found in Section I.4 of Appendix I.

The radiation doses to decommissioning workers are calculated using the manpower requirements estimated for each area and estimates of the average radiation dose rates associated with each area. The dose rate estimates are based on the data given in Reference 3 for an operating uranium fabrication facility. The radiation doses computed in Appendix I are based on constant values of dose rates for a work area, regardless of where the worker is located within the area.

The major radionuclides within the facility have long half-lives and do not decay significantly within the few years considered in this study. Therefore, occupational radiation doses do not decrease with time. 
TABLE 11.3-1. Estimated Occupational Radiation Dose for DECON

Estimated Total

Area

Estimated Total Occupational Dose

Area

(man-hours)(a)

(man-rem)

Area 1: Drum Receiving

180

$6.6 \times 10^{-3}$

Area 2: ADU Slurry

255

$8.4 \times 10^{-1}$

Area 3: Sampling Station

285

$9.5 \times 10^{-1}$

Area 4: Laboratory

720

$2.7 \times 10^{-2}$

Area 5: $\mathrm{UF}_{4}$ Slurry

1275

$4.1 \times 10^{0}$

Area 6: Ore Dissolution

1740

$5.8 \times 10^{0}$

Area 7: Solvent Extraction

2700

$7.7 \times 10^{0}$

Area 8: Uranyl Nitrate

2315

$2.4 \times 10^{-1}$

Area 9: Denitration

2460

$2.7 \times 10^{-1}$

Area 10: Nitric Acid

1260

$1.4 \times 10^{-1}$

Area 11: Reduction Systems

2315

$2.2 \times 10^{-1}$

Area 12: Hydrofluorination

1905

$2.1 \times 10^{-1}$

Area 13: Fluorination

2263

$2.5 \times 10^{-1}$

Area 14: Cylinder Loading

1410

$2.1 \times 10^{-2}$

Area 15: $\mathrm{F}_{2}$ Production

630

$2.4 \times 10^{-2}$

Area 16: $F_{2}$ Cell

510

$1.8 \times 10^{-2}$

Area 17: Instrument Repair

1050

$3.9 \times 10^{-2}$

Area 18: Ammonia Cracking

Area 19: Waste Gas Disposal

735 .

$2.7 \times 10^{-2}$

Area 20: $\mathrm{H}_{2}$ Condensing

525

$1.9 \times 10^{-2}$

Area 21: Temporary Radwaste

477

$1.8 \times 10^{-2}$

Area 22: DECON Area

300

$3.1 \times 10^{-2}$

Area 23: Incinerator

180

$2.1 \times 10^{-2}$

Area 24: Laundry

660

$2.5 \times 10^{-2}$

Area 25: Overall Cleanup

555

$2.1 \times 10^{-2}$

Building Area Totals

180

$2.7 \times 10^{4}$

$\frac{3.1 \times 10^{-2}}{2.1 \times 10^{7}}$ 
IABLE 11.3-1. (Contd)

\begin{tabular}{|c|c|c|}
\hline Area & $\begin{array}{l}\text { Estimated Total } \\
\text { (man-hours) }(\mathrm{a})\end{array}$ & $\begin{array}{c}\text { Estimated Total } \\
\text { Occupational Dose } \\
\text { (man-rem) }\end{array}$ \\
\hline \multicolumn{3}{|l|}{ Site Areas: $(b)$} \\
\hline Extraction Waste Pond & 5670 & $1.8 \times 10^{1}$ \\
\hline Fluoride Waste Lagoons & 6060 & $2.0 \times 10^{3}$ \\
\hline Misc. Buried Waste & 735 & $2.4 \times 10^{\mathrm{D}}$ \\
\hline Drum Storage & 495 & $1.8 \times 10^{-2}$ \\
\hline Cylinder Storage & 1275 & $4.7 \times 10^{-2}$ \\
\hline Plant Stack & 660 & $2.5 \times 10^{-2}$ \\
\hline Overall Cleanup & 1095 & $4.0 \times 10^{-2}$ \\
\hline Site Area Totals & $1.6 \times 10^{4}$ & $4.1 \times 10^{7}$ \\
\hline DECON Totals & $4.3 \times 10^{4}$ & $6.2 \times 10^{1}$ \\
\hline
\end{tabular}

(a) Based on a 6-hour effective work day.

(b) Only the waste exhumation, packaging, offsite disposal option is considered.

The total occupational radiation dose for in-plant decommissioning tasks for DECON is estimated to be about 21 man-rem. For onsite waste exhumation, an additional occupational dose of 41 man-rem is calculated; thus the total occupational dose for DECON is about 62 man-rem. Specific areas that result in the highest accumulated worker doses are: 1) onsite waste relocation, 2) Area 7, solvent extraction, 3) Area 6, ore concentrate dissolution, 4) Area $5, U F_{6}$ slurry processing, 5) Area 3, sampling station, and 6) Area 2, ADU slurry receiving and storage. The estimated occupational dose for tasks during preparations for safe storage is about 0.12 man-rem. During safe storage, the radiation doses are estimated to be about $8.7 \times 10^{-2}$ man-rem per year, and since most of the radionuclides present have long half-lives, the doses for deferred decontamination are considered to be the same as those estimated for DECON.

The estimated external occupational radiation doses for decommissioning the reference $\mathrm{UF}_{6}$ conversion plant are summarized in Table 11.3-3. The total 
TABLE 11.3-2. Estimated Occupational Radiation Dose for SAFSTOR

Estimated Tota]

Phase/Task

Estimated Totals Occupational Dose (man-hours)(a) (man-rem)

Preparations for Safe Storage:

Equipment Deactivation

Audit of Pumps and Pipelines

180

$1.9 \times 10^{-2}$

Secure Valves, Hoops, Conveyors

210

$2.3 \times 10^{-2}$

Disconnect Unneeded Services

270

$9.9 \times 10^{-3}$

Tag Equipment for Status

270

$7.7 \times 10^{-3}$

Safety Audit

210

$7.7 \times 10^{-3}$

Isolation of Areas

Install Locks and Signs

120

$4.4 \times 10^{-3}$

Building Systerns Check

180

$6.6 \times 10^{-3}$

Install Fence and Locks

90

$6.6 \times 10^{-4}$

Final Preparations

Complete Offsite Shipments

225

$6.1 \times 10^{-3}$

Install Instrusion Alarms

300

$1.1 \times 10^{-2}$

Install Rad. Monitoring System

240

$8.8 \times 10^{-3}$

Comprehensive Rad. Survey

Building Area Totals

270

Onsite Waste Stabilization

Totals for Preparations

Safe Storage Period(b)

Deferred Decontamination (c)

$2.5 \times 10^{3}$

$\frac{1.8 \times 10^{-2}}{1.2 \times 10^{-1}}$

$\frac{540}{3.0 \times 10^{3}}$

$\frac{6.5 \times 10^{-2}}{1.8 \times 10^{-1}}$

1170

$8.7 \times 10^{-2}$

$4.3 \times 10^{4}$

$6.2 \times 10^{7}$

(a) Based on a 6-hour effective work day.

(b) Labor and dose estimates per year during safe storage.

(c) Labor and dose estimates same as for DECON. 
TABLE 11.3-3. Summary of Estimated Collective Occupational Radiation Doses at the Reference $U_{6}$ Conversion Plant

\begin{tabular}{lccc} 
Decommissioning Alternative & $\begin{array}{c}\text { Time After } \\
\text { Facility Shutdown } \\
\text { (Years) }\end{array}$ & $\begin{array}{c}\text { Estimated } \\
\text { Dose } \\
\text { (man-rem) }\end{array}$ \\
\cline { 1 - 2 } DECON & 0 & 62 \\
Preparations for Safe Storage & 0 & 0.18 \\
Safe Storage Period & 10 & 0.87 \\
& 30 & 2.6 \\
Deferred Decontamination & 50 & 4.4 \\
Totals for Passive SAFSTOR & 0 to 50 & 62 \\
& 10 & 63 \\
& 30 & 65 \\
& 50 & 67
\end{tabular}

(a) Rounded to two significant figures.

occupational dose is given for DECON, and a breakdown of passive SAFSTOR activites into preparations for safe storage, the safe storage period, and deferred decontamination is presented.

Estimates of occupational radiation dose are sensitive to management philosophy and to the decommissioning methods utilized. Administrative controls are assumed to be in place that monitor radiation records for each individual and assure that no one worker exceeds recommended limits. Estimates contained in Table 11.3-3 are based on decommissioning methods that utilize technicians who are highly trained in effective radiation work procedures. Different basic assumptions, decommissioning procedures, or increased manpower may change the occupational radiation dose estimates significantly.

11.3.2 Evaluation of Industrial Accidents

As a result of decomissioning activities, the potential exists for worker injuries and fatalities. As with any industrial operation, proper management and industrial safety practices will minimize the potential for worker accidents. 
The following estimates of worker injuries and fatalities are based on data provided by the U.S. AEC for the period 1943 to 1970. (4) Table 11.3-4 Tists the estimates of worker injuries and activities that are conducted during OECON and during preparations for safe storage. (5) As shown in the table, about 0.25 lost-time injuries and 0.002 fatalities are calculated for OECON and about 0.02 lost-time injuries and 0.0001 fatalities are calculated for preparations for safe storage.

TABLE 11.3-4. Estimated 0ccupational Lost-Time Injuries and Fatalities During DECON and Preparations for Safe Storage

\begin{tabular}{|c|c|c|c|c|c|c|c|c|}
\hline \multirow[b]{2}{*}{ Activity } & \multicolumn{2}{|c|}{$\begin{array}{c}\text { Frequency (a) } \\
\text { (Accidents Per 106 man-hours) }\end{array}$} & \multicolumn{3}{|c|}{ OECON } & \multicolumn{3}{|c|}{ Preparations for Safe storage } \\
\hline & $\begin{array}{l}\text { Lost-Tine } \\
\text { Injuries } \\
\end{array}$ & Fatalftes & $\begin{array}{l}\text { Estimated } \\
\text { Man-Hours (b) }\end{array}$ & $\begin{array}{l}\text { Lost-T1me } \\
\text { Injuries }\end{array}$ & Fatalities & $\begin{array}{l}\text { Esting ted } \\
\text { Mn-Hours (c) } \\
\end{array}$ & Injuries & Fatalities \\
\hline Heavy construction & 10.0 & $4.2 \times 10^{-2}$ & $7.8 \times 10^{3}$ & $7.8 \times 10^{-2}$ & $3.3 \times 10^{-4}$ & $5.6 \times 10^{2}$ & $5.6 \times 10^{-3}$ & $2.4 \times 10^{-5}$ \\
\hline Light Construction & 5.4 & $3.0 \times 10^{-2}$ & $2.1 \times 10^{4}$ & $1.1 \times 10^{-1}$ & $6.3 \times 10^{-4}$ & $1.5 \times 10^{3}$ & $8.1 \times 10^{-3}$ & $4.5 \times 10^{-5}$ \\
\hline $\begin{array}{l}\text { Operational Support } \\
\text { Totals }\end{array}$ & 2.1 & $2.3 \times 10^{-2}$ & $\frac{2.9 \times 10^{4}}{5.8 \times 10^{4}}$ & $\frac{6.1 \times 10^{-2}}{2.5 \times 10^{-1}}$ & $\frac{6.7 \times 10^{-4}}{1.6 \times 10^{-3}}$ & $\frac{2.0 \times 10^{3}}{4.1 \times 10^{3}}$ & $\frac{4.2 \times 10^{-3}}{1.8 \times 10^{-2}}$ & $\frac{4.6 \times 10^{-5}}{1.2 \times 10^{-4}}$ \\
\hline
\end{tabular}

(a) The frequency of injury and fatallty accidents is taken from Reference 4 .

(b) Man-hour estimates for OECOK are from Table H.2-1 in Appendfx $H$.

(c) Man-hour estimates for preparations for safe storage are fram Tabie H.3-1 in Appendix H.

Estimates of the number of injuries and fatalities that could occur to the surveillance and maintenance staff from industrial-related accidents for safe storage activities are given in Table 11.3-5. As shown in this table, about 0.08 lost-time injuries and $5.6 \times 10^{-4}$ fatalities are estimated over 10 years of safe storage.

TABLE 11.3-5. Estimated Occupational Lost-Time Injuries and Fatalities During Safe Storage

\begin{tabular}{|c|c|c|c|c|c|c|}
\hline \multirow[b]{2}{*}{ Occupation (a) } & \multirow[b]{2}{*}{$\begin{array}{l}\text { Estimated } \\
\text { Man-Hours/yr }\end{array}$} & Storage for 10 Years & \multicolumn{2}{|c|}{ Storage for 30 Years } & \multicolumn{2}{|c|}{ Storage for 50 Years } \\
\hline & & $\begin{array}{l}\text { Lost-Time } \\
\text { Injuries Fatalities }\end{array}$ & $\begin{array}{l}\text { Lost-Time } \\
\text { Injuries }\end{array}$ & Fatalities & $\begin{array}{l}\text { Lost-Time } \\
\text { Injuries } \\
\end{array}$ & Fatalities \\
\hline ity Manager & 500 & $1.1 \times 10^{-2} 1.2 \times 10^{-4}$ & $3.3 \times 10^{-2}$ & $3.6 \times 10^{-4}$ & $5.5 \times 10^{-2}$ & $6.0 \times 10^{-4}$ \\
\hline $\begin{array}{l}\text { Maintenance and } \\
\text { Operations Man }\end{array}$ & 1000 & $5.4 \times 10^{-2} 3.0 \times 10^{-4}$ & $1.6 \times 10^{-1}$ & $9.0 \times 10^{-4}$ & $2.7 \times 10^{-1}$ & $10^{-3}$ \\
\hline Secretary & 500 & $1.1 \times 10^{-2} 1.2 \times 10^{-4}$ & $3.3 \times 10^{-2}$ & $3.6 \times 10^{-4}$ & $5.5 \times 10^{-2}$ & $6.0 \times 10^{-4}$ \\
\hline $\begin{array}{l}\text { Three-Party 1nspec- } \\
\text { tion Team }\end{array}$ & 60 & $1.3 \times 10^{-3} 1.4 \times 10^{-5}$ & $3.9 \times 10^{-3}$ & $4.2 \times 10^{-5}$ & $6.5 \times 10^{-3}$ & $1.0 \times 10^{-5}$ \\
\hline Totals & 2060 & $7.7 \times 10^{-2} 5.6 \times 10$ & $2.3 \times 10^{-1}$ & $1.7 \times 10^{-3}$ & $3.9 \times 10^{-1}$ & $2.8 \times 10^{-3}$ \\
\hline
\end{tabular}

(a) All lost-time and fatality estimates are based on the operational support accident frequency data shown in Table $11.3-4$, except for the maintenance and operations category whose estimates are based on the
light construction dccident frequencies. The labor estimates (in man-hours/yr) are from Table $10.3-2$. 


\subsection{TRANSPORTATION SAFETY}

Radioactive wastes collected during deconmissioning tasks at the reference $\mathrm{UF}_{6}$ conversion plant are assumed to be packaged and shipped offsite as part of planned operations. These wastes are assumed to be shipped by truck to a lowlevel waste burial ground located $800 \mathrm{~km}$ away. The methods used to estimate radiation doses to transportation workers and members of the public along the transportation route are based on information in Reference 6 . The discussion of transportation accidents resulting in atmospheric releases of radioactivity is based on information contained in Reference 7. The following sections contain a summary of the radiation dose calculations discussed in Section I.5 of Appendix I, and estimates of casualties resulting from traffic accidents during waste transport. Radiation doses received by workers unloading the radioactive waste at a repository or disposal site are not estimated in this study since they are assumed to occur at a separate licensed facility. For onsite wastes recovered from the extraction pond and fluoride lagoons, the only option considered is the removal, packaging, and offsite disposal option.

\subsubsection{Radiation Doses from Routine Decommissioning Transportation Tasks}

Department of Transportation (DOT) regulations ${ }^{(8)}$ set the following exposure limits for shipments of radioactive material:

- $1000 \mathrm{mR} / \mathrm{hr}$ at $1 \mathrm{~m}$ from the external surface of any package transported in a closed vehicle

- $200 \mathrm{mR} / \mathrm{hr}$ at the external surface of the vehicle

- $10 \mathrm{mR} / \mathrm{hr}$ at any point $2 \mathrm{~m}$ from the vehicle

- $2 \mathrm{mR} / \mathrm{hr}$ at any normally occupied position in the vehicle.

Each shipment of wastes collected within the main process building is assumed to contain enough radioactive material to result in the maximum exposure rates allowed by these DOT regulations. Wastes collected onsite from the pond and lagoons are assumed to have dose rates that are only $10 \%$ of these 1 imits. 
For DECON, the amount of radioactive waste collected is shown in Table 10.1-5 to require 51 shipments from the main process building and 1877 shipments from recovered onsite wastes. The calculated radiation doses from routine waste transportation tasks are listed in Table 11.4-1. Total doses for DECON are calculated to be 17 man-rem to transport workers and 1.7 man-rem to members of the public. If the 1877 shipments of exhumed onsite waste are omitted, disposal of wastes from the main process building result in 3.6 manrem to transport workers and 0.35 man-rem to members of the public.

TABLE 11.4-7. Calculated Radiation Doses from Routine Radioactive Waste Transportation

\begin{tabular}{|c|c|c|c|}
\hline Alternative/Group & $\begin{array}{l}\text { Radiation Dose } \\
\text { per Shipment } \\
\text { (man-rem) (a) }\end{array}$ & $\begin{array}{l}\text { Nunber of } \\
\text { Shipments }\end{array}$ & $\begin{array}{l}\text { Total Population } \\
\text { Dose per Grgup } \\
\text { (man-rem) }\end{array}$ \\
\hline \multicolumn{4}{|l|}{ DECON-Building Wastes } \\
\hline $\begin{array}{l}\text { Truck Drivers } \\
\text { Garagemen }\end{array}$ & $\begin{array}{l}6.7 \times 10^{-2} \\
3.3 \times 10^{-3}\end{array}$ & $\begin{array}{l}51 \\
51\end{array}$ & $\begin{array}{l}3.4 \\
0.17 \\
\end{array}$ \\
\hline Total Transport Worker Dose & & & 3.6 \\
\hline $\begin{array}{l}\text { Onlcokers } \\
\text { General Public }\end{array}$ & $\begin{array}{l}5.0 \times 10^{-3} \\
1.8 \times 10^{-3}\end{array}$ & $\begin{array}{l}51 \\
51\end{array}$ & $\begin{array}{l}0.26 \\
\underline{0.092} \\
\end{array}$ \\
\hline Total Pub1ic Dose & & & 0.35 \\
\hline \multicolumn{4}{|l|}{ DECON-Site Wastes } \\
\hline $\begin{array}{l}\text { Truck Drivers } \\
\text { Garagemen }\end{array}$ & $\begin{array}{l}6.7 \times 10^{-3} \\
3.3 \times 10^{-4}\end{array}$ & $\begin{array}{l}1877 \\
1877\end{array}$ & $\begin{array}{l}13 \\
0.52 \\
\end{array}$ \\
\hline Total Transport Worker Dose & & & 14 \\
\hline $\begin{array}{l}\text { Onlookers } \\
\text { General Public }\end{array}$ & $\begin{array}{l}5.0 \times 10^{-4} \\
1.8 \times 10^{-4}\end{array}$ & $\begin{array}{l}1877 \\
1877\end{array}$ & $\begin{array}{l}0.94 \\
\underline{0.38} \\
\end{array}$ \\
\hline Total Public Dose & & & 1.3 \\
\hline \multicolumn{4}{|l|}{ Totals for DECON } \\
\hline $\begin{array}{l}\text { Truck Drivers } \\
\text { Garagemen }\end{array}$ & $\begin{array}{l}--(c) \\
--\end{array}$ & $\log _{1928}(\mathrm{~d})$ & $\begin{array}{l}16 \\
0.79 \\
\end{array}$ \\
\hline Total Transport Worker Dose & -- & & 17 \\
\hline $\begin{array}{l}\text { Onlookers } \\
\text { General Public }\end{array}$ & $\begin{array}{l}-- \\
--\end{array}$ & $\begin{array}{l}1928(\mathrm{~d}) \\
1928\end{array}$ & $\begin{array}{l}1.2 \\
0.47 \\
\end{array}$ \\
\hline Total Public Dose & & & 1.7 \\
\hline
\end{tabular}

(a) Based on one-way trips of $800 \mathrm{~km}$.

(b) A1l doses are rounded to two significant figures.

(c) Dashes indicate that weighted average dose rates mere not separately calculated.

(d) Total shipments are found by adding building waste plus site waste shipments. 


\subsubsection{Radiation Doses from Postulated Transportation Accidents}

Transportation accidents have a wide range of severities. Most accidents occur at low vehicle speeds and have relatively minor consequences. In general, as speed increases, accident severity also increases. However, accident severity is not a function of vehicle speed only. Other factors such as the type of accident, the kind of equipment involved, and the location of the accident can have an important bearing on accident severity.

Furthermore, damage to a package in a transportaton accident is not directly related to accident severity. In a series of accident of the same severity, or in a single accident involving a number of packages, damage to packages may vary from none to extensive. In relatively minor accidents, serious damage to packages can occur from impacts on sharp objects or from being struck by other cargo. Conversely, even in very severe accidents, damage to packages may be minimal.

Probabilities of rail and truck accidents and the calculation of airborne concentrations of radioactivity from such accidents are discussed in Section 1.5.3 of Appendix I. Most of the information about moderate and severe accidents is obtained from Reference 9. Two realistic accidents involving combustible radioactive wastes in Type $A$ packages are defined. Both, however, are judged to have a low frequency of occurrence. The calculated radiation doses to the lung of the maximum-exposed individual resulting from these accidents are shown in Table 11.2-3. These transportation accidents are ranked with the other postulated decommissioning accidents by order of magnitude of atmospheric release.

The severe transportation accident is assumed to involve rupture and fire in 40 waste containers, each containing about $5.5 \times 10^{-4} \mathrm{Ci}$ of uranium. The total fifty-year committed radiation dose equivalent to the lung of the maximum-exposed individual from the total release of $1.1 \times 10^{-5} \mathrm{Ci}$ is calculated to be $3.5 \times 10^{7}$ mrem. For the minor accident, only one container is assumed to rupture and burn. In this case, $2.8 \times 10^{-7} \mathrm{Ci}$ of uranium are released, resulting in a fifty-year committed dose equivalent to the lung of the maximumexposed individual of about $9.0 \times 10^{3}$ mrem. A more complete discussion of the methods used to calculate these doses is found in Section I.5.3 of Appendix I. 


\subsubsection{Casualties from Traffic Accidents}

As with any transportation task, a certain potential for accidental injury or death exists from traffic accidents during decomissioning tasks. (6) A summary of the casualties calculated to result during the transportation tasks considered in this study is shown in Table 11.4-2. As shown in this table, 1.5 injuries and $9.0 \times 10^{-2}$ fatalities are estimated for DECON shipments of radioactive wastes. This total is dominated by shipments associated with the offsite disposal of exhumed wastes.

TABLE 11.4-2. Estimated Casualties from DECON Transportation Accidents

\begin{tabular}{|c|c|c|c|c|c|c|}
\hline Transportation Task & $\begin{array}{c}\text { Accident Frequency (a) } \\
\text { (Accidents per } \\
\text { Yehicle Kilometer) } \\
\end{array}$ & $\begin{array}{c}\text { Injuries } \\
\text { Per Acciddent } \\
\end{array}$ & $\begin{array}{l}\text { Fatalities } \\
\text { Per Accident }\end{array}$ & $\begin{array}{l}\text { Total } 1 \text { (b) } \\
\text { Kilometers } \\
\text { (Round Irips) }\end{array}$ & $\frac{\text { Estimated C }}{\text { Injuries }}$ & $\frac{\text { asualties }(c)}{\text { Fatalities }}$ \\
\hline \multicolumn{7}{|l|}{ DECON: } \\
\hline Building Hastes & $1.0 \times 10^{-6}$ & 0.51 & 0.03 & $8.2 \times 10^{4}$ & $4.2 \times 10^{-2}$ & $2.5 \times 10^{-3}$ \\
\hline $\begin{array}{l}\text { Wastes Exhumed Onsite } \\
\text { Totals for DECON }\end{array}$ & $1.0 \times 10^{-6}$ & 0.51 & 0.03 & $\frac{3.0 \times 10^{6}}{3.1 \times 10^{6}}$ & $\frac{1.5 \times 10^{0}}{1.5 \times 10^{0}}$ & $\frac{9.0 \times 10^{-2}}{9.0 \times 10^{-2}}$ \\
\hline
\end{tabular}

(a) Accident frequencies are from Reference 6 .

(b) Assuming a truck transportation distance of $1600 \mathrm{~km}$ round-trip, with 51 trips required for building wastes and 1877 trips required for exhumed wastes.

(c) Rounded to two significant figures. 


\section{REFERENCES}

1. E. S. Murphy and G. M. Holter, Technology, Safety and Costs of Decommissioning a Reference Low-Level waste Burial Ground, NUREG/CR-0570, Prepared by Pacific Northwest Laboratory for the U.S. Nuclear Regulatory Commission, June 1980 .

2. United Nations Scientific Committee on the Effects of Atomic Radiation, Ionizing Radiation: Levels and Effects, Volume 1, United Nations, pp. 29-63, 1972 .

3. H. K. Elder and D. E. Blahnik, Technology, Safety and Costs of Decomissioning a Reference Uranium Fuel Fabrication Plant, NUREG/CR-1266, Prepared by Pacific Northwest Laboratory for the U.S. Nuclear Regulatory Commission, October 1980.

4. Operational Accidents and Radiation Exposure Experiences within the U.S. AEC 1943-1970, WASH-1192, 1971.

5. American National Standards Institute, Method of Recording and Measuring Work Injury Experience, ANSI $216.1,1967$.

6. Directorate of Regulatory Standards, Environmenta] Safety of Transportation of Radioactive Materials to and from Nuclear Power Plants, WASH-1238, U.S. Atomic Energy Commission, Washington, D.C., 1972.

7. Technology for Commercial Radioactive Waste Management, DOE/ET-0D28, Vol. 4, Chapter 6.2, Prepared by Pacific Northwest Laboratory for the U.S. Department of Energy, Richland, Washington, May 1979.

8. U.S. Code of Federa] Regulations, Title 49, Parts 17D-189, "Transportation," Superintendent of Documents, GPO, Washington, D.C. 20555, January 1977.

9. Environmental Aspects of Commercial Radioactive Waste Management, DOE/ET0029 , Volume 2, Chapter 7.3, Prepared by Pacific Northwest Laboratory for the U.S. Department of Energy, Richland, Washington, May 1979. 


\subsection{DISCUSSION OF STUDY RESULTS}

There are no commercial $U_{6}$ facilities for which decommissioning is reported in the open literature and for which direct comparisons can be made with the results of this study. DECON is the most likely decomissioning alternative for commercial $U_{6}$ plants. DECON of a facility requires that contaminated components, building surfaces and materials either be: 1) decontaminated to unrestricted release levels, or 2) packaged and shipped to an authorized disposal site.

SAFSTOR would be an acceptable decommissioning alternative for facilities where the owner wished to keep open the option of later reactivating the facility or if waste disposal space is not available at the time of decomissioning.

If the owner wants to maintain the site for nuclear use, DECON of the plant with stabilization and long-tem care of the waste lagoon site would be the least expensive method of decomissioning. However, the acceptability of this method by the NRC would have to be negotiated on a case-by-case basis.

Major conclusions of this study related to technology, cost, and safety are discussed in the following sections.

\subsection{DECOMMISSIONING TECHNOLOGY}

No major technical impediments exist to the successful decommissioning of uranium containment facilities. Decommissioning of UF 6 plants can be accomplished using technology and equipment that are in common industrial use.

The technology for the removal of radioactivity from contaminated surfaces is based on a cleaning technology that has been established for several decades. Almost all of the procedures and chemicals used in decontaminating nuclear equipment and facilities were first developed and used for cleaning equipment and facilities in non-nuclear industries.

Although no $\mathrm{UF}_{6}$ plants have been decomissioned, experience has been gained in decommissioning fuel cycle facilities and decontamination techniques 
are well documented. (1-4) Decormissioning involves many of the same procedures and techniques that are used to decontaminate a facility during its operating Iifetime.

Decommissioning of the waste lagoons may involve onsite burial with site stabilization procedures or it may involve the removal of radioactive waste and contaminated soil. A variety of techniques exist for stabilizing the residues in the lagoons to prevent radionuclide transport. These techniques are described in detail in another report ${ }^{(5)}$ in this series. The removal of radioactive materials such as the waste lagoon residues can be accomplished using standard earthmoving techniques and equipment.

\subsection{DECOMMISSIONING COSTS}

The decontamination of uranium-contaminated facilities is a labor-intensive, hands-on effort. Thus, labor is a major fraction of the total decommissioning costs. Development of facility and equipment designs and decontamination systems and techniques that can minimize labor could reduce overall decomissioning costs for UF 6 facilities.

The cost of handling, packaging, transporting, and disposing of radioactive waste materials is a significant fraction of the total decommissioning cost. Development of facility designs and decontamination techniques that minimize the quantities of contaminated material that must be disposed of as radioactive waste could reduce overall decomissioning costs and the waste management burden.

One of the most significant waste management items for the reference $U_{6}$ plant is the disposal of the waste lagoon residues. The solvent extraction wastes contain uranium that can be potentially valuable to the plant owner. It is estimated that the uranium residues will have a value of about $\$ 2.8$ milion by the end of the 40-year plant life. Thus, there is an economic incentive to process the waste and recover the residual uranium in addition to the advantage of removing of the waste material, thereby completing the DECON alternative. 


\subsection{PUBLIC AND OCCUPATIONAL SAFETY}

Workers engaged in the decommissioning of fuel cycle facilities generally experience the same levels of radiation exposure as workers engaged in normal facility operations. An exception exists for decommissioning operations that result in the production of significant quantities of airborne radioactivity. Operations in an environment with the potential for high inhalation exposure to radiation may require worker use of protective respiration equipment. The use of this equipment could result in a reduction of the inhalation dose by one or two orders of magnitude.

Decommissioning studies of reference fuel cycle facilities have shown that the 50-year committed dose equivalent to the populace living within 80 kilometers of the site, from airborne releases during normal decommissioning operations, is a small fraction of the dose that results from naturally occurring radiation. Potential radiation doses to the pubtic from postulated decommissioning accidents are also found to be small. The impact on public safety from decommissioning of $\mathrm{UF}_{6}$ plants is therefore estimated to be negligible. 


\section{REFERENCES}

1. J. W. Ayres, ed., Decontamination of Nuclear Reactors and Equipment, The Ronald Press Co., New York, New York, 1970.

2. W. E. Sande, et at., Decontamination and Decommissioning of Nuclear Facilitjes: A Literature Search, BNWL-1917, Pacific Northwest Laboratory, Richland, Washington, May 1975.

3. G. J. Konzek and C. R. Sample, Decommissioning of Nuclear Facilities - An Annotated Bibliography, NUREG/CR-0131, Pacific Northwest Laboratory for U.S. Nuclear Regulatory Conmission, October 1978.

4. C. S. Fore and N. P. Knox, Decommissioning of Nuclear Facilities - A Selected Bibliography, Volume T, ORNL/EIS-T54/VT, Oak Ridge National Laboratory, Oak Ridge, Tennessee, September 1979.

5. E. S. Murphy and G. M. Holter, Technology, Safety and Costs of Decommissioning a Reference Low-Level Waste Burial Ground, NUREG/CR-D570, Pacific Northwest Laboratory for U.S. Nuclear Regulatory Commission, June 1980. 


\subsection{CONSIDERATIONS FOR THE FACILITATION OF DECOMMISSIONING}

Titie 10 Code of Federal Regulations, Part 50, Appendix F.4 describes the Nuclear Regulatory Commission's position regarding facilitation of decommissioning of fuel reprocessing plants: "A design objective shall be to facilitate decontamination and removal of all significant radioactive wastes at the time the facility is permanently decommissioned." Application of this NRC objective to other fuel cycle facilities is a logical extension of the intention of this regulation. In addition, NRC Regulatory Guide 8.8, Information Relevant to Ensuring that 0ccupational Radiation Exposures at Nuclear Power Stations be as Low as is Reasonably Achievable (ALARA), explicitly points out that "design concepts and station features should reflect consideration of the activities of station personnel (including decontamination and decommissioning) that might be anticipated."

This study on decomissioning of a uranium hexafluoride conversion (UF ${ }_{6}$ ) plant describes activities that can be used to conceptually decomission a reference facility. With this study as a basis, insights have been gained as to plant design characteristics that could simplify the task of decommissioning. This section summarizes some of these potential plant and equipment design features.

It is recognized that some of the considerations intended to enhance decommissioning may not always be compatible with those plant characteristics that are desirable for normal production operations. Some of the characteristics may be also be prohibitively expensive. However, the aim of this discussion is to point out design characteristics that would expedite and simplify the decomissioning task. These findings regarding desirable features for decommissioning are presented with no attempt to rank their relative importance or to determine impacts on the rest of the plant designs, on plant production operations, or on plant process performance. These insights are aimed only at areas that present obvious complexity or difficulty to decommissioning a $U_{6}$ conversion plant; they are not all-inclusive, and do not consider details, side effects, or variations of the alternatives. Such as analys is would require an in-depth study beyond the scope of this report. 
The general criteria used in selecting design features for consideration are based on the effect they might be expected to have on decreasing deconmissioning cost, improving occupational or public safety, reducing total decomissioning time, creating less radioactive waste, and the general ease of performing the decommissioning. In evaluating new design features for future decommissioning application, appropriate balance must be maintained between designs that meet these criteria and potential negative effects on plant construction and operating costs and operating characteristics. For the considerations given below, qualitative comments are made about the possible effects a given design feature might have in satisfying the selection criteria.

Three periods in which specific decommissioning facilitation activities may be implemented are design and construction, operation, and decomissioning. The benefits of various facilitation activities within these periods are discussed in the following subsections.

\subsection{DESIGN AND CONSTRUCTION}

The design and construction period affords an early opportunity to take steps to facilitate decommissioning. Facilitation steps that can be taken during the two phases of this period are discussed below.

\subsubsection{Design}

Careful attention to design of the equipment and facility can help reduce efforts required for routine maintenance and eventual decomissioning. Standardization of plant design would allow direct application of experience gained in the operation and decommissioning of one facility to other similar plants. Improvement of access to contaminated equipment would reduce worker exposure and effort during maintenance and decommissioning. Installation of removable wall and ceiling panels could be used for this purpose. Minimizing crevices in process equipment and hoods would reduce holdup of radioactive materials, allowing easier decontamination. Hoods and process equipment designed for easy disassembling without cutting would facilitate maintenance and decontamination, possibly allowing extended use of the equipment for salvage as scrap upon decommissioning. 


\subsubsection{Construction}

Accurate as-built drawings and photos should be kept to facilitate later maintenance, decontamination, and decommissioning efforts. Scale models of the facility with details for concrete pours and penetrations, and placement of reinforcing steel, and dry mock-ups of equipment would aid in developing better maintenance, decontamination and deconmissioning procedures. Exposure and effort of workers could be reduced as a result.

Pretreatment of a 11 surfaces subject to radioactive contamination and/or corrosion prior to operation of the facility would reduce effort required for later decontamination by minimizing the holdup of materials, making surfaces more corrosion resistant, and reducing the amount of surface material to be removed during decontamination.

Pre-polishing of metal piping and process equipment may be accomplished by vibratory finishing followed by electropolishing. Vibratory finishing is a process in which parts are placed in a bath containing abrasive particles in a cleaning solution and vibrated at high frequency. Electropolishing is essentially an electroplating process operated in reverse. When used together, these processes produce a very smooth surface which resists material holdup and corrosion. These processes can be most fully exploited by installing equipment for vibratory finishing and electropolishing at the facility during construction. The capability will then exist for use of these surface treatment techniques during all three periods of the plant life cycle.

Concrete or brick floors, walls, and ceilings may be made much more contamination-resistant by seaing or covering them. Concrete and brick surfaces may be sealed and covered using epoxy or phenolic coatings. Linoleum or steel plate may be used to cover areas of concrete surface. These coverings are preferable to tile, which may allow contaminants to leak into cracks. The surface of contaminated concrete usually must be removed to a depth of 4 inches for decommissioning purposes. Effective methods for preventing surface contamination of concrete and brick will greatly aid cleanup efforts, and reduce the amount of contaminated material that must be removed during decomissioning. 
The capability to flush process equipment, piping, tanks, and hoods should be provided to facilitate routine clean-up, maintenance, and eventual decommis. sioning. Covered and/or sealed ceilings, walls, floors, and auxilliary equipment should be spray rinsible. Spray rinsing equipment should be installed to take advantage of this feature, and appropriate drains or sumps, especially in dry processing areas, should be provided. These provisions would minimize timeconsuming manual cleaning techniques.

Provisions for remote maintenance of equipment may be desirabie in some instances from the standpoint of reduction of personnel exposure and effort required to perform some maintenance tasks due to the reduced amount of premaintenance cleanup required. If such provisions are included, the role of the use of this equipment for decommissioning should be incorporated into their design.

\subsection{OPERATION}

Routine maintenance and decontamination activities may lead to the development of special tools or techniques that will reduce the effort required to complete a specific task and therefore reduce worker exposure. These tools or techniques may later prove to be useful during decommissioning. Information regarding their design and use should be recorded in detail.

Maintenance procedures providing for routine decontamination of plant areas and equipment subject to holdup and/or spills will help minimize the amount of material that must be removed during decommissioning. Frequent recovery or disposal of materials stored in settling ponds and effluent lagoons would reduce the amount of waste to be disposed of during decommissioning.

The total volume of radioactive waste due to routine operation and decommissioning can be reduced by practicing various radwaste reduction techniques. Combustible solids and some liquids may be reduced in volume by incineration, with a typical volume reduction of at least 5 to 1 . Process equipment, piping, tools, auxiliary equipment, and hoods may be partially or completely decontaminated by vibratory finishing and electropolishing. These techniques are 
effective in removing surface deposits and corrosion-containing radioactive contamination. Where only corrosion and surface contamination exist, vibratory finishing and electropolishing may remove enough of these materials so the part may be returned to active service, or disposed of with other noncontaminated waste. The amount of contaminated material remaining to be disposed of is thus reduced to the corrosion and surface materials the processes removed.

Computerized data systems can be used to store information, and make it more readily available. Information concerning routine operation and maintenance procedures, unusual techniques, and experiences from other facilities would be useful in developing better procedures during operation and decomissioning. Scale modeis should be updated to show areas of high radiation dose and system modification, information which would be useful during operation, maintenance, and decomissioning to reduce workers exposure and effort.

\subsection{DECOMMISSIONING}

Features designed into the facility and equipment, techniques, and procedures developed during the operation of the facility can be exploited to reduce worker exposure and effort during decommissioning.

Some special decommissioning tools have been developed for removal of concrete and stee]. Methods for cutting and/or demolishing concrete include thermic lancing, explosive cutting, and heating followed by wrecking. Methods for cutting or sectioning steel components include the plasma arc torch, arc saw, oxyacetylene torch, explosive cutting, and thermic lancing.

Information stored in computerized data systems can faciljtate decommissioning, particularily in the case of deferred decontamination. In that case, operating personnel will probably not be available for consultation, and accurate information concerning maintenance procedures and experiences recorded during the deconnissioning of similar facilities will be helpful.

Reduction of radioactive waste volume during decomissioning should be a primary goal. Methods for achieving this goal are available for different kinds of waste. In many cases, combustible solid and some liquid wastes can be 
incinerated for a significant volume reduction. For surface contaminated process equipment, vibratory finishing and electropol shing can often be used to remove corrosion and surface deposits to the extent that the equipment can be released as uncontaminated. In such cases, only the contaminated surface material removed will require disposal at a licensed burial site. Concrete that has surface contamination can be surface-spalled, to a depth of 50 to $90 \mathrm{~mm}$, so that only the spalled material must be disposed of at a licensed burial site. Concrete that has been sealed or covered may not require spalling or licensed burial.

Recovery of stored materials, such as the reprocessing of uranium-bearing muds of settling ponds and storage lagoons, can reduce the amount of stored wastes that must be disposed of at licensed burial sites, and at the same time result in the recovery of valuable materials. 


\subsection{GLOSSARY}

Abbreviations, acronyms, symbols, terms, and definitions used in this study and directly related to deconmissioning work and related technology are defined and explained in this section. The section is divided into two parts, with the first part containing abbreviations, acronyms, symbols, and a conversion table to International system of Units (SI), and the second part containing terms and. definitions (including those used in a special sense for this study). Common terms covered adequately in standard dictionaries are not included.

\subsection{ABBREVIATIONS, ACRONYMS, SYMBOLS, AND SI UNITS}

Abbreviations and Acronyms

AEC

ALARA

CFR

$\mathrm{Ci}$

$\mathrm{DF}$

DOT

DPM

EDTA

FSAR

GB

HEPA

HP

HVAC

LWR

$\mathrm{mR}$

mrad

mrem

MT
Atomic Energy Commission

As Low As is Reasonably Achievable (a)

Code of Federal Regulations (a)

Curie ${ }^{(a)}$

Decontamination Factor $(a)$

Department of Transportation

Disintegrations per Minute ${ }^{(a)}$

Ethylenediamine tetraacetic acid

Final Safety Analysis Report

Glove Box

High Efficiency Particulate Air (Filters)

Health Physicist(a)

Heating, Ventilation and Air Conditioning

Light Water Reactor

Milliroentgen (a)

Militirad (a)

Millirem, see rem also

Metric Ton (a)

(a) See Section 14.2 for additional information or explanation. 


\begin{tabular}{|c|c|}
\hline MTHM & Metric Ton of Heavy Metal \\
\hline MWd/MTU & $\begin{array}{l}\text { Therma } 7 \text { Megawatt-day per Metric Ton of Uranium, } \\
\text { the Burnupla) }\end{array}$ \\
\hline NRC & Nuclear Regulatory Commission \\
\hline Q.A. & Quality.Assurance $e^{(a)}$ \\
\hline Q.C. & Quality Control ${ }^{(a)}$ \\
\hline$R$ & Roentgen $(a)$ \\
\hline rad & Radiation Absorbed Dose ${ }^{(a)}$ \\
\hline rem & Roentgen Equivalent $\operatorname{Man}^{(a)}$ \\
\hline SNM & Special Nuclear Material ${ }^{(a)}$ \\
\hline SS & Stainless Steel \\
\hline$S x$ & Solvent Extraction \\
\hline$T_{1} / 2, T_{R}$ & Half Life, Radiological (a) \\
\hline UF & Urea-formaldehyde \\
\hline $\mathrm{UF}_{6}$ & Uranium Hexafluoride Conversion \\
\hline
\end{tabular}

Symbols

a Alpha Radiation (a)

$B$ Beta Radiation (a)

$\gamma$ Gamma Radiation (a)

$X$ Chi, Concentration, $\mathrm{pCi} / \mathrm{m}^{3}$

Q Released Quantity of Radioactive Material, $\mathrm{Ci}$

Q' Release Rate of Radioactive Material, $\mathrm{Ci} / \mathrm{sec}$

$\bar{X} / Q^{\prime} \quad$ Chi-bar/Q prime, normalized annual average air concentration ( $\mathrm{pCi} / \mathrm{m}^{3}$ ) per $\mathrm{Ci} / \mathrm{sec}$ released, also written $\left.\mathrm{sec} / \mathrm{m}^{3}\right)$. Also called the annual average atmospheric dilution factor.

SI Units

SI units for use with radioactivity and ionizing radiations are as follows:

\begin{tabular}{|c|c|c|c|c|}
\hline Quantity & $\begin{array}{l}\text { New Named Unit } \\
\text { and Symbol }\end{array}$ & $\begin{array}{l}\text { In Other } \\
\text { SI Units }\end{array}$ & $\begin{array}{c}\text { 0ld Special } \\
\text { Unit and } \\
\text { Symbol } \\
\end{array}$ & $\begin{array}{l}\text { Relationship } \\
\text { New to old Units }\end{array}$ \\
\hline Exposure & -- & coulomb $/ \mathrm{kg}(\mathrm{C} / \mathrm{kg})$ & röentgen ( $R$ ) & $1 \mathrm{c} / \mathrm{kg} \approx 3876 \mathrm{R}$ \\
\hline Absorbed dose & gray (Gy) & joule $/ \mathrm{kg}(\mathrm{J} / \mathrm{kg})$ & $\operatorname{rad}(\mathrm{rad})$ & $1 \mathrm{~Gy}=100 \mathrm{rad}$ \\
\hline $\begin{array}{l}\text { Dose equivalent } \\
\text { Activity }\end{array}$ & $\begin{array}{l}\text { sievert }(\mathrm{Sv}) \\
\text { becquerel }(\mathrm{Bq})\end{array}$ & $\begin{array}{l}\mathrm{J} / \mathrm{kg} \\
\text { seconds }^{-1}\left(\mathrm{~s}^{-1}\right)\end{array}$ & $\begin{array}{l}\text { rem (rem) } \\
\text { curie (Ci) }\end{array}$ & $\begin{array}{l}1 \mathrm{~Sv}=100 \mathrm{rem} \\
1 \mathrm{~Bq} \$ 2.70 \times 10^{-11} \mathrm{Ci}\end{array}$ \\
\hline
\end{tabular}

(a) See Section 14.2 for additional information or explanation. 


\subsection{GLOSSARY DEFINITIONS}

Actinides:

Activity:

Airborne Radioactive Material:

ALARA :

Aipha Decay:

Alpha Particle:

Alpha Emitter:

Atomic Number (Z):

Background:

Bag Out:

Beta Decay:
A series of heavy radioactive metallic elements of increasing atomic number $(Z)$ beginning with actinium (89) or thorium (90) through element hahnium of atomic number 105 .

See Radioactivity.

Radioactive particulates, mists, fumes, and/or gases in air.

A philosophy to maintain exposure to radiation As Low As is Reasonably Achievable.

Radioactive decay in which an alpha particle is emitted. This transformation lowers the atomic number of the nucleus by two and its mass number by four.

A positively charged particle emitted by certain radioactive materials. It is made up of two neutrons and two protons, hence it is identical with the nucleus of a helium atom. It is the least penetrating of the three cormon types of radiation (a)pha, beta and gamma) emitted by radioactive material.

A radionuclide that undergoes transformation by emission of alpha particles.

The number of protons in the nucleus of an atom; also its positive charge. Each chemical element has its characteristic atomic number, and the atomic numbers of the known elements form a complete series from 1 (hydrogen) through 105 (hahnium).

That level of radioactivity from sources other than the one directly under consideration, in this case those existing without the presence of the U-Fab plant.

Term used to describe the techniques for transferring objects into and/or out of glove boxes without loss of confinement, utilizing various types of containers, sealing and packaging techniques.

Radioactive decay in which a beta particle is emitted or in which an orbital electron capture occurs. 
Beta Particle:

Burial Grounds:

Burnup, Specific:

Byproduct Materia1:

Calcine:

Cask:

Chemical Limits:

Code of Federal

Regulations (CFR):

Contact Maintenance:
An electron, of either positive or negative charge, which has been emitted by an atomic nucleus in a nuclear transformation.

Areas designated for storage of packaged radioactive wastes in soils just below the surface.

The total energy released per unit mass of a nuclear fuel. It is comonly expressed in megawatt-days per metric ton of fuel material. (Also called fuel irradiation lever.)

Any radioactive material (except special nuclear material) yielded in or made radioactive by exposure to the radiation incident to the process of producing or utilizing special nuclear material.

To heat a substance to a high temperature, but below its melting point, causing loss of volatile constituents such as moisture. Material produced by this process is also called Calcine.

A heavily shielded shipping container for radioactive materials. Some casks weigh as much as 100 metric tons.

Maximum concentrations or quantities imposed upon chemical releases to the environment in gaseous or liquid effluents discharged from a facility, and consistent with known air or water quality standards.

The Code of Federal Regulations is a documentation of the general rules by the Executive departments and agencies of the Federal Government. The Code is divided into 50 titles that represent broad areas subject to Federal regulation. Each title is divided into Chapters that usually bear the name of the issuing agency. Each Chapter is further subdivided into Parts covering specific regulatory areas.

"Hands-on", or maintenance performed by direct contact of personnel with the equipment. It includes maintenance with protective equipment or clothing, such as through gloves in glove boxes. Most nonradioactive maintenance is contact maintainance. 

Contamination: Undesired materials that have been deposited on the surfaces, or are internally ingrained into structures or equipment, or that have been mixed with another material.
Critical:
Critical Mass:
Curie:
A condition wherein a medium is capable of sustaining a nuclear chain reaction at a constant rate.
Prompt critical is being capable of sustaining a chain reaction without the aid of delayed neutrons
The mass of fissionable material that will support a self-sustaining nuclear chain reaction.
A special unit of radioactivity. One curie equals $3.7 \times 1010$ nuclear transformations per second. (Abbreviated Ci.) Several fractions of the curie are in common usage:

Custodial SAFSTOR:

Decay, Radioactive:

Decommissioning:
- Millicurie. One-thousandth of a curie. Abbreviated $\mathrm{mCi}\left(3.7 \times 10^{7} \mathrm{~d} / \mathrm{s}\right)$.

- Microcurie. One-millionth of a curie. Abbreviated $\mu \mathrm{Ci}\left(3.7 \times 10^{4} \mathrm{~d} / \mathrm{s}\right)$.

- Nanocurie. One-billionth of a curie. Abbreviated $\mathrm{nCi}(37 \mathrm{~d} / \mathrm{s})$.

- Picocurie. One-millionth of a microcurie. Abbreviated $\mathrm{pC} i$; replaces the term $\mu \mathrm{CC} i$ $(0.037 \mathrm{~d} / \mathrm{s})$.

A minimum cleanup and decontamination preparation followed by safe storage and terminated by deferred decontamination. The active protection systems (i.e., ventilation, utilities, fire) are kept in service, the site is secured against intrusion by physical barriers and by guards, and use of the facjlity and site is limited to nuclear activities.

A spontaneous nuclear transformation in which a particle, gamma radiation, or $x$-ray radiation are emitted.

The retirement from active service of nuclear facilities, including all activities to remove the radioactive material to levels that allow unrestricted release of the facility and its site. 
DECON:

Decontamination:

Decontamination

Agents:

Decontamination Factor (DF):

Deferred Decontamination:

Design Basis

Accident:

Discount Rate:

Disintegration, Nuclear:

Disintegration Rate:

Dismantlement:
Those actions required inmediately after shutdown to remove sufficient radioactive or contaminated materials from the facility and site, to permit release of the property for unrestricted use.

Those activities employed to reduce the levels of contamination in or on structures, equipment and materials. Also used to infer decontamination to levels corresponding to unrestricted release.

Those chemical materials used to effect decontamination.

The ratio of the initial concentration of an undesired material to the final concentration resulting from a treatment process. The term may also be used as a ratio of quantities.

Those actions required after the safe storage period of SAFSTOR to disassemble and remove sufficient radioactive or contaminated materials from the facility and site, to permit release of the property for unrestricted use.

A postulated accident believed to have the most severe expected impacts on a facility. It is used as the basis for safety and structural design.

The rate of return on capital that could have been realized in al ternative investments, if the money were not committed to the plan being evaluated, i.e., the opportunity costs of a]ternative investments. This cost is equivalent to the weighted average cost of capital.

The transformation of the nucleus of an atom from one element to another, characterized by a definite half-life and the emission of particles or radiation.

The rate at which disintegrations occur, characterized in units of inverse time; i.e., disintegrations per minute $(\mathrm{dpm})$, etc.

Those actions required to disassemble and/or remove radioactive or contaminated materials from the facility and site. 
Dispersion:

Disposal:

Dose, Absorbed:

Dose, Equivalent:

Dose, Occupationa1:

Dose Rate:

Dosimeter:

Enrichment:

ENTOMB :

Exposure:
A process of mixing one material within a larger quantity of another. For example, the mixing of material released to the atmosphere with air causes a reduction in concentration with distance from the source.

The disposition of materials with the intent that the materials will not enter man's environment in sufficient amounts to cause a health hazard.

The mean energy imparted to matter by ionizing radiation per unjt mass of irradiated material at the place of interest. The unit of absorbed dose is the rad. One rad equals 0.01 joules/kilogram in any medium (100 ergs per gram).

Expresses the amount of radiation that is effective in the human body, expressed in rems. Modifying factors associated with human tissue and body are considered. Equivalent dose is the product of absorbed dose multiplied by a quality factor multiplied by a distribution factor. Referred to as Dose in this report.

The exposure of an individual to radiation as a result of his employment, expressed in rems.

The radiation dose delivered per unit time and measured, for instance, in rems per hour.

A device, such as a film badge or ionization chamber, that measures radiation dose.

The ratio (usually expressed as a percentage) of fissile isotope to the total amount of the element (e.g., the $\%$ of $235 \mathrm{U}$ in uranium.)

The encasement of radioactive materials in concrete or other structural materials sufficiently strong and durable to assure retention of the radioactivity until it has decayed to levels that permit unconditional release of the site.

A measure of the ionization produced in air by $x$ or gamma radiation. It is the sum of the electrical charges on all ions of one sign produced in air when all electrons liberated by photons in a volume element of air are completely 
Facility:

Fission:

Fission Products:

Fluoride Waste:

Food Chain:

Fuel Assembly:

Fuel Cycle:

Fue] Element: stopped in air, divided by the mass of air in the volume element. The special unit of exposure is the roentgen. (See Roentgen.)

The physical complex of buildings and equipment within a site.

The splitting of a heavy atomic nucleus into two lighter parts (atomic nuclides of lighter elements), accompanied by the release of a relatively large amount of energy and generally one or more neutrons. Fission can occur spontaneously but usually it is caused by nuclear absorption of gamma rays, neutrons, or other particles.

The lighter atomic nuclides (fission fragments) formed by the fission of heavy atoms. It also refers to the nuclides formed by the fission fragments' radioactive decay.

Liquid waste generated primarily by the hydrofluorination system off-gas scrubber. This waste collected in the fluoride waste lagoons.

The pathways by which any material (such as radioactive material from fallout) passes through man's environment through edible plants and/or animals to man.

A grouping of fuel elements (hollow rods filled with nuclear fuel for LWRs) that supply the nuclear heat in a nuclear reactor. A fuel element or rod is the smallest structurally discrete part of a reactor or fuel assembly that has nuclear fuel as its principal constituent.

The series of steps involved in supplying fuel for nuclear power reactors, handling the spent fuel and the radioactive waste, including transportation.

Head end: Mining, milling, conversion, enrichment, and fabrication of fuel.

Back end: Includes reactors, spent fuel storage, spent fuel reprocessing, mixed-oxide fuel fabrication and waste management.

A rod, tube, or other form into which nuclear fuel is fabricated to use in a reactor. 
Gamma Rays:

Gaseous:

Glove Box:

Greenhouse:

Guard:

Half-Life, Biological:

Half-Life, Effective:

Half-Life Radioactive:

Health Physicist:
Short-wavelength electromagnetic radiation. Gamma radiation frequently accompanies alpha and beta emissions and always accompanies fission. Gamma rays are best stopped or shielded against by dense materials such as lead or uranium. These rays usually originate from within the nucleus of the atom.

Material in the vapor or gaseous state, but can include entrained liquids and solids. A gas will completely fill its container regardless of container shape or size.

A box, usually made of stainless steel and large panes of glass or transparent rigid plastic, in which workers using gloves attached to, sealed, and passing through, openings in the box can safely handle radioactive materials from the outside by inserting their hands into the gloves and manually performing manipulations.

In nuclear terms, a temporary structure, frequently constructed of wood and plastic $f i 1 \mathrm{~m}$, used to provide a confinement barrier between a radioactive work area and a nonradioactive area.

An individual whose primary duty is the guarding and protection of material against the ft and/or the protection of the facility against vandatism or undesired intruders.

The time required for a biological system, such as a man or animal, to eliminate by natural processes, half the amount of a substance that has been absorbed by it.

The time required for a radionuclide contained in a biological system, such as a man or animal, to reduce its radioactivity by half as a combined result of radioactive decay and biological elimination.

The time in which half the atoms of a particular radioactive substance disintegrate to another nuclear form. Each radionuclide has a unique half-life. Measured half-lives vary from millionths of a second to billions of years.

A person trained to perform radiation surveys, oversee radiation monitoring, estimate the degree of radiation hazard, and advise on operating procedures for minimizing radiation exposures. 
Health Physics:

Heavy Meta 1:

Hood:

Hot Spots:

Immobilization:

Intrusion Alarm:

Ion Exchange:

Lagoon Waste:

Layaway:

Licensed Materia]:
The science concerned with recognition, evaluation, and control of heal th hazards from radiation.

Jargon used in reference to metals with atomic numbers 90 and greater. It usually refers to nuclear fissile or fertile fuels such as thorium, uranium, and plutonium.

Vented containment space, enclosed on 5 sides, with the sixth side covered by a movable glass window to allow access and to maintain sufficient in-flow of air and splash control to protect the worker from the hazardous materials handled inside.

Areas of radioactive contamination higher than average.

Treatment and/or emplacement of materials (e.g., radioactive contamination) so as to impede its movement.

Concepts for interim storage include bulk or compartmented storage of solid, 1 iquid and gaseous wastes or other materials.

A means of detecting intrusion of individuals into a protected area utilizing an electromechanical, electro-optical, electronic, mechanical or similar device with a visible or audible alarm signal.

A chemical process involving the selective absorption or desorption of various chemical ions in a solution onto a solid material, usually a plastic or resin. The process is used to separate and purify chenlicals, such as fission products from plutonium or "hardness" from water (i.e., water softening).

Waste in the solvent extraction waste lagoons or the fluoride waste lagoons.

See Custodial SAFSTOR.

Nuclear source material, special nuclear material, or nuclear by-product material received, possessed, used, or transferred under a license issued by the Nuclear Regulatory Commission. 
Long-Lived Nuclides: For this study, radioactive isotopes with long half-lives typically taken to be greater than about ten years. Most nuclides of interest to waste management have half-lives on the order of one year to millions of years.

Management (Waste): The planning, execution, and surveillance of essential functions related to radioactive waste, including treatment, solidification, packaging, interim or long-term storage, transportation and disposal.

Man-rem:

A measure of radiation dose distributed to a population. To calculate radiation dose to the population, the dose equivalent in rem received by each person in the population is summed.

Mass Number:

The number of nucleons (protons and neutrons) in the nucleus of an atom. (Symbol: A).

Maximum Exposed Individual:

The hypothetical member of the public who receives the maximum radiation dose to an organ of reference. For the common case where exposures from airborne radionuclides result in the highest radiation exposure, this individual resides at the location of the highest airborne radionuclide concentration and eats food grown at that location.

Megawatt-day:

A unit for expressing the energy generated in a reactor; specifically, the number of millions of watt-days of heat output per metric ton of fuel in the reactor. Also, the net electrical output in millions of watts of electrical energy averaged over one day.

Megawatts per Metric Ton of Uranium:

Amount of thermal megawatts produced per metric ton of uranium.

Amount of thermal megawatt-days produced per

Megawatt Days per

Metric Ton of Uranium: metric ton of uranium; also called burnup. (See also specific power.)

Metric Ton:

1000 kilograms (See Tonne.)

Mixed Oxide:

A mixture of uranium dioxide and plutonium dioxide.

Monitoring:

Taking measurements or observations for recognizing the status or adequacy, or significant changes in conditions or performance of a facility or area. 
Mothbal1:

Norma1 Operating

Conditions:

Nuclear Reaction:

Offsite:

Onsite:

Operable:

Overpack:

Package:

Packaging:

Passive SAFSTOR:

Plant:

Present Value of Money:

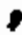

Primary Wastes:
See Passive SAFSTOR

Operation (including startup, shutdown, and maintenance) of systems within the normal range of applicable parameters of an operating facility.

A reaction involving a change in an atomic nucleus, such as fission, fusion, particle capture, or radioactive decay.

Beyond the boundary line marking the limits of plant property.

Within the boundary line marking the limits of plant property.

Capable of performing the required function.

Secondary (or additional) external containment or cushioning for packaged materials.

The packaging plus the contents of radioactive materials.

The assembly of radioactive material in one or more containers and other components necessary to assure compliance with prescribed regulations.

A partial cleanup and decontamination preparation followed by safe storage and terminated by decontamination. All systems are deactivated, the structures are secured by rigid physical barriers and continuous remote monitoring, and the plant is limited to nuclear use only, while the site may have non-nuclear uses.

The physical complex of buildings and equipment, including the site.

The present value of a future stream of costs or payments is the present investment necessary to secure or yield the future stream of payments with compound interest at a given discount or interest rate.

Wastes that are generated as a part of the principal operation of a facility. Secondary wastes are generated from supporting operations, such as waste treatment. 
Process Cells:

Process Equipment:

Protective Clothing:

Protective Storage:

Protective Survey:

Quality Assurance:

Quality Control:

Rad:

Radiation:
Shielded rooms housing (radioactive) processing systems.

The functional equipment items or systems associated directly with the operation of a chemical or mechanical operation.

Special clothing worn by a person in a radioactively contaminated area to minimize the potential for contamination of his body or personal clothing.

See Passive SAFSTOR.

An evaluation of the radiation and its hazards incidental to the production, use or existence of radioactive materials. It normally includes a physical survey of the arrangement and use of equipment and measurements of the radiation dose rates under expected conditions of use. Also called protection survey.

The systematic actions necessary to provide adequate confidence that a material, component, system, process, or facility performs satisfactorily, or as planned, in service.

The quality assurance actions that control the attributes of the material, process, component, system, or facility in accordance with predetermined quality requirements.

A unit of absorbed dose. The energy imparted to matter by ionizing radiation per unit mass of irradiated material at the place of interest. One rad equals 0.01 joule/kilogram of absorbing material.

(1) The emission and propagation of radiant energy: for instance, the emission and propagation of electromagnetic waves, or of sound and elastic waves. (2) The energy propagated through space or through a material medium. for example, energy in the form of alpha, beta, and gamma emissions from radioactive nuclei. 
Radiation Area:

Radioactive

Series:

Radioactivity:

Radioactivity, Natural:

Radiological Protection:

Regulatory Guides:
Any area, accessible to personne1, in which there exists radiation at such levels that a major portion of the body could receive in any one hour a dose in excess of 5 millirem, or in any 5 consecutive days a dose in excess of 100 millirems. (10 CFR 20.202)

See background.

Al1 radiation coming from a source housing except the useful beam.

Any material or combination of materials which spontaneously emit ionizing radiation and which has a specific radioactivity in excess of 0.002 microcuries per gram of material.

(49 CFR 173.389 (e)).

A succession of nuclides, each of which transforms by radioactive disintegration into the next until a stable nonradioactive nuclide results. The first member is called the "parent," the intermediate members are called "daughters," and the final stable member is called the "end product."

The number of nuclear transformations occurring in a given quantity of material per unit of time with the emission of particles, gamma radiation, or $x$-ray radiation. Often shortened to "activity."

The property of radioactivity exhibited by more than fifty naturally occurring radionuclides.

Protection against the effects of internal and external exposure to radiation and to radioactive materials.

Regulatory Guides are issued by the NRC, to describe and make available to the public, methods acceptable to the NRC staff, for implementing specific parts of the NRC's regulations, to delineate techniques used by the staff in evaluating specific problems or postulated accidents, or to provide other guidance to applicants for nuclear operations. Guides are not substitutes for regulations and compliance with them is not explicitly required. Methods and solutions different from those set out in the guides may be acceptable if they provide 
Rem:

Remote Maintenance:

Reporting Levels:

Repository (Federal):

Restricted Area:

Roentgen:

SAFSTOR:

Safe Storage: a basis for the findings requisite to the issuance or continuance of a permit or license by the NRC.

A unit of radiation dose equivalence. The radiation dose equivalence in rems is numerically equal to the absorbed dose in rads multiplied by the quality factor, the distribution factor, and any other necessary modifying factors.

Maintenance by remote means, i.e., the operator is separated by a shielding wall from the item being maintained.

Those levels or parameters called out in the Environmental Technical Specifications, the Decommissioning Order, and/or the Amended License that do not limit decommissioning activities, but which may indicate a measurable impact on the environment.

A site owned and operated by the Federal Government for long-term storage or disposal of radioactive materials.

Any area to which access is controlled for protection of individuals from exposure to radiation and radioactive materials.

A unit of exposure to ionizing radiation. It is that amount of gamma or x-rays required to produce ions carrying one electrostatic unit of electrical charge (ejther positive or negative) in one cubic centimeter of dry air under standard conditions. One roentgen equals $2.58 \times 10^{-4}$ coulombs per kilogram of air. (See also Exposure.)

The decommissioning alternative wherein a preparatory period after shutdown is followed by safe storage, which, in turn, is terminated by deferred decontamination.

A period of time starting after the initial decommissioning activities cease and wherein surveillance and maintenance takes place. The duration of time can vary from a few years to more than 100 years; called "continuing care" in some other NRC decommissioning reports. 
Safety-Related:

Scarfing:

Secondary Wastes:

Security officer:

Shield:

Short-Lived

Radionuclides:

Shutdown:

Site:

Solid Radioactive Waste:

Solidification:
Structures, systems, and components whose functions tend to prevent or mitigate the exceeding of safety limits, as defined in Regulatory Guide 3.6, and set forth in Technical Specifications that are part of the Operating License for a nuclear power plant.

A technique used to mechanically decontaminate concrete by chipping, cutting, jackhammering, or blasting the surface layer(s) away.

Forms and quantities of all wastes that result from treatment of primary wastes or effluents.

A guard or watchman whose primary duty is the protection of material and property.

A body of material used to reduce the passage of particles or electromagnetic radiation. A shield may be designated according to what it is intended to absorb (as a ganma ray shield or neutron shield), or according to the kind of protection it is intended to give (as a background, or thermal shield).

It may be required for the safety of personnel or to reduce radiation enough to allow use of counting instruments for research or for locating contamination or airborne radioactivity.

For this study, those radioactive isotopes with half-lives less than about 10 years.

The time during which a facility is not in productive operation.

The geographic area upon which the facility is located that is subject to controlled public access by the facility ficensee (includes the restricted area as designated in the NRC 1 icense).

Material that is essentially solid and dry but may contain sorbed radioactive fluids in sufficiently small amounts as to be immobile.

Conversion of radioactive wastes (gases or Tiquids) to dry, stable solids. 
Solvent Extraction Waste:

Special Nuclear Material:

Specific Power (of Fuel Assemblies):

Surface Contamination:

Surveillance:

Survey:

Technica 7

Specifications:

Tonne:

Transuranic Elements:
Liquid Waste from the solvent extraction system. Primarily a solution of ammonium nitrate, nitric acid, heavy metal salts and uranium and daughter products of nomal uranium decay. This waste collected in the solvent extraction waste lagoons.

Plutonium, uranium enriched in the isotopes 233 or 235, and any other material as defined in 10 CFR 51 by the NRC.

Commonly expressed in units of thermal megawatts per metric ton of uranium (MW/MTU). It represents the rate at which thermal energy is extracted from the fuel; burnup, commonly expressed in thermal megawatt-days per metric ton of uranium (MWd/MTU), represents the total integrated energy extracted. For MOX fuel, the unit of fuel is a metric ton of heavy metal (MTHM); i.e., a metric ton of $(U+P u)$.

Contamination that is the result of the deposition and attachment of foreign materials to a surface.

Those activities necessary to assure that the site remains in a safe condition (including inspection and monitoring of the site, maintenance of barriers to access to radioactive materials left on the site, and prevention of activities on the site that might impair these barriers).

An evaluation of the radiation hazards incident to the production, use, release, disposal or presence of radioactive materiais or other sources of radiation under a specific set of conditions.

Requirements and limits that encompass nuclear safety but are simplified to facilitate use by plant operation and maintenance personnel. They are prepared in accordance with the requirement of 10 CFR 50.36, and are incorporated by reference into the amended license issued by the NRC.

A metric ton, or $1000 \mathrm{~kg}$, or $2204.6 \mathrm{ib}$.

Elements with atomic number ( $Z$ number) greater than 92 . 
Transuranic Waste:

Underground Solid

Waste Storage Area:

Wastes, Radioactive:

Wastes, Low-Level:

Wastes, High-Leve1:
Any waste material measured or assumed to contain more than a specified concentration (i.e., proposed as 10 nanocuries of alpha emitters per gram of waste, or more presently proposed as 100 nanocuries $/ \mathrm{cm}^{3}$ of waste $239_{U}$ ) of transuranic elements.

Area within an exclusion area where radioactive solid waste is stored by burial.

Equipment and materials (from nuclear operations) that are radioactive and for which there is no further known use.

Wastes containing types and concentrations of radioactivity such that little or no shielding to minimize personnel exposure is required.

Wastes resulting from the operation of the first cycle solvent extraction system, or equivalent, in a facjlity for reprocessing irradiated reactor fuels (10 CFR 50, App. F.2). It is also applied generally to radioactive wastes of other origins, where the rate of heat evolution becomes of concern in waste disposal or the external radiation dose rates are extremely high.

$x-$ ray:

A penetrating form of electromagnetic radiation emitted either when the inner orbital electrons of an excited atom return to their normal state (characteristic $x$-rays) or when a metal target is bombarded with high speed electrons. X-rays are always non-nuclear in origin; $i . e$. , they originate external to the nucleus of the atom. 


\section{REFERENCES}

American National Standard Glossary of Terms In Nuclear Science and Technology, American Nuclear Society, Hinsdale, IL, 1976.

McGraw-Hi11 Dictionary of Scientific and Technical Terms, McGraw-Hill, Inc., New York, NY, 1976.

Radiological Health Handbook, Public Health Service Publication No. 2016, Revised Edition, U.S. Government Printing Office, Washington, DC, January 1970.

Glossary of Nuclear Industry Terms, Standards and Specifications, Atomic Power Equipment Department, General Electric Company, San Jose, CA, September 1969. 

APPENDICES 


\section{APPENDIX A}

\section{REFERENCE URANIUM HEXAFLUORIDE CONVERSION FACILITY DESCRIPTION}

Major features of the reference uranium hexafluoride $\left(U_{6}\right)$ conversion plant are presented in Section 7. This appendix describes in more detail the processes used for $\mathrm{UF}_{6}$ conversion and the portions of the facility and site that are important to decommissioning. The detailed reference site description is presented in Appendix B.

The reference plant used in this study is representative of contemporary $\mathrm{UF}_{6}$ conversion plants in the United States. Existing plants are expected to require decommissioning in the future.

Much of the detailed plant design information in this appendix has been extracted from the Special Nuclear Materials License Application for the KerrMcGee Hexafluoride facility in Sequoyah County, Oklahoma, (1) from the Final Environmental Impact Statement for the Kerr-McGee Sequoyah Hexafluoride Faci1ity, ${ }^{(2)}$ and from the Environmental Impact Appraisal of the Allied Chemical Plant at Metropolis, Illinois. (3)

This appendix is divided into two main sections. Section A.l presents details of the process description. Section A.2 presents details of the plant structures and the equipment in the main process, waste treatment, and supporting facilities.

\section{A. 1 PROCESS DESCRIPTION}

The production method used at the reference plant invoives: a) feed preparation, b) dissolution of the ore concentrate in nitric acid, c) purification of the uranium solution by solvent extraction, d) denitration of the uranyl nitrate to prepare uranium trioxide, e) hydrogen reduction of the uranium trioxide to uranium dioxide, f) conversion of the uranium dioxide to uranium tetrafluoride by reaction with anhydrous hydrogen fluoride, and $g$ ) formation of uranium hexafluoride by contacting the uranium tetrafluoride with elemental fluorine. 
Pulse columns and pumper decanters are used for solvent extraction; fluid beds or mechanically agitated beds for denitration, reduction, and hydrofluorination; and flame reactors for fluorination.

Figures A.1-1 and A.1-2 respectively show a block diagram and schematic flowsheet of the reference plant production process.

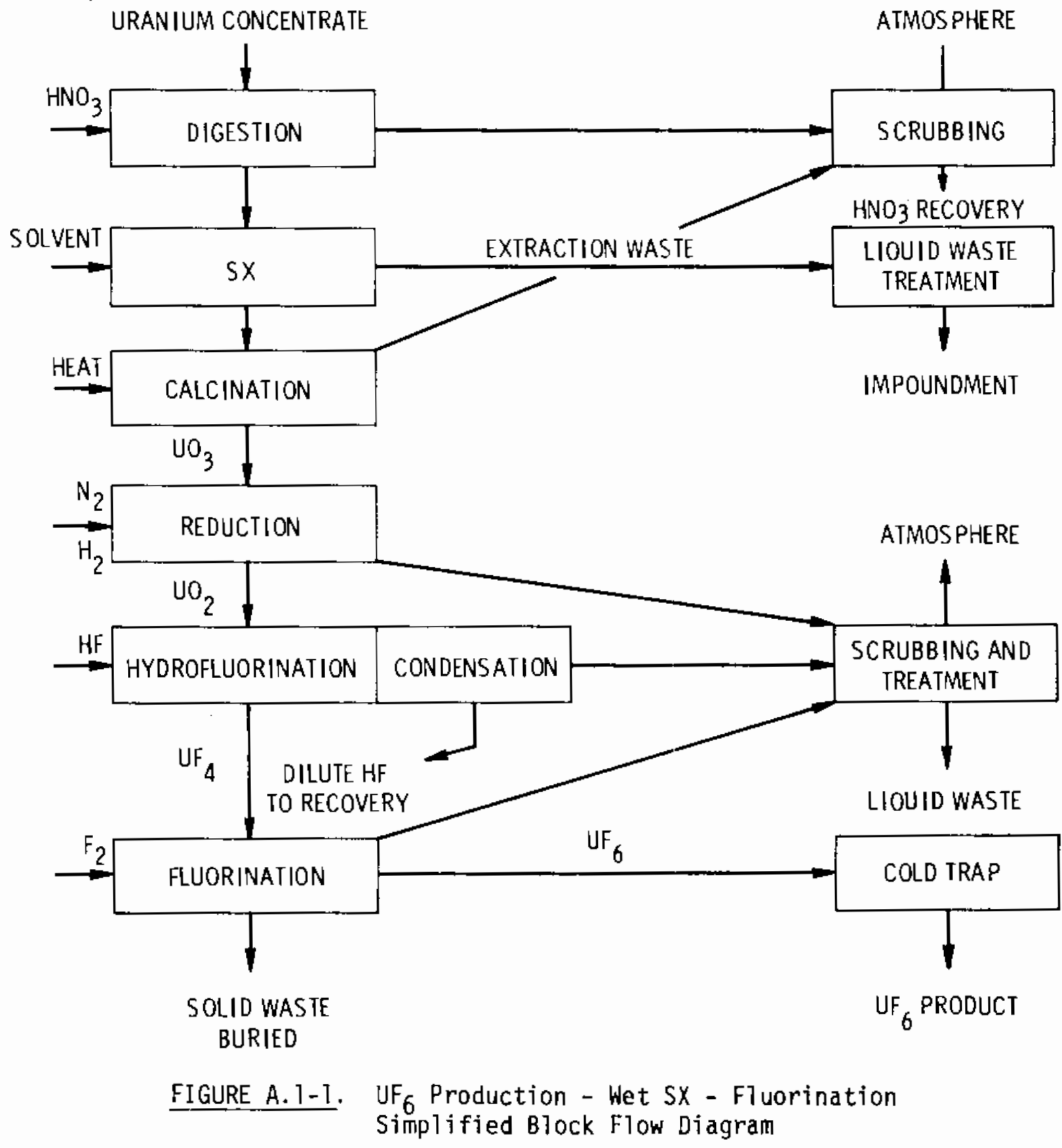




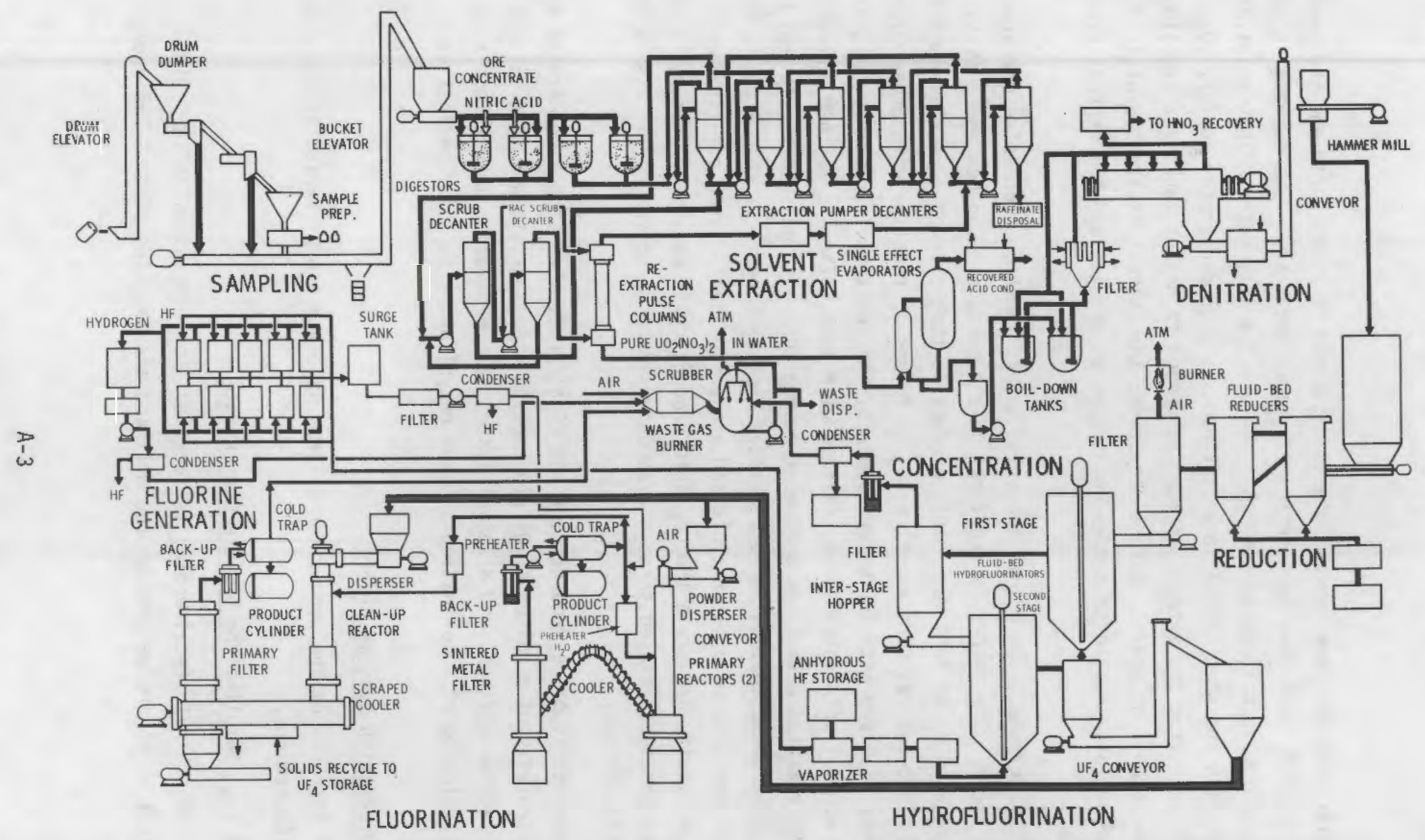

FIGURE A.1-2. Schematic Flow Sheet of the Reference Plant 
After sampling, ore concentrate is dissolved in nitric acid and the uranium extracted with TBP-hexane in a series of pumper decanters. The extract is passed through pulse columns to reextract the uranium into water. This solution is evaporated and then heated in a continuous trough denitrator to form $\mathrm{UO}_{3}$. The raffinate from the extraction step is pumped to holdup tanks for sampling and then to holding ponds. Before recycling, the solvent is treated with ammonium sulfate-caustic to remove any traces of uranium and TBP degradation products.

After grinding, the $\mathrm{UO}_{3}$ is converted to $\mathrm{UF}_{6}$ in three successive dry processing steps. The powder is fed first to a two-stage fluid-bed where it is contacted with $\mathrm{H}_{2}$ to form $\mathrm{UO}_{2}$. This product is then charged to series-connected stirred fluid-bed reactors in which $\mathrm{UF}_{4}$ is formed by reaction with anhydrous HF. Any excess HF along with the water formed by the reaction is condensed to produce an aqueous acid which is neutralized with 1 ime. The $\mathrm{UF}_{4}$ is then converted to $U F_{6}$ by reaction with $F_{2}$ in a flame-type reactor. The gaseous $U F_{6}$ formed is collected by desublimation in refrigerated heat-exchangers or cold traps. These units are operated on a batch-cycle and are periodically taken off-line and heated to liquify and drain the $\mathrm{UF}_{6}$ into product cylinders. For economy, fluorine vent gases are passed through a secondary or cleanup reactor to assure complete usage of gas.

Elemental fluorine required for the final processing step is generated by the electrolysis of a molten KF-HF electrolyte. Appropriate gas feed systems, dust collection devices, and disposal systems are provided. The process also includes grinding of fluorination ash and recycling it to the fluorination system.

\section{A.1.1 Production Systems Descriptions}

Descriptions of the production systems involved are presented in the following subsections.

\section{A.1.1.1 Sampling the Dry Ore Concentrate}

Dry concentrate (yellowcake) is received from uranium mi11s in $0.21-\mathrm{m}^{3}$ steel drums which are weighed at the mill and the sampling plant. The drums 
of ore concentrate are weighed and sampled by a dry splitter system. Powder discharged from the falling-stream sampler is conveyed to the digestor feed hopper.

The drums are emptied one at a time through a falling-stream sampling unit. This unit consists of two samplers in series, each taking a small cut. This produces an initial sample weight of about $1 \%$ or less of the total lot. The sample is split down again by a factor of about 50 and is collected in trays. The material collected in the trays is processed to a final sample pulp by the operations of drying, pulverizing, riffling, sieving, and blending.

The sampled ore concentrate is usually fed directly into the digestor feed hopper. The sampled concentrate can also be redrumed if desired.

\section{A.1.1.2 Ore Concentrate to Purified $\mathrm{UO}_{2}-\left(\mathrm{NO}_{3}\right)_{2}$}

The process of purifying ore concentrate sufficiently for production of pure $\mathrm{UO}_{2}\left(\mathrm{NO}_{3}\right)_{2}$ involves nitric acid digestion and solvent extraction.

\section{A.1.1.3 Digestion of Dry Yellowcake}

Yellowcake and $40 \%$ nitric acid are fed to three $15-m^{3}$ digestors which operate on a batch basis. After digestion, the digestor tank contents are transferred to two $15-\mathrm{m}^{3}$ adjustment tanks where adjustment chemicals are added. Overall residence time varies from 12 to 24 hours.

\section{A.1.1.4 Unloading, Sampling, and Digestion of Wet Yellowcake}

Wet yellowcake slurry delivered from a uranium mill contains approximately $38 \mathrm{wt} \%$ of water. The slurry is transported in a stainless steel cargo tank. A special yellowcake slurry receiving area is provided. This area contains facilities and equipment for dissolving the ADU slurry with nitric acid, unloading the cargo tank, and sampling the uranyl nitrate solution (see Figure A. 1-5).

Tanks for receiving, weighing, and sampling the uranium product are enclosed in a building which rests on a concrete curbed foundation with sufficient volume to contain spillage in case of accidental release. There are three tanks provided, one $3.8-\mathrm{m}^{3}$ tank and two $37.8-\mathrm{m}^{3}$ tanks. The $3.8-\mathrm{m}^{3}$ tank is used for 


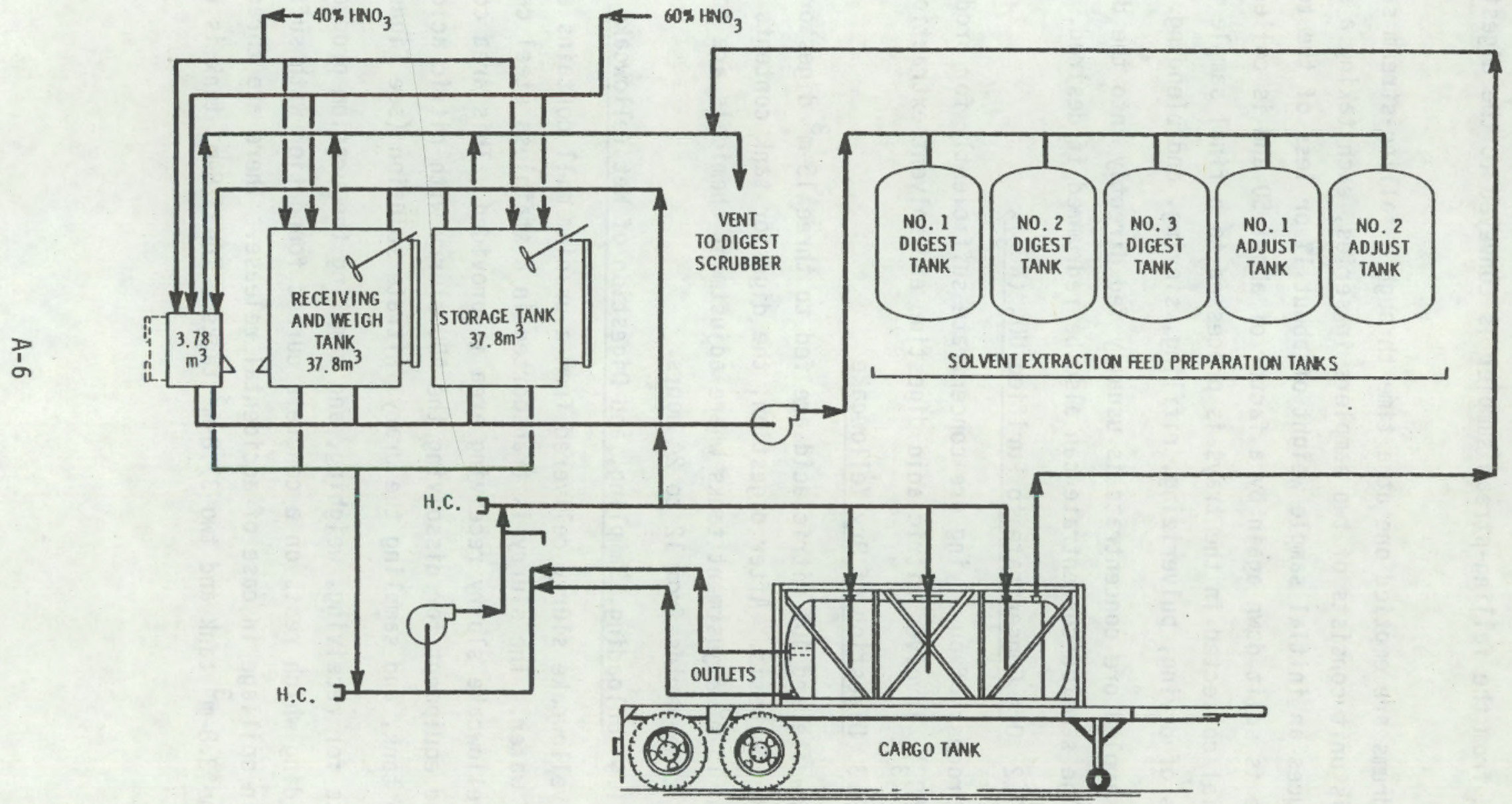

FIGURE A.1-3. ADU Slurry Receiving and Storage Flow Sheet 
non-routine, small operations and for calibration of the load cells on the $37.8-\mathrm{m}^{3}$ receiving and weigh tank. The second $37.8-\mathrm{m}^{3}$ tank is used for measured storage. The receiving and transfer pumps are contained in a small building with a curbed foundation that drains to the large curb in case of spillage in the pump house. The area where the cargo tank is parked is also curbed adequately to contain the entire tank volume.

The cargo tank will arrive at the facility $260 \%$ full, with blind flanges on all openings except the pressure relief valve (tank rated at $207 \mathrm{kPa}$ ). The cargo tank will be "spotted" and the blinds removed. Three equally spaced pumpdischage-bayonets are inserted to within $76 \mathrm{~mm}$ of the bottom of the tank, and two pump suction lines are attached to two diptubes, one at the bottom and one one-third tank diameter from the top. The vent line and a fail-safe level switch are attached.

A predetermined amount of either 60 or $40 \% \mathrm{HNO}_{3}$ is pumped into the receiving tank. The receiving tank, cargo tank, and receiving pump are valved to allow pumping acid into the cargo tank. The cargo tank vent valve is opened. The acid is pumped into the cargo tank until the level switch indicates proper level. (High level shuts down the upper outlet in the cargo tank.) The pump is restarted, providing circulation of acid in the cargo tank. When acid has been consumed, the contents of the cargo tank are pumped back to the receiving and weighing tank. The dissolving operation is repeated until the slurry is totally dissolved. The contents of the cargo tank are pumped to the receiving tank using the lower outlet. The cargo tank may be acid rinsed before being disconnected and prepared for return to the shipper.

The uranyl nitrate in the receiving tank is mixed, weighed, sampled, and transferred to the $37.8-\mathrm{m}^{3}$ storage tank. The storage tank contents are pumped to the process tankage used to prepare the feed for solvent extraction purification.

\section{A. 1.1.5 Unloading, Sampling, and Digestion of Wet UF}

The $\mathrm{UF}_{4}$ slurry as received is approximately $50 \%$ water. It is contained in heavy polyethylene drums, each containing approximately $0.2-m^{3}$ of slurry. 
The $\mathrm{UF}_{4}$ slurry receiving building rests on a curbed foundation with sufficient volume to contain the contents of the digestion tank in case of an accidental release. The UF 4 slurry processing equipment is shown in Figure A. 1-4.

The full drums are placed on a roller conveyor using a fork truck. The drum lids are removed and the drums are emptied by inversion over the process feed hopper using a mechanical drum dumper. The slurry is pumped into the digestor containing a pre-mixed quantity of $\mathrm{HNO}_{3}-\mathrm{AL}\left(\mathrm{NO}_{3}\right)_{3}$ solvent. After digestion, the resulting solution is mixed, weighed, and sampled. It may then be pumped to the storage tank or to process tankage for preparation as feed for the solvent extraction operation.

\section{A.1.1.6 Purification}

Recovery of the uranium from the digestor product is accomplished by extraction with $30 \%$ tributyl phosphate (TBP) in hexane, using a series of 1.2-m-diameter by 1.8-m-high pumper-decanters. The loaded solvent is scrubbed in mixer settlers to remove residual impurities and entrained aqueous solution. The scrubber liquid and impurities are returned to the feed stream where they become part of the waste product after further processing. The uranyl nitrate is reextracted into water using pulse columns as contactors. The purified solution is subsequently boiled down and denitrated to $\mathrm{UO}_{3}$.

After uranium has been removed from the solvent, it is treated with ammonium sulfate-caustic to remove the residual uranium and TPB degradation products. The waste from the solvent extraction step (pumper decanters) is stored in onsite ponds.

\section{A.1.1.7 Preparation of Uranium Trioxide}

The aqueous uranyl nitrate prepared in the solvent extraction step is converted to dry uranium trioxide by a two-step procedure. The solution is first concentrated by evaporation to form uranyl nitrate hexahydrate (UNH) which is then heated to yield uranium trioxide. Continuous processes utilize stirred trough denitrators. 


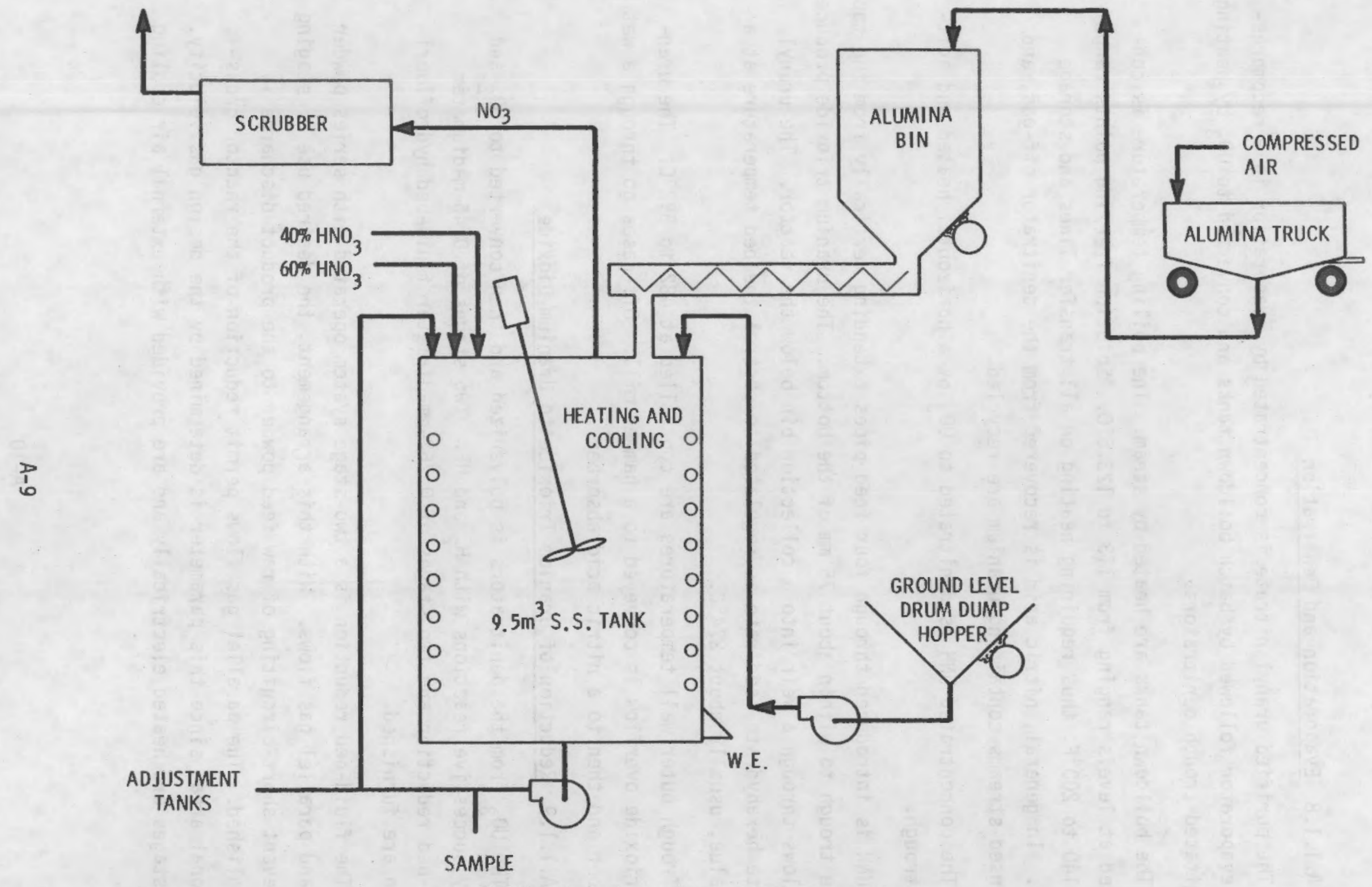

FIGURE A.7-4. UF 4 Slurry Processing 


\section{A.1.1.8 Evaporation and Denitration}

The purified uranyl nitrate is concentrated by evaporation in a recompression evaporator followed by batch boildown tanks and converted to $\mathrm{UO}_{3}$ by heating in agitated trough denitrators.

The boildown tanks are heated by steam. The boiling temperature is controlled at levels ranging from 113 to $123.5^{\circ} \mathrm{C}$. Solution freezing points range from 140 to $200^{\circ} \mathrm{F}$, thus requiring heating on all transfer lines and storage tanks. In general, nitric acid is recovered from the denitrator off-gas, and condensed streams containing uranium are recycled.

The concentrated UNH is denitrated to $\mathrm{UO}_{3}$ by a horizontal heated and agitated trough.

UNH is introduced through four feed pipes extending vertically from the top of the trough to within about $75 \mathrm{~mm}$ of the bottom. The uranium trioxide produce overflows through a weir into a collection bin below the reactor. The uranyl nitrate hexahydrate feed rate is regulated to control the bed temperature at a set value, usually about $274^{\circ} \mathrm{C}$.

Trough outer wall temperatures are controlled at 482 to $592^{\circ} \mathrm{C}$. The uranium trioxide overflow is conveyed to a hammer mill. Off-gases go through a wet scrubber and then to a nitric acid absorber.

\section{A.1.1.9 Reduction of Uranium Trioxide to Uranium Dioxide}

The $\mathrm{UO}_{3}$ from the denitrators is pulverized and then converted to $\mathrm{UO}_{2}$ and $\mathrm{UF}_{4}$ by successive reactions with $\mathrm{H}_{2}$ and $\mathrm{HF}$. Two stages of 0.46 -m-diameter fluid-bed reduction and two stages of 0.762 -mm-diameter fluid-bed hydrofluorination are furnished.

The fluid-bed reduction is a two-stage system operated with series powder flow and parallel gas flows. With this arrangement, the desired use of staging to prevent short-circuiting of raw feed powder to the product discharge is accomplished. The parallel gas flows permit reduction of the reactor crosssectional area, since this parameter is determined by the design gas velocity. Both stages are heated electrically and are provided with external air cooling coils. 
Uranium trioxide is screw-fed from a weighed storage hopper into the reducer near the top of the bed. The outlet gases carry the uranium dioxide product into a collection hopper and are vented through sintered metal filters. The filter tubes are pulsed periodically with nitrogen to dislodge powder which drops into the hopper. The uranium dioxide is transferred to a seal bin.

The hydrogen gas is supplied by cracking ammonia. A mixture of 75 mole\% hydrogen and 25 mole\% nitrogen is formed by dissociation of ammonia and is passed through the fluid beds. The off gases after filtering are vented through a burner.

\section{A.1.1.10 Hydrofluorination of Uranium Dioxide to Uranium Tetrafluoride}

The fluid-bed hydrofluorinator consists of a 406-mm-diameter by 3.7-m-long feed screw reactor with $762-m m$-diameter fluid beds arranged in series. The 152-mm-deep powder bed in each reactor is agitated slowly with a wall scraping type stirrer. Uranium dioxide powder is screw fed into the screw reactor near the top of the bed. The partially reacted product powder and the outlet gases are discharged into an intermediate hopper which feeds the second reactor. The outlet gases vent through carbon filters. The second fluid bed functions like the first, with the exception that the outlet gases carry the powder to the uranium tetrafluoride product hopper and are then introduced without filtering to the bottom of the first reactor. Both reactors are provided with electrical heating and external forced-air cooling.

Hydrogen fluoride economy in the fluid-bed system can be accomplished in several ways. A procedure is to sell dilute acid. The hydrogen fluoride flow to the reactor is adjusted to give the desired outlet concentration, and the aqueous acid is collected in tanks after condensation in a heat exchanger. When there is no market for the acid, the hydrogen fluoride is neutralized with lime.

\section{A.1.1.11 Fluorination and Condensation}

The $\mathrm{UF}_{4}$ is converted to $\mathrm{UF}_{6}$ by reaction with $\mathrm{F}_{2}$ in a system consisting of primary and cleanup flame reactors. Primary reactors operate with an excess of $\mathrm{F}_{2}$ gas to consume as much $\mathrm{UF}_{4}$ as possible, while the cleanup units use an excess of $\mathrm{UF}_{4}$ powder to remove the $\mathrm{F}_{2}$ from the vent gas stream. The primary reactors are $203 \mathrm{~mm}$ in diameter by $3.7 \mathrm{~m}$ long. Primary and secondary cold traps are provided for $\mathrm{UF}_{6}$ collection. 


\section{A.1.1.12 Fluorination of Uranium Tetrafluoride to Uranium Hexafluoride}

The production process use flame reactors (fluorinating towers) for the conversion of uranium tetrafluoride to uranium hexafluoride.

In principle, a primary reactor is used in which uranium tetrafluoride is essentially converted completely to uranium hexafluoride using an excess of fluorine. The unused fluorine is then passed through a secondary or cleanup reactor which operates with an excess of uranium tetrafluorine and consumes the fluoride. A single cleanup reactor can service a bank of primary reactors.

The fluorinator consists of a vertical 203-mm-diameter, 3.7-m-long pipe, provided with external cooling coils which are continuously welded to the shell and are used to remove the large amount of heat released by the reaction. Steam is used as the coolant. Uranium tetrafluoride is charged by a screw conveyor and drops through a powder disperser into the top of the reactor. Dispersion is accomplished by a spined shaft rotating at 1,750 rpm. Fluorine is introduced through an annulus at the bottom of the disperser where it reacts essentially instantaneously with the uranium tetrafluoride. When viewed through a sight port, a whitehot flame is observed just below the point at which the reactants are charged. If gas flows are controlled in the desirable range, $95 \%$ or more of the uranium tetrafiuoride is consumed. In fact, under closely controlled pilot-plant conditions, more than $99 \%$ of the uranium tetrafluoride reacts. Most of the remaining solids are collected in an ash receiver mounted directly below the tower. The gases and a small part of unreacted uranium tetrafluoride are discharged through a gas cooler and a sintered metal filter. Solids collected in the filter usually contain a high pencentage of non-volatile impurities and are reprocessed through a wet uranium recovery system. Ash in the tower receiver consists of uranium fluorides and impurities and is ground and recycled.

The gas leaving the primary fluorinator is passed through a heat exchanger (cold trap) which operates at $1.7^{\circ} \mathrm{C}$ and removes a large portion of the uranium hexafluoride by desublimation. The gas is compressed and flows to the cleanup reactor.

In the cleanup reactor, an excess of uranium tetrafluoride is contacted with the vent gas in a flame-type unit which has heat supplied to hold the wall 
temperature above a minimum of $454^{\circ} \mathrm{C}$. Cooling coils are also provided as in the primary towers. At this temperature level, the fluorine is consumed, and uranium hexafluoride and other uranium fluorides are present. The hot gas and solid stream are cooled before filtering. As the stream is cooled, the reaction of the uranium hexafluoride with the uranium tetrafluoride forms low-melting compounds. Caking is prevented by cooling in a horizontal section equipped with a wall-scraping ribbon-screw. The solid discharged from the cooler is an uranium fluoride material which is recycled to the fluorination reactor.

\section{A.1.1.13 UF 6 Condensation}

Uranium hexafluoride in the gases leaving the cleanup reactor is removed in a refrigerated cold trap operating at minus $24^{\circ} \mathrm{C}$. The uranium hexafluoride content of the gas leaving the cold trap is about $50 \mathrm{ppm}$. This gas is then vented to the waste gas disposal system.

The $\mathrm{UF}_{6}$ product is collected in two different types of heat exchangers. The first or primary cold trap operates at approximately $4.4^{\circ} \mathrm{C}\left(40^{\circ} \mathrm{F}\right)$ and removes most of the $\mathrm{UF}_{6}$. This trap is of tube and shell construction.

U-tubes are used to minimize thermal stresses and to allow easy removal of the core from the containing vessel. The heat exchange surface consists of flat plate fins attached to the tubes. Baffles are provided to give side-toside flow. A water-glycol solution is circulated through the tubes during the cooling cycle. The trap is heated to liquify and drain the UF ${ }_{6}$. Heated glycol is passed through the tubes when the trap is heated.

The secondary traps heating and cooling system is similar to the primary traps except that they operate at $-50^{\circ} \mathrm{C}$. Freon is recirculated and used as the coolant.

After collection, the $U_{6}$ is heated to above its triple point of $64^{\circ} \mathrm{C}$, filtered, and drained into an evacuated shipping cylinder.

\section{A.1.1.14 Fluorine Production}

The production system consists of 60 electrolytic cells with two conditioning systems. Fluorine is produced from HF by the electrolys is of HF dissolved in a fused saltbath of KF-HF in medium-temperature, water-cooled cells. Hydrogen is produced as a byproduct and subsequently burned. 
A metered continuous flow of gaseous hydrogen fluoride is fed to the electrolyte to maintain the optimum composition and also to hold sufficiently high liquid level to prevent mixing of the hydrogen and fluorine.

The fluorine is compressed with a centrifugal unit and is charged to the uranium hexafluoride production reactors. Hydrogen flows to a gas burner. Both the hydrogen and fluorine headers are controlled at about $25 \mathrm{~mm}$ of water positive pressure on the cell side. Close control of the pressure of both these streams is provided to prevent mixing fluorine and hydrogen.

Both the hydrogen and the fluorine leaving the cell contain $10 \%$ or more hydrogen fluoride. This concentration is reduced before use in the uranium hexafluoride manufacturing systems. The fluorine stream is passed through condensers which collect hydrogen fluoride as a liquid and reduce the concentration to about $4 \%$. The condensed anhydrous hydrogen fluoride is reused. Reduction to the $4 \%$ level is adequate to prevent deposition of hydrogen fluoride in subsequent uranium hexafluoride collection cold traps.

\section{A.1.2 Effluent and Waste Disposal}

Normal operation of the UF ${ }_{6}$ plant produces waste heat along with a variety of solid, liquid, and gaseous wastes which are treated to meet federal and state pollution control standards before being released to the environment. Liquid wastes containing significant quantities of radioactive materials are currently impounded in settling basins and stored. Other liquid wastes which contain traces of radioactivity are diluted and released. All airborne effluents are treated to remove uranium contamination and noxious gases produced in the manufacturing process.

\section{A.1.2.1 Liquid Waste Treatment and Disposal Systems}

The plant process generates two major liquid waste streams of varying composition which are treated. The solvent extraction waste treatment flow sheet is shown in Figure A. 1-5.

The waste stream from the extraction system is primarily a solution of ammonium nitrate, nitric acid, metallic salts, and minute quantities of uranium and the radioactive daughter products of normal uranium decay. This stream 


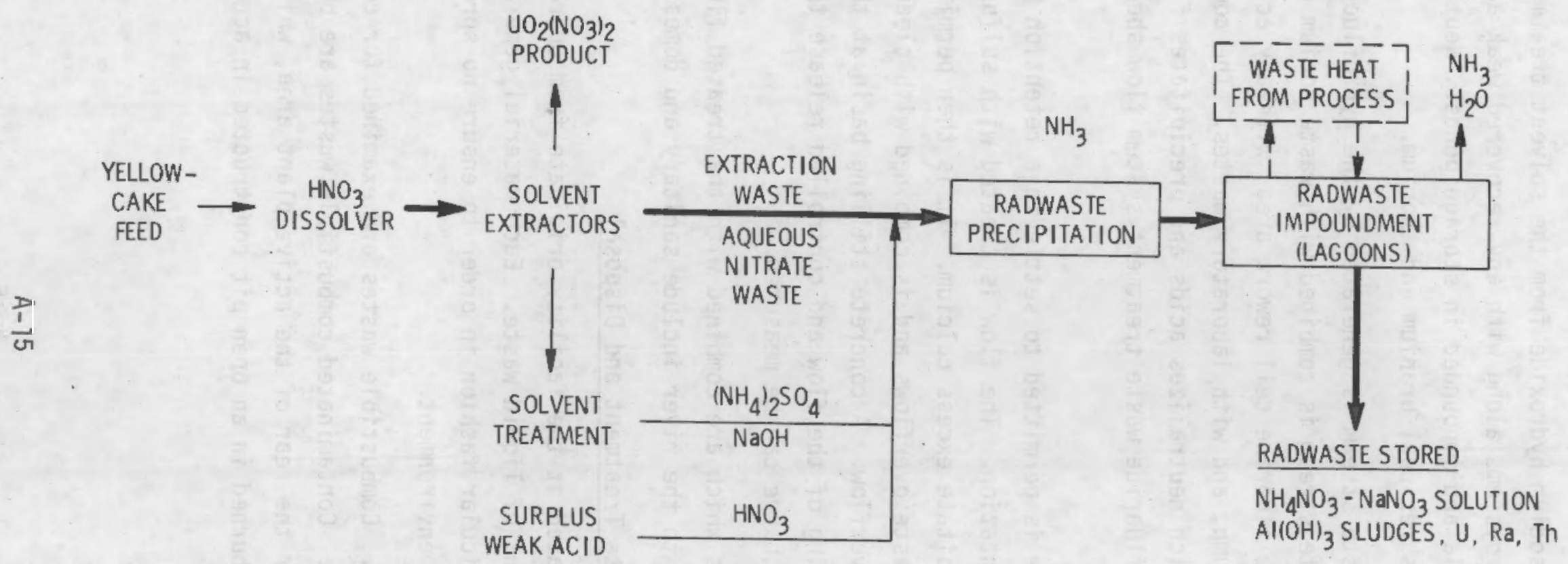

FIGURE A.1-5. Solvent Extraction Waste Treatment System Flow Sheet 
is combined with spent sodium hydroxide from the solvent treatment and miscellaneous digester scrubber systems along with any recovered weak acids. This liquid is neutralized by ammonia and impounded in storage ponds. Neutralization of the extraction waste removes residual uranium and thorium.

A second liquid waste stream is generated by the hydrofluoric acid scrubber. This fluoride waste stream is combined with waste sodium carbonate solutions originating in the fluorine cell rework area, with any acid spilled in the HF vaporizer room sump, and with laboratory wastes. The combined stream is treated with lime which neutralizes acids and precipitates fluorides as calcium fluoride. The fluoride waste treatment system flow sheet is shown in Figure A. 1-6.

The alkaline sludge is permitted to settle in a retention basin to permit flocculation and sedimentation. The flow is treated with sulfuric acid to adjust the $\mathrm{pH}$ and precipitate excess calcium. It is then permitted to clarify. The clarified treated waste overflows and is combined with clean bypass water and the sewage lagoon overflow. A concrete stilling basin at the point of combination allows for mixing of the flow and controlled release through a flume so that the rate of discharge can be measured.

Other plant streams which are combined with the treated fluorine effluent before being discharged to the river include sanitary and domestic waste liquids.

\section{A.1.2.2 Solid Waste Treatment and Disposal}

Solid wastes generated at the facility originate from operations in the facility or the treatment of liquid waste. Each material generated must be treated in its own particular fashion in order to ensure no spread of radioactive materials to the environment.

Combustible Wastes. Combustible wastes are examined for contamination and disposed of in two ways. Contaminated combustible wastes are buried onsite at a designated location near the rear of the active plant area, while non-contaminated combustible wastes are burned in an open pit constructed in accordance with air pollution regulations. 


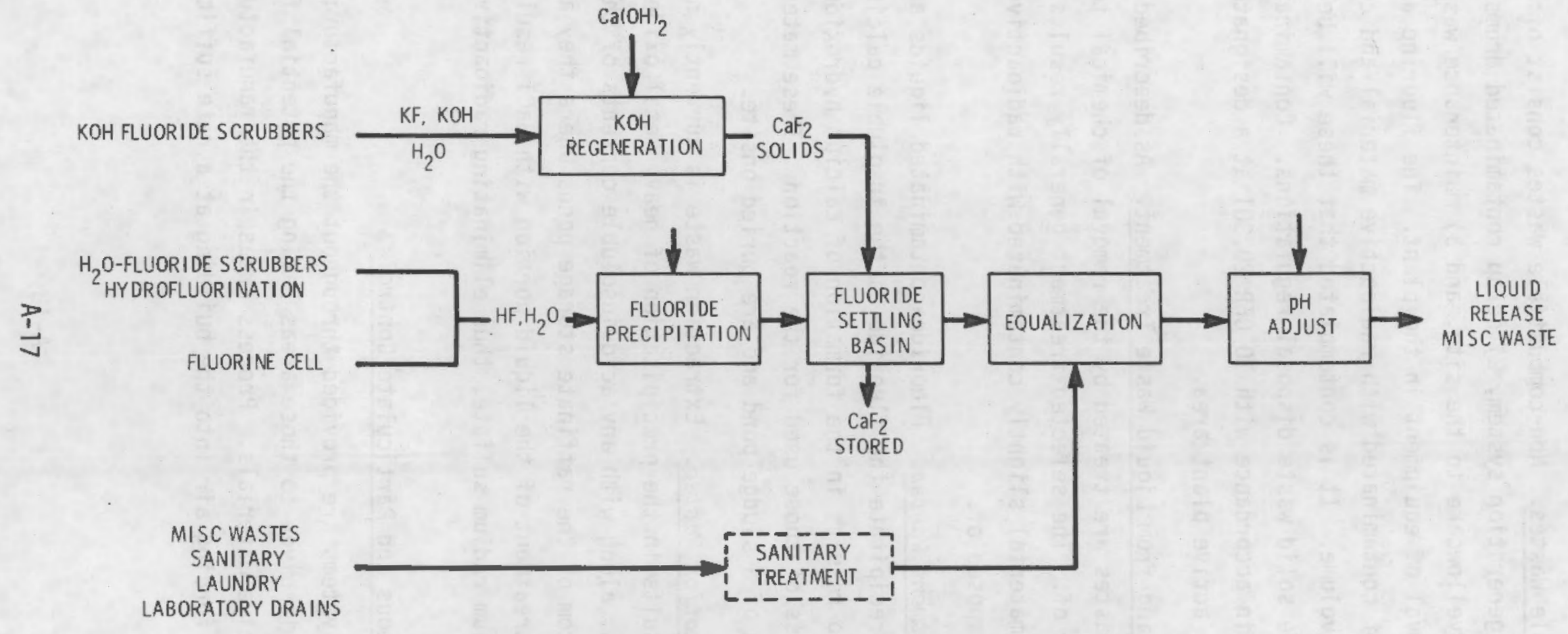

FIGURE A.1-6. Fluoride Waste Treatment Flow Sheet 
Non-Combustible Wastes. Non-combustible wastes consist of: 1) used anodes from the fluorine generation system, 2) scrap contaminated drums resulting from transportation of yellowcake to the site, and 3) maintenance waste generated by the repair or removal of equipment in the plant. The fluorine anodes composed of graphite are not contaminated with radioactive material and constitute a waste of very low volume. It is contemplated that these will be buried in accordance with the solid waste disposal regulations. Contaminated solids are buried onsite in accordance with 10 CFR 20.301 at a designated location at the rear of the active plant area.

Solids Resulting from Liquid waste Treatment. As described in previous sections, liquid wastes are treated by the removal of chemical toxicity and subsequently disposed of. The selected treatment generally results in the precipitation of a solid material slightly contaminated with radioactive elements that must be further disposed of.

Fluoride Treatment Wastes. Fluoride-contaminated liquids are treated with lime in order to precipitate the fluoride as the insoluble calcium fluoride. This procedure also results in the formation of calcium hydroxide and calcium carbonates in excess of those used for the reaction. These materials precipitate at the bottom of a sludge pond and are buried onsite.

Solvent Extraction Wastes. Extraction waste is currently neutralized with ammonia, which results in the precipitation of heavy metal oxides and hydroxides. These precipitates, along with any acid-insoluble contents of the concentrate, settle to the bottom of the raffinate storage ponds where they accumulate as sludge. Further treatment of the liquid portion with $\mathrm{BaCl}$ results in the precipitation of barium radium sulfate, thus eliminating radioactivity from the liquid wastes.

\section{A.1.2.3 Gaseous and Particulate Control}

Ventilation systems are provided throughout the manufacturing facility. Special attention is given to those areas having the potential for contamination with radioactive materials. Process areas in the manufacturing building are ventilated by forcing air into the building at a rate sufficient to provide 
10 air changes per hour as the air is exhausted through eleven $8.5-\mathrm{m}^{3} / \mathrm{min}$ vents as well as through non-powered roof hatches. Both vents and hatches are sampled to evaluate radioactive discharges to the atmosphere in accordance with 10 CFR 40.65 .

Fumes from the fluorine cell maintenance area are discharged directly to the atmosphere by means of a $450-m^{3} / m i n$ exhaust fan.

The exhaust from each laboratory fume hood is conveyed to the sampling area roof through separate sampled ducts.

Equipment used to remove particulates from gas streams include cyclones, bag filters, and porous carbon or porous metal filters. A central, all-purpose dust collection system is provided to service all dry-processing areas within the plant. Dust collection hoods are installed around packing glands, routinely opened equipment, solids transfer areas, and the discharge from special-duty dust collectors or vacuum systems. The size and shape of the hoods and the exhaust air velocities are all designed to obtain efficient collection of the generated dust. The dust collector is a $785-\mathrm{m}^{3} / \mathrm{min}, 5$-zone plenum pulse (reverse jet), bag-type filter which discharges to the atmosphere through a monitored stack. Collected solids are drummed and recycled to process. The stack sampler operates continuously, with a 24-hour sample collected and analyzed daily.

Four additional vacuum cleaning and dust collection systems providing separate vacuum sources, cyclone separators, and bag filters are used in specialized plant areas. The sampling plant has separate vacuum cleaner and dust collection systems for recovery and direct recycle of spilled yellowcake, with the filtered air from the vacuum cleaner discharged to the sample plant dust collector. Filtered air from this system in turn discharges to the main plant dust collector, thus providing three stages of filtration. Two additional vacuum recovery systems, each consisting of a cyclone, bag filter, and vacuum pump in series, are provided, with both bag filters discharging to the main plant dust collector for backup filtration. One system services all areas after yellowcake sampling through the reduction area and discharges collected solids 
to the miscellaneous digester. The second unit, the UF 4 ash vacuum system, services the hydrofluorination and fluorination areas, with collected solids drummed for transfer to the ash grinding system. Both systems are used for general plant clean-up in their respective service areas and for removal of uranium materials from equipment components prior to maintenance operations.

The entire ash grinding system provided for all-purpose crushing, pulverizing, and screening of fluorination tower ash or other materials capable of direct recycle is housed in an enclosure which is vented to the main plant dust collection system.

The primary vent system for the digesters provides for removal of entrained dust and liquid from the off-gas vapor with return to the digestion tanks. The vent system discharges to the nitric acid recovery system where oxides of nitrogen are removed. The system is maintained at a slight negative pressure to prevent leakage to the atmosphere. Off-gas from the miscellaneous digester is processed through a water scrubbing system and a caustic scrubber to remove nitrogen oxides, HF vapor, and entrained uranium or fluoride bearing liquids or solids. After scrubbing, the off-gas is routed to the nitric acid recovery system. Spent scrubber liquids are disposed of with the solvent extraction waste. Denitrator off-gases are scrubbed with nitric acid and then cooled before being fed to the nitric acid absorber.

Off-gases from the reduction system are vented through a sintered metal filter and a backup filter for $98 \%$ removal of 0.7 -micron particles. Excess hydrogen is burned and vented to the steam boiler stack.

Gases passing through the hydrofluorinator back-up filter and the HF condenser are combined with the off-gases from the waste gas burner servicing the fluorine plant and the fluorination system off-gases and are scrubbed with water before being vented to the atmosphere. The scrubber liquor is discharged to the fluoride treatment ponds.

The fluorination system uses a once-through fluorine process, with the UF 6 leaving the primary reactor through sintered metal filters and passing through a back-up filter before entering a primary cold trap. Residual gas is fed to a 
cleanup reactor, with the $\mathrm{UF}_{6}$ leaving this unit passing through two sintered metal filters and then into the secondary cold trap.

\section{A.1.3 Ventilation Systems}

Ventilation systems are provided for the various areas of the facility. Special attention is given to obtain adequate air changes in areas having air contamination potentials.

Ducts in the solvent extraction and fluorine areas are of aluminum. Galvanized steel ducts are used in the office and laboratory, shops, and maintenance facility and utility areas.

Air for the heating and ventilation of the main process area is provided by two fan-coil units (total capacity $2600 \mathrm{~m}^{3} / \mathrm{min}$ ), one at each end of the process area. Ventilating air is introduced to maintain a minimum of six air changes per hour. Ten air changes is typical in the main process area.

The fluorine cell area is ventilated by four fans, for a total of about $1020 \mathrm{~m}^{3} / \mathrm{min}$ of exhaust air, resulting in approximately 31 air changes per hour.

The ventilation of the solvent extraction building provides for a minimum of 12 air changes per hour by a supply fan-coil unit with a $680 \mathrm{~m}^{3} / \mathrm{min}$ capacity.

\section{A.1.3.1 Main Plant Dust Collection System}

A central, all-purpose dust collection system is provided. The system services all "dry-processing" areas within the plant, sampling/digestion and $\mathrm{UO}_{3}$ pulverizing through ash grinding. The dust collection hoods servicing the areas are installed around packing glands, routinely opened equipment, solids transfer areas, and the discharge from special-duty dust collectors or vacuum systems. Size and shape of hoods and exhaust air volume are designed to efficientiy collect the dust normally generated by the source.

The $785-\mathrm{m}^{3} / \mathrm{min}, 5$-zone, "plenum pulse" (reverse jet), bag-type dust collector discharges through a monitored stack above the plant to the atmosphere. The collector is periodically cleaned (back-blown) stepwise, one zone at a time. 
It can also operate with one or two zones out of service for maintenance. The solids are drummed off and reprocessed. The stack sampler operates continuously. A 24-hour sample is collected and analyzed for radioactivity daily.

Vacuum Systems for Recovering Soiled Solids. The sampling plant has a separate vacuum for recovery and direct recycle of spilled yellowcake. Two other vacuum recovery systems are provided. Both are used for general plant clean-up and for "vacuum gulping" of uranium compounds from equipment components prior to maintenance servicing. The main plant vacuum system services all areas after yellowcake sampling to hydrofluorination. The $\mathrm{UF}_{4}$ ash vacuum system services all areas from hydrofluorination through fluorination. The main plant system discharges to the miscellaneous digester. The $U_{4}$ ash system discharges to drums for transfer to the ash grinding system. Each vacuum system has one vacuum source with a cyclone separator and bag filter in series.

The general cleanup piping system is provided with hose connections at convenient points. Piping sizing provides a minimum gas velocity of $91.4 \mathrm{k} / \mathrm{min}$.

The $\mathrm{UF}_{4}$ ash system depends on screens in the ash grinding system to protect conveyors and screws when it is re-fed to the primary process stream.

A portable vacuum cleaner is also provided.

Ash Grinding System for Direct Recycle of Fluorination. An ash grinding system is provided for all-purpose crushing, pulverizing, and screening of fluorination tower ash, or any other material capable of direct recycle. The pulverized product is normally re-fed directly to fluorination through the $\mathrm{UF}_{4}$ storage bin. The product can be redrummed. The system consists of a jaw-crusher, a hammer mill pulverizer, and a vibrating screener. Material is fed to the system via a drum elevator. The entire system is housed in an enclosure which is vented to the main plant dust collection system.

The hammer mill is protected from pieces of upstream equipment or other foreign matter by $25-\mathrm{mm}$ screen in the feedstream, after the crusher. Collected solids from the $\mathrm{UF}_{4}$ ash vacuum system are also recycled through the ash grinding system. 


\section{A.1.3.2 $\mathrm{F}_{2}$ Cell Maintenance Area Fume Exhaust}

Fumes from the dip tank and electrolyte area are exhausted by a $450-\mathrm{m}^{3} / \mathrm{min}$ exhaust fan to the atmosphere.

Laboratory System. The exhaust from each laboratory fume hood is conveyed to the roof of the sampling area through separate ducts. Sampling of these ducts is done until ample data shows it is no longer necessary.

Off-Gas Handling. Off-gas handling systems are described below.

Digestion. The primary vent system for the digestion vessels provides for removal of entrained dust and solution from the vapor stream and return to the digesters. The primary vent system for the digestion vessels exhausts to the plant nitric acid recovery system, where $\mathrm{NO}_{2}$ and $\mathrm{NO}$ are scrubbed out. The digestion system is maintained to assure that all air flow is inward.

Off-gas from the miscellaneous digester is processed through a water scrubbing system and a caustic scrubber to remove nitrogen oxides, HF vapor, and entrained uranium or fluoride bearing solutions or solids. After scrubbing, the off-gas is routed to the $\mathrm{HNO}_{3}$ recovery system. Spent scrubbing liquor is disposed of with the raffinate.

Denitrator off-gases are wet-scrubbed with nitric acid and then pass through a gas cooler before passing on to the nitric absorber column.

Gases from reduction to $\mathrm{UO}_{2}$ are vented through a sintered metal filter then through a back-up filter (nominal 10-micron pore size for $98 \%$ removal of 0.7 -micron particles). Excess hydrogen is burned before venting. Burned gases are vented via the boiler stack.

Hydrofluorination. Only small amounts of gases containing traces of HF are vented from the HF condensers except when purging the reactors. In the latter case, very little HF should be present. The vent gases are combined with other similar gases and scrubbed with water prior to being vented through a pipe associated with the main boiler stack. The waste scrub liquor is discharged to the fluoride treatment ponds. 
Fluomination. The system uses a once-through fluorine process. The $\mathrm{UF}_{6}$ laden gas leaving the sintered metal filters from the primary reactor passes through a back-up filter and then through a primary cold trap. Gas passes through a tower-type cleanup reactor. The $\mathrm{UF}_{6}$ gas leaving this reactor is removed in the secondary cold trap and the gas is sent to off-gas disposal. Under normal conditions with the fluorine clean-up reactor performing properly, little $F_{2}$ is discharged from the system. Any waste $F_{2}$ is burned with $\mathrm{H}_{2}$ from the fluorine plant to form HF, which is quenched and scrubbed with water. The scrubbed waste gases are discharged to the atmosphere through pipe associated with the boiler stack. The waste scrub liquor is discharged to the fluoride treatment ponds.

\section{A.2 PLANT DESCRIPTION}

This section provides details of the reference $U_{6}{ }_{6}$ conversion plant to supplement the general plant description given in Section 7.3 of Section 7 . The plant is assumed to be located on the reference site described in Section 7.1 and Appendix B. The plant area, shown in Figure A.2-1, includes an area of about 30.4 hectares that contains the main process building waste treatment facilities, equipment and materials storage pads, and other supporting facilities.

The sanitary lagoons are used for holding discharge from the plant nonradioactive laundry, showers, sinks, and toilets. The sewage treatment plant and sanitary lagoon have very little contamination and are not considered to be part of the decommissioning activities.

Figures A.2-2 shows a plan of the main building layout. An isometric drawing of the plant is shown in Figure 7.3-1 of Section 7.

\section{A.2.1. Buildings}

The main plant building occupies $7500 \mathrm{~m}^{2}$ of manufacturing, laboratory, maintenance, decontamination, storage, and office floor space. Contaminated waste incineration operations occupy another $220 \mathrm{~m}^{2}$ of floor space in a separate building located 30 meters to the west of the main building. Other auxiliary facilities include fluoride and extraction waste treatment lagoons, liquid 


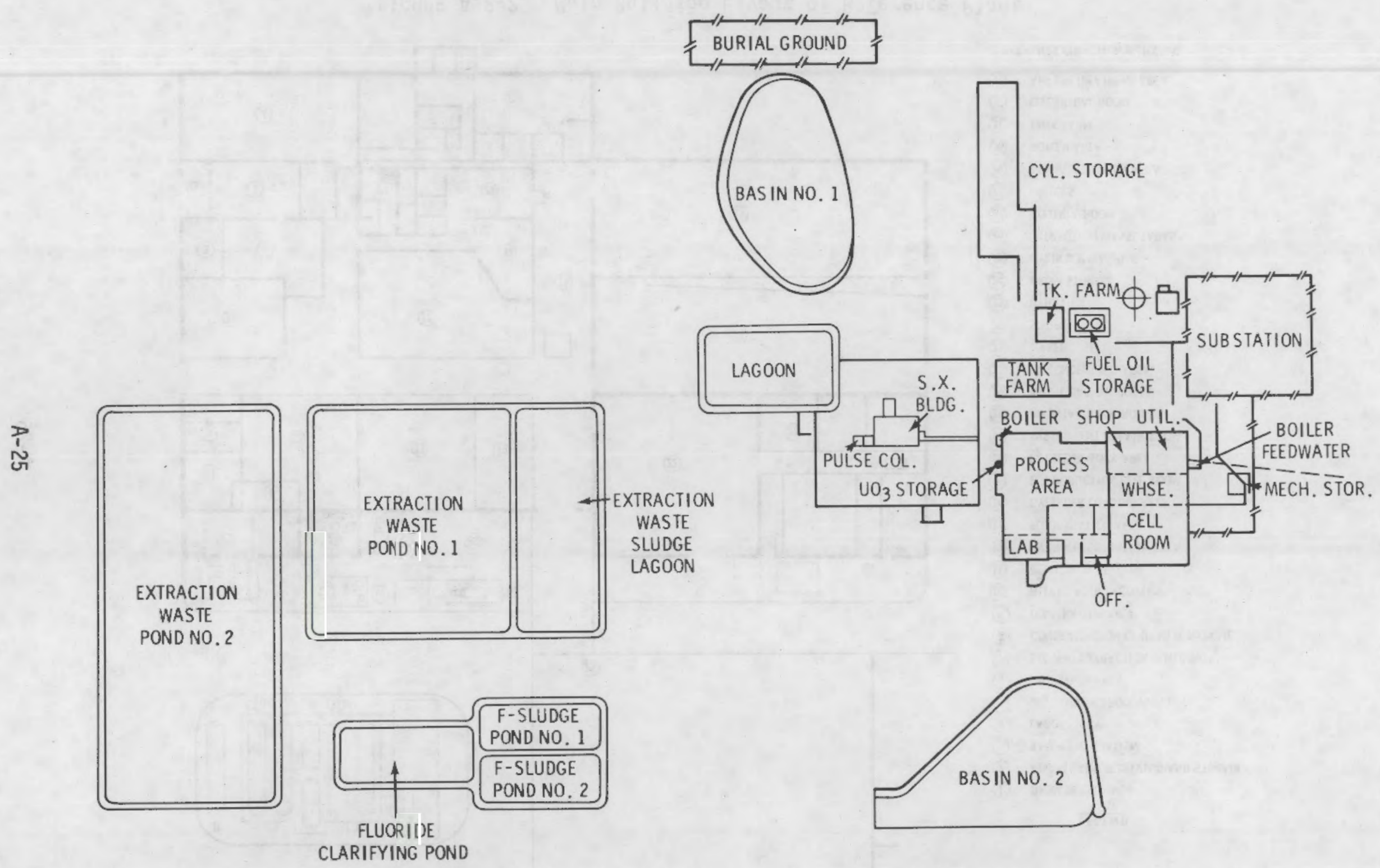

FIGURE A.2-1. Site Layout of the Reference Plant 

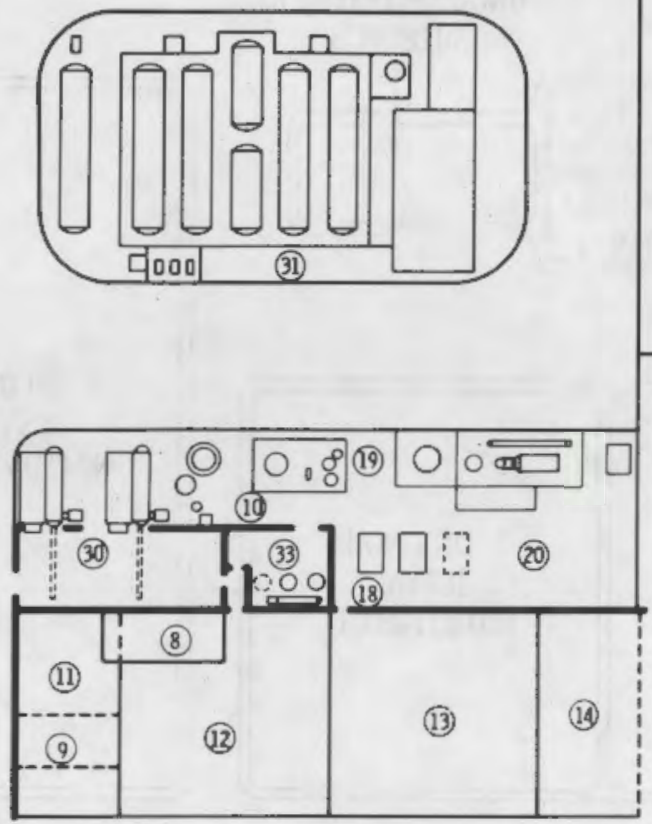

(2)
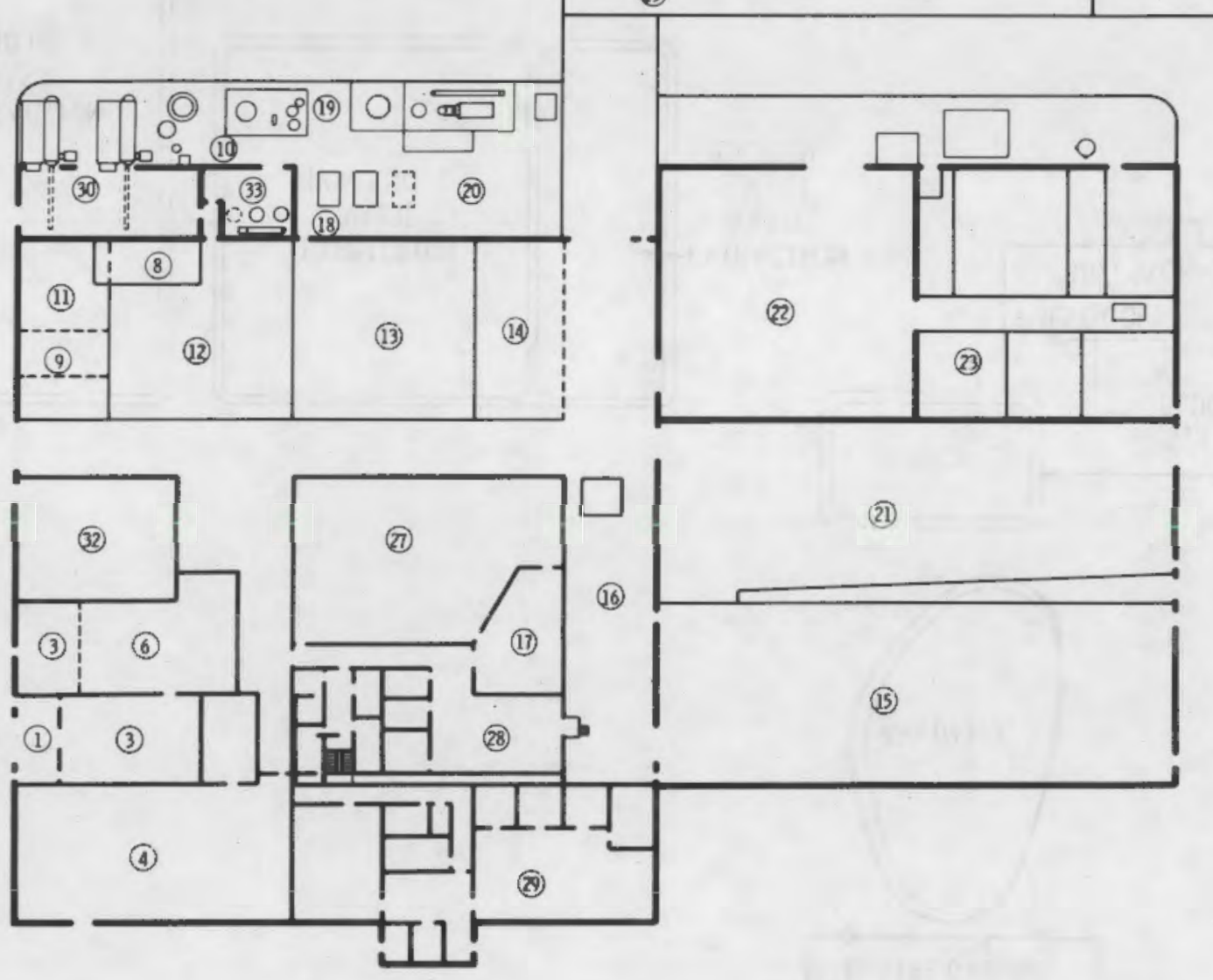

\section{LEGEND}

(1) DRUM RECEIVING

(2) ADU SLURRY RECEIVING AND STORAGE-

(3) SAMPLING STATION

(4) UABORATORY

(5) UE 4 SLURRY PROCESSING

(6) DIGESTION AREA

(7) SOVENT EXTRACTION BUILDING.

(B) CONCENTRATION OF URANYL NITRATE

(9) DENITRATION AREA

(10) NITRIC ACID RECOVTRY

(I1) REDUCTION AREA

(12) HYOROFUORINATION AREA

(13) FLUORINATION AREA

(14) CYLINDER LOADING AREA

(15) F PRODUCTION CELL ROOM

(16) $F_{2}$ CELL REWORK AREA

(17) INSTRUMENT REPAIR ROOM

(18) AMONIA CRACKING AREA

(19) HASTE GAS DISPOSAL

(20) $\mathrm{H}_{2}$ CONDENS ING AREA

(21) WAREHOUSE

(22) SHOPS

(23) UTILITIES

(24) DRUM STORAGE

(25) CYINDER WASHING

(26) EXTRACTION WASTE INNKS

(27) CaNTRO ROOM

(27) OFFICES

(29) ADMINISTRATION AREA

(30) BOILER AREA

(31) TANK FARM

(32) ELECTRICAL ROOM

(33) AHF PRETREATMENT AREA

- solvent extraction building

FIGURE A.2-2. Main Building Layout of Reference Plant 
chemical waste treatment lagoons, a sanitary waste treatment plant, a tank and pump station, equipment storage yards, uranium storage yards, an electrical substation, and a warehouse.

\section{A.2.1.1 Main Building}

The main building is an 55-m by 100-m structure fabricated of 38-mm insulated metal siding attached to a steel framework. The interior walls are constructed of 200 - by $200-$ by $410-\mathrm{mm}$ concrete block and $13-\mathrm{mm}$ sheet rock in the office, laboratory, and control room areas and sheet metal in the process areas. The mezzanine area floors are steel grating or reinforced concrete. The steel beams supporting the building steel framework are anchored in the outside 1-mhigh walls. The roof consists of a $35-\mathrm{mm}$ insulated corrugated metal deck that is capped with $38 \mathrm{~mm}$ of asphalt and gravel.

The processing areas or rooms within the main building are generally partitioned with painted sheet-metal walls, or in some instances, with painted wall board. The floors of the production areas are generally of painted concrete or steel plate. The chemical area has a sealed concrete floor. Nonproduction and noncontaminated areas in the facility generally have a concrete floor. Offices and change rooms have either tiled or painted floors.

\section{A.2.1.2 Solvent Extraction Building}

The solvent extraction building has a steel frame with metal sidings and sealed concrete floors.

\section{A.2.2 Detailed Plant Descriptions}

The following sections describe the process and laboratory areas of the plant. The descriptions include tabulations of the equipment items located in each area. Estimates of shipping volumes and weights are included with these tabulations.

\section{A.2.2.1 Sampling Station}

Table A.2-1 lists the equipment in the sampling station room of the main building. 
IABLE A.2-1. Sampling Station Equipment and Laboratory

Unit Dimension Shipping Estimated $_{3}$

\begin{tabular}{|c|c|c|c|c|}
\hline Equipment I tem & Quantity & $\mathrm{L} \times \mathrm{W} \times \mathrm{H}(\mathrm{m})$ & Volume $\left(\mathrm{m}^{\mathrm{C}}\right)$ & Weight $(\mathrm{Mg})$ \\
\hline Drum Elevator & 2 & $5 \mathrm{D}$ length & 12.8 & 4.4 \\
\hline Yellowcake Receiving Bin & 2 & $1.5 \times 1.5 \times 2.8$ & 12.5 & 6.3 \\
\hline Primary Sampler I & 1 & $1.7 \times 0.9 \times 2$ & 2.7 & 2.6 \\
\hline Primary Sampler II & 1 & $1.7 \times 0.9 \times 2$ & 2.7 & 2.6 \\
\hline Secondary Sampler & 1 & $1.5 \times 0.9 \times 2$ & 2.5 & 1.8 \\
\hline Yellowcake Transfer Screw & 2 & 33 length & 4.2 & 1.5 \\
\hline Bucket Elevator & 2 & 30 length & 4.8 & 1.1 \\
\hline Digestor Feed Bin & 2 & $1 \times 1 \times 2.6$ & 2.6 & 3.1 \\
\hline Hood and Ductwork & -- & -- & 4.1 & 4.8 \\
\hline Stacker and Forklift & -- & -- & 12 & 5.0 \\
\hline Stora'ge Racks & -- & -- & 23 & 5.0 \\
\hline
\end{tabular}

The receiving and sampling area covers about $765 \mathrm{~m}^{2}$ and contains sampling equipment. The room contains elevators, bins, samplers, and transfer equipment.

\section{A.2.2.2 ADU Slurry Receiving and Storage}

Table A.2-2 lists the equipment in the ADU sTurry receiving and storage area.

TABLE A.2-2. Wet Yellowcake System Equipment

\begin{tabular}{|c|c|c|c|c|}
\hline Equipment Item & Quantity & $\begin{array}{l}\text { Unit Dimension } \\
\mathrm{L} \times W \times H(m)\end{array}$ & $\begin{array}{l}\text { Shipping } \\
\text { Volume }\left(\mathrm{m}^{3}\right)\end{array}$ & $\begin{array}{l}\text { Estimated } \\
\text { weight }(\mathrm{Mg})\end{array}$ \\
\hline J Storage Tank & 2 & $38 \mathrm{~m}^{3}$ & 76 & 12.6 \\
\hline ceiving and Weight Tanks & 1 & $3 \mathrm{~m}^{3}$ & 3.8 & 3.0 \\
\hline ing & -- & -- & 2.6 & 2.0 \\
\hline scellaneous Equipment & -- & -- & 2.0 & 3.0 \\
\hline Receiving Pumps & 2 & $0.9 \times 0.9 \times 1.4$ & 3.0 & 4.0 \\
\hline ransfer Pump & 2 & $0.7 \times 0.7 \times 1.4$ & 2.8 & 3.5 \\
\hline
\end{tabular}




\section{A. 2.2.3 $\mathrm{UF}_{4}$ Slurry Processing}

Table A.2-3 lists the equipment in the $U_{4}$ slurry sampling and digestion area.

The ADU receiving and storage area covers $50 \mathrm{~m}^{2}$ and contains facilities and equipment for dissolving ADU slurry with nitric acid including tanks, piping, pumps, and equipment.

A receiving building for the $U_{4}$ is located adjacent to the west wall of the yellowcake slurry receiving area. The $\mathrm{UF}_{4}$ slurry receiving building rests on a curbed foundation with volume to contain the tank contents. The equipment includes a process feed hopper, a mechanical drum drumper, a digester tank, a scrubber, a pump, and process piping.

\section{TABLE A.2-3. UF 4 Slurry Equipment}

\begin{tabular}{|c|c|c|c|c|}
\hline Equipment Item & Quantity & $\begin{array}{l}\text { Unit Dimension } \\
L \times W \times H(m) \\
\end{array}$ & $\begin{array}{l}\text { Shipping } \\
\text { volume }\left(m^{3}\right)\end{array}$ & $\begin{array}{r}\text { Estimated } \\
\text { Weight }(\mathrm{Mg}) \\
\end{array}$ \\
\hline Process Feed Hopper & 1 & $2 \times 2 \times 3$ & 12.0 & 3.0 \\
\hline Mechanical Drum Dumper & 1 & -- & 3.0 & 2.0 \\
\hline Digester Tank & 1 & $17 \mathrm{~m}^{3}$ & 17.0 & 4.5 \\
\hline Scrubber System & 1 & -- & 6.8 & 1.4 \\
\hline Pumps & 1 & $1.1 \times 1.1 \times 1.6$ & 2.3 & 1.0 \\
\hline
\end{tabular}

\section{A.2.2.4 0issolution of Ore Concentrate}

Table A.2-4 lists the equipment in the ore concentrate dissolution system.

The digestion area covers $200 \mathrm{~m}^{2}$ of the main building and contains digestion tanks, adjustment tank piping and pumps.

TABLE A.2-4. Ore Concentrate Dissolution Equipment

Equipment Item

Digestion Tanks

Adjus tment Tanks

Piping
Unit Dimension Shipping Quantity $\mathrm{L} \times \mathrm{W} \times \mathrm{H}(\mathrm{m})$ Volume $\left(\mathrm{m}^{3}\right)$

2.5 dia. $\times 2.7$

44

2.6 dia. $\times 2.7$

2

$--$
3

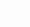

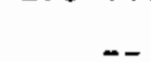

Estimated

Weight $(\mathrm{Mg})$

12.0

8.0

2.0 


\section{A. 2.2.5 Solvent Extraction}

Table A.2-5 lists the equipment in the solvent extraction system.

The solvent extraction building covers $377 \mathrm{~m}^{2}$ and contains decanters, pulse columns, holding tanks and piping and pumps.

TABLE A.2-5. Solvent Extraction Equipment

\begin{tabular}{|c|c|c|c|c|}
\hline Equipment Item & Quantity & $\begin{array}{l}\text { Unit Dimension } \\
\mathrm{L} \times \mathrm{W} \times \mathrm{H}(\mathrm{m})\end{array}$ & $\begin{array}{l}\text { Shipping } \\
\text { volume }\left(\mathrm{m}^{3}\right)\end{array}$ & $\begin{array}{l}\text { Estimated } \\
\text { Weight (Mg) }\end{array}$ \\
\hline Pumper Decanters & 6 & 1.2 dia. $\times 1.9$ & 14 & 8.3 \\
\hline Scrub Decanters & 2 & 1.2 dia. $\times 1.9$ & 4.3 & 3.5 \\
\hline Re-extraction Pulse Column & 2 & 0.8 dia. $\times 2.5$ & 2.5 & 6.0 \\
\hline Raffinate Holding Tank & 3 & 2.8 dia. $\times 2.8$ & 36 & 16.5 \\
\hline Piping & -- & -- & 6.4 & 4.0 \\
\hline Miscellaneous Equipment & -- & -- & 5.7 & 3.0 \\
\hline
\end{tabular}

\section{A.2.2.6 Concentration of Uranyl Nitrate}

Table A.2-6 lists the equipment in the concentration area of the main building. The area covers $130 \mathrm{~m}^{2}$ and includes the evaporator tanks, filters, and piping.

TABLE A.2-6. Uranyl Nitrate Concentration Equipment

Unit Dimension Shipping Estimated $_{3}$

Equipment Item

Evaporator

Boildown Tanks

UNH Filter

Piping

Miscellaneous Equipment

Hood and Ductwork

Quantity $\mathrm{L} \times \mathrm{WXH}(\mathrm{m})$

Weight $(\mathrm{Mg})$

$2.4 \times 1.8 \times 1.8$

7.9

6.8

$3 \quad 3.0$ dia. $\times 3.0$

42

15.0

3

$0.8 \times 0.8 \times 0.8$

1.5

1.5

$--\quad-$

3.4

2.1

0.9

0.3

6.3

7.3 


\section{A. 2.2.7 Denitration Area}

Table A.2-7 lists the equipment in the denitration area of the main building. The area covers $130 \mathrm{~m}^{2}$ and includes denitrators, scrubbers, elevators, bins, piping, pumps, and equipment.

TABLE A.2-7. Denitration Equipment

\begin{tabular}{|c|c|c|c|c|}
\hline Equipment I tem & Quantity & $\begin{array}{l}\text { Unit Dimension } \\
\mathrm{L} \times \mathrm{W} \times \mathrm{H}(\mathrm{m})\end{array}$ & $\begin{array}{c}\text { Shipping } \\
\text { volume }\left(\mathrm{m}^{3}\right)\end{array}$ & $\begin{array}{c}\text { Es timated } \\
\text { Weight }(\mathrm{Mg}) \\
\end{array}$ \\
\hline Denitrator & 4 & - & 27.2 & 6.4 \\
\hline Denitrator Scrubber Cooler & 4 & $0.6 \times 0.6 \times 1.2$ & 2 & 5.0 \\
\hline Cooling Screw & 4 & -- & 5.4 & 4.0 \\
\hline $\mathrm{UO}_{3}$ Vertical Elevator & 2 & -- & 4.3 & 1.8 \\
\hline Hammer Mil1 & 2 & $1.9 \times 1.9 \times 2.2$ & 16.2 & 4.0 \\
\hline Surge Bin & 2 & -- & 19.0 & 2.9 \\
\hline Piping & -- & -- & 6.8 & 5.4 \\
\hline Hood and Ductwork & -- & - & 7.4 & 1.8 \\
\hline Miscellaneous Equipment & - & -- & 1.5 & 0.9 \\
\hline
\end{tabular}

\section{A. 2.2.8 Reduction Area}

Table A.2-8 lists the equipment in the reduction area of the main building. The area covers $270 \mathrm{~m}^{2}$ and includes storage bins, reactor feeder and piping, and equipment.

TABLE A.2-8. Uranium Trioxide to Uranium Dioxide Reduction Equipment

\begin{tabular}{|c|c|c|c|c|}
\hline Equipment Item & Quantity & $\begin{array}{l}\text { Unit Dimension } \\
\mathrm{L} \times \mathrm{W} \times \mathrm{H}(\mathrm{m})\end{array}$ & $\begin{array}{l}\text { Shipping } \\
\text { volume }\left(\mathrm{m}^{3}\right)\end{array}$ & $\begin{array}{r}\text { Estimated } \\
\text { Weight }(\mathrm{Mg})\end{array}$ \\
\hline $\mathrm{UO}_{3}$ Storage Bin & 2 & $3 \times 3 \times 3.8$ & 68.4 & 12.6 \\
\hline Screw Feeder & 2 & -- & 5.2 & 1.2 \\
\hline $\begin{array}{l}\text { Fluid Bed Reduction } \\
\text { Reactors }\end{array}$ & 4 & 0.5 dia. $\times 4.6$ & 34. D & 30.5 \\
\hline Piping & -- & -- & 20.0 & 7.6 \\
\hline Miscellaneous Equipment & -- & -- & 5.0 & 1.7 \\
\hline Hoods and Ductwork & -- & -- & 50.0 & 7.7 \\
\hline Ammonia Dissociater & 2 & $2.1 \times 2.1 \times 2.8$ & 24.6 & 18.8 \\
\hline
\end{tabular}




\section{A.2.2.9 Hydrofluorination Area}

Table A.2-9 lists the hydrofluorination equipment in the main building. The area covers $260 \mathrm{~m}^{2}$ and includes hydrofluorinators, storage hoppers, conveyors, piping, and equipment.

\section{TABLE A.2-9. Hydrofluorination Equipment}

\begin{tabular}{|c|c|c|c|c|}
\hline Equipment Item & Quantity & $\begin{array}{l}\text { Unit Dimension } \\
L \times W \times H(m)\end{array}$ & $\begin{array}{l}\text { Shipping } \\
\text { Volume }\left(\mathrm{m}^{3}\right)\end{array}$ & $\begin{array}{l}\text { Estimated } \\
\text { Weight }(\mathrm{Mg}) \\
\end{array}$ \\
\hline Screw Feeder & 4 & -- & 19.5 & 3.2 \\
\hline $\mathrm{UO}_{2}$ Filter Bin & 4 & -- & 24.5 & 4.1 \\
\hline $\begin{array}{l}\text { 1st Stage Fluid Bed } \\
\text { Hydrofluorinator }\end{array}$ & 4 & 0.8 dia. $\times 9.0$ & 16.3 & 112 \\
\hline $\begin{array}{l}\text { 2nd Stage Fluid Bed } \\
\text { Hydrofluorinator }\end{array}$ & 4 & 0.8 dia. $\times 9.0$ & 16.3 & 112 \\
\hline $\mathrm{UF}_{4}$ Seal Hopper & 4 & -- & 10.8 & 2.4 \\
\hline Interstage Hopper & 4 & -- & 10.8 & 2.4 \\
\hline $\mathrm{UF}_{4}$ Purge Conveyor & 4 & 36 length & 5.2 & 4.4 \\
\hline Redler Conveyor (509) & 4 & 36 length & 5.2 & 4.4 \\
\hline $\mathrm{UF}_{4}$ Storage Hopper & 4 & -- & 10.8 & 2.4 \\
\hline Redler Conveyor (510) & 4 & 36 length & 5.2 & 4.4 \\
\hline Piping & -- & -- & 4.6 & 4.D \\
\hline
\end{tabular}

\section{A.2.2.10 Fluorination Area}

Table A.2-10 lists equipment in the fluorination area. The area covers $270 \mathrm{~m}^{2}$ of the main building. Equipment in the area includes fluorination towers, conveyors, filters, storage hoppers, clean-up reactors, and piping.

\section{A.2.2.11 Fluorine Generation Area}

The fluorine generation equipment located in the main building is 7 isted in Table A.2-11. The area covers $1500 \mathrm{~m}^{2}$ and includes cells, tanks, filters, condenser tanks, and piping and equipment. 
TABLE A.2-10. Fluorination Equipment

\begin{tabular}{|c|c|c|c|c|}
\hline Equipment Item & Quantity & $\begin{array}{l}\text { Unit Dimension } \\
\mathrm{L} \times \mathrm{W} \times \mathrm{H}(\mathrm{m})\end{array}$ & $\begin{array}{l}\text { Shipping } \\
\text { volume }\left(m^{3}\right)\end{array}$ & $\begin{array}{r}\text { Estimated } \\
\text { Weight }(M g)\end{array}$ \\
\hline Primary Fluorinator Tower & 5 & 1.1 dia. $\times 7.6$ & 36.1 & 7.0 \\
\hline Redler Conveyor (511) & 2 & 36 length & 2.5 & 3.9 \\
\hline Primary Filter & 4 & $0.9 \times 0.9 \times 1.2$ & 12.2 & 2.2 \\
\hline Primary Cold Trap & 6 & $2.4 \times 2.4 \times 3.0$ & 60.5 & 38.2 \\
\hline Product Cylinder & 2 & -- & 34.4 & 12.6 \\
\hline Back-up Filter & 2 & -- & 2.4 & 1.6 \\
\hline $\begin{array}{l}\text { Cleanup Reactor Feed Hop- } \\
\text { per }\end{array}$ & 2 & -- & 5.2 & 6.2 \\
\hline Cleanup Reactor & 2 & 1.1 dia. $\times 7.6$ & 14.6 & 2.8 \\
\hline Redler Conveyor (512) & 2 & 36 length & 2.5 & 3.9 \\
\hline Backup Filter & 2 & -- & 2.4 & 1.6 \\
\hline Secondary Cold Trap & 4 & $1.8 \times 1.8 \times 2.0$ & 25.9 & 5.1 \\
\hline Piping & -- & -- & 22.0 & 10.2 \\
\hline Hoods and Ductwork & -- & -- & 6.8 & 4.2 \\
\hline
\end{tabular}

IABLE A.2-11. Fluorine Generation Equipment

\begin{tabular}{|c|c|c|c|}
\hline Equipment Item & Quantity & $\begin{array}{c}\text { Shipping } \\
\text { Volume }\left(m^{3}\right) \\
\end{array}$ & $\begin{array}{r}\text { Estimated } \\
\text { Weight }(\mathrm{Mg}) \\
\end{array}$ \\
\hline Waste Gas Burner & 2 & 22.5 & 12.0 \\
\hline Fluorine Cells & 60 & 160 & 95.0 \\
\hline Fluorine Surge Tank & 2 & 18.0 & 120 \\
\hline Fluorine Filter & 4 & 5.6 & 2.1 \\
\hline HF Condenser & 2 & 12.6 & 4.3 \\
\hline HF Backup Filter & 4 & 8.4 & 2.2 \\
\hline Hydrogen Surge Tank & 2 & 16.4 & 12.5 \\
\hline Fluorine Filter & 2 & 7.2 & 3.1 \\
\hline HF Storage Tank & 2 & 9.5 & 4.2 \\
\hline Piping & -- & 8.4 & 6.5 \\
\hline Miscellaneous Equipment & -- & 3.2 & 1.6 \\
\hline Instruments and Controls & -- & 4.6 & 1.1 \\
\hline
\end{tabular}




\section{A. 2.2.12 Nitric Acid Recovery Area}

Table A.2-12 lists the nitric acid recovery equipment.

\section{TABLE A.2-12. Nitric Acid Recovery Equipment}

\begin{tabular}{|c|c|c|c|c|}
\hline Equipment Item & Quantity & $\begin{array}{l}\text { Unit Dimension } \\
\mathrm{L} \times \mathrm{W} \times \mathrm{H}(\mathrm{m})\end{array}$ & $\begin{array}{l}\text { Shipping } \\
\text { volume }\left(m^{3}\right)\end{array}$ & $\begin{array}{l}\text { Estimated } \\
\text { Weight (Mg) }\end{array}$ \\
\hline Tanks & 2 & (1.3 dia. $\times 1.5$ length) & 8.0 & 8.6 \\
\hline Piping & -- & -- & 6.4 & 2.1 \\
\hline Equipment & - & -- & 3.2 & 1.8 \\
\hline Pumps & 2 & $0.7 \times 0.7 \times 1.4$ & 4.7 & 3.1 \\
\hline
\end{tabular}

\section{A.2.2.13 Instrument Repair Shop}

Table A.2-13 lists the equipment located in this shop. This shop has about $110 \mathrm{~m}^{2}$ of floor area and about $515 \mathrm{~m}^{3}$ of volume. The shop contains equipment for doing maintenance on electrical and electronic equipment.

\section{TABLE A.2-13. Equipment in the Instrument Repair Shop}

\begin{tabular}{|c|c|c|c|c|}
\hline Equipment Item & Quantity & $\begin{array}{l}\text { Unit Dimension } \\
\underline{L} \times W \times H(m)\end{array}$ & $\begin{array}{l}\text { Shipping } \\
\text { Volume }\left(\mathrm{m}^{3}\right) \\
\end{array}$ & $\begin{array}{l}\text { Estimated } \\
\text { Weight (Mg) } \\
\end{array}$ \\
\hline Scopes and Testers & 4 & $0.6 \times 0.5 \times 0.9$ & 1.0 & 0.4 \\
\hline Bénches and Tables & 4 & $1.8 \times 0.9 \times 0.9$ & 10.2 & 1.2 \\
\hline Braze and Solder Booth & 1 & $1.5 \times 0.9 \times 2.4$ & 0.6 & 0.3 \\
\hline Cabinets & 6 & $1.2 \times 0.6 \times 1.8$ & 8.4 & 1.5 \\
\hline Cleaning Hood & 1 & $1.5 \times 0.9 \times 2.1$ & 3.0 & 0.3 \\
\hline Miscellaneous & -- & -- & 3.0 & 0.6 \\
\hline
\end{tabular}

\section{A. 2.2.14 Temporary Radwaste Facility}

The equipment in the temporary radwaste facility is listed in Table A.2-14. Tanks and a centrifuge take up the bulk of the volume of the equipment. 
TABLE A.2-14. Equipment in the Radwas te Room

\begin{tabular}{|c|c|c|c|c|}
\hline Equipment Item & Quantity & $\begin{array}{l}\text { Unit Dimension } \\
L \times W \times H(m)\end{array}$ & $\begin{array}{l}\text { Shipping } \\
\text { Volume }\left(\mathrm{m}^{3}\right)\end{array}$ & $\begin{array}{r}\text { Estimated } \\
\text { Weight (Mg) }\end{array}$ \\
\hline Quarantine Tank & 1 & 4.1 dia. $\times 6.1$ & $81.7^{(a)}$ & 2.1 \\
\hline Slab Tanks & 1 & $3.7 \times 3.7 \times 3.7$ & $48.9^{(a)}$ & 18.6 \\
\hline Centrifuge & 1 & $1.2 \times 0.9 \times 1.5$ & 1.7 & 0.9 \\
\hline $\begin{array}{l}\text { Miscellaneous (pumps, } \\
\text { small tanks, etc.) }\end{array}$ & - & -- & 3.6 & 1.1 \\
\hline
\end{tabular}

(a) Noncompacted volume.

\section{A.2.2.15 Decontamination Facility}

The list of equipment in the facility is provided in Table A.2-15.

TABLE A.2-15. Equipment in the Decontamination Facility

\begin{tabular}{|c|c|c|c|c|}
\hline Equipment Item & Quantity & $\begin{array}{l}\text { Unit Dimension } \\
\mathrm{L} \times \mathrm{W} \times \mathrm{H}(\mathrm{m})\end{array}$ & $\begin{array}{c}\text { Shipping } \\
\text { volume }\left(\mathrm{m}^{3}\right)\end{array}$ & $\begin{array}{r}\text { Estimated } \\
\text { Weight }(\mathrm{Mg}) \\
\end{array}$ \\
\hline $\begin{array}{l}\text { Oecontamination Spray } \\
\text { Booth }\end{array}$ & 1 & $3.7 \times 3.1 \times 3.1$ & 6.8 & 2.6 \\
\hline Cleaning Sinks & 2 & $1.2 \times 0.9 \times 1.1$ & 2.4 & 0.3 \\
\hline Sorting Tables & 1 & $3.7 \times 0.9 \times 0.8$ & 3.1 & 0.7 \\
\hline Box Dumper & 1 & $1.2 \times 1.2 \times 1.8$ & 0.5 & 0.2 \\
\hline Band Saw & 1 & $1.2 \times 0.9 \times 2.7$ & 0.6 & 0.4 \\
\hline Compacting and Packaging & 2 & $0.9 \times 0.9 \times 1.5$ & 2.0 & 0.4 \\
\hline $\begin{array}{l}\text { Radiation and Uranium } \\
\text { Scanner }\end{array}$ & l & $1.2 \times 1.2 \times 1.2$ & 1.8 & 0.5 \\
\hline Miscellaneous & -- & -- & 1.8 & 0.5 \\
\hline
\end{tabular}

\section{A. 2.2.16 Laundry Facility}

The equipment in the laundry room is listed in Table A.2-16. This room has about $830 \mathrm{~m}^{2}$ of floor space and $4,050 \mathrm{~m}^{3}$ of room volume. 
TABLE A.2-16. Equipment in the Laundry

\begin{tabular}{|c|c|c|c|c|}
\hline Equipment Item & Quantity & $\begin{array}{l}\text { Unit Dimension } \\
\mathrm{L} \times \mathrm{W} \times \mathrm{H}(\mathrm{m})\end{array}$ & $\begin{array}{l}\text { Shipping } \\
\text { volume }\left(\mathrm{m}^{3}\right)\end{array}$ & $\begin{array}{r}\text { Estimated } \\
\text { Weight }(\mathrm{Mg}) \\
\end{array}$ \\
\hline Washing Machines & 2 & $1.5 \times 1.5 \times 1.2$ & 5.7 & 0.9 \\
\hline Dryers & 2 & $2.4 \times 1.2 \times 2.4$ & 14.5 & 1.7 \\
\hline Sorting and Folding Tables & 4 & $3.1 \times 1.2 \times 0.8$ & 2.3 & 0.9 \\
\hline Miscellaneous & - & -- & 3.6 & 1.1 \\
\hline
\end{tabular}

\section{A. 2.2.17 Change Rooms}

The equipment in these rooms is listed in Table A.2-17. The change rooms are maintained essentially contamination-free. Like the laundry room, there is about $830 \mathrm{~m}^{2}$ of floor space and $4,050 \mathrm{~m}^{3}$ of room volume.

TABLE A.2-17. Equipment in the Change Rooms

\begin{tabular}{|c|c|c|c|c|}
\hline Equipment I tem & Quantity & $\begin{array}{l}\text { Unit Dimension } \\
\mathrm{L} \times \mathrm{W} \times \mathrm{H}(\mathrm{m})\end{array}$ & $\begin{array}{l}\text { Shipping } \\
\text { volume }\left(\mathrm{m}^{3}\right)\end{array}$ & $\begin{array}{r}\text { Estimated } \\
\text { Weight (Mg) }\end{array}$ \\
\hline Hand and Foot Counters & 3 & $0.8 \times 0.8 \times 2.1$ & 3.7 & 0.9 \\
\hline Miscellaneous Survey & - & -- & 1.8 & 0.4 \\
\hline Miscellaneous & -- & -- & 2.0 & 0.4 \\
\hline
\end{tabular}

\section{A.2.2.18 Incinerator Facility}

The Incinerator Facility is located immediately west of the main plant, as shown in Figure A.1-2. A list of equipment in the Incinerator Facility is given in Table A.2-18.

The Incinerator Facility has a floor area of $150 \mathrm{~m}^{2}$.

\section{A.2.2.19 Piping, Ductwork, Trays, and Light Fixtures}

Table A.2-19 provides an estimate of the piping, ductwork, trays, and light fixtures in the areas of the plant to be decommissioned. Piping includes process piping, service piping, independent electrical conduit and instrument lines. Ventilation ducts and hood ducts are included in the ductwork estimates. Special and separate ductwork has already been included in previous room discussions in 
this report. The trays include hangers and trays with piping and conduit, which is batched and supported by the trays. Light fixtures include all main overhead lighting, most of which are fluorescent lamps.

TABLE A.2-18. Equipment in the Incinerator Facility

\begin{tabular}{|c|c|c|c|c|}
\hline Equipment I tem & Quantity & $\begin{array}{l}\text { Unit Dimension } \\
\mathrm{L} \times \mathrm{W} \times \mathrm{H}(\mathrm{m}) \\
\end{array}$ & $\begin{array}{l}\text { Shipping } \\
\text { volume }\left(\mathrm{m}^{3}\right)\end{array}$ & $\begin{array}{r}\text { Estimated } \\
\text { Weight }(\mathrm{Mg}) \\
\end{array}$ \\
\hline $\begin{array}{l}\text { Input and Output U-Scan- } \\
\text { ners }\end{array}$ & 2 & $1.2 \times 1.2 \times 1.2$ & 3.6 & 0.8 \\
\hline Shredder & 1 & $2.4 \times 0.9 \times 1.8$ & 4.1 & 1.3 \\
\hline Blow Tube Unit & 1 & $1.5 \times 0.6 \times 0.6$ & 0.6 & 0.2 \\
\hline $\begin{array}{l}\text { Vortex Incinerator } \\
\text { Chamber }\end{array}$ & 1 & $2.4 \times 2.4 \times 2.4$ & 14.5 & 8.9 \\
\hline $\begin{array}{l}\text { Offgas Scrubber } \\
\text { w/Demister }\end{array}$ & 1 & $2.4 \times 1.2 \times 1.2$ & 3.6 & 0.7 \\
\hline $\begin{array}{l}\text { Scrubber Ancillaries } \\
\text { (Tank, etc.) }\end{array}$ & 1 & $1.2 \times 1.2 \times 0.9$ & 1.4 & 0.3 \\
\hline Ash Recovery System & 1 & $1.2 \times 0.6 \times 2.4$ & 1.8 & 0.4 \\
\hline Packaging Equipment & 2 & $1.2 \times 1.2 \times 1.2$ & 3.6 & 0.8 \\
\hline Blower Unit & 1 & $1.5 \times 1.5 \times 1.5$ & 3.5 & 0.6 \\
\hline HEPA Filter Unit & 1 & $1.5 \times 1.5 \times 1.8$ & 4.3 & 1.0 \\
\hline Miscellaneous & -- & -- & 3.6 & 1.1 \\
\hline
\end{tabular}

TABLE A.2-19. Volumes and Weights of Piping, Ductwork, Trays and Light Fixtures

\begin{tabular}{|c|c|c|c|c|c|c|}
\hline \multirow{2}{*}{ Location } & \multicolumn{2}{|c|}{ Piping and Conduit } & \multicolumn{2}{|c|}{ Duct and Supports } & \multicolumn{2}{|c|}{ Trays and Light Fixtures } \\
\hline & $\begin{array}{l}\text { Compacted } \\
\text { Volume }\left(\mathrm{m}^{3}\right)\end{array}$ & Height $(\mathrm{Mg})$ & $\begin{array}{l}\text { Non-Compacted } \\
\text { Volume }\left(\mathrm{m}^{3}\right)\end{array}$ & Weight $(M k s)$ & $\begin{array}{c}\text { Compacted } \\
\text { Volume }\left(\mathrm{m}^{3}\right) \\
\end{array}$ & Weight $(\mathrm{Mg})$ \\
\hline Sampling Roon & 0.3 & 0.5 & 15.2 & 0.9 & 4.5 & 5.2 \\
\hline Laboratory & 4.1 & 4.8 & 60.6 & 3.1 & 11.5 & 10.3 \\
\hline $\begin{array}{l}\text { UF }_{\text {Area }} \text { Slurry Processing } \\
\text { Are }\end{array}$ & 3.1 & 3.5 & 44.6 & 2.5 & 4.5 & 5.2 \\
\hline Digestion Area & 1.6 & 1.8 & 27.7 & 2.7 & 6.2 & 7.2 \\
\hline Solvent Extraction Bidg. & 54.4 & 74.6 & 125.0 & 12.3 & 68.0 & 70.5 \\
\hline Concentration Area & 7.8 & 9.0 & 109.0 & 5.5 & 20.0 & 22.1 \\
\hline Denonstration Area & 9.3 & 10.7 & 50.4 & 9.8 & 13.3 & 15.4 \\
\hline Hydrofluorination Area & 7.8 & 5.9 & 50.8 & 2.3 & 11.8 & 13.6 \\
\hline Loading Area & 1.4 & 1.6 & 19.4 & 0.9 & 2.5 & 2.9 \\
\hline$F_{2}$ Cell & 0.4 & 0.4 & 32.4 & 1.5 & 2.5 & 2.9 \\
\hline Cell Rework & 1.7 & 2.0 & 5.5 & 0.3 & 3.0 & 3.5 \\
\hline Instrument Room & 0.5 & 0.5 & 3.7 & 0.2 & 1.5 & 1.7 \\
\hline
\end{tabular}




\section{REFERENCES}

1. Special Nuclear Material License Application for Kerr-McGee Sequoyah Facility, License No. SOB-1010, Docket No. 40-8027, Kerr-McGee Nuclear Corporation, July 1, 1975.

2. U.S. Nuclear Regulatory Commission, Final Environmental Impact Statement Related to Sequoyah Uranium Hexafluoride Plant of Kerr-McGee Nuclear Corporation, Docket No. 40-8027, February 1975.

3. U.S. Nuclear Regulatory Commission, Environmental Impact Appraisal of the Allied Chemical Corporation Nuclear Service Division Uranium Hexafluoride Conversion Facility, Metropolis, Illinois, Docket No. 40-3392, pp. 4-1 through 4-16, August, 1979. 


\section{APPENDIX B}

\section{REFERENCE SITE DESCRIPTION *}

A reference site is used to assess the public safety and potential environmental effects of conceptually decommissioning various nuclear fuel cycle facilities. (1-3) A summary of the site description found in References 1 through 3 is presented in this appendix. Only information directly relating to the radiation and chemical exposure pathway analysis, required in determining acceptable residual contamination levels and in calculating radiation doses for the public radiological safety analysis, is included here. The meteorological parameters and population distribution for the year 2000 are based on information presented in Reference 4. Other necessary site information is based on data reported in the site description of an operating nuclear power station. Estimates of the annual radioactive and chemical releases during operation of the reference $U F_{6}$ conversion plant are also included in this appendix. The remainder of the information is obtained from a variety of sources or is developed specifically for this study. All of the information is representative of potential sites for nuclear fuel cycle facilities in the midwestern or middle southeastern United States.

Individual features of an actual site (for a specific facility) may vary from those of this reference site. However, it is believed that this approach (i.e., use of a reference site) results in a more meaningful overall analysis of the potential impacts associated with decommissioning most nuclear fuel cycle facilities. A site-specific assessment is required for a similar analysis of a specific UF 6 conversion plant.

\section{B. 1 SITE LOCATION AND SIZE}

The reference site is located in a rural area with characteristics similar. to those found in the midwestern or middle southeastern United States. The site occupies about $4.7 \mathrm{~km}^{2}$ in a rectangular shape of about $2 \mathrm{~km}$ by $2.35 \mathrm{~km}$. A moderate-size river flows through one corner of the site. 


\section{B.2 DEMOGRAPHY}

The site is located in a rural area with a relatively low population density, with highest population densities occurring at distances of 20 to $60 \mathrm{~km}$. Population distribution data for the year 2000 is given in Table B.2-1. The total population residing within an $80-\mathrm{km}$ radius of the site is about 3.52 million.

TABLE B.2-1. Population Distribution Around the Reference Site for the Year $2000(4)$

\begin{tabular}{ccrrr}
$\begin{array}{c}\text { Distance From } \\
\begin{array}{c}\text { Site Boundary } \\
(\mathrm{km})\end{array}\end{array}$ & $\begin{array}{c}\text { Population } \\
\text { Density } \\
\left.\text { (Persons } / \mathrm{km}^{2}\right)\end{array}$ & $\begin{array}{c}\text { Total Population } \\
\text { In AnnuTus(a,b) }\end{array}$ & $\begin{array}{r}\text { Cumulative } \\
\text { Population }\end{array}$ \\
\cline { 1 - 1 } 0 to 2 & $-(c)$ & 10 & 10 \\
2 to 3 & 136 & 2130 & 2140 \\
3 to 5 & 104 & 5230 & 7370 \\
5 to 6 & 230 & 7940 & 15300 \\
6 to 8 & 133 & 11700 & 27000 \\
8 to 20 & 85 & 89300 & 116000 \\
20 to 30 & 239 & 375000 & 491000 \\
30 to 50 & 175 & 878000 & 1370000 \\
50 to 60 & 298 & 1030000 & 2400000 \\
60 to 80 & 127 & 1120000 & 3520000
\end{tabular}

(a) It is assumed that the population in each annulus is uniformly divided in each of 16 uniform 22.5 degree sectors. (b) Totals are rounded to three significant figures, (c) Indicates a population density less than $1.0 / \mathrm{km}^{2}$.

\section{B. 3 LAND USE}

Use of any part of the total site area for anything other than $U F_{6}$ conversion operations is assumed to be prohibited during the 40-year plant operational lifetime. The major plant facilities are located inside a 30.4-hectare fenced portion of the site. The minimum distance from the point of airborne release to the outer site boundary is $1 \mathrm{~km}$. The outer site boundary is fenced and marked. 
About $80 \%$ of the land within $16 \mathrm{~km}$ of the site is used for farming. The main crops are soybeans (60\%), corn, oats, and other grains (30\%), and hay (10\%). It is expected that this area will remain largely agricultural, and that the population will not change significantly because of the operation of the $U_{6}$ conversion plant.

A wildlife refuge and a state forest and campground are located about $14 \mathrm{~km}$ from the site. A state park is located about $10 \mathrm{~km}$ from the site in the opposite direction.

There are large truck gardens in the area. The nearest dwelling (the residence location of the maximum-exposed individual for the public safety analysis of decomissioning) is a farm located about $1.3 \mathrm{~km}$ from the site. A milk cow is kept at this farm and is maintained on fresh pasture 7 months of the year. A family garden with a growing season of 5 months is kept for fresh vegetables. River water is used to irrigate the crops on this farm.

\section{B.4 METEOROLOGY}

The reference site has a typical continental climate. It is characterized by wide variations in temperature, modest winter precipitation, normally ample spring and summer rainfall, and a general tendency to extremes in all climatic features. January is the coldest month and July is the warmest. Table B.4-] shows monthly meteorological statistics.

TABLE B.4-1. Monthly Meteorological Statistics at the Reference Site

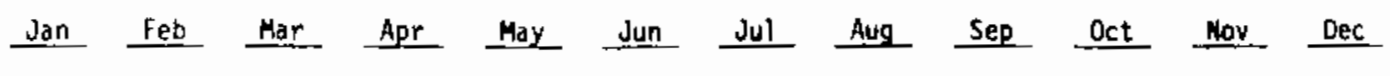

Air Temperature $\left({ }^{\circ} \mathrm{C}\right)$

\begin{tabular}{|c|c|c|c|c|c|c|c|c|c|c|c|c|}
\hline Maximum & -6.1 & -4.4 & 3.3 & 12.8 & 20 & 25 & 28.3 & 26.7 & 22.2 & 15 & 4.4 & -3.3 \\
\hline Minimum & -16.1 & -14.4 & -6.7 & 1.7 & 7.8 & 13.3 & 16.1 & 15 & 10 & 3.9 & -4.4 & -12.2 \\
\hline Mean & -11.1 & -9.4 & -1.7 & 7.2 & 13.9 & 18.9 & 22.2 & 21.1 & 16.1 & 9.4 & 0.0 & -7.8 \\
\hline Extreme Maximum & 15 & 16.1 & 27.8 & 32.8 & 40.6 & 39.4 & 41.7 & 40 & 40.6 & 32.2 & 23.9 & 17.2 \\
\hline Extreme Mininum & -38.9 & -36.7 & -34.4 & -15.6 & -6.7 & 0.6 & 5.6 & 3.3 & -5.6 & -13.3 & -27.8 & -33.9 \\
\hline
\end{tabular}

Mean Relative Humidity (莒)

$\begin{array}{llllllllllll}74 & 75 & 73 & 66 & 62 & 66 & 68 & 70 & 70 & 66 & 73 & 78\end{array}$


On the average, 12 days per year have maximum temperatures of $32^{\circ} \mathrm{C}$ and above. Annually, an average of 168 days have minimum temperatures of $0^{\circ} \mathrm{C}$ and below, with 40 of them at $-18^{\circ} \mathrm{C}$ or below. The January average relative humidities at 7:00 a.m., 1:00 p.m., and 7:00 p.m. are 76, 68, and 70\%, respectively. The corresponding relative humidities for July are 86,55 , and $55 \%$.

The average annual rainfall in the area is $610 \mathrm{~mm}$. The months of May through September have the greatest amounts of rainfall, with an average during this period of 432 to $457 \mathrm{~mm}$ ( $70 \%$ of the annual total). The maximum $24-\mathrm{hr}$ total rainfall for the perjod 1894 through 1965 was 127 man and occurred in May. Thunderstorms, with an average annual frequency of 36, are the chief source of rain from May through September. Snowfall in the area averages $1070 \mathrm{~mm}$ annually, with occurrences recorded in all months except June, July, and August. The extremes in annual snowfall of record are 152 mom minimum and 2235 man maximum.

Annually, the winds are predominantly bimodal. This bimodal distribution is characteristic of the seasonal wind distributions as well. The average wind speed for spring is $11 \mathrm{~km} / \mathrm{hr}$ and for the other seasons is about $16 \mathrm{~km} / \mathrm{hr}$. The maximum reported wind speed of $148 \mathrm{~km} / \mathrm{hr}$ was associated with a tornado. Tornadoes and other severe storms occur occasionally. Eight tornadoes were reported from 1961 through 1967 in the county where the site is located. The probability of a tornado striking a given point in this area is about $5 \times 10^{-4}$ per year. For design purposes a wind velocity of $480 \mathrm{~km} / \mathrm{hr}$ is assumed to be associated with tornadoes.

Natural fog that restricts visibility to $0.4 \mathrm{~km}$ or less occurs about $30 \mathrm{hr} / \mathrm{yr}$. Icing caused by freezing rain can occur between 0ctober and Apri1, with an average of one to two storms per year. The mean duration of icing on utility lines is $36 \mathrm{hr}$.

Diffusion climatology comparisons with other locations indicate that the site is typical of the region, with relatively favorable atmospheric dilution conditions prevailing. Thermal inversions occur about $32 \%$ of the year, and the frequency of thermal stabilities is $19 \%$ slightly stable, $27 \%$ stable, $20 \%$ neutral, and $34 \%$ unstable. 
Data from a number of river sites used for nuclear power reactors are used to calculate the "typical" annual atmospheric dispersion pattern in an average 22.5-degree sector around the site. Dispersion factors at selected distances for the average sector are determined from joint-frequency distributions for each site. This is done by calculating the dispersion factor. $\bar{X} / Q^{\prime}$, for each sector at selected downwind distances and then calculating the average dispersion factor at each distance. In other words, the dispersion factors in those sectors corresponding to overland trajectories are added without regard to direction and divided by the number of sectors involved. Thus, an average dispersion factor is obtained for each selected downwind distance for all 16 sectors, based on data given in Reference 4.

Standard groups of meteorological data are interpolated from the specific site data. The groupings provide four stability classes based on vertical temperature gradient and five wind speed classes based on the Beaufort wind scale. (6) The stability classes are based on Reference 7 information, with Pasquill Classes A, B, and C classified as B (unstable); Pasquill Class D (neutra1); Pasquill Class E (slightly stable); and Pasquill Classes $F$ and $G$ classified as F (moderately stable).

Some of the wind-speed data is available for only one height. In this event, the measured values are extrapolated to the 1D-m level for ground level release calculations and to the 150-m level for reference stack release calculations. Where measurements at two heights are available, the highest is extrapolated to $150 \mathrm{~m}$ and the lowest to $10 \mathrm{~m}$, using a standard power-law extrapolation procedure. (6)

The ratio of the maximum sector dispersion factor to the average sector dispersion factor is 2.5. This value is used for all release heights in this study. Investigation of the change in this ratio with increasing distance from the site shows that the ratio remains essentially constant. The dispersion factors for the average sector as a function of height of release and downwind distance are shown in Figure B.4-1. 


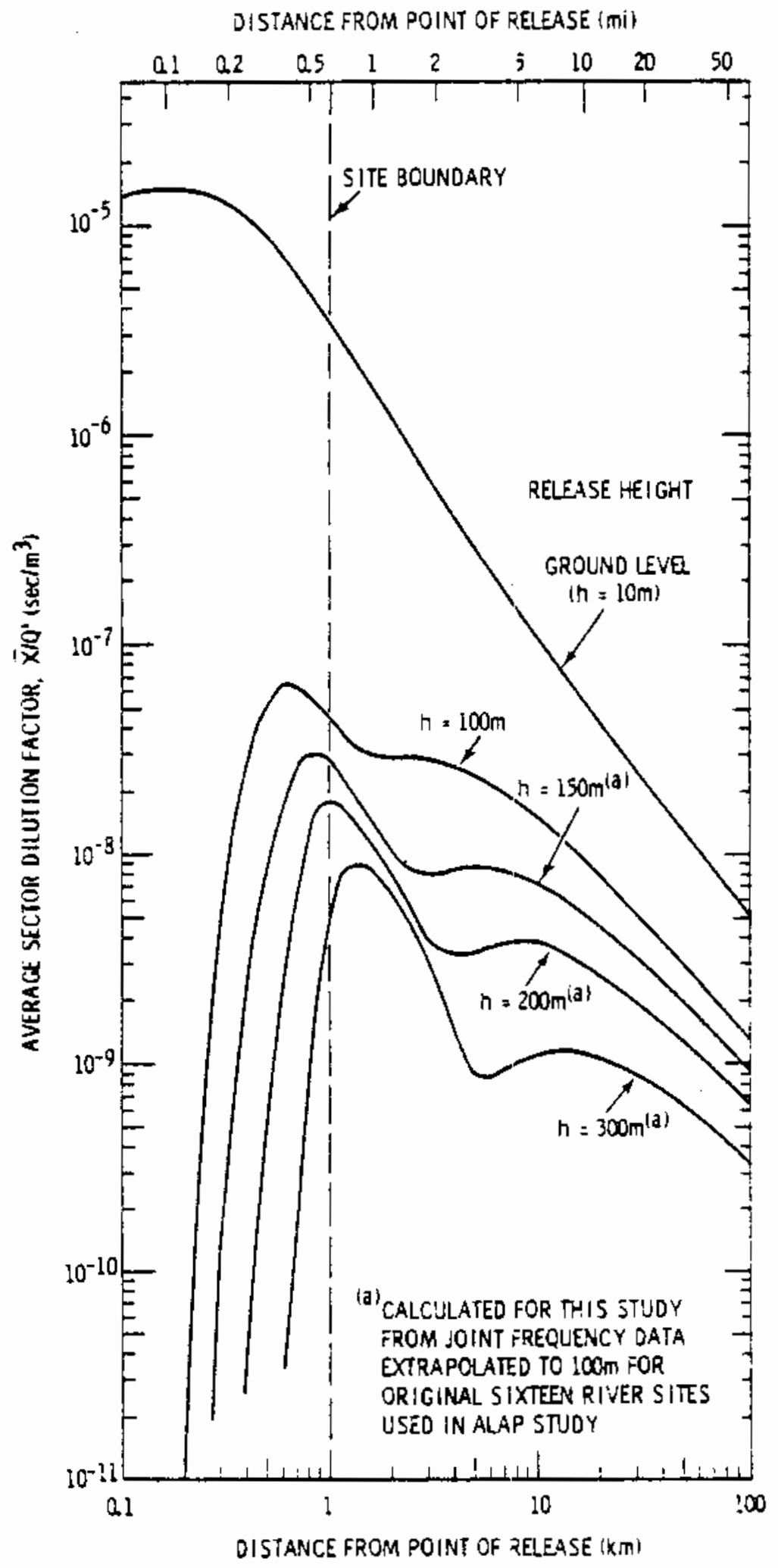

FIGURE B.4-1. Average $\left(\bar{X} / Q^{\prime}\right)$ Values Versus Distance in a Sector from the Reference Site 
No credit for plume rise from either momentum or buoyancy is taken in this study. Where large volumes of heated air are being ejected, the plume rise constant for momentum is estimated to be about $50 \mathrm{~m}^{2} / \mathrm{sec}$. Assuming an annual average wind speed of 2 to $3 \mathrm{~m} / \mathrm{sec}$, the increase in effective stack height due to momentum would be about 15 to $25 \mathrm{~m}$. Plume rise from buoyancy (heat effect) would add at least another 25 to $100 \mathrm{~m}$ of effective stack height, depending on the temperature of the exhaust gases. Thus, the $\bar{X} / Q^{\prime}$ values illustrated in Figure B.4-1 are larger than they would be if credit had been taken for momen: tum and buoyancy.

\section{B.5 ESTIMATES OF RESIDUAL RADIOACTIVITY}

In order to make decisions on alternative uses for a site, information is needed on the levels and nature of the radioactive contamination present at the time of decommissioning. This section discusses the potential site radioactive contamination, the origin of this contamination, and its expected levels at the time of plant shutdown.

Naturally occurring radionuclides and radionuclides from nuclear weapons testing will be present on any nuclear facility site consistent with the level generally found in the local region. Naturally occurring radiation results from both extraterrestrial and terrestrial sources. Extraterrestrial radiation originates in outer space as cosmic radiation which interacts with particles in the upper atmosphere to emit radiation that exposes people on the planet surface. A typical dose rate at sea level from this source is about $30 \mathrm{mrem} / \mathrm{yr}$. The dose rate from this source is altitude-dependent, and it is about $120 \mathrm{mrem} / \mathrm{yr}$ in Colorado. (8) Terrestrial radiation is emitted by naturally occurring radionuclides in the soil, rocks, or atmosphere. Terrestrial radioactivity results in an internal dose rate of about $20 \mathrm{mrem} / \mathrm{yr}$ (most]y from ${ }^{40} \mathrm{~K}$ ), and in an external dose rate of about $50 \mathrm{mrem} / \mathrm{yr}$. Radioactive contamination levels resulting from atmospheric nuclear weapons testing vary markedly from region to region. Radiation from deposited ${ }^{137} \mathrm{Cs}$ is the main long-term contributor to external dose, while radionuclides like ${ }^{90} \mathrm{Sr},{ }^{137} \mathrm{Cs},{ }^{129} \mathrm{I}, 131 \mathrm{I}$, and plutonium isotopes contribute to internal dose rates. 
Radioactive contamination is also expected to be present on the site as a result of effluents released during normal operations over the anticipated operating $\mathrm{UF}_{6}$ conversion plant life of 40 years.

Accidental releases during plant operation are not expected to significantly increase these levels because it is assumed that normal operating practice is to clean up contaminated areas immediately following such events. Estimates of the ground contamination levels are based on the deposition of predicted normal operating releases of gaseous effluents.

The estimated annual atmospheric release of radionuclides from the reference $U F_{6}$ conversion plant are listed in Table B.5-1.

TABLE B.5-1. Estimated Annual Atmospheric Release of Radionuclide from the Reference $U \mathrm{FF}_{6}$ Conversion Plant (a)

\begin{tabular}{|c|c|c|}
\hline Radionuclide & $\begin{array}{l}\text { Half-Life } \\
\text { (days) }\end{array}$ & $\begin{array}{l}\text { Release } \\
(i \mathrm{i} / \mathrm{yr})\end{array}$ \\
\hline${ }^{230} \mathrm{Th}(b)$ & $2.8 \times 10^{7}$ & $1.4 \times 10^{-3}$ \\
\hline${ }^{234} \mathrm{Th}^{(\mathrm{b})}$ & $2.4 \times 10^{1}$ & $1.2 \times 10^{-1}$ \\
\hline $22.6_{\mathrm{Ra}}(\mathrm{b})$ & $5.8 \times 10^{5}$ & $8.3 \times 10^{-5}$ \\
\hline $234 u^{(c)}$ & $8.9 \times 10^{7}$ & $1.6 \times 10^{-1}$ \\
\hline $235{ }_{u}(c)$ & $2.6 \times 10^{11}$ & $7.4 \times 10^{-3}$ \\
\hline $238_{U}(c)$ & $1.6 \times 10^{12}$ & $1.6 \times 10^{-1}$ \\
\hline Total & & $4.5 \times 10^{-1}$ \\
\hline
\end{tabular}

(a) Based on information given in Reference 9.

(b) Based on isotopic ratios in yellowcake.

(c) Based on the ratio of radionuclides in natural uranium. 
The concentration of deposited radionuciides is estimated using an NRC computer model X0Q00Q. ${ }^{(10)}$ Constant annual releases are assumed over the 40-year plant life. The release point is assumed to be at ground leve $(10 \mathrm{~m})$, with no credit taken for plume rise due to either buoyancy or momentum. Meteorological data on joint frequency of wind speed and wind direction by atmospheric stability are not available for the reference site. Therefore, data are taken from the Barnwell Environmental Report. (11) Deposition values reported are representative of the plant facilities area (area within a radius of $1000 \mathrm{~m}$ from the point of release). Often the contamination levels would be generally lower.

The procedure used to estimate relative deposition rates in the NRC model is based on numerical solutions to the flux-gradient ("K-Theory") diffusion equation. (12) The effluent is not allowed to diffuse beyond a height of $200 \mathrm{~m}$ in a stable condition and $1000 \mathrm{~m}$. in neutral and unstable conditions. At the ground surface, a partial sink boundary condition involving the deposition velocity is assumed. The wind and eddy diffusivity profiles required as input to the diffusion equation are those presented by Markee. (12) The deposition velocity is allowed to vary with wind speed in accordance with an empirical equation $^{(13)}$ and assumes an areal grass density of approximately $70 \mathrm{~g} / \mathrm{m}^{2}$. Resulting deposition velocities are $1.2,12$, and $8.8 \mathrm{~mm} / \mathrm{sec}$ for stable, neutral, and unstable conditions, respectively.

The estimated surface concentrations of the individual radionuclides averaged over the entire site are shown in Table B.5-2. The effect of radioactive decay and daughter buildup of the residual contamination is demonstrated by site contamination estimates for four decay times following plant shutdown: $5,10,30$, and 100 years.

The radioactivity levels calculated for the site are expected to be maximum values, since no allowance is made for normal weathering such as runoff, soil, and vegetational coverage, or for resuspension of the deposited material. Except for random concentrations of the contamination, the radioactivity level of the radionuclides is expected to be some fraction of the values in Table B.5-2. 
TABLE B.5-2. Estimated Quantities of Radioactive Materials Deposited on the Reference Plant Site After a 40-Year Dperating Lifetime(a)

\begin{tabular}{|c|c|c|c|c|c|}
\hline \multirow[b]{2}{*}{ Radionuclide } & \multirow[b]{2}{*}{ Shutdown } & \multicolumn{4}{|c|}{$\begin{array}{l}\text { Deposited Radioactivity }\left(\mu \mathrm{Ci} / \mathrm{m}^{2}\right) \text { at } \mathrm{Plant} \\
\text { Shutdown and Selected Times After Shutdown }\end{array}$} \\
\hline & & 5 Years & 10 Years & 30 Years & 100 Years \\
\hline${ }^{230}{ }_{\text {Th }}$ & $8.8 \times 10^{-4}$ & $1.1 \times 10^{-3}$ & $1.3 \times 10^{-3}$ & $2.1 \times 10^{-3}$ & $5.0 \times 10^{-3}$ \\
\hline${ }^{231} \mathrm{Th}$ & $6.8 \times 10^{-3}$ & $6.8 \times 10^{-3}$ & $6.8 \times 10^{-3}$ & $6.8 \times 10^{-3}$ & $6.8 \times 10^{-3}$ \\
\hline${ }^{234} \mathrm{Th}$ & $7.5 \times 10^{-2}$ & $7.5 \times 10^{-2}$ & $7.5 \times 10^{-2}$ & $7.5 \times 10^{-2}$ & $7.5 \times 10^{-2}$ \\
\hline${ }^{231} \mathrm{~Pa}$ & $9.0 \times 10^{-6}$ & $1.1 \times 10^{-5}$ & $1.3 \times 10^{-3}$ & $2.2 \times 10^{-5}$ & $5.3 \times 10^{-5}$ \\
\hline${ }^{34 \mathrm{~m}} \mathrm{~Pa}$ & $1.0 \times 10^{-1}$ & $1.0 \times 10^{-1}$ & $1.0 \times 10^{-1}$ & $1.0 \times 10^{-1}$ & $1.0 \times 10^{-1}$ \\
\hline${ }^{234} \mathrm{~Pa}$ & $1.0 \times 10^{-4}$ & $1.0 \times 10^{-4}$ & $1.0 \times 10^{-4}$ & $1.0 \times 10^{-4}$ & $1.0 \times 10^{-4}$ \\
\hline${ }^{226} \mathrm{Ra}$ & $5.2 \times 10^{-5}$ & $5.2 \times 10^{-5}$ & $5.2 \times 10^{-5}$ & $5.2 \times 10^{-5}$ & $5.2 \times 10^{-5}$ \\
\hline${ }^{234} U$ & $1.0 \times 10^{-1}$ & $1.0 \times 10^{-1}$ & $1.0 \times 10^{-1}$ & $1.0 \times 10^{-1}$ & $1.0 \times 10^{-1}$ \\
\hline $235_{U}$ & $4.5 \times 10^{-3}$ & $4.5 \times 10^{-3}$ & $4.5 \times 10^{-3}$ & $4.5 \times 10^{-3}$ & $4.5 \times 10^{-3}$ \\
\hline $238_{u}$ & $1.0 \times 10^{-1}$ & $1.0 \times 10^{-1}$ & $1.0 \times 10^{-1}$ & $1.0 \times 10^{-1}$ & $1.0 \times 10^{-1}$ \\
\hline Totals & $3.9 \times 10^{-1}$ & $3.9 \times 10^{-1}$ & $3.9 \times 10^{-1}$ & $3.9 \times 10^{-1}$ & $3.9 \times 10^{-1}$ \\
\hline
\end{tabular}

(a) Based on the ratio of radionuclides in uranium and the isotopic ratios given in Reference 9.

\section{B.6 ESTIMATES OF RESIDUAL CHEMICALS}

The release of toxic chemicals during normal operations of the reference $\mathrm{UF}_{6}$ conversion plant is of primary concern. Since uranium is a valuable commodity, the nuclear industry uses sophisticated technology to minimize losses during chemical processing. The uranium process streams contain excess reagents which can escape from the plant as airborne or liquid releases. This section contains a discussion of the chemical effluents expected from the operating $\mathrm{UF}_{6}$ conversion plant. 


\section{B.6.1 Gaseous Chemical Releases}

Discharges that contain nitrogen and fluorine are considered to be the most significant, since these materials account for the major part of the total waste discharge. Table B.6-1 contains a listing of the annual gaseous effluents from the reference $U F_{6}$ conversion plant. The gaseous effluents in Table B.6-1 are a summary of literature information. $(9,14-16)$

IABLE B.6-1. Estimated Annual Gaseous Effluents from the Reference UF 6 Conversion Plant

$\begin{array}{llll}\text { Effluent } & \frac{\mathrm{kg} / \text { day }}{n n n} & \mathrm{~kg} / \mathrm{yr} \\ \mathrm{HF} & 1.5 \times 10^{1} & 5.4 \times 10^{3} \\ \mathrm{SO}_{2} & 5.6 \times 10^{2} & 2.0 \times 10^{5} \\ \mathrm{NH}_{3} & 2.4 \times 10^{1} & 8.7 \times 10^{3} \\ \mathrm{H}_{2} \mathrm{~S} & 8.6 \times 10^{-3} & 6.0 \times 10^{0} \\ \mathrm{Hexane}^{2} & 4.4 \times 10^{2} & 1.6 \times 10^{5} \\ \mathrm{NO}_{2} & 2.6 \times 10^{2} & 9.5 \times 10^{4}\end{array}$

The atmospheric concentrations of these releases are all estimated to be below existing standards for air quality. Information on the environmental concentrations of the gaseous chemical releases is not available at this time; however, it is felt that none of the chemicals listed in Table B.6-1 will result in any significant residual contamination of the reference site.

\section{B.6.2 Liquid Chemica] Releases}

Estimates of the annual releases of liquid chemicals from the reference $\mathrm{UF}_{6}$ conversion plant are listed in Table B.6-2. $(9,14-16)$ The major liquid effluent consists of several combined fluoride treatment streams containing a weak hydrofluoric acid solution. The fluoride effluent stream is slaked with lime (calcium hydroxide) to neutralize the acid and raise the $\mathrm{pH}$ to 12 . The resulting slurry flows to a fluoride sludge pond where most of the excess 1 ime and calcium fluoride precipitate settles out. Overflow from the settling pond is neutralized to a $\mathrm{pH}$ of 7 by adding sulfuric acid. The resulting solution 

TABLE B.6-2. Estimated Annual Liquid Effluents from the Reference $\mathrm{UF}_{6}$
Conversion Plant

\begin{tabular}{|c|c|c|}
\hline Effluent & $\mathrm{kg} /$ day & $\mathrm{kg} /$ year \\
\hline $\mathrm{NO}_{3}^{-}$ & $7.8 \times 10^{0}$ & $2.8 \times 10^{3}$ \\
\hline $\mathrm{F}^{-2}$ & $1.8 \times 10^{0}$ & $6.6 \times 10^{2}$ \\
\hline $\mathrm{SO}_{4}{ }^{--}$ & $2.9 \times 10^{2}$ & $1.1 \times 10^{5}$ \\
\hline $\mathrm{NH}_{4}^{+}+$ & $4.5 \times 10^{-1}$ & $1.6 \times 10^{2}$ \\
\hline $\mathrm{Ca}^{++}$ & $1.9 \times 10^{0}$ & $6.9 \times 10^{2}$ \\
\hline $\mathrm{Na}^{+}$ & $1.0 \times 10^{3}$ & $3.6 \times 10^{5}$ \\
\hline $\mathrm{K}^{+}$ & $1.3 \times 10^{2}$ & $4.8 \times 10^{4}$ \\
\hline $\mathrm{HCO}_{3}^{-}$ & $2.6 \times 10^{3}$ & $9.5 \times 10^{5}$ \\
\hline $\mathrm{Cl}^{-2}$ & $7.8 \times 10^{0}$ & $2.8 \times 10^{3}$ \\
\hline $\mathrm{Fe}$ & $1.6 \times 10^{0}$ & $5.6 \times 10^{2}$ \\
\hline
\end{tabular}

is drained to a clarifying pond where most of the remaining calcium fluoride and caicium sulfate settle out. The overflow from the clarifying pond is combined with "clean" effluent water and sewage lagoon overflow prior to discharge from the facility to the receiving river. 


\section{REFERENCES}

1. K. J. Schneider and C. E. Jenkins, Technology, Safety and Costs of Decommissjoning a Reference Nuclear Fuel Reprocessing Plant, NUREG-0278, Prepared by Pacific Northwest Laboratory for the U.S. Nuclear Regulatory Comuission, October 1977.

2. R. I. Smith, G. J. Konzek and W. E. Kennedy, Jr., Technology, Safety and Costs of Decommissioning a Reference Pressurized water Reactor Power Station, NUREG/CR-0130, Prepared by Pacific Northwest Laboratory for the U.S. Nuclear Regulatory Commission, June 1978.

3. C. E. Jenkins, E. S. Murphy and K. J. Schneider, Technology, Safety and Costs of Decommissioning a Reference Smal1 Mixed 0xide Fuel Fabrication Plant, NUREG/CR-0129, Prepared by Pacific Northwest Laboratory for the U.S. Nuclear Regulatory Commission, February 1979.

4. U.S. AEC, Final Environmental Statement Concerning Proposed Rule-Making Action: Numerical Guides for Design Objectives and Limiting Conditions for Operation to Meet the Criteria "As Low As Practicabte" for Radioactive Material in Light-Water-Cooled Nuclear Power Reactor Effluents, WASH-1258, Directorate of Regulatory Standards, Volume 1 of 3 , Figure 6B-1, $\mathrm{P} .6 \mathrm{~B}-43$ and Figure 6C-8, p. 6C-12, Table 6B-6, p. 6B-36, July 1973.

5. U. S. AEC, Final Environmental Statement Related to Operation of Montice110 Nuclear Generating Plant, Docket No. 50-263, pp. II-15 through II -26, November 1972 .

6. Meteorology and Atomic Energy 1968. TID 24190, Edited by D. H. Slade, p. 73 , July 1968 .

7. U.S. NRC, Regulatory Guide 1.23, "Onsite Meteorological Programs (Safety Guide 23), "February 1972.

8. United Nations Scientific Committee on the Effects of Atomic Radiation, Ionizing Radiation: Levels and Effects, Volume 1, United Nations, pp. 29-63, 1972 .

9. U.S. NRC, Environmental Impact Appraisal of the Allied Chemical Corporation Nuclear Services Division Uranium Hexafluoride Conversion Faciljty Metropolis, Illinois, Docket No. 40-3392, pp. 4-T through 4-16, August 1977.

10. J. F. Sagendorf and J. T. Go11, XOQDOQ - Program for the Meteorological Evaluation of Routine Effluent Releases at Nuclear Power Stations, Draft NRC Report, December 1976.

11. Environmental Report, Barnwe11 Nuclear Fuel Plant, Docket No. 50-332, Appendix IV, P. 18, A11ied Chemical Nuclear Products, Inc., November 1971. 
12. E. H. Markee, Jr., A Parametric Study of Gaseous Plume Depletion by Ground Surface Adsorption, USAEC Meteorological Information Meeting, AECL-2787, pp. 602-613, 1967.

13. C. A. Pelletier and J. D. Zimbrick, "Kinetics of Environmental Radioiodine Transport Through the Milk-Food Chain," in Environmental Surveillance in the Vicinity of Nuclear Facilities, W. C. Reinig, Editor, Thomas Publishers, Springfield, IL, 1970 .

14. C. M. Heeb, R. L. Enge1, R. A. Aaberg, W. E. Kennedy, Jr., B. M. Cole, M. A. Lewallen, A Survey of Environmental Control Technology Performance and Cost, PNL-2287, Pacific Northwest Laboratory, pp. 3.7 through 3.10 and 4.42 through 4.48, March 1980.

15. U. S. AEC, Environmental Survey of the Uranium Fuel Cycle, WASH-1248, Fuels and Materials, Directorate of Licensing, S-9 through S-33 and C-1 through C-28, April 1974.

16. U.S. DOE, Technology Characterizations - Environmenta] Information Handbook, $\mathrm{DOE} / \mathrm{EV}-0072$, Assistant Secretary for Environment, Office of Environmental Assessments, p.9, June 1980. 
APPENDIX C

\section{RESIDUAL RADIONUCLIDE INVENTORY ESTIMATES}

This appendix contains details of estimates of the radioactivity remaining in the reference facility following plant shutdown and final inventory cleanout. The final inventory cleanout is considered to be part of production operations in this study and includes collection of the more accessible amounts of uranium for accounting purposes and chemical decontamination in some areas. The residual radionuclide estimates developed in the study are used to calculate radiation exposure to workers and to the public during decommissioning.

\section{C.1 KEY ASSUMPTIONS}

Residual uranium estimates in various areas of the plant are calculated based on several assumptions. Residual uranium left on the surfaces of process areas has been evaluated in a study showing that $\mathrm{PuO}_{2}$ and/or $\mathrm{UO}_{2}$ powder is visible on stainless steel surfaces polished to 600 grit at a quantity of $7.5 \mathrm{~g} \mathrm{Pu} / \mathrm{m}^{2}$. (1) Using conventional wiping techniques to clean this polished stainless steel typically reduces the contamination level by a factor

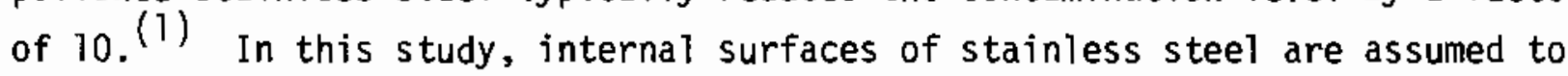
be contaminated with uranium compounds and materials that are barely visible. To account for the greater roughness of the stainless steel in the UF ${ }_{6}$ plant over the roughness level used in Reference 1, the quantity of oxide powder estimated to be barely visible is assumed to be increased about $100 \%$, to $20 \mathrm{~g} \mathrm{U} / \mathrm{m}^{2}$. For moderately contaminated areas, the quantity is assumed to be $100 \mathrm{~g} \mathrm{~V} / \mathrm{m}^{2}$ and for highly contaminated areas, the quantity is assumed to be $1 \mathrm{~kg} \mathrm{U} / \mathrm{m}^{2}$.

For stainless steel surfaces in wet processing areas that are acid flushed during inventory cleanout, the uranium contamination levels are assumed to be decreased by a factor of 10 from those in the dry processing system, to about $1 \mathrm{~g} \mathrm{U} / \mathrm{m}^{2}$. The above numbers apply to flat surfaces having no crevices or other properties that may alter the amount of contamination retained. 
To calculate the residual uranium contamination levels, or inventory, in equipment and dry and wet processing systems, a correction factor is applied to account for the potential order of magnitude differences in contamination on different types of surfaces. These correction factors are derived for each piece of equipment or system cleaned, using engineering judgement based on the process operations performed, the system design, and the physiochemical forms of the uranium present. The range of the correction factors is 0.5 to 20 . The estimated total surface area to be cleaned and the grams of uranium per unit area are multiplied by the correction factor to estimate the residual radionuclide inventory.

Key assumptions used to estimate the residual radionuclide inventories in various plant process areas are:

- Residual uranium contamination levels are $11 \mathrm{~g} \mathrm{U} / \mathrm{m}^{2}$ for stainless steel and $1 \mathrm{~g} \mathrm{U} / \mathrm{m}^{2}$ for acid-flushed stainless steel. These are values for flat surfaces. For areas where corrosion has occurred, correction factors up to 20 apply.

- Major contamination incidents or episodes are reasonably well-cleaned up immediately following the event.

- The final inventory cleanout, to account for the uranium inventory, involves routine nondestructive decontamination operations. As a result, contamination levels are generally expected to be relatively low throughout the plant. The quantity and mixture of radioactivity left in the plant after final inventory cleanout is an accumulation of fairly difficult-to-clean contamination that has accumulated at the rate of $1 / 40 \mathrm{per}$ year during the assumed 40 years of plant operations.

\section{C.2 REFERENCE RADIONUCLIDE MIXTURE FOR THE UF $6-$ CONVERSION PLANT}

Table C.2-1 presents the specific radioactivity levels for the radionuclide mixture present at the $\mathrm{UF}_{6}$ conversion plant at the time of plant shutdown and $5,10,30$, and 100 years after plant shutdown. This mixture is used to estimate public radiation doses from decommissioning operations and to determine acceptable 
residual contamination levels in the released decommissioned $U_{6}$ conversion plant. The radionuclides in Table C.2-1 are the radionuclides in natural uranium mixtures and the isotopic ratios given in Reference 2 .

TABLE C.2-1. Specific Radioactivity of Residual Uranium in the UF 6 Plant at the Time of Plant Shutdown and at Various Times After Shutdown

\begin{tabular}{|c|c|c|c|c|c|}
\hline \multirow[b]{2}{*}{ Radionuclide } & \multicolumn{5}{|c|}{ Specific Activity, $\mu \mathrm{Ci} / \mathrm{g}$ of Mixture ${ }^{(a)}$} \\
\hline & Shutdown & 5-Year & $10-$ Year & $30-Y e a r$ & 100 -Year \\
\hline${ }^{230} \mathrm{Th}$ & $2.9 \times 10^{-3}$ & $3.7 \times 10^{-3}$ & $4.4 \times 10^{-3}$ & $7.2 \times 10^{-3}$ & $1.7 \times 10^{-2}$ \\
\hline${ }^{231} \mathrm{Th}$ & $2.2 \times 10^{-2}$ & $2.2 \times 10^{-2}$ & $2.2 \times 10^{-2}$ & $2.2 \times 10^{-2}$ & $2.2 \times 10^{-2}$ \\
\hline${ }^{234} \mathrm{Th}$ & $2.5 \times 10^{-1}$ & $2.5 \times 10^{-1}$ & $2.5 \times 10^{-1}$ & $2.5 \times 10^{-1}$ & $2.5 \times 10^{-1}$ \\
\hline${ }^{231} \mathrm{~Pa}$ & $3.0 \times 10^{-5}$ & $3.7 \times 10^{-5}$ & $4.4 \times 10^{-3}$ & $7.4 \times 10^{-3}$ & $1.8 \times 10^{-2}$ \\
\hline${ }^{234} \mathrm{~m}_{\mathrm{pa}}$ & $3.3 \times 10^{-1}$ & $3.3 \times 10^{-1}$ & $3.3 \times 10^{-1}$ & $3.3 \times 10^{-1}$ & $3.3 \times 10^{-1}$ \\
\hline${ }^{234} \mathrm{~Pa}$ & $3.3 \times 10^{-4}$ & $3.3 \times 10^{-4}$ & $3.3 \times 10^{-4}$ & $3.3 \times 10^{-4}$ & $3.3 \times 10^{-4}$ \\
\hline${ }^{226} \mathrm{Ra}$ & $3.0 \times 10^{-4}$ & $3.0 \times 10^{-4}$ & $3.0 \times 10^{-4}$ & $3.0 \times 10^{-4}$ & $3.0 \times 10^{-4}$ \\
\hline $234 \mathrm{U}$ & $3.3 \times 10^{-1}$ & $3.3 \times 10^{-1}$ & $3.3 \times 10^{-1}$ & $3.3 \times 10^{-1}$ & $3.3 \times 10^{-1}$ \\
\hline $235 U$ & $1.5 \times 10^{-2}$ & $1.5 \times 10^{-2}$ & $1.5 \times 10^{-2}$ & $1.5 \times 10^{-2}$ & $1.5 \times 10^{-2}$ \\
\hline $238_{u}$ & $3.3 \times 10^{-1}$ & $3.3 \times 10^{-1}$ & $3.3 \times 10^{-1}$ & $3.3 \times 10^{-1}$ & $3.3 \times 10^{-1}$ \\
\hline Tot & 1.3 & 1.3 & 1.3 & 1.3 & 1.3 \\
\hline
\end{tabular}

(a) Based on the ratio of radionuclides in uranium and the isotopic ratios given in Reference 2.

\section{C.3 ESTIMATES OF RESIOUAL RADIOACTIVITY LEVELS IN THE UF 6 PLANT}

Table C.3-1 contains the estimates of the amounts of uranium in the facility after the final inventory cleanout (final inventory cleanout terminates plant operations), and after chemical decontamination operations (part of decommissioning).

After final inventory cleanout, the uranium inventory remaining is expected to be difficult-to-remove material. Final inventory cleanout operations are assumed to be the same as those conducted between processing campaigns. Final inventory cleanout operations and decommissioning decontamination operations are described in Appendix F, Section F.I. 
As shown in Table C.3-1, the inventory of uranium in the process buildings and equipment, after final inventory cleanout, is estimated to be approximately $9,200 \mathrm{~kg}$, based on the above method of calculating the inventory. By combining the decontamination factor of 10 for flat polished stainless steel surfaces and correcting for crevices, the overall chemical decontamination factor is reduced to approximately 2 before conventional chemical decontamination techniques become non-beneficial. (1) Thus, after chemical decontamination and before disassembly of equipment, the building inventory is reduced to approximately $4,100 \mathrm{~kg}$ of uranium. Further reductions in the building uranium inventory occur as the equipment is disassembled and either packaged for disposal at a federal repository or further decontaminated.

It should be emphasized that these estimates, based on the assumptions used in this study and for any specific case, are highly dependent upon the operating philosophy of the plant owner. The estimates of residual uranium are believed to be reasonable for the assumptions used. (3) The strict accounting methods required for special nuclear materials are believed to effectively limit the material accumulations to the ranges estimated. 
TABLE C.3-1. Estimated Inventory of Uranium in Process Areas of the Reference UF 6 Plant

\begin{tabular}{|c|c|c|c|c|c|c|c|c|}
\hline Location & Equ iprent & $\begin{array}{c}\text { Estimated } \\
\text { Contani- } \\
\text { nated } \\
\text { Surface } \\
\text { Area }\left(\mathrm{m}^{2}\right) \\
\end{array}$ & $\begin{array}{l}\text { Process } \\
\text { Operation }\end{array}$ & $\begin{array}{c}\text { Form of } \\
\text { Uraniun } \\
\text { Contaunination }\end{array}$ & $\begin{array}{l}\text { Approximate } \\
\text { Chemical } \\
\text { Decontami- } \\
\text { nation } \\
\text { Correction } \\
\text { Factor } \\
\end{array}$ & $\begin{array}{c}\text { Estimated } \\
\text { Uranium Concen- } \\
\text { tration Level } \\
\text { After Final } \\
\text { Operational } \\
\text { Cleangutt } \\
-\left(\mathrm{g} / \mathrm{m}^{2}\right) \\
\end{array}$ & $\begin{array}{l}\text { Estimated } \mathrm{kg} \text { of } \\
\text { Mfter } \\
\text { Operational } \\
\text { Cleanout. } \\
\end{array}$ & $\begin{array}{c}\text { Uranium (kg of U) } \\
\text { After } \\
\text { Decontamination }\end{array}$ \\
\hline \multirow[t]{10}{*}{ Sampling Station } & Drum Elevator & 37.0 & Sampling & $\mathrm{U}_{3} \mathrm{O}_{8}$ & 20 & 20 & 5 & 2.5 \\
\hline & Yellowcake Receiving Bin & 37.5 & Sampling & $\mathrm{y}_{3} \mathrm{O}_{8}$ & 20 & 20 & 50 & 25 \\
\hline & Primary Sampler I & 月.1 & Sampling & $\mathrm{U}_{3} \mathrm{O}_{8}$ & 20 & 20 & 10 & 5 \\
\hline & Primary Sampler II & 8.1 & Sampling & $\mathrm{U}_{3} \mathrm{O}_{8}$ & 20 & 20 & 10 & 5 \\
\hline & Secondary Sampler & 7.5 & Samplíng & $v_{3} 0_{8}$ & 20 & 20 & 10 & 5 \\
\hline & $\begin{array}{l}\text { Yellowcake Trarisfer } \\
\text { Screw }\end{array}$ & 12.6 & Sampling & $\mathrm{U}_{3} \mathrm{O}_{8}$ & 20 & 20 & 40 & 20 \\
\hline & Bucket Elevator & 18.4 & Sampling & $\mathrm{U}_{3} \mathrm{O}_{8}$ & 20 & 20 & 25 & 12.5 \\
\hline & Digest Feed 8in & 8.8 & Sampling & $\mathrm{U}_{3} \mathrm{D}_{\mathrm{B}}$ & 20 & 20 & 50 & 25 \\
\hline & Piping & 20.0 & Sanıling & $\mathrm{U}_{3} \mathrm{O}_{8}$ & 1 & 20 & 5 & 2.5 \\
\hline & Hood and Ductwork & 12.3 & Sampling & $\mathrm{U}_{3} \mathrm{O}_{8}$ & 20 & 20 & $\frac{10}{215}$ Subtotal & $\frac{5}{107.5 \text { Subtotal }}$ \\
\hline \multirow[t]{4}{*}{$\begin{array}{l}\text { Solvent Extraction Build- } \\
\text { ing }\end{array}$} & Digestors & 132.0 & $\begin{array}{l}\text { Solvent } \\
\text { Extraction }\end{array}$ & $\mathrm{U}_{3} \mathrm{v}_{\mathrm{B}}$ & 20 & 1000 & 700 & 350 \\
\hline & Adjustment Tanks & 90.0 & $\begin{array}{l}\text { Solvent } \\
\text { Extraction }\end{array}$ & $\mathrm{U}_{3} \mathrm{O}_{8}$ & 20 & 1000 & 100 & 50 \\
\hline & Pumper Decanters & 42.0 & $\begin{array}{l}\text { Solvent } \\
\text { Extraction }\end{array}$ & $\mathrm{U}_{3} \mathrm{O}_{8}$ & 20 & 100 & 50 & 25 \\
\hline & Scrub Cecanter & 12.9 & $\begin{array}{l}\text { Solvent } \\
\text { Extraction }\end{array}$ & $v_{3} 0_{8}$ & 20 & 20 & 60 & 30 \\
\hline
\end{tabular}




\section{TABLE C.3-T. (Contd)}

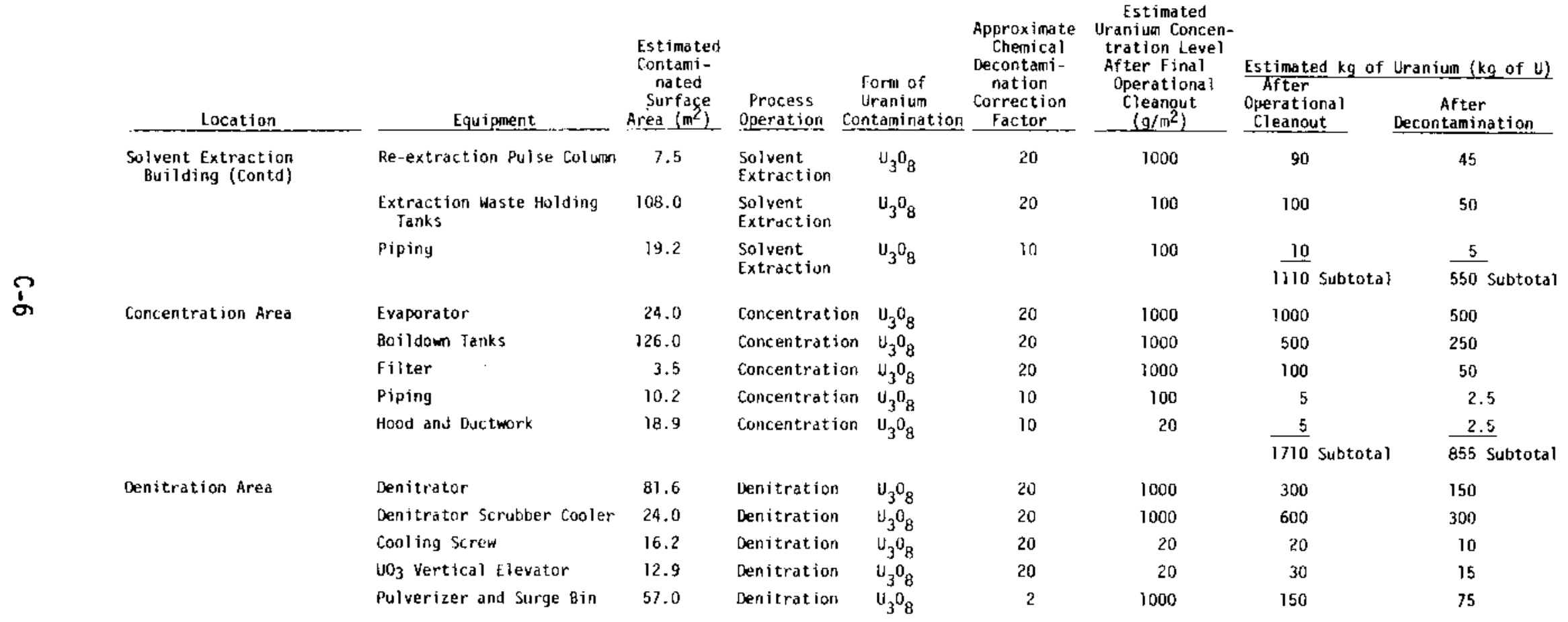


TABLE C.3-1. (Contd)

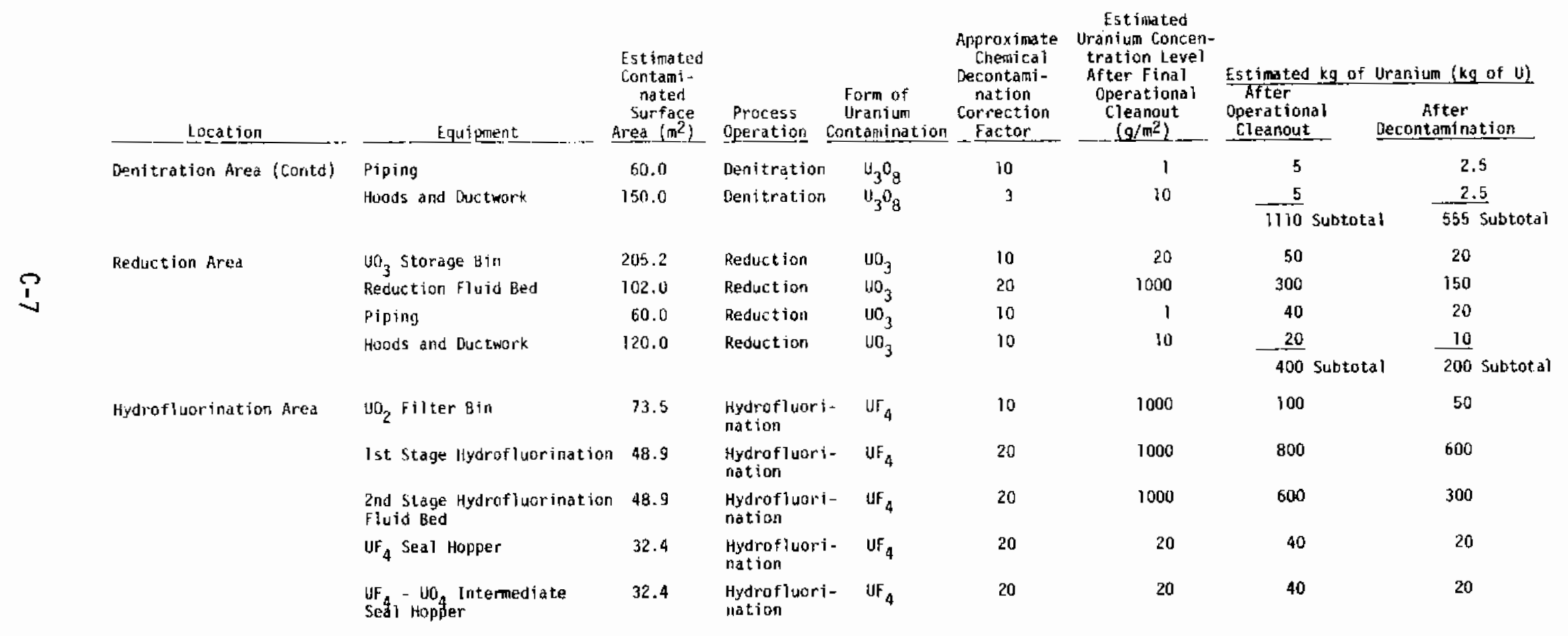


Table C.3-1. (Contd)

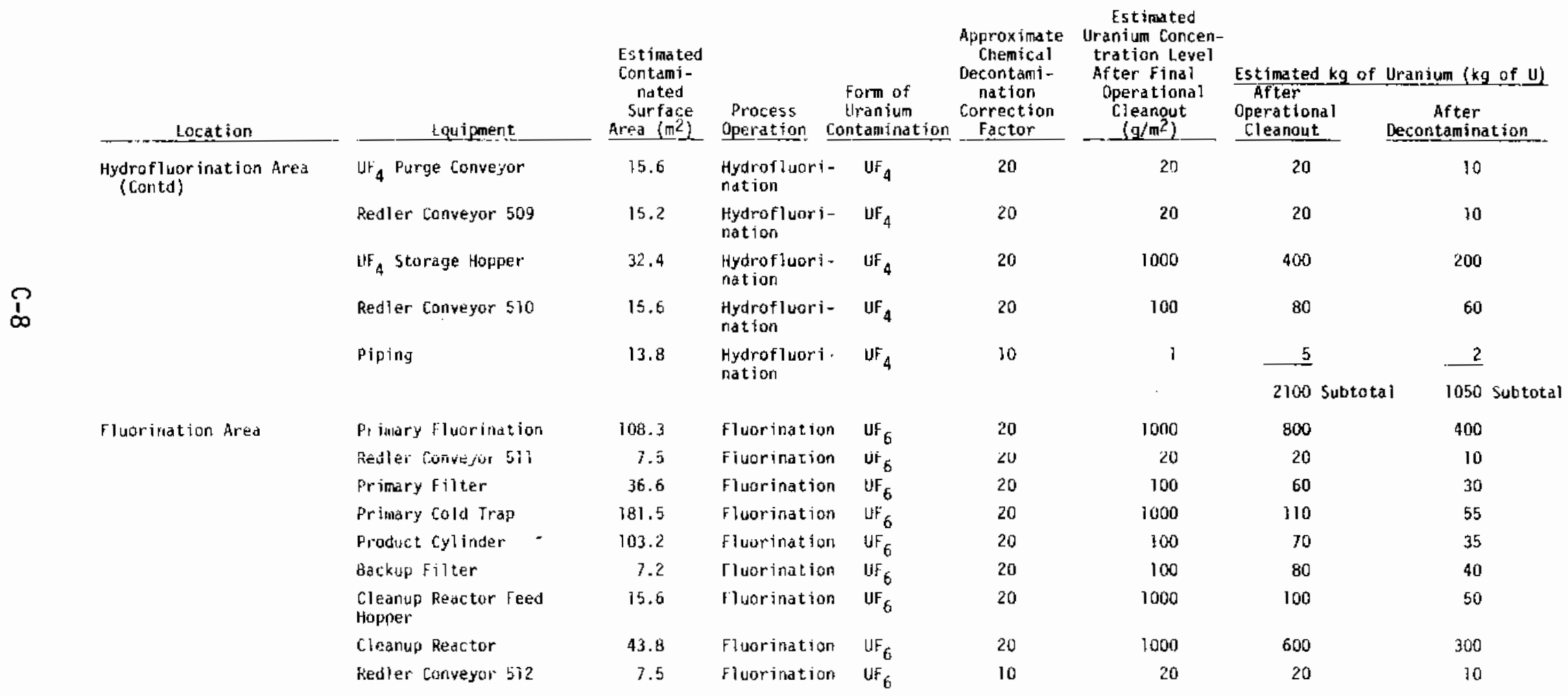


TABLE C.3-1. (Contd)

\begin{tabular}{|c|c|c|c|c|c|c|c|c|}
\hline Location & Equipment & $\begin{array}{l}\text { Fstimated } \\
\text { Contalnj- } \\
\text { nated } \\
\text { Surface } \\
\text { Area }\left(\mathrm{mi}^{2}\right)\end{array}$ & $\begin{array}{l}\text { Process } \\
\text { Operation co }\end{array}$ & $\begin{array}{l}\text { Form of } \\
\text { Uraniun } \\
\text { Cuntamination }\end{array}$ & $\begin{array}{l}\text { Approximate } \\
\text { Chemical } \\
\text { Decontaini- } \\
\text { nation } \\
\text { Correction } \\
\text { Factor } \\
\end{array}$ & $\begin{array}{c}\text { Estimated } \\
\text { Uranium Concen- } \\
\text { tration Level } \\
\text { After Final } \\
\text { Operational } \\
\text { Cleanout } \\
\left(g / \mathrm{m}^{2}\right) \\
\end{array}$ & $\begin{array}{l}\text { Estimated } \mathrm{kg} \text { of } \\
\text { After } \\
\text { Cperational } \\
\text { Cleanout }\end{array}$ & $\begin{array}{l}\text { Uranium (kg of } \mathrm{u}) \\
\text { After } \\
\text { Decontamination }\end{array}$ \\
\hline \multirow[t]{5}{*}{ Fluorination Area (Contd) } & Eackup Filter & 7.2 & Fluorination & $\mathrm{UF}_{6}$ & 20 & 1000 & 500 & 250 \\
\hline & Secondury cold Trap & 77.1 & Fluorination & $\mathrm{UF}_{6}$ & 20 & 1000 & 200 & 100 \\
\hline & Piping & 66.0 & Fluorindtion & $\mathrm{UF}_{6}$ & 10 & 20 & 5 & 2.5 \\
\hline & Hoods and Ductwork & 19.4 & Fluorination & $\mathrm{UF}_{6}$ & 10 & 20 & $\underline{5}$ & 2.5 \\
\hline & & & & & & & 2600 Subtotal & 1300 Subtotal \\
\hline \multirow[t]{12}{*}{ Fluorine Generation Area } & Waste Gas Burner & 36.0 & $\begin{array}{l}\text { Tluorine } \\
\text { Generation }\end{array}$ & $\mathrm{UF}_{4}$ & 1 & 1 & $>0.01$ & $>0.005$ \\
\hline & Cells & 160.0 & $\begin{array}{l}\text { Fluorine } \\
\text { Generation }\end{array}$ & $\mathrm{UF}_{4}$ & 1 & 1 & 0.16 & 0.08 \\
\hline & Fluorine Surge Tank & 36.0 & $\begin{array}{l}\text { Fluorine } \\
\text { Generation }\end{array}$ & $U F_{4}$ & 1 & 1 & $>0.01$ & $>0.005$ \\
\hline & Fluorine Filter & 16.8 & $\begin{array}{l}\text { Fluorine } \\
\text { Generation }\end{array}$ & $\mathrm{UF}_{4}$ & 1 & 1 & $>0.01$ & $>0.005$ \\
\hline & Thuarine - HF Condenser & 37.8 & $\begin{array}{l}\text { Fuorine } \\
\text { Generation }\end{array}$ & $\mathrm{UF}_{4}$ & 1 & 1 & $>0.01$ & $>0.005$ \\
\hline & HF Buckup rilter & 25.2 & $\begin{array}{l}\text { Fluorine } \\
\text { Generation }\end{array}$ & $\mathrm{UF}_{4}$ & 1 & 1 & $>0.01$ & $>0.005$ \\
\hline & Hydrugen Surģe Talık & 49.2 & $\begin{array}{l}\text { Fluorine } \\
\text { Generation }\end{array}$ & $\mathrm{UF}_{4}$ & 3 & 1 & $>0.01$ & $>0.005$ \\
\hline & Fluorine Filter & 21.6 & $\begin{array}{l}\text { Fluorine } \\
\text { Generation }\end{array}$ & $\mathrm{UF}_{4}$ & 1 & 1 & $>0.01$ & $>0.005$ \\
\hline & Aqueous Hf Storage Tank & 28.5 & $\begin{array}{l}\text { Fluorine } \\
\text { Generation }\end{array}$ & $\mathrm{UF}_{4}$ & 1 & 1 & $>0.01$ & $>0.005$ \\
\hline & Ammonia Disassociater & 7.2 & $\begin{array}{l}\text { Iluorine } \\
\text { Generation }\end{array}$ & $\mathrm{UF}_{4}$ & $i$ & 1 & $>0.01$ & $>0.005$ \\
\hline & Piping & 25.2 & $\begin{array}{l}\text { Fluorine } \\
\text { Generation }\end{array}$ & $\mathrm{UF}_{4}$ & 1 & 1 & $\frac{\geq 0.0 \mathrm{l}}{0.2 \text { Subtotal }}$ & $\frac{>0.005}{0.1 \text { Subtota\} }}$ \\
\hline & & & & & & & 9200 Total & $4100 \quad$ Total \\
\hline
\end{tabular}




\section{REFERENCES}

1. R. P. Allen, H. W. Arrowsmith, L. A. Charlot and J. L. Hooper, Electropolishing as a Decontamination Technique: Progress and Application, PNL-SA-6858, Pacific Northwest Laboratory, Richland, Washington, Apri1 1978.

2. U. S. Nuclear Regulatory Commission, Environmental Impact Appraisal of the Allied Chemical Corporation Nuclear Service Division Uranium Hexafluoride Conversion Facility, Metropolis, Illinois, Docket No. 40-3392, pp. 4-1 through 4-16, August 1977.

3. C. H. Kendle, In Situ Measurement of Residual Plutonium, ARH-SA-248, Atlantic Richfield Hanford Company, Richland, Washington, June 1977. 


\section{APPENDIX D}

\section{PAYMENTS NEEDED TO FINANCE DECOMMISSIONING.}

The purpose of this appendix is to illustrate the payment schedules required to provide funds for decommissioning of the reference $\mathrm{UF}_{6}$ conversion plant. Payments are computed for the prepayment and sinking fund financial assurance options discussed in Section 6 . The annual cost of the third financial assurance option, the use of a surety bond that guarantees decomissioning performance, is likely to be between 1 and $2 \%$ of the guaranteed amount, as discussed in Section 6 .

\section{1 FORMULAS FOR COMPUTATION OF PAYMENTS}

For the prepayment financial assurance option, an amount of money is deposited into a fund at the time of plant startup that, when compounded at an annual fractional rate of return, $r$, will provide the required funding for decormissioning. If $S$ is the cost of decommissioning estimated in dollars of the year of plant startup, the required prepayment, $P$, is obtained from:

$$
S(1+j)^{n}=P(1+r)^{n}
$$

Where $n$ is the anticipated plant operating life, and $j$ is the anticipated annual fractional cost escalation rate.

For the sinking fund financial assurance option, the money deposited into the fund plus interest on the money compounded annually over the plant operating life must equal the anticipated decommissioning cost. If the initial annual payment is $R_{0}$, the value of the sinking fund after $n$ years is:

$$
S(1+j)^{n}=R_{0} \sum_{a=1}^{n}(1+j)^{a-1}(1+r)^{n-a}
$$


The initial payment, $R_{0}$, is given by:

$$
R_{0}=\left\{\frac{s(1+j)^{n}}{\sum_{a=1}^{n}(1+j)^{a-1}(1+r)^{n-a}}\right\}
$$

and the annual payment in the kth year is

$$
R_{k}=R_{0}(1+j)^{k-1}
$$

The estimated costs of decommissioning (in 1981 dollars) as given in Section 10 are: for DECON, $\$ 4.85$ million; for SAFSTOR, $\$ 0.94$ million initially, $\$ 0.22$ million annually for safe storage, and a final decontamination cost of $\$ 5.30$ million.

\section{D.2 COMPUTATION OF PAYMENTS}

For purpose of making illustrative payment calculations, several simplifying assumptions are made. It is assumed that the plant initiates production on January 1, 1981 and that it permanently ceases production on December 31, 202D after a 40-year operating 1 ife. It is further assumed that decommissioning costs escalate in nominal (i.e., current) dollars at the rate of $10 \%$ per year and that the trustee realizes an annual return of $10 \%$ by investing in trust funds. In actual practice it can be expected that the trustee will be able to earn 1 to $3 \%$ more than the general inflation rate by investing in debt instruments whose interest is subject to federal taxes. (1) There is also no clear reason to expect decomissioning costs to escalate at a rate that exceeds the general inflation rate. However, a portion of the incremental return above decommissioning cost escalation will be needed for administrative expenses and may also be needed for payment of taxes (see Section 6). Consequently, no incremental return is assumed. 
The prepayment financial assurance alternative is the most straightforward. Under DECON, payment of $\$ 4.85$ milition into a trust fund prior to startup will provide sufficient funds if costs escalate at $10 \%$ and the trustee earns $10 \%$ annually after expenses.

Using the sinking fund option, with a 40-year plant operating life followed by DECON, the initial year's payment (from Equation D. 3 ) is $\$ 0.132$ million in 1981 dollars, assuming an estimated DECON cost of $\$ 4.85$ million in 1981 dollars. Subsequent annual payments are escalated at a 10\% annual rate until the final payment is $\$ 5.43$ million in dollars of that year. The summation of all annual payments is equal to the cost of DECON in escalated dollars, \$217.2 million. Obviously, if the SAFSTOR alternative is selected this value will be larger due to the larger total cost of SAFSTOR and the additional escalation during the safe storage period. 


\section{REFERENCES}

1. R. S. Wood, Assuring the Availability of Funds for Decomissioning Nuclear Facilities, NUREG-0584, Rev. 2, U.S. Nuclear Regulatory Comission, p. 26, October 1980. 


\section{APPENDIX E}

\section{RADIATION DOSE MODELS AND CALCULATED}

MAXIMUM ANNUAL DOSES

This appendix contains information to support the discussions in Sections 8 and 11. Terminology, models, equations and parameters used in radiation dose calculations, as well as tabulated maximum annual doses to the maximum-exposed individual, are presented. The tabulated maximum annual doses are based on the reference radionuclide inventory detailed in Appendices $B$ and $C$. These doses are used to determine the acceptable contamination levels for public release of the decommissioned reference $\mathrm{UF}_{6}$ conversion plant. It should be noted that the occupational radiation doses during decommissioning operations are not calculated using the dose models presented in this appendix.

\section{E.I RADIATION DOSE TERMINOLOGY AND DEFINITIONS}

The following terminology and definitions apply for the radiation dose calculations made for this study:

Routine Release. An atmospheric release of radionuclides from routine decommissioning tasks that is assumed to occur at a constant rate for 1 year.

Acute Release. A short-duration (usually less than 8 hours) release of radionuclides. The accident analysis, discussed in Section 11 and Appendix I, is based on acute releases.

Organs of Reference. The organs of the human body for which radiation doses are calculated. For this study, the organs of reference are the total body, lungs, bone, and lower large intestine (LLI) of the GI-tract. The total body is the head and trunk of the human body and includes active blood-forming organs, eye lenses, and gonads.

Exposure Pathways. The potential routes by which people may be exposed to radionuclides or radiation. Radiation exposure pahtways in the environment that are considered in this study are: external exposure to contamination 
deposited on the ground, ingestion of food products containing radionuclides, and inhalation of airborne radionuclides. Radiation exposure pathways inside the $U_{6}$ conversion plant are: external exposure from contaminated room surfaces and inhalation of airborne radionuclides. External exposure from airborne radionuclides (air submersion) is not considered, since previous decommissioning studies have shown this exposure pathway to be insignificant compared to the others. $(1-3)$

Maximum-Exposed Individual. The individual who receives the maximum radiation dose to an organ of reference. The maximum-exposed individual is assumed to reside at the location of the highest airborne radionuclide concentration. Maximized exposure pathway parameters are used.

Radiation Dose Equivalent. A quantity used to express the absorbed dose from all radiations on a common scale in units of rem. It is defined as the product of the absorbed dose in rads, a quality factor intended to allow for the effect of the microscopic distribution of absorbed energy, and other modifying factors as defined by the International Commission on Radiological Protection (ICRP).

Committed Radiation Dose Equivalent. The dose equivalent accumulated over a specific number of years from radionuclides deposited in the body from the various radiation pathways during a given year.

Collective Dose. The summation of radiation close equivalents received by all individuals in the population of concern. It is calculated by multiplying the dose to the average individual by the population distribution for the site listed in Appendix B. Average individual exposure parameters values are used for the exposure pathways.

First-Year Dose. The radiation dose equivalert accumulated during the year of the release period.

Fifty-Year Committed Dose Equivalent. The committed radiation dose equivalent for 50 years following a 1-year exposure to radionuclides.

Annual Dose. The radiation dose equivalent calculated during any year following the start of continuous exposure. It is the sum of the dose received 
by an organ of reference during the year of interest from all exposure pathways and the dose received that year from radionuclides deposited in the organ of reference during previous years of exposure.

Maximum Annual Dose. The largest of the 50 annual doses calculated to occur during the 50 years following the start of continuous exposure.

Biological Half-life. The time required for the body to eliminate half of any substance by regular body elimination processes.

Solubility Classes $W$ and $Y$. Radionuclides are classified according to the rate of which they are dissolved into body fluids in the lung after inhalation. The two classifications used in this appendix are: Class $W$ materials, with a maximum biological half-life ranging from a few days to a few months; and Class $Y$ materials, with a maximum biological half-life of from 6 months to a few years. (4)

\section{E.2 GENERAL MODELS FOR ESTIMATING RADIATION DOSE}

The methodology and parameters necessary to calculate the first-year dose or the fifty-year committed dose equivalent are presented in this section. The fundamental relationship for calculating radiation doses to people from any radionuclide or exposure pathway is given in Equation E. (5) $^{(5)}$

$$
R_{i p r}=C_{i p} U_{p} D_{i p r}
$$

where:

$R_{i p r}$ - first-year dose or fifty-year committed dose equivalent from radionuclide $i$ via exposure pathway $p$ to organ $r$

$C_{i p}$ - concentration of radionuclide $i$ in the media of exposure pathway $p$; for calculations involving airborne radionuclides, $c_{i p}$ is replaced with the term $\bar{\chi}_{i}$, which represents the average airborne concentration of radionuclide $i$

$U_{p} \quad$ - Usage parameter (exposure rate or intake rate) associated with exposure pathway $p$ 
$D_{\text {ipr }}$ - Radiation dose equivalent factor or fifty-year committed radiation dose equivalent factor (for a given radionuclide $i$, exposure pathway $p$, and organ $r$ ) that converts the concentration and usage parameters to the first-year dose or fifty-year committed dose equivalent.

Each of the terms in the general dose equation (Equation E.l) are discussed in detail below:

$C_{i p}$. An analysis of the radiation doses from separate exposure pathways requires a calculation of the radionuclide concentrations associated with each pathway. An external exposure analysis requires a soil concentration or surface contamination level. The radionuclide concentration in food crops grown in contaminated soi] is directly related to the radionuclide concentration in the soil plow layer (a depth of $0.15 \mathrm{~m}$ ). Exposure pathways that require the concentration of radionuclides in air from airborne radionuclide releases use dilution factors discussed in the site description in Appendix $B$. They are: $7.2 \times 10^{-8} \mathrm{sec} / \mathrm{m}^{3}$ for the maximum-exposed individual located $1 \mathrm{~km}$ from the site and $2.3 \times 10^{-11}$ $\mathrm{sec} / \mathrm{m}^{3}$ for the average member of the population residing within $80 \mathrm{~km}$ of the site.

$U_{p}$. Each radiation exposure pathway has an associated exposure rate or intake rate. Parameters used to calculate radiation doses from the consumption of food products grown in contaminated soil are listed in Table E.2-1. For the inhalation pathway, the intake rate (or ventilation rate) is assumed to be $2.7 \times 10^{-4} \mathrm{~m}^{3} / \mathrm{sec}$ for members of the public and $3.3 \times 10^{-4} \mathrm{~m}^{3} / \mathrm{sec}$ for workers with a 40-hour work week.

Dipr. The radiation dose equivalent factors and the fifty-year committed radiation dose equivalent factors that are used in this study for internal exposure pathways are obtained from several sources. Those for ingestion are obtained primarily from References $5,7,8,9$, and 10, which are derived from information given by the ICRP for the body burden and the maximum permissible concentration of each radionuclide. (11) Ingestion factors not obtainable from the references are calculated by the method given in Reference 10 . In this 
TABLE E.2-1. Parameters Used for Cajculation of Radiation Doses from
Consumption of Foods

\begin{tabular}{|c|c|c|c|c|c|}
\hline Food & $\begin{array}{l}\text { Growing } \\
\text { Period } \\
\text { (days) }\end{array}$ & $\begin{array}{c}\text { Yield } \\
\left(\mathrm{kg} / \mathrm{m}^{2}\right)\end{array}$ & $\begin{array}{l}\text { Holdup } \\
\text { (days) (b) }\end{array}$ & $\begin{array}{l}\text { Up, Maximum } \\
\text { Individual } \\
\text { Consumptign } \\
\text { (kg/year) }(\mathrm{c}) \\
\end{array}$ & $\begin{array}{l}\text { Up, Average } \\
\text { Individua] } \\
\text { Consumption } \\
\text { (kg/yr) } \\
\end{array}$ \\
\hline $\begin{array}{l}\text { Leafy Vegetables } \\
\text { 0ther above-Ground Vegetables } \\
\text { Potatoes }\end{array}$ & $\begin{array}{l}90 \\
60 \\
90\end{array}$ & $\begin{array}{l}1.5 \\
0.7 \\
4.0\end{array}$ & $\begin{array}{r}1 \\
1 \\
10\end{array}$ & $\begin{array}{r}30 \\
30 \\
110\end{array}$ & $\begin{array}{l}15 \\
15 \\
71\end{array}$ \\
\hline $\begin{array}{l}\text { Other Root Vegetables } \\
\text { Berries } \\
\text { Melons }\end{array}$ & $\begin{array}{l}90 \\
60 \\
90\end{array}$ & $\begin{array}{l}5.0 \\
2.7 \\
0.8\end{array}$ & $\begin{array}{l}1 \\
1 \\
1\end{array}$ & $\begin{array}{l}72 \\
30 \\
40\end{array}$ & $\begin{array}{r}47 \\
6 \\
8\end{array}$ \\
\hline $\begin{array}{l}\text { Orchard Fruit } \\
\text { Wheat } \\
\text { Other Grain }\end{array}$ & $\begin{array}{l}90 \\
90 \\
90\end{array}$ & $\begin{array}{l}1.7 \\
0.72 \\
1.7\end{array}$ & $\begin{array}{r}10 \\
10 \\
1\end{array}$ & $\begin{array}{r}265 \\
80 \\
8\end{array}$ & $\begin{array}{r}50 \\
72 \\
8\end{array}$ \\
\hline $\begin{array}{l}\text { Eggs } \\
\text { Mijk } \\
\text { Beef }\end{array}$ & $\begin{array}{l}90 \\
30 \\
90\end{array}$ & $\begin{array}{l}0.84(d) \\
1.3(d) \\
0.84\end{array}$ & $\begin{array}{r}2 \\
2 \\
15\end{array}$ & $\begin{array}{r}30 \\
274 \\
40\end{array}(e)$ & $\begin{array}{r}20 \\
230 \\
40\end{array}$ \\
\hline $\begin{array}{l}\text { Pork } \\
\text { Poultry }\end{array}$ & $\begin{array}{l}90 \\
90\end{array}$ & $\begin{array}{l}0.84 \\
0.84\end{array}(\mathrm{~d})$ & $\begin{array}{r}15 \\
2\end{array}$ & $\begin{array}{l}40 \\
18\end{array}$ & $\begin{array}{r}30 \\
8\end{array}$ \\
\hline
\end{tabular}

(a) Based on information in Reference 6 .

(b) Time between harvest and consumption.

(c) Only that fraction of the diet grown locally (and, therefore, potentially contaminated) is listed.

(d) Yield of animal feeds (i.e., grain or pasture grass).

(e) Units of $\ell /$ year.

method, effective decay energies for the radionuclides are calculated from the ICRP model, which assumes that all of a given radionuclide is in the center of a spherical organ with an appropriate effective radius. Dose factors for inhalation are calculated using the computer code DACRIN. (12) This code incorporates the ICRP Task Group Lung Model to calculate the dose to the lung and other organs of reference. A particle size of 1 micrometer in diameter is assumed. Radiation dose equivalent factors for internal pathways have units of mrem per year per pCi taken into the body during that same year. Conmitted radiation dose equivalent factors have units of mrem/50-yr per $\mathrm{pC} i$ taken into the body in the first year. External exposure can arise from either contaminated land or contaminated building 
surfaces. Contaminated ground resulting from deposition of airborne radionuclides is assumed to be a large, uniform, thin (approximately $20 \mathrm{~mm}$ deep) plane source for the purpose of calculating doses from external exposure. Dose rate factors for converting surface contamination to gamma dose, one meter above a uniformly contaminated plane have been estimated. $(5,9)$ Dose rate factors for exposure to contaminated soil have units of $\mathrm{mrem} / \mathrm{hr}$ per $\mathrm{pCi} / \mathrm{m}^{2}$ of surface. These dose rate factors are adjusted for a finite plane source by multiplying by 0.3 when determining acceptable residual contamination levels inside the $\mathrm{UF}_{6}$ conversion plant.

Discussion of the various radiation exposure pathways considered in this study, together with appropriate modifications to the general dose equation and its parameters, are given in the following sections.

\section{E.2.1 External Exposure}

Calculation of the radiation dose resulting from external total body exposure to surface contamination is done with no modification to Equation E.l. Soil concentrations are calculated using a simple cloud-depletion model, as is described for the food ingestion pathway analysis in the next section. For routine releases from decommissioning operations, the maximum-exposed individual is assumed to be exposed to contaminated soil for 12 hours a day for a full year. The average individual is assumed to be exposed for 6 hours a day for a full year. The fifty-year committed dose equivalent for external exposure to surface contamination is equal to the first-year dose, since there is no internal radionuclide deposition.

\section{E.2.2 Ingestion}

The radiation dose equivalent or comitted radiation dose equivalent to a person consuming vegetation grown on the contaminated site is given in Equation E.2

$$
R_{v r}=\sum_{i=1}^{n} C_{i v} U_{v} D_{i r}
$$


Similary, the radiation dose equivalent or committed radiation dose equivalent to a person consuming a contaminated animal product is given in Equation E.3.

$$
R_{a r}=\sum_{i=1}^{n} C_{i a} U_{a} D_{i r}
$$

Where:

$R_{v r}, R_{a r}$ - radiation dose equivalent or committed radiation dose equivalent from vegetation ( $v$ ) or animal (a) food product pathways, mrem or mrem/50 yr

$C_{i v}, C_{i a}-$ concentration of radionuclide $i$ in vegetation $(v)$ or animal product (a), $\mathrm{pCi} / \mathrm{kg}$ or $\mathrm{pCi} / \mathrm{l}$

$U_{v}, U_{a}$ - annual consumption of contaminated vegetable $(v)$ or anima 7 products (a), $\mathrm{kg}$ or $\ell$

$D_{\text {ir }}$ - radiation dose equivalent factor or committed radiation dose equivalent factor, mrem/pCi or mrem/50 yr per $\mathrm{pCi}$.

Specific values of $U_{v}$ and $U_{a}$ are shown in Table E.2-1.

\section{E.2.2.1 Deposition on Food Products or Ground Surfaces}

Equation E.4 is used to describe the deposition of airborne particulate radionuclides directly on food products or ground surfaces.

$$
d_{i}=86,400 \bar{x}_{i} v_{d i}
$$

where:

\footnotetext{
$d_{i}$ - deposition rate of flux of radionuclide $i, p C i /\left(m^{2}-\right.$ day $)$

86,400 - dimensional conversion factor, seconds/day

$V_{d i} \cdot$ deposition velocity of radionuclide $i, m / s e c o n d$

$\bar{x}_{j}$ - annual average air concentration from airborne releases of radionuclide $\mathrm{i}, \mathrm{pCi} / \mathrm{m}^{3}$.
} 
Specific values of the deposition velocity, $V_{d i}$, are obtained from Reference 13.

\section{E.2.2.2 Concentration in Vegetation}

The concentration of radioactive material in vegetation resulting from direct deposition onto plant foliage and uptake of prior depositions from the soil is given in Equation E.5.

$$
c_{i v}=d_{i}\left[\frac{r_{v}\left(1-e^{-\lambda} E i t_{e}\right)}{Y_{v} \bar{\lambda}_{E i}}+\frac{B_{v i}\left(1-e^{\left.-\lambda_{i} t_{b}\right)}\right.}{P \lambda_{i}}\right] e^{-\lambda_{i} t_{h}}
$$

where:

$C_{i v}$ - concentration of radionuclide $i$ in the edible portion of the vegetation ( $v$ ), pCi/kg

$d_{i}$ - deposition rate or flux or radionuclide $i, p C i /\left(m^{2}\right.$-day $)$

$r$ - fraction of deposition retained on the vegetation (dimensionless), assumed to be 0.25 in this study

$T_{v}$ - factor for translocation of externally deposited radionuclides to the edible parts of the vegetation (dimensionless). For simplicity it is assumed in this study to be independent of the radionuclide and is 1.0 for leafy vegetables and fresh forage, and 0.1 for all other produce, including grain. (Reference 8 lists values of this parameter for various radionuclides.)

$\lambda_{i}$ - radiological decay constant for radionuclide $i$, day $^{-1}$

$\lambda_{E i}$ - effective removal constant for radionuclide $i$, day ${ }^{-1} ; \lambda_{E i}=\lambda_{i}+\lambda_{w}$, where $\lambda_{i}$ is as defined above and $\lambda_{w}$ is the weathering removal constant for vegetation, day ${ }^{-1}$, assumed to be $0.693 / 14=5 \times 10^{-2}$ day $^{-1}$

$Y_{v}$ - yield of vegetation ( $v$ ), $\mathrm{kg}$ (wet weight) $/ \mathrm{m}^{2}$

$B_{v i}$ - concentration factor for uptake of radionuclide $i$ from the soil in vegetation ( $\mathrm{v}$, $\mathrm{pCi} / \mathrm{kg}$ (net weight) per $\mathrm{pCi} / \mathrm{kg}$ (dry soil) 
$t_{b}$ - time for buildup of radionuclides in the soil, days; assumed in this study to be 40 years of routine $U_{6}$ conversion plant operation at $75 \%$ efficiency

$t_{e}$ - time of exposure of above-ground vegetation to contamination during growing season, days

$t_{h}$ - holdup time between harvest and food consumption, days

- soil "surface density," $\mathrm{kg}$ (dry soil) $/ \mathrm{m}^{2}$; a value of $224 \mathrm{~kg} / \mathrm{m}^{2}$ is used assuming the contaminated ground is plowed to a depth of $0.15 \mathrm{~m}$ after decommissioning.

The first term inside the brackets of Equation E.5 relates to the concentration resulting from direct deposition on foliage during the growing season. The second term relates to the uptake from the soil and reflects the deposition throughout the $U_{6}$ conversion plant operating life. Specific values for the parameters in Equation E.5 are obtained from References 6, 7, and 13 .

\section{E.2.2.3 Concentration in Animal Products}

The radionuclide concentration in animal products such as meat, milk, or eggs is dependent on the amount of contaminated forage or feed eaten by the animal. This concentration is described by Equation E.6.

$$
C_{i a}=S_{i a} C_{j F} Q_{F}
$$

where:

$\mathrm{C}_{\mathrm{ia}}$ - concentration of radionuclide $i$ in animal products $(\mathrm{a}), \mathrm{PCi} / \mathrm{kg}$ or $\mathrm{pCi} / \ell$

$S_{j a}$ - transfer coefficient of radionuclide $i$ to the edible portion of animal product (a) from daily intake by the animal, $\mathrm{pCi} / \mathrm{l}$ (milk) per $\mathrm{pCi} /$ day or $\mathrm{pCi} / \mathrm{kg}$ (animal product) per $\mathrm{pCi} /$ day.

$C_{i F}$ - concentration of radionuclide $i$ in feed or forage $F, p C i / k g$; calculated from Equation E.5

$Q_{F}$ - animal consumption rate of contaminated feed or forage $F, \mathrm{~kg} / \mathrm{day}$. 
Specific values for the parameters used in Equation E.6 are obtained from References 6,7 , and 13. Where data are lacking, comparisons are made with biological data from chemically similar elements.

\section{E.2.3 Inhalation}

The radiation dose equivalent or the committed radiation dose equivalent via inhalation is calculated using Equation E.7.

$$
R_{i r}=\sum_{j=1}^{n} \bar{x}_{i} \text { B T } D_{i r}
$$

where:

$\mathrm{R}_{\text {ir }}$ - radiation dose equivalent or committed radiation dose equivalent to organ $r$ from radionuclide $i$, mrem or mrem/50 $\mathrm{yr}$

$\bar{X}_{i}$ - annual average airborne concentration of radionuclide $i, p C i / \mathrm{m}^{3}$

B - ventilation rate of exposed individual:

for a chronic release, $B=2.7 \times 10^{-4} \mathrm{~m}^{3} / \mathrm{sec}$;

for an acute release, $B=3.3 \times 10^{-4} \mathrm{~m}^{3} / \mathrm{sec}^{(11)}$

$T$ - time of exposure to the airborne radionuclide concentration, sec

$\mathrm{D}_{\text {ir }}$ - radiation dose equivalent factor or committed radiation dose equivalent factor, mrem/pCi or mrem/50 yr per $\mathrm{pCi}$.

The inhalation dose model presented in Equation E.7 is consistent with the ICRP Task Group Lung Model.

\section{E.3 MODEL FOR ESTIMATING ANNUAL DOSE}

The determination of acceptable residual contamination levels at the decommissioned reference $U_{6}$ conversion plant (discussed in Section 8 ) is made by direct comparisons of calculated annual doses with an assumed annual dose limit. The annual dose to internal body organs from internally deposited radionuclides tends to increase for a time lafter the start of continuous exposure 
to a radioactively decaying source) until a maximum is reached. The annual dose then tends to decrease with time because of radioactive decay, decrease in the radionuclide concentrations of specific exposure pathways, and biological elimination of radionuclides deposited in the organ. For continuous exposure to a radioactively decaying source, the year in which the annual dose is a maximum depends on the chemical and physical characteristics of the radionuclides in the source, the organ of reference, and the exposure pathway.

The calculated first-year dose from ingested or inhaled radionuclides will most likely underestimate the maximum annual dose during continuous exposure, and therefore does not provide the best comparison to annual dose limit. Nor is it appropriate to compare a fifty-year dose (accounting for 50 years of committed radiation dose equivalent) to an annual dose limit. Therefore, an extension of the general dose relationship given in Equation E.1 is required to calculate annual doses for each year of a continuous exposure period. The maximum annual dose occurring in the continuous exposure period is then compared to the annual dose 1 imit to determine acceptable residual contamination levels.

Calculation of the annual dose to an organ of reference requires the dose equivalent from exposure during the year of interest. It also requires a detailed accounting of the committed dose equivalents to that organ from radionuclides deposited during previous years of intake. The general expression for annual dose calculations is deduced by inspecting the annual dose equations for the first 3 years of continuous exposure. The annual dose for the first year to an organ of reference is simply the summation of the radiation dose equivalents from all internal and external exposure pathways. For the second year, the annual dose is calculated by the following expression:

$$
A_{2}=R_{2}^{*}+\left(R_{1,2}-R_{1,1}\right)
$$

where:

\footnotetext{
$A_{2}$ - the annual dose during the second year from all exposure pathways to the organ of the reference, mrem
} 


$$
\begin{aligned}
& \mathrm{R}_{2}^{*} \text { - the radiation dose equivalent in the second year to the organ of } \\
& \text { reference from all internal and external exposure pathways from } \\
& \text { intake and exposure in the second year of continuous exposure, mrem } \\
& \mathrm{R}_{1,2} \text { - the committed dose equivalent to the organ of reference for the } \\
& \text { first two years from radionuclides internally deposited during } \\
& \text { intake from exposure pathways in the first year, mrem } \\
& \mathrm{R}_{1,1} \text { - } \text { the radiation dose equivalent to the organ of reference for the } \\
& \text { first year from radionuclides internally deposited during intake } \\
& \text { from exposure pathways in the first year (no external component } \\
& \text { to the dose equivalent), mrem. }
\end{aligned}
$$

The second-year annual dose to an organ of reference ( $A_{2}$ in Equation E.8a) is the summation of the radiation dose equivalents from all exposure pathways during the second year and the dose equivalent resulting from the radionuclides internally deposited in that organ during the first year. The term in parentheses in Equation E.8a is the expression for the dose equivalent to the organ of reference from radionuclides deposited in that organ in the first year. It is found by subtracting the first-year dose equivalent from internaliy deposited radionuclides from the two-year committed dose equivalent.

The mathematical expression for the annual dose to an organ of reference in the third year of continuous exposure is shown in Equation E.8b.

$$
A_{3}=R_{3}^{\star}+\left(R_{1,3}-R_{1,2}\right)+\left(R_{2,2}-R_{2,1}\right)
$$

where:

$A_{3}$ - the annual dose during the third year from all exposure pathways to the organ of reference, mrem

$R_{3}^{*}$ - the radiation dose equivalent in the third year to the organ of reference from all internal and external exposure pathways from intake and exposure in the third year of continuous exposure, mrem. 
The terms $R_{1,3}, R_{1,2}, R_{2,2}$, and $R_{2,1}$ are of similar form, each having two subscripts. The first subscript defines the year of intake or exposure after the start of continuous exposure, and the second defines the number of years used in calculating the committed dose equivalent.

The quantity in the first parentheses in Equation E.8b is the dose equivalent to the organ of reference in the third year from radionuclides deposited in the first year of continuous exposure (i.e., the difference between the 3-year committed dose equivalent and the 2-year committed dose equivalent). The quantity in the second parentheses is the dose equivalent in the third year to the organ of reference from radionuclides deposited in the second year of continuous exposure (i.e., the difference between the 2-year committed dose equivalent and the first-year committed dose equivalent).

The general expression for calculating the annual dose to an organ of reference during any year after the start of continuous exposure can be expressed as:

$$
A_{t}=R_{t}^{*}+\sum_{i=1}^{t-1}\left[R_{i,(t-i+1)}-R_{i,(t-i)}\right]
$$

where:

$A_{t}$ - the annual dose during the year $t$ from all exposure pathways to the organ of reference, mrem

$R_{t}^{\star}$ - the radiation dose equivalent in year $t$ to the organ of reference from all internal and external exposure pathways from intake and exposure in the year $t$, mrem.

The summation term represents the dose equivalent delivered to the organ of reference in year $t$ from radionuclides deposited in the organ from intake in all previous years since the start of continuous exposure.

The summation term in Equation $E .9$ is valid only for integer values of $t$ greater than 1. For values of $t$ equal to or less than 1 , the subscripts define a non-real case, and the sumation term is set equal to zero. 
The annual dose, $A_{t}$, to the organ of reference is calculated for each value of $t$ from 1 to 50 , and the maximum annual dose is determined by inspection. The radionuclide inventories are adjusted for radionuclide decay and daughter-product buildup during the calculation.

Resuspended surface or ground contamination is assumed to be the only source of airborne radionuclides following decomissioning of the reference $U_{6}$ conversion plant. Airborne radionuclide concentrations for the decommissioned $\mathrm{UF}_{6}$ conversion plant are calculated using a resuspension analysis. The average airborne concentration is the product of a resuspension factor and the surface contamination level as shown in Equation E.10.

$$
\bar{x}=s_{f} s_{A}
$$

where:

$\overline{\mathrm{X}}$ - average airborne concentration, $\mathrm{Ci} / \mathrm{ml}^{3}$

$s_{f}$ - resuspension factor, $m^{-1}$

$\mathrm{S}_{\mathrm{A}}$ - surface radioactivity deposition, $\mathrm{Ci} / \mathrm{m}^{2}$.

Inside the decommissioned $\mathrm{UF}_{6}$ conversion plant, airborne concentrations are calculated using a constant resuspension factor of $5 \times 10^{-6} \mathrm{~m}^{-1}$. This value is one-tenth of the value suggested by the IAEA for surfaces with removable contamination. (15) This lower value is assumed since unrestricted release of nuclear facilities should not be contemplated with readily removable contamination remaining on accessible surfaces. Actual facility surface resuspension factors may be considerably lower than this value.

Airborne radionuclide concentrations on the reference site are calculated using a time dependent suspension factor to account for the environmental "aging" of radionuclides. The relationship for this factor is given in Equation E.11.

$$
S_{f}=\left(10^{-4} e^{-\lambda \sqrt{t}}\right)+10^{-9}
$$


where:

$S_{f} \cdot$ resuspension factor, $m^{-1}$
$10^{-4} \cdot$ resuspension factor at time $t=0, \mathrm{~m}^{-1}$

$\lambda$ - effective decay constant controlling the availability of material for resuspension, 0.15 day $^{-1 / 2}$

$t$ - time after deposition, days

$10^{-9}$ - resuspension factor after 17 years, $\mathrm{m}^{-1}$.

The second term in Equation E. $11\left(10^{-9}\right)$ is added based on the assumption that there is no further measureable decrease in the resuspension factor process after 17 years, which is the longest period for which data are available. This is deemed appropriate since this model is derived empirically to simulate experimental measurements and contains no fundamental understanding of the resuspension process. (16) The time dependence of the site resuspension factor is illustrated in Figure E.3-1.

$\checkmark$

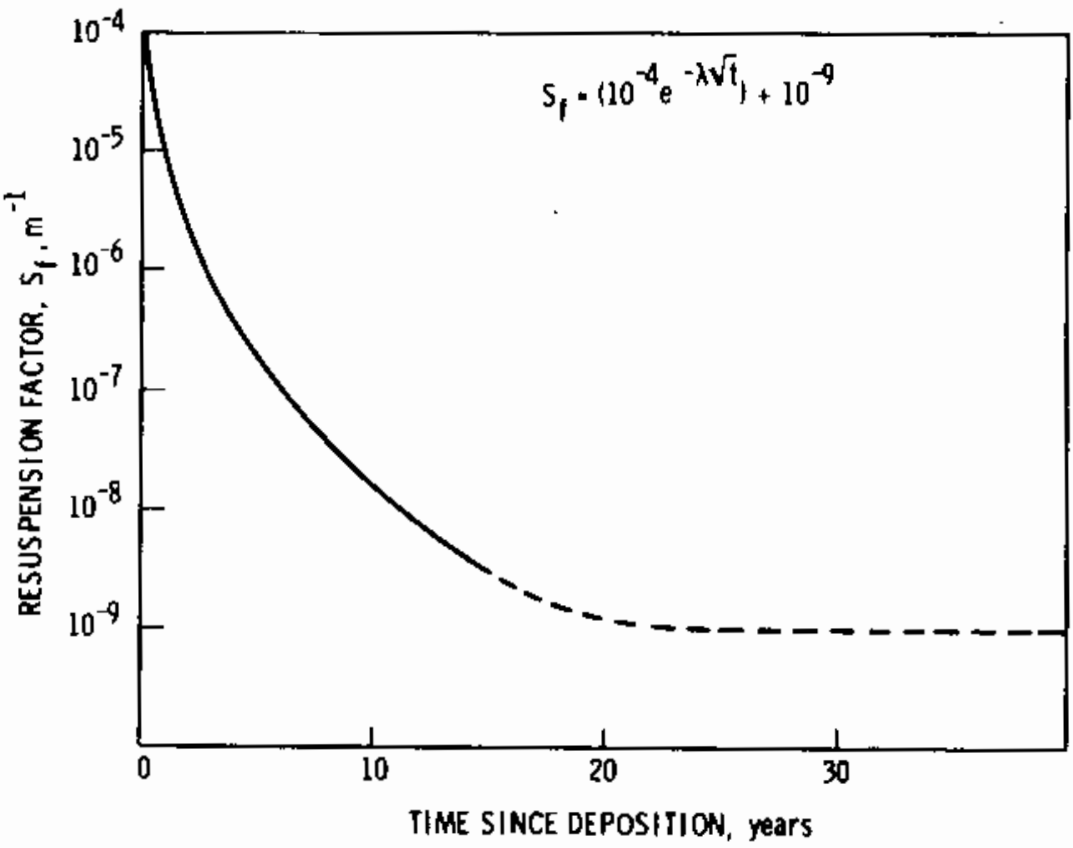

FIGURE E.3-1. Time-Dependent Surface Resuspension Factor for the Site 
After decommissioning, unrestricted use of the site will allow activities such as unlimited farming. Therefore, the amount, of surface contamination available for resuspension must be defined. For the calculation of the maximum annual doses, it is assumed that the site surface is plowed after decomissioning to a depth of $0.15 \mathrm{~m}$, and the original surface contamination is assumed to be uniformly mixed into that volume of soil. This reduces the amount of material available for resuspension.

\section{E.4 CALCULATED MAXIMUM ANNUAL DOSES AT THE DECOMMISSIONED REFERENCE UF 6 CONVERSION PLANT}

This section contains the assumptions, specifies the radionuclide inventories, and presents listings of the resultant calculated maximum annual doses. These maximum annual doses are used in determining the acceptable residual contamination levels for the decommissioned reference $U F_{6}$ conversion plant that are presented in Section 8. Doses are calculated and reported for the maximum-exposed individual working in the $\mathrm{UF}_{6}$ conversion plant or residing on its site after decommissioning.

\section{E.4.1 Assumptions for Calculating Maximum Annual Dose}

The following assumptions are used in calculating the maximum annual doses at the decomissioned $U_{6}$ conversion plant:

- The radionuclide inventories are undisturbed, except for radioactive decay after plant shutdown. Doses are calculated for the mixtures at shutdown, and for decay periods of $10,30,50$, and 100 years. Since the radionuclide inventory contains radionuclides with very long half-lives, the inventory composition does not change significantly with time. Thus, doses are calculated for the inventory at shutdown only.

- The maximum-exposed individual is considered to have realistically maximized exposure pathway parameters.

- The maximum-exposed individual working in the facility receives continuous exposure for 40 hours a week, 50 weeks a year.

- The maximum-exposed individual residing on the site is continuously exposed. 
- The airborne radionuclide concentrations are calculated using a resuspension factor of $5 \times 10^{-6} \mathrm{~m}^{-1}$ inside the facility, and the time dependent factor from Equation E. 11 on the site.

\section{E.4.2 Radionuclide Inventories for Calculating Maximum Annual Doses}

The radionuclide inventory used to calculate the maximum annual doses at the deconmissioned $\mathrm{UF}_{6}$ conversion plant is presented and discussed in Appendix $\mathrm{C}$. Table C.2-1 contains the reference radionuclide mixture that characterizes surface contamination inside the reference $U_{6}{ }_{6}$ conversion plant. Table B.5-2 contains the radionuclide inventory that characterizes the contamination deposited on the reference site during the lifetime of plant operations.

\section{E.4.3 Maximum Annual Dose Listings}

Calculated maximum annual doses to the maximum-exposed individual using the decomissioned $U_{6} F_{6}$ conversion plant or its site are listed in Tables E.4-1 through E.4-4. These doses are calculated using the models, parameters, and assumptions presented earlier in this appendix. Dose pathways of concern in the decomissioned reference $\mathrm{UF}_{6}$ conversion plant are inhalation of resuspended surface contamination and external exposure to surface contamination. The calculated maximum annual doses to an individual working in the decommissioned facility for 40 hours a week, 50 weeks a year, are listed in Tables E.4-1 and E.4-2 for translocation classes $W$ and $Y$, respectively. Dose pathways of concern on the deconmissioned reference site are inhalation of resuspended ground contamination, external exposure to ground contamination, and ingestion of food products raised on the site. The calculated maximum annual doses to an individual residing on the reference site 24 hours a day, 52 weeks a year, are listed in Tables E.4-3 and E.4-4 for translocation classes $W$ and $Y$, respectively. These tables contain doses calculated using the radionuclide mixtures present at plant shutdown. They are used to determine the acceptable residual contamination levels for unrestricted release of the decommissioned $U_{6}$ conversion plant, which are presented and discussed in Section 8. 
TABLE E.4-1. Calculated Maximum Annual Radiation Doses to the Maximum-Exposed Individual Working in the Released Decommissioned $\mathrm{UF}_{6}$ Conversion Plant - Class W Material(a)

\begin{tabular}{|c|c|c|c|c|}
\hline \multirow[b]{2}{*}{ Organ of Reference } & \multirow[b]{2}{*}{ Radionuclide ${ }^{(\mathrm{b})}$} & \multicolumn{3}{|c|}{ Maximum Annual Dose (mrem) Via: } \\
\hline & & Inhalation & External $^{(c)}$ & A11 Pathways \\
\hline \multirow[t]{2}{*}{ Total Body at 2 Years $(d)$} & $\begin{array}{l}234 U \\
235_{U}^{U}+D^{(e)} \\
238_{U}+D\end{array}$ & $\begin{array}{l}1.2 \times 10^{-6} \\
5.2 \times 10^{-8} \\
1.1 \times 10^{-6} \\
\end{array}$ & $\begin{array}{l}3.3 \times 10^{-8} \\
2.6 \times 10^{-7} \\
1.6 \times 10^{-6} \\
\end{array}$ & $\begin{array}{l}1.2 \times 10^{-6} \\
3.2 \times 10^{-7} \\
2.7 \times 10^{-6} \\
\end{array}$ \\
\hline & Totals & $2.4 \times 10^{-6}$ & $1.9 \times 10^{-6}$ & $4.2 \times 10^{-6}$ \\
\hline \multirow[t]{2}{*}{ Bone at 2 Years } & $\begin{array}{l}234 U \\
235 U+D \\
238 U+D\end{array}$ & $\begin{array}{l}1.7 \times 10^{-5} \\
7.8 \times 10^{-7} \\
1.5 \times 10^{-5} \\
\end{array}$ & $\begin{array}{l}3.3 \times 10^{-8} \\
2.6 \times 10^{-7} \\
1.6 \times 10^{-6} \\
\end{array}$ & $\begin{array}{l}1.7 \times 10^{-5} \\
1.0 \times 10^{-6} \\
1.7 \times 10^{-5} \\
\end{array}$ \\
\hline & Totals & $3.3 \times 10^{-5}$ & $1.9 \times 10^{-6}$ & $3.5 \times 10^{-5}$ \\
\hline \multirow[t]{2}{*}{ Lungs at 1 Year } & $\begin{array}{l}234 U \\
235 U+D \\
238 U+D\end{array}$ & $\begin{array}{l}1.3 \times 10^{-4} \\
5.7 \times 10^{-6} \\
1.1 \times 10^{-4} \\
\end{array}$ & $\begin{array}{l}3.3 \times 10^{-8} \\
2.6 \times 10^{-7} \\
1.6 \times 10^{-6} \\
\end{array}$ & $\begin{array}{l}1.3 \times 10^{-4} \\
6.2 \times 10^{-6} \\
1.1 \times 10^{-4} \\
\end{array}$ \\
\hline & Totals & $2.5 \times 10^{-4}$ & $1.9 \times 10^{-6}$ & $2.5 \times 10^{-4}$ \\
\hline \multirow[t]{2}{*}{ LLI at 1 Year } & $\begin{array}{l}234 T h+D \\
234 \\
235_{U}^{U}+D \\
238 U+D\end{array}$ & $\begin{array}{l}1.3 \times 10^{-7} \\
1.1 \times 10^{-7} \\
5.7 \times 10^{-9} \\
9.7 \times 10^{-8} \\
\end{array}$ & $\begin{array}{r}(f) \\
3.3 \times 10^{-8} \\
2.6 \times 10^{-7} \\
1.6 \times 10^{-6} \\
\end{array}$ & $\begin{array}{l}1.3 \times 10^{-7} \\
1.4 \times 10^{-7} \\
2.7 \times 10^{-7} \\
1.7 \times 10^{-6} \\
\end{array}$ \\
\hline & Totals & $3.4 \times 10^{-7}$ & $1.9 \times 10^{-6}$ & $2.2 \times 10^{-6}$ \\
\hline
\end{tabular}

(a) The mixture of radionuclides at shutdown normalized to $1 \mathrm{pCi} / \mathrm{m}^{2}$ is used.

(b) Only radionuclides that contribute more than $1 \%$ of the total dose of any pathway are Tisted.

(c) External dose from floor contamination.

(d) The time the annual dose peaks after exposure begins.

(e) The $+D$ notation indicates that after deposition in the organ of reference, the decay energy of the daughter is included with the parent.

(f) A dash indicates no external dose component. 
TABLE E.4-2. Calculated Maximum Annual Radiation Doses to the Maximum-Exposed Individual Working in the Released Decommissioned $U_{6}$ Conversion
Plant - Class Y Material $(a)$

Maximum Annual Dose (mrem) Via:

\begin{tabular}{|c|c|c|c|c|}
\hline \multirow[b]{2}{*}{ Organ of Reference } & \multirow[b]{2}{*}{ Radionuclide ${ }^{(b)}$} & \\
\hline & & Inhalation & Externa] $(\mathrm{c})$ & A11 Pathways \\
\hline \multirow[t]{2}{*}{ Total Body at 2 Years $(d)$} & $\begin{array}{l}{ }^{234} U \\
235 U+D(e) \\
238 U+D\end{array}$ & $\begin{array}{l}1.9 \times 10^{-7} \\
8.3 \times 10^{-9} \\
1.6 \times 10^{-7} \\
\end{array}$ & $\begin{array}{l}3.3 \times 10^{-8} \\
2.6 \times 10^{-7} \\
1.6 \times 10^{-6} \\
\end{array}$ & $\begin{array}{l}2.2 \times 10^{-7} \\
2.7 \times 10^{-7} \\
1.7 \times 10^{-6} \\
\end{array}$ \\
\hline & Totals & $4.3 \times 10^{-7}$ & $1.9 \times 10^{-6}$ & $2.2 \times 10^{-6}$ \\
\hline \multirow[t]{2}{*}{ Bone at 4 Years } & $\begin{array}{l}{ }^{23 D^{T h}} \\
234 U \\
235_{U}+D \\
238 U+D\end{array}$ & $\begin{array}{l}2.2 \times 10^{-6} \\
2.6 \times 10^{-6} \\
1.2 \times 10^{-7} \\
2.3 \times 10^{-6} \\
\end{array}$ & $\begin{array}{l}1.8 \times 10^{-9} \\
3.3 \times 10^{-8} \\
2.6 \times 10^{-7} \\
1.6 \times 10^{-6} \\
\end{array}$ & $\begin{array}{l}2.2 \times 10^{-6} \\
2.7 \times 10^{-6} \\
3.8 \times 10^{-7} \\
3.9 \times 10^{-6} \\
\end{array}$ \\
\hline & Totals & $7.2 \times 10^{-6}$ & $1.9 \times 10^{-6}$ & $9.1 \times 10^{-6}$ \\
\hline \multirow[t]{2}{*}{ Lungs at 2 Years } & $\begin{array}{l}234 U \\
235 U+D \\
238 U+D\end{array}$ & $\begin{array}{l}5.9 \times 10^{-4} \\
2.6 \times 10^{-5} \\
5.0 \times 10^{-4}\end{array}$ & $\begin{array}{l}3.3 \times 10^{-8} \\
2.6 \times 10^{-7} \\
1.6 \times 10^{-6} \\
\end{array}$ & $\begin{array}{l}5.9 \times 10^{-4} \\
2.6 \times 10^{-5} \\
5.0 \times 10^{-4} \\
\end{array}$ \\
\hline & Totals & $1.1 \times 10^{-3}$ & $1.9 \times 10^{-\overline{6}}$ & $1.1 \times 10^{-3}$ \\
\hline \multirow[t]{2}{*}{ LLI at 1 Year } & $\begin{array}{l}234 \mathrm{Th}+\mathrm{D} \\
234 \mathrm{U} \\
235 \mathrm{U}+\mathrm{D} \\
238 \mathrm{U}+\mathrm{D}\end{array}$ & $\begin{array}{l}1.5 \times 10^{-7} \\
1.1 \times 10^{-8} \\
5.7 \times 10^{-9} \\
9.9 \times 10^{-8} \\
\end{array}$ & $\begin{array}{c}(f) \\
3.3 \times 10^{-8} \\
2.6 \times 10^{-7} \\
1.6 \times 10^{-6} \\
\end{array}$ & $\begin{array}{l}1.5 \times 10^{-7} \\
4.4 \times 10^{-7} \\
2.7 \times 10^{-7} \\
1.7 \times 10^{-6} \\
\end{array}$ \\
\hline & Totals & $2.6 \times 10^{-7}$ & $1.9 \times 10^{-6}$ & $2.2 \times 10^{-6}$ \\
\hline
\end{tabular}

(a) The mixture of radionuclides at shutdown normalized to $1 \mathrm{pCi} / \mathrm{m}^{2}$ is used.

(b) Only radionuclides that contribute more than $1 \%$ of the total dose of any pathway are listed.

(c) External dose from floor contamination.

(d) The time the annual dose peaks after exposure begins.

(e) The $+D$ notation indicates that after deposition in the organ of reference, the decay energy of the daughter is included with the parent.

(f) A dash indicates no external dose component. 
TABLE E.4-3. Calculated Maximum Annual Radiation Doses to the Maximum-Exposed Individual Residing on the Released Decommissioned UF ${ }_{6}$ Conversion Plant Site - Class W Material

\begin{tabular}{|c|c|c|c|c|c|}
\hline \multirow[b]{2}{*}{ Organ of Reference } & \multirow[b]{2}{*}{ Radionuclide ${ }^{(\mathrm{a})}$} & \multicolumn{4}{|c|}{ Maximum Annual 0ose (mrem) Via: } \\
\hline & & \multirow{2}{*}{$\begin{array}{l}\text { Ingestion } \\
4.0 \times 10^{-2} \\
1.7 \times 10^{-3} \\
3.4 \times 10^{-2} \\
\end{array}$} & \multirow{2}{*}{$\begin{array}{l}\text { Inhalation } \\
1.2 \times 10^{-3} \\
5.3 \times 10^{-5} \\
1.1 \times 10^{-3}\end{array}$} & \multirow{2}{*}{$\begin{array}{l}\begin{array}{c}\text { Externa } \\
\text { Ground }\end{array} \\
8.5 \times 10^{-4} \\
6.5 \times 10^{-3} \\
4.2 \times 10^{-2}\end{array}$} & \multirow{2}{*}{$\begin{array}{l}\text { A11 Pathways } \\
4.2 \times 10^{-2} \\
8.2 \times 10^{-3} \\
7.7 \times 10^{-2}\end{array}$} \\
\hline Total Body at 3 Years (c) & $\begin{array}{l}234 u \\
235 U+0^{(d)} \\
238 U+0\end{array}$ & & & & \\
\hline & Totals & $7.6 \times 10^{-2}$ & $2.4 \times 10^{-3}$ & $4.9 \times 10^{-2}$ & $1.3 \times 10^{-1}$ \\
\hline \multirow[t]{2}{*}{ Bone at 50 Years } & $\begin{array}{l}231 \mathrm{~Pa} \\
230 \mathrm{Th} \\
234 \mathrm{U} \\
235 \mathrm{U}+0 \\
238 \mathrm{U}+0\end{array}$ & $\begin{array}{l}1.8 \times 10^{-3} \\
1.2 \times 10^{-1} \\
6.5 \times 10^{-1} \\
2.9 \times 10^{-2} \\
5.6 \times 10^{-1} \\
\end{array}$ & $\begin{array}{l}5.8 \times 10^{-4} \\
2.7 \times 10^{-2} \\
6.0 \times 10^{-4} \\
2.5 \times 10^{-5} \\
5.3 \times 10^{-4} \\
\end{array}$ & $\begin{array}{l}1.9 \times 10^{-4} \\
4.6 \times 10^{-5} \\
8.5 \times 10^{-4} \\
6.5 \times 10^{-3} \\
4.2 \times 10^{-2} \\
\end{array}$ & $\begin{array}{l}2.6 \times 10^{-3} \\
1.5 \times 10^{-1} \\
6.5 \times 10^{-1} \\
3.4 \times 10^{-2} \\
6.0 \times 10^{-1} \\
\end{array}$ \\
\hline & Totals & $1.4 \times 10^{0}$ & $2.9 \times 10^{-2}$ & $5.0 \times 10^{-2}$ & $1.5 \times 10^{0}$ \\
\hline \multirow[t]{2}{*}{ Lungs at 1 Year } & $\begin{array}{l}234 U \\
235 U+D \\
238 U+D\end{array}$ & $\begin{array}{l}-(e) \\
--(e) \\
--\end{array}$ & $\begin{array}{l}1.6 \times 10^{-1} \\
6.5 \times 10^{-3} \\
1.4 \times 10^{-1} \\
\end{array}$ & $\begin{array}{l}8.5 \times 10^{-4} \\
6.5 \times 10^{-3} \\
4.2 \times 10^{-2} \\
\end{array}$ & $\begin{array}{l}1.6 \times 10^{-1} \\
1.3 \times 10^{-2} \\
1.8 \times 10^{-1} \\
\end{array}$ \\
\hline & Totals & -- & $3.1 \times 10^{-1}$ & $4.9 \times 10^{-2}$ & $3.5 \times 10^{-1}$ \\
\hline \multirow[t]{2}{*}{ LLI at I Year } & $\begin{array}{l}234 T h+D \\
234 U \\
235 U+0 \\
238 U+0\end{array}$ & $\begin{array}{l}9.6 \times 10^{-2} \\
5.5 \times 10^{-2} \\
3.1 \times 10^{-3} \\
4.7 \times 10^{-2} \\
\end{array}$ & $\begin{array}{l}1.6 \times 10^{-4} \\
1.4 \times 10^{-4} \\
6.5 \times 10^{-6} \\
1.2 \times 10^{-4} \\
\end{array}$ & $\begin{array}{l}8.5 \times 10^{-4} \\
6.5 \times 10^{-3} \\
4.2 \times 10^{-2} \\
\end{array}$ & $\begin{array}{l}9.6 \times 10^{-2} \\
5.5 \times 10^{-2} \\
9.6 \times 10^{-3} \\
8.9 \times 10^{-2} \\
\end{array}$ \\
\hline & Totals & $2.0 \times 10^{-1}$ & $4.3 \times 10^{-4}$ & $4.9 \times 10^{-2}$ & $2.5 \times 10^{-1}$ \\
\hline
\end{tabular}

(a) Only radionuclides that contribute more than $1 \%$ of the total dose of any pathway are listed.

(b) External dose from ground contamination plowed to a depth of $0.15 \mathrm{~m}$.

(c) The time the annual dose peaks after exposure begins.

(d) The $+D$ notation indicates that after deposition in the organ of reference, the decay energy of the daughter is included with the parent.

(e) A dash indicates no organ data is available for the exposure pathway and radionuclide shown. 
TABLE E.4-4. Calculated Maximum Annual Radiation Doses to the Maximum-Exposed Individual Residing on the Released Decommissioned $\mathrm{UF}_{6}$ Conversion Plant Site - Class Y Material

Maximum Annual Dose (mrem) Via:

\begin{tabular}{|c|c|c|c|c|c|}
\hline \multirow[b]{2}{*}{ Organ of Reference } & \multirow[b]{2}{*}{ Radionuclide $^{(a)}$} & \\
\hline & & \multirow[b]{2}{*}{$\begin{array}{l}\text { Ingestion } \\
3.4 \times 10^{-4} \\
3.7 \times 10^{-3} \\
2.7 \times 10^{-5} \\
4.0 \times 10^{-2} \\
1.6 \times 10^{-3} \\
3.4 \times 10^{-2} \\
\end{array}$} & \multirow[b]{2}{*}{$\begin{array}{l}\text { Inhalation } \\
4.2 \times 10^{-8} \\
3.4 \times 10^{-4} \\
1.0 \times 10^{-5} \\
1.6 \times 10^{-5} \\
6.5 \times 10^{-7} \\
1.4 \times 10^{-5} \\
\end{array}$} & $\begin{array}{l}\text { Externa } \\
\text { Ground }\end{array}$ & All Pathways \\
\hline Total Body at 50 Years $(c)$ & $\begin{array}{l}226 \mathrm{Ra} \\
230 \mathrm{Th} \\
231 \mathrm{~Pa} \\
234 \mathrm{Pd} \\
235 \mathrm{U}+\mathrm{D}^{(\mathrm{d})} \\
238 \mathrm{U}+\mathrm{D}\end{array}$ & & & $\begin{array}{l}9.6 \times 10^{-6} \\
4.6 \times 10^{-5} \\
1.9 \times 10^{-4} \\
8.5 \times 10^{-4} \\
6.5 \times 10^{-3} \\
4.2 \times 10^{-2} \\
\end{array}$ & $\begin{array}{l}3.5 \times 10^{-4} \\
4.1 \times 10^{-3} \\
2.2 \times 10^{-4} \\
4.1 \times 10^{-2} \\
8.1 \times 10^{-3} \\
7.6 \times 10^{-2} \\
\end{array}$ \\
\hline & Totals & $8.0 \times 10^{-2}$ & $3.8 \times 10^{-4}$ & $5.0 \times 10^{-2}$ & $1.3 \times 10^{-1}$ \\
\hline \multirow[t]{2}{*}{ Bone at 50 Years } & $\begin{array}{l}230 \mathrm{Th} \\
231 \mathrm{~Pa} \\
234 \mathrm{U} \\
235 \mathrm{U}+\mathrm{D} \\
238 \mathrm{U}+\mathrm{D}\end{array}$ & $\begin{array}{l}1.2 \times 10^{-1} \\
1.9 \times 10^{-3} \\
6.5 \times 10^{-1} \\
2.8 \times 10^{-2} \\
5.8 \times 10^{-1} \\
\end{array}$ & $\begin{array}{l}1.1 \times 10^{-2} \\
2.4 \times 10^{-4} \\
2.5 \times 10^{-4} \\
1.1 \times 10^{-5} \\
2.3 \times 10^{-4} \\
\end{array}$ & $\begin{array}{l}4.6 \times 10^{-5} \\
1.9 \times 10^{-4} \\
8.5 \times 10^{-4} \\
6.5 \times 10^{-3} \\
4.2 \times 10^{-2} \\
\end{array}$ & $\begin{array}{l}3.4 \times 10^{-1} \\
2.3 \times 10^{-3} \\
6.5 \times 10^{-1} \\
3.4 \times 10^{-2} \\
6.2 \times 10^{-1} \\
\end{array}$ \\
\hline & Totals & $1.4 \times 10^{0}$ & $\overline{1.2 \times 10^{-2}}$ & $5.0 \times 10^{-2}$ & $1.4 \times 10^{0}$ \\
\hline \multirow[t]{2}{*}{ Lungs at 3 Years } & $\begin{array}{l}234 \\
235 U+D \\
238 U+D\end{array}$ & $\begin{array}{l}--(e) \\
--(e) \\
--(e) \\
\end{array}$ & $\begin{array}{l}8.5 \times 10^{-1} \\
3.6 \times 10^{-2} \\
7.4 \times 10^{-1} \\
\end{array}$ & $\begin{array}{l}8.5 \times 10^{-4} \\
6.5 \times 10^{-3} \\
4.2 \times 10^{-2} \\
\end{array}$ & $\begin{array}{l}8.5 \times 10^{-1} \\
4.2 \times 10^{-2} \\
7.9 \times 10^{-1} \\
\end{array}$ \\
\hline & Totals & -- & $1.6 \times 10^{0}$ & $4.9 \times 10^{-2}$ & $1.7 \times 10^{0}$ \\
\hline \multirow[t]{2}{*}{ LLI at 1 Year } & $\begin{array}{l}234 \mathrm{Th}+0 \\
234 \mathrm{~T} \\
235 \mathrm{U}+\mathrm{D} \\
238 \mathrm{U}+\mathrm{D}\end{array}$ & $\begin{array}{l}9.6 \times 10^{-2} \\
5.5 \times 10^{-2} \\
3.1 \times 10^{-3} \\
4.7 \times 10^{-2} \\
\end{array}$ & $\begin{array}{l}1.8 \times 10^{-4} \\
1.4 \times 10^{-4} \\
6.5 \times 10^{-6} \\
1.2 \times 10^{-4} \\
\end{array}$ & $\begin{array}{l}8 .-- \\
8.5 \times 10^{-4} \\
6.5 \times 10^{-3} \\
4.2 \times 10^{-2} \\
\end{array}$ & $\begin{array}{l}9.6 \times 10^{-2} \\
5.6 \times 10^{-2} \\
9.6 \times 10^{-3} \\
8.9 \times 10^{-2} \\
\end{array}$ \\
\hline & Totals & $2.0 \times 10^{-1}$ & $4.4 \times 10^{-4}$ & $4.9 \times 10^{-2}$ & $2.5 \times 10^{-1}$ \\
\hline
\end{tabular}

(a) Only radionuclides that contribute more than $1 \%$ of the total dose of any pathway are 1 isted.

(b) External dose from ground contamination plowed to a depth of $0.15 \mathrm{~m}$.

(c) The time the annual dose peaks after exposure begins.

(d) The +0 notation indicates that after deposition in the organ of reference, the decay energy of the daughter is included with the parent.

(e) A dash indicates no organ data is available for the exposure pathway and radionuclide shown. 
REFERENCES

1. K. J. Schneider and C. E. Jenkins, Technology, Safety and Costs of Decommissioning a Reference Nuclear Fuel Reprocessing Plant, NUREG-0278, Prepared by Pacific Northwest Laboratory for the U.S. Nuclear Regulatory Commission, October 1977.

2. R. I. Smith, G. J. Konzek and W. E. Kennedy, Jr., Technology, Safety and Costs of Decommissioning a Reference Pressurized water Reactor Power Station, NUREG/CR-0130, Prepared by Pacific Northwest Laboratory for the U.S. Nuclear Regulatory Commission, June 1978.

3. C. E. Jenkins, E. S. Murphy and K. J. Schneider, Technology, Safety and Costs of Decommissioning a Reference Small Mixed Oxide Fuel Fabrication Plant, NUREG/CR-0129, Prepared by Pacific Northwest Laboratory for the U.S. Nuclear Regulatory Commission, February 1979.

4. Task Group on Lung Dynamics for Committee 2 of the International Conmission on Radiological Protection, "Deposition and Retention Models for Internal Dosimetry of the Human Respiratory Tract," Health Physics, 12, pp. 173-207, February 1966.

5. J. K. Soldat, et al., Models and Computer Codes for Evaluating Environmental Radiation Ooses, US AEC Report BNWL-1754, Pacific Northwest Laboratory, Richiand, Washington, February 1974.

6. U.S. AEC, Final Environmental Statement Concerning Proposed Rule-Making Action: Numerical Guides for Design Objectives and Limjting Conditions for Radioactive Material in Light Water-Cooled Nuclear Power Reactor Effluents, WASH-1258, Directorate of Regulatory Standards, Volume 1 of 3 , Tables 6B-4 and 6B-5, pp. 6B-34 and 6B-35, July 1973.

7. D. A. Baker, G. R. Hoenes and J. K. Soldat, "FOOD - An Interactive Code to Calculate Internal Radiation Doses from Contaminated Food Products." in Environmental Modeling and Simulation, pp. 204-208, EPA, Proceedings of a conference held in Cincinnati, Ohio, April 20-22, 1976. Washington, DC, 1976 .

8. J. F. Fletcher and W. L. Dotson (compilers), HERMES - Digital Computer Code for Estimating Regional Radiological Effects from the Nuclear Power Industry, US AEC Report HEDL-TME-71-169, Hanford Engineering Development Laboratory, Richland, Washington, 1971.

9. J. K. Soldat, Modeling of Environmental Pathways and Radiation Doses from Nuclear Facilities, USAEC Report, BNWL-SA-3939, Pacific Northwest Laboratory, Richland, Washington, 1971 . 
10. G. R. Hoenes and J. K. Soldat, Age-Specific Radiation Dose Commitment Factors for a One Year Chronic Intake, NUREG-0172, a report of the U.S. Nuclear ReguTatory Commission, to be published as a supplement to Regulatory Guide 1.109.

11. International Commission on Radiological Protection, Report of ICRP Committee II on Permissible Dose for Internal Radiation, ICRP Publication 2, Pergamon Press, New York, New York, 1959.

12. J. R. Houston, D. L. Strenge and E. C. Watson, DACRIN - A Computer Program for Calculating Organ Dose from Acute or Chronic Inhalation, BNWL-B-389, Pacific Northwest Laboratory, Richtand, Washington, December 1974.

13. D. A. Baker, User Guide for Computer Program F00D, US ERDA Report, BNWL-2209, Pacific Northwest Laboratory, Richland, Washington, February 1977.

14. International Commission on Radiological Protection, Report of the Task Group on Reference Man, Report 23, Pergamon Press, 0xford, New York, 1975.

15. Monitoring of Radioactive Contamination on Surfaces, International Atomic Energy Agency, Technical Report Series No. 120, p. 4, Vienna, 1970.

16. L. R. Anspaugh, J. H. Shinn and P. L. Phelps, Resuspension and Redistribution of Plutonium in Soils, UCRL-76419, pp. 14-18, January 1975. 


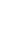


APPENDIX $F$

\section{GENERAL DECOMMISSIONING CONSIDERATIONS}

This appendix gives general descriptions of chemical and physical decontamination and surface cleaning procedures employed in decommissioning a uranium hexafluoride conversion $\left(\mathrm{UF}_{6}\right)$ plant and of techniques for the removal of contaminated structural material. Special equipment items used in these activities are described. Methods and procedures for packaging and shipment offsite of radioactive wastes generated during decommissioning are also discussed. Quality assurance considerations important to decomissioning are addressed. Finaliy, the scope of environmental surveillance programs needed for DECON and for long-term care during passive SAFSTOR are outlined. Detailed descriptions of specific activities for the DECON and passive SAFSTOR decommissioning alternatives are given in Appendix $G$.

\section{F.1 GENERAL DECONTAMINATION METHODS}

Removal of radioactive material from contaminated surfaces can be accomplished in three basic ways: 1) by physical cleaning of the surface, 2) by the use of chemicals that dissolve surface films containing the radioactive material, and 3 ) by removal of the surface itself.

Physical cleaning methods include sweeping and vacuuming, handwiping, sandblasting, and washing with various cleansing agents. Chemical decontamination involves the use of acid solutions to dissolve residual contamination from surfaces and sometimes part of the surfaces themselves. It is typically applied to wet processing systems, pumps, piping, storage tanks, etc. If physical cleaning and chemical decontamination techniques do not reduce contamination levels on equipment and building surfaces to acceptable radioactivity release levels, it will be necessary to use more extensive methods such as physical methods to remove major surface layers in which radioactivity has become embedded. Surface removal techniques employed in this study are abrasive blasting for metal surfaces and jack harmering and surface spalling for concrete surface layers. 


\section{F.1.1 Surface Cleaning Procedures}

Removal of contamination from sealed surfaces such as painted walls and floors, tank exteriors, etc., can be accomplished using a variety of techniques. For small quantities of loose contamination on floors, vacuuming or simple sweeping compounds are often effective. For more tenacious contaminants, various cleansing compounds combined with handwiping, handscrubbing, and power scrubbing techniques can be used. Several proprietary decontamination solutions are available. Ordinary household detergents are quite effective but produce sizable quantities of waste water to process. Aerosol-type foaming cleansers have proven effective and eliminate the problem of large volumes of waste water, but their use produces sizable quantities of contaminated wiping material.

Freon, acetone, alcohol and other solvents are effective degreasing agents that can be used in removing contaminated films from equipment surfaces. Organic solvents have an advantage of not being corrosive to equipment and electrical connections. However, their use generates organic solutions that must be processed and disposed of. These organic solutions can degrade plastic material, can require use of sizable quantities of contaminated wiping material, and can increase the risk of fire in the contaminated material.

Variable pressure, high- or low-velocity liquid jets can be effective for some types of surface decontamination work. The devices can be operated by one man, at pressures up to $30,400 \mathrm{kPd}(300 \mathrm{~atm})$ using a hand-held jet lance. On those contaminants for which the liquid jet is effective, the jet is a very rapid decontamination method. Its use can produce significant volumes of contaminated liquid that must be processed for disposal.

\section{F.1.2 Chemical Decontamination}

In the reference plant, the principal systems to be chemically decontaminated are the pipelines, tanks, process equipment and the chemical processing system.

During the decommissioning planning and preparation stage, procedures and results from routine chemical decontamination efforts carried out during plant operation are reviewed to obtain maximum berefit from previous 
experience. Current as-built drawings are reviewed to identify system deadlegs and to facilitate the planning of any system modifications required to achieve decontamination. Existing procedures are reviewed for applicability to the present effort and modified as necessary. A detailed step-by-step procedure is developed for the decommissioning decontamination campaign, with checklists for valve settings, etc., to assure proper operation of the systems.

Some typical chemical solutions that might be used for chemical decontamination of the plant are given below:

1) A solution of $0.025 \underline{\mathrm{MK}}-0.1 \mathrm{M} \mathrm{AlNO}_{3}$ may be used to remove uranium deposits.

2) Many sludge deposits may be removed by using a solution of $20 \% \mathrm{HNO}_{3}-$ $6 \% \mathrm{AlF}_{3}$.

3) A solution of $10 \mathrm{M} \mathrm{HNO}_{3}-0.1 \mathrm{wt} \% \mathrm{CaF}$ may be used to remove uranium contamination from stainless steel surfaces with only modest surface corrosion.

4) A tri-sodiuni phosphate (TSP) solution.

The chemical solution chosen must be compatible with the materials used in the system.

Chemical decontamination is postulated to be accomplished with batches of acid flush solution. Up to five flushes may be required, with recirculation times averaging 3 to 4 days per flush.

\section{F.1.3 Concrete Remova] Techniques}

There will likely be concrete surfaces in the plant that are contaminated to a depth of a few centimeters and that cannot be cleaned to acceptable release levels by surface wiping or washing techniques. In these instances, the concrete surfaces must be physically removed and packaged for disposal. Severai criteria must be considered in selecting a concrete removal method for a particular location. The method should facilitate control of airborne contamination and minimize any spread of contamination. The method should 
minimize the potential for personnel exposure to radioactivity, and the size and weight of removed materials must be controlled to facilitate packaging and shipping for disposal.

The various methods available for removal of concrete and reinforcing steel are listed in Table F.1-1, together with the advantages and disadvantages of each. Methods of particular interest to this study are the surface-spalling and rock-splitting techniques for localized removal of concrete surfaces. In this study, the modified rock-splitting tool described in Section F.2.3 is the principal device used for removal of contaminated concrete surfaces. Use of this device permits localized removal of concrete surfaces at depths of 5 to $8 \mathrm{~cm}$ with no explosions and relatively little dust. The principal source of dust is the drilling of the hole in the concrete into which the splitting tool is

\section{TABLE F.1-1. Concrete and Reinforcing Steel Removal Methods}

\begin{tabular}{|c|c|c|}
\hline Removal Method & Advantages & Disadvantages \\
\hline Flane Cutting & $\begin{array}{l}\text { - Concrete, steel liner, and rebar may be cut in } \\
\text { one operation } \\
\text { - Fast cutting speed } \\
\text { - Adaptable for remote operation } \\
\text { - Adaptabie for pivoted circumferential cutting } \\
\text { - Adaptable for cutting on irregular surfaces } \\
\text { - Ho vibration/shock } \\
\text { - Low noise level } \\
\text { - Controlled rate of material removal }\end{array}$ & $\begin{array}{l}\text { - Generates copious quantities of toxic gases and } \\
\text { smoke } \\
\text { - Consumes large quantity of gas } \\
\text { - Smoke could potentially spread gross contamination } \\
\text { throughout contamination control envelope unless } \\
\text { adequately controlled } \\
\text { - Requires a through starter-hole made by a core drill } \\
\text { to provide an outlet gas-flow path }\end{array}$ \\
\hline $\begin{array}{c}\text { Thermic Lance } \\
\text { Cutting }\end{array}$ & $\begin{array}{l}\text { - Cuts both concrete and steel without diffi- } \\
\text { culty } \\
\text { - Fast "hole punching" speed } \\
\text { - ldeally suited for cutting irregular surfaces } \\
\text { - Remote operation is possible for up to approxi- } \\
\text { mately } 3 \text { meters } \\
\text { - No vibration/shock } \\
\text { - Low noise level } \\
\text { - Controlled rate of material removal }\end{array}$ & $\begin{array}{l}\text { - Generates moderate quantities of toxic gases } \\
\text { and smoke } \\
\text { - Requires need for rock jack to break out } \\
\text { concrete sections } \\
\text { - Consumes large quantity of bottied oxygen } \\
\text { - Smoke could potentially spread gross contami- } \\
\text { nation throughout contamination control envelope } \\
\text { unless adequately controlled }\end{array}$ \\
\hline $\begin{array}{l}\text { Core Boring } \\
\text { and Rock- } \\
\text { Splitting }\end{array}$ & $\begin{array}{l}\text { - Proven technique used extensively in con- } \\
\text { ventional mining operations } \\
\text { - Low noise level } \\
\text { - Low vibration/shock level } \\
\text { - Ho toxic gases generated } \\
\text { - Water cooling minimizes airborne particulate } \\
\text { material } \\
\text { - Woderate-to-slow cutting speeds } \\
\text { - Controiled rate of material removal }\end{array}$ & $\begin{array}{l}\text { - Cutting through steel rebar or structuraf steel } \\
\text { slows cutting speed and tears diamonds off core } \\
\text { drili } \\
\text { - Requires additional operation of oxyacetylene } \\
\text { torch for rebar } \\
\text { - Cooling water required for drilling may have to } \\
\text { be filtered and recycled } \\
\text { - Hot ldeally suited for operation on irregular } \\
\text { surfaces or in cramped quarters }\end{array}$ \\
\hline
\end{tabular}


inserted. Use of portable vacuum cleaners with collection at the tool location can minimize scatter of contaminated dust. When decontaminating wall surfaces, work starts at the top of the contaminated area to prevent potential recontamination of the clean surface by falling dust or debris. The material removed is packaged for disposal.

Electric or pneumatic hammers may also be used, particularly on floor surfaces. These devices have the disadvantage of creating significant quantities of dust and small fragments that tend to recontaminate the areas being cleaned unless special precautions are taken.

Two techniques for cutting concrete and steel reinforcing bars in a single operation are flame cutting and thermic lance cutting. Flame cutting utilizes commercially available 3-m-long by 19-mm-diameter thin-walled conduit burning bars. Each bar contains up to seven dissimilar metals in the form of strips or strands and is encased in an outer tube into which oxygen is forced during the burning process. Once ignited, a bar is consumed as it burns. After 4 to 5 minutes and with about $0.6 \mathrm{~m}$ of bar left, the oxygen supply is shut off and the exothermic chemical reaction stops. The final $0.6 \mathrm{~m}$ of the first bar can be attached to a second bar and the burning process repeated, thus minimizing the use of bar material.

The thermic lance uses powders of material similar to those in the strands of the burning bar. The powders are forced through a tube or nozzle with oxygen and ignited to form a high-temperature cutting medium. In both of these techniques, copious quantities of toxic gases and/or smoke are produced and extensive provisions must be made for adequate ventilation of the work area and control of the associated dust.

\section{F.2 SPECIAL EQUIPMENT REQUIREMENTS}

Some of the decontuissioning activities described in the previous section require special tools or equipment. Some of this equipment may be available as part of the facility's normal operating equipment complement. Other equipment will require offsite procurement or manufacture. 
Several activities are involved in meeting the need for special tools and equipment. These activities include: the development of functional and operational requirements for devices needed in the decommissioning work; the preparation of detailed designs for noncommercial devices and modifications to commercialiy available equipment; procurement or fabrication of the identified equipment items; and the establishment of a mock-up facility for use in testing and development of operational parameters for remotely operated equipment.

A listing of special tools and equipment needed for plant decomissioning activities, together with the functions of the equipment, is given in Table F.2-1. Descriptions of some of the more unique devices are presented in this section.

\section{F.2.1 High-Speed Cutting Devices}

For rapid cutting of steel, the oxyacetylene torch will be used. Since this torch is a relatively common device, it will not be discussed here.

More sophisticated cutting devices such as the plasma-arc torch (1) and arc saw ${ }^{(2)}$ can also be used.

\section{F.2.2 Mechanical Cutting Devices}

Four mechanical cutting techniques for sectioning contaminated components are used to dismantle the reference plant. The first technique uses a conventional tubing cutter to section mild or stainless steel pipe of up to $0.10 \mathrm{~m}$ 0.D. into appropriate lengths. The tubing cutter is placed on the pipe and a hardened sharp circular blade is gradually tightened and revolved about the pipe until the pipe is sectioned. This sectioning technique is only useful for smaller diameter pipe and requires complete accessibility to all sides of the pipe.

The second cutting technique uses a heavy-duty reciprocating saw with blades that are 0.30 to $0.60 \mathrm{~m}$ long to section stainless steel pipe of up to $0.20 \mathrm{~m} \mathrm{0.D.} \mathrm{The} \mathrm{saw} \mathrm{is} \mathrm{equipped} \mathrm{with} \mathrm{a} \mathrm{pivot} \mathrm{bracket} \mathrm{that} \mathrm{uses} \mathrm{the} \mathrm{weight} \mathrm{of}$ the saw to provide the necessary cutting force. A typical cutting time for a $0.20-m$-diameter stainiess steel Schedule 10 pipe is approximately 5 minutes. Cutting oil can be used to help cool the reciprocating saw blade and to contain the contamination inside the pipe. 
IABLE F.2-1. Special Tools and Equipment for Dismantlement

\begin{tabular}{|c|c|c|}
\hline Item & $\begin{array}{c}\text { Estimated } \\
\text { Unit Cost } \\
\text { (\$ Thousands) } \\
\end{array}$ & Functions \\
\hline Oxyacetylene torch & 1 & $\begin{array}{l}\text { Sectioning of hoods, tanks, piping, } \\
\text { support structures, etc. }\end{array}$ \\
\hline Guillotine pipe saw & 4 & Pipe and tube cutting \\
\hline Tube cutter & 0.41 & Pipe and tube cutting \\
\hline Ratcheting pipe cutter & 0.07 & Pipe and tube cutting \\
\hline Reciprocating saw & 0.8 & Pipe and tube cutting \\
\hline Nibbler & 1 & $\begin{array}{l}\text { Cutting ductwork and other thin } \\
\text { gauge materials }\end{array}$ \\
\hline $\begin{array}{l}\text { Assorted tools such as impact } \\
\text { wrenches, bolt cutters, etc. }\end{array}$ & 6.9 & $\begin{array}{l}\text { Disassembly, handling and packaging } \\
\text { of contaminated materiais }\end{array}$ \\
\hline High-velocity liquid jet & 6.9 & $\begin{array}{l}\text { Surface decontamination of piping, } \\
\text { tanks and equipment }\end{array}$ \\
\hline Low-velocity liquid jet & 2.76 & \\
\hline $\begin{array}{l}\text { Hydraulic concrete surface } \\
\text { spalling device }\end{array}$ & 5 & $\begin{array}{l}\text { Removal of contaminated concrete } \\
\text { surfaces }\end{array}$ \\
\hline Concrete drilis & 0.28 & $\begin{array}{l}\text { Drilling holes in concrete as } \\
\text { required for spalling and volume } \\
\text { blasting }\end{array}$ \\
\hline Electric/pneumatic hamers & 0.70 & Breaking up concrete \\
\hline Portable A-frames & 4.10 & $\begin{array}{l}\text { Lift and transport large equip- } \\
\text { ment items and components }\end{array}$ \\
\hline Portable wash tanks & 2.76 & $\begin{array}{l}\text { Used to wash, scrub and rinse for } \\
\text { decontamination of equipment } \\
\text { components, pipes, etc. }\end{array}$ \\
\hline Portable greenhouse erection kit & 2.76 & $\begin{array}{l}\text { Contain spread of contamination } \\
\text { from equipment disassembied in } \\
\text { dusty plant areas and for outside } \\
\text { decontamination activities }\end{array}$ \\
\hline Portable spray cleaning booth & 5.52 & $\begin{array}{l}\text { Used to clean large pieces of } \\
\text { equipment in original rooms }\end{array}$ \\
\hline Portable power brushes & 0.21 & $\begin{array}{l}\text { An assortment of sizes and types of } \\
\text { brushes which are powered to } \\
\text { improve productivity in decontami- } \\
\text { nating equipment, walls, ceilings, } \\
\text { etc. }\end{array}$ \\
\hline Portable abrasive blasting unit & 27.6 & $\begin{array}{l}\text { Abrasive ciean corroded metal } \\
\text { surfaces in large tanks, pifes, } \\
\text { etc. }\end{array}$ \\
\hline
\end{tabular}


The third cutting method uses a hand-held reciprocating saw with short (approximately 75-min) blades. The tool is used to cut small-diamater pipe (less than $50 \mathrm{~mm}$ 0.D.). Saw blade life is shorter and the work is harder for the operators than with other techniques.

The fourth cutting technique uses a nibbler device with a scissor action to section large-diameter, contaminated steel ducting into pieces suitable for decontamination and compaction.

Studies have shown that mechanical cutting techniques can be used to safely and effectively section pipe, ducting, and other contaminated components into sizes and geometries suitable for decontamination and/or packaging. Typical sectioning times are 10 minutes or less and contamination can be restricted to the saw blades and the immediate cutting area.

\section{F.2.3 Tools for Concrete Surface Removal}

Instances may occur throughout the facility where concrete surfaces are contaminated to a depth such that surface washing with decontamination solutions is ineffective, and removal of the surface layers is the only effective decontamination method.

Concrete spallers (rock splitters) have been developed to facilitate this type of decontamination effort. A schematic of this device is illustrated in Figure F.2-1. This device permits localized concrete removal to depths of 50 to $75 \mathrm{~mm}$ with no explosions and very little dust. (The principal source of dust is the drilling of the hole into which the splitting tool is inserted.) A dust shield with a vacuum attachment minimizes the spread of contaminated dust and can be used to collect all but the largest pieces of rubble.

The concrete spaller consists of three basic parts: a hydraulic cylinder, a push rod, and a bit with expanding wedges. The hydraulic cylinder is attached at one end and activates the push rod, which is installed inside the bit.

The spaller is operated by inserting the bit into a predrilled hole about $55 \mathrm{~mm}$ deep and $25 \mathrm{~mm}$ in diameter. The hydraulic cylinder is then activated, forcing the push rod toward the end of the bit. The wedges in the bit are 


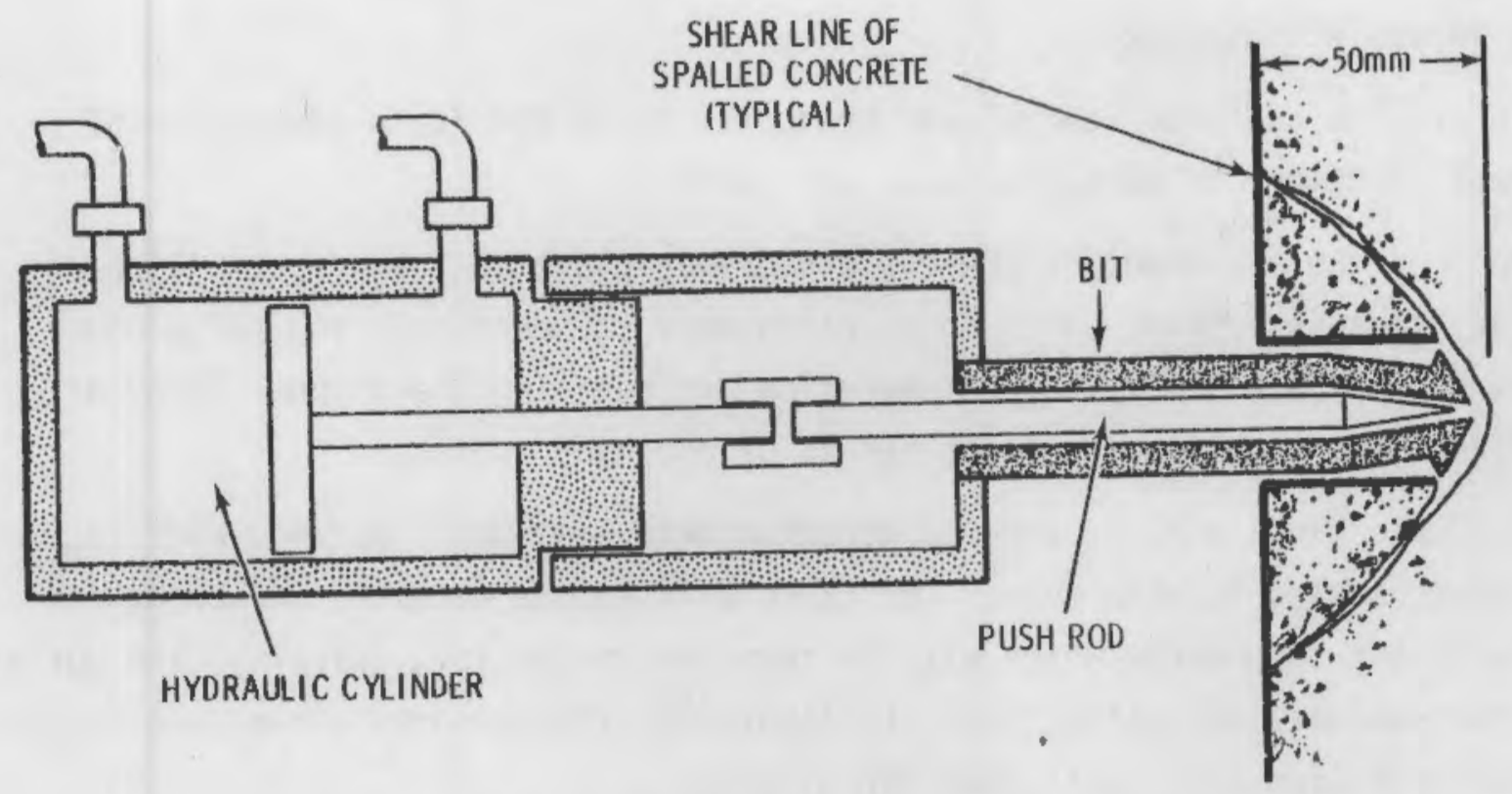

FIGURE F.2-1. Schematic of Concrete Spaller

forced radially outward into the walls of the hole. Then, when the tip of the push rod reaches the bottom of the hole, it forces the wedges away from the bottom and causes the concrete to be spalled off.

The spaller is sma11, lightweight, and fully portable, and can be readily adapted to remote operation. It is connected to the hydraulic power source with hydraulic hoses. The spaller is about $0.4 \mathrm{~m}$ long, with a mass of about $10 \mathrm{~kg}$.

For rapid removal of large surface areas, several devices can be ganged together with a corresponding set of concrete drills and operated as a unit. The spacing between holes and the pattern of the holes (square or triangular array) are important parameters in the effectiveness of this technique for removing concrete surfaces. Arrangement of the concrete drills and the splitting tools into a fixed-geometry array assures a relatively uniform removal pattern. Combining these ganged units with a vacuum transfer system for rubble removal would result in a fast and dust-free concrete removal method, one ideally suited to nuclear facility decommissioning applications. 


\section{F.2.4 Portable Equipment}

To provide adequate control and productivity in the field processing of equipment, a number of portable items are needed.

Much of the equipment in the UF ${ }_{6}$ conversion plant is large. It will be necessary to have A-frame units which can handle the equipment and large components during disassembly, decontamination and handling operations. Many of the areas within the plant are not served by overhead cranes.

Portable tanks will be used to decontaminate equipment, piping, etc., as it is disassembled in each room. The tanks will enable washing, scrubbing and rinsing of the components which will in turn save packaging, shipping, and burial costs for radioactive wastes $\left(\approx \$ 530\right.$ to $\left.\$ 706 / \mathrm{m}^{3}\right)$. The components can then be sold as scrap or hauled to a local dump for disposal.

A portable spray cleaning booth can be used to clean large equipment and components in the field. It can be used in conjunction with the portable A-frames for the cleaning operation.

Portable greenhouses can be erected in dusty areas (e.g., disassembling hammer mills) or outside (e.g., decontaminating pipes).

Portable powered brushes will expedite cleanup of tight spaces (e.g., tooth brush size) to large areas (e.g., large rotary brushes) for decontaminating ceilings and walls.

Portable abrasive blasting equipment can be used to clean painted or corroded surfaces where at least partial removal of the surface is necessary.

\section{F.3 PACKAGING ANO SHIPPING OF RADIOACTIVE MATERIALS}

Large quantities of radioactive wastes are removed during the dismantlement of a $\mathrm{UF}_{6}$ conversion plant. These materials must be properly packaged and shipped to an authorized disposal site.

Radioactive material removed during dismantlement include:

- contaminated process equipment and tanks 
- contaminated piping, ducts, and fixtures

- concrete rubble from the mechanical decontaminativin of contaminated floors, walls, and abutments

- contaminated lagoon liners and soil

- miscellaneous non-combustible materials

The bulk of the material that must be packaged for disposal will be contaminated with uranium. Contact radiation dose rates from waste materials generated during dismantlement operations will vary from a few micro-roentgen per hour to a few milli-roentgen per hour. The radioactive wastes are assumed to be disposed of at licensed shallow-land burial sites.

\section{F.3.1 Packaging of Radioactive Materials}

Only solid wastes are assumed to be transported to a commercial burial ground.

Waste from decommissioning operations is packaged for shipment in $0.21-\mathrm{m}^{3}$ steel drums or in plywood boxes. Packages of non-TRU waste qualify as low specific activity (LSA) material ${ }^{(a)}$ and can be shipped without shielding.

\section{F.3.2 Shipping of Radioactive Materials}

All shipments of radioactive materials must be made in compliance with federal, state and local regulations. Federal transportation regulations of

(a) Radioactive materials are classified for transportation purposes into one of seven transport groups according to their potential hazard if released to the environment. Transport Group I is the most restrictive. Plutonium and other transuranic elements are in this transport group. Transport Group VII is the least restrictive. Shipments that pose a negligible risk to the public health may be classified as low specific activity (LSA) material 10 CFR $71.4(\mathrm{~g})$. If the radioactivity is essentially distributed uniformly, with a concentration of not more than $0.1 \mu \mathrm{Ci} / \mathrm{g}$ of Group I material, or $5 \mu \mathrm{Ci} / \mathrm{g}$ of Group II material, or $300 \mu \mathrm{Ci} / \mathrm{g}$ of Group III or IV material, the waste qualifies as LSA material. Externally contaminated nonradioactive materials may be considered as low specific activity provided that the radioactive contamination averaged over $l \mathrm{~m}^{2}$ does not exceed $0.1 \mu \mathrm{Ci} / \mathrm{cm}^{2}$ for Group I radionuclides or $1.0 \mu \mathrm{Ci} / \mathrm{cm}^{2}$ for others. Basically, only strong, tight packaging that will not leak in normal transport is required for the shipment of LSA material. 
DOT and NRC establish container requirements, dose rate 1 imits and handling procedures that ensure the safety of the public and transportation workers during shipment of radioactive materials. (4) Federal regulations applicable to the transport of radioactive materials are:

- Title 49 Code of Federal Regulations Parts 170-199 (49 CFR 170-199) -Department of Transportation regulations governing the transport of hazardous materials.

- 10 CFR 71--NRC regulations governing the packaging and shipment of radioactive materials.

In addition, for highway transport, state agencies regulate vehicle sizes and weights and, in some cases, transportation routes and times of travel.

Dose rates, for shipments in exclusive-use, closed transport vehicles, musi not exceed the following values (DOT, 49 CFR 173.393):

1) 1000 millirem per hour at $21 \mathrm{~m}(3 \mathrm{ft})$ from the external surface of the package

2) 200 millirem per hour at any point on the external surface of the vehicle

3) 10 millirem per hour at $2 \mathrm{~m}$ from the external surface of the vehicle

4) 2 millirem per hour at any normally occupied position in the transport vehicle.

These dose rate limits are illustrated in Figure F.3-1 for truck transport. (5) All of these criteria must be met on a given shipment, with an exclusive-use vehicle, properly placarded.

Shipments of non-TRU waste are transported to licensed commercial low-level waste burial grounds. Because none of the currently licensed commercial burial grounds has a rail siding, it is assumed that all non-TRU waste shipments are made by truck in exclusive-use vans. 


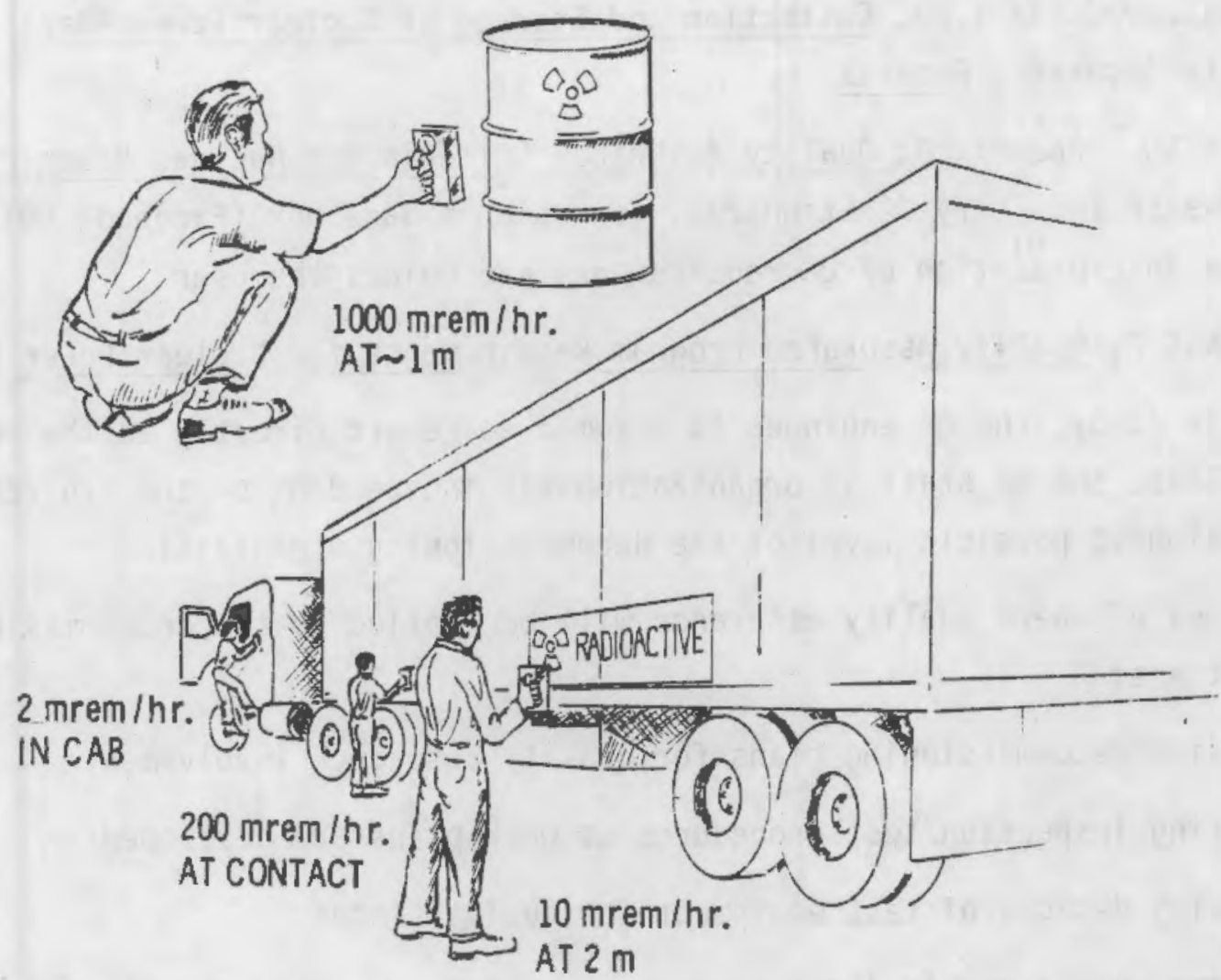

FIGURE F.3-1. Radiation Dose Limits for Exclusive-Use Vehicles

\section{F.4 QUALITY ASSURANCE}

Quality assurance (QA) planning is required from the earliest stages of the deconmissioning effort. During the planning and preparation phase of decommissioning, as each detailed procedure is developed, the QA portions are included. While not specifically related to $\mathrm{UF}_{6}$ conversion plants or to the decommissioning of nuclear facilities, the following documents provide valuable information about $Q A$ requirements and procedures:

- Regulatory Guide 1.58, Qualification of Nuclear Power Plant Inspection, Examination and Testing Personnel for the Construction Phase of Nuclear Power Plants (a)

(a) Although not written specifically for the decommissioning phase, the $Q A$ principles and objectives found herein would, however, apply to all activities of decommissioning. 
- Regulatory Guide 1.88, Collection and Storage of Nuclear Power Plant Quality Assurance Records

- 10 CFR 50, Appendix B, Quality Assurance Criteria for Nuclear Power Plants (a)

- MIL-Q-985A (Military QA Standard), for which a handbook (Handbook 50) helps in the interpretation of $Q A$ requirements and guides the user

- ANSI N45.2, Quality Assurance Program Requirements for Nuclear Power Plants.

In this study, the $Q A$ engineer is assumed to report directly to the project manager. Thus, the QA staff is organizationally independent of the project staff, up to the highest possible level of the decommissioning organization.

Examples of where quality assurance will be applied to the decommissioning project are:

- reviewing decommissioning plans for quality assurance involvement

- preparing inspection/test procedures as work plans are developed

- reviewing designs of test equipment for quality input

- ordering any inspection/test equipment required to perform quality assurance/quality control function

- receiving procured equipment, verifying acceptance

- qualifying suppliers for fabrication of radioactive shipping containers

- preparing inspection/test procedures to be imposed on subcontractors

- preparing inspection plans for shipment of radioactive materials, containers, trucks, etc.

- finalizing formal Quality Assurance Plan.

QA efforts during the actual dismantlement period involve:

- performing QA functions for procurements

- auditing all program activities

(a) Although not written specifically for the decommissioning phase, the QA principles and objectives found herein would, however, apply to all activities of decommissioning. 
- monitoring performances of specialists, utility operators, laborers, craftsmen, and health physics technicians for compliance with work procedures

- verifying compliance of radioactive shipments with appropriate procedures and regulations

- performing dimensional, visual, nondestructive examinations, or other required inspection services to assure compliance with work plans

- maintaining auditable files on the QA audits

- preparing a final report on overall performance of the decommissioning program with regard to the QA function.

\section{F.4.1 Methods Review}

Whenever a new procedure is written, a documented peer review of the procedure is assumed to be held. The review assures that the planning includes suitable controls for application to physics, radiation, safety, accident, security, thermal, stress, QA/QC, and hydraulic analyses. The controls may include other checks, tests, and formal design reviews as necessary. Other aspects of the planning that are reviewed are reliability criteria, the choice of test methods, and the choice of processes or materials. The conservatism in margins of safety established for procedures, equipment, or structures also receives documented review.

\section{F.4.2 Procurement Document Control}

The project's suppliers, including fixed-price contractors and the shipping cask vendors, are selected from a QA list of Qualified Suppliers. QA inspections of the vendor's plant are performed as needed to place new firms on the qualified list.

Procurement Document Control is a $Q A$ procedure to verify that any $Q A$ requirements for specified hardware or services are identified in procurement documents or purchase orders. This includes references to applicable drawings, specifications, standards, codes, regulations, required records, test data, certifications, and qualifications of personnel or procedures. Special handling, 
shipping, or packaging requirements are also identified to vendors. This control is applied to any supplier of the specific devices and equipment vital to the project, such as environmental monitoring equipment, and safety devices, radiation detection equipment, chemicals and explosives.

\section{F.4.3 Work Instructions, Procedures, and Drawings}

Formal documentation of work instructions, procedures, and drawings, and of the sequence of action for preparation, review, approval, and control of information is required. The people responsible for the sequence are clearly identified. These procedures verify the proper completion of activities or steps in the decomissioning process; for example, the disassembly sequences which ensure that vital services remain intact. The latest revisions of drawings, plans and work instructions are required to be at the work place. Also included are work instructions for vendors to review hardware for quantitative (dimensions, tolerances, or limits) and for qualitative (finish, workmanship) acceptability criteria. Changes in planning receive the same level of review and approval as original planning.

\section{F.4.4 Document Control}

Document Control verifies that all essential documentation receives review, approval, release, change and distribution control. A procedure is used to purge the system of obsolete or erroneous information.

\section{F.4.5 Identification and Control of Procured Items}

A program of supplier surveillance or source inspection for vendors of critical items is established. (Also see the Inspection and Test Section.) Records, such as certification of conformance, are required from vendors to show they meet the $Q A$ requirements. Inspection of purchased materials or items is performed upon receipt of the items. Items must be sufficiently identified to allow proper selection for use, completion of processing, or segregation of nonconforming items. The shelf life of chemicals must be clearly stated. 


\section{F.4.6 Special Processes}

Decommissioning may have several tasks involving new or very unusual work procedures (e.g., large-scale chemical decontamination work). Special provisions are made to identify and control any unusual processes, using reviews, procedures, and audits.

\section{F.4.7 Inspection and Test}

All items produced for the project are properly inspected or verified. Inspections in the vendor's plant may be necessary for some items. Adequate inspection instructions are prepared, and inspection records are prepared and retained.

Verification procedures assure inspection of each essential operation, as well.

\section{F.4.8 Calibration}

All measurements require the use of properly calibrated equipment. Therefore, a system of calibration control is used to assure instrument reading validity. The accuracy requirements and tolerances for the project measurements are identified. Examples of equipment with calibration requirements include radiation monitoring devices, portable radiation detection equipment used in dose rate surveys of shipping packages, and devices used to monitor for releasability as cleaned or uncontaminated scrap. Instruments for monitoring environmental effluents and vital services probably have calibration procedures already in place. For this equipment, the existing program is maintained.

\section{F.4.9 Shipping and Receiving}

Special instructions for handling, packaging, shipping, receiving, storing and marking of components for the project are prepared. Included are radioactive shipments that require written QA procedures for each package type, specifying all steps in the package inspection, preparation, loading, and closing. Signed checklists are used. Seals are carefully verified on contaminated units for which no additional outside packaging is used. 


\section{F.4.10 Operating Status}

Sufficient identification is applied to prevent the inadvertent operation of systems no longer functional or needed, or the use of discrepant items. Restricted use may be necessary in many cases for some systems, such as pumps, that may not have been fully removed from service.

\section{F.4.11 Nonconformance and Corrective Action}

All nonconformances are identified, and the records are retained as part of the project records.

\section{F.4.12 Special Quality Records}

An index of records and their required retention periods is maintained. These records include operating logs, results of reviews, inspections, training and qualifications of personnel, procedures, drawings, specifications, criteria documents, procurement documents, shipping records, nonconformance and corrective action reports, and audit reports. Extensive records of dose rate surveys are also maintained.

\section{F.4.13 Quality Auditing}

Regular audits are performed to verify that each of the QA procedures is being followed. Examples include witnessing radioactive shipments, calibration audits, verification that the correct procedures are at all work locations, vendor inspection, receiving and storage inspections, and audits for complete QA procedures and record retention.

\section{F.5 ENVIRONMENTAL SURVEILLANCE PROGRAM}

The levels of environmental surveillance needed for decontamination operations and for the period of safe storage are different. The scopes of the necessary programs for these two cases are outlined in the following sections.

\section{F.5.1 Environmental Surveillance Program During DECON}

The objectives of an environmental surveillance program for operating nuclear facilities are generally recognized as valid and that rationale can be applied to facilities undergoing deconmissioning as well. The following objectives are taken from ICRP No. $7 .^{(6)}$ 
- Detection of sudden changes and evaluation of long-term trends of concentration in the environment, with the intent to detect failure or lack of adequate control of releases and to initiate appropriate actions.

- Assessment of the actual or potential exposure of man to radioactive materials or radiation present in his environment, or the estimation of the probable upper 1 imits of such exposure.

- Determination of the fate of contaminants released to the environment, especially with the intent of detecting previously unconsidered mechanisms of exposure.

- Demonstration of compliance with applicable regulations and legal requirements concerning releases to the environment.

Basic radiation exposure criteria and radioactive effluent release criteria applicable to population exposure are given in 10 CFR 20, Sections 20.1, 20.105, 20.106, and 20.303. For nonradioactive contaminants, consideration must be given to applicable standards such as Water Quality Criteria ${ }^{(7)}$ and ambient air quality standards listed by the Environmental Protection Agency (EPA). ${ }^{(8)}$ Local or state air quality criteria would presumably also apply on a site-specific basis.

In addition, the interfaces of the environmental monitoring program between the plant owner, the appropriate state agencies, and the EPA should be stipulated in the application for the amended license, as may be required by 10 CFR, Part 70, Section 70.23(a), 70.32(b), and 70.34.

A suggested minimum program of environmental radiological surveillance to be conducted outside the plant during decommissioning operations for the purpose of establishing population dose is shown in Table F.5-1. This minimum program continues until all radioactive waste shipments from the site have been completed. At that time, the program is reduced in scope.

The analytical detection limits given in Table F.5-1 are based on the practicability of routine radioactivity measurement techniques, and in all cases should be sufficient to quantify radionuclide concentrations that would 
TABLE F.5-1. Recommended Basic Environmental Monitoring Program for the Period of Active Decommissioning Operations

\begin{tabular}{|c|c|c|c|c|c|}
\hline $\begin{array}{l}\text { Sample } \\
\text { Type }\end{array}$ & Frequency & Analysis & $\begin{array}{r}\text { Analytical } \\
\text { Detectjop } \\
\text { Limit }\end{array}$ & $\begin{array}{l}\quad \text { Number } \\
\text { Sampl ing } \\
\text { Onsite }\end{array}$ & $\begin{array}{l}\text { of } \\
\text { Sta } \\
\text { Off } \\
\end{array}$ \\
\hline \multicolumn{6}{|c|}{ Terrestrial Samples } \\
\hline \multirow[t]{3}{*}{ Air Particulate } & Weekly & Gross Alpha & $0.002 \mathrm{pCi} / \mathrm{m}^{3}$ & 2 & \\
\hline & Monthly & Gross Beta & $0.002 \mathrm{pCi} / \mathrm{m}^{3}$ & 2 & \\
\hline & Monthly & Gamma Scan ${ }^{(b)}$ & $0.3 \mathrm{pCi} / \mathrm{m}^{3} /$ isotope & 2 & \\
\hline Direct Radiation & Quarterly & TLD ${ }^{(c)}$ & $\begin{array}{l}1.25 \text { mrem/quarter } \\
\text { increase }\end{array}$ & 8 & \\
\hline \multirow[t]{2}{*}{ Rainfall } & Monthly & Gross Alpha & $0.5 \mathrm{pCi} / \mathrm{\ell}$ & 1 & 2 \\
\hline & Monthly & Gamma Scan $(d)$ & $25 \mathrm{pCi} / \mathrm{l} /$ isotope & 1 & 2 \\
\hline Soil & Semiannually & Gamma Scan & $\begin{array}{l}0.1 \mathrm{pCi} / \mathrm{g} / \text { isotope } \\
\text { (dry) }\end{array}$ & 3 & \\
\hline Vegetation & Semiannualiy & Gamma Scan & $\begin{array}{l}50 \mathrm{pCi} / \mathrm{kg} / \text { isotope } \\
\text { (wet) }\end{array}$ & 2 & \\
\hline Animals & Semiannually & Gamma Scan & $\begin{array}{l}50 \mathrm{pCi} / \mathrm{kg} / \mathrm{i} \text { sotope } \\
\text { (wet) }\end{array}$ & 2 & \\
\hline \multicolumn{6}{|l|}{ Aquatic Samples } \\
\hline \multirow[t]{2}{*}{ Surface Water } & Monthly & Gross Alpha & $0.5 \mathrm{pCi} / \mathrm{l}$ & 2 & 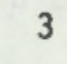 \\
\hline & Monthly & Gamma $\operatorname{Scan}(e)$ & $25 \mathrm{pCi} / \mathrm{l} /$ isotope & 2 & \\
\hline \multirow[t]{2}{*}{ Well Water } & Quarterly & Gross Alpha & $0.5 \mathrm{pCi} / \mathrm{\ell}$ & 1 & \\
\hline & Quarterly & Gamma Scan $(d)$ & $25 \mathrm{pCi} / \mathrm{l} /$ isotope & 1 & 3 \\
\hline Bottom Sediment & Semiannually & Gamma Scan & $\begin{array}{l}0.1 \mathrm{pCi} / \mathrm{g} / \text { isotope } \\
\text { (dry) }\end{array}$ & 1 & \\
\hline Vegetation & Semiannualiy & Gamma Scan & $\begin{array}{l}100 \mathrm{pCi} / \mathrm{kg} / \text { isotope } \\
\text { (wet) }\end{array}$ & 1 & 3 \\
\hline Shoreline Soil & Semiannually & Gamma Scan & $\begin{array}{l}0.1 \mathrm{pCi} / \mathrm{kg} / \text { isotope } \\
\text { (dry) }\end{array}$ & 0 & 3 \\
\hline Fish & Semiannually & Gamma Scan & $\begin{array}{l}100 \mathrm{pCi} / \mathrm{kg} / \text { isotope } \\
\text { (wet) }\end{array}$ & 1 & \\
\hline
\end{tabular}

(a) Analytical detection limit is defined here as that concentration that is three standard deviations above the average concentration in a blank sample, and assures accuracy 1 imits of $\pm 25 \%$.

(b) To be performed if gross alpha exceeds $0.1 \mathrm{pCi} / \mathrm{m}^{3}$.

(c) TLD: thermoluminescent dosimeter.

(d) To be performed if gross alpha exceeds $10 \mathrm{pCi} / \mathrm{l}$. 
result in conservatively estimated whole body and individual organ doses in the range of 1 to $50 \mathrm{mrem} /$ year from specific nuclides. These nuclides are identified upon completion of the operational monitoring program. They are then defined in terms of concentrations in environmental media at levels which, if sustained, would result in doses in excess of acceptable limits. The derivation of these levels corresponds with the site-specific method of assessing offsite doses from radioactive materials in estimated gaseous and liquid effluents (if any), and is assumed to be consistent with the recommendations of the Federal Radiation Councif ${ }^{(9)}$ and the International Commission on Radiological Protecion. (10) The environmental radiological monitoring program is designed to integrate fully with any ongoing programs of the state where the reference $\mathrm{UF}_{6}$ conversion plant is located. Quality assurance is achieved, in part, by the site-specific state QA program and by participation in the EPA analytical quality assurance program. Sample collections and radiation measurements required to meet the schedule suggested in Table F.5-1 are assumed to be conducted at locations and in amounts previously established during the operational lifetime of the reference plant. The program and any changes thereto are reportable items to the NRC and to other appropriate regulatory agencies, as environmental technical specifications, in accordance with the terms of the amended license. Quality control mechanisms are exercised for all procedures involved.

Environmental monitoring during the period of decommissioning activities is carried out by the Health Physics group of the decommissioning organization as a part of their normal duties.

\section{F.5.2 Environmental Surveillance Program for the Safe Storage Period of Passive SAFSTOR}

An abbreviated version of the environmental monitoring program conducted during decommissioning is carried out during the safe storage period. During this time there is no intent to provide a surveillance program adequate for all potential nonroutine or accidental releases, although the proposed program will be useful in evaluating most lapses of control. For the emergency situation involving releases from events such as fire or malicious acts that may 
require prompt emergency actions to minimize public risk, special surveillance requirements apply. The purpose of the program is to identify and quantify any releases of radioactivity to the environment.

Quality control mechanisms are exercised for all procedures involved. The surveillance system operation is assumed to be checked at least quarterly. Instrument calibrations are run at least quarterly and following maintenance. Remedial measures are taken as needed. Sampling quality control may necessitate temporary reinstatement of some aspects of the facility's former procedures, e.g., multiple sampling, sample splitting, and varying sampling locations. Similar analytical quality assurance procedures, such as treating audit samples of known concentrations, could be expected to be instituted.

Changes in background levels, in environmental accumulations (e.g., fallout from nuclear weapons testing), and especially in land usage and population distribution may, over a period of years, justify modifications in the postoperation surveillance program. Experience will indicate, and the licensee should be alert for, relationships between local environmental results that would reasonably permit reduction of the program.

The entire program should be reviewed on a periodic basis to assess its adequacy and to determine whether changes and/or reductions should be made. 


\section{REFERENCES}

1. "Welding, Cutting, and Related Process," Welding Handbook, 6 th Edition, Section Three, Part A, American Welding Society, 1970.

2. G. A. Beite1, and Max P. Schlienger, Arc Saw Testing, ARH-LD-147, Atlantic Richfield Hanford Company, Richland, WA, and Schlienger, Inc., San Rafael, CA, July 1976.

3. R. P. Allen, H. W. Arrowsmith, L. A. Charlot and J. L. Hooper, Electropolishing as a Decontamination Process: Progress and Application, PNL-SA-6858, Pacific Northwest Laboratory, Richland, WA, April 1978.

4. F. B. Conlon and G. L. Pettigrew, Summary of Federal Regulations for Packaging and Transportation of Radioactive Materials, (BRH/DMRE-71-1), U.S. Department of Health, Education and Welfare, Public Health Service, Bureau of Radiological Health, Rockville, MD, February 1971.

5. Radioactive Materials Transportation Manual, Nuclear Transport Division, Tri-State Motor Transit Co., Joplin, M0, 1974.

6. International Commission on Radiological Protection, Principles of Environmental Monitoring Related to the Handling of Radioactive Materials, ICRP Pub. 7, Pergamon Press, Oxford, 1966.

7. Federal Water Quality Administration, Guidelines for State Water Quality Legislation.

8. Title 40, Code of Federal Regulations, Part 50, Government Printing 0ffice, Washington, DC, issued annually.

9. Federal Radiation Council, Background Material for Development of Protection Standards, Report No. 2, 1961.

10. International Commission on Radiological Protection, Report of Committee II on Permissible Dose for Internal Radiation, Publication No. 2, 1959. 



\section{APPENDIX G}

\section{DECOMMISSIONING ACTIVITY DETAILS}

The details presented in this appendix are specifically for decommissioning the uranium hexafluoride conversion $\left(U_{6}\right)$ plant by the DECON alternative or by the passive SAFSTOR alternative. Section G.l contains information common to both decomissioning alternatives in regard to final processing inventory cleanout. Section G.2 contains information specific to the DECON alternative, and Section G.3 contains details necessary to complete passive SAFSTOR. Section G.4 summarizes details of lagoon waste onsite disposal, and Section G.5 gives details of lagoon waste stabilization. The details presented here amplify the information presented in Section 9 and provide the basic information needed to assess the safety and costs of decommissioning the reference UF $_{6}$ conversion plant.

\section{G.1 FINAL PROCESSING INVENTORY CLEANOUT}

After termination of production operations, an extensive process inventory cleanout is conducted. Final cleanout operations are similar to those operations conducted periodically to audit the uranium inventory. These cleanout operations are charged to operations and not to decommissioning. In general, the following activities are conducted during final inventory cleanout:

- A11 unneeded process chemicals are removed.

- All uranium products $\left(U_{6}\right.$ and $\mathrm{U}_{3} \mathrm{O}_{8}$ powder; scrap liquids and solids; contaminated liquid and solid wastes) in the building are removed and shipped offsite to appropriate dispositions.

- Vacuuming and conventional handwiping and brushing of contaminated surfaces are performed.

- All scrap materials stored on outside pads and in other buildings are shipped to appropriate disposition sites.

- The sludge in $U_{6}$ and HF scrubbers is cleaned out.

- The wet processing equipment is flushed with water and appropriate cleaners (minimum of three flushes). 
- The extraction fluoride waste systems are flushed twice with tributyl phosphate (TBP) and rinse water.

- A comprehensive radiation survey is performed to determine residual uranium inventory and to locate and identify localized contamination (hot spots that may require special handling or decontamination techniques).

All contaminated noncombustible solids generated during these cleanout operations are processed through the decontamination facility to recover their uranium content. The resulting contaminated liquid waste is processed through the radwaste recovery system before decommissioning operations begin. Combustible solid wastes are packaged in plastic and burned in an incinerator facility to recover uranium. The recovered uranium is shipped offsite for reuse. After removal of the in-process powder, scrap, and rework uranium materials, it is estimated (see Section 3) that cleanout operations recover approximately onehalf of the uranium remaining in the building.

\section{G.2 DECON ACTIVITIES}

Figure G.2-1 shows the sequence and schedule for the DECON activities. The order of decommissioning for plant areas is shown in Figure A.2-2 in Appendix A.

Upon completion of final processing inventory cleanout, DECON activities commence. These are outlined as follows:

1. The areas close to uranium receiving areas are decontaminated first to provide staging areas for the storage, packaging, and shipment of equipment and materials from the plant.

2. To improve accessibility, the remaining plant-controlled areas are decontaminated, generally in the order of decreasing amount of contamination and increasing distance from the staging area.

3. The decontamination, radwaste, and incinerator facility are decontaminated near the end of the campaign, so they can be used to support the decommissioning operations.

4. The temporary laundry room and change rooms are the final rooms to be decontaminated. 
TIME, weeks

SEQUENCE OF DECONTAMINATION

AREA

0

510

15

20

25

30

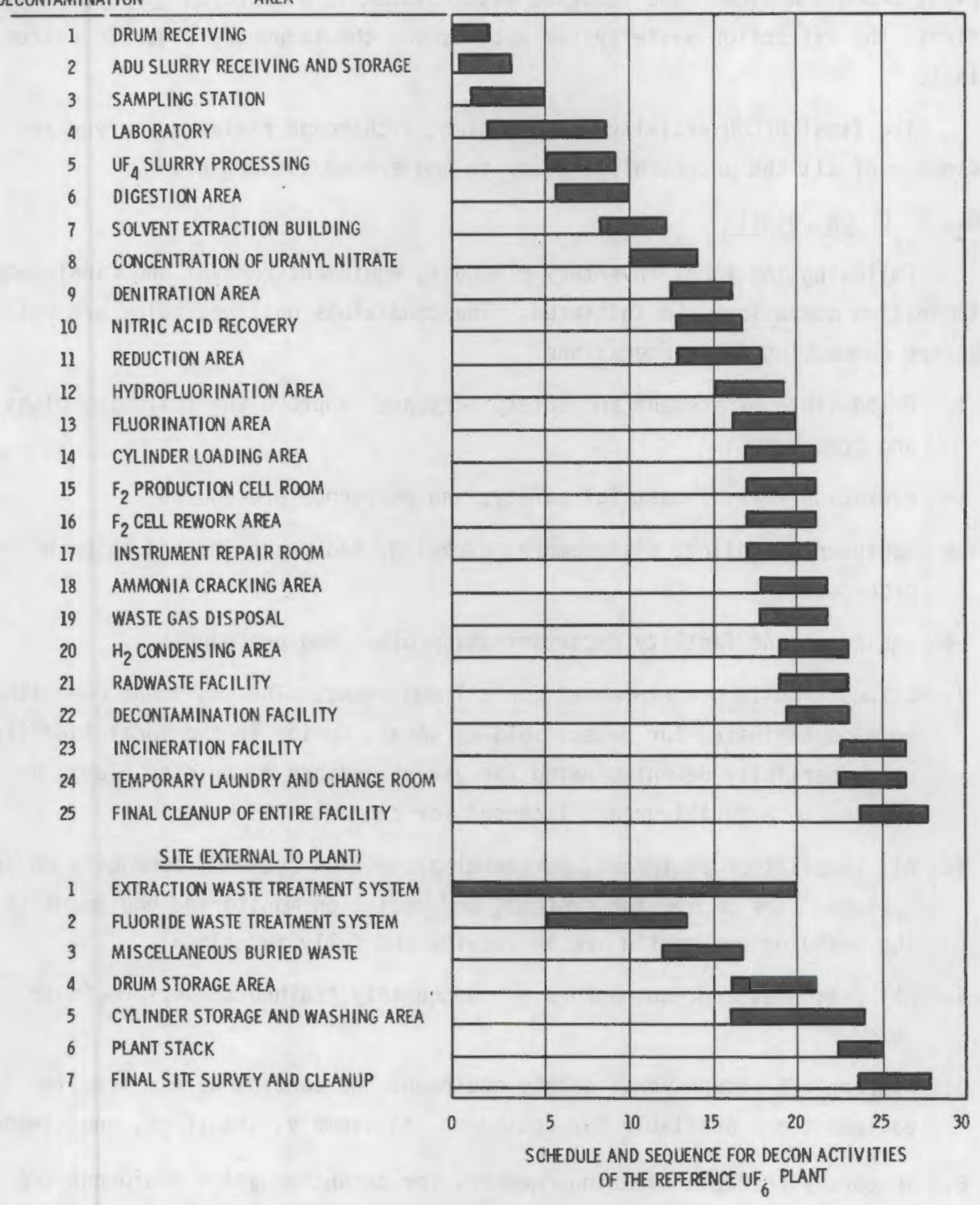

FIGURE G.2-1. Schedule and Sequence for DECON Activities of the Reference $\mathrm{UF}_{6}$ Conversion Plant 
Concurrent with steps 1 through 4 above, the field facilities outside the plant are dismantled. The fluoride waste system is dismantled and decontaminated first, the extraction waste systein second, and the temporary radwaste system last.

The final DECON activity is to conduct a thorough radiation survey and cleanup of all the uncontrolled areas in and around the $\mathrm{UF}_{6}$ plant.

\section{G.2.1 DECON Details}

Following the final inventory cleanout, equipment removal and final decontamination operations are initiated. The conditions outlined below are met before commencing these operations.

1. Responsible management and safety personnel approve the following plans and procedures:

- radiation work, industrial safety, and emergency procedures

- equipment handling, disassembly, cleaning, and packaging and shipping procedures

- equipment and facility decontamination plans and procedures.

2. Disposition is predetermined for all equipment. The equipment can either be decontaminated for reuse, sold as scrap, buried in the local landfill dump, partially decontaminated for use at another restricted plant, or shipped to a burial ground licensed for contaminated materials.

3. All ventilation equipment, personnel protection systems, emergency power systems, fire protection systems, and radiation monitoring equipment in the building and onsite are in service and fully functional.

4. All personnel and contractors are adequately trained to perform their jobs.

5. Appropriate occupational safety equipment and continuous air sampling equipment are available for equipment disassembly, transfers, and cleanup.

6. Temporary portable cleaning chambers for decontaminating equipment are available (e.g., greenhouse with tank for water and steam rinsing of equipment, washing tanks, degreasers, etc.). 
7. Packaging materials and shipping containers are available.

8. All equipment for dismantlement and decontamination operations is available.

9. A comprehensive radiation survey is completed, with all results mapped and used as a basis for each room's work plan.

10. The system and procedures for the functions of special nuclear material accountability measurements and measurement control are established.

11. All process material supplies (e.g., hydrogen, nitric acid, antonium hydroxide, fluoride) are disconnected from the plant and disposed of.

\section{G.2.2 DECON Operations}

This section identifies the major DECON steps for each area wherein contaminated processing equipment is disassembled and decontaminated (in its original area, using portable cleaning chambers and tanks where practicable), wrapped in plastic, removed to the staging area, and packaged for shipment to final disposition. Where practical, equipment is packaged in the original area. Some equipment requiring decontamination for unrestricted use is sent to the cylinder storage area for cleanup when in-situ cleanup is not practical.

In this study it is assumed that most equipment items are completely disassembled and decontaminated in their original location. After being released for unrestricted use, the parts are packaged and shipped to a local dump. Parts that cannot be cleaned sufficiently for release are packaged in plywood boxes and shipped to a licensed burial ground.

The pattern for final cleanup and decontamination of individual rooms and areas in the plant is dictated by doing the most contaminated areas first and improving the accessibility to staging areas. The need to use certain areas (e.g., scrap or waste handling facilities and hot maintenance) during DECON operations will delay their decomissioning.

For an individual area, accessibility to the equipment dictates the order of equipment removal. It is also desirable to remove the least contaminated equipment from the room earliest. 
Figure G.2-1 illustrates the order and schedule for which DECON operations are postufated to take place. Certain operations are common for each area or room to be decontaminated. Equipment is carefully surveyed for radioactivity, before, during, and after all operations. Strict accountability records are kept for equipment and appurtences being decontaminated and shipped. Decommissioning personnel must wear appropriate protective clothing and breathing apparatus whenever contamination levels warrant it. Because external radiation doses to workers are relatively low, all decontamination operations are hands-on operations. Plastic tents are constructed when appropriate to contain contamination where equipment heavily contaminated with powders is being disassembled (e.g., grinder, electrostatic precipitator, hammermi11, baghouse, etc.). Disassembly of piping, valves, pumps, ancilliary equipment, and ductwork external to equipment and hoods is conducted using strict contamination-control methods. Proper precautions and steps are taken to prevent spills or to confine contamination spills that may inadvertently occur. Health physics personnel observe and monitor operations to ensure that safe radiation and industrial practices are followed at all times.

To provide access, the equipment nearest the exit area of the room is generally removed first. Where possible, equipment external to the process equipment and hoods is removed first, followed by all external pipes, conduits, controls, etc., attached to the process equipment. The equipment is disconnected from exhaust ductwork and the open duct end is sealed or fitted with a filter to prevent spread of contamination.

The process equipment is disassembled and decontaminated in-situ as much as practicable to meet final disposition requirements. Portable greenhouses and tanks can be used to contain detergent washing and steam or water rinsing operations. Ends of piping, conduit, ductwork, etc., are always sealed or plugged with caps. Equipment is sealed with plastic, packaged, and removed to one of the staging areas for storage and shipment. Equipment that cannot be packaged in the original room is packaged in the staging areas.

Next, all remaining piping, electrical conduit, local filter systems, ductwork, etc., are dismantled and prepared for final disposition (most items 
will be fully decontaminated and compacted in the original room). Ventilation exhausts and hood exhausts are plugged or fitted with filters to preclude contamination spread from back pressures. Light fixtures that cannot be sufficiently decontaminated are replaced with new units. The final step is to carefully survey for radiation and decontaminate the ceiling, walls, and floor with detergent cleanser, powered brushes, and handwipes. Floor tiles or strippable seal coat are removed. Where hot spots occur, the concrete floor is chipped and vacuumed to ensure complete decontamination. The recirculating room air ducts and fans are decontaminated and the filters are removed for incineration. A final survey is conducted prior to releasing the area for unrestricted use.

Details of decontaminating the individual work areas in their proper order are provided in the following subsections. Figures A.2-1 and A.2-2 in Appendix A provide plant layouts showing the area locations and decontamination sequences.

\section{G.2.2.1 Drum Receiving - Area ]}

The drum receiving area is used to store $0.21-\mathrm{m}^{3}$ drums containing yel lowcake. The only equipment to be cleaned and decontaminated are the storage pallets, the stacking equipment, and the fork-1ift truck. The pallets are checked and sent to the incinerator if contaminated. The equipment is decontaminated and transferred for use at another facility.

\section{G.2.2.2 ADU Slurry Receiving and Storage Area - Area 2}

The first building area decontaminated is the ADU slurry receiving and storage area. Contamination is light in this area, which contains facilities and equipment for dissolving the ADU slurry with nitric acid. The sequence in which the equipment is dismantled, packaged, and removed is listed in Table G.2-1.

\section{G.2.2.3 Sampling Station - Area 3}

Sampling of dry concentrate is done by a dry-splitter sampling system. Drums are emptied through a falling-stream sampling unit. The general sequence in which the equipment is dismantled, packaged, and removed is listed in Table G.2-2. 
TABLE G.2-1. General Sequence of Equipment Removal from the ADU S1urry Receiving and Storage Area

\begin{tabular}{|c|c|c|c|}
\hline $\begin{array}{l}\text { Sequence of } \\
\text { Remova I }\end{array}$ & Equipment Removal & $\begin{array}{c}\text { Final (a) } \\
\text { Disposition }\end{array}$ & Notes \\
\hline 1 & 2 ADR Storage Tanks & FDS & Decontaminate and Scrap \\
\hline 2 & $\begin{array}{l}1 \text { Receiving and weigh } \\
\text { Tank }\end{array}$ & FDS & Decontaminate and Scrap \\
\hline 3 & 2 Receiving Pumps & PDB & Disassemble and Package \\
\hline 4 & 2 Transfer Pumps & PDB & Disassemble and Package \\
\hline 5 & Miscellaneous Equipment & PDB & Disassemble and Package \\
\hline
\end{tabular}

(a) PDB - Partially Decontaminated, Licensed Burial. FDS - Fully Decontaminated, Unrestricted Scrap.

TABLE G.2-2. General Sequence of Equipment Removal from the Sampling Station

\begin{tabular}{|c|c|c|c|}
\hline $\begin{array}{l}\text { Sequence of } \\
\text { Removal } \\
\end{array}$ & Equipment Removed & $\begin{array}{c}\text { Final } \\
\text { Disposition }\end{array}$ & Notes \\
\hline 1 & 2 Drum Elevators & PDB & Disassemble and Package \\
\hline 2 & $\begin{array}{l}2 \text { Yellowcake Receiving } \\
\text { Bins }\end{array}$ & FDS & Decontaminate and Scrap \\
\hline 3 & 2 Primary Samplers & PDB & Disassemble and Package \\
\hline 4 & I Secondary Sampler & PDB & Disassemble and Package \\
\hline 5 & $\begin{array}{l}2 \text { Yel lowcake Transfer } \\
\text { Screws }\end{array}$ & $\mathrm{PDB}$ & Disassemble and Package \\
\hline 6 & 2 Bucket Elevators & PDB & Disassemble and Package \\
\hline 7 & 2 Digestor Feed Bins & FDS & Decontaminate and Scrap \\
\hline 8 & Hood and Ductwork & $70 \% \mathrm{FDB}$ & $\begin{array}{l}\text { Disassemble and Decon- } \\
\text { taminate }\end{array}$ \\
\hline 9 & Stack and Forklift & FDS & $\begin{array}{l}\text { Decontaminate and } \\
\text { Transfer }\end{array}$ \\
\hline 10 & Storage Racks & FDS & Decontaminate and Scrap \\
\hline
\end{tabular}

(a) PDB - Partially Decontaminated, Licensed Burial. FDS - Fully Decontaminated, Unrestricted Scrap.

\% FDB - Percent Fully Decontaminated to Unrestricted Burial; Remainder to Licensed Burial Packaged in Plywood Boxes. 


\section{G.2.2.4 Laboratory - Area 4}

The laboratory is located in the main plant building, as shown in Figure A.2-1. Most of the laboratory is used for testing and analysis of material that could cause contamination. The laboratory contains typical lab equipment, chemical hoods, isotopic instrumentation, physical testing, radiography scales, and other miscellaneous lab equipment. All of the equipment is decontaminated and excessed for unrestricted use. The general sequence of equipment removal is given in Table G.2-3.

TABLE G.2-3. General Sequence of Equipment Removal from the Laboratory

Sequence of Removal
13 Laboratory Hoods

$2 \quad$ Miscellaneous Equipment

3

Miscellaneous Work Benches, Tables, and Cabinets Disposition (a)

FDS

FDS

FDS
Notes

Decontaminate and Release Decontaminate and Release

Decontaminate and Release

(a) PDB - Partially Decontaminated, Licensed Burial.

FDS - Fulty Decontaminated, Unrestricted Scrap.

\section{G.2.2.5 $\mathrm{UF}_{4}$ Slurry Processing - Area 5}

$\mathrm{UF}_{4}$ slurry contained in drums is sampled and prepared for feed to the solvent extraction operation. The general sequence of dismantlement for this area is shown in Table G.2-4.

\section{G.2.2.6 Ore Concentrate Dissolution - Area 6}

Yellowcake and nitric acid are fed to digestors on a batch basis in this area. The general sequence of equipment removal for the ore concentrate dissolution area is shown in Table G.2-5.

\section{G.2.2.7 Solvent Extraction Building - Area 7}

This building contains equipment to recover uranium from the digestor product. The general sequence of equipment removal is shown in Table G.2-6. 
TABLE G.2-4. General Sequence of Equipment Removal from the $U_{4}$ Slurry Processing Area

Sequence of Removal

1

1

2

3

4

5

rat

-

Equipment Removal

\begin{abstract}
Process Feed Hopper
\end{abstract}
Mechanical Drum Pumper

2 Digestion Tanks

2 Scrubbers

2 Pumps Fisposition (a)

PDB

PDB

FDS

PDB

PDB
Notes.

Disassemble and Package

Disassemble and Package

Decontaminate and Scrap

Disassemble and Package

Disassemble and Package

(a) PDB - Partially Decontaminated, Licensed Burial.

FDS - Fully Decontaminated, Unrestricted Scrap.

TABLE G.2-5. General Sequence of Equipment Removal from the Ore Concentrate Dissolution Area

\begin{tabular}{|c|c|c|c|}
\hline $\begin{array}{l}\text { Sequence of } \\
\text { Removal }\end{array}$ & Equipment Removal & $\begin{array}{c}\text { Final } \\
\text { Disposition }\end{array}$ & Notes \\
\hline 1 & 3 Digestion Tanks & FDS & Decontaminate and Scrap \\
\hline 2 & 2 Adjustment Tanks & FDS & Decontaminate and Scrap \\
\hline 3 & Piping & FDS & Decontaminate and Scrap \\
\hline
\end{tabular}

(a) PDB - Partially Decontaminated, Licensed Burial. FDS - Fully Decontaminated, Unrestricted Scrap.

TABLE G.2-6. General Sequence of Equipment Removal from the Solvent Extraction Building

\begin{tabular}{|c|c|c|c|}
\hline $\begin{array}{l}\text { Sequence of } \\
\text { Removal }\end{array}$ & Equipment Remova] & $\begin{array}{c}\text { Final } \\
\text { Disposition }\end{array}$ & Notes \\
\hline 1 & 6 Pumper Decanters & PDB & Disassemble and Package \\
\hline 2 & 2 Scrub Decanters & PDB & Disassemble and Package \\
\hline 3 & $\begin{array}{l}2 \text { Re-extraction Pulse } \\
\text { Columns }\end{array}$ & PDB & Disassemble and Package \\
\hline 4 & $\begin{array}{l}3 \text { Extraction Waste Holding } \\
\text { Tanks }\end{array}$ & FDS & Decontaminate and Scrap \\
\hline
\end{tabular}

(a) PDB - Partially Decontaminated, Licensed Burial. FDS - Fully Decontaminated, Unrestricted Scrap. 


\section{G.2.2.8 Urany] Nitrate Concentration - Area 8}

Concentration of uranyl nitrate is accomplished by the utilization of a primary and secondary evaporation system. The general sequence in which equipment is removed from the area is shown in Table G.2-7.

TABLE_G.2-7. General Sequence of Equipment Removal from the Uranyl Nitrate Concentration Area

Sequence of Removal
1

2

3

4

5

6

(1)

\section{Evaporator}

3 Boildown Tanks

3 Unit Filters

Miscellaneous Equipment

Hood and Ductwork

Piping Fisposition (a)

PDB

FDS

PDB

PDB

$50 \% \mathrm{FDB}$

FDS
Notes

Disassemble and Package Decontaminate and Scrap Disassemble and Package Disassemble and Package Decontaminate and Scrap Decontaminate and Scrap

(a) PDB - Partially Decontaminated, Licensed Burial.

FDS - Fully Decontaminated, Unrestricted Scrap.

\% FDB - Percent Futiy Decontaminated to Unrestricted Burial; Remainder to Licensed Burial Packaged in Plywood Boxes.

\section{G.2.2.9 Denitration Area - Area 9}

Uranyl nitrate is converted to $\mathrm{UO}_{3}$ by heating in agitated trough denitrators. The general sequence in which denitrator equipment is removed for DECON is shown in Table G.2-8.

\section{G.2.2.10 Nitric Acid Recovery - Area 10}

A conventional absorption system is utilized for recovering nitrogen oxides from ore concentrate and fluorination ash dissolution and denitration of UNH to $\mathrm{UO}_{3}$. The general sequence of equipment removal is shown in Table G.2-9.

\section{G.2.2.11 Reduction Systems - Area 11}

Uranium trioxide is converted to $\mathrm{UO}_{2}$ using dissociated ammonia. The general sequence of equipment removal is shown in Table G.2-10. 
TABLE G.2-8. General Sequence of Equipment Removal from the Denitration Area Sequence of Removal

\begin{tabular}{|c|c|c|}
\hline Equipment Removed & $\begin{array}{c}\text { Fina } 1 \\
\text { Disposition (a) } \\
\end{array}$ & Notes \\
\hline 4 Denitrators & PDB & Disassemble and Package \\
\hline $\begin{array}{l}4 \text { Denitrator Scrubber } \\
\text { Coolers }\end{array}$ & PDB & Disassemble and Package \\
\hline 4 Cooling Screws & PDB & Disassemble and Package \\
\hline $2 \mathrm{UO}_{3}$ Vertical Elevators & PDB & Disassemble and Package \\
\hline 2 Hammer Mills & PDB & Disassemble and Package \\
\hline 2 Surge Bins & FDS & Decontaminate and Scrap \\
\hline Hoods - and Ductwork & FDS & Decontaminate and Scrap \\
\hline Miscellaneous Equipment & PDB & Disassemble and Package \\
\hline
\end{tabular}

(a) PDB - Partially Decontaminated, Licensed Burial. FDS - Fully Decontaminated, Unrestricted Scrap.

TABLE G.2-9. General Sequence of Equipment Removal from the Nitric Acid Recovery Area

\begin{tabular}{|c|c|c|c|}
\hline $\begin{array}{l}\text { Sequence of } \\
\text { Removal }\end{array}$ & Equipment Removal & $\begin{array}{c}\text { Final }(a) \\
\text { Disposition }\end{array}$ & Notes \\
\hline 1 & 2 Tanks & FDS & Decontaminate and Scrap \\
\hline 2 & 2 Scrubbers & PDB & Disassemble and Package \\
\hline 3 & 2 Nitric Acid Absorbers & PDB & Disassemble and Package \\
\hline 4 & 2 Pumps & $\mathrm{PDB}$ & Disassemble and Package \\
\hline 5 & Miscellaneous Equipment & PDB & Disassemble and Package \\
\hline 6 & Piping & FDS & Decontaminate and Scrap \\
\hline
\end{tabular}

(a) PDB - Partially Decontaminated, Licensed Burial. FDS - Fulty Decontaminated, Unrestricted Scrap. 
TABLE G.2-10. General Sequence of Equipment Removal from the Reduction System Area

\begin{tabular}{|c|c|c|c|}
\hline $\begin{array}{l}\text { Sequence of } \\
\text { Removal }\end{array}$ & Equipment Removal & $\begin{array}{c}\text { Final } \\
\text { oisposition }\end{array}$ & Notes \\
\hline 1 & $2 \mathrm{UO}_{3}$ Storage Bins & FDS & Decontaminate and Scrap \\
\hline 2 & 2 Screw Feeders & PDB & Disassemble and Package \\
\hline 3 & $\begin{array}{l}4 \text { Fluid Bed Reduction } \\
\text { Reactors }\end{array}$ & PDB & Disassemble and Package \\
\hline 4 & 2 Ammonia Disassociators & PDB & Disassemble and Package \\
\hline 5 & Miscellaneous Equipment & POB & Disassemble and Package \\
\hline 6 & Hood and Ductwork & FOS & Decontaminate and Scrap \\
\hline
\end{tabular}

(a) PDB - Partially Decontaminated, Licensed Burial. FDS - Fully Decontaminated, Unrestricted Scrap.

\section{G.2.2.12 Hydrofluorination - Area 12}

Uranium dioxide is converted to uranium tetrafluoride by reaction with anhydrous $H F$ at high temperature. The general sequence of equipment removal is shown in Table G.2-11.

IABLE G.2-11. General Sequence of Equipment Removal from the Hydrofluorination Area

\begin{tabular}{|c|c|c|c|}
\hline $\begin{array}{l}\text { Sequence of } \\
\text { Removal }\end{array}$ & Equipment Removed & $\begin{array}{c}\text { Final } \\
\text { Disposition (a) }\end{array}$ & Notes \\
\hline 1 & 2 Screw Feeders & PDB & Decontaminate and Package \\
\hline 2 & $2 \mathrm{UO}_{2}$ Fitter Bins & fas & Decontaminate and Scrap \\
\hline 3 & $\begin{array}{l}2 \text { ist-Stage Fluid } \\
\text { Bed Hydrofluorinators }\end{array}$ & $75 \% \mathrm{FDB}$ & $\begin{array}{l}\text { Oisassemble and Decon- } \\
\text { taminate }\end{array}$ \\
\hline 4 & $\begin{array}{l}2 \text { 2nd-Stage Fluid Bed Hydro- } \\
\text { Hydrofluorinators }\end{array}$ & $70 \%$ FDB & $\begin{array}{l}\text { Disassemble and Decon- } \\
\text { taminate }\end{array}$ \\
\hline 5 & $2 \mathrm{UF}_{4}$ Seal Hoppers & POB & Decontaminate and Package \\
\hline 6 & 2 Interstage Hoppers & POB & Decontaminate and Package \\
\hline 7 & $2 \mathrm{UF}_{4}$ Purge Conveyors & PDB & Decontaminate and Package \\
\hline 8 & 2 Conveyors & POB & Decontaminate and Package \\
\hline 9 & $2 \mathrm{UF}_{4}$ Storage Hoppers & $60 \%$ FDB & $\begin{array}{l}\text { Disassemble and Decon- } \\
\text { taminate }\end{array}$ \\
\hline 10 & 2 Conveyors & $60 \% F 08$ & $\begin{array}{l}\text { Disassemble and Decon- } \\
\text { taminate }\end{array}$ \\
\hline 11 & Piplng & FDS & Decontaminate and Scrap \\
\hline
\end{tabular}

(a) PDS - Partially Decontaminated, Licensed Burial.

FDS - Fully Decontaminated, Unrestricted Scrap.

: FDB - Percent Fully Decontaminated to Unrestricted Burial; Remainder to

Licensed Burial Packaged in Plymood Boxes. 


\section{G.2.2.13 Fluorination - Area 13}

$\mathrm{UF}_{4}$ is converted to $\mathrm{UF}_{6}$ by reaction with elemental fluorine. The general sequence of equipment removal is shown in Table G. 2-12.

TABLE G.2-12. General Sequence of Equipment Removal from the Fiuorination Area

Sequence of Removal

1

2

32 Primary Filters

46 Primary Cold Traps

52 Product Cylinders.

62 Backup Filters

72 Feed Hoppers

8

9

10

11

12

13
2 Cleanup Reactors

2 Backup Conveyors

2 Backup Filters

2 Secondary Cold Traps Hood and Ductwork piping
Final Disposition (a)

$60 \%$ PDB

Disassemble and Decontaminate

PDB Decontaminate and Package

PDB Decontaminate and Package

PDB Decontaminate and Package

PDB Decontaminate and Package

PDB Decontaminate and Package

PDB Decontaminate and Package

PDB Disassemble and Decontaminate

70\% F[JB Disassemble and Decontaminate

60\% F[B Disassemble and Decontaminate

PDB Decontaminate and Package

FDS Disassemble and Scrap

FDS Disassembie and Scrap

(a) PDB - Partially Decontaminated, Licensed Burial. FDS - Fully Decontaminated, Unrestricted Scrap.

\% FDB-Percent fully Decoritaminated to Unrestricted Burial; Remainder to Licensed Burial Packaged in Plywood Boxes.

\section{G.2.2.14 Cylinder Loading - Area 14}

Loading of cylinders used for transport of $U_{6}$ is completed in this area. The equipment needed for cylinder loading is dismantled, packaged, and sent to licensed burial. Miscellaneous tools, test equipment, etc, are decontaminated and excessed for unrestricted use. 


\section{G.2.2.15 Fluorine Generation - Area 15}

The general sequence of equipment removal in the fluorine area is shown in Table G.2-13.

TABLE G.2-13. General Sequence of Equipment Removal from the Fluorine Generation Area

\begin{tabular}{|c|c|c|c|}
\hline $\begin{array}{l}\text { Sequence of } \\
\text { Removal } \\
\end{array}$ & Equipment Removed & $\begin{array}{c}\text { Final } \\
\text { Disposition }\end{array}$ & Notes \\
\hline 1 & 2 Waste Gas Burners & $60 \%$ FDB & $\begin{array}{l}\text { Disassemble and Decon- } \\
\text { taminate }\end{array}$ \\
\hline 2 & 120 Fluorine Cells & PDB & Package in Plywood Boxes \\
\hline 3 & 2 Surge Tanks & $6 \mathrm{D} \% \mathrm{FDB}$ & $\begin{array}{l}\text { Disassemble and Decon- } \\
\text { taminate }\end{array}$ \\
\hline 4 & 4 Fluorine Filters & PDB & Package \\
\hline 5 & 2 HF Condensers & $70 \% \mathrm{FDB}$ & $\begin{array}{l}\text { Disassemble and } \\
\text { Decontaminate }\end{array}$ \\
\hline 6 & 2 HF Backup Filters & FDS & Disassemble and Scrap \\
\hline 7 & 2 Hydrogen Surge Tanks & FDS & Disassemble and Scrap \\
\hline 8 & $\begin{array}{l}2 \text { Fiuorine Filters for } \\
\text { Backup System }\end{array}$ & FDS & Disassemble and Scrap \\
\hline 9 & 2 HF Storage Tanks & FDS & Disassemble and Scrap \\
\hline 10 & Miscellaneous Equipment & PDB & Package \\
\hline 11 & Instrument Controls & PDB & Package \\
\hline 12 & Piping & FDS & Disassemble and Scrap \\
\hline
\end{tabular}

(a) PDB - Partially Decontaminated, Licensed Burial.

FDS - Fully Decontaminated, Unrestricted Scrap.

\% FOB - Percent Fully Decontaminated to Unrestricted Burial; Remainder to Licensed Burial Packaged in Plywood Boxes.

\section{G. 2.2.16 $\mathrm{F}_{2}$ Cell] Rework - Area 16}

This area has a low level of contamination. A thorough radiation survey is made and any spots of contamination found are cleaned. Equipment is excessed for unrestricted use. 


\section{G.2.2.17 Instrument Repair Shop - Area 17}

In this shop, which is maintained very clean, electrical and electronic maintenance work is performed on restricted-area instrumentation equipment and components. The shop contains equipment such as scopes, testers, brazing and soldering, spare components, cleaning, and standards. All of this equipment is fully decontaminated and excessed for unrestricted use.

\section{G.2.2.18 Ammonia Cracking - Area 18}

This area has very slight contamination. Three ammonia dissociators provide hydrogen gas which is delivered to the reduction reactors. The equipment is disassembled, fully decontaminated, and excessed for unrestricted use.

\section{G.2.2.19 Waste Gas Disposal - Area 19}

Waste gases from the hydrofluorinator backup =ilter and the HF condenser are combined with off gases from the waste gas burner servicing the fluorine plant and the fluorinator system off gases. The gases are then scrubbed with water before being vented. This equipment is disassembied, partially decontaminated, and sent to burial or scrap.

\section{G.2.2.20 Hydrogen Fluoride Condensing - Area 20}

The hydrogen fluoride condensing system recovers HF from the fluorine production gas streams. Three ammonia disassociators are installed outdoors to provide hydrogen gas. The equipment is dismantled, decontaminated, and packaged for disposal.

\section{G.2.2.21 Temporary Radwaste Facility = Area 21]}

This temporary facility is used to process contaminated liquid waste from decommissioning the plant. Liquids are collected in collection tanks and pumped through a centrifuge where suspended uranium compolinds and other solids are removed. The clarified water enters a quarantine tank where it is sampled. If the liquid meets internal action guides, it is pumped on to the process liquid waste disposal system. If not, it is returned to the system for rework. Solids removed from the centrifuge are sealed in containers while they are still wet. 
The equipment is dismantled and decontaminated sufficiently for shipment offsite to an LLW burial ground.

\section{G.2.2.22 Temporary Decontamination Facility - Area 22}

This facility is used to sort solid wastes into combustible and noncombustible categories. Combustible waste is packaged in plastic and sent to the incinerator facility. Noncombustible waste, equipment, etc., is either decontaminated or packaged for disposal at a licensed burial ground.

The decontamination room contains sorting tables, radiation survey equipment, U-material scanners, cleaning sinks, decontamination spray booths, and compacting and packaging equipment, some of which are fully decontaminated and sold as unrestricted excess equipment. The only exception is uranium survey and scanning equipment, which is sold for restricted use elsewhere.

\section{G.2.2.23 Incinerator Facility - Area 23}

This facility is left until the last decontamination phase of the plant, because it is used to burn combustible cleanup and decontamination items generated during dismantlement activities. Uranium is recovered from the ashes and HEPA filters.

The incinerator facility contains an input uranium scanner, a shredder, a blow tube unit, a vortex incinerator chamber, an offgas scrubber and filters, an ash recovery system, an output uranium scanner, and packaging equipment to prepare ashes and filters for offsite reprocessing to recover uranium.

The scanners and packaging equipment are decontaminated and excessed for further use. The remaining equipment is partially decontaminated, packaged, and shipped to a licensed burial ground.

\section{G.2.2.24 Laundry and Change Rooms - Area 24}

The laundry room has sorting and folding tables, washers, and dryers. The tables are decontaminated and excessed. The washers and dryers and HEPA filters are packaged and shipped to a licensed burial ground.

The last portion of the building to be dismantled and decontaminated contains the change rooms. These areas contain very little, if any, contamination. 
The survey equipment is decontaminated and shipped to another restricted-use facility for reuse. The remaining equipment (toilets, showers, benches, lockers, cabinets, etc.) are fully decontaminated. These rooms are decontaninated using standard procedures and are released for unrestricted use to support new activities within the plant.

\section{G.2.2.25 Final Cleaning of the Entire Facility}

The original unrestricted building areas (offices, computer rooms, shipping, halls, etc.) are given a comprehensive fina? survey and thorough cleanup to ensure that no spots of contamination exist. " the entire building is released for unrestricted use upon completion of this campaign. The timing should be such that decontamination of the full site around the building (Section G.2.3 items included) is also completed for unrestricted use.

\section{G.2.3 Site Decontamination Operations (Excludes Main Building and Solvent Extraction Building)}

This section describes the decontamination activities employed to prepare the entire site for unrestricted use. These activities are performed in parallel with the main building decontamination activities.

The general order of site decontamination is:

1. extraction waste treatment system

2. fluoride waste effluent treatment system

3. miscellaneous buried waste

4. drum storage area

5. cylinder storage and washing area

6. plant stack

7. overall final site survey and cleanup.

\section{G.2.3.1 Extraction Waste Treatment System}

The waste stream from the extraction system is primarily a solution of ammonium nitrate, nitric acid, metallic salts, minute quantities of uranium, and the radioactive daughter products of normal uranium decay. This stream is combined with spent sodium hydroxide from the solvent treatment and 
miscellaneous digester scrubber systems, along with any recovered weak acids. This liquid is neutralized by ammonia and impounded in storage lagoons. Neutralization of the extraction waste removes residual uranium and thorium. Since the effluents come from plant operation, decontamination work can start on this system after conversion operations are stopped. A schematic of the extraction waste system is shown in Figure G.2-2.

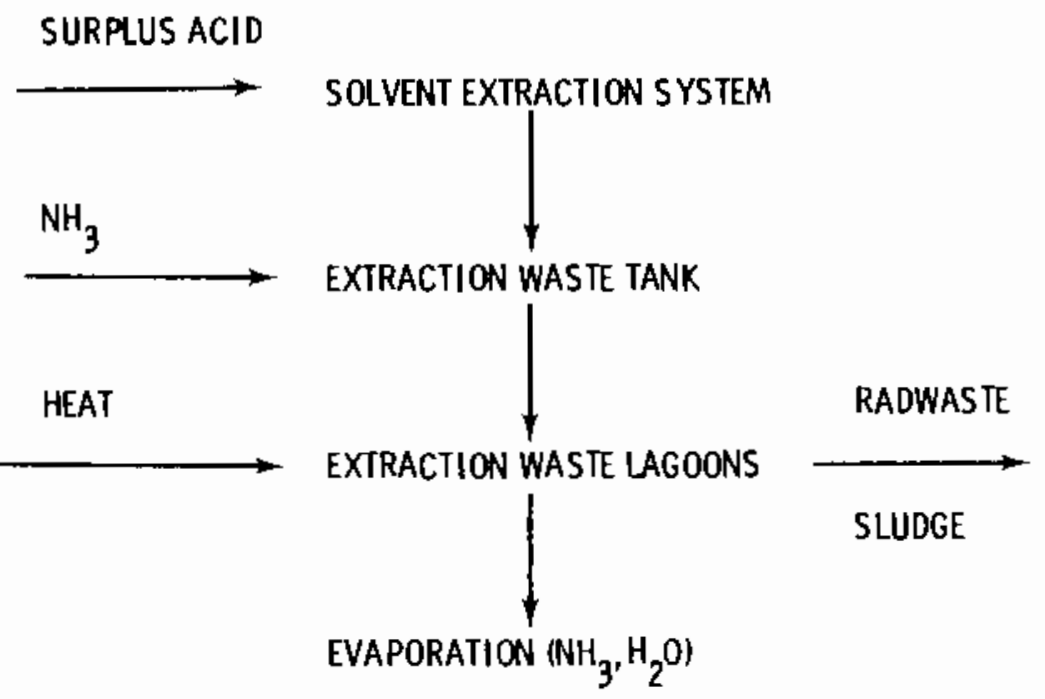

FIGURE G.2-2. Schematic of the Extraction Waste Treatment System

The pipelines and tanks are first thoroughly flushed by chemical and water rinses appropriate for the pipe and equipment construction materials. The entire system is then drained and blown out.

The pipeline is disassembled in sections, using procedures to prevent contamination from spreading. Pipe containing contamination is bagged in plastic and taken to a portable decontamination station where powered rotary brushes and detergent are used for cleanup. Heavily scaled pipes are cleaned with rotary wire brushes or sand-blasting units. Pumps, valves, etc., are packaged for disposal at a licensed burial ground.

Tanks are cleaned manually with brushes, wipes, and detergents. Small tanks that cannot be cleaned sufficiently by flushing are sectioned, decontaminated, and scrapped. 
Other pieces of equipment such as the pumps are disassembled and manually cleaned in scrub tanks or with handwipes. Such equipment is excessed or scrapped out.

The liquids in the lagoons are allowed to evaporate or are concentrated using the submerged combustion burners. After the lagoons are drained, the residual material is removed from the site for disposal. The extraction waste is loaded on $10-\mathrm{m}^{3}$ dump trucks and covered with flastic sheeting for transport to a mill for reprocessing, or to LLW burial, or to a commercial dump. Contaminated sections of liner are cut out and packaged for shipment to a licensed burial ground. Earth contaminated below the clay liners is also packaged and shipped to licensed burial. The liner is punctured in place to allow drainage, and the cavity is filled with earth. Native vegetation is planted on the restored surfaces.

The general sequence in which the system is decontaminated is listed in Table G.2-14.

TABLE G.2-14. General Sequence of Dismantling the Extraction Waste Effluent Treatment System

\begin{tabular}{|c|c|c|c|}
\hline $\begin{array}{l}\text { Sequence of } \\
\text { Removal }\end{array}$ & Equipment Removed & $\begin{array}{c}\text { Fina1 } \\
\text { Disposition }\end{array}$ & Notes \\
\hline 1 & $\begin{array}{l}\text { Pipelines Between Tanks, } \\
\text { Equipment and Lagoons }\end{array}$ & FDS & Decontaminate and Scrap \\
\hline 2 & $\begin{array}{l}\text { Pumps, Valves and } \\
\text { Controls }\end{array}$ & PDB & Package in P1ywood Boxes \\
\hline 3 & $\begin{array}{l}3 \text { Extraction Waste Stor- } \\
\text { age Tanks }\end{array}$ & FDS & $\begin{array}{l}\text { Disassemble and Decon- } \\
\text { taminate }\end{array}$ \\
\hline 4 & Ammonia Reaction Tank & FDE & Decontaminate and Excess \\
\hline 5 & 4 Lagoon Heaters & PDB & Package and Ship \\
\hline 6 & $\begin{array}{l}4 \text { Settling Lagoons (clay- } \\
\text { lined) }\end{array}$ & $\begin{array}{l}\text { Remove and } \\
\text { PDB }\end{array}$ & $\begin{array}{l}\text { Remove for Recovery; Decon- } \\
\text { taminate Liner; Cut Out } \\
\text { Porous Liner Sections and } \\
\text { Remove Along with Contani- } \\
\text { nated Earth. }\end{array}$ \\
\hline
\end{tabular}

(a) FDS - Fully Decontaminate, Unrestricted Scrap. FDE - Fully Decontaminate, Unrestricted Excess. PDB - Partially Decontaminate, Licensed Burial. 


\section{G.2.3.2 Fluoride Waste Effluent Treatment System}

The effluent is generated by the hydrofluoric acid scrubber. This fluoride waste stream is combined with waste sodium carbonate solutions originating in the fluorine cell rework area, with any acid spilled in the HF vaporizer room sump, and with laboratory wastes. The combined stream is treated with lime, which neutralizes acids and precipitates fluorides as caicium fluoride.

The alkaline sludge is permitted to settle in a retention basin to permit flocculation and sedimentation. The flow is treated with sulfuric acid to adjust the $\mathrm{pH}$ and precipitate excess calcium. It is then permitted to clarify. The clarified treated waste overflows and is combined with clean bypass water and the sewage lagoon overflow. A concrete stilling basin at the point of combination allows for mixing of the flow and controlled release through a flume so that the rate of discharge can be measured.

Other plant streams which are combined with the treated fluorine effluent before being discharged to the river include sanitary and domestic waste liquids.

The fluoride waste treatment system is shown schematically in Figure G.2-3. The effluent is generated primarily from the hydrofluorination system offgas scrubber.

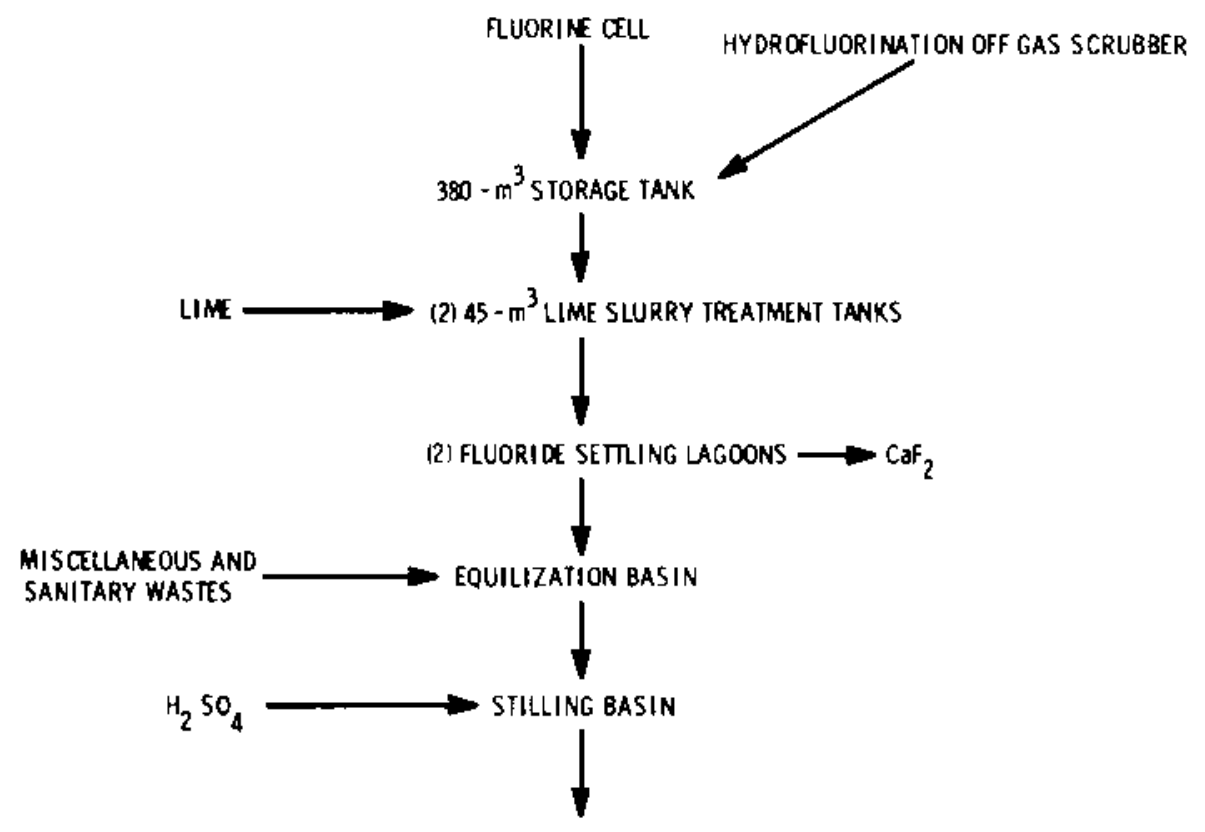

ORAINACE DITCH TO RIVER

FIGURE G.2-3. Schematic of the Fluoride Waste Treatment System 
Dismantlement of components in the fluoride waste treatment system is handled similar to dismantlement of components in the extraction waste treatment system.

Outlined in Table G.2-15 is the sequence of dismantling the fluoride waste treatment system. The cleanout of the fluoride lagoons may also be considered as an option in the earlier final inventory closeout phase of the project.

TABLE G.2-15. General Sequence of Dismantling the Fluoride Waste Effluent Treatment System

\begin{tabular}{|c|c|c|c|}
\hline $\begin{array}{c}\text { Sequence of } \\
\text { Removal } \\
\end{array}$ & Equipment Removed & $\begin{array}{c}\text { Final }(a) \\
\text { Disposition }\end{array}$ & Notes \\
\hline 1 & $\begin{array}{c}\text { Pipelines Between Tanks, } \\
\text { Equipment and Lagoons }\end{array}$ & FDS & Decontaminate and Scrap \\
\hline 2 & $\begin{array}{l}\text { Pumps, Valves and } \\
\text { Controls }\end{array}$ & PDB & Package in Plywood Boxes \\
\hline 3 & $250-m^{3}$ Storage Tank & FDE & Decontaminate and Excess \\
\hline 4 & $\begin{array}{l}245-m^{3} \text { Lime Treatment } \\
\text { Tanks }\end{array}$ & FDE & Decontaminate and Excess \\
\hline 5 & $\begin{array}{l}2 \text { Fluoride Settling Lagoons } \\
\text { (clay-lined) }\end{array}$ & SIP & Stabilize and Revegetate \\
\hline 6 & Equilization Basin & SIP & Stabilize and Revegetate \\
\hline 7 & Stilling Basin & SIP & Stabilize and Revegetate \\
\hline
\end{tabular}

(a) FDS - Fully Decontaminate, Unrestricted Scrap.

FDE - Fully Decontaminate, Unrestricted Excess.

PDB - Partially Decontaminate, Licensed Burial.

SIP - Stabilize in Place.

\section{G.2.3.3 Miscellaneous Buried Waste}

Radioactive waste materials such as scrapped equipment, gloves, respirators, and other miscellaneous contaminated solids are buried onsite in accordance with the provisions of 10 CFR 20.304. This material is removed and packaged for burial at a licensed low-level waste burial ground. 


\section{G.2.3.4 Drum Storage Area}

The drum storage pads are thoroughly surveyed. All uranium containers are removed during the inventory cleanout activities of Section G.1. Contamination is not anticipated, but some hot spots might occur. These spots are removed by scrubbing and chipping, if necessary. Any radioactive materials are packaged in steel drums and shipped to a licensed burial ground.

\section{G.2.3.5 Cylinder Storage and Washing Area}

The cylinder storage and washing area is thoroughly surveyed. All $\mathrm{UF}_{6}$ cylinders are removed during the inventory cleanout activities of Section G.1. Any contaminated spots will be removed by scrubbing and chipping. Any radioactive materials removed are packaged in steel drums and shipped to licensed burial.

\section{G.2.3.6 Plant Stack}

The plant stack will be demolished and the material surveyed. If any material is contaminated, it will be packaged and shipped to low-level waste burial.

\section{G.2.3.7 Overall Final Site Survey and Cleanup}

A thorough general radiation and chemical survey of the entire site is made to ensure that no inadvertent contamination remains. Spots with excessive contamination are decontaminated and the contaminated materials are packaged in $19-\ell$ drums for shipment to a licensed burial ground.

At the conclusion of this step and the final fuel fabrication building survey, the entire site is available for unrestriced use.

\section{G. 3 PASSIVE SAFSTOR ACTIVITIES}

After completion of final processing inventory cleanout, the remaining uranium is spread primarily throughout the processing areas in the main building and solvent extraction building, in locations relatively inaccessible without initiating dismantlement (e.g., crannies, equipment internals, between equipment buttressed to walls, exhaust ducts, etc). The total amount of 
residual uranium is estimated to be about $1200 \mathrm{~kg}$. This amount should not present a problem for the passive SAFSTOR alternative as long as access to the facility is restricted.

Outside the facility, the main concern of this decommissioning alternative is to take steps to secure the waste treatment lagoons until restartup of the plant or deferred decontamination is undertaken.

The main activities undertaken to prepare the facility for safe storage are:

- stabilization of waste treatment facilities

- deactivation of unneeded equipment

- isolation of contaminated areas.

\section{G.3.1 Stabilization of Waste Treatment Facilities}

The extraction waste and fluoride lagoons require stabilization after $\mathrm{UF}_{6}$ conversion is discontinued. The effluents settling out in the lagoons contain uranium that must be confined to the site during the safe storage period.

The extraction waste lagoons are drained and residual solids are packaged and shipped to a commercial uranium milling facility for recovery of the uranium.

The fluoride lagoons are drained and weighted plastic covers are placed over the remaining solids. A possible alternative is to remove residual materials from the lagoons and ship them to an offsite licensed burial ground.

The remainder of the waste treatment facilities are comprised of pipes, pumps, valves, tanks, etc., that provide a closed system to contain any residual uranium left after being flushed.

\section{G.3.2 Deactivation of Unneeded Equipment}

Essential systems (such as lighting, utilities, radiation detection alarms, security monitoring, fire detection and portable fire fighting equipment) remain in operation during the safe storage period. All other equipment that is unneeded during safe storage is deactivated for reasons of safety, energy conservation, and cost savings. Equipment is left in a condition that permits startup or salvage at a later date. 
Equipment deactivation steps are:

- conducting a safety audit to ensure that all flamable and other hazardous materials are removed

- closing and securing valves

- disconnecting electrical, compressed air, and other utilities

- shutting down ventilation systems in contaminated areas, and capping exhaust stacks

- sealing process hoods

- tagging a11 deactivated equipment and systems for identification and status.

\section{G.3.3 Isolation of Contaminated Areas}

Portions of the main building containing uranium contamination are isolated by the installation of security locks on entryways. Indirect access routes, however unlikely, are also secured (e.g., roof access panels and pipe trenches). Signs are posted to warn against unauthorized entry. The same steps are taken for the incinerator and waste treatment buildings. Fences around the extraction waste treatment lagoons and fluoride storage lagoons are also secured and posted with warning signs.

\section{G.3.4 Final Preparations for Safe Storage}

Final preparations for safe storage are:

- installing and/or upgrading uranium sampling, monitoring systems and radiation alarms

- installing or relocating intrusion alarms

- shipping all recovered uranium materials offsite for disposition

- performing a comprehensive radiation survey of both restricted and unrestricted areas at the site. Any spots of excessive contamination in the areas to be unrestricted are decontaminated

- training of personnel and contractors

- conducting final release survey. 
No additional steps are needed to meet the requirements of passive SAFSTOR. All radioactivity is confined onsite. Periodic surveillance, environmental monitoring, and security by the manager and contractor will maintain the confinement of radioactivity. Adjacent facilities and unrestricted areas in the fuel plant can be put to other uses.

\section{G.4 DECOMMISSIONING ACTIVITIES FOR ONSITE DISPOSAL OF LAGOON WASTE}

Decomissioning begins with planning and preparation activities that include a radiological survey of the site, the preparation of documentation describing anticipated environmental effects of proposed decommissioning procedures, and the formulation of written work procedures.

The initial radiological survey provides data to guide the planning of decommissioning operations. The survey includes the following measurements:

- measurements of external gamma radiation levels at $1 \mathrm{~m}$ above the ground surface on the lagoon and on the site

- surface soil samples at several onsite locations

- measurements of the rate of radon emanation from the waste

- measurements of the concentrations of radon and daughters in air on the site

- measurements of gamma radiation at various depths in core holes drilled into the soil near the edge of the lagoon

- subsurface soil samples obtained from these core holes.

At the reference site, cores are dritled to a depth of 8 meters and soil samples are obtained from each core. The samples are sent to a commercial laboratory for analysis of ${ }^{226} \mathrm{Ra},{ }^{232} \mathrm{Th}$, and ${ }^{238} \mathrm{U}$ concentrations.

Lagoon waste stabilization details are described in Section G.5. To provide an example of the costs of stabilization, the following set of techniques is assumed for stabilization of the reference plant lagoon wastes. The lagoon waste is covered with a 50-mm-thick layer of asphalt. This asphalt layer is then covered with $1 \mathrm{~m}$ of soil. The soil is mounded slightly at the center of the lagoon to allow water to drain from the soil cover and to prevent the 
accumulation of runoff from rainfall or snow melt. After compaction and contouring of the soil cover, the area is seeded with grass.

Long-term care activities following stabilization include administrative control, site maintenance, environmental monitoring, and vegetation management.

\section{G.5 LAGOON WASTE STABILIZATION DETAILS}

Various stabilization techniques can be used to reduce the potential for radionuclide migration from the waste lagoons analyzed in this study. Some stabilization techniques are described in this section. These techniques are:

- soil cover

- site topography adjustment

- revegetation

- leachability reduction.

A more complete description of stabilization techniques is given in Reference 1.

\section{G.5.1 Soil Cover}

A layer of soil (backfil1) can be added to a contaminated site to provide a cover over the radioactive material. The backfill used is generally selected to provide a suitable base for subsequent revegetation of the area. The material is hauled in, dumped, and graded to form a layer of uniform specified depth. Standard earthmoving techniques are used. The soit is then compacted either by packing the area using heavy rolling equipment (e.g., a sheepsfoot roller, (a) wobbly-wheel roller, (b) or road roller) or by vibrating the earth with a vibrating baseplate compactor. In addition, other measures can be taken to aid in compaction, the most common being the use of water sprays to wet the soil. Little or no surface preparation is needed prior to backfilling and compaction of an area, although removal of vegetation and debris is desirable. Reference 2 provides a detailed treatment of fill compaction.

The new surface can be graded to preserve the original site contours, or new contours can be established. Site contours are chosen to control the

(a) A sheepsfoot roller is a cylindrical steel drum to which knob-headed spikes are fastened.

(b) A wobbly-wheel roller is a roller with freely suspended pneumatic tires. 
drainage from the area and to reduce the potential for the accumulation of water on the surface. After completion of the contouring operation, the surface is revegetated or otherwise stabilized.

Backfilling and compaction can be used as a control measure against subsidence. Backfill returns the surface to its original level, and compaction reduces the extent of subsidence that might be caused by future settling.

The addition of a layer of soil can be used to reduce the background radiation level existing on the site from contaminated surface soil or from tailings dumped on the ground. The thickness of backfill required depends on the level of surface contamination and the radionuclides involved. In general, a soil thickness of $0.3 \mathrm{~m}$ to $3.0 \mathrm{~m}$ is required.

\section{G.5.2 Site Topography Adjus tment}

Site topography adjustment is the grading, scraping, or other movement of surface soils to alter site contours. Site topography is adjusted using standard earthmoving and surface contouring techniques. After completion of the contouring operation, the surface is stabilized as desired, using one of the surface stabilization techniques described in this section.

Adjustment of site topography can be very effective in reducing radionuclide migration. Topography is a factor in both wind and water erosion, and adjustment therefore provides a method of reducing erosion damage. The alteration of site contours is a means of controlling runoff from rainfall and snow melt, and therefore is useful in adjusting the riydrological parameters of a site.

\section{G.5.3 Revegetation}

Revegetation is the establishment of a vegetative ground cover on a site whose surface has been disturbed. A variety of vegetation types and species can be used, depending on soil and climate conditions and also on the results desired. Shallow-rooted plants are preferred in order to limit plant-root penetration into buried radioactive material.

Before revegetation begins, soil tests are made at the site to determine the plant species to be used and the nutrient balance in the soil. Then, after 
the surface to be revegetated is graded or leveled as desired and cleared of debris, the area is planted with selected vegetation species. Use of fertilizers and soil amendments to improve soil texture and nutrient balance is common, as is the use of mulches and/or chemical stabilizers to conserve moisture and protect the surface until the vegetation becomes established.

A vegetated surface must be managed to ensure the continued viability of the vegetative community and to provide remedial measures for incidental problems. A vegetation management program can include, but is not limited to, the following elements: herbicides, acting at the surface and/or subsurface to control undesirable plant growth and to limit plant-root penetration; use of competing plant species to control growth of undesirable species; periodic clearing of undesirable vegetation from the site; use of bacterial and/or insect controls to 1 imit the growth of undesirable species; and replanting of areas damaged by erosion, pests, or human activities.

Revegetation can be used to control wind and water erosion of the ground surface. $(3,4)$ It also affects the site moisture balance by reducing runoff and increasing moisture return to the atmosphere through evapotranspiration. Revegetation may, in some cases, reduce mass wasting by anchoring the soit. One possible disadvantage of revegetation is that plant roots may penetrate areas where radioactivity is located.

The erosion protection afforded a site by a vegetation cover increases as the plant community becomes more established. This results in a gradual improvement of the site over several years, until the plant community reaches maturity.

\section{G.5.4 Leachability Reduction}

Leachability reduction involves the injection of suitable material into the buried radioactive material (e.g., a tailings pile) to chemically and/or physicaliy bond the radionuclides into a stable mass, thus reducing leaching. The technique involves the injection of grout material into the radioactive waste and the surrounding soil. Possible grouting materials include cement, clays, asphalts, bitumens, silicates, lignochromes, lignosulfates, epoxy resins, acrylamide, polyester resins, polyphenolics, resorcinolformaldehyde, and other chemical polymers. (5) These materials are injected by pumping through distribution pipes drive into the soil. Injection techniques are described in Reference 6 . 
By reducing waste leachability, radionuclide releases caused by hydrological action are decreased by limiting or eliminating dissolution of the radionuclides. Grouting to reduce leachability is a relatively expensive operation with costs ranging as high as $\$ 350 / \mathrm{m}^{3}$. (5) A useful life of 25 to 100 years is anticipated for the technique, assuming no regular maintenance. 


\section{REFERENCES}

1. E. S. Murphy and G. M. Holter, Technology, Safety and Costs of Decommissioning a Reference Low-Level waste Buria] Ground, NUREG/CR-0570, Pacific Northwest Laboratory for U.S. Nuclear Regulatory Commission, June 1980.

2. R. L. Soderberg and R. A. Busch, Design Guide for Metal and Nonmetal Tailings Disposal, IC-8755, Pp. 60-63, U.S. Department of the Interior, Bureau of Mines, 1977.

3. K. C. Dean, R. Havens, and M. W. Glantz, Methods and Costs of Stabilizing Fine-Sized Mineral Wastes, RI-7896, pp. 7-13, U.S. Department of the Interjor, Bureau of Mines, 1974.

4. R. P. Donovan, R. M. Felder, and H. H. Rogers, Vegetative Stabilization of Mineral Waste Heaps, EPA-600/2-76-087, Research Triangle Institute for U.S. Environmental Protection Agency, Apri1 1976.

5. Study of Engineering and Water Management Practices That Will Minimize the Infiltration of Precipitation into Trenches Containing Radioactive Waste, ORP LV-78-5, SCS Engineers for U.S. Environmental Protection Agency, June 1978.

6. R. Bowen, Grouting in Engineering Practice, Applied Science Publishers, Ltd., London, England, 1975. 

APPENDIX H

COST ASSESSMENT DETAILS

This appendix provides the details for the cost estimate information given in Section 10. Section H.l gives the basic data used for making cost estimates. Cost details for DECDN and for preparations for the safe storage period of passive SAFSTOR are presented in Sections $H .2$ and H.3, respectively. In section H. 4 cost estimates for onsite burial of the lagoon wastes is provided.

\section{H. 1 COMPILATION OF UNIT COST FACTORS}

For ease in applying the information developed during this study to other decomissioning situations, the basic data used for making the decomissioning cost estimates are presented in this section. Categories for which basic cost data are given include salaries, waste management costs, and costs of special equipment and services. Al1 data are based on early 1981 costs.

\section{H.1.1 Unit Manpower Costs}

Salary data for typical decommissioning staff positions are given in Table H.1-1. The original 1978 data base has been adjusted by a factor of 1.19 to account for escalation between 1978 and 1981 based on the Handy-Whitman Index. (1)

\section{H.1.2 Unit Waste Management Costs}

Waste management costs include the costs of shipping containers, transportation costs, and waste disposal charges.

\section{H.1.2.1 Unit Shipping Container Costs}

The cost of containers for packaging radioactive materials for offsite shipment is a major cost item for decommissioning. The containers assumed to be used in this study, together with their unit costs, are listed in Table H.1-2.

\section{H.1.2.2 Unjt Transportation Costs}

Transport of radioactive waste materials from the $\mathrm{UF}_{6}$ conversion plant to a commercial low-level waste burial site is assumed to be by truck. The distance 
IABLE H.1-l. Decommissioning Labor Cost Data

\begin{tabular}{|c|c|c|c|c|}
\hline Position & $\begin{array}{c}\text { Base Pay } \\
\text { (\$/yr) }\end{array}$ & $\begin{array}{l}\text { Assume } \\
\text { Overhead } \\
\text { Ratte (ón) }\end{array}$ & $\begin{array}{c}\text { Cost } \\
(\$ / y r)\end{array}$ & Referen \\
\hline \multicolumn{5}{|l|}{ Management and Support Staff } \\
\hline Decommissioning Superintendent & 52000 & 70 & 89100 & a \\
\hline Decommissioning Engineer & 44700 & 70 & 76000 & a \\
\hline Asst. Decommissioning Engineer & 30800 & 70 & 52400 & a \\
\hline Secretary & 16100 & 50 & 24200 & d \\
\hline Clerk & 16100 & 50 & 24200 & $d$ \\
\hline Health and Safety Supervisor & 35200 & 70 & 59800 & d \\
\hline Health Physicist & 27600 & 70 & 46900 & d \\
\hline Industrial Safety Specialist & 30800 & 70 & 52400 & d \\
\hline Radioactive Shipment Specialist & 23100 & 70 & 39300 & $d$ \\
\hline Procurement Specialist & 23100 & 70 & 39300 & $d$ \\
\hline Contracts and Accounting Specialist & 27700 & 70 & 47100 & a \\
\hline Accounting Clerk & 16100 & 50 & 24200 & $d$ \\
\hline Security Supervisor & 32900 & 70 & 55900 & $d$ \\
\hline Security Shift Supervisor & 21400 & 70 & 36400 & $d$ \\
\hline Security Patrolman & 16900 & 50 & 25400 & $b$ \\
\hline Quality Assurance Supervisor & 30700 & 70 & 52200 & d \\
\hline Quality Assurance Engineer & 27600 & 70 & 46900 & d \\
\hline Quality Assurance Technician & 18500 & 50 & 27800 & d \\
\hline Control Room Attendant & 23000 & 50 & 34500 & $d$ \\
\hline Tool Crib Attendant & 18500 & 50 & 27800 & c \\
\hline Protective Equipment Attendant & 18500 & 50 & 27800 & 9 \\
\hline Consultant & 100000 & -- & 100000 & $d$ \\
\hline \multicolumn{5}{|l|}{ Decomissioning Workers } \\
\hline Shift Engineer & 30700 & 70 & 52200 & d \\
\hline Craft Supervisor & 27600 & 70 & 46900 & d \\
\hline Craftstinan & 21400 & 50 & 32. 100 & c \\
\hline Crew Leader & 26100 & 70 & 44400 & $\mathrm{c}$ \\
\hline Utility Operator & 21400 & 50 & 32100 & c \\
\hline Laborer & 20600 & 50 & 30900 & b \\
\hline Health Physics Technician & 20000 & 50 & 30000 & c \\
\hline
\end{tabular}

(a) U.S. Department of Labor, Bureau of Labor Statistics, Bulietin March 1975. (2)

(b) R. S. Heans Company, Building Construction Cost Data - 1975, 33rd Edition. (3)

(c) Hanford Atomic Metai Trades Council Pay Scales. (4)

(d) Author's Estimate. 
TABLE H.1-2. Unit Costs of Shipping Containers

\begin{tabular}{|c|c|c|}
\hline Description & $\begin{array}{l}\text { Burial }{ }_{3} \text { Volume } \\
\left(\mathrm{m}^{3}\right) \\
\end{array}$ & $\begin{array}{l}\text { Estimated Unit } \\
\quad \text { Cost }(\$) \\
\end{array}$ \\
\hline $\begin{array}{l}\text { Standard }{ }_{3} \text { Steel Drum } \\
0.21 \mathrm{~m}^{3}, 23 \mathrm{~kg} \text { empty }\end{array}$ & 0.21 & 30 \\
\hline $\begin{array}{l}\text { Small Stęel Drum } \\
0.11 \mathrm{~m}^{3}, 18 \mathrm{~kg} \text { empty }\end{array}$ & 0.11 & 20 \\
\hline Polyethylene Drum Liner & (a) & 1 \\
\hline $\begin{array}{l}\text { Fiberglassed Plywood Box } \\
1.2 \mathrm{~m} \times 1.2 \mathrm{~m} \times 2.4 \mathrm{~m}, 175 \mathrm{~kg} \text { empty }\end{array}$ & 3.64 & 100 \\
\hline Fiberglassed Plywood Box & Variable & $\begin{array}{l}40 / \pi^{3} \text { of } \\
\text { surface }\end{array}$ \\
\hline
\end{tabular}

(a) Included in outer steel drum, no added burial volume.

from the plant to the low-level waste burial site is assumed to be $800 \mathrm{~km}$. Truck rate schedules that form the basis for transportation costs used in this study are shown in Table H.1-3. The table is reproduced from the published rates ${ }^{(5)}$ of a carrier licensed to transport radioactive materials.

The gross vehicle weight (GVW) for normal shipments by truck is assumed to be less than $20.41 \mathrm{Mg}$. The maximum allowed GVW varies from state to state, ranging from $30.21 \mathrm{Mg}$ to $45.36 \mathrm{Mg}$. Overweight charges by states vary widely. ${ }^{(5)}$ For this study, the maximum allowed GVW and the overweight charges for the state of Washington are assumed to apply (those rates being among the highest). These overweight changes are shown in Table H.1-4. An additional surcharge of $\$ 0.131$ per $\mathrm{km}$ is imposed by the carrier for shipments with GVW between $21.32 \mathrm{Mg}$ and $38.55 \mathrm{Mg}$. Shipments in excess of $38.55 \mathrm{Mg} \mathrm{GVW}$ require special equipment and special permission. Costs for these cases would have to be determined on a case-by-case basis.

For this study, the GVW of an unloaded exclusive-use van or tractor-trailer is assumed to be $12.70 \mathrm{Mg}$. Therefore, the payload per shipment in an exclusiveuse van is $7.7 \mathrm{Mg}$, legal weight, and $20.41 \mathrm{Mg}$, overweight.

To ensure rapid turnaround on shipments, a second driver may be required, costing an additional $\$ 0.093 / \mathrm{km}(\$ 0.15 / \mathrm{mi})$. 
TABLE H.1-3. Transportation Rates for Legal-Size and -Weight
Shipments $(a, b, c)$ Kilometers
One-Way $\frac{\text { Rate in Cents per Kilometer }}{\text { Column Columi Cometers }} \begin{gathered}\text { Rate in Cents per Kilometer } \\ \text { One-way }\end{gathered}$ Column

(Not Over)

1 (d)

$2(\mathrm{e})$

Co] umin

(Not Over) 1 (d)

(e)

160

233

244

168

86

103

$3(f)$

200

214

226

155

1200

82

100

71

240

209

143

1280

81

99

71

280

192

133

1360

80

98

71

$320 \quad 155$

169

121

1440

79

97

71

$360 \quad 147$

162

115

1520

77

95

71

$400 \quad 141$

156

108

1600

77

94

71

$440 \quad 134$

150

101

144

$480 \quad 128$

141

96

1760

77

94

71

$520 \quad 125$

137

91

1920

77

93

71

$560 \quad 121$

132

88

2240

77

92

71

$600 \quad 116$

128

84

2400

77

92

71

$640 \quad 111$

124

82

2560

77

91

71

$680 \quad 108$

119

80

2720

77

91

71

$\begin{array}{ll}720 & 102\end{array}$

117

78

2880

77

90

71

$760 \quad 100$

114

76

3040

77

89

71

800

96

111

75

3200

77

89

71

880

94

73

3360

77

88

71

960

92

109

71

3520

77

88

71

1040

89

106

71

3680

77

87

71

1120

87

104

71

3840

77

86

71

4000

77

86

71

and

(a) Reproduced from the published rates of a carrier ${ }^{(5)} 1$ icensed to transport radioactive materials.

(b) Effective August 15, 1980.

(c) Rates do not include a fuel surcharge, which amounted to $18 \%$ of the base rate as of February 13, 1981.

(d) Column 1 rates applicable to one-way shipments having a destination east of the Mississippi River.

(e) Column 2 rates applicable to one-way shipments having a destination west of the Mississippi River.

(f) Column 3 rates apply to continuous excursion moves in which a subsequent shipment is made available to the carrier within 24 hours after arrival at the point of loading or unloading. 
TABLE H.1-4. Additional Charges when Gross Vehicle Weight Exceeds $21.32 \mathrm{Mg}^{(\mathrm{a}, \mathrm{b})}$

\begin{tabular}{cccccc}
$\begin{array}{c}\text { Goss Vehicle } \\
\text { Weight } \\
(\mathrm{Mg})\end{array}$ & $\begin{array}{c}\text { State Surcharge } \\
(\$)\end{array}$ & $\begin{array}{c}\text { Carrier } \\
\text { Surcharge } \\
(\$)\end{array}$ & $\begin{array}{c}\text { Total Overweight } \\
\text { Surcharge }(\$)\end{array}$ \\
\cline { 1 - 1 } 21.32 to 23.12 & $10+0.031 / \mathrm{km}$ & $0.131 / \mathrm{km}$ & $10+0.162 / \mathrm{km}$ \\
23.13 to 25.84 & $10+0.062 / \mathrm{km}$ & $0.131 / \mathrm{km}$ & $10+0.193 / \mathrm{km}$ \\
25.85 to 28.56 & $10+0.093 / \mathrm{km}$ & $0.131 / \mathrm{km}$ & $10+0.224 / \mathrm{km}$ \\
28.57 to 31.28 & $10+0.155 / \mathrm{km}$ & $0.131 / \mathrm{km}$ & $10+0.286 / \mathrm{km}$ \\
31.29 to 34.00 & $10+0.218 / \mathrm{km}$ & $0.131 / \mathrm{km}$ & $10+0.349 / \mathrm{km}$ \\
34.01 to 36.72 & $10+0.280 / \mathrm{km}$ & $0.131 / \mathrm{km}$ & $10+0.411 / \mathrm{km}$ \\
36.73 to 38.55 & $10+0.373 / \mathrm{km}$ & $0.131 / \mathrm{km}$ & $10+0.504 / \mathrm{km}$
\end{tabular}

(a) State surcharge is based on rates for the state of Washing-

(b) Carrier surcharge is based on the published rates ${ }^{(5)}$ of a carrier licensed to transport radioactive materials.

\section{H.1.2.3 Unit Waste Disposal Costs}

Radioactive wastes generated during the decommissioning of a UF 6 plant will be disposed of by burial at a licensed low-level waste burial site.

The costs for low-level waste burial used in this study are based on a November 17,1980 price list ${ }^{(6)}$ from U.S. Ecology, Inc., which operates burial sites at Richland, Washington, and Beatty, Nevada. The costs in this study are given in Table H. I-5.

\section{H.1.3 Unit Costs of Special Equipment and Supplies}

The various types of special equipment needed for decommissioning activities are described in some detail in Section F.2 of Appendix F. Estimated unit costs for these equipment items and for decommissioning supplies are given in Table H.T-6. Costs of construction-type items (hoists, cranes, 1 ifts, etc.) are based on costs shown in the 1981 catalog of building construction costs published by R. S. Means Company. (7) 
TABLE H.1-5. Commercial Shallow-Land Burial Charges (a,b)

I. DISPOSAL CHARGES, NON-TRU WASTE

A. Steel Drums, Wood Boxes

\begin{tabular}{|c|c|c|}
\hline \multicolumn{2}{|c|}{$\begin{array}{c}\text { Container Surface } \\
\text { Dose Rate } \\
(\mathrm{R} / \mathrm{hr})(\mathrm{C}) \\
\end{array}$} & \multirow{2}{*}{$\begin{array}{l}\text { Price per Unit } \\
\text { Volume }\left(\$ / \mathrm{m}^{3}\right)\end{array}$} \\
\hline 0.00 & to 0.20 & \\
\hline 0.201 & to 1.00 & 335.45 \\
\hline 1.01 & to 2.00 & 376.05 \\
\hline 2.01 & to 5.00 & 459.05 \\
\hline 5.01 & to 10.00 & 542.00 \\
\hline 10.01 & to 20.00 & 702.65 \\
\hline 20.01 & to 40.00 & 870.40 \\
\hline 40.01 & to 60.00 & 1332.95 \\
\hline 60.01 & to 80.00 & 1601.30 \\
\hline 80.01 & to 100.00 & 1765.50 \\
\hline & $>100$ & by request \\
\hline
\end{tabular}

Minimum disposal charge: $\$ 224.00 /$ shipment

B. Disposable Liners

\begin{tabular}{|c|c|c|c|}
\hline $\begin{array}{r}\text { Containe } \\
\text { Dose } \\
\text { (R/1 } \\
\end{array}$ & $\begin{array}{l}\text { er Surface } \\
\text { e Rite } \\
\text { hr) (c) }\end{array}$ & $\begin{array}{c}\text { Surcharge per } \\
\text { Liner (S) }\end{array}$ & $\begin{array}{l}\text { Price per Unit } \\
\text { Volume }\left(\mathrm{s} / \mathrm{m}^{3}\right\}\end{array}$ \\
\hline 0.00 & 0.20 & None & 307.20 \\
\hline 0.201 & 1.00 & 119.00 & 307.20 \\
\hline 1.01 & 2.00 & 292.00 & 307.20 \\
\hline 2.01 & 5.00 & 411.00 & 307.20 \\
\hline 5.01 & to 10.00 & 594.00 & 307.20 \\
\hline 10.01 & to 20.00 & 758.00 & 307.20 \\
\hline 20.01 & to 40.00 & 941.00 & 307.20 \\
\hline 40.01 & to 60.00 & 1116.00 & 307.20 \\
\hline 60.01 & to 80.00 & 1288.00 & 307.20 \\
\hline 80.01 & to 100.00 & 1463.00 & 307.20 \\
\hline & $>100$ & by reques $t$ & by request \\
\hline
\end{tabular}

II. SURCHARGES

A. State of Washington Surcharge: $\quad \$ 10.60 / \mathrm{m}^{3}$

B. Curie Surcharge (per load):

Less than 100 curies No charge

101 to 300 curies $\quad \$ 650.00$

301 to License Limits $\$ 660.00+\$ 0.09 / \mathrm{Ci}$

(i.e.. 50,000 Ci)

c. Handling Surcharge
$0-4.54$
No charge
$>4.54 \mathrm{Mg}$
$\$ 87.50+\$ 0.044 / \mathrm{kg}$
Special Equipment
By spectal quotation
D. Cask Handling Fee:
$\$ 335.00$ per cask

(a) Reproduced from the published rates ${ }^{(8)}$ of a licensed burial ground operator.

(b) Prices effectlve November 17, 1980.

c) Maximum reading at contalner surface, irrespective of physical size or configuration. 
TABLE H.1-6. Unit Costs for Special Tools and Equipment

\section{Item}

Arc Saw

Portable Plasma-Arc Torch

Portable Oxyacetylene Torch

Guillotine Pipe Saw

Power-Operated Reciprocating Hacksaw

Nibbler

Submersible Pump with Disposable Filter

High-Pressure Water Jet

Electropolishing System

Mobile Chemical Decontamination Unit

Mobile Chemical Mixing \& Heating Unit

Powered Floor Scrubber

Wet-Dry Vacuum Cleaner (HEPA Filtered)

Supplied-Air Plastic Suit

Respirator Facepiece

Power-Operated Mobile Manlift

10-Ton Mobile Hydraulic Crane

10-Ton Forklift

Concrete Drill with HEPA Filtered Dust

Collection System

Concrete Surface Spaller

Front-End Loader (Light Duty)

Portable Filtered Ventilation Enclosure

Filtered-Exhaust Fan Unit

Blasting Mat

Paint Sprayer

HEPA Filter

Roughing Filter

waste Compactor
Estimated Unit Cost (\$ thousands)

100

20
1
4
0.8
1
2
20
$100^{(a)}$
20
5
0.3
1 to $5^{(b)}$
0.05
0.1
40
28
28
2
5
20
2 to $10^{(b)}$
5
0.5
0.5 to $1^{(c)}$
0.2
0.7
12

50
28
20


TABLE H. I-6. (contd)

Item

Incinerator

Tube Cutter

Ratcheting Pipe Cutter

High-Velocity Liquid Jet

Low-Velocity Liquid Jet

Concrete Drill

Electric/Pneumatic Hamner

Portable A-Frames

Portable Wash Sinks

Portable Spray Clean Booth

Portable Greenhouse Erection Kit

Portable Powered Brushes

Hand-Powered Brushes

Soap (per thousand $\mathrm{kg}$ )

Freon (per $\mathrm{m}^{3}$ )
Estimated Unit Cost (\$ thousands)

100 to 300 (c)

0.41

0.07

6.90

2.76

0.28

0.70

4.10

2.76

5.52

2.76

0.21

0.21

0.28

2.76

(a) Electrolyte tank has dimensions of $1.2 \mathrm{~m} \times 2.4 \mathrm{~m}$.

(b) Depends on size and complexity.

(c) Depends on capacity of system.

\section{H.2 CDST ASSESSMENT DETAILS FOR DECDN}

This section provides amplifying details on manpower requirements and on was te management requirements and costs for DECON.

\section{H.2.1 Decommissioning Manpower Details for DECON}

This section provides information about manpower requirements for DECON summarized in Section 10.1.1.

\section{H.2.1.1 Staff Labor Job Descriptions}

Decommissioning work force organizational charts for DECON and for passive SAFSTOR are presented respectively in Figures 10.1-1 and 10.2-1. For this study, 
the decommissioning staff is categorized into two broad groups: 1) support staff and 2) decommissioning workers. Summaries of the functions performed by key individuals in the decomissioning staffs are presented below.

Project Manager. This person is responsible to corporate management for the complete planning, coordination and supervision of all activities carried out to dismantle the reference plant. He directs the project engineer and the health and safety supervisor to insure that the dismantlement plan is developed and implemented in a safe and cost-effective manner. He provides necessary liaison with regulatory agencies and implements regulatory requirements.

Project Engineer. This person is responsible for planning, coordinating, and carrying out the decommissioning activities in a safe manner. He provides engineering services and detailed procedures necessary to implement the decommissioning plan. He is responsible for the preparation of all routine and special reports and he compiles a chronological history of the entire decommissioning project.

Health and Safety Supervisor. This person is responsible for recommending policy in matters of radiological and industrial safety and for enforcing these policies when they are approved. He establishes and implements radiological safety, industrial safety, and emergency preparedness programs.

Security Force Supervisor. This person is responsible for all site security matters. He supervises the decommissioning security force.

Contracts and Accounting Specialist. This person is responsible for preparing documents to purchase needed supplies, equipment, and contractual services. He maintains a complete record of all costs incurred during the decommissioning project. He disburses funds with the approval of the project manager.

Radioactive Shipment Specialist. This person oversees all shipments of radioactive and nonradioactive materials that leave the site for disposal or transfer to insure that the shipments are properly packaged and decontaminated and conform with all applicable federal, state, and local regulations. He arranges with suppliers to provide shipping containers and contracts with carriers to transport all radioactive wastes. 
Quality Assurance Engineer. This person prepares the decommissioning quality assurance plan and works with the project manager to implement the quality assurance program. He reports directly to corporate headquarters in quality assurance matters. He supervises the quality assurance technician, who monitors the performance of decommissioning activities and equipment suppliers and provides other QA functions as outlined in Section F.4 of Appendix F.

Maintenance and Crafts Supervisor. This person is responsible for maintaining plant equipment and services in the appropriate operating condition during decommissioning activities. He also schedules and supervises the activities of the craftsmen who assist the decommissioning crews in their decontamination and dismantlement tasks.

Operations Supervisor. This person develops detailed working procedures and supervises the performance of all decommissioning tasks. He writes specifications for special equipment and tools that must be procured or fabricated to carry out the decomissioning project and prepares routine and special reports as requested by the project engineer.

Safety Review Committee. This committee meets periodically to advise corporate headquarters on safety-related matters. It is composed of six voting members, two from corporate headquarters and four independent consultants. The project manager, health and safety supervisor, quality assurance engineer, and project engineer are nonvoting members.

\section{H.2.1.2 Decommissioning Worker Manpower Requirements}

Detailed estimates of the decomissioning worker manpower required to perform DECON of the reference plant are shown in Table H.2-l. These estimates for the decommissioning workers, plus those for the support staff, are summarized in Table 10.1-3.

\section{H.2.2 Waste Management Details for DECON}

This section provides data on waste management requirements and costs for DECON that are summarized in Section 10.1.3. 
TABLE H.2-1. Estimated Deconmissioning Worker Manpower Requirements for DECON of the Reference Plant

\begin{tabular}{|c|c|c|c|c|c|}
\hline \multirow{2}{*}{ Decomissioning Activity } & \multicolumn{5}{|c|}{ Estimated Man-Weeks (a) } \\
\hline & \multirow[t]{2}{*}{ Foremen } & \multirow[t]{2}{*}{ Technicians } & \multirow[t]{2}{*}{$\begin{array}{c}\text { Health } \\
\text { Physicists } \\
\end{array}$} & \multirow[t]{2}{*}{ Craftsmen } & \multirow[t]{2}{*}{ Total } \\
\hline Buildings (Plant Restricted Areas) & & & & & \\
\hline Drum Receiving Area & 1 & 4 & 0.5 & 0.5 & 6 \\
\hline ADU STurry Recieving Area & 1 & 6 & 0.5 & 1 & 0.5 \\
\hline Sampling Station & 1 & 7 & 0.5 & 1 & 9.5 \\
\hline Laboratory & 3 & 15 & 1 & 5 & 24 \\
\hline $\mathrm{UF}_{4}$ Slurry Processing & 5.5 & 30 & 2 & 5 & 42.5 \\
\hline Digestion & 6 & 41 & 2.5 & 6.5 & 56 \\
\hline Solvent Extraction Building & 10.5 & 56 & 4 & 9.5 & 80 \\
\hline Concentration of Uranyl Nitrate & 9 & 56.5 & 4 & 7.5 & 77 \\
\hline Denitration Area & 9.5 & 61 & 4 & 7.5 & 82 \\
\hline Nitric Acid Recovery & 5 & 31 & 2 & 4 & 42 \\
\hline Reduction Area & 9 & 56.5 & 4 & 7.5 & 77 \\
\hline Hydrofluorination Area & 7.5 & 40 & 3 & 13 & 63.5 \\
\hline Fluorination Area & 6.5 & 45 & 2.5 & 7.5 & 61.5 \\
\hline Cylinder Loading Area & 5 & 31 & 2 & 9 & 47 \\
\hline $\mathrm{F}_{2}$ Production Cel1 Room & 2.5 & 15 & 1 & 2.5 & 21 \\
\hline $\mathrm{F}_{2}$ Cell Rewark Area & 2 & 12 & 1 & 2 & 17 \\
\hline Instrument Repair Room & 3.5 & 17 & 1.5 & 13 & 35 \\
\hline Ammonia Cracking Area & 2.5 & 13.5 & 1 & 7.5 & 24.5 \\
\hline Waste Gas Disposal Area & 2 & 12 & 1 & 2.5 & 17.5 \\
\hline $\mathrm{H}_{2}$ Condensing Area & 5.5 & 34 & 2 & 5 & 46.5 \\
\hline Temporary Radwaste & 1 & 7 & 1 & 1 & 10 \\
\hline Decontamination Area & 1 & 4 & 0.5 & 1 & 6.5 \\
\hline Incinerator Facijity & 2 & 15 & 1 & 4 & 22 \\
\hline Temporary Laundry and Change Room & 2 & 34 & 1 & 1.5 & 18.5 \\
\hline Overa!l Cleanup and Survey & 3 & 22 & 1 & 2 & 28 \\
\hline \multicolumn{6}{|l|}{ Site (External to Plant) } \\
\hline Extraction Waste Treatment System & 20 & 148 & 8 & 13 & 189 \\
\hline F) uoride Waste Treatment System & 22 & 160 & 5 & 15 & 202 \\
\hline Miscellaneous Buried Waste & 2.5 & 17 & 1 & 4 & 24.5 \\
\hline Orum Storage Area & 2 & 12 & 0.5 & 2 & 16.5 \\
\hline Cylinder Storage and Wash Area & 5.5 & 30 & $i$ & 6 & 42.5 \\
\hline Plant Stack & 2 & 15 & $?$ & 4 & 22 \\
\hline Overall Cleanup and Survey of Site & -4 & 31 & -1.5 & $\underline{0}$ & 36.5 \\
\hline Total Man-Weeks & 164.5 & 1058.5 & 62.5 & 170.5 & 1456.0 \\
\hline Total Man-Years (b) & 3.29 & 21.17 & 1.25 & 3.41 & 29.12 \\
\hline
\end{tabular}

(a) Number of significant figures shown is for computational completeness and does not imply accuracy to the number of figures shown.

(b) A total of 50 weeks/year is assumed. 


\section{H.2.2.1 Waste Management Requirements}

Detailed estimates of volumes and weights of contaminated tanks and equipment, piping and ductwork, concrete rubble, solid waste buried onsite, and miscellaneous contaminated scrap from DECON of the reference plant are presented in this section. These estimates form the bases for determining packaging and shipping requirements and costs that are summarized in Section 10.1.3.

Equipment. Estimated shipping volumes for contaminated equipment are presented in the equipment tables in Section A.2 of Appendix A.

Table H.2-2 summarizes shipping volumes for contaminated equipment and materials in terms of the volumes of waste material shipped to sanitary landfill and to low-level waste burial.

HEPA and Roughing Filters. HEPA filters are located on the laboratory exhaust and the temporary decommissioning tents.

HEPA and roughing filters attached to hoods are $0.2 \times 0.2 \times 0.1 \mathrm{~m}$ thick. A11 of these filters are assumed to be incinerated and the residue is processed to recover any uranium.

HEPA filters for the decomissioning tents are $0.6 \times 0.6 \times 0.3 \mathrm{~m}$ thick. Roughing filters are $0.6 \times 0.6 \times 0.15 \mathrm{~m}$ thick. Ventilation HEPA and roughing filters that are not incinerated are assumed to be packaged in plywood boxes and shipped to a low-level waste burial site for disposal.

The average bulk density of the filters is assumed to be $320 \mathrm{~kg} / \mathrm{m}^{3}$.

Concrete Rubble. The volume of potentiality contaminated concrete assumed to be removed from floors and walls of the reference plant and shipped to lowlevel waste burial is shown in Table H.2-3. The estimated volumes shown in the table assume concrete would be removed to a depth of $0.05 \mathrm{~m}$. A fraction of the surface area of each room (based on the type of operation in a specific room) is estimated to calculate the volume of concrete removed. The fraction ranges from 0.1 to 0.5 of the room area.

The shipping volume of the concrete rubble is assumed to be twice the volume of the concrete removed from the walls. The average bulk density of the concrete rubble as shipped is thus assumed to be $1200 \mathrm{~kg} / \mathrm{m}^{3}$. 
IABLE H.2-2. Shipping Volumes of Equipment, Pipes, Ducts, and Other Materials(a)

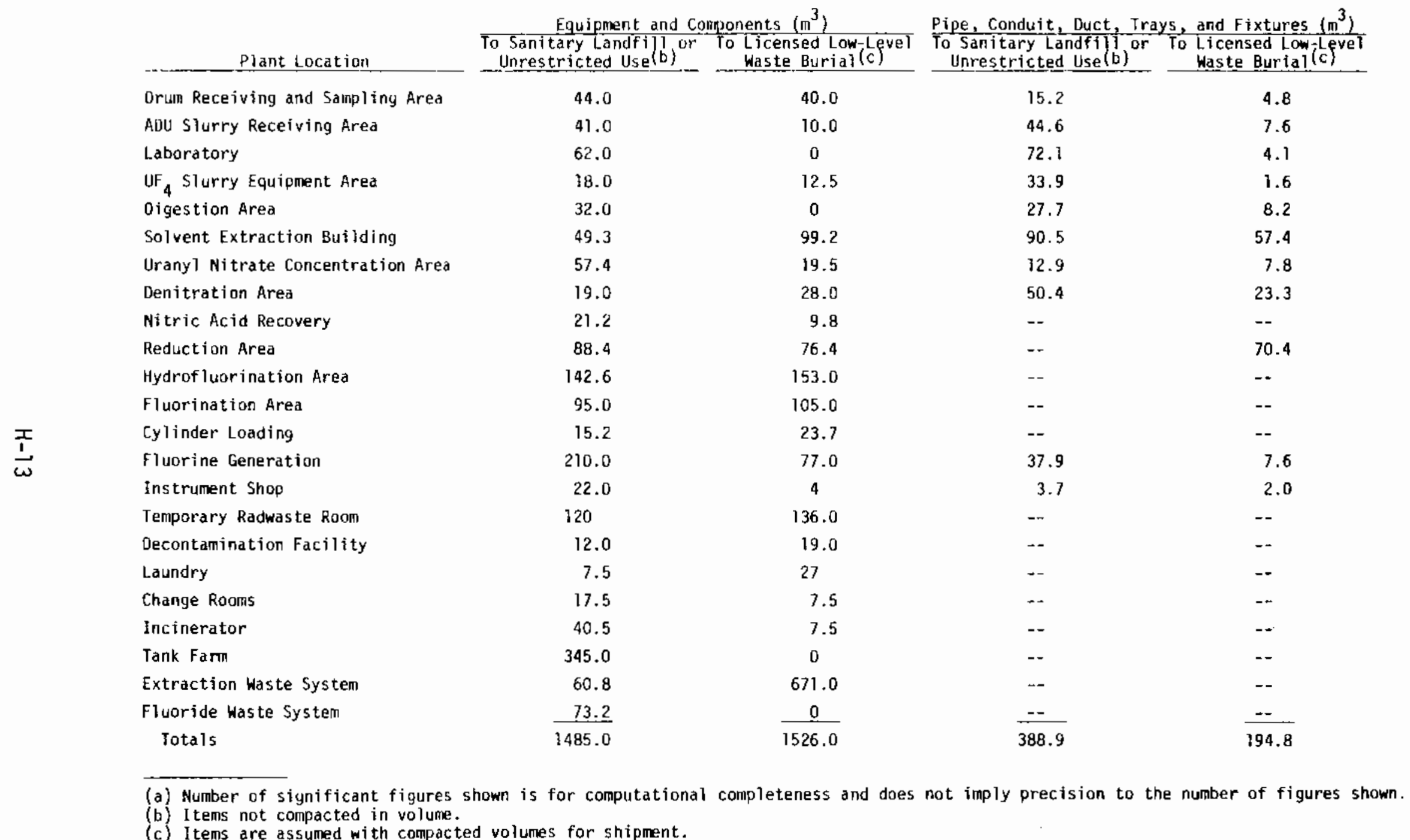


TABLE H.2-3. Postulated Sources of Concrete Rubble Generated During DECON(a)

\begin{tabular}{|c|c|c|c|}
\hline Location & $\begin{array}{l}\text { Floor } \\
\text { Area }\left(m^{2}\right)\end{array}$ & $\begin{array}{l}\text { Volume } \\
\text { Removed } \\
\left(\mathrm{m}^{3}\right)\end{array}$ & $\begin{array}{c}\text { Shipping } \\
\text { Volyme } \\
\left(\mathrm{m}^{3}\right) \\
\end{array}$ \\
\hline \multicolumn{4}{|l|}{ Main Process Building } \\
\hline $\begin{array}{l}\text { Drum Receiving and } \\
\text { Sampling Area }\end{array}$ & 165 & 4.2 & 8.4 \\
\hline ADU Slurry Receiving Area & 50 & 0.6 & 1.2 \\
\hline Laboratory & 175 & 2.2 & 4.4 \\
\hline $\mathrm{UF}_{4}$ Slurry Equipment Area & 200 & 2.5 & 5.0 \\
\hline Digestion Area & 200 & 5.0 & 10.0 \\
\hline $\begin{array}{l}\text { Uranyl Nitrate Concentra- } \\
\text { tion Area }\end{array}$ & 130 & 3.2 & 6.4 \\
\hline Dentitration Area & 130 & 3.2 & 6.4 \\
\hline Reduction Area & 270 & 6.7 & 13.4 \\
\hline Hydrofluorination & 260 & 3.2 & 6.4 \\
\hline Fluorination Area & 270 & 3.2 & 6.4 \\
\hline Cylinder Loading & 130 & 1.6 & 3.2 \\
\hline Solvent Extraction Building & 377 & 14.1 & $\underline{28.2}$ \\
\hline Totals & 2357 & 49.7 & 99.4 \\
\hline
\end{tabular}

(a) Number of significant figures shown is for computational completeness and does not imply precision to the number of figures shown.

\section{H.2.2.2 Waste Management Costs}

Details of waste management cost calculations for radioactive wastes from DECON are shown in Table H.2-4. These calculations are based on estimated waste quantities described in Section H.2.2.1 and on un t cost data for packaging, transportation, and waste disposal given in Section H.1.2.

For a particular waste form, the total waste management cost is the sum of the packaging cost plus the transportation cost pius the disposal cost. 
TABLE H.2-4. Details of Estimated Costs for Radioactive Waste Management for DECON $(a)$

\begin{tabular}{|c|c|c|c|c|c|c|c|c|c|c|c|}
\hline & Waste Category & $\begin{array}{c}\text { Shipping } \\
\text { Height } \\
\text { (kg) }\end{array}$ & $\begin{array}{l}\text { Shipping } \\
\text { Volume } \\
\left(\mathrm{m}^{3}\right) \\
\end{array}$ & $\begin{array}{c}\text { Type } \\
\text { of } \\
\text { Container }\end{array}$ & $\begin{array}{c}\text { Number } \\
\text { of } \\
\text { Shipments }\end{array}$ & $\begin{array}{c}\text { Total } \\
\text { Packaging } \\
\text { Cost } \$)\end{array}$ & $\begin{array}{c}\text { Basic } \\
\text { Transporta- } \\
\text { tion Cost } \\
\text { (\$) }\end{array}$ & $\begin{array}{l}\text { Overweight } \\
\text { Charge } \\
\text { (\$) }\end{array}$ & $\begin{array}{c}\text { Total } \\
\text { Transparta- } \\
\text { tion Cost } \\
(\$) \\
\end{array}$ & $\begin{array}{c}\text { Burias } \\
\text { Cost } \\
\text { (\$) } \\
\end{array}$ & $\begin{array}{l}\text { Total Waste } \\
\text { Management } \\
\text { Cost }(\$)\end{array}$ \\
\hline & \multicolumn{11}{|l|}{ To Low-Level Waste Burial } \\
\hline & Equipment and Components & 380000 & 855 & Plywood Baxes & 24 & 23500 & 25830 & 5730 & 31560 & 262650 & 317700 \\
\hline II & $\begin{array}{l}\text { Pipe, Conduit, Ductwork, } \\
\text { Trays, Fixtures, etc. }\end{array}$ & 219200 & 195 & Pl ywood Boxes & 12 & 5400 & 12910 & 2870 & 15780 & 59900 & 81100 \\
\hline \multirow{5}{*}{$\vec{G}$} & Concrete Rubble & 64000 & 99 & Steel Drums & 7 & 14160 & 7530 & 980 & 8510 & 30410 & 53100 \\
\hline & Solid Waste Buried Onsite & 48000 & 80 & Stecl Drums & 5 & 11430 & & & 6580 & 24580 & 42600 \\
\hline & Miscellaneous & 17500 & 12 & Steel Drums & 1 & 1710 & 1100 & 220 & 1320 & 3690 & 6700 \\
\hline & Miscell aneous & 12000 & 18 & Plywond Boxes & $?$ & -500 & $2 \underline{200}$ & 230 & 2430 & $\underline{5} 5 \underline{50}$ & 8500 \\
\hline & Totals & 740700 & $\overline{1259}$ & & 51 & 56700 & & & 66200 & 386700 & 509700 \\
\hline
\end{tabular}

(a) Number of significart figures shom is for computational completeness and does not inply precision to the number of figures shown. 
The total transportation cost is the sum of the basic transportation cost plus the overweight charge. Overweight charges are based on charges for the state of Washington. In some instances, the quantity of waste per shipment is limited by weight restrictions (i.e., the 33.1-Mg limit discussed in Section H.1.2.2) rather than by volume limits.

\section{H.2.2.3 Lagoon Waste Management Costs}

Cost data for the lagoon waste management alternatives summarized in Section 10.1.3.3 are provided in this section. The costs of the various alternatives are summarized in Table 10.1-7.

Onsite Burial. Details of the onsite burial option are shown in Table H.2-5. These costs are based on the estimated waste quantity shown, assuming site stabilization of the fluoride waste. The solvent extraction waste cannot be buried onsite and allow the site to be released for unrestricted release; thus, no costs are included for that option for the DECJN alternative.

TABLE H.2-5. Details of Costs for the Onsite Burial Option

\begin{tabular}{lr}
\multicolumn{1}{c}{ Item } & $\begin{array}{c}\text { Fluoride } \\
\text { Waste }\end{array}$ \\
\cline { 1 - 1 } Volume $\left(\mathrm{m}^{3}\right.$ & 5720 \\
Costs $(\$)$ & \\
Manpower & 15000 \\
Equipment & 11000 \\
Materiar & 22500 \\
Soil Analysis & 2500 \\
Contractors Fee & $\underline{3900}$ \\
$\quad$ Total & 54900
\end{tabular}

Shipment to Uranium Mi11. The solvent extraction waste can be shipped to a uranium mill to remove the uranium and dispose of the remainder of the waste with the mill tailings. It is not feasible to ship the fluoride waste to a mill due to the low uranium content. Table H.2-6 summarizes the estimated costs of shipment of the extraction waste to a mill for recovery of the uranium. Included 
TABLE H.2-6. Details of Lagoon Waste Management Costs for Shipment to Uranium Mill (a)

\begin{tabular}{|c|c|c|c|c|c|c|c|c|}
\hline Waste rategory & $\begin{array}{c}\text { Shipping } \\
\text { We ight } \\
\langle\mathrm{Mg}\rangle \\
\end{array}$ & $\begin{array}{c}\text { Shipping } \\
\text { volume } \\
\left(m^{3}\right) \\
\end{array}$ & $\begin{array}{c}\text { Type } \\
\text { of } \\
\text { Container } \\
\end{array}$ & $\begin{array}{c}\begin{array}{c}\text { Number } \\
\text { of } \\
\text { Shipments }\end{array} \\
\end{array}$ & $\begin{array}{c}\text { Total } \\
\text { Packaging } \\
\text { Cost }\langle \$\rangle \\
\end{array}$ & $\begin{array}{c}\text { Total } \\
\text { Transporta- } \\
\text { tion Cost } \\
\text { (\$) }\end{array}$ & $\begin{array}{c}\text { Burial } \\
\text { Cost } \\
(\$ 1 \\
\end{array}$ & $\begin{array}{c}\text { Total Waste } \\
\text { Management } \\
\text { Cost }(\$) \\
\end{array}$ \\
\hline $\begin{array}{l}\text { Contaminated Liner and } \\
\text { Soil to LLW Burial }\end{array}$ & 469 & 670 & $\begin{array}{l}\text { Plywood } \\
\text { Box }\end{array}$ & 37 & ]B 500 & 45920 & 206130 & 270600 \\
\hline $\begin{array}{l}\text { Extraction Waste to Mill } \\
\text { Subtotal } \\
\text { Value of Recovered } \\
\text { Uranium }\end{array}$ & 37260 & 21600 & $\begin{array}{l}\text { Plywood } \\
\text { Box }\end{array}$ & 1840 & 5934002 & 511600 & $-{ }^{(b)}$ & 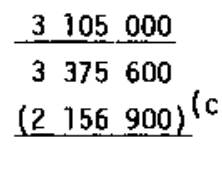 \\
\hline Total & & & & & & & & 1218700 \\
\hline
\end{tabular}

(a) Number of significant figures shown is for computational completeness and does not imply precision to the number of figures shown.

(b) Not applicable

(c) Value of uranium at $\$ 66 / \mathrm{kg} \times 34400 \mathrm{~kg} \times 0.95=\$ 2,156,900$. 
is the shipment of about $670 \mathrm{~m}^{3}$ of contaminated 1 iner and soil material to an LLW burial ground as part of the decommissioning cost. The cost of shipment of the waste to the uranium mill is partly of fset by the value of the recovered uranium at $\$ 66$ per kilogram times $34,400 \mathrm{~kg}$ of uranium recovered. The efficiency of recovery of uranium at the mill is assumed to be 0.95 .

Shipment to LLW Burial Ground. Costs for shipment of all lagoon waste to an LLW burial ground is covered in this section. Fable H.2-7 shows the details of the cost of shipment to an LLW burial ground for both extraction and fluoride wastes. For the extraction waste, costs are shown for the liner and soil shipped to the burial ground.

Shipment to Commercial Waste Dump. It is not feasible to ship the extraction waste to a commercial dump. It would have to be mixed with soil at a 9 part soil to 1 part waste ratio, which would make it very costly. Costs for shipment of fluoride waste to a commercial dump are shown in Table H.2-8.

\section{H.3 COST ASSESSMENT OETAILS FOR PREPARATIONS FOR THE SAFE STORAGE PERIOD OF PASSIVE SAFSTOR}

This section provides details additional to those provided in Section 10 on manpower requirements and costs for preparations for safe storage.

\section{H.3.1 Decommissioning Worker Manpower Requirement's for Preparations for Safe Storage}

Detailed estimates of the number of man-weeks required to perform the decommissioning tasks required to prepare the reference plant for safe storage are shown in Table H.3-1. These estimates for decommissioning workers plus those for the support staff are summarized in Table 10.2-3. 
IABLE H.2-7. Details of Lagoon Waste Management Costs for Shipment to LLW Burial(a)

Shipping Shipping Type Number

Wype Total Transporta- Burial Total Waste

\begin{tabular}{|c|c|c|c|c|c|c|c|c|c|}
\hline Waste Category. & $\begin{array}{l}\text { Shipping } \\
\text { Weight } \\
\text { (Mg) }\end{array}$ & $\begin{array}{l}\text { Shipping } \\
\text { volune } \\
\left(\mathrm{m}^{3}\right) \\
\end{array}$ & $\begin{array}{c}\text { Type } \\
\text { of } \\
\text { Container }\end{array}$ & $\begin{array}{l}\text { Number } \\
\text { of } \\
\text { Shipments }\end{array}$ & $\begin{array}{l}\text { Total } \\
\text { Packaging } \\
\text { Cost }(\$) \\
\end{array}$ & $\begin{array}{c}\text { Transporta- } \\
\text { tion Cost } \\
(\$ 1) \\
\end{array}$ & $\begin{array}{l}\text { Burial } \\
\text { Cost } \\
(\$)\end{array}$ & & $\begin{array}{l}\text { otal Was te } \\
\text { Management } \\
\text { Cost }(\$)\end{array}$ \\
\hline Extraction Waste & 37260 & 21600 & $\begin{array}{l}\text { Plywood } \\
\text { Box }\end{array}$ & 1840 & 593400 & 2511600 & 6635 & 500 & 9740500 \\
\hline $\begin{array}{l}\text { Liner and Soil } \\
\text { Total }\end{array}$ & 469 & 670 & $\begin{array}{l}\text { Plywood } \\
\text { Box }\end{array}$ & 37 & 18500 & 45900 & 206 & 100 & $\frac{207.600}{10011100}$ \\
\hline Fluoride Haste & 18200 & 5720 & $\begin{array}{l}\text { Plywood } \\
\text { Box }\end{array}$ & 552 & 817500 & 726340 & 1757 & 200 & 3301000 \\
\hline
\end{tabular}

(a) Number of significant figures shown is for computational completeness and does not imply precision to the number of figures shown. 
TABLE H.2-8. Details of Estimated Costs for Shjpment of Lagoon Wastes to a Commercial Waste Jump (a)

$\begin{array}{lr}\text { Item } & \text { Fluoride Waste } \\ \text { Shipping Weight }(\mathrm{Mg}) & 18200 \\ \text { Shipping Volume }\left(\mathrm{m}^{3}\right) & 5720 \\ \text { Number of Shipments } & 552\end{array}$

Cost $(\$)$

$\begin{array}{lr}\text { Packaging } & 85000 \\ \text { Transportation } & 726300 \\ \text { Burial } & 200000 \\ \text { Total Cost } & 1011300\end{array}$

(a) Number of significant figures shown is for computational completeness and does not imply precision to the number of figures shown.

TABLE H.3-1. Estimated Decommissioning Worker Manpower Requirements While Preparing the Reference Plant for Safe Storage

\begin{tabular}{|c|c|c|c|c|c|}
\hline \multirow[b]{2}{*}{ Decomissioning Activity } & \multicolumn{5}{|c|}{ Estimated Man-Weeks } \\
\hline & Foremen & Technicians & $\begin{array}{l}\text { Health } \\
\text { Physicists }\end{array}$ & Craftsmen & Total \\
\hline \multicolumn{6}{|l|}{ Waste Treatnent Facilities Stabilization } \\
\hline Drain Lagoons and Cover w/Plastic and Wefghts & 2 & 12 & 2 & 2 & 1B \\
\hline \multicolumn{6}{|l|}{ Equipment Deactivation } \\
\hline Audit all Punps and Pipelines & 1 & 2 & 1 & 2 & 6 \\
\hline Secure Valves, Hoods, and Conveyors & 1 & 3 & 1 & 2 & 7 \\
\hline $\begin{array}{l}\text { Disconnect Services No Longer Required (electri- } \\
\text { cal, air, etc.) }\end{array}$ & 2 & 2 & 1 & 4 & 9 \\
\hline Tag Equipment and Systems to Identify Status & 1 & 2 & 2 & 2 & 7 \\
\hline Safety Audit & 1 & 2 & 2 & 2 & 7 \\
\hline \multicolumn{6}{|l|}{ Isolation of Contaminated Areas } \\
\hline Install Building Access Locks and Warning signs & 1 & 1 & 0 & 2 & 4 \\
\hline Perform Building Systems Check & 1 & 2 & 1 & 2 & 6 \\
\hline Install Fence and Lacks on Outside Facilities & 1 & 1 & 0 & 1 & 3 \\
\hline \multicolumn{6}{|l|}{ Final Preparations for $5 a f e$ storage } \\
\hline Complete offsite Shipment of all Recovered Uranium & 1 & 4 & 2 & 0.5 & 7.5 \\
\hline Complete intrusion Alarm System lnstaliation & 1 & 2 & 1 & 6 & 10 \\
\hline Complete Radiation Honitoring System Installation & $i$ & 2 & 1 & 4 & 8 \\
\hline Perform Comprenensive Radiation Survey & 1 & 4 & $\stackrel{4}{-}$ & $\underline{0}$ & 9 \\
\hline Tota1 man-weeks ${ }^{(a)}$ & 16 & 39 & 18 & 29 & 101.5 \\
\hline
\end{tabular}

(a) A total of 50 weeks/year is assumed. 


\section{H.4 LAGOON WASTE ONSITE BURIAL}

Cost data for onsite burial of lagoon waste are provided in this section.

Cost details for the onsite burial of lagoon waste are shown in Table H.4-1. These costs are based on the estimated waste quantities shown assuming site stabilization of the solvent extraction waste and the fluoride waste.

TABLE H.4-1. Details of Costs for Lagoon Waste Onsite Burial

\begin{tabular}{|c|c|c|}
\hline Item & $\begin{array}{c}\text { Extraction } \\
\text { Waste } \\
\end{array}$ & $\begin{array}{l}\text { Fluoride } \\
\text { Waste }\end{array}$ \\
\hline Volume $\left(\mathrm{m}^{3}\right)$ & 21600 & 5720 \\
\hline \multicolumn{3}{|l|}{ Costs $\langle \$\rangle$} \\
\hline Manpower & 37200 & 15000 \\
\hline Equipment & 26000 & 11000 \\
\hline Material & 86800 & 22500 \\
\hline Soil Analysis & 6200 & 2500 \\
\hline Contractors Fee & 12000 & 3900 \\
\hline Subtotal & 168200 & 54900 \\
\hline $25 \%$ Contingency & 42000 & 13700 \\
\hline Totals & 210200 & 68600 \\
\hline
\end{tabular}




\section{REFERENCES}

1. Handy-Whitman Index of Public Utility Construction Costs, Bulletin No. 112, Amended July 1, 1980.

2. U.S. Department of Labor, Bureau of Labor Statistics, Bulletin, March 1975.

3. R. S. Godfrey, ed., Building Construction Cost Data - 1975, R. S. Means Co., Inc., Duxbury, Massachusetts, 1975.

4. Hanford Atomic Metal Trades Council Pay Scales, Richland, Washington, 1975.

5. MF-I.C.C. No. 195, Local Commodity Tariff No. 1045-E, Tri-State Motor Transit Co., Joplin, Missouri, August 1980.

6. Price List, Nuclear Engineering Company, San Ramon, California, November $17,1980$.

7. R. S. Godfrey, ed., Building Construction Cost Data - 1981, 39th Edition, R. S. Means Co., Inc., Kingston, Massachusetts, 1980.

8. Washington Nuclear Center and Nevada Nuclear Center Schedule of Charges, U.S. Ecology Inc., November 17, 1980. 
APPENDIX I

\section{SAFETY ASSESSMENT DETAILS}

The purpose of this appendix is to quantify the parameters and define the methodology for estimating the public and occupational safety impacts of decommissioning the reference $\mathrm{UF}_{6}$ conversion plant.

The impacts of decommissioning on the safety of the public are principally related to the hazards associated with the atmospheric release of radioactive materials during decommissioning, both from planned tasks and from accidents. For DECON and SAFSTOR, atmospheric releases of radioactivity are calculated for the decommissioning tasks that are assumed to be performed. The scenarios analyzed are designed to use realistically maximized parameters. These parameters are carefully chosen to cover a broad spectrum of conditions. Atmospheric release mechanisms are quantified using either measured release factors or information about known physical or chemical behaviors under the postulated conditions. The estimated routine radionuclide releases to the atmosphere are tabulated in the chronological order of the decommissioning tasks for each area of the main building, for each decommissioning alternative. A detailed probabilistic analysis of the postulated accident scenarios is not within the scope of this study. However, selected generic operational accident categories are considered.

Estimates of occupational radiation doses are based on the postulated dose rates in various areas of the reference $U F_{6}$ conversion plant and the estimated staff labor required to complete the decommissioning work.

The following sections contain detailed discussions of the technical approach and public and occupational safety details for DECON, SAFSTOR, and waste transportation. A summary of this information is given in Section 1 .

\section{I.I TECHNICAL APPROACH}

To estimate the public and occupational safety impacts of the release of radioactivity to the atmosphere from decommissioning tasks, the following basic assumptions are made: 
1. The facility has fulfilled existing criteria for the containment of radionuclides for accidents and natural phenomena during its operational lifetime.

2. All production process solutions are emptied and flushed from all piping, equipment, and sumps. All process chemicals not required for decommissioning are safely removed from the site.

3. All systems used during the various phases of decommissioning are functional and their operability is verified by appropriate tests.

4. To ensure proper air flow for the decommissioning workers, and to protect against uncontrolled atmospheric releases of radioactivity, the main process building is equipped with adequate ventilation, as defined in Appendix $A$. The air flow rates used in this analysis are $1.6 \times 10^{5} \mathrm{~m}^{3} / \mathrm{h}$ for the main building, $6.2 \times 10^{4} \mathrm{~m}^{3} / \mathrm{h}$ for the fluorine cell, and $4.1 \times 10^{4}$ $\mathrm{m}^{3} / \mathrm{h}$ for the solvent extraction area. All of the exhaust air is assumed to pass through a bag-type dust collector that results in an overall building transmission factor of $1 \times 10^{-1}$.

5. In selected areas with potentially higher levels of radioactive contamination, a temporarily installed "greenhouse," or contamination control envelope, is used. The contamination control envelope has a HEPA filter with a transmission factor of $5 \times 10^{-4(1)}$ to reduce the airborne radionuclide concentrations in the $\mathrm{UF}_{6}$ conversion plant from selected decommissioning tasks.

6. The leakage rate from a contamination control envelope is $10 \%$ for a 11 tasks involving its use. This assumed leakage is used as a maximized value to account for routine ruptures or failures of the temporary structures.

7. The airflow rate in this study for contamination control envelopes is: $3000 \mathrm{~m}^{3} / \mathrm{hr}$. 
8. Unneeded hazardous chemicais and equipment are removed after the reference $\mathrm{UF}_{6}$ conversion plant is shut down. Decontamination agents such as phosphoric acid, ethylenediaminetetraacetic acid (EDTA), oxalic acid, and citric acid are available in the plant. Unneeded ion exchange resins and resin beds are removed.

9. The reference radionuclide inventory used in this appendix for the radiation dose calculations is defined in Appendix $C$ and is used for all surfaces including building structural materials and process equipment.

10. All chemical or manual decontamination tasks remove $90 \%$ of the surface contamination.

11. The airborne concentrations of dust or liquid droplets are $1 \times 10^{-2} \mathrm{~g} / \mathrm{m}^{3}$, equal to the concentrations observed at the Elk River reactor decommissioning. $(2,3)$ For explosions, the airborne concentration is a factor of 10 higher, or $1 \times 10^{-1} \mathrm{~g} / \mathrm{m}^{3} .(4)$

12. All radioactive wastes shipped offsite are shipped in accordance with Department of Transportation (DOT) regulations to a low-level waste burial ground $800 \mathrm{~km}$ away. The cumulative dose to the public from truck shipments is based on the methods and data given in WASH-1238. ${ }^{(5)}$

13. Atmospheric dispersion conditions given in NRC Regulatory Guide $1.4^{(6)}$ for a 0 - to 8-hour ground-level release are used to calculate the radiation doses resulting from accidental releases during decommissioning. The maximum-exposed individual is located 1000 meters from the point of release. For transportation accidents, the maximum-exposed individual is located $100 \mathrm{~m}$ from the release point.

14. Radiation doses to the maximum-exposed individual and to the population residing within $80 \mathrm{~km}$ of the reference site are calculated using the environmental data and assumptions discussed in Appendix $E$ of this study. These methods are consistent with the methods outlined in Regulatory Guide 1.109.(7) 
15. For onsite waste exhumation operations, atmospheric releases are found by using the mechanical mixing resuspension analysis defined for exhumation operations at a low-level waste burial ground. ${ }^{(8)}$ A constant resuspension rate of $1 \times 10^{-7} \mathrm{sec}^{-1}$ is assumed. ${ }^{(9)}$ It is further assumed that only $10 \%$ of the waste/soil mixture is of a correct physical form and particle size to permit airborne transport. $(10,11,12)$ Because of the wet nature of waste in the bottom of the ponds and lagoons, the airborne dust concentration is assumed to be further reduced by a factor of 10 .

Other assumptions relating to specific decommissioning tasks are made and discussed where they apply to the analysis.

\section{I.2 DECON PUBLIC SAFETY ASSESSMENT}

The first option considered in the safety evaluation of decommissioning the reference $\mathrm{UF}_{6}$ conversion plant is $\mathrm{DECON}$ (irmediate decontamination) of the facility. This alternative results in removal of the radioactively contaminated portions of the buildings, the equipment, and the site so that unrestricted use by the public can be permitted.

The assessment of public safety during DECON includes a consideration of both routine tasks and postulated accidents. These tasks and accidents can generate considerable amounts of airborne radioactivity, primarily in the form of solid particles and/or suspended liquid droplets. Airborne contamination control measures are assumed to be used where they are considered necessary. The use of other appropriate controls is also considered.

In the following sections, the atmospheric releases from DECON are described for both routine tasks and postulated accidents. The atmospheric releases are estimated by determining the realistic maximum atmospheric release for each task or accident, and using this value whenever the task or accident is encountered, even for areas containing lower contamination levels.

\section{I.2.1 Routine DECON Tasks}

A complete discussion of the tasks for DECON at the reference $U_{F}$ conversion plant is contained in Appendix G. The chronological sequence of DECON 
tasks is listed in Figure G.2-1. The following subsections contain discussions of the methods used for calculating atmospheric releases of radioactivity and the public radiation doses from $D E C O N$ of the reference $U F_{6}$ conversion plant.

\section{I.2.1.1 Methods for Calculating Atmospheric Releases of Radioactivity}

Reference DECON methods are defined and analyzed in the following paragraphs so that generic airborne release mechanisms can be determined. A summary of the reference DECON tasks considered in this study is given in Table I.2-1. A complete discussion of each task considered is given below:

Radiation Survey. Radiation surveys are performed at the start of decommissioning, prior to termination of the nuclear license, and at other times during decommissioning to determine the residual levels of radioactive contamination. Radiation surveys involve crews of health physics technicians who walk through the plant and who are assumed to disturb settled radioactivity. The general housekeeping practices followed prior to and during dismantlement determine the amount of loose surface contamination, which varies with location within the reference $U_{6}$ conversion plant.

The relationship between the amount of material in the air above a surface and the contamination level of that surface has been studied experimentally. This relationship is shown by Equation I.I.

$$
s_{f}=\frac{c_{a}}{c_{s}}
$$

where:

$S_{f}$ - the resuspension factor, $\mathrm{m}^{-1}$

$c_{a}$ - the concentration of airborne radioactivity at a given location inside a building, $\mathrm{Ci} / \mathrm{m}^{3}$

$\mathrm{C}_{\mathrm{s}}$ - the concentration of radioactivity on bujlding surfaces, $\mathrm{Ci} / \mathrm{m}^{2}$.

Measured values of $S_{f}$ vary between $1 \times 10^{-5}$ and $2 \times 10^{-3} \mathrm{~m}^{-1}$, depending upon experimental conditions and measurement methods. (13-15) 


\section{TABLE I.2-1. DECON Safety Analysis Summary}

Task

Radiation Survey

2. Vacuuming

Surface cleaning

I. Sweeping

3. Water-jet
Operatian Description

Crews of Health Physics Tech-

nicians Walk Through the Pl

Residual Radioactive Contami-

nation

Small Quantities of Loose Contamination on floors are

Removed by Manual
Sweeping Compounds

Small Quantities of Loose Contamination on Surfaces are Renoved by Manual Vacuuming Procedures

Hand-Held High-Pressure Water Spray is Used to Remave Loose and Soivble Surface Contamination

4. Hand Washing

Limt ted Areas Are Cleaned with Mops or Sponges

quids are Made Airborne as Sprays

Airtorne Dust is Renoved

Airborne Dust is Removed from Floor Surfaces During Vacuuming

Airborne Particles are Caused by High-Pressure water Sprays
Routipe Airborne Release Routine Atmospheric Release Calculation Sullmary

Resuspension Analysis:

Surface Radioactive $x$

(Air Volume Covering Foncentration) $x$

(Air volume covering Floor) $x$

(Atmospheric Release)

Resuspensfon Factor)

(Surface Radioactivity Concentration) $x$

(Afr Yolume Covering Floor) $x$

(Building Transmission Factor) =

(Atmospheric Release)

Airborne Oust is Removed Resuspension Analysis:
from Floor Surfaces Dur- Resuspension Factor) $x$

Surface Radioactivity Concentration) $x$

Air Volume Through Vacuum Cleaner) $x$

Vacuum HEPA Transmission Factor) $x$

Building (ransmission Factor) =

(Atmospheric Release)

\section{Entrainment of Contaminated water:}

(Surface Contanination Removal Fraction) $x$

Surface Radioactive Concentration) $x$

(hater-Jet Cleaning Rate)

(Liquid Flow Rate) : (Solution Density)

(Airborne Concentration) $\times$ (Building Air Flow

Rate) $x$ (Water-Jet Use $x$ (Ime) $x$

Building iransmission Factor)

Atmospheric Release

- None Analyzed

Chenical Decontamination

1. Liquid Leaks

Loop Chemiçal Decontamination is Used in P ping and Equipment
Lquids are Hade Airborne Entrainnent of Contaminated Water:

from Liquid Leaks Contami-

- Fire in Con

taminated

Compound

- Vacuum Bag

Rujture

- Spilling Contaminated

- Loss of Services

- Seal Fatlures
Entrainnent of Contaminated water:

- Loss of Volema) Surfe Area) $x$ (Leak-Welghted Air of Lef $x$ (A) (Density of Linutio $x$ (Butlding

Transmission Factor) = (Atmospheric Release)

Spilis 


\section{TABLE I.2-1. (Contd)}

Postulated

Hazardous

Task

Operation Description

Routine Airtorne Release Routine Atmospheric Release Calculation Summary

Situations

Chemical Decontamina-

tion (Contd)

2. Spray Laaks

Loop Chemical Decontamination is Used in Piping and Equip

Liquids are Made Airborne from Spray Leaks

Entrainment of Spray:

- Loss of Internal Surface Radioactivity Concentration) x * Haterial Internal Surface Area) $x$ (Volume of Leak) $x$ (Total Liquid Volunie) $\times$ (Fraction of Leak to
Reach Filter System) $\times$ (Building Filter Trans

Failures

- Seal Failures inission Factor) $=$ (Atmospteric Release)

Piping or Equipment and Segmentation in Air

Piping and Equipment is Segnen-

Yaporized Metal is Made Airtorne (Contamina.

Contaminated Piping or Equipment:

Length of $\bar{C} u t) \times$ (Width of $\overline{C u} \bar{t}$ ) $\times$ (Surface nission Factor) = (Atmospheric Release) Activated Piping or Equipment:

Sanve as Above $x$ (Material T̄hickness) (Material Density)

- Loss of exyaletylene

Explosion

- Exal Loss nation con-

Moles are Drilled for insertion of Concrete 5pallers or Explosive Charges

Concrete Dust is Made Airborne (Contamination Control Envelope)

Concrete Dust Generation

(Number of Holes) $x$ (Surface Area per Hole) $x$ (Surface Radioactivity Concentration) $x$ Flow Rate) $x$ (Orilling Time) $\times$ (Control Envelope Leak Rate) $x$ (Building Filter Trans. mission Factor) : (Volume of Holes Drilled) trol

- Luss of

Services

- Equilure

- Local Loss of (Density of Concrete) = (Atmospheric Release) Contanination Control

2. Spalling

Hydraulically Controlled Concrete 5 pallers

3. Packaging

LNG-Powered Front-End Loader

Onsite Waste Exhumation

1. Exhumation/Pack- Crews Use Front-end Loaders, aging Dozers, toading Bins, Lift Trucks, and Other Equipment As Necessary to Exhume and Package Waste
Concrete Dust is Made Airborne (Contamination Control Envelope

Not Calculated

- Loss of

- Loss of contamination Control

Concrete Dust is Made Airborne (Contamination Control Envelope)

Not Calculated

- LNG Explo-

sion

Dust Generated During Exhumation and Packagin Operations in Open Air

Resuspension Rate) $\times$ (rotal Mixing Time) $\left(\begin{array}{l}\text { Yol ume of Waste) } x \\ \text { Atmospheric Release) }\end{array}\right.$ 
The concentration of airborne radioactivity at a given location inside a building is calculated by rearranging Equation I.I as shown in Equation I.2.

$$
c_{a}=S_{f} C_{s}
$$

where the terms $S_{f}, C_{s}$, and $C_{a}$ are the same as defined for Equation I.1.

The total radioactivity made airborne in a building is calculated by using an assumed average resuspension factor associated with the radiation survey of $1 \times 10^{-4} \mathrm{~m}^{-1}$, the surface radionuclide concentrations in the building, and the total volume of air contaminated during the radiation survey as shown in Equation I.3.

$$
Q_{s}=\left(1 \times 10^{-4} \mathrm{~m}^{-1}\right) c_{5} v_{s}
$$

where:

$Q_{S}$ - the total airborne radioactivity inside a building, $\mathrm{Ci}$

$\mathrm{C}_{\mathrm{s}}$ - the surface radioactivity concentration on building surfaces, $\mathrm{Ci} / \mathrm{m}^{2}$

$V_{s}$ - the volume of air covering the surface involved in the radiation survey (assumed to be $1 \mathrm{~m}$ deep), $\mathrm{m}^{3}$.

The airborne radioactivity generation rate during the radiation survey is found by dividing the airborne radioactivity, $Q_{S}$, by the time required to perform the survey. The total radioactivity released to the atmosphere is found by multiplying the airborne radioactivity generated by the building transmission factor.

Surface Cleaning. The surface cleaning operations considered are sweeping, vacuuming, and water-jet sprays.

1. Sweeping. Loose floor contamination is assumed to be removed by manual sweeping operations with the use of sweeping compounds. The amount of airborne radioactivity generated during sweeping is determined by using a resuspension factor analysis similar to the one discussed for the radiation survey. The amount of radioactivity made airborne is highly variable and 
is characterized by the properties of the loose contamination and the sweeping method. Sweeping compounds are designed to lower the resuspension by binding small particles of surface contamination to larger particles of sweeping compound.

Data from experimental studies of resuspension during sweeping are 1 imited. One study suggests a resuspension factor of $1.9 \times 10^{-4} \mathrm{~m}^{-1}$. (14) For this study, a conservatively large resuspension factor of $5 \times 10^{-4} \mathrm{~m}^{-1}$ is used. This factor is 5 times larger than the resuspension factor assumed for the radiation survey. The resuspended radioactivity is assumed to be confined in the lower meter of air in the room in which the sweeping occurs. Thus, the airborne radioactivity in a building is calculated using the volume of air disturbed by sweeping (assumed to be the volume $1 \mathrm{~m}$ deep above the surface area swept), the surface radioactivity concentration, and the assumed resuspension factor. The total atmospheric radioactivity released from sweeping is found by multiplying the airborne radioactivity generated in each location in the building by the building transmission factor.

2. Vacuuming. Vacuuming can be used as an alternative to manual sweeping for removal of loose surface contamination. Thus, certain areas of the building are designated for vacuuming. The vacuum exhaust is assumed to be fitted with a $99.95 \%$-efficient HEPA filter system. The airborne radioactivity in a building resulting from vacuuming is calculated by finding the product of the surface contamination level, the total area vacuumed, the assumed surface contamination removal fraction for vacuuming (0.5), and the vacuum system HEPA filter transmission factor. The total radioactivity released to the atmosphere is found by multiplying the airborne radioactivity from vacuuming by the building transmission factor.

3. Water-Jet Sprays. The water-jet is a hand-held high-pressure water spray designed to remove loose surface contamination. The operating water pressure is about $3.1 \times 10^{4} \mathrm{kPa}$. The principal mechanism for the generation of airborne radioactivity from the water-jet is the resuspension of liquid droplets containing contamination removed from surfaces. The water spray produces fine droplets smaller than $300 \mu \mathrm{m}$ in diameter (about the size of the droplets found in fogs or mists). Larger droplets are broken into 
smaller droplets as they impact on the contaminated surfaces. Thus, there is the potential for a significant formation of small droplets with a considerable variation in the total quantity of radioactivity contained in the droplets.

Direct data are not available to define the quantity of droplets formed. A conservative estimate is made by assuming that a sufficient quantity of droplets are generated to maintain an airborne liquid concentration of $1 \times 10^{-2} \mathrm{~g} / \mathrm{m}^{3}$ with vigorous mixing in air. This is the maximum mass concentration that can be found in air velocities less than $0.046 \mathrm{~m} / \mathrm{sec}$. (3) Measurements have shown that there is fairly constant distribution of 10 to 20-um diameter particles in a water-jet spray at a concentration of about $1 \times 10^{-2} \mathrm{~g} / \mathrm{m}^{3}$, including the gross entrainment of larger particles. Since particles smaller than $10 \mu \mathrm{m}$ are in the respirable-size range, they are potentially hazardous. The quantity of radioactivity found in these airborne droplets is influenced by factors such as the quantity of radioactivity on the surface, the solubility of the surface radioactivity in the liquid, and the contact between the liquid and the surface.

Operating parameters of the water-jet vary with the requirements of the surface decontamination effort. For this study, a water flow rate of $2.3 \times 10^{-2} \mathrm{~m}^{3} / \mathrm{min}$ and a cleaning rate of $0.77 \mathrm{~m}^{2} / \mathrm{min}$ are assumed. The water-jet is assumed to remove $90 \%$ of the surface contamination.

The concentration of radioactivity in the liquid resulting from use of the water-jet is defined by Equation I.4.

$$
c_{v}=0.9 c_{s}\left(\frac{0.77 \mathrm{~m}^{2} / \mathrm{min}}{2.3 \times 10^{-2} \mathrm{~m}^{3} / \mathrm{min}}\right)
$$


where:

$C_{v}$ - the concentration of radioactivity in the liquid resulting from use of the water-jet, $\mathrm{Ci} / \mathrm{m}^{3}$

0.9 - the fraction of the surface contamination removed by the water spray

$\mathrm{C}_{5}$ - the radioactivity concentration on the building surfaces, $\mathrm{Ci} / \mathrm{m}^{2}$

0.77 - the water-jet cleaning rate, $\mathrm{m}^{2} / \mathrm{min}$

$2.3 \times 10^{-2}$ - the water flow rate for the water-jet, $\mathrm{m}^{3} / \mathrm{min}$.

The airborne radioactivity generated in a building resulting from use of the water-jet is calculated from the liquid radioactivity concentration using Equation I.5.

$$
Q_{h}=\frac{C_{v}}{\rho}\left(1 \times 10^{-2} \mathrm{~g} / \mathrm{m}^{3}\right) F_{v} t
$$

where:

$Q_{h}$ - the airborne radioactivity in the building resulting from waterjet operations, $\mathrm{C} i$

$\mathrm{C}_{\mathrm{v}} \cdot$ liquid radioactivity concentration, $\mathrm{Ci} / \mathrm{m}^{3}$

$\rho$ - the density of the water-jet solution, $\mathrm{g} / \mathrm{m}^{3}$

$1 \times 10^{-2}$ the airborne concentration, $\mathrm{g} / \mathrm{m}^{3}$

$\mathrm{F}_{\mathrm{v}}$ - the building ventilation flow rate, $\mathrm{m}^{3} / \mathrm{h}$

$t$ - the time spent using the water-jet, $h$.

The atmospheric release of radioactivity from water-jet sprays is calculated by multiplying the airborne radioactivity in the building by the building transmission factor.

Chemical Decontamination. Liquid and spray leaks are assumed to occur during loop chemical decontamination of piping and equipment.

1. Liouid Leaks. A liquid leak results in a small airborne release in a building, since the liquid will retain most of the dissolved radioactive contamination until it reaches a floor drain. Therefore, only a small volume of air is assumed to contain $1 \times 10^{-2} \mathrm{~g} / \mathrm{m}^{3}$ of airborne radioactivity. 
The concentration of radioactivity in the decontamination solution is a function of the radioactivity removal fraction, the surface contamination level, and the volume of decontamination solution, as shown in Equation I.6.

$$
C_{V}=\frac{0.9 C_{S}}{V_{C}} A_{S}
$$

where:

$\mathrm{C}_{\mathrm{v}}$ - the liquid radioactivity concentration, $\mathrm{Ci} / \mathrm{m}^{3}$

0.9 - the surface contamination removal fraction

$C_{s}$ - surface concentration of radioactivity on internal pipe and equipment surfaces, $\mathrm{Ci} / \mathrm{m}^{2}$

$V_{c}$ - the volume of decontamination solution in the loop, $\mathrm{m}^{3}$

$A_{s}$ - the internal surface area decontamination, $m^{2}$.

It is assumed that only a small volume of air above a liquid leak becomes contaminated. This volume is assumed to be the amount of air $2 \mathrm{~m}$ deep above the floor surface area contaminated by the liquid leak. The floor surface covered by a leak is assumed to be $1 \mathrm{~m}^{2}$ for each liter of leak. Thus, the total airborne radioactivity is calculated using Equation I.7.

$$
\left.Q_{1}=\frac{V_{r}}{\rho} 1 \times 10^{-2} \mathrm{~g} / \mathrm{m}^{3}\right) C_{v}
$$

where:

$\mathrm{Q}_{1}$ - the airborne radioactivity in the building resulting from the liquid leak, $\mathrm{Ci}$

$V_{r}$ - the volume of room air containing the airborne release (the volume of air $2 \mathrm{~m}$ deep over the surface area contaminated, which is assumed to be $1 \mathrm{~m}^{2}$ per $1 \times 10^{-3} \mathrm{~m}^{3}$ of leak), $\mathrm{m}^{3}$

$1 \times 10^{-2}$ - the airborne concentration, $\mathrm{g} / \mathrm{m}^{3}$

$\rho$ - the density of the decontamination liquid, $\mathrm{g} / \mathrm{m}^{3}$

$C_{v}$ - the liquid radioactivity concentration, $\mathrm{C} i / \mathrm{m}^{3}$. 
The total radioactivity released to the atmosphere from a liquid leak is calculated by multiplying the airborne radioactivity in the building by the building HEPA filter transmission factor.

2. Spray Leaks. Spray leaks of chemical decontamination liquids can lead to a major airborne release since the radioactive iiquids are directly entrained in the building air. For this study, $0.3 \%$ of the airborne contamination in the building is assumed to be of the correct particle size to reach the building filter. (17) Thus, the total release to the environment from spray leaks is $0.3 \%$ of the leaked radioactivity multiplied by the building HEPA filter transmission factor.

Piping or Equipment Removal. Contaminated piping and equipment are assumed to be removed and segmented for disposal during DECON. For this study, four cutting methods are assumed to be used: arc saw, plasma-arc torch, oxyacetylene torch, and power hacksaw. A sumary of the cutting parameters for these methods is listed in Table I.2-2.

TABLE_I.2-2. Cutting Parameters for Piping and Equipment Remova 1 Cutting Method Cut (kerf) Width (m) Arc Saw $9.5 \times 10^{-3}$

Plasma Torch

0xyacetylene Torch

Power Hacksaw
$3.1 \times 10^{-3}$ to $6.4 \times 10^{-3}$

$$
6.4 \times 10^{-3}
$$$$
6.4 \times 10^{-3}
$$

Airborne Release

Meta 1 Fragments, Vapors

Condensed Metals, Gases, Smoke Particles Condensed Metals, Vapors Metal Fragments, Vapors

For piping or equipment containing surface contamination, the airborne release in the building from cutting tasks. in air is calculated using Equation I.8.

$$
Q_{C}=L K C_{S}
$$

where:

\footnotetext{
$Q_{C}$ - the airborne radioactivity from cutting contaminated pipe or equipment, $\mathrm{Ci}$

$L$ - the length of cut, $m$
} 
$K$ - the width of the cut (kerf), $m$

$\mathrm{C}_{\mathrm{s}}$ - the surface radioactivity concentration, $\mathrm{Ci} / \mathrm{m}^{2}$.

Equation 1.8 is based on the conservative assumption that all of the surface radioactive contamination associated with the cut width is vaporized and made airborne during cutting operations.

Contaminated Concrete Removal. Structural concrete that cannot be decontaminated to unrestricted-use levels by surface cleaning methods must be mechanically removed. For this study, the only method considered is the use of concrete spallers to remove these contaminated concrete areas. Airborne contamination control is assumed to be provided by the use of a vacuum exhaust system during this dusty task. Holes are drilled into the concrete surfaces for insertion of the concrete spaller. To calculate the airborne radioactivity in a building associated with the dust generated during drilling, the volume of concrete for each hole, the number of holes drilled, the radioactive contamination level and the effectiveness of the vacuum system mist be determined. Each hole is assumed to be $0.051 \mathrm{~m}$ deep and to remove a conteminated surface area of $0.05 \mathrm{~m}^{2}$.

For structural concrete with surface contamination only, the total radioactivity associated with drilling is found by multiplying the number of holes drilled by the surface area per hole by the surface contamination level. The surface contamination is assumed to be uniformly mixed in volume of dust associated with drilling the holes. A vacuum exhaust system is used to collect the dust generated during drilling. This system is assumed to have an airflow of $1000 \mathrm{~m}^{3} / \mathrm{hr}$ and reduce the air concentration of dust by a factor of 0.3 . The quantity of airborne radioactivity generated by drilling is given by Equation I.9.

$$
Q_{d}=\frac{N_{h}\left(7.8 \times 10^{-5} \mathrm{~m}^{2} / \text { hole }\right) C_{s}}{V_{h^{\rho}}} F_{v} t(0.3) 1 \times 10^{-1} \mathrm{~g} / \mathrm{m}^{3}
$$

where:

$Q_{d}$ - the quantity of radioactivity made airborne during drilling, Ci

$\mathrm{N}_{h}$ - the number of holes drilled 
$7.8 \times 10^{-5}$ the surface area removed per hole, $\mathrm{m}^{2} /$ hole

$\mathrm{C}_{\mathrm{s}}$ - the concentration of surface radioactivity, $\mathrm{Ci} / \mathrm{m}^{2}$

$V_{h}$ - the total volume of all holes drilled, $\mathrm{m}^{3}$

$\rho$ - the density of concrete, $2.5 \times 10^{3} \mathrm{~kg} / \mathrm{m}^{3}$

$F_{v}^{\prime} \cdot$ the vacuum system airflow rate, $1.0 \times 10^{3} \mathrm{~m}^{3} / \mathrm{h}$

$t$ - the duration of the drilling operation, $h$

0.3 - airborne cleanup factor

$1 \times 10^{-1}$. the airborne concentration in the vacuum system, $\mathrm{g} / \mathrm{m}^{3}$.

The radioactivity released to the atmosphere is found by multiplying the quantity of radioactivity generated by the leakage factor from the control envelope (if one is used) and by the building transmission factor.

After the holes are drilled, the concrete spaller is inserted into the holes and the concrete surface is scarfed. The concrete fractures and spalls in large pieces with a relatively small amount of dust generated. Water sprays are assumed to be used to control the airborne dust during the concrete spalling. Thus, the airborne release from concrete spalling is assumed to be insignificant when compared to the drilling operations and is not considered further in this study.

Onsite Waste Exhumation. Uranium-contaminated soil is assumed to be removed from the extraction waste pond, the fluoride waste lagoons, and from miscellaneous waste burial locations onsite. A summary of options considered for the DECON alternative is given in Appendix $H$. Only the option that results in the max $i-$ mum atmospheric release is considered in this public safety assessment. Atmospheric releases are found using the mechanical mixing resuspension analys is defined for low-level waste exhumation operations. ${ }^{(8)}$ The airborne radioactivity resulting from mechanical resuspension is calculated by determining the product of the mechanical mixing resuspension rate $\left(1 \times 10^{-7} \mathrm{~s}^{-1}\right)$, the volume of waste disturbed $\left(\mathrm{m}^{3}\right)$, the total disturbance time ( $\left.\mathrm{s}\right)$, and the specific activity of the waste $\left(\mathrm{ci} / \mathrm{m}^{3}\right)$. The time estimates used are for the exhumation, waste packaging, and offsite disposal option discussed in Appendix $H$. The waste is assunied to be in a wet form that reduces its atmospheric concentration from resuspension by a factor of 10 . It is also assumed that only $10 \%$ of the waste is of the proper physical form and particle size to permit airborne transport. 


\section{I.2.1.2 Atmospheric Releases from DECON Tasks.}

Releases of radioactivity resulting from DECON tasks at the reference $\mathrm{UF}_{6}$ conversion plant are calculated using the general methods described in Section I.2.1.1. The operational data used for each area is shown in Table 1.2-3. The areas listed in this table are based on the DECON tasks discussed in Appendix G. Table I.2-3 contains the necessary safety analys is data, operational times, and contamination levels associated with DECON operations for each building area.

The calculated atmospheric releases for DECON tasks at the reference $\mathrm{UF}_{6}$ conversion plant are shown in Table I.2-4. This table contains the calculated airborne radioactivity generation rates, the total airborne contamination generated inside the main building, and the total atmospheric release associated with each area considered. These atmospheric releases are used in the radiation dose calculations to estimate the impact of DECON tasks on the public, as discussed in the following subsection.

\section{I.2.1.3 Pub1ic Radiation Doses from DECON Tasks}

Radiation doses to the public from atmospheric releases resulting from DECON tasks are calculated using the radiation dose models discussed in Appendix $E$. The first-year doses and the fifty-year committed dose equivalents to both the maximum-exposed individual and to the population residing within $80 \mathrm{kml}$ of the site are calculated for each process area considered. Each of the atmospheric releases is assumed to be a chronic release; that is, one that occurs at a uniform rate for a period of 1 year. This is done so that direct comparisons of the impacts of DECON tasks can be made.

Radiation doses from atmospheric releases of radioactivity are calculated for direct exposure, inhalation, and ingestion radiation exposure pathways. Radiation doses from air submersion are not calculated since they have been shown to be insignificant in previous decommissioning studies. $(18,19,20)$ For inhalation, radionuclides are assumed to have soluble clearance times (as defined in Appendix F) for the organs of reference, except for the lung where insoluble clearance times are assumed. For this study, the organs of reference for which radiation dose is calculated include: total body, bone, lung, and GI-tract (lower large intestine). 
TABLE 1.2-3. Public Safety Analys is Data Summary for DECON and Preparations for Safe Storage of the UF ${ }_{6}$ Conversion Plant

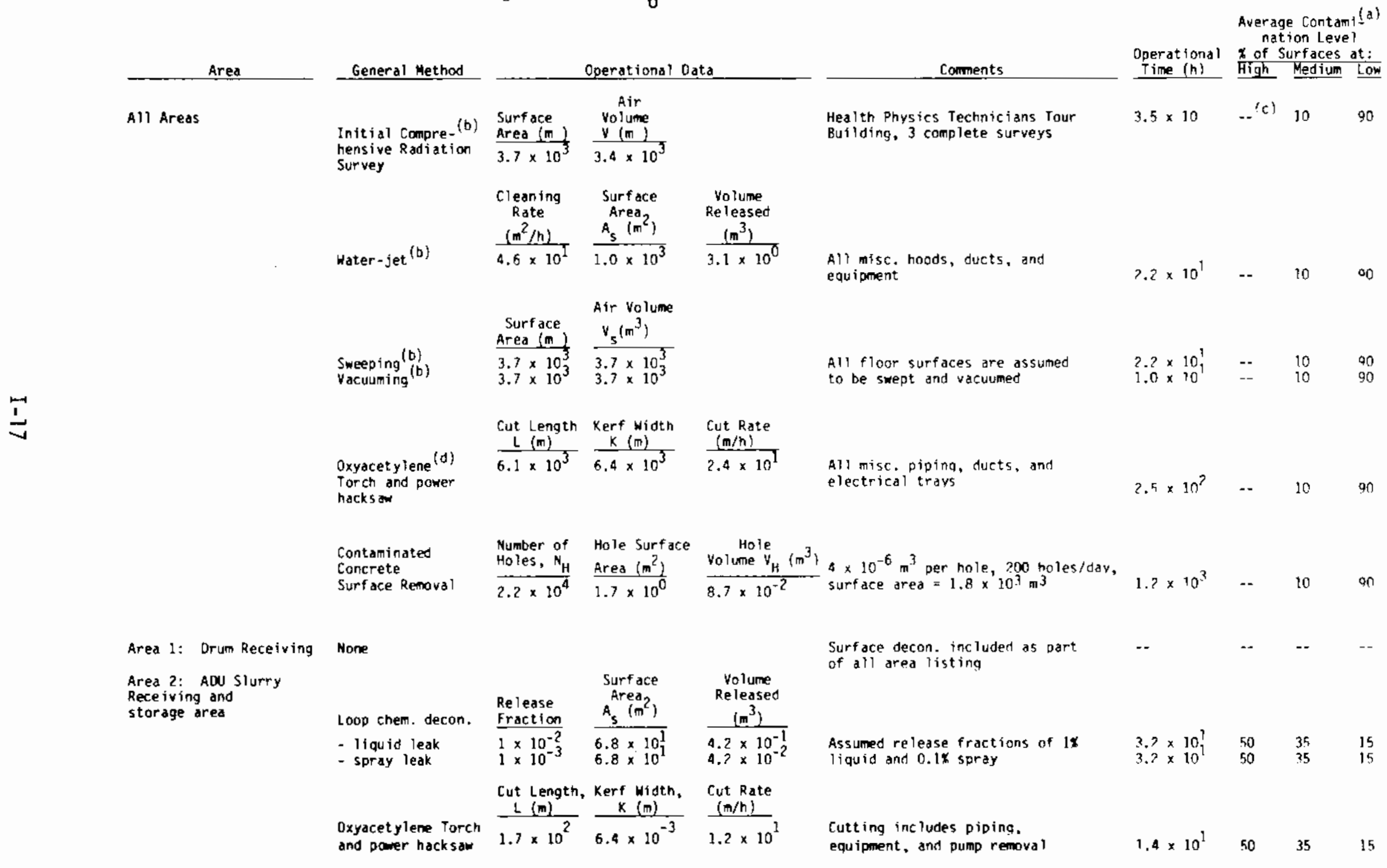


TABLE I.2-3. (Contd)

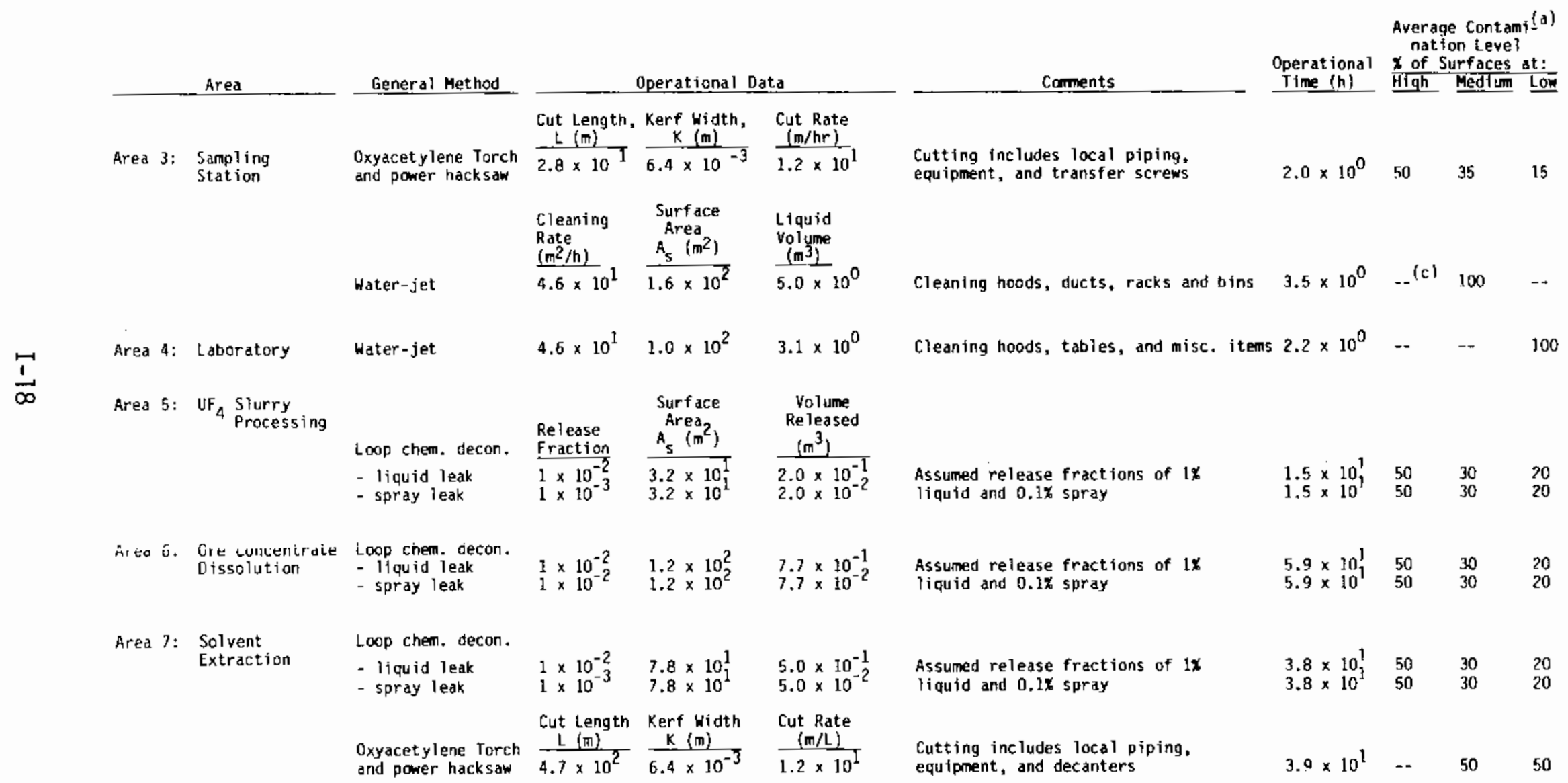




\section{TABLE I.2-3. (Contd)}

\begin{tabular}{|c|c|c|c|c|c|c|c|c|c|c|}
\hline & & & & & & & Operational & $\begin{array}{l}\text { Avera } \\
\text { nat } \\
\text { nof }\end{array}$ & $\begin{array}{l}\text { e Contam } \\
\text { on Level } \\
\text { urfaces }\end{array}$ & $\begin{array}{l}i(0) \\
i \text { at: }\end{array}$ \\
\hline & Area & General Methad & & Operationa! & & Comnents & Iine (h) & High & Medium & Low \\
\hline Ared 8: & $\begin{array}{l}\text { Uranyl Nitrate } \\
\text { Concentration }\end{array}$ & $\begin{array}{l}\text { 0xyacetylene Torch } \\
\text { and power hacksaw }\end{array}$ & $2.4 \times 10^{2}$ & $6.4 \times 10^{-3}$ & $1.2 \times 10^{1}$ & $\begin{array}{l}\text { Cutting tncludes local pipina, } \\
\text { equipment, and evaporators }\end{array}$ & $2.0 \times 10^{1}$ & -- & 100 & -- \\
\hline & & Load chem, decon & $\begin{array}{l}\text { Release } \\
\text { Fraction }\end{array}$ & $\begin{array}{l}\text { Surface } \\
\text { Area } \\
A_{S}\left(m^{2}\right)\end{array}$ & $\begin{array}{l}\text { Volume } \\
\text { Released } \\
\left.\text { (m } \text { m }^{3}\right) \\
\end{array}$ & & & & & \\
\hline & & $\begin{array}{l}\text { - liquid leak } \\
\text { - spray leak }\end{array}$ & $\begin{array}{l}1 \times 10^{-2} \\
1 \times 10^{-3}\end{array}$ & $\begin{array}{l}6.6 \times 10^{1} \\
6.6 \times 10^{1}\end{array}$ & $\begin{array}{l}4.2 \times 10^{-1} \\
4.2 \times 10^{-2}\end{array}$ & liquid and $0.1 \%$ spray & $\begin{array}{l}3.2 \times 10^{1} \\
3.2 \times 10^{1}\end{array}$ & $\begin{array}{l}50 \\
50\end{array}$ & $\begin{array}{l}30 \\
30\end{array}$ & $\begin{array}{l}20 \\
20\end{array}$ \\
\hline Area 9: & Denitration & Oxyacetylene Torch & $\begin{array}{l}\text { Cut Length } \\
\mathrm{L}(\mathrm{m}) \\
\end{array}$ & $\begin{array}{l}\text { Kerf Width } \\
\mathrm{K}(\mathrm{m}) \\
\end{array}$ & $\begin{array}{l}\text { Cut Rate } \\
(\mathrm{m} / \mathrm{L})\end{array}$ & Cutting includes local piping, & & & & \\
\hline & & and power hacksaw & $4.6 \times 10^{2}$ & $6.4 \times 10^{-3}$ & $1.2 \times 10^{1}$ & equipment, denitrator, and scrubber & $3.8 \times 10^{1}$ & -- & 50 & 50 \\
\hline Area 10: & $\begin{array}{l}\text { Nitric Acid } \\
\text { Recovery }\end{array}$ & Loop chem. decon. & $\begin{array}{l}\text { Release } \\
\text { Fraction }\end{array}$ & $\begin{array}{c}\text { Surf ace } \\
\text { Area } \\
\mathrm{A}_{5}\left(\mathrm{~m}^{2}\right)\end{array}$ & $\begin{array}{l}\text { Volume } \\
\text { Released } \\
\left(m^{3}\right) \\
\end{array}$ & & & & & \\
\hline & & $\begin{array}{l}\text { - liquid leak } \\
\text { - spray leak }\end{array}$ & $\begin{array}{l}1 \times 10^{-2} \\
1 \times 10^{-3}\end{array}$ & $\begin{array}{l}3.6 \times 10^{1} \\
1.6 \times 10^{1}\end{array}$ & $\begin{array}{l}1.0 \times 10^{-2} \\
1.0 \times 10^{-2}\end{array}$ & $\begin{array}{l}\text { Assumed release fractions of } 1 x \\
\text { liquid and } 0.1 \% \text { spray }\end{array}$ & $\begin{array}{l}7.6 \times 10^{0} \\
7.6 \times 10^{0}\end{array}$ & -- & $\begin{array}{l}50 \\
50\end{array}$ & $\begin{array}{l}50 \\
50\end{array}$ \\
\hline Area 11: & $\begin{array}{l}\text { Reduction } \\
\text { Systems }\end{array}$ & & $\begin{array}{c}\text { Cleaning } \\
\text { Rate } \\
\left(\mathrm{m}^{2} / \mathrm{h}\right) \\
\end{array}$ & $\begin{array}{c}\text { Surface } \\
\text { Area }_{2} \\
\mathrm{~A}_{\mathrm{s}}\left(\mathrm{m}^{2}\right) \\
\end{array}$ & $\begin{array}{c}\text { Liquid } \\
\text { volume } \\
\left(\mathrm{m}^{3}\right) \\
\end{array}$ & & & & & \\
\hline & & Water-jet & $4.6 \times 10^{1}$ & $1.7 \times 10^{2}$ & $5.3 \times 10^{0}$ & Cleaning hoods, ducts, and bins & $3.7 \times 10^{0}$ & -- & 100 & - \\
\hline & & Oxyacetylene Torch & $\begin{array}{l}\text { Cut Length } \\
\mathrm{L}(\mathrm{m}) \\
\end{array}$ & $\begin{array}{l}\text { Kerf Hidth } \\
K(m) \\
\end{array}$ & $\begin{array}{l}\text { Cut Rate } \\
(\mathrm{m} / \mathrm{L})\end{array}$ & Cutting includes local piping. & & & & \\
\hline & & and power hacksaw & $1.5 \times 10^{2}$ & $6.4 \times 10^{\circ}$ & $1.2 \times 10^{2}$ & equipment, and reduction reactors & $1.2 \times 10^{2}$ & -- & 100 & -- \\
\hline Area 12: & $\begin{array}{l}\text { Hydrof lueri- } \\
\text { nation }\end{array}$ & $\begin{array}{l}\text { Oxyacetylene Torch } \\
\text { and power hacksaw }\end{array}$ & $2.8 \times 10^{1}$ & $6.4 \times 10^{-3}$ & $3.2 \times 10^{1}$ & $\begin{array}{l}\text { Cutting includes feeders, hoppers, } \\
\text { and conveyors }\end{array}$ & $2.2 \times 10^{0}$ & 10 & 40 & 50 \\
\hline
\end{tabular}


TABLE I.2-3. (Contd)

\begin{tabular}{|c|c|c|c|c|c|c|c|c|c|c|}
\hline & Aręa & General Method & & Operational & & Comments & $\begin{array}{l}\text { Operational } \\
\text { Iime (h) }\end{array}$ & $\begin{array}{l}\text { Aver } \\
\text { nat } \\
x \text { of } \\
\text { Bigh }\end{array}$ & $\begin{array}{l}\text { ge Contan } \\
\text { ion Leve } \\
\text { surfaces } \\
\text { Medium }\end{array}$ & it: \\
\hline \multirow[t]{3}{*}{ Area 13: } & \multirow[t]{3}{*}{ Fluorination } & $\begin{array}{l}\text { Oxyacet ylene Torch } \\
\text { and power hacksaw }\end{array}$ & & $6.4 \times 10^{-3}$ & & \multirow[t]{2}{*}{$\begin{array}{l}\text { Cutting includes fluorinator towers, } \\
\text { product cylinders, and cold traps }\end{array}$} & \multirow[t]{2}{*}{$2.3 \times 10^{?}$} & \multirow[t]{2}{*}{10} & \multirow[t]{2}{*}{40} & \multirow[t]{2}{*}{50} \\
\hline & & Loop chem. decon. & $\begin{array}{l}\text { Release } \\
\text { Fraction }\end{array}$ & $\begin{array}{r}\text { Surf ace } \\
\text { Area } \\
A_{s}\left(m^{2}\right) \\
\end{array}$ & $\begin{array}{c}\text { Yolume } \\
\text { Releassed } \\
\left(\mathrm{m}^{3}\right)^{2}\end{array}$ & & & & & \\
\hline & & $\begin{array}{l}\text { - liquid leak } \\
\text { - spray leak }\end{array}$ & $\begin{array}{l}1 \times 10^{-2} \\
1 \times 10^{-3}\end{array}$ & $\begin{array}{l}2.1 \times 10^{2} \\
2.1 \times 10^{2}\end{array}$ & $\begin{array}{l}1.3 \times 10^{0} \\
1.3 \times 10^{-1}\end{array}$ & $\begin{array}{l}\text { Assumed release fractions of } 1 \% \\
\text { iq quid and } 0.1 \% \text { spray }\end{array}$ & $\begin{array}{l}9.9 \times 10^{9} \\
9.9 \times 10^{7}\end{array}$ & $\begin{array}{l}10 \\
10\end{array}$ & $\begin{array}{l}40 \\
40\end{array}$ & $\begin{array}{l}50 \\
50\end{array}$ \\
\hline Area 14: & Cylinder loading & & None & & & $\begin{array}{l}\text { Surface decon. included } \\
\text { part of all area listing }\end{array}$ & -- & - & -- & -- \\
\hline \multirow[t]{3}{*}{ Area 15: } & \multirow[t]{3}{*}{$\begin{array}{l}\text { Fluorine } \\
\text { Generation }\end{array}$} & Loop chen. decon. & $\begin{array}{l}\text { Release } \\
\text { Fraction }\end{array}$ & $\begin{array}{c}\text { Surface } \\
\text { Area }_{2} \\
A_{\mathrm{s}}\left(\mathrm{m}^{2}\right) \\
\end{array}$ & $\begin{array}{c}\text { Volume } \\
\text { Rereased } \\
\left(m^{3}\right) \\
\end{array}$ & & & & & \\
\hline & & $\begin{array}{l}\text { - liquid leak } \\
\text { - spray leak }\end{array}$ & $\begin{array}{l}1 \times 10^{-2} \\
1 \times 10^{-3}\end{array}$ & $\begin{array}{l}7.1 \times 10^{1} \\
7.1 \times 10^{1}\end{array}$ & $\begin{array}{l}4.4 \times 10^{-1} \\
4.4 \times 10^{-2}\end{array}$ & $\begin{array}{l}\text { Assumed release fractions of } 1 \% \\
1 \text { iquid and } 0.1 \% \text { spray }\end{array}$ & $\begin{array}{l}3.4 \times 10^{1} \\
3.4 \times 10^{9}\end{array}$ & $=$ & $\begin{array}{l}20 \\
20\end{array}$ & $\begin{array}{l}80 \\
80\end{array}$ \\
\hline & & $\begin{array}{l}\text { Oxyacet ylene Torch } \\
\text { and power hacksaw }\end{array}$ & $\begin{array}{l}\text { Cut Length } \\
\frac{\mathrm{L}(\mathrm{m})}{6.7 \times 10^{2}}\end{array}$ & $\begin{array}{l}\text { Kerf Width } \\
\frac{x}{6.4 \times 10^{-3}}\end{array}$ & $\frac{\begin{array}{l}\text { Cut Rate } \\
(\mathrm{m} / \mathrm{L})\end{array}}{1.2 \times 10^{1}}$ & $\begin{array}{l}\text { Cutt ing inc ludes fluor ine cells, } \\
\text { surge tanks, and storage tanks }\end{array}$ & $5.5 \times 10^{1}$ & -- & 20 & 80 \\
\hline \multirow{4}{*}{\multicolumn{2}{|c|}{ Areas 16 through 24}} & Loop chem. decon. & $\begin{array}{l}\text { Release } \\
\text { Fraction }\end{array}$ & $\begin{array}{l}\text { Area } \\
A_{s}\left(m^{2}\right) \\
\end{array}$ & $\begin{array}{l}\text { Surface } \\
\text { Released } \\
\left(\mathrm{m}^{3}\right)\end{array}$ & volume & & & & \\
\hline & & $\begin{array}{l}\text { - Itquid leak } \\
\text { - spray leak }\end{array}$ & $\begin{array}{l}1 \times 10^{-2} \\
1 \times 10^{-3}\end{array}$ & $\begin{array}{l}2.3 \times 10^{2} \\
2.3 \times 10^{2}\end{array}$ & $\begin{array}{l}1.4 \times 10^{0} \\
1.4 \times 10^{-1}\end{array}$ & $\begin{array}{l}\text { Assumed release fractions of } 1 \% \\
\text { liquid and } 0.1 \% \text { spray }\end{array}$ & $\begin{array}{l}1.1 \times 10^{2} \\
1.1 \times 10^{2}\end{array}$ & $\begin{array}{l}-- \\
--\end{array}$ & $\begin{array}{l}50 \\
50\end{array}$ & $\begin{array}{l}50 \\
50\end{array}$ \\
\hline & & & $\begin{array}{l}\text { Cleaning } \\
\text { Rate } \\
\left(\mathrm{m}^{2} / \mathrm{h}\right)\end{array}$ & $\begin{array}{l}\text { Surf ace } \\
\text { Area } \\
A_{s}\left(m^{2}\right) \\
\end{array}$ & $\begin{array}{l}\text { Yolume } \\
\text { Released } \\
\left(m^{3}\right)\end{array}$ & & & & & \\
\hline & & Water-jet & $4.6 \times 10^{1}$ & $2.9 \times 10^{2}$ & $9.0 \times 10^{0}$ & $\begin{array}{l}\text { Released surfaces of all pipina } \\
\text { and equipment }\end{array}$ & $6.3 \times 10^{0}$ & $\ldots$ & 50 & 50 \\
\hline
\end{tabular}


TABLE 1.2-3. (Contd)

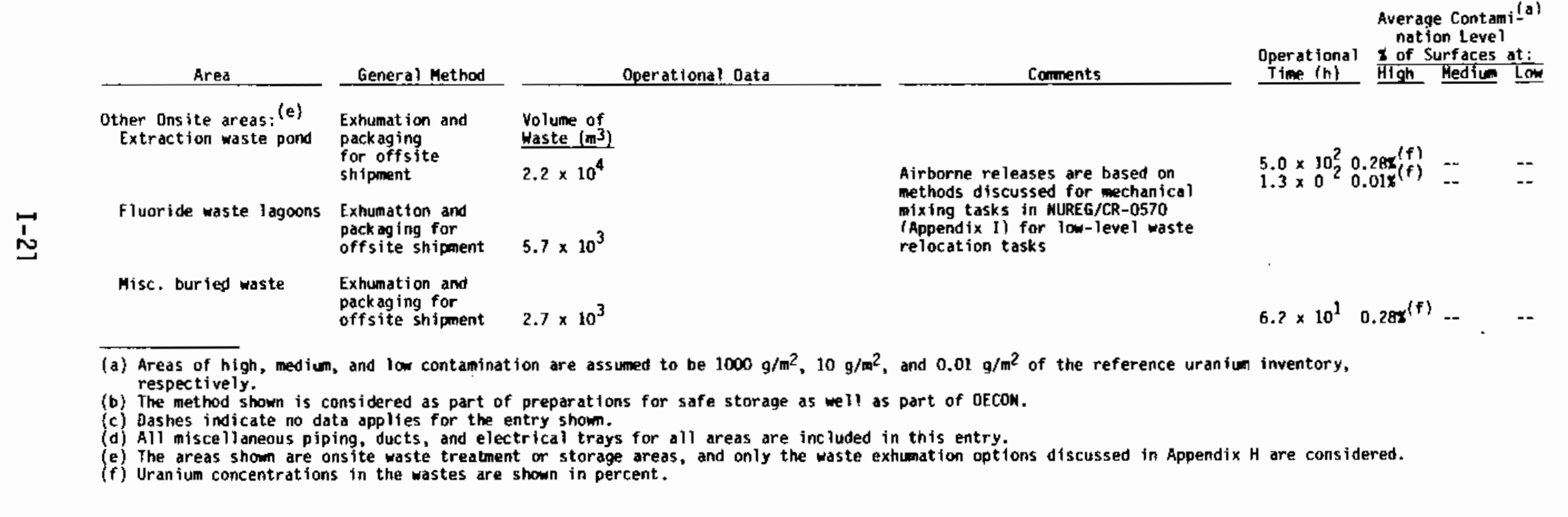


TABLE I.2-4. Calculated Atmospheric Releases for DECON at the Reference UF 6 Conversion Plant

\begin{tabular}{|c|c|c|c|c|c|c|c|}
\hline & Area & General Method & $\begin{array}{l}\text { Operational } \\
\text { Iime }(h) \\
\end{array}$ & $\begin{array}{c}\text { Airborne } \\
\text { Generation Rate } \\
\text { Inside 8uilding } \\
\text { or Control } \\
\text { Envelope }(\mathrm{Ci} / \mathrm{h}) \\
\end{array}$ & $\begin{array}{l}\text { Total Airborne } \\
\text { Radioactivity } \\
\text { Inside guilding } \\
\text { or Control } \\
\text { Envelope (Ci) } \\
\end{array}$ & $\begin{array}{l}\text { Contanination }(a) \\
\text { Control System } \\
\text { Transmission } \\
\text { Eactor } \\
\end{array}$ & $\begin{array}{c}\text { Tota }{ }^{(b)} \\
\text { Atmospheric } \\
\text { Release } \\
\text { (Ci i/yr) } \\
\end{array}$ \\
\hline \multirow{6}{*}{\multicolumn{2}{|c|}{ A11 Areas }} & $\begin{array}{l}\text { Initial Comprehensive (c) } \\
\text { Radiation Survey }\end{array}$ & $3.5 \times 10^{1}$ & $1.4 \times 10^{-8}$ & $4.8 \times 10^{-7}$ & $1 \times 10^{-1}$ & $4.8 \times 10^{-8}$ \\
\hline & & Hater-Jet $(c)$ & $2.2 \times 10^{1}$ & $6.9 \times 10^{-8}$ & $1.5 \times 10^{-6}$ & $1 \times 10^{-1}$ & $1.5 \times 10^{-7}$ \\
\hline & & Sweeping $(c)$ & $2.2 \times 10^{1}$ & $1.1 \times 10^{-7}$ & $2.4 \times 10^{-6}$ & $1 \times 10^{-1}$ & $2.4 \times 10^{-7}$ \\
\hline & & Vacuuming $(c)$ & $1.0 \times 10^{1}$ & $1 . ? \times 10^{-7}$ & $1.2 \times 10^{-6}$ & $1 \times 10^{-1}$ & $1.2 \times 10^{-8}$ \\
\hline & & $\begin{array}{l}\text { Oxyacet ylene Torch } \\
\text { and Power Hacksaw (d) }\end{array}$ & $2.5 \times 10^{2}$ & $2.2 \times 10^{-7}$ & $5.5 \times 10^{-5}$ & $1 \times 10^{-1}$ & $5.6 \times 10^{-6}$ \\
\hline & & $\begin{array}{l}\text { Contaminated Concrete } \\
\text { Surf ace Removal }\end{array}$ & $1.2 \times 10^{3}$ & $3.4 \times 10^{-10}$ & $4.0 \times 10^{-7}$ & $1 \times 10^{-1}$ & $4.0 \times 10^{-8}$ \\
\hline Area 1: & Drum Receiving & None & $--(e)$ & -- & -- & $\omega$ & -- \\
\hline \multirow[t]{3}{*}{ Area 2: } & \multirow[t]{3}{*}{$\begin{array}{l}\text { ADU Slurry } \\
\text { Receiving and } \\
\text { Storage Area }\end{array}$} & $\begin{array}{l}\text { Loop Chem. Decon. } \\
\text { - Liquid Leak }\end{array}$ & $3.2 \times 10^{1}$ & $2.6 \times 10^{-10}$ & $8.5 \times 10^{-9}$ & $1 \times 10^{-1}$ & $8.5 \times 10^{-10}$ \\
\hline & & - Spray Leak & $3.2 \times 10^{1}$ & $4.1 \times 10^{-9}$ & $1.3 \times 10^{-7}$ & $1 \times 10^{-1}$ & $1.3 \times 10^{-8}$ \\
\hline & & $\begin{array}{l}\text { 0xyacetylene Torch } \\
\text { and Power Hacks }\end{array}$ & $1.4 \times 10^{1}$ & $5.1 \times 10^{-5}$ & $7.1 \times 10^{-4}$ & $1 \times 10^{-2}$ & $7.1 \times 10^{-6}$ \\
\hline \multirow[t]{2}{*}{ Area 3: } & \multirow[t]{2}{*}{ Sampling Station } & $\begin{array}{l}\text { 0xyacetylene Torch } \\
\text { and rower riacksaw }\end{array}$ & $2.0 \times 10^{0}$ & $6.0 \times 10^{-5}$ & $1.2 \times 10^{-4}$ & $1 \times 10^{-2}$ & $1.2 \times 10^{-6}$ \\
\hline & & Water-Jet & $3.5 \times 10^{0}$ & $6.1 \times 10^{-7}$ & $2.1 \times 10^{-6}$ & $1 \times 10^{-1}$ & $2.1 \times 10^{-7}$ \\
\hline Area 4: & Laboratory & Water-Jet & $2.2 \times 10^{0}$ & $6.1 \times 10^{-9}$ & $1.3 \times 10^{-8}$ & $1 \times 10^{-1}$ & $1.3 \times 10^{-9}$ \\
\hline \multirow[t]{2}{*}{ Area 5: } & $\begin{array}{l}\text { UF }_{4} \text { Slurry } \\
\text { Processing }\end{array}$ & $\begin{array}{l}\text { Loop Chem. Decon. } \\
\text { - Liquid Leak }\end{array}$ & $1.5 \times 10^{1}$ & $5.5 \times 10^{-10}$ & $5.2 \times 10^{-9}$ & $1 \times 10^{-1}$ & $5.2 \times 10^{-10}$ \\
\hline & & - Spray Leak & $1.5 \times 10^{1}$ & $5.2 \times 10^{-9}$ & $7.8 \times 10^{-8}$ & $1 \times 10^{-1}$ & $7.8 \times 10^{-9}$ \\
\hline \multirow[t]{2}{*}{ Area 6: } & $\begin{array}{l}\text { Ore Concentrate } \\
\text { Dissolution }\end{array}$ & $\begin{array}{l}\text { Loop Chem. Decon. } \\
\text { - Liquid Leak }\end{array}$ & $5.9 \times 10^{1}$ & $2.0 \times 10^{-10}$ & $1.2 \times 10^{-8}$ & $1 \times 10^{-1}$ & $1.7 \times 10^{-9}$ \\
\hline & & - Spray Leak & $5.9 \times 10^{1}$ & $3.3 \times 10^{-9}$ & $1.9 \times 10^{-7}$ & $1 \times 10^{-1}$ & $1.9 \times 10^{-8}$ \\
\hline
\end{tabular}


TABLE I.2-4. (Contd)

\begin{tabular}{|c|c|c|c|c|c|c|c|}
\hline & Area & General Method & $\begin{array}{l}\text { Operational } \\
\text { Iime }(h) \\
\end{array}$ & $\begin{array}{c}\text { Airborne } \\
\text { Generat ion Rate } \\
\text { Inside Building } \\
\text { or Controf } \\
\text { Envelope (Ci/h) }\end{array}$ & $\begin{array}{l}\text { Total Airborne } \\
\text { Radioactivity } \\
\text { Inside Building } \\
\text { or Control } \\
\text { Envelope (Ci) } \\
\end{array}$ & $\begin{array}{l}\text { Contamination (a) } \\
\text { Controf System } \\
\text { Transmission } \\
\text { Factor } \\
\end{array}$ & $\begin{array}{l}\text { Total }(\mathrm{b}) \\
\text { Atmospheric } \\
\text { Release } \\
(\text { C } 1 / \mathrm{yr}) \\
\end{array}$ \\
\hline \multirow[t]{3}{*}{ Area 7: } & $\begin{array}{l}\text { Solvent } \\
\text { Extraction }\end{array}$ & $\begin{array}{l}\text { Loop Chem. Decon. } \\
\text { - Liquid Leak }\end{array}$ & $3.8 \times 10^{1}$ & $2.9 \times 10^{-10}$ & $1.1 \times 10^{-8}$ & $1 \times 10^{-1}$ & $1.1 \times 10^{-9}$ \\
\hline & & - Spray Leak & $3.8 \times 10^{1}$ & $4.2 \times 10^{-9}$ & $1.6 \times 10^{-7}$ & $1 \times 10^{-1}$ & $1.6 \times 10^{-8}$ \\
\hline & & $\begin{array}{l}\text { Oxyacet ylene Torch } \\
\text { and Power Hacks }\end{array}$ & $3.9 \times 10^{1}$ & $5.0 \times 10^{-7}$ & $2.0 \times 10^{-5}$ & $1 \times 10^{-2}$ & $2.0 \times 10^{-7}$ \\
\hline \multirow[t]{3}{*}{ Area 8: } & $\begin{array}{l}\text { Uranyi Nitrate } \\
\text { Concentration }\end{array}$ & $\begin{array}{l}\text { Oxyacet ylene Torch } \\
\text { and Power Hacks }\end{array}$ & $2.0 \times 10^{1}$ & $1.0 \times 10^{-6}$ & $2.0 \times 10^{-5}$ & $1 \times 10^{-2}$ & $2.0 \times 10^{-7}$ \\
\hline & & $\begin{array}{l}\text { Loop Chem. Decon. } \\
\text { - Liquid Leak }\end{array}$ & $3.2 \times 10^{1}$ & $2.6 \times 10^{-10}$ & $8.5 \times 10^{-9}$ & $1 \times 10^{-1}$ & $8.5 \times 10^{-10}$ \\
\hline & & - Spray Leak & $3.2 \times 10^{1}$ & $4.1 \times 10^{-9}$ & $1.3 \times 10^{-7}$ & $1 \times 10^{-1}$ & $1.3 \times 10^{-8}$ \\
\hline Area 9: & Denitration & $\begin{array}{l}\text { Oxyacetylene Torch } \\
\text { and Power Hacksaw }\end{array}$ & $3.2 \times 10^{1}$ & $5.0 \times 10^{-7}$ & $1.9 \times 10^{-5}$ & $1 \times 10^{-2}$ & $1.9 \times 10^{-7}$ \\
\hline \multirow[t]{2}{*}{ Area 10: } & $\begin{array}{l}\text { Nitric Acid } \\
\text { Recovery }\end{array}$ & $\begin{array}{l}\text { Loop Chem. Decon. } \\
\text { - Liquid Leak }\end{array}$ & $7.6 \times 10^{0}$ & $5.3 \times 10^{-12}$ & $4.0 \times 10^{-11}$ & $1 \times 10^{-1}$ & $4.0 \times 10^{-12}$ \\
\hline & & - Spray Leak & $7.6 \times 10^{0}$ & $7.9 \times 10^{-11}$ & $6.0 \times 10^{-10}$ & $1 \times 10^{-1}$ & $6.0 \times 10^{-11}$ \\
\hline \multirow[t]{2}{*}{ Area 11: } & $\begin{array}{l}\text { Reduction } \\
\text { Sustems }\end{array}$ & Water-Jet & $3.7 \times 10^{0}$ & $6.2 \times 10^{-7}$ & $2.3 \times 10^{-6}$ & $1 \times 30^{-1}$ & $2.3 \times 10^{-7}$ \\
\hline & & $\begin{array}{l}\text { Oxyacet ylene Torch } \\
\text { and Power Hacksaw }\end{array}$ & $1.2 \times 10^{2}$ & $1.0 \times 10^{-4}$ & $1.2 \times 10^{-4}$ & $1 \times 10^{-2}$ & $1.2 \times 10^{-6}$ \\
\hline Area 12: & $\begin{array}{l}\text { Hydrof luori- } \\
\text { nation }\end{array}$ & $\begin{array}{l}\text { Dxyacet ylene Torch } \\
\text { and Power Hacksaw }\end{array}$ & $2.2 \times 10^{0}$ & $1.1 \times 10^{-5}$ & $2.4 \times 10^{-5}$ & $1 \times 10^{-2}$ & $2.4 \times 10^{-7}$ \\
\hline \multirow[t]{3}{*}{ Area 13: } & Fluorination & $\begin{array}{l}\text { Oxyacet ylene Torch } \\
\text { and Power Hacksaw }\end{array}$ & $2.3 \times 10^{1}$ & $1.1 \times 10^{-11}$ & $4.6 \times 10^{-9}$ & $1 \times 10^{-7}$ & $2.5 \times 10^{-6}$ \\
\hline & & $\begin{array}{l}\text { Loop Chen. Decon. } \\
\text { - Liquid Leak }\end{array}$ & $9.9 \times 10^{1}$ & $4.2 \times 10^{-11}$ & $4.6 \times 10^{-9}$ & $1 \times 10^{-1}$ & $4.6 \times 10^{-10}$ \\
\hline & & - Spray Leak & $9.9 \times 101$ & $6.3 \times 10^{-10}$ & $6.2 \times 10^{-8}$ & $1 \times 10^{-1}$ & $6.2 \times 10^{-9}$ \\
\hline Area 14: & $\begin{array}{l}\text { Cyclinder } \\
\text { Loading }\end{array}$ & None & -- & -- & -- & -- & -- \\
\hline
\end{tabular}




\section{TABLE 1.2-4. (Contd)}

\begin{tabular}{|c|c|c|c|c|c|c|c|}
\hline & Area & Gener al Method & $\begin{array}{l}\text { Operational } \\
\text { Time }(h) \\
\end{array}$ & $\begin{array}{c}\text { Airborne } \\
\text { Generation Rate } \\
\text { lnside Building } \\
\text { or Control } \\
\text { Envelope (Ci/h) }\end{array}$ & $\begin{array}{l}\text { Total Airborne } \\
\text { Radioactivity } \\
\text { Inside Euilding } \\
\text { or Control } \\
\text { Envelope (Ci) } \\
\end{array}$ & $\begin{array}{l}\text { Contamination (a) } \\
\text { Control System } \\
\text { Transmission } \\
\text { Factor } \\
\end{array}$ & $\begin{array}{c}\text { Total }{ }^{(b)} \\
\text { Atmospheric } \\
\text { Release } \\
\text { (Ci/yr) } \\
\end{array}$ \\
\hline \multirow{3}{*}{\multicolumn{2}{|c|}{$\begin{array}{l}\text { Area 15: Fluorine } \\
\text { Generation }\end{array}$}} & $\begin{array}{l}\text { Loop Chem. Oecon. } \\
\text { - Liquid Leak }\end{array}$ & $3.4 \times 10^{1}$ & $1.2 \times 10^{-12}$ & $4.0 \times 10^{-11}$ & $1 \times 10^{-1}$ & $4.0 \times 10^{-12}$ \\
\hline & & - Spray Leak & $3.4 \times 10^{1}$ & $1.8 \times 10^{-11}$ & $6.1 \times 10^{-10}$ & $1 \times 10^{-1}$ & $6.1 \times 10^{-11}$ \\
\hline & & $\begin{array}{l}\text { 0xyacety lene Torch } \\
\text { and Power Hacksaw }\end{array}$ & $5.5 \times 10^{1}$ & $2.1 \times 10^{-7}$ & $1.2 \times 10^{-5}$ & $1 \times 10^{-2}$ & $1.2 \times 10^{-7}$ \\
\hline \multirow{3}{*}{\multicolumn{2}{|c|}{ Areas 16 Through 24}} & $\begin{array}{l}\text { Loop Chem. Decon. } \\
\text { - Liquid Leak }\end{array}$ & $1.1 \times 10^{2}$ & $2.1 \times 10^{-12}$ & $2.3 \times 10^{-10}$ & $1 \times 10^{-1}$ & $2.3 \times 10^{-11}$ \\
\hline & & - Spray Leak & $1.1 \times 10^{2}$ & $3.2 \times 10^{-11}$ & $3.5 \times 10^{-9}$ & $1 \times 10^{-1}$ & $3.5 \times 10^{-10}$ \\
\hline & & Water-Jet & $6.3 \times 10^{-7}$ & $3.4 \times 10^{-7}$ & $2.2 \times 10^{-6}$ & ]$\times 10^{-1}$ & $2.2 \times 10^{-7}$ \\
\hline \multicolumn{2}{|c|}{$\begin{array}{l}\text { Other Onsite Areas: (f) } \\
\text { tasto Extrattinn Pond }\end{array}$} & $\begin{array}{l}\text { Exhumation and Pack ag ing } \\
\text { Fnr of faite Shipnent }\end{array}$ & $5.0 \times 10^{2}$ & $9.6 \times 10^{-6}$ & $4.8 \times 10^{-3}$ & 1.0 & $4.8 \times 10^{-3}$ \\
\hline \multicolumn{2}{|c|}{ Fluoride Waste Lagoons } & $\begin{array}{l}\text { Exhumation and Packaging } \\
\text { For of fsite Shipment }\end{array}$ & $1.3 \times 10^{2}$ & $9.2 \times 10^{-8}$ & $1.2 \times 10^{-5}$ & 1.0 & $1.2 \times 10^{-5}$ \\
\hline \multicolumn{2}{|c|}{ Misc. Buried Waste } & $\begin{array}{l}\text { Exhumation and Packaging } \\
\text { For Off site Shipment }\end{array}$ & $6.2 \times 10^{1}$ & $1.2 \times 10^{-6}$ & $7.3 \times 10^{-5}$ & 1.0 & $7.3 \times 10^{-5}$ \\
\hline \multicolumn{8}{|c|}{$\begin{array}{l}\text { (a) The assumed building transmission factor for all atmospheric releases from ventilation is } 1 \times 10^{-1} \text {. For contamination control envelopes, } \\
\text { the transmission factor is controlled by the assumed lox leakage, and is } 1 \times 10^{-1} \text {. Thus, the total for a control envelope and the huilding } \\
\text { is } 1 \times 10-2 \text {. } \\
\text { (b) For comparison, dose calculations are made based on annual releases. } \\
\text { (c) The method shown is considered as part of preparations for as well as part of OECON. } \\
\text { (d) All miscellaneous piping, ducts, and electrical trays for all areas are included in this entry. } \\
\text { (e) Dashes indicate no data applies for the entry shown. } \\
\text { (f) The areas shown are onsite waste treatment or storage areas, and only the waste exhumation options discussed in Appendix } H \text { are considered. }\end{array}$} \\
\hline
\end{tabular}


Radiation doses to the maximum-exposed individual are shown in Table 1.2-5, and doses to the population are shown in Table I.2-6. The atmospheric dispersion $\left(\bar{X} / Q^{\prime}\right)$ values used in the dose calculations for routine atmospheric releases are $7.5 \times 10^{-6} \mathrm{sec} / \mathrm{m}^{3}$ for the maximum-exposed individual and $2.4 \times 10^{-9} \mathrm{sec} / \mathrm{m}^{3}$ for the population. The total population within $80 \mathrm{~km}$ of the site is $3.5 \times 10^{6}$, as discussed in Appendix B.

\section{I.2.2 Postulated Accidents During DECON}

During DECON, situations may arise that lead to the accidental atmospheric release of radioactivity. Accident scenarios and calculated airborne radioactivity releases considered for DECON in this study are listed in Table 1.2-7. The accidents are listed by decreasing atmospheric release. Accident scenarios are based on the technologies used during DECON tasks. A general estimate of the frequency of occurrence of the level of the atmospheric release associated with each postulated accident is also given. The frequency of occurrence is arrived at by considering not only the probability of the accident but also the probability of an atmospheric release of the calculated magnitude. The frequency of occurrence is listed as "high" if the occurrence of a release of similar or greater magnitude per year is greater than $10^{-2}$, as "medium" if between $10^{-2}$ and $10^{-5}$, and as "low" if less than $10^{-5}$.

While it is beyond the scope of this study to try to evaluate every potential accident for decommissioning a reference $U_{6}$ conversion plant, operational, natural phenomena, and indirect man-related events are discussed in the following subsections. Multiple failure-event accidents are not considered; that is, for each accident, only one failure event is analyzed.

\subsubsection{Postulated Operational Accidents}

Accidental atmospheric releases from incidents such as equipment failure, human error, or service conditions during routine DECON tasks are discussed in this section. The accident analyses are based on the assumed technologies for DECON tasks.

Oxyacetylene Explosion. 0xyacetylene cutting torches are assurned to be used for removing and segmenting various steel components during DECON. Acetylene gas has a flammability range of 2.5 to 80 volume $\%$ mixed in air. $(21,22)$ Violent 
TABLE I.2-5. Radiation Doses to the Maximum-Exposed Individual from Atmospheric Releases During Routine DECON and Preparations for Safe Storage Tasks at the Reference UF 6

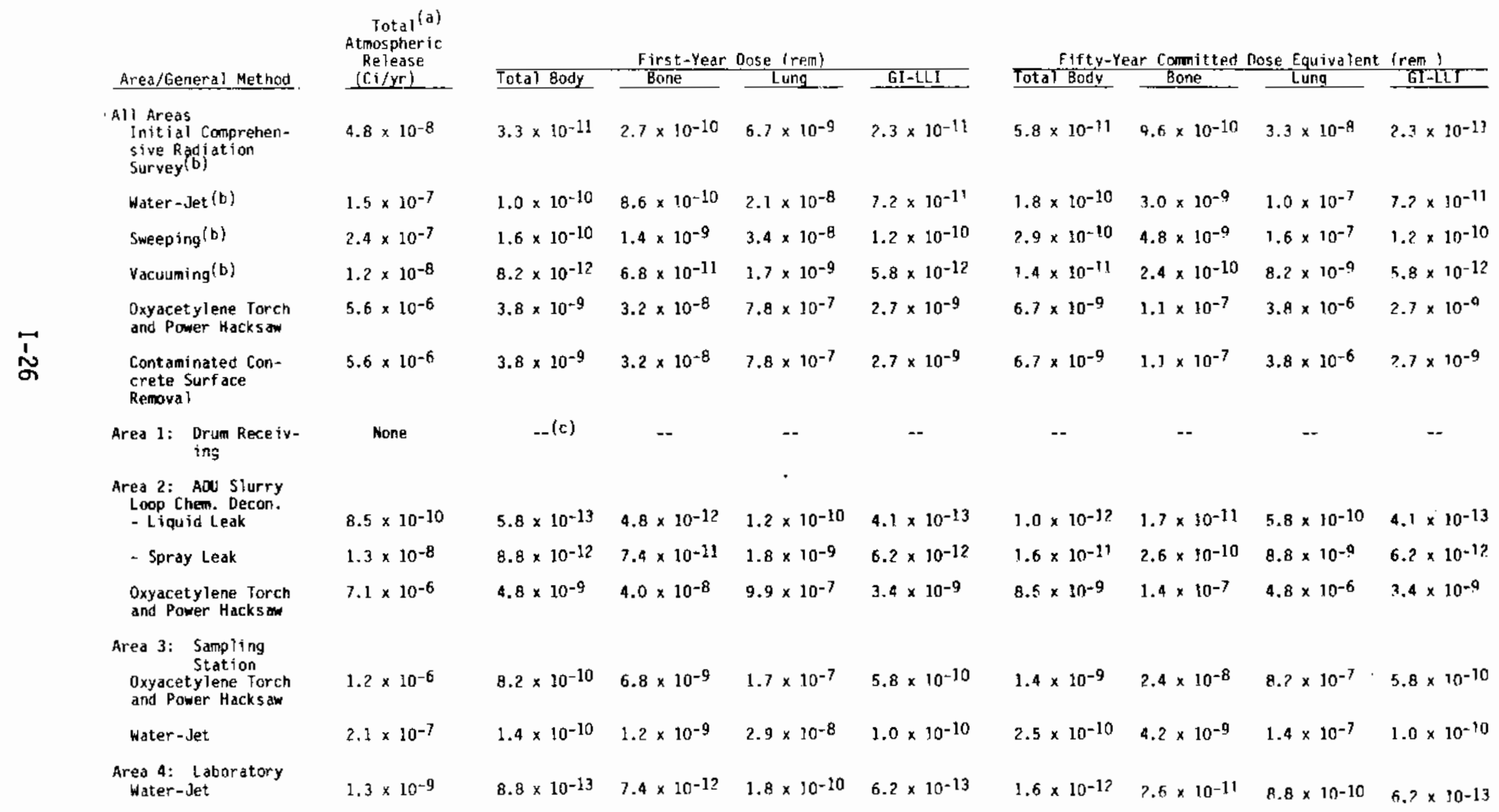


TABLE I.2-5. (Contd)

\begin{tabular}{|c|c|c|c|c|c|c|c|c|c|}
\hline Area/General Method & $\begin{array}{l}\text { Total (a) } \\
\text { Atmotapheric } \\
\text { Release } \\
\text { (Ci/yr) } \\
\end{array}$ & Total Body & $\begin{array}{l}\text { First-Year } \\
\text { Bone }\end{array}$ & $\frac{\text { Dose (rem) }}{\text { Lung }}$ & GI-LLI & $\begin{array}{l}\text { Fifty-ye } \\
\text { Total Bady }\end{array}$ & $\frac{\text { ar Committed }}{\text { Bone }}$ & $\begin{array}{l}\text { lose Equivalent } \\
\text { Lung }\end{array}$ & $\frac{(\mathrm{rem})}{\mathrm{GI}-\mathrm{LLI}}$ \\
\hline 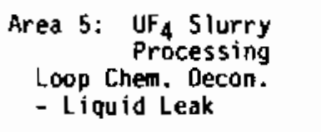 & $5.2 \times 10^{-10}$ & $3.5 \times 10^{-13}$ & $3.0 \times 10^{-12}$ & $7.3 \times 10^{-11}$ & $2.5 \times 10^{-13}$ & $6.2 \times 10^{-13}$ & $1.0 \times 10^{-13}$ & $3.5 \times 10^{-10}$ & $2.5 \times 10^{-13}$ \\
\hline - Spray Leak & $7.8 \times 10^{-9}$ & $5.3 \times 10^{-12}$ & $4.4 \times 10^{-11}$ & $1.1 \times 10^{-9}$ & $3.7 \times 10^{-12}$ & $9.4 \times 10^{-12}$ & $1.6 \times 10^{-10}$ & $5.3 \times 10^{-9}$ & $3.7 \times 10^{-12}$ \\
\hline $\begin{array}{l}\text { Area 6: Ore Conc. } \\
\text { Loops Chem. Decon. } \\
\text { - Liquid Leak }\end{array}$ & $1.2 \times 10^{-9}$ & $8.2 \times 10^{-13}$ & $6.8 \times 10^{-12}$ & $1.7 \times 10^{-10}$ & $5.8 \times 10^{-13}$ & $1.4 \times 10^{-12}$ & $2.4 \times 10^{-11}$ & $8.2 \times 10^{-10}$ & $5.8 \times 10^{-13}$ \\
\hline - Spray Leak & $1.9 \times 10^{-8}$ & $1.3 \times 10^{-11}$ & $1.1 \times 10^{-10}$ & $2.7 \times 10^{-9}$ & $9.9 \times 10^{-12}$ & $2.3 \times 10^{-11}$ & $3.8 \times 10^{-10}$ & $1.3 \times 10^{-8}$ & $9.1 \times 10^{-12}$ \\
\hline $\begin{array}{l}\text { Area 7: Solvent } \\
\text { Extraction } \\
\text { toop Chem. Oecon. } \\
\text { - Liquid Leak }\end{array}$ & $1.1 \times 10^{-9}$ & $8.1 \times 10^{-13}$ & $6.5 \times 10^{-12}$ & $1.6 \times 10^{-10}$ & $5.7 \times 10^{-13}$ & $1.3 \times 10^{-12}$ & $2.2 \times 10^{-11}$ & $8.0 \times 10^{-10}$ & $5.7 \times 10^{-13}$ \\
\hline - Spray Leak & $1.6 \times 10^{-8}$ & $1.1 \times 10^{-11}$ & $9.1 \times 10^{-11}$ & $2.2 \times 10^{-9}$ & $7.7 \times 10^{-12}$ & $1.9 \times 10^{-11}$ & $3.2 \times 10^{-10}$ & $1.1 \times 10^{-8}$ & $7.7 \times 10^{-12}$ \\
\hline $\begin{array}{l}\text { Oxyacetylene Torch } \\
\text { and Power Hacks on }\end{array}$ & $2.0 \times 10^{-7}$ & $1.4 \times 10^{-10}$ & $1.1 \times 10^{-9}$ & $2.7 \times 10^{-8}$ & $9.6 \times 10^{-11}$ & $2.4 \times 10^{-10}$ & $4.1 \times 10^{-9}$ & $1.3 \times 10^{-7}$ & $9.6 \times 10^{-11}$ \\
\hline $\begin{array}{l}\text { Area 8: Urany } \\
\text { Nitrate Conc. } \\
\text { Oxyacet ylene Torch } \\
\text { and Power hacks }\end{array}$ & $2.0 \times 10^{-7}$ & $1.4 \times 10^{-10}$ & $1.1 \times 10^{-9}$ & $2.7 \times 10^{-8}$ & $9.6 \times 10^{-11}$ & $2.4 \times 10^{-10}$ & $4.1 \times 10^{-9}$ & $1.3 \times 10^{-7}$ & $9.6 \times 10^{-11}$ \\
\hline $\begin{array}{l}\text { Loop Chem. Decon, } \\
\text { - Liquid Leak }\end{array}$ & $8.5 \times 10^{-10}$ & $5.8 \times 10^{-13}$ & $4.8 \times 10^{-12}$ & $1.2 \times 10^{-10}$ & $4.1 \times 10^{-13}$ & $1.0 \times 10^{-12}$ & $1.7 \times 10^{-11}$ & $5.8 \times 10^{-10}$ & $4.1 \times 10^{-13}$ \\
\hline - Spray Leak & $1.3 \times 10^{-8}$ & B.8 $\times 10-12$ & $7.4 \times 10^{-11}$ & $1.8 \times 10^{-9}$ & $6.2 \times 10^{-12}$ & $1.6 \times 10^{-11}$ & $2.6 \times 10^{-10}$ & $8.8 \times 10^{-9}$ & $6.2 \times 10^{-12}$ \\
\hline $\begin{array}{l}\text { Area 9: Oenitration } \\
\text { 0xyacetylene Torch } \\
\text { and Power Hacks ow }\end{array}$ & $1.9 \times 10^{-7}$ & $1.3 \times 10^{-10}$ & $1.0 \times 10^{-9}$ & $2.7 \times 10^{-8}$ & $9.1 \times 10^{-11}$ & $2.3 \times 10^{-10}$ & $3.8 \times 10^{-9}$ & $1.3 \times 10^{-7}$ & $9.1 \times 10^{-11}$ \\
\hline
\end{tabular}


TABLE I.2-5. (Contd)

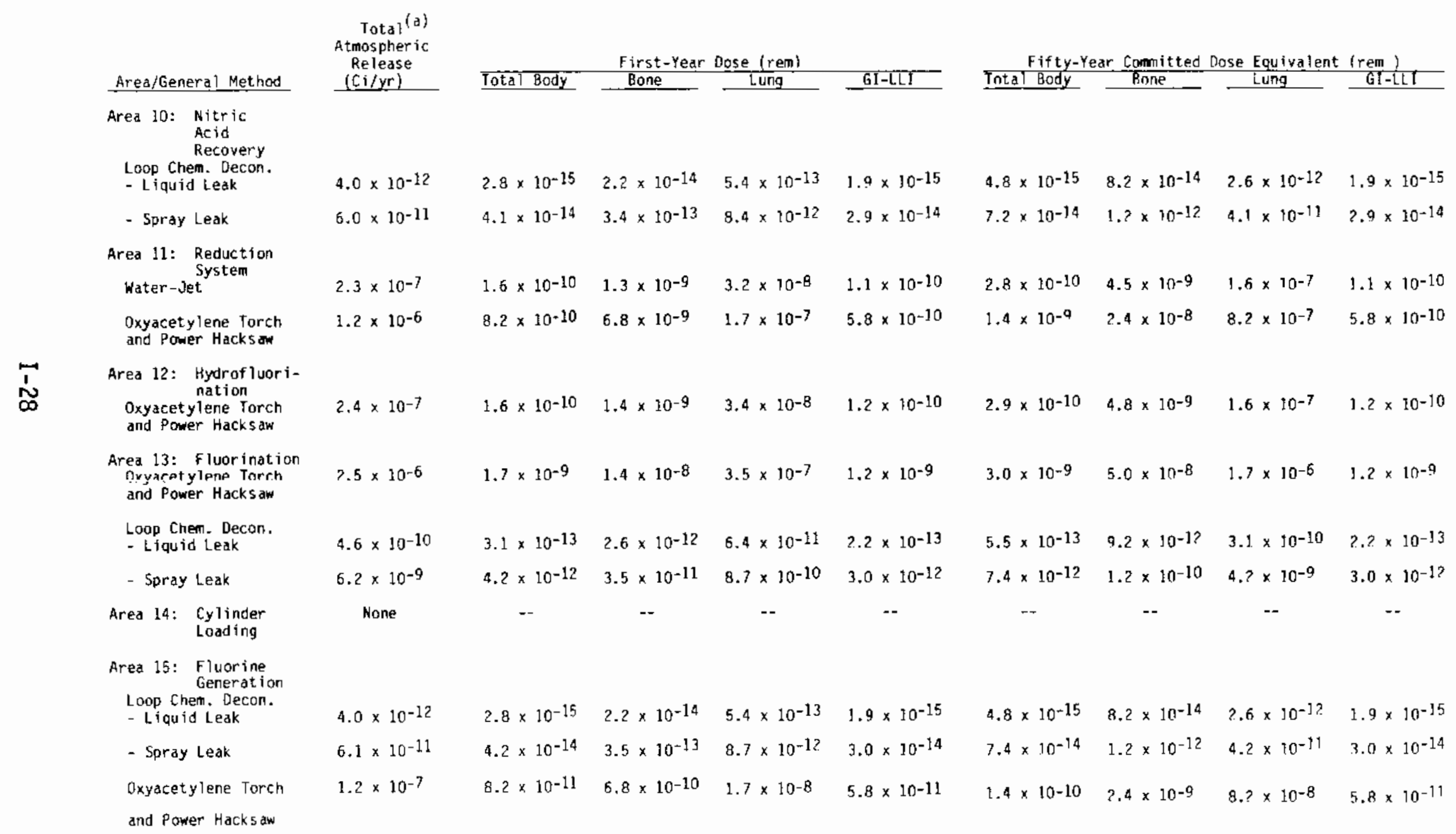




\section{TABLE I.2-5. (Contd)}

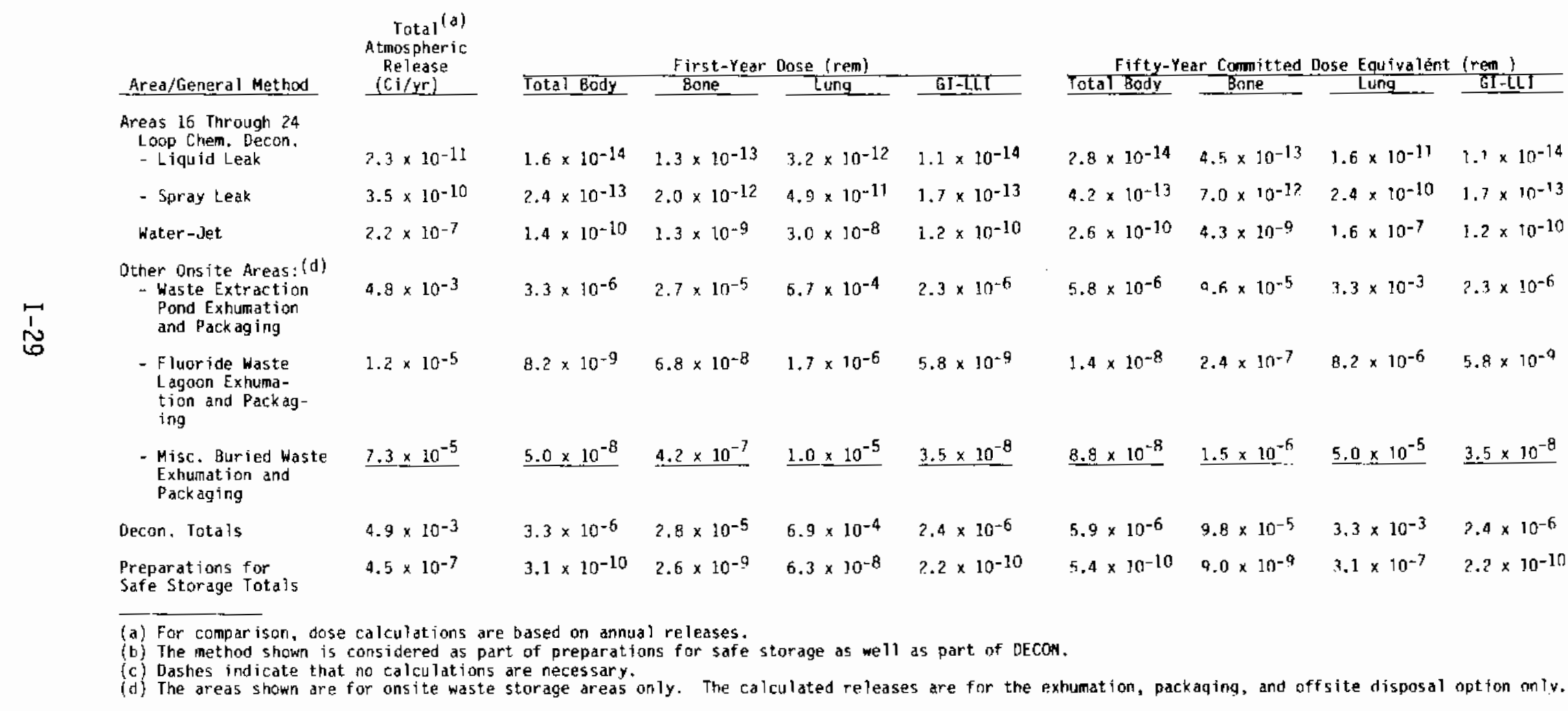


TABLE I.2-6. Radiation Doses to the Poputation from Atmospheric Releases During Routine DECON Tasks in the Reference $\mathrm{UF}_{6}$ Conversion Plant(a)

\begin{tabular}{|c|c|c|c|c|c|c|c|c|c|}
\hline Area/General Method & $\begin{array}{l}\text { Total (b) } \\
\text { Atmospheric } \\
\text { Release } \\
\text { (ci/yr) } \\
\end{array}$ & Total Body & $\begin{array}{l}\text { First-Year } \\
\frac{\text { Bone }}{4}\end{array}$ & $\frac{\text { se (man-rem) }}{\text { Lung }}$ & GI-LLI & $\begin{array}{l}\text { Fifty-Year } \\
\text { Iota) } 80 \text { dy }\end{array}$ & $\frac{\text { Committed Do }}{\text { Bane }}$ & $\frac{\text { Equivalent }}{\text { Lung }}$ & $\frac{\text { an-rem ! }}{G !-L L !}$ \\
\hline $\begin{array}{l}\text { All Areas } \\
\text { Initial Comprehen- } \\
\text { sive Radfation } \\
\text { Survey(c) }\end{array}$ & $4.8 \times 10^{-8}$ & $3 \times 10^{-8}$ & $3 \times 10^{-7}$ & $8 \times 10^{-6}$ & $2 \times 10^{-8}$ & $6 \times 10^{-8}$ & $1 \times 10^{-6}$ & $4 \times 10^{-5}$ & $2 \times 10^{-8}$ \\
\hline Water-Jet (c) & $1.5 \times 10^{-7}$ & $1 \times 10^{-7}$ & $9 \times 10^{-7}$ & $3 \times 10^{-5}$ & $5 \times 10^{-8}$ & $2 \times 10^{-7}$ & $3 \times 10^{-6}$ & $1 \times 10^{-4}$ & $5 \times 10^{-8}$ \\
\hline Sweep ing $(c)$ & $2.4 \times 10^{-7}$ & $2 \times 10^{-7}$ & $1 \times 10^{-6}$ & $4 \times 10^{-5}$ & $8 \times 10^{-8}$ & $3 \times 10^{-7}$ & $5 \times 10^{-6}$ & $2 \times 10^{-4}$ & $8 \times 10^{-8}$ \\
\hline Vacuuming(c) & $1.2 \times 10^{-8}$ & $8 \times 10^{-9}$ & $7 \times 10^{-8}$ & $2 \times 10^{-6}$ & $4 \times 10^{-9}$ & $1 \times 10^{-8}$ & $2 \times 10^{-7}$ & $9 \times 10-6$ & $4 \times 10^{-9}$ \\
\hline $\begin{array}{l}\text { oxyacetylene Torch } \\
\text { and Power Hacksaw }\end{array}$ & $5.6 \times 10^{-6}$ & $4 \times 10^{-6}$ & $3 \times 10^{-5}$ & $9 \times 10^{-4}$ & $2 \times 10^{-6}$ & $7 \times 10^{-6}$ & $1 \times 10^{-4}$ & $4 \times 10^{-3}$ & $2 \times 10^{-6}$ \\
\hline $\begin{array}{l}\text { Contaminated Con- } \\
\text { crete Surface } \\
\text { Removal }\end{array}$ & $4.0 \times 10^{-8}$ & $3 \times 10^{-8}$ & $2 \times 10^{-7}$ & $7 \times 10^{-6}$ & $1 \times 10^{-8}$ & $5 \times 10^{-8}$ & $8 \times 10^{-7}$ & $3 \times 10^{-5}$ & $1 \times 10^{-8}$ \\
\hline $\begin{array}{l}\text { Area 1: Drum Receiv- } \\
\text { ing }\end{array}$ & None & $--(d)$ & -- & -- & -- & -- & -- & -- & $\cdots$ \\
\hline $\begin{array}{l}\text { Area 2: AOU Slurry } \\
\text { Loop Chem. Decon. } \\
\text { - Liquid Leak }\end{array}$ & $8.5 \times 10^{-10}$ & $6 \times 10^{-10}$ & $5 \times 10^{-9}$ & $1 \times 10^{-7}$ & $3 \times 10^{-10}$ & $1 \times 10^{-9}$ & $2 \times 10^{-8}$ & $6 \times 10^{-7}$ & $3 \times 10^{-10}$ \\
\hline - Spray Leak & $1.3 \times 10^{-8}$ & $9 \times 10^{-9}$ & $7 \times 10^{-8}$ & $2 \times 10^{-6}$ & $4 \times 10^{-9}$ & $2 \times 10^{-8}$ & $3 \times 10^{-7}$ & $1 \times 10^{-5}$ & $4 \times 10^{-9}$ \\
\hline $\begin{array}{l}\text { oxyacet ylene Torch } \\
\text { and Power Hacks sow }\end{array}$ & $7.1 \times 10^{-6}$ & $5 \times 10^{-6}$ & $4 \times 10^{-5}$ & $1 \times 10^{-3}$ & $? \times 10^{-6}$ & $8 \times 10^{-6}$ & $1 \times 10^{-4}$ & $5 \times 10^{-3}$ & $2 \times 10^{-6}$ \\
\hline $\begin{array}{c}\text { Area 3: Sampling } \\
\text { Station } \\
\text { oxyacetylene Torch } \\
\text { and Power Hacksaw }\end{array}$ & $1.2 \times 10^{-6}$ & $8 \times 10^{-7}$ & $7 \times 10^{-6}$ & $2 \times 10^{-4}$ & $4 \times 10^{-7}$ & $1 \times 10^{-6}$ & $2 \times 10^{-5}$ & $9 \times 10^{-4}$ & $4 \times 10^{-7}$ \\
\hline Water-Jet & $2.1 \times 10^{-7}$ & $1 \times 10^{-7}$ & $1 \times 10^{-6}$ & $4 \times 10^{-5}$ & $7 \times 10^{-8}$ & $2 \times 10^{-7}$ & $4 \times 10^{-6}$ & $2 \times 10^{-4}$ & $7 \times 10^{-8}$ \\
\hline $\begin{array}{l}\text { Area 4: Laboratory } \\
\text { Water-Jet }\end{array}$ & $1.3 \times 10^{-9}$ & $9 \times 10^{-10}$ & $7 \times 10^{-9}$ & $2 \times 10^{-7}$ & $4 \times 10^{-10}$ & $2 \times 10^{-9}$ & $3 \times 10^{-8}$ & $1 \times 10^{-6}$ & $4 \times 10^{-10}$ \\
\hline
\end{tabular}




\section{TABLE I.2-6. (Contd)}

\begin{tabular}{|c|c|c|c|c|c|c|c|c|c|}
\hline Area/General Method & $\begin{array}{l}\text { Total (b) } \\
\text { Atmospheric } \\
\text { Release } \\
\text { (Ci/yr) } \\
\end{array}$ & Total Body & $\begin{array}{c}\text { First-Year } \\
\text { Bone }\end{array}$ & ose (man-rem) & GI-LLI & $\begin{array}{l}\text { Fifty-Year } \\
\text { TotaTBody }\end{array}$ & $\frac{\text { Cormitted Dose }}{\text { Bone }}$ & $\begin{array}{l}\text { Equivalent } \\
\text { Lung }\end{array}$ & $\frac{(\operatorname{man}-\text { rem })}{\text { GI-LL! }}$ \\
\hline $\begin{array}{l}\text { Area 5: UF } 4 \text { Slurry } \\
\text { Processing } \\
\text { Loop Chem. Decon. } \\
\text { - Liquidd Leak }\end{array}$ & $5.2 \times 10^{-10}$ & $3 \times 10^{-10}$ & $3 \times 10^{-9}$ & $9 \times 10^{-8}$ & $2 \times 10^{-10}$ & $6 \times 10^{-10}$ & $1 \times 10^{-8}$ & $4 \times 10^{-7}$ & $2 \times 10^{-10}$ \\
\hline - Spray Leak & $7.8 \times 10^{-9}$ & $5 \times 10^{-9}$ & $4 \times 10^{-8}$ & $1 \times 10^{-6}$ & $2 \times 10^{-9}$ & $9 \times 10^{-9}$ & $2 \times 10^{-7}$ & $6 \times 10^{-6}$ & $2 \times 10^{-9}$ \\
\hline $\begin{array}{l}\text { Ared 6: Ore Conc. } \\
\text { Diss. } \\
\text { Loop Chem. Decon. } \\
\text { - Liquid Leak }\end{array}$ & $1.2 \times 10^{-9}$ & $8 \times 10^{-10}$ & $7 \times 10^{-9}$ & $2 \times 10^{-7}$ & $4 \times 10^{-10}$ & $1 \times 10^{-9}$ & $2 \times 10^{-8}$ & $9 \times 10^{-7}$ & $4 \times 10^{-10}$ \\
\hline - Spray Leak & $1.9 \times 10^{-8}$ & $2 \times 10^{-8}$ & $1 \times 10^{-7}$ & $3 \times 10^{-6}$ & $6 \times 10^{-9}$ & $2 \times 10^{-8}$ & $4 \times 10^{-7}$ & $1 \times 10^{-5}$ & $6 \times 10^{-9}$ \\
\hline $\begin{array}{l}\text { Area 7: Solvent } \\
\text { Loop Chem, Dection. } \\
\text { - Liquid Leak }\end{array}$ & $1.1 \times 10^{-9}$ & $8 \times 10^{-10}$ & $7 \times 10^{-9}$ & $2 \times 10^{-7}$ & $4 \times 10^{-10}$ & $1 \times 10^{-9}$ & $2 \times 10^{-8}$ & $9 \times 10^{-7}$ & $4 \times 10^{-10}$ \\
\hline - Spray Leak & $1.6 \times 10^{-8}$ & $1 \times 10^{-8}$ & $9 \times 10^{-8}$ & $3 \times 10^{-6}$ & $5 \times 10^{-9}$ & $2 \times 10^{-8}$ & $3 \times 10^{-7}$ & $1 \times 10^{-5}$ & $5 \times 10^{-9}$ \\
\hline $\begin{array}{l}\text { Oxyacet ylene Torch } \\
\text { and Power Hacksaw }\end{array}$ & $2.0 \times 10^{-7}$ & $1 \times 10^{-7}$ & $1 \times 10^{-6}$ & $4 \times 10^{-5}$ & $7 \times 10^{-8}$ & $2 \times 10^{-7}$ & $4 \times 10^{-6}$ & $2 \times 10^{-7}$ & $7 \times 10^{-B}$ \\
\hline $\begin{array}{c}\text { Area 8: Uranyl } \\
\text { Nitrate Conc. } \\
\text { oxyacetylene Torch } \\
\text { and Power Hacksaw }\end{array}$ & $2.0 \times 10^{-7}$ & $1 \times 10^{-7}$ & $1 \times 10^{-6}$ & $4 \times 10^{-5}$ & $7 \times 10^{-8}$ & $2 \times 10^{-7}$ & $4 \times 10^{-6}$ & $2 \times 10^{-4}$ & $7 \times 10^{-B}$ \\
\hline $\begin{array}{l}\text { Loop Chem. Decon. } \\
\text { - Liquid Leak }\end{array}$ & $8.5 \times 10^{-10}$ & $6 \times 10^{-10}$ & $5 \times 10^{-9}$ & $1 \times 10^{-7}$ & $3 \times 10^{-10}$ & $1 \times 10^{-9}$ & $2 \times 10^{-8}$ & $6 \times 10^{-7}$ & $3 \times 10^{-10}$ \\
\hline - Spray Leak & $1.3 \times 10-8$ & $9 \times 10-9$ & $7 \times 10-8$ & $2 \times 10^{-6}$ & $4 \times 10^{-9}$ & $2 \times 10^{-8}$ & $3 \times 10^{-7}$ & $1 \times 10^{-5}$ & $4 \times 10^{-9}$ \\
\hline $\begin{array}{l}\text { Area 9: Denitration } \\
\text { Oxyacety lene Torch } \\
\text { and Power Hacksaw }\end{array}$ & $1.9 \times 10^{-7}$ & $1 \times 10^{-7}$ & $1 \times 10^{-6}$ & $3 \times 10^{-5}$ & $6 \times 10^{-8}$ & $2 \times 10^{-7}$ & $4 \times 10^{-6}$ & $1 \times 10^{-4}$ & $6 \times 10^{-8}$ \\
\hline
\end{tabular}


TABLE I.2-6. (Contd)

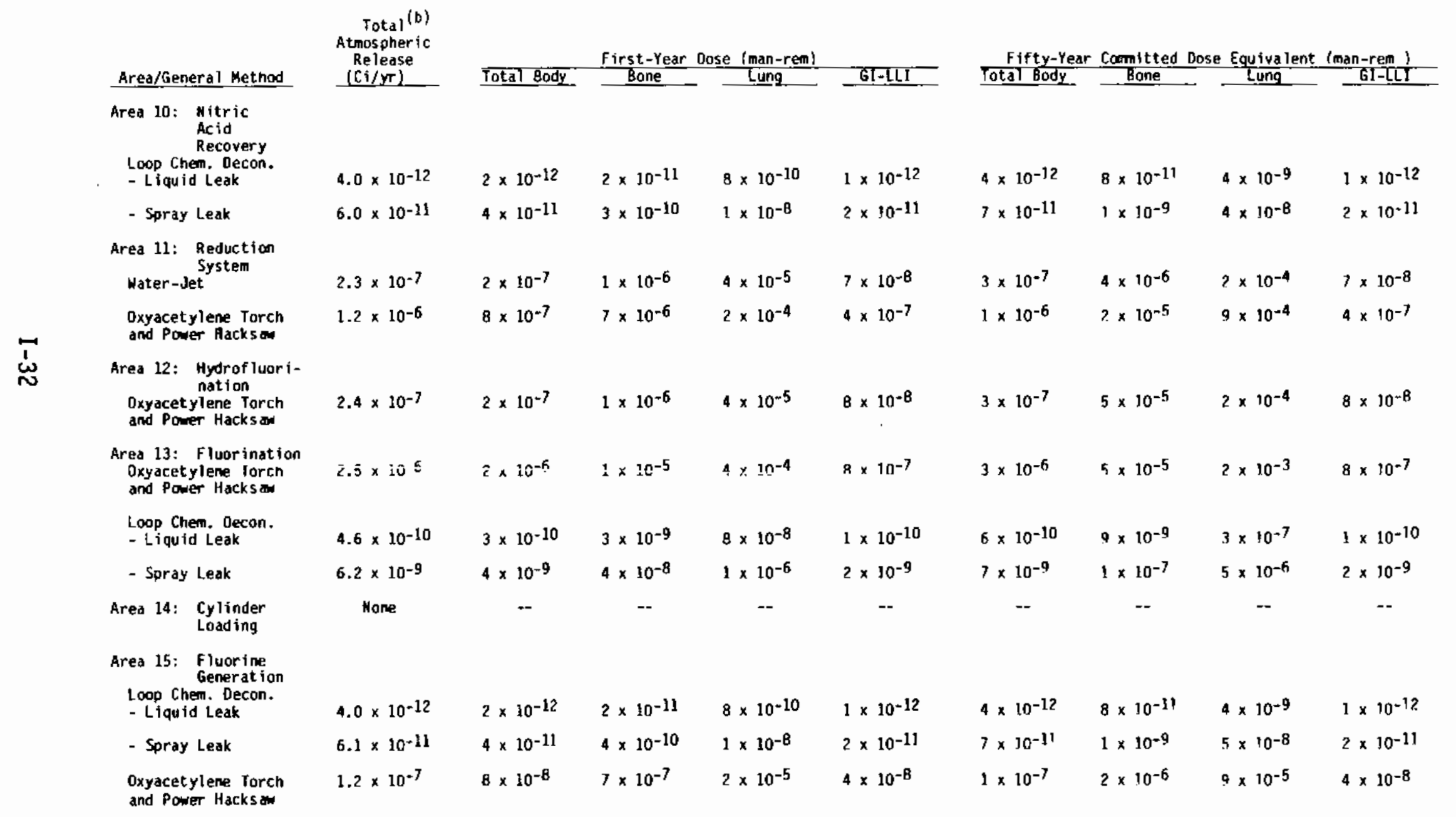




\section{TABLE I.2-6. (Contd)}

\begin{tabular}{|c|c|c|c|c|c|c|c|c|c|}
\hline Area/General Method & $\begin{array}{l}\text { Total }(\mathrm{b}) \\
\text { Atmospheric } \\
\text { Re lease } \\
\text { (Ci } \mathrm{i} / \mathrm{yr}) \\
\end{array}$ & Total Body & $\begin{array}{l}\text { First-Year D } \\
\text { Bone }\end{array}$ & $\frac{\text { ose }(\operatorname{man}-r e m)}{[\text { Lung }}$ & GI-LLI & $\begin{array}{l}\text { Fifty-Year } \\
\text { Total Body }\end{array}$ & $\begin{array}{l}\text { Conmit ted Dose } \\
\text { Bone }\end{array}$ & $\frac{\text { Equiva lent }}{\text { Lung }}$ & $\begin{array}{r}\text { iman-rem } 1 \\
\text { GI-LLI } \\
\end{array}$ \\
\hline $\begin{array}{l}\text { Areas } 16 \text { Through } 24 \\
\text { Loop Chem. Decon. } \\
\text { - Liquid Leak }\end{array}$ & $2.3 \times 10^{-11}$ & $8 \times 10^{-9}$ & $7 \times 10^{-8}$ & $2 \times 10^{-6}$ & $4 \times 10^{-9}$ & $1 \times 10^{-8}$ & $2 \times 10^{-7}$ & $9 \times 10^{-6}$ & $4 \times 10^{-9}$ \\
\hline - Spray Leak & $3.5 \times 10^{-10}$ & $2 \times 10^{-10}$ & $2 \times 10^{-9}$ & $6 \times 10^{-8}$ & $1 \times 10^{-10}$ & $4 \times 10^{-3.0}$ & $7 \times 10^{-9}$ & $3 \times 10^{-7}$ & $1 \times 10^{-10}$ \\
\hline Water-Jet & $2.2 \times 10^{-7}$ & $1 \times 10^{-7}$ & $1 \times 10^{-6}$ & $4 \times 10^{-5}$ & $7 \times 10^{-8}$ & $3 \times 10^{-7}$ & $4 \times 10^{-6}$ & $2 \times 10^{-4}$ & $7 \times 10^{-8}$ \\
\hline $\begin{array}{l}\text { Other Onsite Areas: (e) } \\
\text { - Waste Extraction } \\
\text { Pond Exhumation } \\
\text { and Packaging }\end{array}$ & $4.8 \times 10^{-3}$ & $3 \times 10^{-3}$ & $3 \times 10^{-2}$ & $8 \times 10^{-1}$ & $2 \times 10^{-3}$ & $6 \times 10^{-3}$ & $1 \times 10^{-1}$ & $4 \times 10^{0}$ & $2 \times 10^{-3}$ \\
\hline $\begin{array}{l}\text { - Fluoride Waste } \\
\text { Lagoon Exhuma- } \\
\text { tion and Packag- } \\
\text { ing }\end{array}$ & $1.2 \times 10^{-5}$ & $8 \times 10^{-6}$ & $7 \times 10^{-5}$ & $2 \times 10^{-3}$ & $4 \times 10^{-6}$ & $1 \times 10^{-5}$ & $? \times 10^{-4}$ & $9 \times 10^{-3}$ & $4 \times 10^{-6}$ \\
\hline $\begin{array}{l}\text { - Misc. Buried Waste } \\
\text { Exhumation and } \\
\text { Packaging }\end{array}$ & $7.3 \times 10^{-5}$ & $5 \times 10^{-5}$ & $4 \times 10^{-4}$ & $1 \times 10^{-2}$ & $\underline{2 \times 10^{-5}}$ & $9 \times 10^{-5}$ & $2 \times 10^{-3}$ & $6 \times 10^{-2}$ & $2 \times 10^{-5}$ \\
\hline
\end{tabular}


TABLE I.2-7. Postulated Accidental Atmospheric Releases During DECON and Preparations for Safe Storage at the Reference $\mathrm{UF}_{6}$ Conversion Plant

\begin{tabular}{|c|c|c|c|c|c|c|}
\hline & Incident & Comments & \multirow{2}{*}{$\begin{array}{l}\begin{array}{l}\text { Frequency of } \\
\text { Occurrence }\end{array} \\
\text { Medium }\end{array}$} & \multirow{2}{*}{ 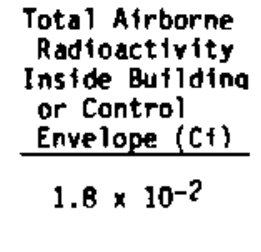 } & \multirow{2}{*}{$\begin{array}{l}\text { Contanination }(b) \\
\text { Control System } \\
\text { Transemission } \\
\text { Factor }\end{array}$} & \multirow{2}{*}{$\begin{array}{c}\text { Total }(\mathrm{C}) \\
\text { Atmospheric } \\
\text { Release } \\
(\mathrm{C} \dagger / \mathrm{h})\end{array}$} \\
\hline & Oxyacetylene Explosion & $\begin{array}{l}\text { Explosion During Area } 2 \text { Piping and } \\
\text { Equipment Removal }\end{array}$ & & & & \\
\hline & $\begin{array}{l}\text { Contamination Control } \\
\text { Envelope Rupture }\end{array}$ & $\begin{array}{l}\text { Leakage During Area } 2 \text { Piping and } \\
\text { Equipment Removal }\end{array}$ & High & $2.9 \times 10^{-4}$ & $1 \times 10^{-1}$ & $2.9 \times 10^{-5}$ \\
\hline & $\begin{array}{l}\text { Yacuum Filter-Bag }(d) \\
\text { Rupture }\end{array}$ & $\begin{array}{l}\text { Rupture of a Full filter-Bag } \\
\text { During Surface Cleaning }\end{array}$ & Medium & $2.4 \times 10^{-4}$ & $1 \times 10^{-1}$ & $2.4 \times 10^{-5}$ \\
\hline & $\begin{array}{l}\text { Contaminated Meta } 1 \\
\text { Cutting }\end{array}$ & $\begin{array}{l}\text { Additional Cutting of Highly } \\
\text { Contaminated Piping in Area } 2\end{array}$ & High & $7.2 \times 10^{-5}$ & $1 \times 10^{-1}$ & $7.2 \times 10^{-6}$ \\
\hline & $\begin{array}{l}\text { Gross Leak During Loop } \\
\text { Chemical Decontamination }\end{array}$ & $\begin{array}{l}\text { A Leak } 10 \text { Times Larger Than the } \\
\text { Routine Leak in Area } 6\end{array}$ & Low & $1.9 \times 10^{-6}$ & $1 \times 10^{-1}$ & $1.9 \times 10^{-7}$ \\
\hline & $\begin{array}{l}\text { Spilling of Contaminated } \\
\text { Solid Wastes }\end{array}$ & $\begin{array}{l}\text { Spill of Contaminated Concrete } \\
\text { From Surface Remova? }\end{array}$ & High & $1.3 \times 10^{-6}$ & $1 \times 10^{-1}$ & $1.3 \times 10^{-7}$ \\
\hline \multirow[t]{8}{*}{$\overleftrightarrow{\mathfrak{w}_{f}}$} & $\begin{array}{l}\text { Explosion of LPG Leaked } \\
\text { From-End Loader }\end{array}$ & $\begin{array}{l}4.5 \mathrm{~kg} \text { of LPG Leaked During Con- } \\
\text { From Surf ace Removal }\end{array}$ & Low & $1.0 \times 10^{-7}$ & 1.0 & $1.0 \times 10^{-7}$ \\
\hline & $\begin{array}{l}\text { Contaminated Syeeping } \\
\text { Compound Fire }\end{array}$ & $\begin{array}{l}\text { A fire Consumes } 0.5 \mathrm{~m}^{3} \text { of Used } \\
\text { Sureeping Compound }\end{array}$ & Medium & $2.0 \times 10^{-7}$ & $1 \times 10^{-1}$ & $2.0 \times 10^{-8}$ \\
\hline & $\begin{array}{l}\text { Cumbystabie idaste } \\
\text { Fireld) }\end{array}$ & $\begin{array}{l}\text { I } m^{3} \text { of Combustibit idaste is } \\
\text { Involved in a Fire }\end{array}$ & ii ign & $\hat{z} . \dot{0} \times i \bar{u}^{-\mathfrak{Q}}$ & $i \times 101$ & $\grave{c} \cdot \overline{\mathrm{u}} \times \hat{\mathrm{i}} \overline{\mathrm{u}} \cdot ?$ \\
\hline & Loss of Services & $\begin{array}{l}\text { Loss of Hater Supply, Electrical } \\
\text { Power, or Air Flow }\end{array}$ & $--(e)$ & -- & +- & -- \\
\hline & Natural Phenomena & $\begin{array}{l}\text { Flood, Earthquakes, Tornadoes or } \\
\text { High Winds }\end{array}$ & -- & $\cdots$ & -- & $\cdots$ \\
\hline & Aircraft Crashes & $\begin{array}{l}\text { Comparison to Routine Operation } \\
\text { Probability }\end{array}$ & -- & -- & -- & -- \\
\hline & Man-Caused Events & $\begin{array}{l}\text { Detailed Analysis is Beyond the } \\
\text { Scope of This Study }\end{array}$ & -- & -- & -- & -- \\
\hline & \multicolumn{6}{|c|}{ 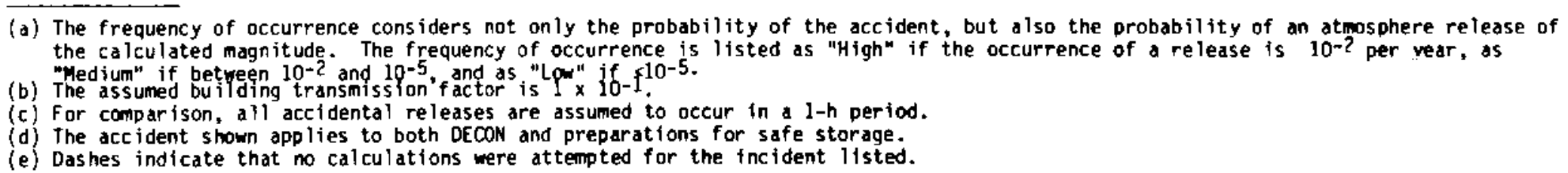 } \\
\hline
\end{tabular}


explosions can occur when acetylene and oxygen are incorrectly mixed. The degree of explosive violence depends on how closely the gas mixture approximates the ratio for complete combustion. Some maximum pressures and pressure rise rates from three acetylene/air mixtures in the explosive range are shown in Table 1.2-8. ${ }^{(23)}$

TABLE 1.2-8. Example Explosive Data for Acetylene/Air Mixtures

\begin{tabular}{ccc}
$\begin{array}{l}\text { Percent of } \\
\text { Acetylene } \\
\text { in Mixture }\end{array}$ & $\begin{array}{c}\text { Maximum } \\
\begin{array}{c}\text { Explosive } \\
\text { Pressure (kPa) }\end{array}\end{array}$ & $\begin{array}{c}\text { Maximum Rate } \\
\text { of Explosive } \\
\text { Pressure Rise } \\
(\mathrm{kPa} / \mathrm{sec})\end{array}$ \\
\hline 5 & 540 & 17000 \\
13 & 1000 & 8300 \\
20 & 690 & 9700
\end{tabular}

Oxyacetylene explosions can occur from such causes as flow reversais, nozzle obstructions, and flashbacks (a flare going back up the gas hose). $(24,25)$ This accident is postulated to occur during removal of piping and equipment in Area 2, the ADU slurry receiving and storage area. This operation is conducted in a contamination control envelope with an assumed volume of $1000 \mathrm{~m}^{3}$. The airborne material generated will fill this volume with a concentration of $1 \times 10^{-1} \mathrm{~g} / \mathrm{m}^{3}$. (4) Thus, a total of $100 \mathrm{~g}$ of radioactive dust with a specific activity of $1.3 \times 10^{-6} \mathrm{Ci} / \mathrm{g}$ is made airborne during the accident. The total airborne activity is calculated to be $1.3 \times 10^{-4} \mathrm{C} i$.

It is reasonable to assume that the contamination control envelope HEPA filter system undergoes routine maintenance to ensure its full effectiveness. The mass of material deposited on filters without causing flow restrictions or an excessive pressure drop ( $>980 \mathrm{~Pa}$ of water gauge at rated flows) varies with filter design and the properties of the deposited material. $(26,27)$ A HEPA filter dust loading of $2.3 \mathrm{~kg}$ is assumed. Three pairs of HEPA and roughing filters in the contamination control envelope are calculated to contain about $14 \mathrm{~kg}$ of uranium dust. If all of this material is made airborne by the oxyacetylene explosion, and using the specific activity of $1.3 \times 10^{-6} \mathrm{Ci} / \mathrm{g}$ for the uranium mixture, a total of about $1.8 \times 10^{-2} \mathrm{Cj}$ are made airborne from the filters. 
Some radioactivity will be deposited on the inside surfaces of the contamination control envelope, and it is assumed to be made airborne in the building by the explosion. The total radioactivity generated during DECON of Area 2 is $7.1 \times 10^{-4} \mathrm{Ci}$ (see Table I.2-4). Assuming that $0.2 \%$ of this radioactivity is deposited on the interior surfaces of the control envelope, and that all of it is made airborne by the explosion, an additional $1.4 \times 10^{-6} \mathrm{Ci}$ could enter the building air.

The total radioactivity made airborne in the building by the postulated oxyacetylene explosion is found by summing the three previous airborne generation terms. They are: the radioactivity generated by the explosion inside the contamination control envelope $\left(1.3 \times 10^{-4} \mathrm{Ci}\right)$, the radioactivity removed from the control envelope HEPA filter system by the explosion $\left(1.8 \times 10^{-2} \mathrm{Ci}\right)$, and the radioactivity removed from interior surfaces in the control envelope $\left(1.4 \times 10^{-6}\right)$. The total airborne radioactivity in the building is $1.8 \times 10^{-2} \mathrm{Ci}$. Thus, the amount of radioactivity released to the environment is found by multiplying the amount of material airborne in the building by the building transmission factor. The total atmospheric release is $1.8 \times 10^{-2}$. An oxyacetylene explosion resulting in this magnitude of airborne release is estimated to have a "medium" frequency of occurrence.

Contamination Control Envelope Rupture. Rupture of the contamination control envelope (greenhouse) during oxyacetylene cutting is assumed to have a "high" frequency of occurrence. Small globules of molten metal have been measured to be projected up to $9 \mathrm{~m}$ from a cutting operation. (28) It is postulated that such molten particles penetrate the sheet plastic walls and increase the leakage from the contamination control envelope from 0.1 to 0.5 . This increase in leakage is assumed to occur during the removal of piping and equipment in Area 2, the ADU slurry receiving and storage area. It is assumed that this large leak goes undetected for the duration of the task, resulting in an increase in the atmospheric release of from $7.1 \times 10^{-6} \mathrm{Ci}$ to $3.6 \times 10^{-5} \mathrm{Ci}$. The net additional release is calculated to be $2.9 \times 10^{-5} \mathrm{C}$. 
Vacuum Filter-Bag Rupture. Sharp objects, such as metal shards, could rupture a filter-bag during surface cleaning operations involving the use of a vacuum cleaner. When the filter-bag is ruptured, all of the collected material in the bag is assumed to become airborne in the building because of the mechanical and aerodynamic forces of the $1.4-\mathrm{m}^{3} / \mathrm{min}$ vacuum cleaner air flow. To maximize the calculation of the atmospheric release, the bag rupture is assumed to occur at the time just prior to bag change (i.e., when the filter bag is full). If vacuuming is assumed to remove 0.5 of the surface contamination from $3.7 \times 10^{3} \mathrm{~m}^{2}$ of area, and if the average contamination level is $1 \mathrm{~g} / \mathrm{m}^{2}$, about $1.8 \times 10^{3} \mathrm{~g}$ are removed. Frequent filter-bag changes are anticipated in dusty areas. Assuming 10 bag changes during the entire task, each bag contains an average of $180 \mathrm{~g}$ of uranium. Assuming all $180 \mathrm{~g}$ becomes airborne during the accident, with a specific activity of $1.3 \times 10^{-6} \mathrm{ci} / \mathrm{g}$, the airborne radioactivity is $2.4 \times 10^{-4} \mathrm{Ci}$. The total release through the building ventilation system is calculated to be $2.4 \times 10^{-5} \mathrm{Ci}$. This accident is estimated to have a "medium" frequency of occurrence.

Accidental Cutting of Contaminated Metal. Segmentation of metal components in the reference facility after those components have been decontaminated is an integral part of DECON. Although rigorous monitoring and administrative controls are exercised to prevent the accidental cutting of components that have not been decontaminated, improper coordination of activities could lead to such an accident.

This accident is postulated to occur during cutting of highly contaminated piping in Area 2. Half of the cutting involves a contamination level of $1 \mathrm{~kg} / \mathrm{m}^{2}$ of internal surface. If an additional $10 \%$ of the piping is not decontaminated below this level prior to cutting, the airborne radioactivity is calculated to increase by $7.2 \times 10^{-5} \mathrm{Ci}$. The resulting release to the atmosphere is calculated to be $7.2 \times 10^{-6} \mathrm{Ci}$. This accident is estimated to have a high frequency of occurrence.

Gross Leak During Loop Chemical Oecontamination. A massive failure of piping during loop chemical decontamination is estimated to have a "low" frequency of occurrence. There have been no such accidents in 30 years of experience with nuclear systems. Massive failures are unknown in high-pressure central steam boilers, for which there is considerably more operating experience than is currently available in the nuclear industry. ${ }^{(29)}$ 
Pipe failures can result from improper system designs, the use of poor quality materials, base metal defects, fabrication defects, or inadequate service conditions. $(30)$ The loop chemical decontamination takes place about 40 years after the piping systems are put in service. In chemical decontamination, a caustic chemical is circulated in piping and equipment to remove built-up internal surface contamination. The chemical solution could deteriorate the pipe or the welds and create localized leaks. Accidental leakage could also be introduced because of human error during the chemical decontamination.

Liquid and spray leaks are assumed to occur as part of the routine release analysis. A gross leak about 10 times larger than the largest spray leak is assumed for this accident. Thus, $1 \%$ of the liquid in the system is assumed to be made airborne. Such a leak would be large enough to be easity detected and is assumed to last only 1 hour. The largest routine spray leak is calculated to occur during DECON tasks in Area 6. Increasing the routine spray leak by a factor of 10 results in a leak of $1.9 \times 10^{-6} \mathrm{Ci}$ in the building, of which $1.9 \times 10^{-7} \mathrm{Ci}$ is released to the atmosphere. A gross leak resulting in a release of this magnitude is estimated to have a "low" frequency of occurrence.

Accidental Spill of Contaminated Solid Wastes. Another substantial operation is the handling of contaminated solid wastes. Accidental dumping or spilling of these wastes would lead to a release of airborne contamination from the plant.

Contaminated concrete dust is generated as a result of concrete drilling, and the dust is collected for disposal. It is postulated that this dust is accidentally spilled during handling. The collected dust should be damp from the water mist used during drilling, and when spilled would exhibit the behavior of damp sand. However, for this analysis, it is assumed that the concrete dust is sufficiently dry to produce a quasi-stable mass concentration of $1 \times 10^{-2} \mathrm{~g} / \mathrm{m}^{3}$ in a $100-\mathrm{m}^{3}$ space surrounding the site of the spill. Thus, as much as $1 \mathrm{~g}$ of dust containing $1.3 \times 10^{-6} \mathrm{Ci}$ could be released to the room ventilation system, resulting in an estimated release to the atmosphere of $1.3 \times 10^{-7} \mathrm{Ci}$ of uranium. A spill of contaminated waste resulting in a release of this magnitude is estimated to have a "high" frequency of occurrence. 
Explosion of LPG Leaked from a Front-End Loader. The use of a liquefied propane gas-powered front-end loader for loading concrete rubble and moving light equipment is assumed in this study, since this method is consistent with current industrial methods. It is anticipated that by the time large-scale decommissioning operations are required, an alternative method with safer fuel supply will be available and used instead of the LPG-powered front-end loader.

Flammability limits for LPG range from a mixture of 2.1 volume $\%$ to a mixture of 9.5 volume $\% .(31,23)$ Information on the rate of pressure rise from explosions of various mixtures of propane in air is given in Table I.2-9.

\begin{tabular}{|c|c|c|}
\hline $\begin{array}{c}\text { Concentration } \\
\text { in Air } \\
\text { (volume \%) } \\
\end{array}$ & $\begin{array}{l}\text { Pre-Detonation } \\
\text { Pressure (kPa) }\end{array}$ & $\begin{array}{l}\text { Rate of Pres- } \\
\text { sure Rise } \\
\text { (kPa/sec) } \\
\end{array}$ \\
\hline 3 & 510 & 8600 \\
\hline 5 & 660 & 17000 \\
\hline 7 & 330 & 240 \\
\hline
\end{tabular}

(a) Summarized from information in Reference 23.

An accidental leak of LPG is postulated to occur during the loading of concrete rubble from contaminated concrete surface spalling. A realistic leak of LPG of $4.5 \mathrm{~kg}$ is assumed, which would require about $110 \mathrm{~m}^{3}$ of air to produce a flammable mixture. An explosion of this mixture would produce a maximum pressure surge of less than $240 \mathrm{kPa}$, which would cause little structural damage unless the explosion occurred after the mixture is drawn into the building ventilation ductwork. This accident is assumed to occur in the ductwork where the force of the explosion is assumed to cause failure of the ventilation system. Loss of the ventilation blowers would aerodynamically isolate the building from the atmosphere. Remedial action such as sealing off vent outlets, would further limit the atmospheric release.

The force of the explosion is assumed to dislodge contaminated material located in the ductwork and filters. Most of the contaminated concrete removed 
is in areas of low contamination, and the average concentration encountered in routine operations is assumed to be about $1 \mathrm{~g}$ of uranium per $\mathrm{m}^{2}$ of surface. This is further mixed with the concrete dust generated, so that the average uranium concentration in the dust is about $1.0 \times 10^{-5} \mu \mathrm{Ci} / \mathrm{g}$. The amount of contaminated dust deposited in the ventilation system is estimated to be about $100 \mathrm{~kg}$. If $10 \%$ of this material is released during the explosion, about $10 \mathrm{~kg}$ or $0.1 \mu \mathrm{Ci}$ of uranium are released to the atmosphere. An explosion of leaked LPG resulting in this magnitude of contamination is estimated to have a "low" frequency of occurrence.

Contaminated Sweeping Compound Fire. Sweeping compound is composed of sawdust treated with oil or other additives to enhance the collection of loose surface contamination. A fire is postulated to occur in used sweeping compound containing radioactivity removed from floor surfaces. The highest contamination level encountered in sweeping occurs on isolated floor surfaces with a contamination level of $10 \mathrm{~g}$ of uranium per $\mathrm{m}^{2}$. The average concentration on floor surfaces is $1 \mathrm{~g}$ of uranium per $\mathrm{m}^{2}$. It is assumed that an average of $2.5 \times 10^{-4} \mathrm{~m}^{3}$ of sweeping compound is used for each $\mathrm{m}^{2}$ of surface swept. It is also assumed that the density of the sweeping compound is about the same as light wood, or about $6.0 \times 10^{5} \mathrm{~g} / \mathrm{m}^{3}$.(33) It is reasonable to assume that the sweeping compound will be stored in small quantities; therefore a fire is postulated to occur in $0.5 \mathrm{~m}^{3}$ ( or $3 \times 10^{2} \mathrm{~kg}$ ) of used sweeping compound. This amount of sweeping compound will cover about 2,000 $\mathrm{m}^{2}$ of floor. Assuming that half of the floor contamination is removed during sweeping, about $1 \mathrm{~kg}$ of uranium is contained in the used sweeping compound.

The release fraction from the fire is assumed to be similar to that measured from burning waste, $1.5 \times 10^{-4}$. (34) Thus, about $0.15 \mathrm{~g}$ of uranium is released inside the building, and about $0.015 \mathrm{~g}$ is released to the atmosphere. With a specific activity of $1.3 \mu \mathrm{Ci} / \mathrm{g}$, this equals an atmospheric release of about $2.0 \times 10^{-8} \mathrm{Ci}$. A release of this magnitude from a fire in contaminated sweeping compound is estimated to have a "medium" frequency of occurrence.

Combustible Waste Fire. Absorbent materials, such as rags or paper wipes, are assumed to be used for a variety of purposes during DECON and are discarded after use. Materials that have come into contact with contaminated surfaces hold small quantities of radionuclides. Anticontamination clothing (coveralls, 
caps, hoods, or shoe covers) become contaminated through use. Plastics are generally considered combustible, although many kinds do not burn readily or are self-extinguishing.

It is postulated that contaminated combustible waste containing low levels of radioactivity ignites and burns in a working area. Large amounts of these wastes are not likely to accumulate in one place, so it is assumed that one cubic meter containing $100 \mathrm{~g}$ of uranium is involved in a combustible waste fire. Using the release fraction from burning waste of $1.5 \times 10^{-4}$, (34) the total release in the building is calculated to be $1.5 \times 10^{-2} \mathrm{~g}$, or $2.0 \times 10^{-8} \mathrm{Ci}$. The atmospheric release resulting from this fire is estimated to be $2.0 \times 10^{-9} \mathrm{Ci}$. A fire in combustible waste that results in a release of this magnitude is estimated to have a "high" frequency of occurrence.

Loss of Services. Loss of services, such as water supply, electrical power, or air flow, are inmediately apparent to the workers performing the various DECON tasks. In the case of manual tasks, the operator would discontinue the task immediately upon the loss of services. Most remotely controlled tasks would be monitored frequently enough to almost immediately detect the loss of a service. Since the loss of services constitutes a lesser magnitude release than other postulated accidents, no further analysis is attempted in this study.

\subsubsection{Natural Phenomena}

The designs of structures, systems, and components are based on withstanding the most severe natural phenomena recorded for the site, plus appropriate margins to account for uncertainties in the recorded data. It is assumed that the structural integrity of the plant is preserved during the operational lifetime of the plant. It is further assumed that the structural integrity is preserved during decommissioning as long as required for safety. It is estimated that, while natural phenomena can cause severe damage to the reference $\mathrm{UF}_{6}$ conversion plant resulting in severe radiological public safety impacts, they are low probability events. Also, the impact of these events will be less than the impacts calculated in the FSAR design-basis accidents for the operating plant. For this reason, no detailed analysis of the impacts of these phenomena is attempted beyond the brief discussions that follow. 
Floods. The FSAR considers runoff floods, surges, seiches, wave action, tsunamis, wind-generated wave action, and combinations of these phenomena. Also, a probable maximum flood is proposed. The plant is designed to be safe from damage by such a flood or other potential flooding.

Earthquakes. It is estimated that the probability of an earthquake that would occur and cause damage to the plant is $10^{-7}$ per year. (35) At this probability, earthquake-induced accidents are extremely unlikely.

Tornadoes. The probability of a large tornado striking the site is on the average less than $5 \times 10^{-6}$ per year. ${ }^{(35)}$ At this probability, tornadoinduced effects during decommissioning are extremely unlikely, and they are not considered further in this study.

High Winds. The design-basis wind velocity for all Category I and Category II structures is $168 \mathrm{~km} / \mathrm{hr}$ at $9.1 \mathrm{~m}$ above nominal ground elevation. For this study it is assumed that DECON tasks do not reduce the ability of these structures to withstand high winds, and no releases are anticipated.

\section{I.2.2.3 Aircraft Crashes}

Each facility site has its own potential risk from aircraft crashes based on its proximity to airports and air-traffic lanes. However, current information leads to the conclusion that the risk of damage from aircraft crashes is low for most sites. (36) Moreover, the risk is not escalated by DECON operations. The aircraft crash probability for most plants is very $10 \mathrm{w}\left(10^{-6}\right.$ to $10^{-8}$ per year) and no further analysis is attempted.

\section{I.2.2.4 Man-Caused Events}

Accidental airborne releases of radioactivity resulting from man-caused events could cover a wide spectrum of magnitudes, ranging from releases induced by casual trespassers to releases induced by armed terrorists. A detailed analysis of man-caused events during decommissioning is beyond the scope of this study. Thus, no airborne release calculations are made. 


\subsubsection{Radiation Doses from Postulated DECON Accidents}

Radiation doses to the maximum-exposed individual from accidental releases of radionuclides during DECON are calculated using the radiation dose models discussed in Appendix $E$. The first-year doses and the fifty-year conmitted dose equivalents to the maximum-exposed individual from inhalation for the accidents listed in TabTe I.2-7 are listed in Table I.2-10. Each accidental release is assumed to occur for one hour so that a comparison of the accidents can be made. The atmospheric dispersion $\left(\bar{X} / Q^{\prime}\right)$ value used for the accidents is $6.5 \times 10^{-4} \mathrm{sec} / \mathrm{m}^{3}$.

\section{3 PASSIVE SAFSTOR PUBLIC SAFETY ASSESSMENT}

The second decommissioning alternative considered for the reference $\mathrm{UF}_{6}$ conversion plant is passive SAFSTOR. This alternative is divided into three potential phases: preparations, safe storage, and deferred decontamination. In this section, the atmospheric releases of radioactivity and the resulting radiation doses to the public from preparations for safe storage are discussed. No atmospheric releases are identified during safe storage, and the resulting doses from deferred decontamination are assumed to be the same as for DECON. The analysis conducted for preparations for safe storage uses the same data and methods defined in Section I.2 for DECON.

\section{I.3.1 Routine Tasks During Preparations for Safe Storage}

After completion of final process inventory cleanout, the remaining uranium is spread throughout the processing areas in relatively inaccessible locations. No major decontamination or inventory reduction tasks are required. The total amount of uranium left in the facility during safe storage is estimated to be about $1200 \mathrm{~kg}$. This amount should not present a problem since access to the facility is restricted.

As described in Appendix $G$, the activities undertaken during preparations for safe storage are quite passive, and only limited releases of radioactivity are anticipated. The only tasks that may result in atmospheric releases are those identified for "all areas" in Table I.2-3 (shown by footnote $\mathrm{c}$ ). The 
IABLE I.2-10. Radiation Doses to the Maximum-Exposed Individual from Atmospheric Releases During DECON

\begin{tabular}{|c|c|c|c|c|c|c|c|c|c|}
\hline Area/General Method & $\begin{array}{l}\text { Total }(a) \\
\text { Atmospheric } \\
\text { ReYease } \\
(\mathrm{C} i / \mathrm{yr})\end{array}$ & & First-Year & Dose (rem) & & Fifty.Ye & $\frac{a r \text { Committed }}{\text { Bone }}$ & $\frac{\text { iose Equivalent }}{\text { Lung }}$ & $\frac{(\text { rem })}{G T-L L !}$ \\
\hline Oxyacetylene Explosion & $1.8 \times 10^{-3}$ & $\overline{15 \times 10-4}$ & $\overline{15 \times 10-3}$ & $51 \times 10-2$ & $32 \times 10-5$ & Dotat body & $31 \times 10-1$ & $13 \times 10-1$ & $12 \times 10-5$ \\
\hline & $2.9 \times 10^{-5}$ & $25 \times 10-6$ & $25 \times 10^{-5}$ & $8.1 \times 10^{-4}$ & $1.8 \times 10^{-7}$ & $29 \times 10^{-6}$ & $49 \times 10^{-5}$ & $20 \times 10^{-3}$ & $1.9 \times 10^{-7}$ \\
\hline $\begin{array}{l}\text { Envelope Rupture } \\
\text { Entrol }\end{array}$ & $2.9 \times 10=0$ & & $2.5 \times 10^{-0}$ & & & & & & \\
\hline $\begin{array}{l}\text { Vacuum } F y \text { ter-Bag } \\
\text { Rupture }(b)\end{array}$ & $2.4 \times 10^{-5}$ & $2.0 \times 10^{-6}$ & $2.0 \times 10^{-5}$ & $6.7 \times 10^{-4}$ & $1.5 \times 10^{-7}$ & $2.4 \times 10^{-6}$ & $4.1 \times 10^{-5}$ & $1.7 \times 10^{-3}$ & $1.5 \times 10^{-7}$ \\
\hline $\begin{array}{l}\text { Contaminated Metal } \\
\text { Cutting }\end{array}$ & $7.2 \times 10^{-6}$ & $6.1 \times 10^{-7}$ & $5.1 \times 10^{-6}$ & $2.0 \times 10^{-4}$ & $4.5 \times 10^{-8}$ & $7.2 \times 10^{-7}$ & $1.2 \times 10^{-5}$ & $5.0 \times 10^{-4}$ & $4.5 \times 10^{-8}$ \\
\hline $\begin{array}{l}\text { Gross Leak During Loop } \\
\text { Chem. Decon. }\end{array}$ & $1.9 \times 10^{-7}$ & $1.6 \times 10^{-8}$ & $1.6 \times 10^{-7}$ & $5.3 \times 10^{-6}$ & $1.2 \times 10^{-9}$ & $1.9 \times 10^{-8}$ & $3.2 \times 10^{-7}$ & $1.3 \times 10^{-5}$ & $1.2 \times 10^{-9}$ \\
\hline $\begin{array}{l}\text { Spilling of cont. } \\
\text { Solid Hastes }\end{array}$ & $1.3 \times 10^{-7}$ & $1.1 \times 10^{-8}$ & $1.1 \times 10^{-7}$ & $3.6 \times 10^{-6}$ & $8.2 \times 10^{-10}$ & $1.3 \times 10^{-8}$ & $2.2 \times 10^{-7}$ & $9.1 \times 10^{-6}$ & $8.2 \times 10^{-10}$ \\
\hline $\begin{array}{l}\text { Explosion of } L P G \\
\text { Leaked From a Front. } \\
\text { End Loader }\end{array}$ & $1.0 \times 10^{-7}$ & $8.5 \times 10^{-9}$ & $8.5 \times 10^{-8}$ & $2.8 \times 10^{-6}$ & $6.3 \times 10^{-10}$ & $1.0 \times 10^{-8}$ & $1.7 \times 10^{-7}$ & $7.0 \times 10^{-6}$ & $6.3 \times 10^{-10}$ \\
\hline $\begin{array}{l}\text { Contaminated Sfeeping } \\
\text { Compound Fire }(b)\end{array}$ & $2.0 \times 10^{-8}$ & $1.7 \times 10^{-9}$ & $1.7 \times 10^{-8}$ & $5.6 \times 10^{-7}$ & $1.3 \times 10^{-10}$ & $2.0 \times 10^{-9}$ & $3.4 \times 10^{-8}$ & $1.4 \times 10^{-6}$ & $1.3 \times 10^{-10}$ \\
\hline $\begin{array}{l}\text { Combystible Haste } \\
\text { fire(b) }\end{array}$ & $2.0 \times 10^{-9}$ & $1.7 \times 10^{-10}$ & $1.7 \times 10^{-9}$ & $5.6 \times 10^{-8}$ & $1.3 \times 10^{-11}$ & $2.0 \times 10^{-10}$ & $3.4 \times 10^{-9}$ & $1.4 \times 10^{-7}$ & $1.3 \times 10^{-11}$ \\
\hline
\end{tabular}

(a) For compar ison, alf re leases are assumed to occur in a 1-hour period.

(b) The accident shom applies to both DECON and preparations for safe storage. 
public safety analysis data for these tasks are identical to the data identified for $D E C O N$, as shown in the table. The resulting atmospheric releases for these tasks are noted by footnote $c$ in Table 1.2-4.

First-year doses and fifty-year committed dose equivalents to both the maximum-exposed individual and the population residing within $80 \mathrm{~km}$ of the site are shown in Tables I.2-5 and I.2-6, respectively. No tasks unique to safe storage are identified that result in atmospheric releases or public radiation doses, thus no further analysis is required.

\section{I.3.2 Postulated Accidents During Preparations for Safe Storage}

No accidents are postulated for preparations for safe storage that are different from the accidents postulated for DECON. Since none of the tasks defined for preparations for safe storage involve loop chemical decontamination or the removal of contaminated concrete, the accidents defined for these DECON tasks do not apply. The only accidents that are considered are those shown in Table I.2-7 by footnote d. Again, the frequency of occurrence shown in Table I.2-7 for each accident is based on both the probability of the accident and on the probability of an atmospheric release of the calculated magnitude. The frequency of occurrence is listed as "high" if the occurrence of a release of similar or greater magnitude is greater than $10^{-2}$, as "medium" if between $10^{-2}$ and $10^{-5}$, and as "Tow" if less than $10^{-5}$. The radiation doses calculated for the maximum-exposed individual from these accidents are shown in Table 1.2-10 by footnote $b$.

\section{I.4 OCCUPATIONAL OOSE ESTIMATES FOR DECON ANL SAFSTOR OF THE REFERENCE UF 6 CONVEFSION PLANT}

Detailed estimates of the work requirements for each DECON and SAFSTOR task identified in this study and dose rates estimated for each area in the main process building are used to estimate the occupational exposures resulting from both decommissioning alternatives. It is assumed that internal exposure of decomissioning personnel is effectively prevented by the use of contamination control envelopes, breathing masks, and other protective measures. Although external dose rates are reduced substantially by the final inventory cleanout, additional cleaning and temporary shielding may reduce localized dose rates even further. 
The results of these analyses are presented in Tables I.4-1 for DECON, 1.4-2 for preparations for safe storage, and I.4-3 for safe storage. The estimates are based on a 6-hour effective working day in radiation zones for each worker. It is assumed that operations and craft personnel spend $50 \%$ of their time in the location of highest dose rate in each area. The balance of all work time is spent in locations where the radiation dose rate is characteristic of the most accessible locations in each area. The radiation dose retes are assumed to be similar to those measured for an operating uranium fuel fabrication facility, as reported in Reference 37.

\section{I.5 RADIATION DOSES FROM WASTE TRANSPORT FOR DECOMMISSIONING THE REFERENCE * UF $_{6}$ CONVERSION PLANT}

During decommissioning of the reference $\mathrm{UF}_{6}$ conversion plant, radioactive waste materials are packaged and shipped offsite for burial. These wastes are assumed to be shipped to a cormercial low-level waste burial facility located about $800 \mathrm{~km}$ from the site. All wastes are assumed to be shipped by truck. The methods used to estimate radiation doses to transportation workers and to members of the public from waste shipments are given in Reference 5. Radiation doses received by workers unloading the radioactive materials at the repository or disposal site are not considered in this study since they are assumed to occur at separate licensed facilities.

\subsubsection{Technical Approach}

The following assumptions are made about truck shipments of radioactive materials:

1. Each shipment of waste from the main process building contains enough material to result in the maximum exposure rates allowed by regulations. Department of Transportation (DOT) regulations set the following exposure 1imits:

- $1000 \mathrm{mR} / \mathrm{hr}$ at $1 \mathrm{~m}$ from the external surface of any package transported in a closed vehicle

- $200 \mathrm{mR} / \mathrm{hr}$ at the external surface of the vehicle 


\section{TABLE I.4-1. Estimated Occupational Radiation Doses for DECON}

\begin{tabular}{|c|c|c|c|c|c|c|c|c|c|c|c|c|c|c|}
\hline \multirow{2}{*}{\multicolumn{2}{|c|}{ Area. }} & \multicolumn{3}{|c|}{ Foremen } & \multicolumn{3}{|c|}{ Tectrictans } & \multicolumn{3}{|c|}{ Health Physicists } & \multicolumn{3}{|c|}{ Craftsmen. } & \multirow[b]{2}{*}{$\begin{array}{c}\text { Ared } \\
\text { Total Dose } \\
\text { (man-rem) } \\
\end{array}$} \\
\hline & & $\begin{array}{l}\text { Averose } \\
\text { Exposure } \\
\text { Rate } \\
\text { Rath } \\
\end{array}$ & $\begin{array}{c}\text { Exposure } \\
\text { Iime } \\
\text { (man-hr) } \\
\end{array}$ & $\begin{array}{c}\text { Total } \\
\text { Dose } \\
\text { (man-rem) } \\
\end{array}$ & $\begin{array}{c}\text { Average } \\
\text { Exposure } \\
\text { Rate } \\
\text { RAhI } \\
\end{array}$ & $\begin{array}{l}\text { Exposure } \\
\text { Time } \\
\text { (man-hr) } \\
\end{array}$ & $\begin{array}{c}\text { Total } \\
\text { Dose } \\
\text { [man-rem } 1 \\
\end{array}$ & $\begin{array}{l}\text { Averadae } \\
\text { Exposure } \\
\text { Rate } \\
\text { IR/hi }\end{array}$ & $\begin{array}{l}\text { Expossure } \\
\text { Time } \\
\text { (mam-tir) } \\
\end{array}$ & $\begin{array}{c}\text { Total } \\
\text { Dose } \\
\text { (man-ren) } \\
\end{array}$ & $\begin{array}{l}\text { Rvergage } \\
\text { Exposure } \\
\text { Rate } \\
(R / h) \\
\end{array}$ & $\begin{array}{l}\text { Exposure } \\
\text { Time } \\
(\text { mon-hr) } \\
\end{array}$ & $\begin{array}{c}\text { Total } \\
\text { Dose } \\
\text { (man-rem) } \\
\end{array}$ & \\
\hline Area 1: & Drum Receiving & $3.7 \times 10^{-5}$ & 30 & $1.1 \times 10^{-3}$ & $3.7 \times 10^{-5}$ & 170 & $4.4 \times 10^{-3}$ & $3.7 \times 10^{-5}$ & 15 & $5.5 \times 10^{-4}$ & $3.7 \times 10^{-5}$ & 15 & $5.6 \times 10^{-4}$ & $6.6 \times 10^{-3}$ \\
\hline Area 2: & ADU Siurry & $1.5 \times 10^{-4}$ & ra & $4.5 \times 10^{-3}$ & $3.7 \times 10^{-3}$ & 180 & $6.7 \times 10^{-1}$ & $3.7 \times 10^{-3}$ & 15 & $5.6 \times 10^{-2}$ & $3.7 \times 10^{-3}$ & 30 & $1.1 \times 10^{-1}$ & $8.4 \times 10^{-1}$ \\
\hline Area 3: & Sampling Station & $1.5 \times 10^{-4}$ & 30 & $4.5 \times 10^{-3}$ & $3.7 \times 10^{-3}$ & 210 & $7.8 \times 10^{-1}$ & $3.7 \times 10^{-3}$ & 19 & $5.6 \times 10^{-7}$ & $3.7 \times 10^{-3}$ & 30 & $1.1 \times 10^{-1}$ & $9.5 \times 10^{-1}$ \\
\hline Area 4: & Laboratory & $3.7 \times 10^{-5}$ & 90 & $3.3 \times 10^{-3}$ & $3.7 \times 10^{-5}$ & 450 & $1.7 \times 10^{-2}$ & $3.7 \times 10^{-5}$ & 30 & $1.1 \times 10^{-3}$ & $3.7 \times 10^{-5}$ & 150 & $5.6 \times 10^{-3}$ & $2.7 \times 10^{-2}$ \\
\hline Ared 5: & UF $_{4}$ Slurry & $1.5 \times 10^{-4}$ & 165 & $2.5 \times 10^{-2}$ & $3.7 \times 10^{-3}$ & 900 & $3.3 \times 10^{0}$ & $3.7 \times 10^{-3}$ & 60 & $2.2 \times 10^{-1}$ & $3.7 \times 10^{-3}$ & 150 & $5.6 \times 10^{-1}$ & $4.1 \times 10^{0}$ \\
\hline Area 6: & $\begin{array}{l}\text { Ore Concentrate } \\
\text { Dissolution }\end{array}$ & $3.5 \times 10^{-4}$ & 180 & $2.7 \times 10^{-2}$ & $3.7 \times 10^{-3}$ & 1230 & $4.6 \times 10^{0}$ & $3.7 \times 10^{-3}$ & 135 & $5.0 \times 10^{-1}$ & $3.7 \times 10^{-3}$ & 195 & $7.2 \times 10^{-1}$ & $5.8 \times 10^{0}$ \\
\hline Area 7: & Solvent-Extraction & $1.5 \times 10^{-4}$ & 315 & $4.7 \times 10^{-7}$ & $3.7 \times 10^{-3}$ & 1680 & $6.2 \times 10^{0}$ & $3.7 \times 10^{-3}$ & 120 & $4.4 \times 10^{-1}$ & $3.7 \times 10^{-3}$ & 285 & $1.0 \times 10^{0}$ & $7.7 \times 10^{0}$ \\
\hline Ared 8: & Uranyl Nitrate & $3.7 \times 10^{-5}$ & 270 & $1.0 \times 10^{-3}$ & $1.2 \times 10^{-4}$ & 1700 & $2.0 \times 10^{-2}$ & $1.2 \times 10^{-4}$ & 120 & $1.4 \times 10^{-2}$ & $1.2 \times 10^{-4}$ & 225 & $2.7 \times 10^{-2}$ & $2.4 \times 10^{-1}$ \\
\hline Ared 9: & Denitration & $3.7 \times 10^{-5}$ & 285 & $1.0 \times 10^{-2}$ & $1.2 \times 10^{-4}$ & 1830 & $2.2 \times 10^{-1}$ & $1.2 \times 10^{-4}$ & 120 & $1.4 \times 10^{-7}$ & $1.2 \times 10^{-4}$ & 225 & $2.7 \times 10^{-2}$ & $2.7 \times 10^{-1}$ \\
\hline Ared 10: & Nitric Acid & $3.7 \times 10^{-5}$ & 150 & $5.6 \times 10^{-3}$ & $1.2 \times 10^{-4}$ & 930 & $1.1 \times 10^{-1}$ & $1.2 \times 10^{-4}$ & 60 & $7.2 \times 10^{-3}$ & $1.2 \times 10^{-4}$ & 120 & $1.4 \times 10^{-2}$ & $1.4 \times 10^{-1}$ \\
\hline Area 11: & Reduction Systems & $3.7 \times 10^{-5}$ & 270 & $1.0 \times 10^{-3}$ & $1.2 \times 10^{-4}$ & 1700 & $2.0 \times 10^{-1}$ & $1.2 \times 10^{-4}$ & 120 & $1,4 \times 10^{-2}$ & $1.2 \times 10^{-4}$ & 225 & $8.3 \times 10^{-3}$ & $2.2 \times 10^{-1}$ \\
\hline Area 12: & Hydrofluorination & $3.7 \times 10^{-5}$ & 225 & $8.3 \times 10^{-3}$ & $1.2 \times 10^{-4}$ & 1200 & $1.4 \times 10^{-1}$ & $1.2 \times 10^{-4}$ & $\infty$ & $1.1 \times 10^{-7}$ & $1.2 \times 10^{-4}$ & 390 & $4.7 \times 10^{-2}$ & $2.1 \times 10^{-1}$ \\
\hline Area 13: & Fluroination & $3.7 \times 10^{-5}$ & 195 & $7.2 \times 10^{-3}$ & $1.2 \times 10^{-4}$ & 1350 & $1.6 \times 10^{-1}$ & $1.2 \times 10^{-4}$ & 493 & $5.9 \times 10^{-7}$ & $1.2 \times 10^{-4}$ & 225 & $2.7 \times 10^{-2}$ & $2.5 \times 10^{-1}$ \\
\hline Area 14: & Cylinder Loading & $3.7 \times 10^{-5}$ & 150 & $5.5 \times 10^{-3}$ & $3.7 \times 10^{-5}$ & 930 & $3.4 \times 10^{-2}$ & $3.7 \times 10^{-5}$ & 60 & $2.2 \times 10^{-3}$ & $3.7 \times 10^{-5}$ & 270 & $1.0 \times 10^{-2}$ & $2.1 \times 10^{-7}$ \\
\hline Area 15: & $F_{2}$ Production & $3.7 \times 10^{-5}$ & 75 & $2.8 \times 10^{-3}$ & $3.7 \times 10^{-5}$ & 450 & $1.7 \times 10^{-2}$ & $3.7 \times 10^{-5}$ & 30 & $1.1 \times 10^{-3}$ & $3.7 \times 10^{-5}$ & 75 & $2.8 \times 10^{-3}$ & $2.4 \times 10^{-2}$ \\
\hline Area 16: & $=F_{2} \mathrm{Cell}$ & $3.7 \times 10^{-5}$ & 60 & $2.2 \times 10^{-3}$ & $3.7 \times 10^{-5}$ & 360 & $1.3 \times 10^{-2}$ & $3.7 \times 10^{-5}$ & 30 & $1.1 \times 10^{-3}$ & $3.7 \times 10^{-5}$ & $\infty$ & $2.2 \times 10^{-3}$ & $1.8 \times 10^{-2}$ \\
\hline Area 17: & Instrument Repair & $3.7 \times 10^{-5}$ & 105 & $3.9 \times 10^{-3}$ & $3.7 \times 10^{-5}$ & 510 & $1.9 \times 10^{-2}$ & $3.7 \times 10^{-5}$ & 45 & $1.7 \times 10^{-3}$ & $3.7 \times 10^{-5}$ & 390 & $1.4 \times 10^{-2}$ & $3.9 \times 10^{-2}$ \\
\hline Area $18:$ & Ammonia Cracking & $3.7 \times 10^{-5}$ & 75 & $2.8 \times 10^{-3}$ & $3.7 \times 10^{-5}$ & 405 & $1.5 \times 10^{-2}$ & $3.7 \times 10^{-5}$ & 30 & $1.1 \times 10^{-3}$ & $3.7 \times 10^{-5}$ & 225 & $8.3 \times 10^{-3}$ & $2.7 \times 10^{-2}$ \\
\hline Area 19: & Waste Gas Disposal & $3.7 \times 10^{-5}$ & 60 & $2.2 \times 10^{-3}$ & $3.7 \times 10^{-5}$ & 360 & $1.3 \times 10^{-2}$ & $3.7 \times 10^{-5}$ & 30 & $1.1 \times 10^{-3}$ & $3.7 \times 10^{-5}$ & 75 & $2.8 \times 10^{-3}$ & $1.9 \times 10^{-2}$ \\
\hline
\end{tabular}




\section{TABLE I.4-1. (Contd)}

\begin{tabular}{|c|c|c|c|c|c|c|c|c|c|c|c|c|c|}
\hline \multirow[b]{2}{*}{ Area } & \multicolumn{3}{|c|}{ Foremen } & \multicolumn{3}{|c|}{ Average Technicians } & \multicolumn{3}{|c|}{ Health Physicists } & \multicolumn{3}{|c|}{ Craftsmen } & \multirow[b]{2}{*}{$\begin{array}{c}\text { Ared } \\
\text { Total Dose } \\
\text { [man-rem! }\end{array}$} \\
\hline & $\begin{array}{c}\text { Aver age } \\
\text { Exposure } \\
\text { Rote } \\
\{\mathrm{R} / \mathrm{h}\} \\
\end{array}$ & $\begin{array}{l}\text { Exposure } \\
\text { Titre } \\
\text { (man-hr) }\end{array}$ & $\begin{array}{c}\begin{array}{c}\text { Total } \\
\text { Dose } \\
\text { (man-rean) }\end{array} \\
\end{array}$ & $\begin{array}{c}\text { Average } \\
\text { Exposure } \\
\text { Rate } \\
\text { R/hl. } \\
\end{array}$ & $\begin{array}{l}\text { Exposure } \\
\text { Time } \\
\text { (man-hr) }\end{array}$ & $\begin{array}{c}\text { Tota) } \\
\text { [nose } \\
\text { (man-ren] }\end{array}$ & $\begin{array}{c}\text { Average } \\
\text { Exposure } \\
\text { Rate } \\
\text { (R/h) } \\
\end{array}$ & $\begin{array}{l}\text { Exposure } \\
\text { Ifine } \\
\text { (manthr) } \\
\end{array}$ & $\begin{array}{c}\text { Total } \\
\text { Dose } \\
\text { (man-rem) } \\
\end{array}$ & $\begin{array}{l}\text { Avêrase } \\
\text { Exposure } \\
\text { Rate } \\
\text { (R/h) } \\
\end{array}$ & $\begin{array}{l}\text { Exposure } \\
\text { Time } \\
\text { (man-hr) } \\
\end{array}$ & $\begin{array}{c}\text { Total } \\
\text { Dose } \\
\text { [man-rem] }\end{array}$ & \\
\hline Area 20: $\mathrm{H}_{2}$ Condensing & $3.7 \times 10^{-5}$ & 265 & $6.1 \times 10^{-3}$ & $3.7 \times 10^{-5}$ & 102 & $3.8 \times 10^{-3}$ & $3.7 \times 10^{-5}$ & 60 & $2.2 \times 10^{-3}$ & $3.7 \times 10^{-5}$ & 150 & $5.6 \times 10^{-3}$ & $1.8 \times 10^{-2}$ \\
\hline Area 21: Temp. Radwaste & $3.7 \times 10^{-5}$ & 30 & $1.1 \times 10^{-3}$ & $1.2 \times 10^{-4}$ & 210 & $2.5 \times 10^{-2}$ & $1.2 \times 10^{-4}$ & 30 & $1.1 \times 10^{-3}$ & $1.2 \times 10^{-4}$ & 30 & $3.6 \times 10^{-3}$ & $3.1 \times 10^{-2}$ \\
\hline Area 22: Decon. Area & $3.7 \times 10^{-5}$ & 30 & $1.1 \times 10^{-3}$ & $1.2 \times 10^{-4}$ & 120 & $1.4 \times 10^{-2}$ & $1.2 \times 10^{-4}$ & 15 & $1.8 \times 10^{-3}$ & $1.2 \times 10^{-4}$ & 30 & $3.6 \times 10^{-3}$ & $2.1 \times 10^{-2}$ \\
\hline Area 23: Incinerator & $3.7 \times 10^{-5}$ & 60 & $2.2 \times 10^{-3}$ & $3.7 \times 10^{-5}$ & 450 & $1.7 \times 10^{-2}$ & $3.7 \times 10^{-5}$ & 30 & $1.1 \times 10^{-3}$ & $3.7 \times 10^{-5}$ & 220 & $4.4 \times 10^{-3}$ & $2.5 \times 10^{-2}$ \\
\hline Area 24: Laundry & $3.7 \times 10^{-5}$ & 60 & $2.2 \times 10^{-3}$ & $3.7 \times 10^{-5}$ & 420 & $1.5 \times 10^{-2}$ & $3.7 \times 10^{-5}$ & 30 & $1.1 \times 10^{-3}$ & $3.7 \times 10^{-5}$ & 45 & $1.7 \times 10^{-3}$ & $2.1 \times 10^{-2}$ \\
\hline Area 25: Overall Clearup & $3.7 \times 10^{-5}$ & 90 & $3.3 \times 10^{-3}$ & $3.7 \times 10^{-5}$ & 660 & $2.4 \times 10^{-2}$ & $3.7 \times 10^{-5}$ & 30 & $1.1 \times 10^{-3}$ & $3.7 \times 10^{-5}$ & 60 & $2.2 \times 10^{-3}$ & $3.1 \times 10^{-2}$ \\
\hline Building Area Totals & & 3200 & $1.8 \times 10^{-1}$ & & $18 \overline{500}$ & $1.7 \times 10^{1}$ & & 1810 & $1.4 \times 10^{0}$ & & 3770 & $2.7 \times 10^{8}$ & $2.1 \times 10^{1}$ \\
\hline Site Areas: $(\mathbf{a})$ & & & & & & & & & & & & & \\
\hline Extraction Maste Pond & $1.5 \times 10^{-4}$ & 600 & $9.0 \times 10^{-2}$ & $3.7 \times 10^{-3}$ & 4440 & $1.6 \times 10^{1}$ & $3.7 \times 10^{-3}$ & 240 & $8.9 \times 10^{-1}$ & $3.7 \times 10^{-3}$ & 390 & $1.4 \times 10^{0}$ & $1.8 \times 10^{1}$ \\
\hline Fluorf de Waste Lagoons & $1.5 \times 10^{-4}$ & 660 & $9.9 \times 10^{-2}$ & $3.7 \times 10^{-3}$ & 4800 & $1.8 \times 10^{1}$ & $3.7 \times 10^{-3}$ & 150 & $5.5 \times 10^{-1}$ & $3.7 \times 10^{-3}$ & 450 & $1.7 \times 10^{0}$ & $2.0 \times 10^{1}$ \\
\hline Misc. Buried Maste & $1.5 \times 10^{-4}$ & 75 & $1.1 \times 10^{-2}$ & $3.7 \times 10^{-3}$ & 510 & $1.9 \times 10^{0}$ & $3.7 \times 10^{-3}$ & 30 & $1.1 \times 10^{-1}$ & $3.7 \times 10^{-3}$ & 120 & $4.4 \times 10^{-1}$ & $2.4 \times 10^{0}$ \\
\hline Orum Storage & $3.7 \times 10^{-5}$ & 60 & $2.2 \times 10^{-3}$ & $3.7 \times 10^{-5}$ & 360 & $1.3 \times 10^{-2}$ & $3.7 \times 10^{-5}$ & 15 & $5.6 \times 10^{-4}$ & $3.7 \times 10^{-5}$ & 60 & $2.2 \times 10^{-3}$ & $1.8 \times 10^{-2}$ \\
\hline Cylinder Storage & $3.7 \times 10^{-5}$ & 165 & $6.1 \times 10^{-3}$ & $3.7 \times 10^{-5}$ & 900 & $3.3 \times 10^{-2}$ & $3.7 \times 10^{-5}$ & 30 & $1.1 \times 10^{-3}$ & $3.7 \times 10^{-5}$ & 180 & $6.7 \times 10^{-3}$ & $4.7 \times 10^{-2}$ \\
\hline PTant Stack & $3.7 \times 10^{-5}$ & 60 & $2.2 \times 10^{-3}$ & $3.7 \times 10^{-5}$ & 450 & $1.7 \times 10^{-2}$ & $3.7 \times 10^{-5}$ & 30 & $1.1 \times 10^{-3}$ & $3.7 \times 10^{-5}$ & 120 & $4.4 \times 10^{-3}$ & $2.5 \times 10^{-2}$ \\
\hline Overall Cleanup & $3.7 \times 10^{-5}$ & 120 & $4.4 \times 10^{-3}$ & $3.7 \times 10^{-5}$ & 930 & $3.4 \times 10^{-2}$ & $3.7 \times 10^{-5}$ & 45 & $1.7 \times 10^{-3}$ & $3.7 \times 10^{-5}$ & 0 & 0 & $4.0 \times 10^{-2}$ \\
\hline Site Area Totals & & 1740 & $2.0 \times 10^{-1}$ & & 12400 & $3.6 \times 10^{1}$ & & 540 & $1.6 \times 10^{0}$ & & 1320 & $3.6 \times 10^{0}$ & $4.1 \times 10^{\mathrm{J}}$ \\
\hline OECON totals & & 4940 & $3.8 \times 10^{-1}$ & & 30900 & $5.3 \times 10^{1}$ & & 2350 & $3.0 \times 10^{0}$ & & 5090 & $6.2 \times 10^{0}$ & $6.2 \times 10^{1}$ \\
\hline
\end{tabular}

(a) Only the waste exhumation. packaging, and offsite disposal option is considered. 
TABLE I.4-2. Estimated Occupational Doses for Preparations for Safe Storage

\begin{tabular}{|c|c|c|c|c|c|c|c|c|c|c|c|c|c|}
\hline \multirow[b]{2}{*}{ Task. } & \multicolumn{3}{|c|}{ Foremen } & \multicolumn{3}{|c|}{ Techntcians } & \multicolumn{3}{|c|}{ Health Physicists } & \multicolumn{4}{|c|}{ Craftsmen } \\
\hline & $\begin{array}{c}\text { Average } \\
\text { Exposure } \\
\text { Rate } \\
\text { [R/h] } \\
\end{array}$ & $\begin{array}{c}\text { Exposure } \\
\text { T ime } \\
\text { (man-lm) }\end{array}$ & $\begin{array}{c}\text { Tota } 1 \\
\text { Oose } \\
\text { [man-rem] } \\
\end{array}$ & $\begin{array}{c}\text { Average } \\
\text { Exposure } \\
\text { Rate } \\
\text { (R/h) } \\
\end{array}$ & $\begin{array}{c}\text { Exposure } \\
\text { Time } \\
\text { (man-hr) }\end{array}$ & $\begin{array}{c}\text { Total } 1 \\
\text { Dose } \\
\text { (man-rem) }\end{array}$ & $\begin{array}{l}\text { Averaoge } \\
\text { Exposure } \\
\text { Rate } \\
(\mathrm{R} / \mathrm{h}) \\
\end{array}$ & $\begin{array}{l}\text { Exposure } \\
\text { Time } \\
\text { (man-hr) }\end{array}$ & $\begin{array}{c}\text { Total } \\
\text { Dose } \\
\text { (man-rean) } \\
\end{array}$ & $\begin{array}{c}\text { Average } \\
\text { Exposure } \\
\text { Rate } \\
\text { (R/h) } \\
\end{array}$ & $\begin{array}{l}\text { Exposure } \\
\text { Time } \\
\text { (man-hr) }\end{array}$ & $\begin{array}{c}\text { Total } \\
\text { Dose } \\
\text { (man-rsin) }\end{array}$ & $\begin{array}{l}\text { Task } \\
\text { Total Dose } \\
\text { (man-rem) }\end{array}$ \\
\hline \multicolumn{14}{|l|}{ Equigment Deactivat i on } \\
\hline $\begin{array}{l}\text { Audit of pumps and } \\
\text { plpelines }\end{array}$ & $3.7 \times 10^{-5}$ & 30 & $1.1 \times 10^{-3}$ & $1.2 \times 10^{-4}$ & $\infty 0$ & $7.2 \times 10^{-3}$ & $1.2 \times 10^{-4}$ & 30 & $3.6 \times 10^{-3}$ & $1.2 \times 10^{-4}$ & 60 & $7.2 \times 10^{-3}$ & $1.9 \times 10^{-?}$ \\
\hline $\begin{array}{l}\text { Secure valves, hoops, } \\
\text { conveyors }\end{array}$ & $3.7 \times 10^{-5}$ & 30 & $1.1 \times 10^{-3}$ & $1.2 \times 10^{-4}$ & 90 & $1.1 \times 10^{-7}$ & $1.2 \times 10^{-4}$ & 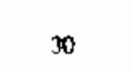 & $3.6 \times 10^{-3}$ & $1.2 \times 10^{-4}$ & 60 & $7.2 \times 10^{-3}$ & $2.3 \times 10^{-2}$ \\
\hline $\begin{array}{l}\text { Disconnect unneeded } \\
\text { services }\end{array}$ & $3.7 \times 10^{-5}$ & 60 & $2.2 \times 10^{-3}$ & $3.7 \times 10^{-5}$ & 60 & $2.2 \times 10^{-3}$ & $3.7 \times 10^{-5}$ & 30 & $1.1 \times 10^{-3}$ & $3.7 \times 10^{-5}$ & 120 & $4.4 \times 10^{-3}$ & $9.9 \times 10^{-3}$ \\
\hline $\begin{array}{l}\text { Tag equipment to } \\
\text { ident ify status }\end{array}$ & $3.7 \times 10^{-5}$ & 30 & $1.1 \times 10^{-3}$ & $3.7 \times 10^{-5}$ & 60 & $2.2 \times 10^{-3}$ & $3.7 \times 10^{-5}$ & 60 & $2.2 \times 10^{-3.3}$ & $3.7 \times 10^{-5}$ & 60 & $2.2 \times 10^{-3}$ & $7.7 \times 10^{-3}$ \\
\hline Safety audit & $3.7 \times 10^{-5}$ & 30 & $1.1 \times 10^{-3}$ & $3.7 \times 10^{-5}$ & 60 & $2.2 \times 10^{-3}$ & $3.7 \times 10^{-5}$ & 60 & $2.2 \times 10^{-3}$ & $3.7 \times 10^{-5}$ & 60 & $2.2 \times 10^{-3}$ & $7.7 \times 10^{-3}$ \\
\hline $\begin{array}{l}\text { Isolat lon of areas } \\
\text { Install buliding } \\
\text { locks and signs }\end{array}$ & $3.7 \times 10^{-5}$ & 30 & $1.1 \times 10^{-3}$ & $3.7 \times 10^{-5}$ & 30 & $1.1 \times 10^{-3}$ & $3.7 \times 10^{-5}$ & 0 & 0 & $3.7 \times 10^{-5}$ & 60 & $2.2 \times 10^{-3}$ & $4.4 \times 10^{-3}$ \\
\hline $\begin{array}{l}\text { Building systems } \\
\text { check }\end{array}$ & $3.7 \times 10^{-5}$ & 30 & $1.1 \times 10^{-3}$ & $3.7 \times 10^{-5}$ & 60 & $2.2 \times 10^{-3}$ & $3.7 \times 10^{-5}$ & 30 & $1.1 \times 10^{-3}$ & $3.7 \times 10^{-5}$ & 60 & $2.2 \times 10^{-3}$ & $6.6 \times 10^{-3}$ \\
\hline $\begin{array}{l}\text { Install fence } \\
\text { and outside locks }\end{array}$ & $7.4 \times 10^{-6}$ & 30 & $2.2 \times 10^{-4}$ & $7.4 \times 10^{-6}$ & 30 & $2.2 \times 10^{-4}$ & $7.4 \times 10^{-5}$ & 0 & D & $7.4 \times 10^{-6}$ & 30 & $2.2 \times 10^{-4}$ & $6.6 \times 10^{-4}$ \\
\hline $\begin{array}{l}\text { Final Preparations } \\
\text { Camplete offsite } \\
\text { shipment of uranium }\end{array}$ & $3.7 \times 10^{-5}$ & 30 & $1.1 \times 10^{-3}$ & $3.7 \times 10^{-5}$ & 120 & $4.4 \times 10^{-3}$ & $3.7 \times 10^{-6}$ & so & $2.2 \times 10^{-3}$ & $3.7 \times 10^{-5}$ & 15 & $5.6 \times 10^{-4}$ & $6.1 \times 10^{-3}$ \\
\hline $\begin{array}{l}\text { Install intrusion } \\
\text { alarm system }\end{array}$ & $3.7 \times 10^{-5}$ & 30 & $1.1 \times 10^{-3}$ & $3.7 \times 10^{-5}$ & 60 & $2.2 \times 10^{-3}$ & $3.7 \times 10^{-5}$ & 30 & $1.1 \times 10^{-3}$ & $3.7 \times 10^{-5}$ & 180 & $6.7 \times 10^{-3}$ & $1.1 \times 10^{-2}$ \\
\hline $\begin{array}{l}\text { Install radiation } \\
\text { monit toring system }\end{array}$ & $3.7 \times 10^{-5}$ & 30 & $1.1 \times 10^{-3}$ & $3.7 \times 10^{-5}$ & 60 & $2.2 \times 10^{-3}$ & $3.7 \times 10^{-5}$ & 30 & $1.1 \times 10^{-3}$ & $3.7 \times 10^{-5}$ & 30 & $4.4 \times 10^{-3}$ & $8.8 \times 10^{-3}$ \\
\hline $\begin{array}{l}\text { Comprehensive } \\
\text { radtation survey }\end{array}$ & $1.2 \times 10^{-4}$ & 30 & $3.6 \times 10^{-3}$ & $1.2 \times 10^{-4}$ & 120 & $1.4 \times 10^{-2}$ & $1.2 \times 10^{-5}$ & 120 & $1.4 \times 10^{-4}$ & $1.2 \times 10^{-4}$ & 0 & 0 & $1.8 \times 10^{-2}$ \\
\hline Butlding Area Totals & & $\overline{390}$ & $1.6 \times 10^{-2}$ & & 810 & $5.1 \times 10^{-2}$ & & 480 & $1.8 \times 10^{-2}$ & & 825 & $4.0 \times 10^{-7}$ & $1.2 \times 10^{-1}$ \\
\hline \multicolumn{14}{|l|}{$\begin{array}{l}\text { Onsite Waste } \\
\text { Stabilization }\end{array}$} \\
\hline $\begin{array}{l}\text { Oratin ponds and } \\
\text { lagoons and } \\
\text { cover with } \\
\text { weighted plastic }\end{array}$ & $1.2 \times 10^{-4}$ & 60 & $7.2 \times 10^{-3}$ & $1.2 \times 10^{-4}$ & 360 & $4.3 \times 10^{-2}$ & $1.2 \times 10^{-4}$ & 60 & $7.2 \times 10^{-3}$ & $1.2 \times 10^{-4}$ & 60 & $7.2 \times 10^{-3}$ & $6.5 \times 10^{-?}$ \\
\hline $\begin{array}{l}\text { Preparations for } \\
\text { Safe Storage Totals }\end{array}$ & & 450 & $\overline{2.3 \times 10^{-2}}$ & & $\overline{1170}$ & $\overline{9.3 \times 10^{-2}}$ & & $\overline{540}$ & $\overline{P .5 \times 10^{-7}}$ & & $\overline{885}$ & $4.7 \times 10^{-2}$ & $1.8 \times 10^{-1}$ \\
\hline
\end{tabular}


TABLE I.4-3. Estimated Occupational Radiation Doses During Safe Storage

\begin{tabular}{|c|c|c|c|c|}
\hline $\begin{array}{l}\text { Employment } \\
\text { Category }\end{array}$ & $\begin{array}{l}\text { Average } \\
\text { Exposure } \\
\text { Rate }(R / h) \\
\end{array}$ & $\begin{array}{l}\text { Total Exposure } \\
\text { (man-hours/yr) }\end{array}$ & $\begin{array}{c}\text { Total Dose } \\
\text { (man-rem/yr) }\end{array}$ & $\begin{array}{c}\text { Total Dose } \\
\text { For 10-Years } \\
\text { of Safe Storage } \\
\text { (man-rem) } \\
\end{array}$ \\
\hline Facility Manager & $3.7 \times 10^{-5}$ & 375 & $1.4 \times 10^{-2}$ & $1.4 \times 10^{-1}$ \\
\hline $\begin{array}{l}\text { Maintenence and } \\
\text { Operations } \\
\text { Man }\end{array}$ & $9.4 \times 10^{-5}$ & 750 & $7.0 \times 10^{-2}$ & $7.0 \times 10^{-1}$ \\
\hline Secretary ${ }^{(a)}$ & 0 & 0 & 0 & 0 \\
\hline $\begin{array}{l}\text { Third-Party } \\
\text { Inspectors }\end{array}$ & $6.6 \times 10^{-5}$ & 45 & $3.0 \times 10^{-3}$ & $3.0 \times 10^{-2}$ \\
\hline TOTALS & & 1170 & $8.7 \times 10^{-2}$ & $8.7 \times 10^{-1}$ \\
\hline
\end{tabular}

(a) Not expected to work in a radiation zone, but included in the analysis.

- $10 \mathrm{mR} / \mathrm{hr}$ at any point $2 \mathrm{~m}$ from the vehicle

- $2 \mathrm{mR} / \mathrm{hr}$ at any normally occupied position in the vehicle. (38)

Shipments of wastes from the extraction pond and fluoride lagoons are assumed to have dose rates of $10 \%$ of these 1 imits.

2. For each truck shipment of radioactive waste, two truck drivers spend 12 hours inside the cab and 1 hour outside of the cab at a distance of $2 \mathrm{~m}$ from the cargo.

3. For each truck shipment of radioactive waste, two garagemen each spend 10 minutes at an average distance of $2 \mathrm{~m}$ from the payload.

4. For each truck shipment of radioactive waste, the maximum-exposed individual is located $30 \mathrm{~m}$ from the route. His dose rate is calculated to be $1.2 \times 10^{-7}$ rem per shipment for wastes from the main process building, and $1.2 \times 10^{-8}$ rem per shipment for wastes from the extraction pond or fluoride lagoon.

5. The population density along the transport corridors is 120 persons $/ \mathbf{k m}^{2}$. 
6. A11 shipments maintain an average speed of $65 \mathrm{~km} / \mathrm{hr}$; thus, the cumulative dose to the pubtic is $2.3 \times 10^{-6} \mathrm{man}-\mathrm{rem} / \mathrm{km}$ for wastes from the main process building, and $2.3 \times 10^{-7} \mathrm{man}-\mathrm{rem} / \mathrm{km}$ for wastes from the extraction pond or fluoride lagoon.

7. The $\bar{\chi} / Q^{\circ}$ value used for calculating the radiation dose to the maximumexposed individual from transportation accidents is $3 \times 10^{-2} \mathrm{sec} / \mathrm{m}^{3}$, as discussed in detail in Appendix $N$ of Reference 39 . This individual is assumed to be located $100 \mathrm{~m}$ downwind from the accident.

Using these assumptions, the following sections contain discussions of the radiation doses during DECON. Both routine and accident conditions are discussed.

\subsubsection{Doses from Routine Offsite Transport of Wastes}

The number of radioactive waste shipments required during DECON for wastes from the main process building is given in Table 10.1-5 as 51. In addition, 1877 shipments of waste recovered from the extraction ponds and fluoride lagoons are required. Using these numbers of shipments and the assumptions discussed in the technical approach, radiation doses to transport workers and to the public are calculated and are listed in I.5-1.

\subsubsection{Transportation Accidents}

Transportation accidents have a wide range of severities. Most accidents occur at low vehicle speeds and have relatively minor consequences. In general, as speed increases, accident severity also increases. However, accident severity is not a function of vehicle speed only. Other factors, (e.g., the type of accident, the kind of equipment involved, and the location of the accident) can have an important bearing on accident severity.

Furthermore, damage to a package in a transportation accident is not directly related to accident severity. In a series of accidents of the same severity, or in a single accident involving a number of packages, damage to packages may vary from none to extensive. In relatively minor accidents, serious damage to packages can occur from impacts on sharp objects or from being struck by other cargo. Conversely, even in very severe accidents, damage to packages may be minimal. 
TABLE I.5-1. Calculated Radiation Doses from Routine Radioactive Waste Transportation

Alternative/Group —— $\begin{gathered}\text { Radiation Dose } \\ \text { per Shiprent } \\ \text { (man-rem) }\end{gathered}$ Namber of $\begin{gathered}\text { Total Population } \\ \text { Dose per Group } \\ \text { Shipments }\end{gathered}$

DECON-Building Wastes

Truck Drivers

Garagemen

$6.7 \times 10^{-2}$
$3.3 \times 10^{-3}$

51

3.4

Total Transport Worker Dose

51

$\underline{0.17}$

3.6

Onlookers

General Public

$5.0 \times 10^{-3}$
$1.8 \times 10^{-3}$

51

0.26

Total Public Dose

51

$\underline{0.092}$

0.35

DECON-Site Wastes

Truck Drivers

Garagemen

$6.7 \times 10^{-3}$

1877

1877

13

$3.3 \times 10^{-4}$

$\underline{0.62}$

Total Transport Worker Dose

Onlookers

General Public

$5.0 \times 10^{-4}$
$1.8 \times 10^{-4}$

1877

14

Total Public Dose

1877

D. 94

$\underline{0.38}$

1.3

Totals for DECON

Truck Drivers

Garagemen

Total Transport Worker Dose

Onlookers

General Pubiic

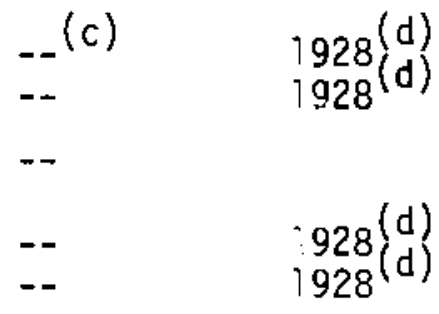

16

$\underline{0.79}$

17

Total Public Dose

$928(d)$

1.2

0.47

1.7

(a) Based on one-way trips of $800 \mathrm{~km}$.

(b) A11 doses are rounded to two significant figures.

(c) Dashes indicate that weighted average dose rates were not separately calculated.

(d) Total shipments are found by adding building waste plus site waste shipments. 
The probabilities of truck accidents in this study are based on accident data supplied in Reference 5. Accidents are classified into five severity categories as functions of vehicle speed and fire duration. The five categories and their associated probabilities for truck accidents are shown in Table 1.5-2.

TABLE I.5-2. Transportation Accident Severity Categories (a)

\begin{tabular}{|c|c|c|c|}
\hline Severity & $\begin{array}{c}\text { Vehicle } \\
\text { Speed }(\mathrm{km} / \mathrm{h})\end{array}$ & $\begin{array}{c}\text { Fire } \\
\text { Duration (h) }\end{array}$ & $\begin{array}{c}\text { Probability per } \\
\text { Vehicle-km } \\
\text { Truck }\end{array}$ \\
\hline Minor & $\begin{array}{r}0-50 \\
0-50 \\
50-80\end{array}$ & $\begin{array}{c}0 \\
<0.5 \\
0\end{array}$ & $\begin{array}{l}2 \times 10^{-7} \\
4 \times 10^{-9} \\
6 \times 10^{-7}\end{array}$ \\
\hline Moderate & $\begin{array}{c}0-50 \\
50-80 \\
80-110 \\
80-110\end{array}$ & $\begin{array}{c}0.5-1.0 \\
<0.5 \\
0 \\
<0.5\end{array}$ & $\begin{array}{l}3 \times 10^{-11} \\
6 \times 10^{-9} \\
2 \times 10^{-7} \\
3 \times 10^{-9}\end{array}$ \\
\hline Severe & $\begin{array}{r}0-50 \\
50-80 \\
50-80 \\
80-110 \\
>110 \\
>110\end{array}$ & $\begin{array}{c}>1.0 \\
>1.0 \\
0.5-1.0 \\
0.5-1.0 \\
0 \\
<0.5\end{array}$ & $\begin{array}{l}3 \times 10^{-12} \\
6 \times 10^{-12} \\
4 \times 10^{-12} \\
4 \times 10^{-12} \\
6 \times 10^{-11} \\
6 \times 10^{-11}\end{array}$ \\
\hline
\end{tabular}

(a) Summarized from material in Reference 5.

The wastes shipped from the $\mathrm{UF}_{6}$ conversion plant during decommissioning will all reouire Type A containers. Some of the wastes will consist of compacted combustible material contaminated with uranium. Accident descriptions involving Type A containers are given in Table I.5-3 for minor accidents and in Table I.5-4 for severe accidents. Type A waste packages containing natural uranium (transport Group III) are limited to contain $3 \mathrm{Ci}$ per container. (40) Since natural uranium is estimated to have a low specific activity $(1.3 \mu \mathrm{Ci} / \mathrm{g}$ from Table C.2-1), and since most combustible wastes come from manual operations conducted in areas of low contamination level, the quantity of material per container is estimated to be about $5.5 \times 10^{-4} \mathrm{Ci}$. This quantity is based on the concentration of contaminated sweeping compound discussed in the 
TABLE 1.5-3. Minor Accidents for Type A Packages During Truck Transportation

\begin{tabular}{|c|c|c|}
\hline Accident Description & Sequence of Events & Atmospheric Release \\
\hline $\begin{array}{l}\text { Truck Collision or } \\
\text { Overturn Involves } \\
\text { Waste Containers }\end{array}$ & $\begin{array}{l}\text { 1. Collision or overturn } \\
\text { accident occurs. } \\
\text { 2. Truck leaves roadway } \\
\text { and may overturn. } \\
\text { 3. Type A packages may rup- } \\
\text { ture, but no fire occurs. } \\
\text { 4. Accident is reported to } \\
\text { local and federal offi- } \\
\text { cials. } \\
\text { 5. Packages recovered. }\end{array}$ & None \\
\hline $\begin{array}{l}\text { Truck Collision or } \\
\text { Overturn and a } \\
\text { Minor Fire }(1 / 2 \\
\text { Hour or Less) } \\
\text { Involves I Type A } \\
\text { Waste Container }\end{array}$ & $\begin{array}{l}\text { 1. Collision or overturn } \\
\text { accident occurs. } \\
\text { 2. Truck leaves roadway } \\
\text { and may overturn. } \\
\text { 3. One Type A waste con- } \\
\text { tainer is involved in } \\
\text { a fire with } 1 / 2 \text { hour } \\
\text { or less duration. } \\
\text { 4. Accident is reported } \\
\text { to local and federal } \\
\text { officials. } \\
\text { 5. Packages recovered. }\end{array}$ & $\begin{array}{l}\text { Release fraction of } \\
5 \times 10^{-4} \text { of the con- } \\
\text { tents of one waste } \\
\text { package is assumed. }\end{array}$ \\
\hline
\end{tabular}

TABLE 1.5-4. Severe Accidents for Type A Packages During Truck Transportation

\begin{tabular}{|c|c|c|}
\hline Accident Description & Sequence of Events & Atmospheric Release \\
\hline $\begin{array}{l}\text { Truck Collision or } \\
\text { Overturn and a } \\
\text { Major Fire ( } 1 \text { Hour } \\
\text { or Longer) Involv- } \\
\text { ing } 40 \text { Type A } \\
\text { Waste Containers. }\end{array}$ & $\begin{array}{l}\text { 1. Collision or overturn } \\
\text { accident occurs. } \\
\text { 2. Truck leaves roadway at } \\
\text { high speed and overturns } \\
\text { 3. Type A packages rupture } \\
\text { and } 40 \text { waste containers } \\
\text { are involved in a fire. } \\
\text { 4. Accident is reported to } \\
\text { local and federal official } \\
\text { 5. Packages recovered. }\end{array}$ & $\begin{array}{l}\text { Release fraction of } \\
5 \times 10^{-4} \text { of the contents } \\
\text { of } 40 \text { waste packages is } \\
\text { assumed. }(34)\end{array}$ \\
\hline
\end{tabular}


fire scenario in Section I.2.2.1. For the minor accident, one package is assumed to burn and release $5 \times 10^{-4(34)}$ of the radioactivity in the container, or about $2.8 \times 10^{-7} \mathrm{Ci}$. The resultins 50-year committed dose equivalent to the maximum-exposed individual is $0.9 \mathrm{mrem}$ to the lung. The minor transportation accident is estimated to have a low frequency of occurrence.

For the severe accident, the contents of 40 waste containers (each containing $5.5 \times 10^{-4} \mathrm{Ci}$ of uranium) are assumed to burn, releasing a total of $1.1 \times 10^{-5} \mathrm{Ci}$. The resulting 50-year committed dose equivalent to the maximumexposed indidividual is $35 \mathrm{mrem}$ to the lung. The severe accident is also estimated to have a low frequency of occurrence. A complete 1isting of the doses to the organs of the maximum-exposed individual from these accidents is given in Table I.5-5.

TABLE 1.5-5. Radiation Doses to the Maximum-Exposed Individual for Releases from Selected Transportation Accidents

\begin{tabular}{|c|c|c|c|c|c|c|c|c|c|}
\hline \multirow[b]{2}{*}{ Incident } & \multirow{2}{*}{$\begin{array}{c}\text { Total } \\
\text { Atmospherjc } \\
\text { Release }(\mathrm{ci} / \mathrm{h})(\mathrm{d})\end{array}$} & \multicolumn{4}{|c|}{ First-Year Dose (rem) } & \multicolumn{4}{|c|}{ Fifty-Year Comitted Dose Equivalent (rem) } \\
\hline & & $\begin{array}{r}\text { Total } \\
\text { Body } \\
\end{array}$ & Bone. & Lung & GI-LLI & $\begin{array}{r}\text { Total } \\
\text { Body } \\
\end{array}$ & Bone & Lung & GI-LLI \\
\hline $\begin{array}{l}\text { Minor Transportation } \\
\text { Accident }\end{array}$ & $2.8 \times 10^{-7}$ & $1.1 \times 10^{-5}$ & $1.1 \times 10^{-5}$ & $3.6 \times 10^{-4}$ & $--^{(b)}$ & $1.3 \times 10^{-5}$ & $2.2 \times 10^{-5}$ & $9.0 \times 10^{-4}$ & -- \\
\hline $\begin{array}{l}\text { Severe Transporta- } \\
\text { tion Accident }\end{array}$ & $1.1 \times 10^{-5}$ & $4.3 \times 10^{-4}$ & $4.3 \times 10^{-4}$ & $1.4 \times 10^{-2}$ & - & $5.3 \times 10^{-5}$ & $8.4 \times 10^{-4}$ & $3.5 \times 10^{-2}$ & $-\cdot$ \\
\hline
\end{tabular}

(a) All releases are assumed to occur in a 1-hour period, for comparison purposes.

(b) For inhalation, no dose result to the GI-LLJ from uranilua.

\section{I.6 HAZARDOUS CHEMICAL RELEASES DURING DECOMMISSIONING OPERATIONS}

The two primary sources of chemical hazards are residual chemicals from plant operation and chemical agents used during decontamination.

\section{I.6.1 Chemical Residuals from Plant Operations}

Several potentially hazardous chemicals are used or produced in operations conducted at the reference $U_{6}$ conversion plant. Residues from these operations may be present during the decommissioning operation, and therefore must be dealt with prior to unconditional release of the site. Table I.6-1 lists the chemicals which are of concern, either because of their relative toxicity, or because of the total amount which may be present on the site at the time of decommissioning. 
TABLE I.6-1. Potential Chemical Residuals from Plant Operations

\begin{tabular}{lll}
\multicolumn{1}{c}{ Material } & Form & Source \\
\cline { 1 - 2 } Acetone & Liquid & Process Use \\
Anhydrous Ammonia & Liquid & Process Use \\
Aqueous Ammonia & Liquid & Process Use \\
Hydrochloric Acid & Liquid & Process Use \\
Hydrofluoric Acid & Liquid & Process Use \\
Nitric Acid & Liquid & Process Use \\
Sodium Hydroxide & Liquid & Process Use \\
Sulfuric Acid & Liquid & Process Use \\
Degreaser (solvent) & Liquid & Process Use \\
Helium & Gas & Process Use \\
Hydrogen & Gas & Process Use \\
Nitrogen & Gas & Process Use \\
Oxygen & Gas & Process Use \\
Propane & Gas & Process Use \\
Uranium Hexafluoride & Gas/ & Product \\
Uranyl Nitrate & Solid & \\
Uranium Dioxide & Solid & Feed Material \\
Calcium Oxide & Solid & Feed Material \\
Calcium Fluoride & Solid & Waste Material \\
Ammonium Nitrate & Solid & Waste Material
\end{tabular}

Most of the chemical species listed will pose no residual toxicity problem. Those in liquid form, primarily strong acids and bases, are stored in tanks and closed systems. The inventory (if any) remaining in the storage and piping systems after plant shutdown will be treated in one of the following ways: solidification and transfer to a chemical waste disposal area; neutralization and disposal in a landfill, and where economicaliy justified, salvage or resale to another user.

The process gases used in the plant also pose little hazard. The inventories in the respective systems will be low at the time of the final plant shutdown. With the exception of hydrogen and propane which are flammable, the gases used 
present almost no biological hazard. The small amounts of propane and hydrogen remaining in those systems will be easily diluted and flushed with an inert gas such as nitrogen before dismantlement of the piping systems begins.

The uranium compounds used as feed material present both radiological and chemical toxicity hazards. The chemical toxicity of uranium compounds is largely a function of their solubility in body fluids; the more soluble compounds such as nitrates and fluorides tend to translocate to the kidney, the site of major biological damage. The threshold limit value (TLV) for all uranium compounds has been set at $0.2 \mathrm{mg} \mathrm{U} / \mathrm{m}^{3}$. (41) The concentration to which the maximum-exposed individual is exposed as a result of the chronic releases from routine decommissioning activities averaged over a 1-year period is $8.9 \times 10^{-7} \mathrm{mg} \mathrm{U} / \mathrm{m}^{3}$. Even if the largest single release $(3.7 \mathrm{~kg} \mathrm{U}$ from onsite waste exhumation) is assumed to occur in a 4-month period, the maximum-exposed individual would be exposed to an air concentration of $2.7 \times 10^{-6} \mathrm{mg} \mathrm{U} / \mathrm{m}^{3}$, or about $1 \times 10^{-5}$ times the TLV for 1 week.

The waste material collected over the plant operating life, principally calcium fluoride, is potentially hazardous. Calcium fluoride has a TLV of $2.5 \mathrm{mg} / \mathrm{m}^{3}$. Using the chronic release $\bar{x} / Q$ for the maximum-exposed individual $\left(7.6 \times 10^{-6}\right)$ and a permissible exposure of $1 / 100 \mathrm{TLV}$, the maximum average $\mathrm{CaF}_{2}$ release rate which can be tolerated is $3.3 \mathrm{~g} / \mathrm{sec}$. Accordingly, transportation and packaging methods must be selected with consideration given to the toxic nature of the fluoride. Occupational exposure to $\mathrm{CaF}_{2}$ will be limited by conventional industrial contamination control techniques.

\section{I.6.2 Chemical Residuals from Decontamination Agents}

Chemical decontamination agents such as detergents, acid solutions, degreasers, and organic solvents may be used for various tasks at the $\mathrm{UF}_{6}$ conversion plant for decontamination. Most such decontamination agents are of low chemical toxicity and are widely used in non-nuclear industry applications.

Nitric acid, which may be used to flush chemical process systems and to wipe down contaminated surfaces, is neutralized with caustic before disposal. The resultant nitrate salts are relatively innocuous. Detergent residues on any cleaned surface should be negligible so long as the decontamination process is carried to completion with a final rinse of the cleaned surfaces. 
Degreasers and solvents such as Freon may be vaporized and released to the atmosphere during cleaning operations. These materials are relatively nontoxic, but they may pose local haczards to decommissioning personnel if allowed to accumulate in unventilated areas.

Under normal conditions, the proper selection and use of chemical decontamination agents should preclude any significani chemical toxicity hazard to workers or to the general public. 


\section{REFERENCES}

1. C. A. Burchsted, J. E. Kahn and A. B. Fuller, Nuclear Air Cleaning Handbook, ERDA 76-21, pp. 42-43, March 1976.

2. Final Elk River Reactor Program Report, C00-651-93, Revised, p. F-9, United Power Association, Elk River, Minnesota, November 1974.

3. Siting of Fuel Reprocessing and Waste Management Facilities, ORNL-4451, pp. 8-47, Oak Ridge National Laboratory, Oak Ridge, Tennessee, July 1970.

4. J. M. Selby, et a1., Considerations in the Assessment of Consequences of Effluents from Mixed Oxide Fuel Fabrication Plants, BNwL-1697, Rev. 1, pp. 78-79, Pacific Northwest Laboratory, Richland, Washington, June 1975.

5. Directorate of Regulatory Standards, Environmental Survey of Transportation of Radioactive Materials to and from Nuclear Power Plants, WASH-1238, U.S. Atomic Energy Conmission, Washington, DC, 1972.

6. U.S. Nuclear Regulatory Commission, Assumptions used for Evaluating the Potential Radiological Consequences of a Loss of Coolant Accident for Pressurized Water Reactors, Regulatory Guide 1.4, Revision 2, June T974.

7. U.S. Nuclear Regulatory Conmission, Calculation of Annual Doses to Man from Routine Releases of Reactor Effluents for the Purpose of Evaluating Compliance with 10 CFR Part 50, Appendix I, Regulatory Guide 1.109, Rev. 1, Washington, DC 20555, 1977.

8. E. S. Murphy and G. M. Holter, Technology, Safety and Costs of Deconmissioning a Reference Low-Level waste Burial Ground, NUREG/CR-0570, Prepared by Pacific Northwest Laboratory for the U.S. Nuclear Regulatory Commission, June 1980.

9. R. C. Milham, J. F. Schubert, J. R. Watts, A. L. Boni and J. C. Corey, "Measured Plutonium Resuspension and Resulting Dose from Agricultural operations on an 01d Field at the Savannah River Plant in the Southeastern United States," IAEA/USERDA International Symposium on Transuranium Nuclides in the Environment, pp. 17-21, November 1975.

10. D. H. Card, Early Waste Retrieval Interim Report, TREE-1047, Idaho National Engineering Laboratory, EG \& G Idaho, Inc., pp. 19-40, February 1977.

11. J. H. Horton, Exhumation of Radioactive Solid Wastes Buried for Fourteen Years, DP-1456, E. I. DuPont de Nemours and Company, Savannah River Laboratory, pp. 5-11, Aiken, South Carolina, 29801, 1977.

12. H. P. Holcomb, Radionuclide Content of an Exhumed Canyon Vessel and Neighboring Soi 1 , DP-446, E. I. Dupont deNemours and Company, Savannah River Laboratory, pp. 5-27, Aiken, South Carolina, 29801, 1976. 
13. R. T. Brunski11, "The Relationship Between Surface and Airborne Contamination," Surface Contamination, Proceedings of a Symposium Held at Gatl inburg, Tennessee, June 1964, pp. 93-105, Pergamon Press, New York, New York, 1967.

14. H. Glauberman, W. R. Bootman and A. J. Breslin, "Studies of the Significance of Surface Contamination," Surface Contamination, Proceedings of a Symposium Held at Gatlingurg, Tennessee, June 1964, Pergamon Press, New York, New York, pp. 169-178, 1967.

15. I. S. Jones and S. F. Pond, "Some Experiments to Determine the Resuspension Factor of Plutonium from Various Surfaces," Surface Contamination, Proceedings of a Symposium Held at Gatlinburg, Tennessee, June 1965, Pergamon Press, New York, New York, pp. 83-92, 1967.

16. E. H. Garner, S. R. M. Ell is and J. A. Lacey, "The Size Distribution and Entrainment of Droplets," Trans. Inst. Chem. Engrs. 32:222-235, 1954.

17. R. Brown and L. J. York, "Sprays Formed by Flashing Liquid Spray," AICHE Journal 8(2):149-153, May 1962.

18. K. J. Schneider and C. E. Jenkins, Technology, Safety and Costs of Decommissioning a Reference Nuclear Fuel Reprocessing Plant, NUREG-0278, Prepared by Pacific Northwest Laboratory for U.S. Nuclear Regulatory Commission, October 1977.

19. R. I. Smith, G. J. Konzek and W. E. Kennedy, Jr., Technology, Safety and Costs of Decommissioning a Reference Pressurized Water Reactor Power Station, NUREG/CR-0130, Prepared by Pacific Northwest Laboratory for the U.S. Nuclear Regulatory Commission, June 1978.

20. C. E. Jenkins, E. S. Murphy and K. J. Schneider, Technology, Safety and Costs of Decommissioning a Reference Small Mixed Oxide Fuel Fabrication Plant, NUREG/CR-0129, Prepared by Pacific Northwest Laboratory for the U.S. Nuclear Regulatory Commission, February 1979.

21. Fire Protection Guide on Hazardous Materials, 6th ed., National Fire Protection Association, Boston, Massachusetts, 1975.

22. R. C. Weast, ed., Handbook of Chemistry and Physics, 54th ed., CRC Press, Cleveland, Ohio, 1973.

23. G. H. Tryon, ed., Fire Protection Handbook, National Fire Protection Assocjation, Boston, Massachusetts, 1969.

24. E, S. Young, "Preventing Reverse Flow Explosions in Gas Cutting Equipment," Plant Engineering, p. 505, December 14, 1972.

25. R. Cecil Smart, The Technology of Industrial Fire and Explosion Hazards, Chapman and Hall, Ltd., London, pp. 41-43 and pp. 128-132, 1947. 
26. C. A. Burchsted and A. B. Fuller, Design, Construction and Testing of High Efficiency Air Filtration Sys tems for Nuclear Applications, ORNLNSIC-65, Nuclear Safety Information Center, Oak Ridge, Tennessee, 1970.

27. H. A. Lee, Guide to Fire Protection in Caves, Canyons and Hot Cells, ARH-3020, Atlantic Richfield Hanford Company, Richland, Washington, July 1974.

28. R. Cecil Smart, The Technology of Industrial Fire and Explosion Hazards, Chapman and Hal1, Ltd, London, pp. 47-43 and pp. 128-139, 1947.

29. M. Eisenbud, "The Primary Air Pollutants--Radioactive, Their Occurrence, Sources, and Effects," Air Pollution Third Edition, Volume 1, Air Pollutants, Their Transformation and Transport, A. C. Stern, ed, , Academic Press, pp. 197-231, New York, New York, 1976.

30. H. Thielsch, "Why High Temperature Piping Rails," Pressure Vessels and Piping Design and Analysis, Volume 4, Quality Assurance--Applications, Components, H. H. Waite, ed., The American Society of Mechanical Engineers, pp. 350-375, New York, New York, 1976.

31. Linde Specialty Gas Catalog, Union Carbide Corporation, Linde Division, New York, New York, 1974.

32. M. G. Zabetakis, Flammability Characteristics of Combustible Gases and Vapors, Bulletin 627, U.S. Bureau of Mines, 1965.

33. G. B. McKinnon, Fire Protection Handbook, National Fire Protection Association, p. 3.202, Boston, Massachusetts, 1976 .

34. J. Mishima and L. C. Schwendiman, Fractional Airborne Release of Uranium (Representing Plutonium) During the Burning of Contaminated Waste, BWNL-1730, Pacific Northwest Laboratory, Richland, Washington, ApriT 1973.

35. U.S. Nuclear Regulatory Commission, Reactor Safety Study: An Assessment of Risks in the U.S. Commercial Nuclear Power PTants, WASH-1400, NUREG 74/014, October T975.

36. I. B. Wal1, "Probabilistic Assessment of Aircraft Risk for Nuclear Power Plants," Nuclear Safety 15(3):276-284, May-June 1974.

37. H. K. Elder and D. E. Blahnik, Technology, Safety and Costs of Decommissioning a Reference Uranium Fuel Fabrication Plant, NUREG/CR-1266, Vol. 2, Appendix I, Prepared by Pacific Northwest Laboratory for the U.S. Nuclear Regulatory Commission, October 1980.

38. U.S. Code of Federal Regulations, Title 49, Part 173.393, "Transportation," Superintendent of Documents, GPO, Washington, DC 20555, January 1978. 
39. H. D. Oak, G. M. Holter, W. E. Kennedy, Jr., and G. J. Konzek, Technology, Safety and Costs of Decommissioning a Reference Boiling Water Reactor Power Station, NUREG/CR-0672, Prepared by Pacific Northwest Laboratory for the U.S. Nuclear Regulatory Commission, June 1980.

40. U.S. Code of Federal Regulations, Title 49, Part 173.389, "Transportation," Superintendent of Documents, GP0, Washington, DC 20555, January 1978.

41. Threshold Limit Values for Chemical Substances and Physical Agents in the Workroom Environment with Intended Changes for 1977, American Conference of Governmental Industrial Hygenists, TLV's, ACGIH, Cincinnati, Ohio, 1977. 


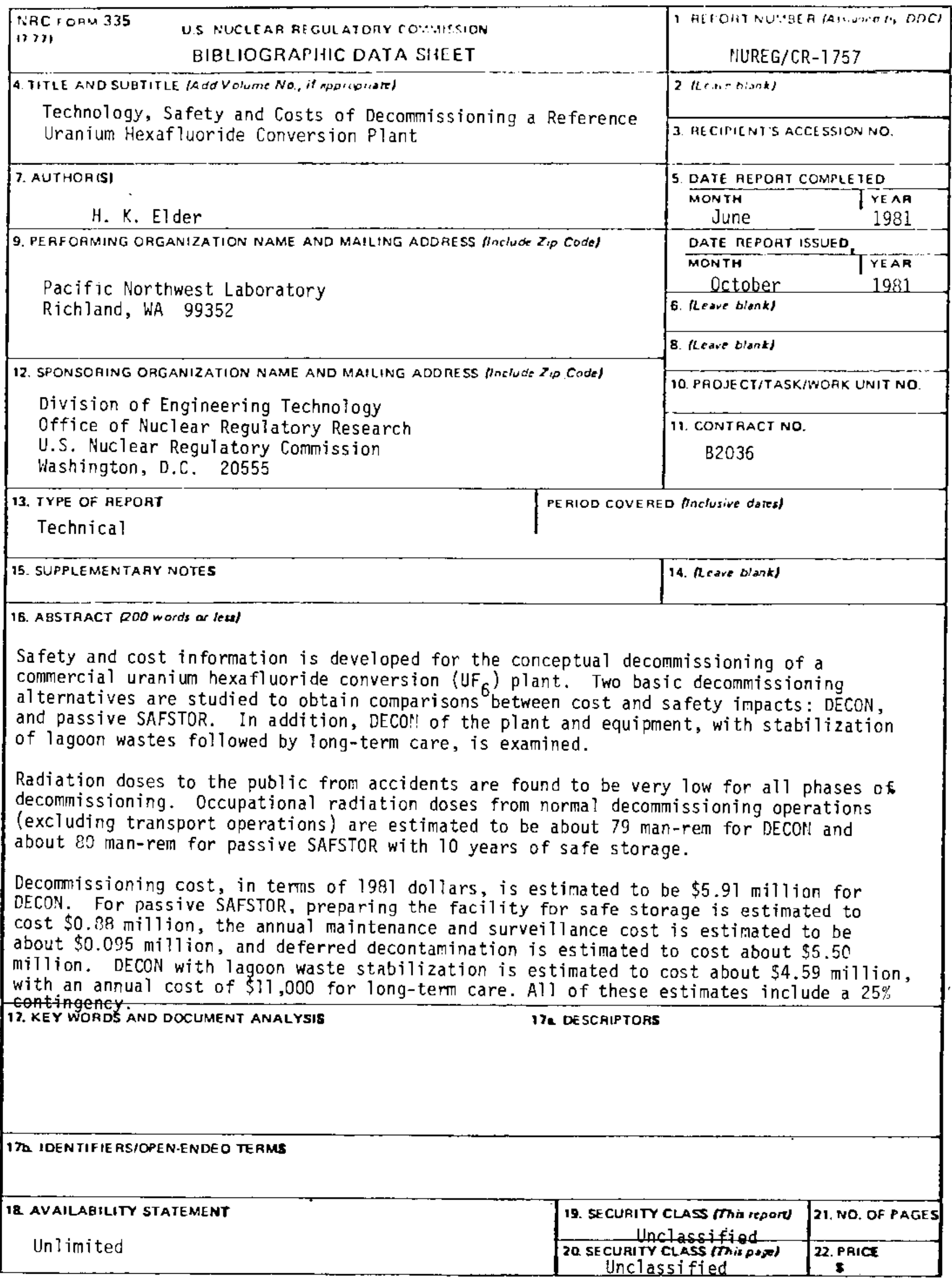


